\title{
DENNIS NIEWERTH
}

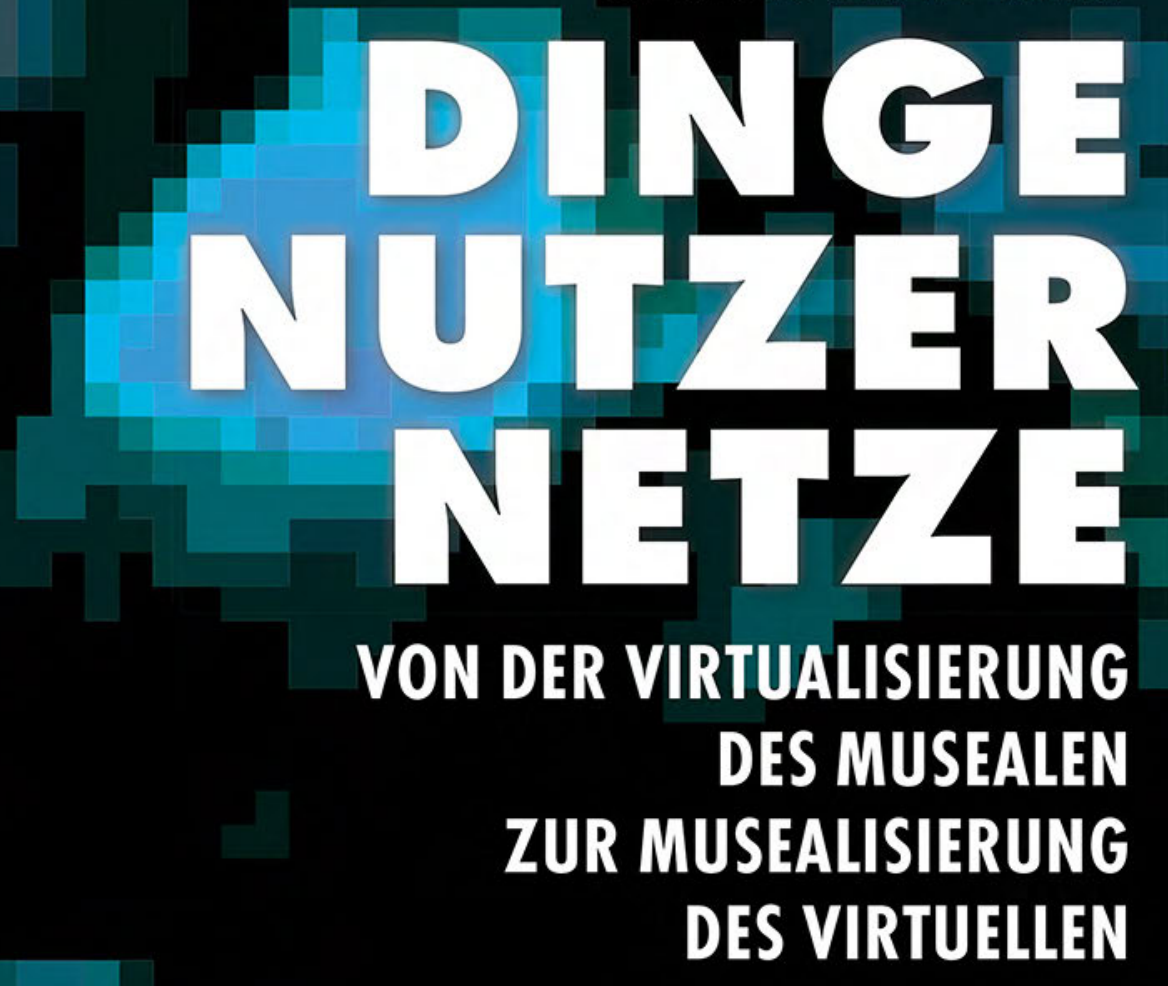

Edition Museum [transcript] 
Dennis Niewerth

Dinge - Nutzer - Netze:

Von der Virtualisierung des Musealen zur Musealisierung des Virtuellen

Edition Museum | Band 30 
Dennis Niewerth, geb. 1985, hat an der Ruhr-Universität Bochum Medienwissenschaft und Geschichte studiert und befasst sich als wissenschaftlicher Mitarbeiter am Deutschen Schifffahrtsmuseum - Leibniz-Institut für Maritime Geschichte in Bremerhaven mit der 3D-Digitalisierung von maritimem Kulturerbe. Zuvor war er Stipendiat der Friedrich-Naumann-Stiftung für die Freiheit sowie der Mercator Research Group 2 (»Räume anthropologischen Wissens«) der Ruhr-Universität Bochum. 
DENNIS NIEWERTH

Dinge - Nutzer - Netze:

Von der Virtualisierung des Musealen

zur Musealisierung des Virtuellen

[transcript] 
Die vorliegende Arbeit wurde der Fakultät für Philologie der Ruhr-Universität Bochum am 25. Mai 2016 unter dem Titel »Von der Virtualisierung des Musealen zur Musealisierung des Virtuellen« als Dissertationsschrift vorgelegt und am 12. Dezember 2016 vor dem zuständigen Promotionsausschuss verteidigt.

Ihre Anfertigung wurde durch ein Promotionsstipendium der Friedrich-Naumann-Stiftung für die Freiheit aus Mitteln des Bundesministeriums für Bildung und Forschung ermöglicht.

Die frei zugängliche digitale Publikation wurde ermöglicht mit Mitteln des BMBF-Projektes OGeSoMo der Universitätsbibliothek Duisburg-Essen. In diesem Projekt wird Open Access für geistes- und sozialwissenschaftliche Monografien gefördert und untersucht. Informationen und Ergebnisse finden Sie unter https://www.uni-due.de/ogesomo.

\section{Bibliografische Information der Deutschen Nationalbibliothek}

Die Deutsche Nationalbibliothek verzeichnet diese Publikation in der Deutschen Nationalbibliografie; detaillierte bibliografische Daten sind im Internet über http://dnb.d-nb.de abrufbar.

\section{(1) $(1) \Theta \Theta$}

Dieses Werk ist lizenziert unter der Creative Commons Attribution-NonCommercialNoDerivs 4.० Lizenz (BY-NC-ND). Diese Lizenz erlaubt die private Nutzung, gestattet aber keine Bearbeitung und keine kommerzielle Nutzung. Weitere Informationen finden Sie unter https://creativecommons.org/licenses/by-nc-nd/4.o/deed.de

Um Genehmigungen für Adaptionen, Übersetzungen, Derivate oder Wiederverwendung zu kommerziellen Zwecken einzuholen, wenden Sie sich bitte an rights@transcript-verlag.de

Die Bedingungen der Creative-Commons-Lizenz gelten nur für Originalmaterial. Die Wiederverwendung von Material aus anderen Quellen (gekennzeichnet mit Quellenangabe) wie z.B. Schaubilder, Abbildungen, Fotos und Textauszüge erfordert ggf. weitere Nutzungsgenehmigungen durch den jeweiligen Rechteinhaber.

\section{(C) 2018 transcript Verlag, Bielefeld}

Umschlaggestaltung: Kordula Röckenhaus, Bielefeld

Umschlagabbildung: »Mona Lisa squares«, goodwin_x / fotolia.com

Druck: Majuskel Medienproduktion $\mathrm{GmbH}$, Wetzlar

Print-ISBN 978-3-8376-4232-2

PDF-ISBN 978-3-8394-4232-6

Gedruckt auf alterungsbeständigem Papier mit chlorfrei gebleichtem Zellstoff. Besuchen Sie uns im Internet: https://www.transcript-verlag.de

Bitte fordern Sie unser Gesamtverzeichnis und andere Broschüren an unter: info@transcript-verlag.de 


\section{Inhalt}

Danksagungen | 11

Einleitung | 13

1 DAS MUSEUM: EIN UMRISS | 29

1.1 Das Museum: Begriff und Institution | 31

1.1.1 Das antike Museion | 31

1.1.2 Mittelalter und frühe Renaissance | 33

1.1.3 Die Kunst-, Naturalien- und Wunderkammern der frühen Neuzeit | 34

1.1.4 Die Geburt des Museums | 36

\section{2 "Wilde Semiosen « und »epistemische Dinge»:}

Die Sperrigkeit des Materials | 38

1.2.1 Historizität und Ästhetik als museale Strategien 39

1.2.2 Museale Darstellung(en) und das politische Moment | 40

1.2.3 Zeichenträger und Gedächtnisorte | 41

1.2.4 Grenzen des Zeichenhaften:

Aleida Assmanns »wilde Semiose« | 43

1.2.5 Museumdinge als »epistemische Dinge« nach Hans Jörg Rheinberger | 45

1.2.6 »Nouophoren $« \mid 48$

1.3 Räume im Museum: Physikalisch, semantisch, transitiv | 50

1.3.1 Räume und Zeichen | 50

1.3.2 Der Raum in der Museumswissenschaft | 52

1.3.3 Museen als > Theater der Dinge | 53

1.3.4 Kommunikationsstrukturen im Museum | 54

1.3.5 Standpunkte und Blickwinkel | 56 
1.3.6 Inszenierungen des Sozialen zwischen Ort und Raum | 59

1.3.7 Authentizität, Aura, Atmosphäre | 66

1.4 Statt einer Definition: Das Museum als Dispositiv | 75

\section{NETZ UND VIRTUALITÄT | 83}

2.1 Virtualitätı zwischen Ontologie und Technologie | 84

2.1.1 Die Virtualität des Digitalen | 85

2.1.2 Interfaces und die >Kultur der Simulation` | 86

2.1.3 Digitale Virtualität und kulturelle Kommunikation | 88

2.2 Zum Begriff des sNetzwerks $\mid 92$

2.2.1 (Ge-)Doppelte Netze | 94

2.3 Hypertext 95

2.3.1 Frühe Formen $\mid 96$

2.3.2 Vannevar Bush und die Memex-Maschine:

Pfade des Wissens $\mid 98$

2.3.3 Das virtuelle Moment textueller Vernetzung | 102

2.3.4 Die Grammatik der Verlinkung | 103

2.4 Zurechtfindung und Navigation in vernetzten Texten | 104

2.4.1 Topologie und Textraum | 105

2.4.2 Anschluss statt Abschluss | 107

2.4.3 >Navigation< als Kulturtechnik | 109

2.4.4 >Connectedness $\ 110$

2.4.5 Detektive und Dandies | 113

\section{3 , VIRTUELLE MUSEEN}

MEDIENWECHSEL UND KONTINUITÄT | 119

\subsection{Zum Begriff des svirtuellen Museumsı| 123}

\subsection{Museen ohne Dinge | 127}

3.2.1 Ding und Information | 129

3.2.2 Stetigkeit vs. Prozeduralität | 131

3.2.3 >Digitale Objekte ‘ als semantische Konstrukte | 135

3.2.4 Das >Objekt< als Bewusstseinsgröße | 144

3.2.5 Materialität und Digitalität | 146

3.2.6 Verkehrsformen | 149 


\subsection{Museen ohne Raum | 152}

3.3.1 Museale Entführungen | 153

3.3.2 Raum als Metapher und Programm | 158

3.3.3 Cyberspace(s) $\mid 161$

3.3.4 Anschauung, Handlung, Raum und Räumlichkeit | 172

3.3.5 Flüssige Architekturen | 176

3.3.6 >Virtuelle Realität $\triangleleft$ und Grenzen der Raum-Metaphorik | 180

3.3.7 Räumlichkeit und Raumlosigkeit virtueller Museen | 182

\section{DAS MUSEUM VON BABEL? | 185}

4.1 Virtuelle Texte: Die Eigendynamik des Codes | 189

4.1.1 Die Suche als Ohnmachtserfahrung | 192

4.2 Nahes und fernes Wissen | 196

4.2.1 Soziometrie und Science Citation Index:

Vorspiel zur Suchmaschine | 197

4.2.2 Google: Kulturelle Relevanz als statistische Korrelation | 199

4.2.3 Das gezähmte Netz: Vom Flanieren zum Finden | 206

4.3 André Malraux: Das imaginäre Museum | 210

4.3.1 Im Universum der Abbilder: Museum und Fotografie | 213

4.3.2 Das Museum ohne Wände und das transformative Objekt | 215

4.4 Pfade durch das Weltmuseum | 222

5 GELENKTE RHIZOME: KULTURELLES ERBE UND KULTURELLE KYBERNETIK | 227

5.1 Verwurzelte und verteilte Texte $\mid 228$

5.2 Partizipation als rhizomatisches Phänomen | 230

5.3 Das vermessene Publikum | 234

5.4 Cybertext: Emanzipation und Fremdbestimmung im gerankten Web | 237

5.5 Algorithmische Autorschaften | 241

5.6 Cultural Analytics:

Die Quantifizierung kultureller Phänomene | 245 


\section{VIRTUALISIERUNG UND MUSEALISIERUNG: SKIZZE EINES SPANNUNGSFELDES | 253}

6.1 Museum und Web: Zwei abduktive Paradigmen | 257

6.1.1 Das Museum der Fragen und das Web der Antworten | 259

6.1.2 Die Individualisierung der Dinge im Museum | 260

6.2 sKurzer Kopf، und slanger Schwanzı

des kulturellen Bewusstseins | 262

6.2.1 Chris Andersons \Long Tail<-Theorie | 264

6.2.2 Der `lange Schwanz` als Problem und Chance für Museen | 268

6.2.3 Der Kurator als Techniker? |270

\subsection{Datenbank und Netzwerk:}

Architekturen des virtuellen Museums | 271

6.3.1 Computer als Werkzeuge musealer Sammlungsverwaltung | 271

6.3.2 Digitalisierung und Professionalisierung |273

6.3.3 Grenzen der Kategorisierbarkeit | 275

6.3.4 Daten versus Information | 279

6.4 Digitale Authentizität | 282

6.4.1 Authentizität als Virtualität | 283

6.4.2 Authentische Software | 285

6.4.3 Authentisierung als mediale Strategie | 289

6.4.4 Manipulierbarkeit und Formatierung digitaler Objekte | 291

6.4.5 >Vertrauen $<$ als Praxis des Authentischen | 297

\subsection{Die Dispositive des virtuellen Museums | 299}

6.5.1 Alläglichkeit und Auratizität des Virtuellen | 300

6.5.2 Musealität zwischen Bildungsauftrag und Wunscherfüllung | 303

6.5.3 Roy Ascotts >postmuseales Szenario< | 307

6.5.4 Das Museum als Akteur-Netzwerk | 312

\section{FALLSTUDIEN | 317}

7.1 Virtuelle Museen als Verlängerungen der physischen Ausstellung | 319

7.1.1 Das J. Paul Getty Museum im Internet (www.getty.edu) | 320

7.1.2 Die digitale Sammlung des Städel Museums (www.staedelmuseum.de) | 323 
7.2 Virtuelle Ausstellungen, distribuierte Sammlungen | 327

7.2.1 Lebendiges Museum Online (www.dhm.de/lemo) | 327

7.2.2 Das Virtual Museum of Canada (www.virtualmuseum.ca) | 334

7.2.3 Europeana (www.europeana.de) $\mid 343$

7.2.4 Das Google Art Project (www.googleartproject.com) | 352

\subsection{Virtuelle Museen als Amateurprojekte | 359}

7.3.1 Das 8bit-Museum (www.8bit-museum.de) $\mid 360$

7.3.2 Das Museum of Fred (www.museumoffred.com) $\mid 366$

\subsection{Das Virtuelle als Ausstellungsobjekt | 372}

7.4.1 Das Digital Art Museum (www.dam.org) | 372

7.4.2 Das Internet Archive (www.archive.org) $\mid 376$

\subsection{Grenzgebiete des Musealen und Virtuellen | 381}

7.5.1 Das Alltägliche kuratieren: www.pinterest.com | 382

7.5.2 Sehende Software: Reverse Image Searches | 385

7.5.3 Überall museal: Ubiquitous Computing und Museumsapps | 390

Schluss und Ausblick | 397

Literatur | 409 



\section{Danksagungen}

Diese Arbeit wurde der Fakultät für Philologie der Ruhr-Universität Bochum am 25. Mai 2016 als Dissertationsschrift vorgelegt und gelangte am 12. Dezember 2016 zur erfolgreichen Verteidigung.

Mein Dank und meine tiefe Verbundenheit gilt meinem Doktorvater Stefan Rieger, ohne dessen aufopferungsvolle Betreuung im Inhaltlichen wie im Menschlichen die Studie in der vorliegenden Form nicht hätte enstehen können. In aller Herzlichkeit danke ich auch meinem Zweitgutachter Claus Pias für seinen Einsatz und die vielen überaus hilfreichen Anmerkungen und Beobachtungen zum eingereichten Manuskript. Nicht ungenannt bleiben sollen mit Anna Tuschling, Christine Horz, Manfred Schneider und Armin Schäfer auch die übrigen Mitglieder der zuständigen Promotionskommission, die an einem fahlen Bochumer Dezembermorgen die Zeit und Geduld für meine Disputation aufgebracht haben.

Sarah Wisbar danke ich für ihren wachen Blick und ihre spitze Feder. Erst ihre minutiöse Gegenlese hat das Manuskript zur Vorzeigbarkeit gebracht. LLAP, liebe Sarah.

Unschätzbar wertvolles Feedback zur entstehenden Qualifikationsarbeit erhielt ich aus Stefan Riegers Doktorandenkolloquium, dessen Teilnehmern ich an dieser Stelle ebenfalls meinen Dank aussprechen möchte, insbesondere Ina Bolinski, Anneke Janssen, Sylvia Kokott, Cecilia Preiss, Michael Andreas, Dawid Kasprowicz, Thomas Kempka, Nils Menzler und Sebastian Sprenger, die das Projekt von seinen Anfängen an mitbegleitet haben. Auch bei meinen Bochumer Studierenden - und hier speziell den Teilnehmern meiner Seminare Geschichtskultur und virtuelle Medien (WiSe 2012/13) sowie Historische Dinge und verdinglichte Geschichte. Die Materialität der Vergangenheit (SoSe 2013) - bedanke ich mich für ihre schwungvolle Mitwirkung und die neuen Perspektiven auf das Thema, die sie mir eröffnet haben.

Mein Dissertationsvorhaben profitierte sehr von einem Praktikum am Essener Ruhr Museum im Oktober/November 2012, das mir wichtige und oft überraschende 
Einblicke in die Museumsarbeit und speziell auch die Museumskommunikation ermöglichte. Silke Koop und Philipp Bänfer danke ich für die vorbildliche Betreuung.

Unzweifelhaft prägend für mich und mein Projekt waren die drei Jahre, die ich als Promotionsstipendiat der Friedrich-Naumann-Stiftung für die Freiheit verbringen durfte. Das Stiftungsleben und die stipendiatische Gemeinschaft werden mir unvergessen bleiben - und zahlreiche Gespräche sowohl mit Stiftungsfunktionären als auch mit Mitstipendiaten haben ihre Spuren in meinem Denken und der vorliegenden Arbeit hinterlassen. Stellvertretend für alle hier Ungenannten möchte ich meinen engsten Mitstreitern aus dem stipendiatischen Arbeitskreis Kultur - Annabelle Heise, Beatrix Kempf, Daniel Hammer und Felix Sattler - für die gemeinsam verbrachte Zeit, das miteinander Verwirklichte und die zahlreichen Anregungen danken, die mein Projekt durch sie erfahren hat.

Nur wenige Wochen nach der Verteidigung meiner Dissertation nahm ich eine Beschäftigung am Deutschen Schifffahrtsmuseum - Leibniz-Institut für Maritime Geschichte in Bremerhaven auf. Die Anfertigung des Typoskriptes bzw. die Aufarbeitung der Abgabefassung für die Drucklegung wurde flankiert von meiner Arbeit in der (virtuellen) Museumspraxis und unzähligen langen wie kurzen, ernsten wie lustigen, problemspezifischen wie grundsätzlichen Gesprächen und Diskussionen über die Rolle >neuer Medien im Museumsbetrieb ebenso wie über den Platz des Museums in seiner kulturellen Umwelt. Viele letzte Änderungen an der Studie - inhaltlicher wie stilistischer Art - sind auf solche Gespräche zurückzuführen, und ich danke allen meinen Kolleginnen und Kollegen sehr herzlich für ihren Input, ihre Offenheit und immer wieder auch ihren Witz. Besonderer Dank gilt unserer wissenschaftlichen Forschungs- und Ausstellungskoordinatorin Ruth Schilling ebenso wie Oliver Radfelder von der Hochschule Bremerhaven für letztminütige Unterstützung bei der Titelfindung.

Dem transcript Verlag zu Bielefeld danke ich für die Aufnahme der Arbeit in das Verlagsprogramm und die reibungslose Umsetzung des Veröffentlichungsvorhabens.

Zuletzt, und doch vor allen anderen, danke ich meinen Eltern, Gudrun (geb. Sandner) und Werner Niewerth, für Alles, und widme ihnen dieses Buch in Liebe und Demut.

Die Anfertigung dieser Arbeit wurde durch ein Promotionsstipendium der FriedrichNaumann-Stiftung für die Freiheit aus Mitteln des Bundesministeriums für Bildung und Forschung ermöglicht. 


\section{Einleitung}

Mit einem Schlag werde ich einer dämmrigen Helligkeit gewahr. Eine Antwort geht in mir auf die Suche nach sich selber, löst sich immer mehr von meinen Empfindungen ab, verlangt nach Ausdruck, Malerei und Bildhauerei - so raunt mir der Dämon des Alles-Deutenmüssens zu - sind ausgesetzte Kinder. Ihre Mutter ist tot, ihre Mutter die Architektur. Solange sie am Leben war, wies sie ihnen ihren Ort zu, ihren Sinn, ihre Bindungen. Die Freiheit zu irren, wurde ihnen nicht zugestanden. Sie hatten ihren Raum, ihr wohlabgestimmtes Licht, ihre Themen, ihre Verbundenheiten. Solange sie am Leben war, wussten sie, was sie wollten. »Gottbefohlen«, sagt mir dieser Gedanke, »weiter eindringen möchte ich nicht.«

(Valéry 1958: 7)

Paul Valéry, so lässt er uns direkt im ersten Satz seines Textes Le problème des musées wissen, liebt die Museen nicht (vgl. ebd.: 7). Das 1925 entstandene und 1958 in der Übersetzung Carlo Schmids erstmals dem breiten deutschen Publikum vorgestellte Essay zeichnet das Bild einer Institution, aus der sich die Musen längst verabschiedet haben und die in ihrer Abwesenheit zu einem Auffanglager für verwaiste Zeugnisse menschlicher Schaffenskraft verkommen ist. Ihre gleichsam baulich wie kulturpolitisch »gefirnisten Einsamkeiten« haben für Valéry »etwas vom Tempel, etwas vom Salon, vom Friedhof und vom Schulraum an sich«, und indem er sie durchschreitet, findet er seine Stimme »ein wenig höher als in der Kirche, doch weniger laut als gemeinhin im Alltag« (ebd.). Sein literarischer Museumsbesuch ist in erster Linie von Schuldbewusstsein geprägt, denn er fühlt sich nicht imstande, dem musealen Raum um sich herum die von der Institution eingeforderte Reverenz zu erweisen, ratlos irrt er durch nichtssagende Zusammenstellungen von Werken, die einander 
fremd sind: »Nur eine weder dem Genuß noch der Vernunft verhaftete Zivilisation hat dieses Haus des Nichtzusammengehörens errichten können« (ebd.).

Die Museumsausstellung ist für Valéry ein kannibalisches Übereinanderherfallen, ein gegenseitiges Sich-»Auffressen« (ebd.) von Exponaten, die doch eigentlich in ihrer historischen Funktion nur sich selbst zugehörig seien und folgerichtig auch alleinstehen sollten. Erst der Verlust ihrer »Mutter«, der Architektur (oder, um es weniger blumig zu fassen, der räumlichen Situation, für die sie geschaffen wurden), gibt die Werke den Zwängen des Museums preis, in denen Valéry wiederum die Auskristallisation einer fundamentalen medialen Verirrung der Moderne sieht:

Doch unsere Erbschaften erdrücken uns. Der Mensch von heute, durch die Übergewalt seiner technischen Mittel außer Atem gekommen, ist gerade durch das Übermaß seiner Reichtümer arm geworden. Der Mechanismus der Schenkungen und Vermächtnisse - der Weitergang des künstlerischen Schaffens und der Ankäufe - und jener andere Anlaß für Erweiterungen, der aus dem Bedachte kommt, den man auf den Wechsel der Moden und des Geschmacks und deren Rückwendung zu jüngst noch mißachteten Werken verschwendet, tragen um die Wette pausenlos ein Kapital zusammen, dessen Übermaß gerade ihm die Nutzbarkeit nimmt. (Ebd.)

Die große Paradoxie des Museums liegt darin, das sein »Vermögen« nicht wächst, wenn sich seine »Speicher« füllen (ebd.): Je mehr Objekte angehäuft werden, desto beliebiger wird das einzelne Schaustück - und je meisterhafter und schöner ein Werk ist, desto schlimmer die Gewalt, welche ihm die Musealisierung antut, denn umso stärker verlangt es nach individueller Herausstellung. Museen werden zu Deponien des Historischen, die alles in sich aufnehmen, was die Vergangenheit ihnen hinterlässt:

Das Museum übt eine nicht abreißende Anziehungskraft auf alles aus, was Menschen tun. Der Mensch, der Werke schafft, der Mensch, der stirbt, füttern es. Alles endet an der Wand oder im Schauschrank... Ich kann mich nicht enthalten, an die Spielbank zu denken, die bei jedem Einsatz gewinnt. (Ebd.)

Der Effekt auf den Besucher ist dann einer der Überwältigung und Überforderung. Er kann nicht hunderten von Meisterwerken simultan die gebührende Würdigung zukommen lassen, sie nicht alle gleichzeitig empfindsam ergründen. Sein Blick kennt keine Tiefe mehr und gleitet nur noch pflichtschuldig über die einzelnen Exponate, deren Anwesenheit zwar registriert, aber nicht mehr gedeutet wird. Kurzum: Das Museum macht uns »oberflächlich« (ebd.).

Valérys Kritik am Museum als kultureller Einrichtung ist freilich keine universelle. Ihr Bezugspunkt ist ganz unverhohlen das Kunstmuseum, und noch konkreter dessen französische Ausformung zur Entstehungszeit des Textes in den 1920er Jahren. Die in ihr angerissenen Phänomenbereiche erschöpfen sich indes nicht im Sinn 
und Unsinn einzelner Schulen der Museumsdidaktik. Das titelgebende >Problem der Museen « ist nämlich, wie Valéry ja selbst andeutet, ein Problem der Moderne und ihrer stetig anschwellenden Wissens- und Überlieferungsschätze schlechthin: Das Wachstum der Speicher eilt den Mitteln ihrer sinnhaften Erschließung voraus.

Der Architekt und Grafikdesigner Richard Saul Wurman sollte 1989 - ohne sich dabei auf Valérys konkreten Fall zu beziehen - eine Diagnose für die von Valéry im Museum durchlittene Malaise liefern: »information anxiety«. Wurman, bekannt geworden vor allem als Begründer der $T E D^{1}$-Konferenzen, definiert diesen Zustand als »the black hole between data and knowledge. It happens when information doesn't tell us what we want or need to know« (Wurman 1989: 34). Die historische Situation, in der Wurman diesen Begriff entwirft, ist die eines >Informationszeitalters`, welches für ihn einen Etikettenschwindel darstellt: Tatsächlich nämlich sei es ein Zeitalter der »non-information« (ebd.: 38), geprägt nicht etwa von der Verfügbarkeit von Wissen, sondern von einer Schwemme weitgehend unnützer und aufgrund ihrer schieren Masse kaum mehr interpretierbarer Daten. Die Duplizität der Fälle ist frappierend.

Wo Valéry jedoch letztlich nicht anders kann, als vor der Dichte der Ausstellung und der Ausgesetztheit der Exponate zu kapitulieren und - >gottbefohlen < - dem Museum den Rücken zu kehren, möchte Wurman Wege aufzeigen, die Informationslawine zu bewältigen und das schwarze Loch zwischen Daten und Wissen zu schließen. Das Mittel hierzu nennt Wurman bezeichnenderweise »information architecture ${ }^{2}{ }^{2}$ Als Disziplin im Grenzbereich von Informationswissenschaft und Design angesiedelt, thematisiert diese die Frage nach der Organisation von Wissensinhalten für einen möglichst optimalen Abruf - und schlägt zugleich begrifflich eine Brücke zwischen dem Abstrakten und dem Konkreten. Die Architektur als Mittel der Ordnung und Organisation des physischen Raumes wird zum Vorbild für den Umgang mit immateriellen Wissensinhalten.

Es ist kein Zufall, dass Paul Valéry seinen eigenen Anfall von information anxiety ausgerechnet im Museum erlebt, und nicht etwa im Archiv oder in der Bibliothek, die ja ebenfalls Speicher kultureller Information und im Allgemeinen nicht weniger gut gefüllt sind als die Museen. Archive und Bibliotheken nämlich häufen für gewöhnlich inhaltlich abgeschlossene, einzelne Dokumente an und gewährleisten ihre Zugänglichkeit über wie auch immer strukturierte Kataloge. Das Museum dagegen arbeitet mit interpretationsoffenen und epistemisch unkonkreten Artefakten, deren

1 Abkürzung für Technology, Entertainment and Design. Diese seit 1984 jährlich zunächst in Monterey und seit 2009 in Long Beach, Kalifornien stattfindenden Konferenzen führen unter dem Motto Ideas Worth Spreading öffentlichkeitswirksam prominente Persönlichkeiten aus Wissenschaft, Wirtschaft und Kultur zusammen, deren Vorträge seit 2007 als Videostreams auf der Homepage www.ted.com verfügbar gemacht werden.

2 Vgl. http://www.wurman.com/rsw/index.html vom 09.12.2012. 
Sinngehalt in erster Linie von ihrer wechselseitigen Bezüglichkeit untereinander abhängig ist. Diese wiederum ist üblicherweise das Produkt der Anordnung dieser Objekte im Raum. Archiven und Bibliotheken kann es im Großen und Ganzen gleichgültig sein, welches Buch in welchem Regal steht und welche Akte in welchem säurefreien Karton liegt - entscheidend ist, dass sie zentral verzeichnet sind und bei Bedarf gefunden werden können. Eine Bibliothek ist keine Anordnung, die etwas mitzuteilen hätte - sie ist lediglich ein Magazin für Mitteilungen. Ein Bibliotheksbestand mag mit zunehmender Größe der Desorganisation anheimfallen, die Integrität des Sinngehaltes des einzelnen Buches bleibt hiervon jedoch unangetastet. Das Museum hingegen ist in letzter Konsequenz immer eine Informationsarchitektur und als solche ein transitiver Raum, der eine Verbindung zwischen Ort und Nicht-Ort herzustellen versucht, zwischen den physisch-konkreten Ausstellungsobjekten und diskursiv-abstraktem >Wissen $<{ }^{3}$ Damit erhält auch ein Mangel informativer Anschlussfähigkeit im Museum eine Eindrucksqualität, die er in anderen Wissensspeichern nicht entwickeln würde. Valérys Text ist Zeugnis einer solchen überwältigenden Konfrontation mit materiell auswuchernder Sinnlosigkeit.

Im April 1968 - 43 lange Jahre also nach der Entstehung von Valérys Essay richtete das New Yorker Metropolitan Museum of Art eine Tagung zum Thema Computers and Their Potential Applications in Museums aus. Diese Konferenz markierte nicht die erste wissenschaftliche Auseinandersetzung mit dem Zusammenhang zwischen Museen und Computern (und damit dem Leitmedium der Informationswissenschaft), ${ }^{4}$ beinhaltete aber einen bemerkenswerten Redebeitrag des damals in Stanford lehrenden Kommunikationswissenschaftlers William J. Paisley, in dem eine fundamentale Veränderung des Zugriffs auf museale Sammlungen vorhergesagt wird:

Sometime in 1980 a scholar will enter a major museum, seat himself at a computer terminal in the research room, ask to review all the works depicting, say, sailing vessels. He will want to see bas-reliefs and sculptures, as well as drawings and paintings. He will expect to see works from all significant collections around the world, including works currently in storage in the museums, and those out in travelling exhibitions. (Paisley 1968: 195)

Der von Paisley prognostizierte Zeitrahmen für die Einrichtung eines universellen computergestützten Abrufsystems für alle musealen Objekte der Welt ist offensicht-

3 Insbesondere Gottfried Korff hat diesen Dualismus von Aktualität und Potentialität wiederholt als zentrales Element seines Museumsbegriffs hervorgehoben. Vgl. hierzu beispielhaft Korff 2002b: 141f.

4 Eine kleine Chronologie bedeutender Studien der 60er und 70er Jahre zu diesem Problemkomplex findet sich bei Parry 2006: 15f. Siehe hierzu auch Kapitel 6.3 der vorliegenden Studie. 
lich zu optimistisch bemessen gewesen, die grundsätzliche Idee einer solchen Entwicklung aber müssen wir fast fünf Jahrzehnte später als sehr weitsichtig würdigen. In Paisleys Szenario nämlich wird das >Problem der Museen` medientechnologisch gelöst: Wo Valéry im unkontrollierten, geschwürartigen Wachstum der Sammlungen die unweigerliche Vernichtung der Bedeutungen des Einzelobjektes wahrnimmt, sieht Paisley schlicht eine Problematik des Abrufs. Was er entwirft, ist nichts geringeres als die Idee einer virtuell vereinigten absoluten Sammlung, die in ihrer Größe alle bisher dagewesenen übertreffen, dabei aber zugleich jederzeit die völlige Verfügbarkeit ihrer Inhalte gewährleisten können soll. Die Museumspraxis und die Museumswissenschaft tun sich indes schwer in ihrer Auseinandersetzung mit den digitalen Medien, und die Verbindung von Museum und Computer hat in den meisten Fällen eher den Charakter einer holprigen Zweckehe als jenen einer Liebesgeschichte.

Dabei ist Musealität im Internet längst allgegenwärtig geworden: Kaum ein $\mathrm{Mu}-$ seum kommt noch ohne ein Online-Vorfeldangebot aus, und kaum ein Interessengebiet ist so obskur, dass nicht kleine, verstreute Gruppen von Enthusiasten ihm ein eigenes Netzmuseum gewidmet hätten - von Heimcomputern ${ }^{5}$ bis hin zu Sicherheitsrasierern ${ }^{6}$. Etablierte Institute wie das J. Paul Getty Museum in Los Angeles ${ }^{7}$ oder

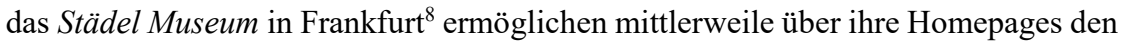
Zugriff auf weite Teile ihrer Sammlungen in Form von Abbildungen und erklärenden Texten. Zugleich erforschen Projekte wie das Virtual Museum of Canada ganz bewusst die Möglichkeiten und Potenziale des Internets als Plattform für virtuelle Darbietungen, die gar nicht länger bestehende Ausstellungen abbilden, sondern gerade das in den Mittelpunkt stellen, was derzeit nicht physisch präsentiert werden kann. Andererseits jedoch hat die Museologie als reflexive Wissenschaft musealer Darstellungen nach einer kurzen Konjunktur des Themas in den 1990er Jahren den Einfluss des Computers und der Vernetzung auf ihren Gegenstand nur unsystematisch thematisiert.

Dabei mangelt es in absoluten Zahlen eigentlich nicht an Publikationen über virtuelle Museumsprojekte. Allein die seit 1997 jährlich in einer anderen nordamerikanischen Stadt tagende Konferenz Museums and the Web publiziert in ihren Procee-

5 Vgl. http://www.8bit-museum.de/, vom 16.02.2016. Siehe auch Kapitel 7.3.1 dieser Arbeit.

6 Vgl. http://www.creekstone.net/razors/ vom 16.02.2016.

7 Vgl. http://www.getty.edu/museum vom 16.02.2016. Siehe auch Kapitel 7.1.1 dieser Arbeit.

8 Vgl. http://www.staedelmuseum.de/ vom 16.02.2016. Siehe auch Kapitel 7.1.2 dieser Arbeit.

9 Vgl. http://www.virtualmuseum.ca vom 16.02.2016. Siehe auch Kapitel 7.2.2 dieser Arbeit. 
dings jedes Jahr dutzende Beiträge zu einzelnen Fragestellungen der Museumskommunikation in digitalen Medien. ${ }^{10}$ In der englischsprachigen Welt stand dabei die Diskussion über den Computereinsatz in Museen Ende der 1990er Jahre zunächst in direkter Verbindung mit einer Debatte um die generelle museale Verwendung von Medien jenseits der tatsächlichen Exponate - was bisweilen dazu führte, dass der Begriff des \Mediums in der museumswissenschaftlichen Literatur implizit zum Gegenbegriff des `Exponats` wurde. Der Titel des 1998 von Selma Thomas und Ann Mintz veröffentlichten und seitdem vielzitierten Sammelbandes The Virtual and the Real. Media in the Museum bildet in diesem Zusammenhang gleich zwei Kern- (und Fehl-)Einschätzungen der museologischen Bewertung der `neuen Medien` ab: erstens nämlich, dass das >Virtuelle ‘ außerhalb des Realen stünde, wenn es ihm nicht gar diametral entgegengesetzt sei, und zweitens, dass ein Auftauchen von Medien im Museumsraum ein Sonderfall und Ausnahmezustand sei, über den es sich zu schreiben gebiete.

Während die erste Annahme sich sowohl an der Begriffsgeschichte ${ }^{11}$ des Wortes >Virtualität` als auch an der Praxis unseres Umgangs mit ihm ${ }^{12}$ zerschlägt, verbirgt sich in der zweiten eine (von Kuratoren womöglich zuweilen auch sich selbst gegenüber betriebene) Verleugnung dessen, was Museen eigentlich sind und leisten, denn: Natürlich sind alle von Museen gesammelten und ausgestellten Gegenstände letztlich Medien. Das, was im Museum steht, ist längst nicht mehr der unmittelbare Überrest einer in unsere Gegenwart hinübergeretteten Vergangenheit, sondern vielmehr das Produkt einer Inszenierung innerhalb von Institutionen (vgl. Korff 2002b: 141; vgl. Waidacher 2000: 4; vgl. Grütter 1997: 671). Was Museen uns zeigen, ist niemals sreal<, sondern wie Valéry bereits so treffend feststellt, eine Scheinwelt - errichtet um Dinge herum, deren >Wirklichkeit` längst erloschen und somit Geschichte geworden ist.

Nichtsdestoweniger kommt kaum eine Museumsdefinition umhin, die Bedeutung des Materiellen und des >Echten ‘ für die Institution und ihren sozialen Auftrag zu betonen (vgl. z.B. Waidacher 2000: 7). Als in den 1990er Jahren erstmals der Begriff des >virtuellen Museums` in Wissenschaft und Öffentlichkeit zu kursieren begann, waren Reibungen vorprogrammiert: Digitale Museumsangebote wurden nicht selten als Konkurrenzmodelle zur klassischen, physischen Museumssituation betrachtet und standen für viele Fachleute zunächst unter einem grundsätzlichen Verdacht der pädagogischen Verflachung (vgl. Samida 2002: 3). Auch musste diese neue Bezeichnung

10 Ein beträchtlicher Teil der betreffenden Papers wird, dem Schwerpunkt der Tagung entsprechend, online verfügbar gemacht, siehe http://www.museumsandtheweb.com/ bibliography/ vom 18.06.2018.

11 Siehe zur Geschichte des Virtualitätsbegriffs Kapitel 2.1 dieser Arbeit.

12 Siehe zur Frage nach Alltäglichkeit und Außergewöhnlichkeit virtueller Erlebnisdimensionen Kapitel 6.5.1 dieser Arbeit. 
unweigerlich Debatten darüber anstoßen, wie dehnbar der Museumsbegriff tatsächlich ist und sein darf: Von der Antwort auf die Frage, ob virtuelle Museen tatsächlich als $>$ Museen $`$ verstanden und behandelt werden dürften, hing letztlich auch $a b$, ob und in wie weit sie überhaupt in den fachlichen Zuständigkeitsbereich der Museologie fallen würden.

Diese Debatten der 1990er und frühen 2000er Jahre werden im Folgenden noch genauer beleuchtet werden. Tatsächlich scheinen sie in der Rückschau ohnehin rein akademischer Natur gewesen zu sein. Alle Zweifel an der didaktischen und institutionellen Legitimität virtueller Museen haben die Museumsvirtualisierung nicht aufhalten können, und vor diesem Hintergrund scheint es fast Methode zu haben, dass das Fach sich im Hinblick auf Digitalisierung und Mediennutzung im Museumsbetrieb fast völlig in Einzeluntersuchungen und Individualdarstellungen konkreter Projekte verlaufen hat. Grundsätzliche Arbeiten über die Natur der eigenen Institution und deren Verhältnis zur inneren Logik digitaler Medien liegen bis dato kaum vor. Bemerkenswerte Ausnahmen bilden Suzanne Keenes Buch Digital Collections. Museums and the Information Age (Keene 1998), das sich mit der Sachgeschichte musealer Computernutzung in der englischsprachigen Welt befasst, und Ross Parrys Monographie Recoding the Museum (Parry 2006), welche die Museumsdigitalisierung als logische Fortsetzung aller musealen Didaktik versteht. Im deutschsprachigen Raum hat vor allem Werner Schweibenz den Begriff des virtuellen Museums stark gemacht und in einer Anzahl von Aufsätzen systematisiert. Ansonsten scheint die Museologie Grundsatzdiskussionen über Digitalisierung und Virtualisierung zu meiden - und mit ihnen auch die Frage, inwiefern derzeit in dieser Richtung stattfindende Entwicklungen möglicherweise auf das Wesen der Institution Museum zurückweisen und dieses zur Disposition stellen.

Es erscheint daher geboten, diese Grundsatzfragen wieder ins Recht zu setzen und sich dabei theoretischer und methodischer Ansätze zu bedienen, die gerade nicht aus dem disziplinären Instrumentarium der Museologie stammen. Virtuelle Museen sind Angebote der kulturellen und kommemorativen Kommunikation, die von digitalen Medientechnologien getragen werden - und insofern liegen sie auch ganz und gar auf dem Interessenspektrum der Medien- und Kommunikationswissenschaften. Diese wiederum haben seit der Jahrtausendwende eine veritable Fülle von Veröffentlichungen zur Rolle der sneuen Medien ( (und speziell des World Wide Web) in der immer wieder politisch proklamierten >Wissensgesellschaft hervorgebracht. Besondere Aufmerksamkeit wird dabei der Vorstellung vom Netz als Tummelplatz für Amateure gezollt, die sich - tatsächlich oder vermeintlich - »strategische Ressourcen unter den Nagel [reißen] «, »einst sorgfältig überwachte Medienkanäle [verstopfen]« und »die Macht der Mandarinklasse« infrage stellen, »Geschwätz von Wissen zu 
trennen « (Lovink 2010: 53). ${ }^{13}$ Diese Rhetorik des niederländischen Medienwissenschaftlers und Web-Aktivisten Geert Lovink bildet ganz unverblümt die Stoßrichtung einer Medienwissenschaft ab, welche die Wissenskultur des WWW zuvorderst als eine liest, in der klassische Institutionsgefüge und Machtmechanismen zerschlagen und entwertet werden. Die freie Online-Enzyklopädie Wikipedia taucht in diesem Zusammenhang immer wieder als Beispiel für eine `Schwarmintelligenz` auf, die ohne jede Form von Institutionalisierung oder Expertenaufsicht sehr erfolgreich Sinn produziert - indem sie letztlich ihr Wissenssystem mit dem sozialen System ihrer Nutzer verschränkt und damit zu einem Aushandlungsort dessen wird, was überhaupt >wissenswert ‘ ist (vgl. Lorenz 2009: 294). Dieser Perspektive diametral gegenüber steht in laufenden Diskussionen der Medienwissenschaft die Frage nach Lenkung und Fremdbestimmung im Umgang mit digitalen Medien - und zwar gerade auch durch kommerzielle Akteure. Die Suchmaschine Google und das in den vergangenen anderthalb Jahrzehnten um sie herum entstandene Wirtschaftsimperium bilden nur das augenfälligste Beispiel einer scheinbar völligen Vereinnahmung der Nutzermassen durch profitorientierte Überwachungs- und Steuerungsmaschinerien ab, denen zu entkommen kaum mehr möglich ist (vgl. u.a. Jeanneney 2007).

Während diese beiden Zugänge in sehr unterschiedliche Richtungen weisen, ist ihnen doch eine zentrale Annahme gemein - nämlich die, dass mit der Digitalisierung klassische und etablierte Wissensinstitutionen wie Archive, Bibliotheken und Museen ebenso wie die sich mit ihnen verbindenden Expertensysteme zugunsten neuer Akteure an Bedeutung verlieren. Entsprechend sind die spezifischen und konkreten Medienwechsel und -wandel, die für diese Einrichtungen mit Digitalisierungserscheinungen einhergehen, meist von sehr viel geringerem Interesse als das Netz und seine epistemischen Eigenarten selbst, für welche konkrete Dienste und Webseiten nur mehr als illustrative Schaustücke herangezogen werden. Insofern bleibt das virtuelle Museum aus der Perspektive der Medien- ebenso wie aus jener der Museumswissenschaft mindestens zur Hälfte unsichtbar: Medien- und Kommunikationswissenschaften sind blind für das institutionelle Selbstbild des Museums bzw. seinen gesellschaftlichen Auftrag und sein Selbstverständnis in seiner konkreten Objektund Raumbezogenheit. Der Museologie wiederum fehlen die medientheoretischen Voraussetzungen, innerhalb derer sich das Museum in seinem Funktionieren als Mediensystem beschreiben und damit im Vollzug seiner Virtualisierung systematisieren ließe.

Problematisch ist auch, dass beide Ansätze den Forschungsgegenstand `virtuelles Museum ‘ als einen im Grunde bereits erschlossenen und benannten voraussetzen. In der Museologie beschreibt der Begriff gemeinhin den Versuch, mittels digitaler Medien ein museales Ausstellungsangebot nachzuahmen (vgl. Samida 2002: 24f.). Dies

13 Das Zitat wird unverkürzt noch einmal in Kapitel 5.4 dieser Arbeit wiedergegeben und genauer eingeordnet. 
führt allzu oft dazu, dass sich die Qualität virtueller Museumsangebote aus Sicht der Museumswissenschaft vor allem danach bemisst, wie sehr und wie erfolgreich diese klassischen Aufgaben und Zielsetzungen der Institution Museum aufgreifen und umsetzen - das virtuelle Museum muss sich also nach den didaktischen Vorgaben des klassischen physischen beurteilen lassen. Blick man hingegen durch die medienwissenschaftliche Brille auf das virtuelle Museum, scheint es zunächst lediglich ein virtuelles Angebot unter vielen zu sein, die gegenwärtig im medialen Alltag auf uns einprasseln. Formal und technisch ist es nicht kategorisch verschieden von virtuellen Archiven, Bibliotheken, Enzyklopädien - oder gar Internet-Kaufhäusern. Das spezifisch >museale verliert sich im technologischen Ökosystem zwischen standardisierten Schnittstellen, die für das World Wide Web und andere digitale Mediendispositive typisch geworden sind. Weder die Museologie noch die Medienwissenschaft sind also bisher aus sich heraus imstande gewesen, das virtuelle Museum als eine souveräne und genuin neue Erscheinungsform kultureller Kommunikation zu verstehen, der es nach ihren eigenen und überhaupt noch nicht ausgehandelten Maßstäben gerecht zu werden gilt. Es gibt noch kein Beschreibungsmodell und Theoriegebäude, innerhalb dessen es sich über virtuelle Museen als solche sprechen ließe.

Ein sich implizit durch nahezu die Gesamtheit der existierenden Literatur zu virtuellen Museen ziehender Topos ist dabei die Vorstellung, dass im Prozess der Museumsvirtualisierung das Museum notwendigerweise das Objekt, der Computer und seine Programmierer hingegen die Subjekte seien. Virtualisierung (und dieser Begriff wird im Laufe dieser Arbeit noch genauer zu erläutern sein, insbesondere in seinem Verhältnis zur Digitalisierung) scheint ein Prozess zu sein, der einseitig auf das Museum einwirkt - während neue Medientechnologien das Museum in seiner institutionellen Gänze erfassen und in Zweifel ziehen, wird die Handlungsmacht der Museen darauf begrenzt gesehen, ihre eigenen virtuellen Vorfelder zu gestalten. Museumsvirtualisierung scheint dementsprechend tatsächlich in erster Linie Virtualisierung des Musealen zu heißen. Museen schaffen sich gediegene Internetauftritte, digitalisieren Sammlungsbestände und Verwaltungsabläufe, interagieren via Facebook und Twitter mit einem Publikum, dass sich zuvor nur sehr bedingt der Institution mitteilen konnte, bieten Handy-Apps als Alternative zum klassischen Audioguide an - kurzum: Digitale Medien, mit ihrem kombinierten Versprechen inhaltlicher Fülle, allgegenwärtiger Abrufbarkeit und ständigen, unmittelbaren >Dabeiseins`zwingen der Institution Museum ihr kulturelles Paradigma auf, während die Museen nach Kompromissen und Winkelzügen suchen, dieser neuen Anforderungslage gerecht zu werden, ohne ihre spezifische Eigenart als Bildungseinrichtungen aufgeben zu müssen. In diesem Sinne erzählt der Großteil der existierenden Literatur die Geschichte der Museumsvirtualisierung zugleich auch als eine Geschichte des Umbruchs: Digitale Medien, so der Tenor, verwerfen die Prinzipien von Materialität, Dauerhaftigkeit, Institutionalisierung und Expertentum zugunsten von Simulation, Flüchtigkeit, Offenheit und Teilhabe. Das virtuelle Museum wird als mediale und diskursive Abkehr vom 
physischen verstanden und somit gewissermaßen als ein >Danach Museumsdispositivs. Arbeiten, die zwischen physischem und virtuellem Museum irgendeine Form von Kontinuität diagnostizieren, findet man kaum: Das erwähnte Buch aus der Feder Ross Parrys bildet hier wohl die prominenteste Ausnahme.

Nimmt man indes die konkrete Funktionalität musealer Vermittlung in den Blick, so fällt unweigerlich auf, dass Museen in ihrer ganzen Anlage einer sehr viel svernetzteren $<$ Vermittlungsphilosophie folgen als alle anderen etablierten Einrichtungen unserer kommemorativen Kultur. Der Grund hierfür ist derselbe wie jener für Valérys Anfall von Informationsangst im Museumsraum: Würden Museen wie Archive oder Bibliotheken arbeiten und den Zugriff auf ihre Ausstellungsstücke über Katalogsysteme abwickeln, dann wären diese Exponate kaum aussagekräftig. Museen vernetzen Ausstellungsstücke auf ganz ähnliche Weise, wie das World Wide Web Webseiten vernetzt: Dinge, die für sich allein unscharf und vieldeutig bleiben müssten, werden Aussagekräftig gemacht, indem man sie zueinander in Relation setzt - und somit natürlich auch zum musealen Raum selbst. Vor diesem Hintergrund erscheint es durchaus folgerichtig, dass die meisten virtuellen Museen in Gestalt ganz gewöhnlicher HTML-Seiten daherkommen, und nicht etwa in jener aufwändig produzierter, computerspielartiger virtual reality-Formate. Stellt man also das Primat das Materiellen für einen Augenblick zur Seite, so scheinen die Kommunikationsstrukturen des Museums sich viel mehr für eine Transposition in bestehende digitale Infrastrukturen zu eignen als jene von Archiv und Bibliothek, die Schriftmedien sammeln - und dies ausdrücklich gerade weil Museen ihr Mitteilungssystem mit materiellen Objekten in der Architektur physischer Räumlichkeiten entfalten.

Die vorliegende Arbeit will keine Streitschrift sein. Sie will auch nicht den anmaßenden Versuch unternehmen, eine alle Diskussion beendende Bestandsaufnahme über das Problemfeld der Museumsvirtualisierung zu werden. Vielmehr möchte der Autor diese Studie als den Versuch zum Anstoß einer erneuten Diskussion nicht nur über virtuelle Museen, sondern vielmehr über die Rolle der Institution Museum in einer von digitalen Medientechnologien durchdrungenen Kulturwelt verstanden wissen. Die von der existierenden Forschungsliteratur weitgehend unbeantwortete (und womöglich für die Zukunft der Institution kardinale) Frage ist nicht länger jene, wie neue Medien mit traditionellen Leitlinien musealer Vermittlung brechen und den Sinn einer vom Versprechen des $\$ Echten $<$ lebenden Einrichtung theoretisch-grundsätzlich und praktisch-konkret ins Zwielicht stellen. Vielmehr muss sie lauten: Wo überlagern sich das Museum und das Web, wo bilden sie Schnittmengen in Funktion und gesellschaftlicher Erwartungshaltung aus, wo greifen sie ineinander (oder könnten sie ineinandergreifen) - und wie ist das Museum womöglich in eine Mediengeschichte einzureihen, deren jüngstes Kapitel eben jenes der sogenannten >Digitalisierung< ist? 
Um sich diesen Fragen zu nähern wird es unvermeidlich sein, den Bedrohungsgestus abzulegen, der zwei Jahrzehnte lang die Auseinandersetzung der Museumswissenschaft mit Computern bestimmt hat - ohne dabei aber diese Befürchtungen blindlings vom Tisch zu fegen. Die zentrale Prämisse dieser Arbeit wird die sein, dass das Museum nach einem Vierteljahrhundert Ausstellungstätigkeit im Internet durchaus keine sterbende Institution ist und dass eine Auflösung des klassischen Museums in digitalen Angeboten bisher weder stattgefunden hat noch im Vollzug zu sein scheint. Diese Prämisse ist freilich schwer zu beweisen. Es existiert derzeit so gut wie keine empirische Besucherforschung, anhand derer sich nachhalten ließe, ob virtuelle Museumsangeboten den physischen Häusern Besucher abjagen oder nicht bzw. ob sie sich womöglich gar positiv auf Besucherzahlen auswirken, was natürlich genau das wäre, was sich Museen von ihren digitalen Präsenzen erhoffen. Die antiapokalyptische Grundhaltung dieser Arbeit der Museumsvirtualisierung gegenüber stützt sich vor diesem Hintergrund auf zwei Sachverhalte: Erstens scheint die grundsätzliche Opposition virtuellen Museumsprojekten gegenüber zumindest in der zum Druck gelangenden Fachliteratur seit Mitte der 2000er Jahre fast völlig erloschen zu sein. Gestritten wird zwar noch über die Berechtigung kleiner wie großer Einzelunternehmungen, kaum aber darüber, dass Museen sich prinzipiell auf die neuen Medien und die Bedürfnisse eines auf diese hinsozialisierten Publikums einstellen müssen. Zweitens ist der Autor dieser Arbeit in zahlreichen Gesprächen mit Museumstheoretikern und -praktikern immer wieder in dem Eindruck bestätigt worden, dass die Virtualisierung bisher an den meisten Häusern zu keinen merklichen Rückgängen der Besucherzahlen geführt hat.

Die zweite zentrale Vorannahme der Studie ist die, dass es keine unabänderliche 〉ssenz` des Museums gibt, sondern vielmehr ein historisches Fluktuieren seiner Betreiber, seiner Öffentlichkeiten, seines sozialen Auftrags und seiner Ausstellungsgegenstände. Die Arbeit will und wird sich nicht an der Frage abarbeiten, ob ein virtuelles Museum tatsächlich ein Museum sein kann oder nicht. Sie setzt stattdessen aus dem historischen Umstand, dass der Museumsbegriff seit der Antike eine Vielzahl sehr unterschiedlicher Institutionen bezeichnet hat, voraus, dass sich sein Geltungsbereich auch in Zukunft verändern, weiten oder auch verengen könnte. Das > virtuelle Museum beschwört einen sozialen Ort ebenso wie dessen mediale Beschaffenheit und entsprechend kann über virtuelle Museen nur im Kontext des klassischen Museums und der neuen Medien gesprochen werden.

Die Kategorien des Materiellen und des Räumlichen müssen in diesem Sinne paradoxerweise sowohl relativiert als aber auch akzentuiert werden. Das Museum als Mediensystem zu verstehen heißt notwendigerweise, sich von allen Verklärungen und aller institutionellen Schwere frei zu machen und den musealen Raum ganz unromantisch als eine Ansammlung von Kommunikationsvorgängen, ihren materiellen Trägern und natürlich den Kommunizierenden selbst zu begreifen. Zugleich aber heißt es auch, sich Raum und Dinge sehr akribisch und systematisch anzuschauen 
und herauszuarbeiten, wie genau sie museale Kommunikation bedingen und strukturieren - nur so kann schließlich über deren Transponierbarkeit in digitale Medien gesprochen werden.

Diesen Grundlagenbetrachtungen widmet sich das erste Kapitel der Arbeit. Seinen Auftakt bildet ein kurzer Galoppritt durch die Geschichte des Museums als Einrichtung und Begrifflichkeit von der Antike bis in die Gegenwart. Die zwei darauffolgenden Unterkapitel befassen sich daran anknüpfend mit eben den zwei Kategorien des musealen Ausstellungsstückes und des musealen Raumes. Als zentrale analytische Zugänge zur Wesensart von Museumsexponaten werden dabei Hans-Jörg Rheinbergers Konzept des epistemischen Dings sowie Aleida Assmanns Vorstellung einer wilden Semiose in der Dingwahrnehmung herangezogen. In Bezug auf den Raum wird zunächst untersucht werden, inwiefern auch die Architektur als Gestaltung von Raumsystemen semiotischen Charakter aufweist - und wie die Museologie sich üblicherweise zur Kategorie des architektonischen Raumes verhält. Es wird nach den Kommunikationsstrukturen von Museumsausstellungen gefragt werden - und nach der Rolle von Standpunkten, Perspektivwechseln und Uneindeutigkeiten in Ausstellungen. Zuletzt werden auch die affektiven Größen musealen Erlebens behandelt werden, bzw. die Frage danach, wie der Raum des Museums das Erfahren von Aura und Atmosphäre ermöglicht - und was eigentlich jene Echtheit oder Authentizität ist, die er verbürgen will. Das letzte Unterkapitel wird dann anstelle einer abschließenden und einengenden Definition den Versuch unternehmen, die Betrachtung des Museums als ein Dispositiv im Sinne Michel Foucaults, Gilles Deleuzes und Giorgio Agambens plausibel zu machen, in dem es vor allem um die Produktion von Subjektrollen und Machtvektoren geht.

Kapitel 2 bildet ebenfalls ein Grundlagenkapitel - und befasst sich mit dem Begriff der Virtualität sowohl in seiner geistesgeschichtlichen Bedeutung als Konzept der Ontologie als aber auch in seiner gegenwärtigen Verwendung als quasi-technischer Begriff, in welcher er bisweilen mit jenem der `Digitalität` austauschbar zu werden scheint. Besondere Aufmerksamkeit wird hier der Bedeutung des Virtuellen in der mittelalterlichen Scholastik und in der postmodernen Philosophie insbesondere Gilles Deleuzes gewidmet werden. Es wird zu klären sein, was an Computern eigentlich >virtuelk ist - und welche Rolle hier Visualisierungssysteme bzw. Benutzeroberflächen und Interfaces spielen. In einem zweiten Schritt wird es heißen, diese Beobachtungen auf die Kategorie des `Netzwerks $\triangleleft$ und damit die zentrale Form computerisierter Mediensysteme zu übertragen. Kapitel 2.3. wird sich der Geschichte und Theorie des Mediums >Hypertext zuwenden. Es soll behandelt werden, worin das virtuelle Moment modularisiert-vernetzter Textorganisation liegt, und welche spezifische `Grammatik» mit hypertextueller >Verlinkung` einhergeht. Unterkapitel 2.4. wird diese Überlegungen an die Kategorie des Raumes und damit das Museumsdispositiv zurückbinden: Es soll aufgezeigt werden, dass Beschreibungsansätze für Hy- 
pertextsysteme meist auf topologische Vorstellungen und damit metaphorische Verräumlichungen hinauslaufen, die es zu >navigieren ‘ gilt und in denen der Nutzer mal zum >Detektiv $<$, mal zum >Flaneur $<$ oder >Dandy $<$ wird. Durch all diese Betrachtungen hindurch wird besonders die Vorstellung von Assoziativität als modernes Paradigma von Wissensorganisation immer wieder aufgegriffen werden.

Das dritte Kapitel führt diese Vorüberlegungen zusammen und beschreibt das svirtuelle Museum` sowohl im Zusammenhang eines Medienwechsels als aber auch in jenem einer Kontinuität zum physischen Museum. Der erste Schritt ist dabei jener einer begrifflichen und begriffsgeschichtlichen Aufarbeitung. Daran anschließend wird es darum gehen, die Kategorie des >Dings $<$ im Hinblick auf ihre möglichen Entsprechungen im digitalen Mediendispositiv näher zu betrachten. Es wird dabei zu klären gelten, wie sich Dinge und Informationen für gewöhnlich im Ausstellungskontext zueinander verhalten - und wie sich diese Beziehung verschiebt, wenn >Dinge < auf einmal wesentlich aus Information bestehen. In einem dritten Schritt wird schließlich die >Räumlichkeit digitaler Informationsvermittlung zum Thema bzw. die Frage, welche Rolle der Raumkategorie in dieser einerseits als Metapher, andererseits aber auch (wie in der information architecture) als didaktischer Leitidee zukommt. Es soll (unter besonderer Berücksichtigung von Raumtheorien wie jener Michel de Certeaus) danach gefragt werden, wie unser Sehen und Handeln in der physischen Welt Raumvorstellungen produziert und welche Entsprechungen es hierzu in virtuellen Umwelten geben könnte. Zu diesem Zweck wird die Arbeit den zugegebenermaßen etwas angestaubten Begriff des Cyberspace heranziehen, mit dem sich die Vorstellung von emergenten und prozesshaften Raumstrukturen verbindet, die sich um die >Bewegungen schließend wird den Grenzen der Raum-Metaphorik im Hinblick auf digitale Informationsvermittlung nachzuspüren sein, und somit auch danach, in wieweit es für virtuelle Museen tatsächlich Sinn ergibt, das Räumlichkeitsparadigma hochzuhalten.

Kapitel 4 nimmt sich unter dem Titel Das Museum von Babel der bei Paisley angeklungenen Idee eines universellen Museums an - und zwar dezidiert unter den augenblicklich gegebenen Voraussetzungen digitaler Datenübertragung. Wie die Kapitelüberschrift bereits andeutet, wird dabei das in Jorge Luis Borges Kurzgeschichte Die Bibliothek von Babel (und zuvor in Kurd Laßwitz' Die Universalbibliothek) entwickelte Phantasma von einer absoluten Bibliothek den Dreh- und Angelpunkt der Überlegungen bilden und an seinem Beispiel die generative Eigendynamik des digitalen Codes thematisiert werden. Es wird danach zu fragen sein, wie sich digitale Daten überhaupt an die menschliche Kulturwelt zurückbinden lassen - und in diesem Zusammenhang eine kleine Geschichte moderner Internet-Suchmaschinen vorgestellt werden. Es ist zu analysieren, wie Suchmaschinen quasi-räumliche Verhältnisse zwischen Wissensgegenständen etablieren, die tatsächlich nicht im Raum ausgedehnt sind, bzw. wie Verlinkungs-Verhältnisse diese Gegenstände einander ınäher oder >ferner` bringen können. Auf Basis dieser Betrachtungen wird die These formuliert, 
dass wir uns längst in einem >gezähmten` Netz bewegen. Mit diesen Vorüberlegungen im Gepäck wird sich das Kapitel dem französischen Abenteurer, Kulturtheoretiker und Staatsmann André Malraux und seiner Theorie vom Imaginären Museum zuwenden. Malraux sieht in der technischen Reproduzierbarkeit von musealen Objekten die Vollendung der Institution Museum in einer Befreiung der Dinge von den Wänden, die sie einst umgaben - und zugleich in der sich laufend wiederholenden Neukontextualisierung dieser Dinge die Voraussetzung ihrer fortlaufenden Anschlussfähigkeit. Diese Überlegungen sind auf ihre Bedeutung für die virtuellen Museen der Gegenwart hin abzuklopfen - und auch darauf hin, ob sie sich womöglich an ihren technischen Gegebenheiten reiben.

Kapitel 5 widmet sich darauf aufbauend dem Wechselspiel von Offenheit und Fremdbestimmung, dem wir im Umgang mit kulturellem Erbe im World Wide Web laufend unterworfen sind. Hier wird das von Gilles Deleuze und Félix Guattari im Anti-Ödipus ausgearbeitete Konzept des Rhizoms den Rahmen der Betrachtung vorgeben, und über Espen Aarseths Vorstellung von Cybertext soll die Rolle der Rezipienten in einer Kulturvermittlung greifbar gemacht werden, die mehr und mehr den technischen Voraussetzungen eines von Ranking-Systemen strukturierten Webs unterworfen ist. Es wird gefragt, wer hier noch in irgendeiner Form als >Autor< oder eben Kurator auftreten kann - und was die Kulturwissenschaften der scheinbaren Beliebigkeit und Massenwillkür von Google und Konsorten entgegenzusetzen haben. In diesem Zusammenhang werden die methodischen Ansätze der Digital Humanities ebenso vorgestellt wie die Cultural Analytics Lev Manovichs, die den Suchmaschinen mit einem im großen Stil gedachten `Gegen-Google begegnen wollen.

Das sechste Kapitel bildet das letzte Theoriekapitel der Arbeit und konfrontiert die in Kapitel drei gemachten Grundsatzfeststellungen über das virtuelle Museum mit den in Kapitel 4 und 5 gemachten Analysen seiner medialen Umwelt unter besonderer Berücksichtigung ganz konkreter Rezeptionssituationen. Dabei wird zunächst betrachtet werden, wie das Museum mit einem Web umgehen kann, dem nicht erst kommerzielle Akteure ein Leitprinzip der Auffindbarkeit und unmittelbaren Bedürfnisbefriedigung eingeimpft haben. Die `Long Tail<-Theorie des Google-Mitbegründers Chris Anderson, der zufolge das Web zwar das bereits Populäre privilegiert, zugleich aber auch neue Räume für marginalisierte und randständige Äußerungen entstehen lässt, wird hier eine besondere Rolle spielen. Anschließend soll die Entwicklung der Computernutzung in Museen seit den 1960er Jahren untersucht und nachgezeichnet werden, wie sehr diese nicht zuletzt auch das Verhältnis der Häuser zu ihren eigenen Sammlungen und ihrem Publikum verändert hat. Das vorletzte Unterkapitel widmet sich der Frage, inwieweit digitale Daten authentisch sein können und welche Verfahren sich heranziehen lassen, um ihnen diese Qualität zu verleihen. Abschließend gilt es, die tatsächlichen medialen Dispositive zu untersuchen, in denen >Besucher` den Weg ins virtuelle Museum finden können: Wie sind unsere Computer 
sozial situiert? Wo benutzen wir welche Geräte? Wie wirkt sich dies auf unsere Erwartungen an unsere Rezeptionserfahrungen aus? Und: Wie verträgt sich die längst nicht mehr hinwegzudiskutierende Alltäglichkeit von Computern mit den hochgradig auratisch aufgeladenen Zukunftsvisionen, die sich stets mit ihnen verbunden haben und immer noch verbinden?

Das siebte Kapitel schließlich ist ein Fallstudienkapitel, das an dreizehn Beispielen fünf Kategorien virtueller Musealität unter die Lupe nimmt. Das erste Unterkapitel widmet sich virtuellen Angeboten, die von individuellen Museen als Verlängerung ihrer physischen Ausstellungen betrieben werden. Das zweite Unterkapitel stellt professionelle und häufig extrem groß angelegte Projekte vor, die weit verstreute Sammlungen über vereinheitlichte virtuelle Plattformen zusammenführen möchten. Kapitel 7.3. befasst sich mit Amateurprojekten, die als virtuelle Museen auftreten und nicht nur neu verhandeln, was ein Museum ausstellen darf und sollte, sondern auch, in welcher Beziehung es sich zu seinem Publikum verstehen kann. Kapitel 7.4. stellt Plattformen vor, deren Ausstellungsgegenstände nicht etwa Digitalisate physischer Objekte, sondern originär digital sind. 7.5. schließlich befasst sich mit >Grenzgebieten` von Musealität und Virtualität - sowohl in Form konkreter Webseiten als aber auch von technischen Entwicklungen, die selbst nicht als Erscheinungen von Museumsvirtualisierung auftreten, aber weitreichende Implikationen für den Umgang mit digitalem Kulturerbe aufweisen.

Am Ende der Studie soll und kann kein 〉Geheimrezept`für gelungene Museumsvirtualisierung und kein `Schlachtplan` für die (womöglich gar nicht erforderliche) >Rettung « des Museums im Informationszeitalter stehen. Was sie stattdessen anbieten möchte ist ein zeitgemäßer Umriss einer Gemengelage, die allzu lange theoretisch und methodisch zu erfassen gar nicht versucht worden ist. Sie will Analysewerkzeuge und Verstehensansätze für das überaus heterogene und vielschichtige Wechselspiel von Museum und Virtualität erschließen und in diesem Sinne das Spektrum der Zugänge zu diesem Problembereich zugleich schärfen als aber auch weiten. Dies bedeutet einerseits, zu einem konziseren und sachgerechteren Verständnis des Gegenstandes zu gelangen, als die Forschungsliteratur es derzeit zugrunde legt - andererseits aber auch, seinen Geltungsbereich auszuloten und kenntlich zu machen, wo und wie er womöglich noch ganz andere, essentielle Fragestellungen von Kulturvermittlung und kulturellem Bewusstsein unter den medialen Voraussetzungen unserer Gegenwart berührt und überlagert. Über virtuelle Museen zu sprechen heißt, so will die vorliegende Arbeit darlegen, sehr grundsätzliche Diskurse darüber zu führen, wie sich Menschen und Gesellschaften inhaltlich und funktional zu institutionalisiertem Wissen verhalten - und zu den Mediensystemen, über die es ihnen vermittelt werden soll.

In diesem Zusammenhang wird es auch darum gehen, ob der genannten und von der Fachliteratur bisher fast ausschließlich thematisierten Virtualisierung des Muse- 
alen (d.h. der Digitalisierung musealer Bestände, Verwaltungs- und Ausstellungstätigkeit) womöglich eine Musealisierung des Virtuellen nachfolgt - und was genau eine solche beinhalten könnte. Diese Frage ist letztlich eine nach dem Ort und der Rolle des Museums in laufenden Entwicklungen innerhalb digitaler Mediensysteme, in denen Valérys Museumskritik ebenso relevant wird wie Wurmans Vorstellung von Informationsarchitektur: Was hat das Museum aus seiner medialen und institutionellen Eigenart heraus beizutragen zu laufenden Debatten über ein Web, das einerseits mitzugestalten so einfach ist wie nie zuvor, das aber andererseits durchdrungen ist von kommerziellen Akteuren wie Suchmaschinenbetreibern und social networks samt ihrer Methoden des data mining und der analytics? Gibt das Web im Sinne Paisleys die späte Antwort auf die information anxiety, die Valéry im Museum erlebt - oder hat vielleicht 90 Jahre später das Museum dem Internet etwas über den Umgang mit >Informationsfluten « und >Wissensexplosionen` beizubringen? Was trägt das Museum mit seinen Sammlungsgegenständen, seiner Pädagogik und seinem Selbstbild heran an digitale Mediendispositive und die virtuellen Communities, die sich mit ihnen verbinden? Wie fügt es sich ein in die Modalitäten des digitalisierten Sich-Mitteilens und -Verständigens, die uns einerseits selbstverständlich geworden sind, deren langfristige kulturelle Implikationen aber in weiten Teilen noch gar nicht abzusehen sind?

Und schließlich: Welche Rolle könnte `das Museale` als Leitfigur von Speicherung und Vermittlung spielen in einer Welt, in der nicht nur kommemorative Kommunikation zunehmend auf digitalem Wege stattfindet, sondern in der auch die Bewahrung und Verfügbarmachung digitaler Daten selbst immer mehr zur Schicksalsfrage von Geschichtskultur wird? 


\section{Das Museum: Ein Umriss}

Mit dem >Museum und der >Virtualität rückt die vorliegende Arbeit zwei Termini in den Brennpunkt ihres Interesses, die zwar scheinbar sehr verschiedene Sachverhalte benennen - der erste eine Institution des kulturellen Lebens, der zweite ein abstraktes ontologisches bzw. medientheoretisches Konzept -, sich aber in Gebrauch und Rezeption auf verschiedenen Ebenen sehr ähneln. Beide Begriffe blicken auf eine bis in die Antike zurückreichende Geschichte zurück und haben über diese hinweg zahlreiche, oft fundamentale, Bedeutungsveränderungen erfahren. Beide sind definitorisch unscharf und in akademischen Diskussionen umfassend problematisiert worden, werden aber in öffentlichen Diskursen mit großer Selbstverständlichkeit verwandt und als bekannt vorausgesetzt. Und: Beide erlebten in den vergangenen Jahrzehnten eine massive Inflation ihrer Verwendung. Befeuert wurde diese zum einen vom Siegeszug des personal computer in den 1980er Jahren, zum anderen von der lawinenartigen Ausbreitung privater Internetanschlüsse in den 1990ern, in deren Zuge sich der Computer, in den Worten Lev Manovichs, von einem Arbeitsgerät mit klar umrissenen Anwendungsfeldern zu einem »filter for all culture« entwickelte, einer »form through which all kinds of cultural and artistic production were mediated « (Manovich 2002: 64). Die Gründe für den prekären Drahtseilakt zwischen inhaltlicher Verschwommenheit und diskursiver Überstrapazierung der beiden Begriffe sind vielschichtig.

Im Falle des >Museums begegnet eine dem Humanismus und der bürgerlichen Aufklärung entstiegene und seit ihrer Frühzeit in staatliche Institutionsgefüge und politische Programmatiken eingebundene Bildungseinrichtung dem Partizipationsversprechen eines die gesamte soziale Welt ergreifenden Medienwandels. Darcy DiNucci, eine weitere Vertreterin der information architecture, hat diesen Wandel im Jahre 1999 folgenreich als jenen vom »Web 1.0« zum »Web 2.0« beschrieben, und damit auch als jenen vom >Web< als bloßer Ansammlung von HTML-Seiten zum >Web< als Modus latenter, allgegenwärtiger Interaktivität zwischen zahllosen, räumlich völlig disparaten Akteuren (vgl. DiNucci 1999: 32). Während hier also ein zuvor 
vermeintlich sehr klar eingegrenzter und mit klaren Konnotationen versehener Begriff eine Aufweichung erlebt, passiert im Falle der >Virtualität ` das genaue Gegenteil. Mit dem Adjektiv >virtuell verbanden sich von der Scholastik des Mittelalters bis zu den Theorien Gilles Deleuzes und Vilém Flussers ontologisch schwierige Zustände des `Beinahe〈-Seins, des Impliziten, des Potenziellen, des Möglichen. Gegenwärtige Diskurse in Politik und Gesellschaft hingegen lassen es zunehmend synonym mit irreal« werden und beschreiben mit ihm eine bestimmte Form scheinbarer, vorgetäuschter Existenz von Dingen und Sachverhalten in Simulationen, die von digitalen Technologien getragen werden. Damit wird >Virtualität zugleich zum Kampfbegriff in einer Auseinandersetzung darüber, was im Zeitalter digitaler Medien noch als >real gelten kann und darf.

In den zwei einleitenden Kapiteln dieser Studie sollen die Begrifflichkeiten von >Museum < und >Virtualität` sowohl in ihrer Historizität als auch in ihrer gegenwärtigen Verwendung thematisiert und geschärft werden. Ziel ist es dabei ausdrücklich nicht, zu abschließenden Definitionen zu gelangen. Vielmehr wird es darum gehen, die Nichtabschließbarkeit ihrer Bedeutungsebenen handhab- und fruchtbar zu machen. Insbesondere sollen Berührungspunkte zwischen der Institution des Museums und dem Konzept der Virtualität herausgearbeitet werden, um diese dann in späteren Kapiteln zu systematisieren und medientheoretisch einzuordnen.

Das Museum wird hier den Anfang machen. Eine umfassende, sämtliche Hintergründe und Entwicklung einbeziehende Geschichte des Begriffs und der Institution würde freilich den Rahmen dieser Arbeit sprengen. ${ }^{1}$ Aber im Rahmen eines kurzen Galopps durch die Entwicklung des Museums seit seinen Ursprüngen in den Schatzhäusern antiker Tempel sollte es zumindest möglich sein, einen Eindruck von seinem Werden als Stätte des Sammelns und der Präsentation von Dingen zu vermitteln. Von diesem historischen Aufriss ausgehend soll das Museum dann einer medientheoretischen Analyse in mehreren Etappen unterzogen werden: Die Erste wird seine Epistemologie und die Grundlagen musealer Wissensproduktion in den Mittelpunkt stellen und dabei insbesondere nach den Eigenarten von >Dingen` als Trägern von Bedeutungen fragen. Eine besondere Rolle wird hier die `Sperrigkeit des Materials` und jene Unbestimmtheit musealer Objekte spielen, welche in der Ausstellungsgestaltung sowohl zur Herausforderung als auch zum konstitutiven Element wird. Es wird diskutiert werden, inwiefern Dinge als Zeichen gelesen werden können - und welche Sinnstiftungsprozesse eben dort erst stattfinden, wo dies nicht mehr möglich ist. Hans Jörg Rheinbergers Konzept des `epistemischen Dings`, welches die Entstehung von Wissensinhalten über die kontextuelle Einbindung unbekannter Objekte in bekannte

1 Tatsächlich steht ein Standardwerk zu diesem Thema auch noch aus. Interessante Detaildarstellungen finden sich u.a. bei Horst Bredekamp (2007) und Krzysztof Pomian (2007). Eine umfassendere, systematische Museumsgeschichte versucht Hildegard Vieregg (2008), und speziell für Deutschland Olaf Hartung (2010). 
Sinngefüge beschreibt, wird in diesem Kontext einen zentralen Erklärungsansatz bilden. Darüber hinaus soll Aleida Assmanns Idee einer >wilden Semiose` diskutiert werden, gemäß derer für die Dingwahrnehmung gerade das Nicht-Verstehen bestimmend ist. In der dritten Etappe der Auseinandersetzung wird die Kategorie des $>$ Raumes in den Blick genommen werden. Nach einem kurzen Exkurs in die Raumphilosophie soll dessen Bedeutung für das Museum sowohl auf der Ebene eines sinntragenden und -vermittelnden Kommunikationsraumes oder semantic space (dieser dem Systemingenieur Alan Wexelblat entlehnte Begriff wird in Kapitel 2 dieser Arbeit noch zu klären sein) als auch jener eines affektiven, atmosphärischen Raumes (im Sinne der phänomenologisch orientierten Ästhetik Gernot Böhmes) untersucht werden. Das Museum wird in diesem Zusammenhang sowohl als ein >Theater der Dinge $<$ wie auch als Schauplatz zwischenmenschlicher Kommunikation diskutiert und auf die Kommunikationsstrukturen hin befragt werden, die sich aus seiner inneren Anlage und äußeren sozialen Einbettung ergeben. In einer letzten Etappe schließlich werden die Einsichten dieses Kapitels zu einem analytischen Modell zusammengeführt, welches sich des auf Michel Foucault zurückgehenden Begriffs des Dispositivs bedient.

\subsection{DAS MUSEUM: BEGRIFF UND INSTITUTION}

Die Geschichten sowohl des Begriffs als auch der Institution >Museum ২ begannen in der Antike, jedoch sollte es bis in die frühe Neuzeit dauern, bevor sie schließlich

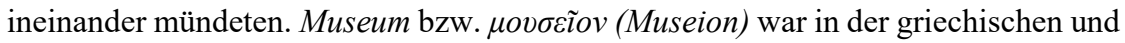
römischen Antike ein vieldeutiger und evokativer Begriff. Ursprünglich bezeichnete er den »Sitz« (Pertsch 2008: 406) oder das »Heiligtum« (Glock 2006) der Musen eine Kultstätte also, an welcher den Schutzgöttinnen der Künste gehuldigt wurde. Erst später weitete sich seine Bedeutung auch auf jene Stätten aus, die der Vermittlung und Pflege von Wissenschaft, Kunst und Philosophie gewidmet waren (vgl. ebd.). Wann genau dies geschah, ist nicht zu rekonstruieren. Ein entscheidender Faktor dürfte jedoch eine wachsende Verschränkung zwischen kultischer Praxis am Museion und schulischer Bildung in den musischen Disziplinen (u.a. Tanz, Musik, Gesang, Dichtung) gewesen sein, die sich besonders gut anhand des attischen Lyceums im vierten vorchristlichen Jahrhundert aufzeigen lässt (vgl. ebd).

\subsubsection{Das antike Museion}

Seine mustergültigste und beeindruckendste Ausformung als räumliche Agglomeration von Musenkult- und Lehrstätten erhielt das antike Museum im hellenistischen Ägypten. Begründet unter der Herrschaft Ptolemaios I. (323-283 v. Chr.) und unter 
dessen Sohn Ptolemaios II. weiter ausgebaut (vgl. ebd.) sollte sich das Museion von Alexandria für anderthalb Jahrhunderte zu einem der bedeutendsten intellektuellen Gravitationszentren der antiken Welt entwickeln. Eratosthenes, der die Welt anhand von Schattenwürfen vermaß; Herophilus von Chalkedon, der erste Beschreibungen des menschlichen Blutkreislaufs verfasste; Euklid, der Vater der Geometrie; Kallimachos, dem die Philologie ihr Dasein verdankt - wie die großen Museen unserer Gegenwart gründete auch das ptolemäische seinen Ruhm auf eine Sammlung. Anders als diese jedoch sammelte es nicht Dinge, sondern Menschen und ihre Ideen, die es räumlich zusammenführte und in Dialog und Austausch treten ließ. Es lebte von dem Gelehrtenkolleg, das an ihm wirkte, und der berühmten Bibliothek, von welcher die Arbeit dieses Kollegs ebenso abhängig war, wie sie sich in ihr verewigte (vgl. Pomian 2007: 23 u. Glock 2006). Dabei blieb das religiöse Element stets nicht nur ein sinnstiftender, sondern auch ein institutioneller Faktor: Die Leitung des Museions nämlich oblag Priestern, die per königlichem Dekret eingesetzt wurden (vgl. Glock 2006). Krzysztof Pomian sieht gerade in diesem Moment des Kultischen und der Einrichtung des Tempels das Bindeglied zwischen Museion und Museum: Wo den Göttern gehuldigt wurde, da fielen auch Opfergaben an, die aufbewahrt und präsentiert werden wollten.

Ein einmal geweihter Gegenstand, so fährt Pomian fort, sei im Grunde der menschlichen Sphäre entrückt. Was man den Göttern zum Geschenk gemacht hat, das kann man sich niemals wieder aneignen, weil es seine rein dingliche Wesensart verloren hat und zum Zeichen und Kristallisationspunkt des Göttlichen geworden ist. Es wieder zu entwenden oder auch nur achtlos zu berühren würde bedeuten, sich eines Verbrechens gegen die Götter selbst schuldig zu machen. Opfergaben sind dem Kreislauf menschlichen Wirtschaftens und Gebrauchs nicht länger zugehörig und auch nicht mehr rückführbar: Wurden in griechischen Tempeln Kultobjekte beschädigt, so begrub man sie entweder, um sie vor weiterer Profanierung zu schützen, oder man schmolz sie, sofern es sich um Metallobjekte handelte, zur Herstellung neuer Kultgegenstände ein (vgl. Pomian 2007: 23f.).

Nun konstituiert eine Sammlung allein noch kein Museum im modernen Sinne des Wortes, und die Objekte, aus denen sich die von Pomian beschriebenen Tempelschätze zusammensetzten, unterschieden sich natürlich in einem ganz entscheidenden Punkt von den Exponaten moderner Museen: jenem nämlich, dass Weihobjekte für den sakralen Kontext geschaffen werden, während Museen sich ja gerade Dinge einverleiben, deren Entstehungs- und Gebrauchskontexte nicht länger bestehen. Dennoch fallen zwei gewichtige Parallelen zwischen Tempel und Museum ins Auge. Erstens sind im Tempel wie im Museum die Objekte einer alltäglichen Verwendung ebenso entzogen wie ihrem Zirkulieren in wie auch immer beschaffenen Marktprozessen. Zweitens tritt in beiden Fällen an die Stelle von Gebrauch und Vermarktung eine neue Funktionalität der Bezeichnung und Repräsentation. Weder im Gotteshaus noch im Museum stehen Objekte ganz für sich allein, sie signifizieren vielmehr ein 
abstraktes $>$ Abwesendes $\measuredangle$, dessen Beschaffenheit an anderer Stelle dieser Arbeit noch näher zu erörtern sein wird.

Für die Tempel und die ihnen angeschlossenen Schatzhäuser des Vorderen Orients lässt sich ein gezieltes Sammeln von mit kultischer Relevanz versehenen Gegenständen etwa bis zurück ins zweite Jahrtausend vor Christi Geburt belegen (Samida 2002: 5 5). Das hellenistische Museion band diese Tempelschätze zwar in ein erweitertes Sinngefüge ein, in dem sich zur Religion nun die innerweltliche Gelehrsamkeit gesellte, aber es veränderte weder ihre Zusammensetzung noch ihre Funktion. Damit ist seine wichtigste Hinterlassenschaft an das moderne Museum wohl vor allem der Begriff selbst, der sich in Laufe der Jahrhunderte zur ausdrücklichen Bezeichnung für eine Einrichtung zur Präsentation kulturell bedeutsamer materieller Gegenstände entwickeln sollte. Die Institution des Museions indes würde ihren Nachfolger in jener der Universität finden.

\subsubsection{Mittelalter und frühe Renaissance}

Die Schätze der antiken Tempel sollten sich für das christliche Mittelalter als nur begrenzt anschlussfähig erweisen. Die Kirche schuf sich ihre eigenen Kultgegenstände und hatte wenig Interesse an jenen, die schon anderen Göttern als jenem Abrahams verschrieben waren. Die geheiligten Objekte des Altertums wurden überwiegend zu kulturellem Abfall. Wo einzelne antike Artefakte als bewahrenswert empfunden wurden und den Weg in die Schatzkammern des katholischen Klerus fanden, verloren sie dabei ihre referentiellen Qualitäten. Das Mittelalter schätzte sie ob ihres Materialwertes oder ihrer kunstreichen Ausführung, nicht jedoch als Zeugnisse einer erinnerungswürdigen Vergangenheit. Sie verkamen $\mathrm{zu}>$ Wundern 〈bzw. »Mirabilien«, deren Attraktion in ihrer schieren Fremdartigkeit lag (vgl. Samida 2002: 5; Pomian 2007: 56). Der größte Teil des Mittelalters erscheint damit als ein dunkler Fleck in der Museumsgeschichte - und das Museum in der Rückschau als eine Institution, in deren Auftreten sich die Neuzeit ankündigt.

Indem der beginnende Humanismus des 14. Jahrhunderts die geistigen Hinterlassenschaften der antiken Philosophie und Literatur neu entdeckte, schuf er zugleich den Kontext für eine Neubewertung des materiellen Erbes der vorchristlichen Vergangenheit (vgl. Pomian 2007: 56). An den weltlichen Höfen Europas begann man ebenso wie in den Schatzkammern der Kirche, gezielt entsprechende Objekte zu sammeln - ein Prozess, der (ebenso wie die Auseinandersetzung mit den antiken Sprachen) unkoordiniert ablief. Obwohl den gesammelten Dingen nun erstmals Zeugniswert zugeschrieben wurde, fehlte noch das notwendige Instrumentarium, um an ihnen tatsächlich etwas Bestimmtes über jene historischen Wirklichkeiten ablesen zu können, deren Hinterlassenschaften sie waren. Mirabilien wurden von bloßen Kuriositäten zu Statussymbolen, an die Stelle der Befremdung mit der Alterität historischer 
Objekte trat eine Fetischisierung des Reliktcharakters an sich. Entsprechend lagen den Sammlungen der Epoche auch keine abstrakten didaktischen Konzepte zugrunde - angestrebt wurden vor allem Umfang und Abwechslungsreichtum. Ihre Funktion war für die Sammler in erster Linie repräsentativer Art und räumlich blieben sie dekorativ über deren Wohnbereich verstreut (vgl. Samida 2002, 5). Erst in der Renaissance begann sich dies zu ändern, und die bestimmende Größe dieses Wandels sollte eine neue, planvolle Form sein, Sammlungen in eigens dafür vorgesehenen Räumlichkeiten anzuordnen: Mit der Geburt der Kunst-, Naturalien- und Wunderkammern, die vom 16. bis ins 18. Jahrhundert die proto-museale europäische Sammlungskultur bestimmen sollten, zwang man den Dingen erstmals konkrete Sinninhalte auf.

\subsubsection{Die Kunst-, Naturalien- und Wunderkammern der frühen Neuzeit}

Der Belgier Samuel Quiccheberg (1529-1567) verfasste im Jahre 1565 unter dem Titel Inscriptiones vel tituli theatri amplissimi einen umfassenden Leitfaden über den Zweck und idealtypischen Aufbau eines solchen Kabinetts. Den unmittelbaren Anlass hierfür bildete die von 1562 bis 1567 andauernde Einrichtung der Münchener Kunstkammer Herzog Albrechts V. von Bayern, mit welcher Quiccheberg als herzöglicher Berater beauftragt worden war. Die Inscriptiones verstanden sich indes ausdrücklich als allgemeingültig (vgl. Bredekamp 2007: 33), enthielten sie doch nichts Geringeres als die Leitlinien zur Abbildung einer Kosmologie durch die Anordnung von Gegenständen in einem nunmehr explizit nur noch diesem Zweck gewidmeten Ausstellungsraum. Beeinflusst von L'idea del theatro des italienischen Philosophen Giulio Camillo (1480-1544) verstand Quiccheberg Sammlungsgegenstände nicht nur als Objekte zauberhafter Befremdung, sondern als mnemotechnische Hilfsmittel für das Erinnern von Wissensinhalten. Sie wurden damit von >Wunderdingen «, deren Wirkung eben gerade in ihrer Nichtanschließbarkeit begründet lag, zu Vermittlungsinstanzen, welche für ihr Funktionieren sehr spezifische Bindungen benötigten (vgl. Hanak-Lettner 2011: 74ff.).

Ganz konkret schlägt Quiccheberg zu diesem Zweck eine Organisation der Sammlung als eine Abfolge von fünf Abteilungen vor, welche nacheinander zu durchschreiten sind. Die erste Abteilung führt über heilsgeschichtliche Darstellungen zu einer Ahnengalerie des Fürsten sowie zu Karten, Modellen und Dioramen des fürstlichen Herrschaftsgebietes und bindet damit die weltliche Herrschaft an die biblische Offenbarung zurück. Die zweite Abteilung widmet sich dem einheimischen, auswärtigen und auch antiken Kunsthandwerk - so z.B. Holzschnitzereien, Steinmetzarbeiten, Glasbläserei, Weberei und Töpferei, ferner aber auch der Edelsteinschneiderei, Münzprägung, Gold- und Silberschmiedearbeiten und schließlich Druckplatten. Diese Abteilung verfolgt ein entschieden historisches Programm: Sie 
führt ihren Besucher aus dem Altertum mit jedem Objekt weiter in die Gegenwart. Die dritte Abteilung rückt die Naturgeschichte in den Fokus, wobei Mineralien sowie Tiere und Pflanzen (also die drei aristotelischen Weltreiche) in Originalpräparat und Nachbildung im Zentrum stehen. Abteilung Vier befasst sich einerseits mit technisch-mechanischen Exponaten, andererseits aber auch jener Objektgruppe, die wir heute als >ethnographisch` bezeichnen würden. Hier finden u.a. Musikinstrumente, Messgeräte aller Art, Uhren, Schreibgeräte, Werkzeuge, Waffen und jede Form von Maschinen ihren Platz. Zugleich werden aber auch Spielzeuge, Kleidungsstücke und Schmuck der Fürstenfamilie sowie Puppen in unterschiedlichsten Landestrachten in dieser Abteilung gesammelt. Die letzte Abteilung thematisiert schließlich abermals das Fürstenhaus, indem sie Gemälde, Stiche, Ahnentafeln, Wandteppiche und Wappen zusammenträgt. Über diese fünf Sektionen hinaus sollte nach dem Quiccheberg'schen Prinzip jede Kunstkammer über eine Bibliothek und ein Ensemble nutzbarer Handwerkstätten verfügen (vgl. Bredekamp 2007: 33ff.; vgl. Hanak-Lettner 2011: 90ff.).

Horst Bredekamp sieht in der Kunstkammer die mikrokosmische Abbildung des mechanistischen Weltsystems, in dem sich die Gelehrten des frühneuzeitlichen Abendlandes bewegten. Dabei weist er darauf hin, dass der Mechanismusbegriff des 15. und 16. Jahrhunderts ein sehr viel weiteres Einzugsgebiet aufweist als jener unserer Gegenwart: Ihm liegt das nur bedingt ins Deutsche übersetzbare Konzept der machinamenta zugrunde, welches nicht nur >Maschinen im Sinne technischer Gerätschaften beinhaltet, sondern schlechterdings alle Zusammenstellungen von Einzelelementen, die einen gemeinsamen Zweck erfüllen. Hierunter fallen auch Kunstobjekte und Gebäude, ebenso wie all jene Gefüge, welche die Natur hervorbringt (vgl. ebd.: 45ff.). ${ }^{2}$ Vor diesem Hintergrund erscheint natürlich die ganze Welt als ein sinnreiches machinamentum, und mit ihr auch die Kunstkammer, welche diese Welt als ein Gefüge von Gefügen abbildet - im Modell Quicchebergs vorne und hinten gerahmt und zusammengehalten von den Zeugnissen weltlicher Herrschaftsgewalt. Zugleich wird die Kunstkammer zu einem medialen Raum, welcher ein bestimmtes Narrativ über die kosmische Ordnung transportiert.

Damit war der erste große Schritt zum modernen Museum bereits getan: Die Kunst-, Naturalien- und Wunderkammern der frühen Neuzeit hatten Mirabilien zu Signifikanten eines räumlich ausgedehnten Bedeutungssystems gemacht. Der $\mathrm{Mu}-$ seologe Friedrich Waidacher sieht gerade in diesem »Erzählen mit Hilfe von Dingen«

2 Angemerkt sei, dass ähnlich weitgefasste Maschinenbegriffe auch in der Gegenwart durchaus noch zur Anwendung kommen. So definiert z.B. Henning Schmidgen in großer Nähe zu den machinamenta >Maschinen< schlicht als Anordnungen heterogener Elemente, die in ihrem Zusammenwirken einen ökonomischen Effekt hervorbringen (vgl. Schmidgen 2007: 145). 
das definitorisch Wesentliche des Museums begründet (vgl. Waidacher 2000: 6). Ferner verwiesen die Objekte nun, im Gegensatz zu den Tempelschätzen der Antike, nicht mehr auf ein unnahbares Heiliges außerhalb der erfahrbaren Welt. Ebensowenig fielen sie in reine Dinghaftigkeit zurück. Sie fanden vielmehr einen neuen kulturellen Ort, der sich in Paul Valérys eingangs erwähnter Feststellung wiederspiegelt, die Menschen sprächen im Museum leiser als im Alltag, doch lauter als beim Gottesdienst.

Der didaktische Anspruch, der das spätere Museum auszeichnen sollte, war ebenfalls in der Anlage der Kunstkammern bereits vorhanden. Sie waren als Idealtypen eines planvoll geordneten »Spielraums« (Bredekamp 2007: 68) konzipiert, in welchem ihre Beschauer die snatürliche` Ordnung der Dinge in komprimierter Form bei der Entfaltung beobachten können sollten - von Gesteinsbrocken über die Königreiche der Pflanzen und Tiere bis zur Welt des Menschen mit ihren künstlerischen und technischen Errungenschaften. In diesem Sinne standen sie auch in der Tradition des utopischen Denkens und fanden ihren Niederschlag in der utopischen Literatur. Bredekamp verweist hier insbesondere auf die 1619 entstandene Schrift Reipublicae Christianopolitanae descriptio des Theologen und Mathematikers Johann Valentin Andreae: Hier erscheint die Stadt \Christianopolis` als eine riesige, ideal gestaltete Kunstkammer, in welcher die Bauwerke selbst die kosmische Ordnung so vollkommen abbilden, dass sich um >Bildung ` niemand mehr bemühen muss - allein in der Bewegung durch diesen perfekten Wissensraum fliegt sie seinen Bewohnern nämlich >spielend ‘ zu. Die Umwelt selbst formt den Verstand (vgl. Bredekamp 2007: 68; vgl. Andreae 1977: 72ff.). Bredekamp identifiziert dementsprechend das Menschenbild hinter der Kunstkammer mit jenem, das Platon in seinem Theaitetos Sokrates in den Mund legt (vgl. Platon 2012: 162f.) und welches in der frühen Neuzeit vor allem von John Locke, Francis Bacon und (im deutschsprachigen Raum) Johann Daniel Major vertreten wurde: jenem der tabula rasa, gemäß dessen der noch unkultivierte Mensch einer unbeschriebenen Wachstafel gleicht, auf der sich sein Umfeld einprägen kann. Interessanterweise spannt Bredekamp hier, freilich ohne das Wort als solches zu benutzen, den Bogen zum modernen Virtualitätsbegriff, indem er die 〉Tafel als Metapher für den menschlichen Geist in genealogische Verbindung zu Alan Turings Idee des tape stellt. Der Magnetbandstreifen, bei Turing der entscheidende materielle Träger für die Kulturtechnik des Programmierens, wird hier zum Symbol von Bewusstseinsprozessen, in welchen die Welt immer wieder aufs Neue erschaffen, ausgelöscht und überschrieben werden kann (vgl. Bredekamp 2007: 100ff.).

\subsubsection{Die Geburt des Museums}

Als erste Museen der Welt werden heute typischerweise das 1661 gegründete Amerbach-Kabinett in Basel und das Ashmolean Museum in Oxford aufgeführt, welches 
seine Türen 1683 dem Publikum öffnete (vgl. Samida 2002: 6). ${ }^{3}$ In der Frühaufklärung war die Grenze zwischen Museum und Kunstkammer aber grundsätzlich eine fließende. Nahezu jedem frühen Museum war eine Naturalien-, Kunst- oder Wunderkammer vorausgegangen, deren Sammlung unverändert das Fundament der Ausstellung bildete. Das entscheidende definitorische Kriterium der Museen war vielmehr, dass sie im Gegensatz zu den Kunstkammern einem breiten Publikum zum Besuch offenstanden. Damit gehörten sie zu einer Gruppe von Institutionen, die Jürgen Habermas in seinem Strukturwandel der Öffentlichkeit als Fokalpunkte der Entstehung bürgerlicher Öffentlichkeiten beschreibt: Wie der Lesesaal, das Theater und das Konzert waren die frühen Museen »öffentlich zugängig gewordene Gebilde der Kultur« (Habermas 1982: 46), welche kulturelle Inhalte überhaupt erst subjektiviert diskutierbar machten:

Die Museeen [sic] institutionalisieren, wie Konzert und Theater, das Laienurteil über die Kunst: die Diskussion wird zum Medium ihrer Aneignung. Die zahllosen Pamphlete, die Kritik und Apologie der herrschenden Kunsttheorie zum Gegenstand haben, knüpfen an die Salongespräche an und werden ihrerseits von diesen aufgenommen - Kunstkritik als Konversation. [...] In dem Maße, in dem die öffentlichen Ausstellungen weitere Kreise anziehen, die Kunstwerke mit dem breiten Publikum über die Köpfe der Kenner hinweg unmittelbar in Berührung bringen, können diese zwar nicht länger ihre Position behaupten, ihre Funktion ist jedoch unentbehrlich geworden; sie wird jetzt von der professionellen Kunstkritik übernommen. (Ebd.: 57)

Diese Charakterisierung des Museums als Katalysator für einen öffentlichen Diskurs über die Kultur (und im Besonderen die Kunst) ist sicher nicht falsch, überakzentuiert aber womöglich die Freiheitsgrade des Besuchers gegenüber dem didaktischen Programm der Ausstellung. Verbunden mit ihrer Öffnung änderte sich auch der Auftrag der früheren Wunderkammern: Hatten diese nämlich noch im Zeichen einer privaten und weitgehend selbstbestimmten Gelehrsamkeit ihrer Besitzer gestanden, waren Museen nun mit dem didaktischen Auftrag versehen, das soziale und kulturelle Programm der Aufklärung in die breite Masse zu tragen (vgl. Smith 1989: 6).

An diesem kulturpolitischen Bekenntnis der Museumsstifter lässt sich das Ausmaß des Wandels in der Bewertung der Sammlungsgegenstände ablesen, den das Prinzip >Kunstkammer` ermöglicht hatte. Museale Objekte waren zu medialen Trägern gesellschaftlicher Sinnbildung geworden, denen historische Prozesse nicht nur a priori Bedeutungen eingraviert hatten, sondern die sich auch im Hier und Jetzt mit neuen belegen ließen. Die Museen sollten so zu Umschlagplätzen kultureller und geistiger Bewegungen im Sinne der Eliten werden, von denen sie gestiftet wurden

3 Letzteres ging aus der Privatsammlung des britischen Politikers, Offiziers und Privatgelehrten Elias Ashmole hervor, welche dieser der Universität acht Jahre zuvor zur Verwendung im Unterricht zur Verfügung gestellt hatte (vgl. Pomian 2007: 66). 
(vgl. ebd.: 8). Und noch in einem anderen Punkt unterschieden sie sich von den privaten Kunst- und Wunderkammern, die ihnen vorausgegangen waren: Sie waren nunmehr auf den Erhalt und die Dauerhaftigkeit ihrer Sammlungen hin angelegt. Während private Sammlungskabinette üblicherweise nach dem Tod ihrer Besitzer aufgelöst wurden (und ohne deren Führung und Anleitung in ihrem Sammlungskonzept meist auch gar nicht zu verstehen waren), lag den Museen nun die Aufgabe zugrunde, sowohl ihre Bestände als auch die ihnen zugeschriebenen Bedeutungen generationsübergreifend zu bewahren (vgl. Pomian 2007: 66ff.).

Entsprechend trifft Habermas' Einreihung des Museums mit dem Lesesaal und dem Konzert als reine Aushandlungsräume des Kulturellen wohl nicht den Kern der Sache. Ebenso wenig folgten die frühen Museen noch dem Quicchebergschen Ansatz, mnemotechnische Erinnerungspaläste zu sein. Ihre Funktion wurde vielmehr zunehmend auf die Zukunft hin ausgerichtet: Sie stellten nun nicht mehr nur Objekte der Vergangenheit für die Gegenwart aus, sondern sollten ihnen auch darüber hinaus einen Ort in der Geschichte zuweisen (vgl. ebd.: 70). Folgt man hier Bredekamps Argumentationslinie vom Museum als Formungsraum für den noch ungeformten Menschen, so impliziert dieser Auftrag zugleich einen Versuch, diese Zukunft gestalt- und beherrschbar zu machen. Wie Wulf Kansteiner feststellt, wirken die Inhalte des historischen Bewusstseins normativ: Was in der Gegenwart erfolgreich historisiert werden kann, bestimmt zugleich auch die Grenzen der Zukunftserwartung mit (vgl. Kansteiner 2009: 33). Damit war die Aufgabe der frühen Museen das Einordnen von Vergangenheit, Gegenwart und Zukunft in einen kontingenten Sinnzusammenhang, der soziale Entwicklungen und Zustände legitimieren oder diskreditieren konnte. Das entscheidende Mittel zu diesem Zweck war weiterhin das materielle Objekt, das in den kommenden Jahrhunderten für die Arbeit des Museums ebenso konstitutiv wie schwierig bleiben sollte.

\section{2 »WILDE SEMIOSEN « UND »EPISTEMISCHE DINGE «: DIE SPERRIGKEIT DES MATERIALS}

Gottfried Korff sieht im Zusammenspiel von Vermittlungsanspruch und Objekten die Wurzeln einer bis heute andauernden Janusköpfigkeit des Museums - es konstituiert sich einerseits erst über seine materiellen Ausstellungsgegenstände, zugleich wird seine Legitimität als Vermittlungsinstitution aber durch deren Unbestimmtheit laufend auf die Probe gestellt. Im Ergebnis müssen Museen Strategien entwickeln, um der Vieldeutigkeit ihrer Exponate Herr zu werden, und solche Strategien können sehr unterschiedliche Gestalten annehmen. Dieses Kernproblem musealer Sinnbildung 
kristallisiert sich für Korff besonders deutlich in einem andauernden Konflikt zwischen dem ästhetischen und dem historischen Prinzip in der musealen Gestaltung aus (vgl. Korff 2002a: 113).

\subsubsection{Historizität und Ästhetik als museale Strategien}

Historische Museen sind für Korff solche, in denen die Entwicklung von Narrativen über die Vergangenheit aus im Raum arrangierten Objekten im Mittelpunkt steht (vgl. ebd.) - man denke in diesem Zusammenhang an Waidachers zuvor schon angesprochene These, dass Ausstellungen in letzter Konsequenz immer Geschichten seien, die mit Dingen erzählt werden (vgl. Waidacher 2000: 6). Dies folgerichtig umzusetzen macht jedoch zweierlei erforderlich: Einerseits muss den Museumsdingen in ihrer Eigenschaft als Sinnvermittler eine sehr hohe Autonomie zugestanden werden, andererseits muss auch der Fähigkeit des Publikums vertraut werden, das intendierte Narrativ aus dem Objektarrangement dechiffrieren zu können. Mit beidem tue sich der deutsche Museumsbetrieb, wie Korff anmerkt, traditionell schwer (vgl. Korff 2002a: 113). Das historische Prinzip des Museums habe seine Heimat daher eher in Frankreich, wo es in enger Verbindung mit der Figur des Archäologen Alexandre Lenoir (1762-1839) steht. Lenoir entwarf im späten 18. Jahrhundert ein auf die soziale Vision des revolutionären Frankreichs abgestimmtes Museumskonzept, welches seine narrativen Strukturen dynamisch aus den ihm zur Verfügung stehenden Objektbeständen zu entwickeln versucht, anstatt diese in das Korsett eines vorgefassten Programms zu zwängen. Hieraus sei eine Museumstradition hervorgegangen, die mit ihren Exponaten vorurteilsfrei und offen umgeht und in Ausstellungsphilosophien wie jener von Henri Rivières Pariser Musée National des Arts et Traditions Populaires bis heute nachwirke (vgl. ebd.: 119).

Das ästhetische Prinzip ist dagegen laut Korff jenes, das seit dem 19. Jahrhundert vor allem die deutsche Museumskultur prägt und in seinen Ursprüngen eng mit der Figur Wilhelm von Humboldts und der preußischen Bildungsreform von 1806 verknüpft ist. In seinem Zentrum steht eine Rückbesinnung auf das Museum als Musentempel und Kultstätte der Ästhetik, und mit dieser Rückbesinnung wiederum die Institution des Kunstmuseums, der alle anderen Formen von Museen nachgeordnet sind. Das ästhetische Museum, wie Korff es beschreibt, will keine expliziten historischen Erzählungen ausbreiten. Seine Aufgabe sei vielmehr, die Historizität seiner Exponate zu verdrängen und sie überzeitlich erscheinen zu lassen - nicht als Hinterlassenschaften historischer Zustände, sondern als Monumente, welche diesen trotzen (vgl. ebd.: 115). Ganz im Sinne der von Bredekamp diagnostizierten Geburt der Wunderkammer aus der Vision eines utopischen >Wissensraumes $<$ heraus, beschreibt Korff auch das Ideal der ästhetischen Museumskonzeption als einen Raum, der die aufgeklärte Empfindsamkeit seiner Besucher schon aus seiner bloßen Anlage heraus 
formen und disziplinieren soll. Im Preußen des 19. Jahrhunderts erschien hier eine konsequente Ausrichtung auf die künstlerischen Ausdrucksformen der griechischen und römischen Antike als das beste Mittel zum Zweck (vgl. ebd.). Das inhaltliche Programm geht den Dingen der Ausstellung also voraus, anstatt aus ihnen entwickelt zu werden. Wie Lenoirs Museumsphilosophie in Frankreich nachwirkt, so wirft nach Korff Humboldt seinen Schatten über die deutsche Museumsgeschichte: Als in deutschsprachigen Ausstellungen der 1970er Jahre die Objekte zeitweise nur noch illustrativ neben Erklärungstafeln drapiert wurden, die nunmehr den eigentlichen Angelpunkt musealer Vermittlung darstellten, sei dies nur die Zuspitzung einer Museumspraxis gewesen, die weder dem Objekt noch dem Besucher vertrauen mochte (vgl. ebd.: 120).

Heinrich Theodor Grütter, Direktor des Essener Ruhr Museums, identifiziert darüber hinaus noch zwei weitere Kriterien, in denen sich historische Ausstellungen von (ästhetischen) Kunstausstellungen unterscheiden: Zum einen sind die Exponate des Kunstmuseums schon zum Zeitpunkt ihrer Entstehung als Träger kulturellen Sinns vorgesehen gewesen, während jene des historischen Museums erst in der Ausstellung dazu werden. Zum anderen (und damit zusammenhängend) steht das Ausstellungsstück im Kunstmuseum in sehr viel höherem Maße für sich allein, während jenes der historischen Ausstellung in seiner Aussagekraft weit stärker vom Gesamtgefüge des musealen Raumes abhängig ist (vgl. Grütter 1997: 668f.).

\subsubsection{Museale Darstellung(en) und das politische Moment}

Beide Museumstraditionen sind Produkte politischer Konjunkturen - Lenoir entwarf sein Museumskonzept für das Frankreich der Revolution als ein Werkzeug zur Emanzipation des Menschen, Humboldts seines für das reformistische Preußen der napoleonischen Ära, welches in erster Linie an dessen Erziehung interessiert war. Die Geschichte des Museums ist zwar zweifelsohne Teil jener der bürgerlichen Öffentlichkeit, seine Beschreibung als reiner Aushandlungsraum für Bedeutungen durch das Laienpublikum greift indes zu kurz: Im 18. Jahrhundert wurden Museen zur Staatsangelegenheit, weil man in ihnen strategische Orte für soziale Weichenstellungen erkannte. Das British Museum entstand 1753 auf einen Parlamentsbeschluss hin und wurde 1759 eröffnet, der Louvre öffnete seine Pforten 1793 für eine revolutionäre Öffentlichkeit (vgl. Samida 2002: 6). Die in Museen räumlich arrangierten Aussagensysteme und die ihnen zugrundeliegenden materiellen Objekte wurden zu hochbrisanten Austragungsorten politischer Sinnstiftung, was sowohl die herausragende Rolle des Museums als Ort politischer Kommunikation in einer sich konstituierenden oder reformierenden Öffentlichkeit unterstreicht, als auch seine prekäre und oft unkontrollierbare Natur als mediale Anordnung. Anders als Bibliotheken und Archive 
sammeln Museen keine diskreten, sinnhaft geschlossenen Texte. Ihre Ausstellungsstücke sind, jedes für sich allein genommen, nahezu nichtssagend. $\mathrm{Zu}$ >erzählen ‘ beginnen die Dinge erst über ihre Einbindung in den Kontext des Museums selbst. Sie sind also epistemisch offen, und als Träger von Bedeutungen macht sie dies paradoxerweise gleichzeitig sowohl formbar als auch sperrig.

\subsubsection{Zeichenträger und Gedächtnisorte}

Museumsdinge $^{4}$ sind, wie Krzysztof Pomian feststellt, eine ganz absonderliche Klasse von Gütern: Sie erfüllen weder den Zweck, für den sie ursprünglich einmal geschaffen wurden, noch sind sie im eigentlichen Sinne >dekorativ^. Die Museen, die ihren Besitz anstreben, schlagen aus ihnen üblicherweise keinen großen ökonomischen Gewinn und können sich glücklich schätzen, wenn sie einigermaßen kostendeckend zu wirtschaften imstande sind. Dennoch werden Museumsdinge unter großem finanziellen, personellen und zeitlichen Aufwand gehegt und gepflegt. Ihnen wird ein beträchtlicher Wert beigemessen, mit dem es sich spekulieren lässt und der sich auf dem Schwarzmarkt in hohe Preise übersetzen kann (vgl. Pomian 2007: 14f.). Im Sinne der marxistischen Wirtschaftstheorie sind sie also anomale Güter, die einen hohen Tauschwert mit einem praktisch nicht vorhandenen Gebrauchswert verbinden (vgl. ebd.: 17) - und damit unweigerlich die Frage aufwerfen, welche Merkmale sie aufweisen, auf die sich ihr Tauschwert gründet.

Pomians Antwort auf diese Frage ergibt sich aus dem medialen Charakter der Museumsdinge. Für ihn zählen sie zu einer Klasse von Gütern, deren einzige Aufgabe es ist, kulturelle Bedeutungen zu transportieren. Er bezeichnet solche Objekte als »Semiophoren« - Zeichenträger (vgl. Pomian 2007: 50). Ihr wirtschaftlicher Wert gründet sich auf ihre Eigenschaft, materielle Brücken zum Abstrakten zu sein, oder, um Pomians eigene Terminologie aufzugreifen, zwischen »Sichtbarem« und »Unsichtbarem« zu vermitteln (ebd.: 41ff.). Pomians 〉Unsichtbares ist dabei ein Abwesendes im weitesten Sinne: das Historische und Vergangene, das Heilige und Göttliche, oder auch einfach nur das geographisch weit Entfernte (vgl. ebd.).

Diese Referenzialität wiederum ist notwendigerweise das Produkt der musealen Arbeit selbst. Im Museum werden aus »Dingen der Vergangenheit « »Dinge für uns« (Korff 2002b: 141). Es ersetzt das »So-Sein« der Objekte durch ein »Für-uns-Sein« (Waidacher 2000: 4). Museale Objekte sind aus ihren Entstehungszusammenhängen notwendigerweise herausgefallen und werden im Museum in neue Bedeutungskontexte einsortiert, die für ein modernes Publikum anschlussfähig sein müssen. Grütter

4 Mit dem Begriff des `Museumsdings` benennt Gottfried Korff jene Objekte, welche den Prozess der Musealisierung durchlaufen haben (vgl. Korff 2002b). 
deutet dieses Phänomen anders als Pomian nicht nur als einen Brückenschlag zwischen An- und Abwesendem, sondern schlechterdings als einen zwischen Realität und Fiktion:

Durch die Loslösung des Objektes aus seinem ehemaligen Entstehungszusammenhang, die Separierung und die Einordnung in einen neuen Bedeutungszusammenhang, der von dem ursprünglichen Kontext grundverschieden ist, die Inszenierung, wird das Objekt vom Gebrauchsgegenstand zum Exponat. Das Objekt ist zwar real, aber es befindet sich nicht mehr im Realen. (Grütter 1997: 671)

Diese Neukontextualisierung, die das Museumsding als solches erst entstehen lässt, macht aus dem Objekt zugleich einen Gedächtnisort im Sinne Pierre Noras: Sein Bedeutungsinhalt ist zugleich Produkt als auch Kolportierung eines Wechselspieles zwischen dem historischen Bruch mit der Welt, die es hervorgebracht hat, und der konstruierten Tradition, welche diese (im Sinne Pomians >unsichtbare $\prec$ ) Welt mit der unseren verbindet (vgl. Nora 1990: 23f.).

Nora macht diesen Zwiespalt am Beispiel des französischen Revolutionskalenders deutlich, der für ihn den Idealtypus eines Gedächtnisortes darstellt. Der Revolutionskalender hat laut Nora nur deshalb überhaupt historischen Referenzcharakter, weil er sich nicht durchzusetzen vermochte. Hätte er dies getan, wäre er zu jenem Bezugssystem avanciert, in welchem jedwedes geschichtliche Geschehen verortet ist - womit er selbst unspezifisch geworden wäre. Erst seine Abgeschlossenheit im historischen Prozess und der Bruch zwischen seiner historischen Situation und der unseren verleiht ihm seine bezeichnende Qualität für eine bestimmte zeitliche Periode. Nur so können wir ihn an einen bestimmbaren Platz in der Geschichte stellen und uns gleichsam zu ihm in Beziehung setzen. Zu diesem Zweck aber muss die historische Welt zugleich in kontingenter Geschlossenheit konstruiert werden - und dies wiederum macht es erforderlich, die geschichtlichen Brüche in narrative Kontinuitäten einzuweben (vgl. ebd.: 26ff.).

Nichts anderes als eben diese Schaffung von Gedächtnisorten leistet das Museum. Seine Exponate sind materiell auskristallisierte Frakturen der Geschichte. Sie stehen auf einer zeitlichen Grenze zwischen einer Welt, in der sie entstanden sind und einer anderen, die sie nun betrachtet und deutet. Tatsächliche Aussagen kann das Museum mittels seiner Exponate nur dann formulieren, wenn es diese Bruchstellen in den Kontext einer Historie eingliedert, die sinnhaft konfiguriert ist und in die Gegenwart des Publikums mündet.

Ausgehend von diesen Überlegungen kann die in der Einleitung dieser Arbeit vorgestellte Museumskritik Paul Valérys durchaus als ein Vorwurf an das Museum gelesen werden, genau diese seine Kerneigenschaft zu verschleiern. Das Museum als Institution, so stellt auch Korff unter Rückgriff auf Valery heraus, möchte seinen Be- 
suchern in erster Linie vermitteln, dass seine Ausstellungszusammenhänge jenen entsprächen, in welchen sich die Objekte auch in ihrer Ursprungssituation befunden hätten (vgl. Korff 2002b: 140). Mit Bezugnahme auf Claude Lévy-Strauss beschreibt Korff das Museum vor diesem Hintergrund als einen quasi-sakralisierten Ort, der Authentizität für eine Welt generiert, in der ebendiese immer knapper wird (vgl. ebd.: 142). Ein überaus sinnfälliges Beispiel für solche musealen Trugbilder findet sich z.B. im Freud Museum in London, in dessen Zentrum eine detaillierte Nachbildung des Arbeitszimmers von Siegmund Freud voller Originalexponate aus der Wiener Berggasse 19 (inklusive der berühmten Couch) steht. ${ }^{5}$

\subsubsection{Grenzen des Zeichenhaften: Aleida Assmanns "wilde Semiose»}

Laut Aleida Assmann findet Dingwahrnehmung häufig im Modus einer »wilden Semiose« (Assmann 1988: 238) statt. Ihrer Ansicht nach erfolgt im Erfahren materieller Objekte ganz ähnlich wie für Pomian die Zusammenführung eines materiellen Vorhandenen mit einem abstrakten Nicht-Vorhandenen, die sich in semiotischen Termini als jene von 〉Signifikant` und 〉Signifikat` beschreiben lässt (vgl. Assmann 1988: 238). Die Orientierung in der materiellen Welt ist für Assmann ein »Anzeichenlesen« (ebd.: 240), welches die physische Erscheinung der Welt zu kulturellen Zuschreibungen und Bedeutungen ins Verhältnis setzt und sie somit als semiotisches System erfahrbar werden lässt (vgl. ebd.: 238f.). Assmann spricht hier von einer »Physiognomik«, die immer auch kreativer und poetischer Natur sei: Nicht nur bereits bestehende und den Dingen eingeschriebene Bedeutungsinhalte würden gelesen und decodiert, sondern auch laufend neue geschaffen und auf die materielle Welt zurückprojiziert (ebd.: 240).

»Wilde Semiose«, wie Assmann sie versteht, passiert nun überall dort, wo die physiognomische Sinnbildung nicht auf Anhieb gelingt und Objekte der materiellen Welt sich nicht als Zeichen >lesen ein transitorisches Schauen zu verstehen, bei dem das gesehene Zeichen vom Betrachter spontan in Signifikant und Signifikat aufgetrennt und somit >begriffen den kann. Gelingt dies aber nicht, so wird das Zeichen-Objekt lediglich >angestarrt Sehen und verstehen fallen nicht zusammen, der Blick bleibt an der Oberfläche hängen (vgl. ebd.: 240ff.). Dieser »lange Blick« (ebd.: 240) des befremdeten Betrachters macht es unmöglich, Museumsdinge vollkommen zuverlässig in Didaktiken und Pädagogiken einzufangen. Der Museumskurator kann Objekte auswählen, auszeichnen und sie in einer bestimmten Form von Anordnung dem Publikum darbieten, doch das

5 Vgl. http://www.freud.org.uk/photo-library/category/10046/house-couch-study/ vom 10.04.2018. 
entscheidende Moment der Rezeption durch den Besucher entzieht sich weitgehend seinem Zugriff.

Damit wird der Begriff des `Zeichens $<$ - und mit ihm Pomians Deutung der Museumsdinge als Semiophoren - schlechthin problematisch. Folgt man z.B. der Zeichenkonzeption des Philosophen Günter Abel, so erhalten Zeichen ihre zeigende Qualität grundsätzlich nur dadurch, dass sie erstens von ihren Beschauern einer Interpretation unterzogen werden, und dass sich zweitens jede ihrer Interpretationen innerhalb eines Regelwerkes gleichsam verbindlicher wie aber auch verhandelbarer Bedeutsamkeiten und Bezüglichkeiten vollzieht:

Zeigende Zeichen sind Zeichen, die das zeigen, was sie zeigen - und zwar weder aufgrund einer den Zeichen vorab eingebauten okkulten Qualität (- das wäre die Magie der Zeichen) noch aufgrund bloß subjektiver und beliebiger Deutungen seitens der Benutzer oder Interpreten (- das wäre relativistische Beliebigkeit der Zeichen). Zeichen sind vielmehr, so die These, die zeigenden Zeichen, die sie sind, aufgrund der zugrundeliegenden und im Zeigen bereits vorausgesetzten sowie in Anspruch genommenen Interpretations-Praxis der Zeichen. Diese Praxis umgrenzt, was sich auf welche Weise in und an einer Zeichenverwendung zeigt. (Abel 2000: 68)

Bemerkenswert ist hier, dass nach Abels Beobachtung die verbal gar nicht artikulierbaren Prozesse der Zeicheninterpretation im Akt des Zeigens nahezu völlig verschwinden und meist vollkommen unsichtbar bleiben. Zeigen und Verstehen scheinen in der Zeichenwahrnehmung eine unmittelbare Einheit zu bilden (vgl. ebd.).

Museumsdinge sind semiotisch zwar hochgradig aufgeladen, zugleich aber ebenso hochgradig unbestimmt. Sie widersetzen sich hartnäckig der klaren und verbindlichen Zuordnung von Signifikanten zu Signifikaten. Eine antike griechische Vase z.B. kann auf eine Vielzahl historischer Sachverhalte und Tatbestände verweisen: An ihrem Stil und ihrer Ausführung lassen sich Schlaglichter auf die Geschichte antiker Kunst werfen, ihr Material und ihre Herstellung können technikgeschichtliche Zeugnisse der Keramikproduktion sein, ihr Fundort kann Rückschlüsse auf den Verlauf von Handelsrouten zulassen. In einem schriftlich niedergelegten Text wie dem hier vorliegenden stellt sich die Sache völlig anders dar: Jeder Buchstabe verweist auf einen klar definierten Laut, den menschliche Stimmbänder erzeugen können. In einigen ebenso klar definierten Fällen kann eine bestimmte Letternfolge zwar durchaus einen Laut bedeuten, der von allen den einzelnen Buchstaben zugewiesenen verschieden ist (man denke an das >sch $)$, aber auch hierfür gibt es ein enges Regelwerk. Museumsdinge funktionieren hingegen nicht über ein kulturell etabliertes Codesystem. Welche Geschichte die Vase im Museum schließlich erzählt, hängt davon ab, wie die Ausstellung um sie herum beschaffen ist. 


\subsubsection{Museumdinge als »epistemische Dinge» nach Hans-Jörg Rheinberger}

Um zu einem systematischeren Zugriff auf die Rolle von Ausstellungsobjekten im Museum zu gelangen, schlägt Gottfried Korff daher vor, den vom Wissenschaftshistoriker Hans-Jörg Rheinberger geprägten Begriffs des »epistemischen Dings« für die Museologie zu entleihen:

In den Dingen hofft man, einer Welt hinter dem Schleier der Bilder und Diskurse habhaft zu werden, also einer Welt des Eigentlichen, des Authentischen zu begegnen, wobei authentisch nicht mehr als historischer Akkreditierungsbegriff, sondern als eine Kategorie verstanden wird, die sich auf Erlebnis- und Ereignisdimensionen bezieht: Im Gegensatz zu diesen primär affektiv und nicht kognitiv zugeschnittenen Konzepten richtet sich das »epistemische Ding« an den erkenntnisbefördernden Eigenschaften des Dings aus, also an den Modi des Gegebenen und des Gegenüber. (Korff 2005: 91)

Diese Übertragung mag zunächst verwundern, denn bei Rheinberger steht dieser Terminus in Verbindung mit einer augenscheinlich vom Museum sehr verschiedenen Art von Einrichtungen: Sein Bezugspunkt sind die Laboratorien der Naturwissenschaften, insbesondere jene der Biologie und Biochemie - und mit ihnen jene Versuchsanordnungen bzw. »Experimentalsysteme«, welche das Substrat aller naturwissenschaftlichen Forschung bilden (Rheinberger 2006: 7). Epistemische Dinge müssen in diesem Kontext nicht zwingend >Dinge $<$ im materiellen Sinne sein. Sie sind vielmehr Gegenstände des Interesses, an welche Wissensanstrengungen herangetragen werden und können auch die Gestalt von »Strukturen, Reaktionen, Funktionen« (ebd.: 27) annehmen. Entscheidend ist, dass epistemische Dinge unbestimmt sind und sich noch im prozeduralen Zustand einer zeitlich ausgedehnten 〉Entstehung < befinden. Sie sind keine sinnhaft geschlossenen und in eindeutige Begrifflichkeiten gebundenen Wissensinhalte, sondern ein (Noch-)Unbekanntes, dessen konzeptuelle und sprachliche Greifbarmachung überhaupt erst die Beweggründe naturwissenschaftlicher Forschung liefert. Damit verfügen sie zugleich auch immer über eine Ebene des Palimpsesthaften, auf der sich ihre früheren, nunmehr überkommenen Beschreibungen und Deutungszusammenhänge einschreiben (vgl. ebd.: 27f.).

Wenn epistemische Dinge innerhalb unserer bestehenden Wissenshorizonte erahnbar werden, lässt sich das, was sie im Eigentlichen sind, für gewöhnlich noch nicht in konziser Sprache benennen. Es existieren noch nicht genügend Anknüpfungspunkte für existierende Wissenssysteme, als dass man mittels eines einzigen Begriffs eine Brücke zwischen dem Gegenstand und den bekannten Konzepten schlagen könnte, innerhalb derer er sich erklären lässt. Entsprechend muss das epistemi- 
sche Ding zunächst beschrieben werden, was üblicherweise bedeutet, seine Eigenschaften und Verhaltensweisen aufzulisten (vgl. ebd.: 29). Um es aus diesem Stadium einer bloßen Auflistung von Eigenarten in das eines diskreten und benennbaren Phänomens zu überführen, muss es anschließend in bestehende Wissenskontexte integriert werden. Hier greifen nun gemäß Rheinberger (dessen wichtigster Bezugspunkt die Synthese von Proteinen im Reagenzglas ist) die »Experimentalsysteme«. Diese sind immer zugleich materiell-physikalische als auch diskursive Gefüge: Sie setzen das Unbekannte ins Verhältnis zum Bekannten und machen es benennbar. Das >Bekannte sind in diesem Falle die technischen Apparatuen (z.B. Reagenzgläser, Teststreifen, Mikroskope, usw.), ebenso wie die Verhaltensregeln und Gepflogenheiten der Laborarbeit und die wissenschaftlichen Aussagesysteme, in welchen die aus der Experimentaltätigkeit hervorgegangenen Beobachtungen schließlich gedeutet werden. Damit ist im Labor also, ganz ähnlich wie im Museum, Wissen stets das Produkt relativer Verhältnisse von Objekten und Sachverhalten. Experimentalsysteme ziehen Grenzen um epistemische Dinge, die mit jeder Wiederholung des Versuchs enger und präziser werden. Sie setzen sich dabei nach Rheinberger aus sog. »technischen Dingen« (ebd.) zusammen.

Technische Dinge sind im Gegensatz zu epistemischen begrifflich vergleichsweise eindeutig erfasst und wir haben eine konkrete Vorstellung davon, ১was ‘ genau sie sind. In Experimentalsystemen erfüllen sie eng definierte Funktionen unter weitgehendem Ausschluss von Nebeneffekten. Wissenschaftliche Wissensproduktion ist in diesem Modell eine kontinuierliche Beobachtung und Aufzeichnung derjenigen Verhaltensweisen, welche das epistemische Ding zeigt, wenn es mit den technischen Dingen interagiert (vgl. ebd.). Diese Systematik erlaubt es der Wissenschaft, eine ‘wilde Semiose zu vermeiden und auch aus noch undefinierten Gegenständen einen Wissensgewinn zu ziehen:

Technische Gegenstände haben mindestens die Zwecke zu erfüllen, für die sie gebaut worden sind; sie sind in erster Linie Maschinen, die Antworten geben sollen. Ein epistemisches Objekt hingegen ist in erster Linie eine Maschine, die Fragen aufwirft. (Ebd.: 33)

Mit seinem Plädoyer, das epistemische Ding zum Begriff der Museumswissenschaft zu machen, stößt Korff auch die Idee an, das Museum als eine Form von `Labor zu begreifen - mit Verweis auf Claude Lévi-Strauss, der das Museum als eine »Verlängerung des Feldes« (Lévi-Strauss 2002: 402) verstand, dabei jedoch eher in Ausbildung befindliche Archäologen und Ethnologen im Blick hatte als ein Laienpublikum (vgl. ebd.: 402ff., vgl. Korff 2005: 91).

Indes scheint sich die Grenzziehung zwischen epistemischen und technischen Dingen im Museum auf den ersten Blick weit schwieriger zu gestalten als im Labor. Intuitiv fällt es zunächst nicht schwer, in einem beliebigen musealen Raum Dinge eindeutig technischer Art zu identifizieren: Vitrinen und Schaukästen, Sockel und 
Podeste, Erklärungstafeln und Wegweiser, ja womöglich sogar die am Ausgang zu erwerbenden Souvenirs sind insofern technische Dinge der musealen Praxis, als dass sie um die Museumsdinge herum einen Ausstellungskontext schaffen, ohne selbst Gegenstand der Ausstellung zu sein. Vielleicht darf man hier sogar noch einen Schritt weitergehen: Erst im Zusammenspiel mit diesen scheinbar banalen technischen Elementen der musealen Anordnung kann ein Objekt tatsächlich >ausgestelltı und damit recht eigentlich >musealisiert ` werden. Der historische Überrest wird erst zum Museumsding, wenn er seinen Weg in einen Schaukasten, in einen Bilderrahmen, auf einen Sockel o.ä. und damit in sowohl die epistemische als auch die affektive Architektur des Museums findet, die ihn vor dem Publikum als museal erfahrbar ausweist und »durch Distanz aufwertet« (Paul 2005: 353). Auch diesen Mechanismus beschreibt Rheinberger in seiner Konzeption des epistemischen Dings, welches er nur innerhalb der gesetzten Horizonte einer technischen Anordnung überhaupt für existenzfähig erachtet:

Ohne ein System hinreichend stabiler Identitätsbedingungen würde der differentielle Charakter wissenschaftlicher Objekte bedeutungslos bleiben; sie würden nicht die Charakteristika epistemischer Dinge an den Tag legen, sondern beliebig werden und verrauschen. Wir sind mit einem scheinbaren Paradox konfrontiert: Die Bedingung wissenschaftlicher Forschung ist, dass sie sich im Bezirk des Technischen abspielt. (Rheinberger 2006: 33)

Museen allerdings sind ihrer gesamten Anlage nach darauf ausgerichtet, Sinnzusammenhänge nicht nur zwischen den noch unscharfen und in ihrem Bedeutungsinhalt eingrenzungsbedürftigen Ausstellungsstücken einer- und ihrem technischen Rahmen andererseits zu etablieren, sondern auch zwischen den Museumsdingen untereinander. Entsprechend ist die Herstellung einer wahrnehmbaren Unterscheidbarkeit zwischen technischen und epistemischen Dingen im Museum ein gleichermaßen ausstellungspraktisches wie theoretisch-grundsätzliches Problem: Die Exponate sind epistemisch, gehören aber immer auch zu einem technischen Gesamtgefüge, das andere Objekte verständlich machen soll.

Laut Rheinberger ist auch das Labor vor solchen Ambiguitäten nicht gefeit. Experimentalsysteme sind samt der sie bevölkernden epistemischen und technischen Dinge wesentlich Prozesse, die einander in der Pragmatik wissenschaftlicher Forschungsarbeit ständig aufs Neue zum diskursiven Dasein verhelfen. Entsprechend können inhaltlich »ausreichend stabilisierte« (ebd.: 27) epistemische Dinge selbst technisch werden. Sie stellen dann nicht länger den Gegenstand des Interesses dar, sondern werden zum Element einer Experimentalanordnung, die ihrerseits andere Sachverhalte erschließbar macht (vgl. ebd.). Damit scheint zugleich impliziert, dass ein epistemisches Ding gerade so lange ein solches bleibt, wie es sich noch im Ablauf der Festigung seiner Identität befindet. Sein Übergang in die Domäne der Technik 
würde entsprechend mit der Beendigung seiner Existenz als fortlaufendes >Geschehen < einhergehen. Tatsächlich aber betrachtet Rheinberger den Sinngehalt epistemischer Gegenstände als nie im strengen Sinne abschließbar. Sobald ein Experimentalsystem einmal läuft, neigen sowohl die epistemischen als auch die technischen Dinge zu Verselbstständigungen und unvorhergesehenen Rollenverschiebungen:

Das [obige] Paradox löst sich dadurch, daß die Wechselwirkungen zwischen epistemischen Dingen und technischen Bedingungen in hohem Maße nicht-technisch sind. Wissenschaftler sind vor allem »Bastler«, Bricoleure, weniger Ingenieure. In seinem nicht-technischen Charakter transzendiert das Experimentalensemble die Identitätsbedingungen der technischen Objekte, die es zusammenhalten. Auf der Seite der Technik finden wir schließlich ein analoges Prinzip. Gängig verwendete Werkzeuge können im Prozeß ihrer Reproduktion neue Funktionen annehmen. Geraten sie in Zusammenhänge, die über ihre ursprüngliche Zwecksetzung hinausgehen, so können Eigenschaften an ihnen sichtbar werden, die bei ihrem Entwurf nicht beabsichtigt waren. (Ebd.: 33f.)

Assmanns Konzept der >wilden Semiose ‘ und Rheinbergers Ausarbeitungen zu Experimentalsystemen greifen an dieser Stelle auf bemerkenswerte Weise ineinander und erlauben es uns, das Funktionieren und Entgleiten von Sinnstiftungsprozessen in musealen Anordnungen auf zwei verschiedenen und gleichermaßen relevanten Ebenen zu beschreiben. Assmann akzentuiert die Fallstricke der individuellen physiognomischen Dingwahrnehmung und das Problem einer möglichen Nichtinterpretierbarkeit materieller Objekte. Rheinberger hingegen liefert ein Modell für die Entstehung von Bedeutungen aus technischen Arrangements von Dingen und Konzepten und wirft zugleich die Frage nach der Beherrschbarkeit solcher Arrangements auf. Während ein schriftlicher Text naturgemäß immer einen Leser adressiert, der mit seinem Schriftsystem und seiner Sprache vertraut ist, müssen im Museum Mediensystem und kommunizierte Botschaft gleichzeitig und in wechselseitiger Abhängigkeit von Besuchern entschlüsselt werden, die zugleich auch noch ihre eigenen Vorurteile und Erfahrungshorizonte an die Ausstellung herantragen (vgl. Grütter 1997: 672). Dieses Element des Sozialen im Museum soll im Unterkapitel über den >Raum` noch genauer behandelt werden.

\subsection{6 «Nouophoren«}

Mit der nunmehr sichtbar gewordenen Abhängigkeit der Vermittlungsqualität musealer Objekte von ihrer wechselseitigen Bezüglichkeit sowohl untereinander als auch mit dem Museum selbst erscheint ihre Charakterisierung als Zeichenträger oder Semiophor entschieden unzureichend. Ziehen wir hierzu noch einmal die Zeichentheorie Günter Abels heran: Abel begreift die Bedeutung eines Zeichens immer als das 
Produkt seiner Interpretation, die aber bei einem Zeichen im eigentlichen Sinne niemals einer tatsächlichen Geistesanstrengung des Betrachters bedarf. Unter Rückgriff auf Wittgenstein stellt Abel fest, dass eine >Bedeutung immer mit ihrer eigenen Erklärung oder Beschreibung identisch ist - womit zugleich impliziert ist, dass jede Bedeutung zugleich ihre eigene Interpretation ist, und jede Interpretation ihre eigene Bedeutung (vgl. Abel 2000: 70). Mit anderen Worten: Zeichen werden deshalb zu Zeichen, weil sie ihre gesamte Interpretationspraxis als kulturelles Anhängsel schon mitliefern und eine bewusste Interpretation beim Adressaten niemals stattfindet. Wilde Semiose, wie Assmann sie versteht, kann im Museum nur vorkommen, weil Museumsdinge eben gerade dies nicht zu leisten imstande sind.

Einen dem des Semiophors wohl vorzuziehenden Terminus bietet Friedrich Waidacher mit dem des »Nouophors« an (Waidacher 2000: 5). Dieser beschreibt das Museumsding nicht länger als Behältnis für Zeichen, sondern für Bedeutungen, was gerade sein polysemes mediales Wesen und seine Unfähigkeit, für sich allein zu stehen, zentral werden lässt. Museumsdinge bedürfen im Gegensatz zum reinen Zeichen einer bewussten Interpretation. Dies heißt wohlgemerkt nicht, dass Museumsdinge nicht auch einen begrenzten Zeichencharakter aufweisen. Aber in Museumdingen als Nouophoren kollidieren die Zeichen mit den kulturellen Kontexten, die über ihre Interpretierbarkeit entscheiden und die sowohl der epistemischen Funktionsweise des Museums über Relationalität als auch den vielen sozialen Skripten innewohnen, die sich mit der Institution als solcher verbinden.

Korff sieht dementsprechend den Nutzen der Rheinberger'schen Begriffe für die Museumsforschung eben gerade in ihrer Betonung von Sinnproduktion über die Relationen zwischen nicht abschließbaren Bedeutungsträgern: Sie rücken, so Korff, das »Ding in seiner Materialität«, »das die Gestaltung diszipliniert« (Korff 2005: 102), gegenüber abstrakten museumspädagogischen Problemstellungen wieder in den Mittelpunkt der Betrachtung und fragen zugleich nach seinem Verhältnis zur Kategorie des >Raumes` (vgl. ebd.). Denken wir zurück an Horst Bredekamps zuvor diskutierte Einordnung der Wunderkammer in das mechanistische Weltbild der Renaissance, so heißt dies vielleicht auch, wieder ein Stück weit nach dem Museum als Sinn-Maschine oder Machinamentum zu fragen. Museumsdinge stehen nicht für sich allein, sondern sie sind Funktionselemente eines gleichermaßen epistemisch-diskursiven wie materiell-technischen Systems, das sich im Raum ausdehnt und in dieser Räumlichkeit erschlossen werden muss, wenn es seinen Sinngehalt preisgeben soll (vgl. ebd., 95).

Insbesondere der Raum, so fährt Korff fort, werde von der Museologie in ihrer Orientierung auf das materielle Ding häufig übersehen, dabei sei er erst das Medium, in dem die Exponate zueinander und die Betrachter mit den Exponaten in Beziehung treten könnten. Räume und ihre Gestaltung werden damit zum zweiten entscheidenden Faktor in der Produktion musealer Bedeutungen (vgl. ebd.). 


\title{
1.3 RÄUME IM MUSEUM: PHYSIKALISCH, SEMANTISCH, TRANSITIV
}

\begin{abstract}
Ähnlich wie die Museumsdinge erscheint auch der die Exponate umgebende museale Raum als ein Zwitterwesen zwischen konkreter Physikalität und abstrakter Diskursivität. Im Raum besitzen die Museumsdinge Ort, Ausdehnung und Peripherie. Der leere physikalische Raum etabliert einerseits die Trennung und Separiertheit der einzelnen Objekte voneinander und ermöglicht es andererseits, sie als assoziativ-kontingent verbunden zu erleben. Das Museum existiert dementsprechend gemeinsam mit seinen Objekten zugleich auf der Ebene der konkreten Orte, an denen es sich manifestiert, und jener der abstrakten Nicht-Orte, auf die es in seiner Medialität verweist (vgl. Schweibenz 2001: 1). Jedes individuelle physische Museum ist objektbezogen und lokal gebunden. Es beruht auf einem bestimmten und begrenzten Fundus von Exponaten und auf Infrastrukturen, die sein Bestehen ermöglichen - ganz grundlegend z.B. dem Gebäude, in dem es untergebracht ist. Zugleich aber ist das Museum auch ein diskursiver Ort und eine soziale Bezugsgröße, die allgegenwärtig ist und über welche laufend kulturelle Inhalte verhandelt werden. Das einzelne physische Museum ist starr, aber als Institution ist >das Museum < eine fließende Erscheinung (vgl. ebd., vgl. Wersig 1997).
\end{abstract}

\subsubsection{Räume und Zeichen}

Dieses `Zwitterhafteく des Museums deutet bereits an, dass es sich beim Raum als Entfaltungsmedium des Kulturellen - im Gegensatz zum Raum als physikalischer Größe - um einen schwierigen Phänomenbereich handelt. Wie die Philosophin Brigitte Scheer feststellt, gibt es in der menschlichen Erfahrungswirklichkeit keinen >Raum an sich. Der Raum sei vielmehr immer eine Abstraktion aus jenen Erscheinungen, die sich in ihm manifestieren (vgl. Scheer 2000: 234f.). In Relation zum leeren, gegenstandslosen Raum kann sich ein wahrnehmender Betrachter nicht als »unmittelbar bestimmt « (ebd.: 235) erfahren. Scheer verweist in diesem Zusammenhang auf die Leibnizsche Definition des Raumes als eine »Ordnung der Existenzen im Beisammen, wie die Zeit eine Ordnung des Nacheinander ist « (Leibniz 1996: 93; vgl. Löw 2000: 27) und auf Kants Feststellung, dass es sich beim Raum in erster Linie um eine »Form der Anschauung« (Scheer 2000: 235, vgl. Kant 1995: 76ff.) handle, welche das Erleben von Gegenständen erst ermöglicht. Er bedingt die Wahrnehmung, ohne selbst wahrnehmbar zu sein (vgl. ebd.) - und erscheint damit, so lässt sich hinzufügen, als ein geradezu ideales Ur-Medium, dessen Vorhandensein mangels einer materiellen Basis völlig verschleiert ist und nur aus seinem Inhalt überhaupt gefolgert werden kann. 
Dementsprechend ist Raumwahrnehmung für Scheer ein »Erfahren« (ebd.) dieses Mediums im allerwörtlichsten Sinne: Den Raum als ein positives `Etwas` (im Gegensatz zu einem formlosen $\gg$ Nichts $\triangleleft$ ) wahrzunehmen, heißt, sich körperlich durch ihn zu bewegen und sich dabei entlang seiner Erscheinungen zu orientieren. Dieses Sich-Orientieren ist für Scheer wiederum ein semiotisches. Der Raum wird erfahrbar, weil Gegenstände - und hier sei noch einmal an Aleida Assmanns Konzept der Dingwahrnehmung als >Pysiognomik « erinnert - als Zeichen gelesen und gedeutet werden (vgl. ebd.). Im Umkehrschluss ist damit für Scheer die gezielte Erfahrbarmachung des Raumes durch menschliche Gestaltungstätigkeit immer zugleich seine semantische Aufladung mit »Sinn«, wobei Sinn hier zunächst nicht mehr bedeutet als »Ausrichtung, den Raum charakterisierende Fügung« (ebd.).

Der wichtigste Modus dieser Sinnstiftung im Raum ist für Scheer die Architektur. Im Zusammenfügen von Gebäuden wird der vorgefundene Raum auf eine Art organisiert, welche dem sich in ihm aufhaltenden Subjekt »etwas zu verstehen« (ebd.) gibt. Indem es einem Stück des räumlichen Kosmos eine Funktion zuweist, wird das Bauwerk »Bedeutungsträger« (ebd.). Die Philosophin Scheer und der Museologe Waidacher greifen also völlig unabhängig voneinander zur selben Wortwahl, um den architektonischen Raum einer- und das museale Ausstellungsobjekt andererseits zu charakterisieren. Führt man beide Überlegungen zusammen, so muss die Frage gestellt werden, ob Architektur und Ausstellungspraxis nicht vielleicht sehr ähnliche Ziele verfolgen. Scheer schreibt:

Die Geschichte menschlicher Bautätigkeiten kann als Prozeß raumerschließender Zeichenvariationen aufgefasst werden. Es gibt eine allgemeine Kultur der menschlichen Lebensräume, zu denen außer den gebauten Räumen auch die Landschaftsräume zählen, die nicht weniger durch Zeichen vergegenwärtigt und durch interpretatorische Akte erschlossen werden. (Ebd.: 236)

Sie stützt sich in diesem Zusammenhang auf Martin Heideggers 1951 gehaltenen Vortrag Bauen Wohnen Denken. Heidegger widmet sich in diesem dem Ursprung des Wortes >bauen $<$ im althochdeutschen buan, welches ganz wie das altsächsische wuan und das gotische wunian, aus welchen das Wort >wohnen< hervorgegangen ist (vgl. Heidegger 1992: V), »das Bleiben, das Sich-Aufhalten« (ebd.) bezeichnet. Er entwickelt aus dieser Beobachtung die These, dass Bauen und Wohnen tatsächlich zwei Seiten derselben Medaille seien bzw. dass in jedem Bauen ein Wohnen schon angelegt wäre - und dass dieses Wohnen wiederum die Art und Weise sei, »wie die Sterblichen auf der Erde sind« (ebd.). Von buan nämlich stamme auch das Wort 〉bin`ab, also die erste Person Singular des >Seins $\triangleleft .{ }^{6}$ Scheer knüpft an Heidegger mit der These an, dass das Bauen (als Formung des Raumes durch architektonische Zeichensetzung) letztlich ein Prozess sei, in dem der Mensch sich selbst erschafft. Das Bauen

6 Vgl. zu diesen Passagen auch Scheer 2000: $236 f$. 
ist für Scheer ein der Sprache verwandtes Sich-Äußern. Bauen heißt: Räume schaffen, in denen Menschen ssein< können. Damit ist jedes Bauwerk eine Artikulation menschlichen Daseins schlechthin. Der Mensch wird sich gemäß dieser Deutung seines Seins erst bewusst, indem er es bauend verortet (Scheer 2000: 237).

\subsubsection{Der Raum in der Museumswissenschaft}

Ähnlich wie Architekten sind auch Museumskuratoren auf der grundsätzlichsten Ebene ihrer Tätigkeit Gestalter von Räumen, bzw. von Zeichensetzungen im ansonsten qualitätslosen Raum. Wie allerdings der Ausstellungsmacher Stefan Paul in einem Aufsatz aus dem Jahre 2005 bemängelt, leiden Museums- und Ausstellungsschaffende häufig an einer gewissen Betriebsblindheit für die Kategorie `Raum`als Grundbedingung ihrer Arbeit. Diese äußere sich vor allem darin, dass die Museologie bisher kaum systematisch-theoretische Ausarbeitungen zu diesem Thema hervorgebracht habe:

Jeder arbeitet mit dem Raum, aber keiner redet darüber. Auch der Fakt, das Ausstellungen und Museen im Unterschied zu vielen anderen vermittelnden Medien physisch zu begehen sind, wird in der Regel übersehen. (Paul 2005: 341)

Besonderen Nachholbedarf sieht Paul hier in der deutschen Museumswissenschaft, die traditionell (und, so darf man hinzufügen, wohl gerade aufgrund des Ursprungs der modernen deutschen Museumskultur im humboldtschen Kunstmuseum) ihren Blick fast ausschließlich auf das individuelle Exponat als Träger musealer Inhalte richtet. Eine viel größere Sensibilität für den Raum schreibt er dagegen der anglikanischen Museologie zu - als Ergebnis einer in den 1960er und 70er Jahren durch die Kommunikationstheorie Marshall McLuhans angestoßenen Debatte über Kommunikationsgefüge im Museum, die letztlich den Blick auf dessen räumliche Bedingtheit lenken musste (vgl. Paul 2005: 342).

Pauls Plädoyer für eine Schärfung des museologischen Blickes auf den Raum verlangt dabei gar nicht nach einer Ontologisierung, wie sie Scheer betreibt. Vielmehr interessiert sich Paul für ganz konkrete museale Raumkonzepte und die kommunikativen Zusammenhänge, die sie zwischen Objekten und Besuchern herstellen. Als ein naheliegendes Beispiel führt er repräsentative Museumsbauten des 19. Jahrhunderts wie die Alte Nationalgalerie in Berlin an, die in ihrer architektonischen Anlage antike Tempel (und damit eben den Ursprung des Museums überhaupt) zitieren: Sie führen ihre Besucher durch eine Serie von Räumen immer tiefer in ihr zentrales »Heiligtum« (ebd.: 344). Dies bewerkstelligen sie, indem sie sie über einen imposanten, häufig mit Treppenaufgang versehenen Eingangsbereich in Empfang nehmen, 
der dann von einem Bereich der »inneren Einkehr« (ebd.) gefolgt wird. Der vorgesehene Weg durch die Ausstellung führt einmal rund durch diesen Bereich und endet wieder am Ausgang - ganz ähnlich wie beim Kirchenbesuch also. Und ganz wie im christlichen Gotteshaus wird, so Paul, auch in diesen Musentempeln der Souvenirladen am Ausgang vom Besucher tendenziell als Störung des Raumkonzeptes erlebt (vgl. ebd.: 344f.).

\subsubsection{Museen als ITheaterı der Dinge}

Das Ergebnis dieser architektonischen Programmatik beschreibt Paul als eine aufsteigende Hierarchisierung der Exponate zum Inneren des Ausstellungsraumes hin, und diese Hierarchisierung wiederum belegt er mit dem Begriff der »Dramaturgie« (ebd.: 345). Die hier angedeutete Verwandtschaft der Einrichtungen >Theater seum` wird in der museologischen Fachliteratur immer wieder verhandelt. Heinrich Theodor Grütter z.B. beobachtet sie sowohl auf der Ebene des Mediums Ausstellung selbst als auch in der Beschaffenheit musealer Arbeit als Kollaborationsprozess: Wie Theaterinszenierungen haben historische Ausstellungen ein »Drehbuch«, meist verfasst von Historikern, welche eben als »Dramaturgen« thematische Ausrichtung und Vermittlungsinteresse festlegen (vgl. Grütter 1997: 670). Ferner ist, ebenfalls wie am Theater, im Museum die letztendliche >Vorführung ‘ das Ergebnis eines Ineinandergreifens verschiedenster Aufgabenfelder, und dementsprechend wird sie niemals gänzlich den Vorgaben des Skriptes entsprechen (vgl. ebd.). Gottfried Korff wiederum erkennt in der musealen Ausstellung ein »Theater des Gedächtnisses« (Korff 1999: 319) und kehrt damit einerseits zu den Wurzeln der Quicchebergschen Wunderkammer im Gedächtnistheater Giulio Camillos zurück, akzentuiert aber andererseits auch das Element des Inszenatorischen und Dramatischen, das stets mit jener Seriosität ausbalanciert werden muss, die das Museum als Vermittlungsinstitution anstrebt (vgl. ebd.: 319f.).

Für Stefan Paul indes verweist die Theatermetapher vor allem auf ein räumlich ausgedehntes Kommunikationsverhältnis im Museum, von welchem sie zugleich in ihre Grenzen verwiesen wird. Paul diagnostiziert in jüngster Vergangenheit vor allem eine inflationäre Verwendung des Begriffs »Szenographie« - und zwar nicht nur unter den Gestaltern musealer und außermusealer Ausstellungen, sondern in einer Vielzahl von Arbeitsbereichen, die sich mit Raumarrangements befassen (vgl. Paul 2005: 354f.). Die Implikationen dieser Wortwahl führen gewissermaßen Grütters Überlegungen vom kollaborativen Charakter des Machens von Ausstellungen mit jenen Korffs zu deren Dramatik zusammen:

Die Ausstellung wird als Bühne begriffen, auf der mit den Objekten ein Stück inszeniert wird und wo eine Vielzahl von Komponenten auf das fertige Produkt wirken. (Ebd.: 354) 
Irreführend wird diese Analogie für Paul jedoch beim Aspekt der Verortung des Rezipienten. Denn während das Theater seinen Besucher statisch gegenüber der Bühne platziert und ihn die Vorführung passiv erfahren lässt, lebt der Museumsraum von der ihm eingeschriebenen Einladung zu seiner aktiven Erschließung. Ja mehr noch: In einer Ausstellung sei es eben gerade erst der Rezipient, der die Dramaturgie durch seine Bewegung im Raum entstehen lässt. Im Gegensatz zum Theaterzuschauer bestimmt der Museumsbesucher viele der Modalitäten seiner Auseinandersetzung mit dem Dargebotenen selbst - so z.B. die Reihenfolge und das Tempo, in denen er sich den Exponaten nähert. Tatsächlich erscheint Paul damit die Museumsausstellung als fotografisches Negativ der Theatervorführung, weil es eben die `Zuschauer sind, die sich bewegen, während die >Darsteller` (in Form der Objekte) sitzen bleiben (vgl. ebd.: 354f.). Daraus ergibt sich für ihn wiederum die Konsequenz, dass es >den « musealen Raum gar nicht gibt. Vielmehr »bauen« (ebd.: 354) sich Rezipienten als mentale Architekten ihre ganz eigenen Erkenntnisräume aus den Bewegungspotentialen, die das Museum ihnen erlaubt. Museen >besucherorientiert anzulegen, heißt also, als Kurator einen Teil der Deutungshoheit über die Objekte an die Rezipienten abzutreten und diese Abtretung durch eine möglichst offene Raumgestaltung zu kommunizieren. Als Alternative nennt Paul dagegen die Logik des »schmalen Ganges« - also die Begrenzung der möglichen Bedeutungsebenen der Objekte durch eine Einschränkung der Bewegungsfreiheit des Besuchers (ebd.).

\subsubsection{Kommunikationsstrukturen im Museum}

Paul nennt nun drei Größen musealer Arbeit, welche konkret die Raumgestaltung bestimmen. Bei der Ersten handelt es sich, ganz erwartungsgemäß, um die Dinge selbst. Moderne Ausstellungspraxis ist es, bestimmte dominante »Leitobjekte« auszuwählen und zentral zu präsentieren, während weniger prominent herausgestellte Exponate sie umrahmen und kommentieren (vgl. ebd.: 351f.). Die zweite Größe ist das Thema: Zeitgenössische historische Ausstellungen verwenden Objekte zweckorientiert. Sie sollen nicht bewundert oder bestaunt, sondern verstanden werden. So entstehen »Themenräume«, die in erster Linie Geschichten erzählen (vgl. ebd.: 352). Drittens und letztens führt Paul den aus medientheoretischer Perspektive etwas missverständlichen Faktor der »Medialisierung« an. Natürlich ist streng genommen das Museum insgesamt eine mediale Anordnung, die Bedeutungen an materielle Träger knüpft. Paul, der ja aus der Sicht des Praktikers schreibt, meint hier speziell den Einzug solcher medialer Formen in den musealen Raum, welche das Präsentationsgefüge ergänzen, ohne selbst Museumsdinge zu sein - so z.B. Hör-, Film-, Tast- und Geruchsinstallationen oder computergestützte Infoterminals. Mit diesem Aspekt verbindet sich für Paul bei schlechter kuratorischer Handhabung zugleich das Risiko, dass 
Ausstellungsräume zu reinen Projektionsflächen für Medientechnologien verkommen, gegen deren hyperreale Erlebnisqualität sich die eigentlichen Exponate nicht mehr behaupten können (vgl. ebd.: 352f.).

Das Kommunikationsmodell, das sich für Paul aus diesem Umgang mit Raumelementen ergibt, ist eine Übertragung des Shannon-Weaver'schen Dreigestirns von Sender - Medium - Empfänger (vgl. Shannon u. Weaver 1963) auf die musealen Funktionsgrößen Objekt, Raum und Besucher (vgl. ebd.: 353). Hiermit jedoch gerät Paul ins Schlingern: Zweifelsohne ist der Besucher der `Empfänger`, aber das Objekt könnte ebenso gut als >Medium ` der Ausstellung begriffen werden, während sich dem in diesem Modell überhaupt nicht auftauchenden Kuratorium auch die >Sender Rolle zuschreiben ließe.

Paul ist sich solcher Einwände durchaus bewusst und verweist für ein alternatives Modell auf einen Vortrag des Kommunikationswissenschaftlers Michael Schmolke, der im Jahre 2002 auf einem Berliner Workshop zum Thema Ausstellungen als Instrumente der Wissensvermittlung gehalten wurde. Schmolkes Prämisse ist, dass die Idee von einem ganz für sich selbst sprechenden Exponat zwar für die Museumsdidaktik als anzustrebendes und disziplinierendes Ideal sinnvoll sein mag, an der Realität des Museumsbesuchers aber vorbeiginge. Sie wüssten über die ausgestellten Objekte entweder zu wenig, um sie ohne jede Hilfestellung interpretieren zu können, oder aber auch zu viel, um unter den verschiedenen möglichen Bedeutungsebenen eine sinnvolle Auswahl treffen zu können. Der Besucher, so Schmolkes These, komme ins Museum, um sich bereits arrangierte Bedeutungen abzuholen - und dementsprechend seien es eben nicht die Dinge selbst, die sich im Museum mitteilen, sondern die Macher der Ausstellung, welche über diese Dinge und das Gesamtgefüge der Ausstellung im Raum eine »Idee« bzw. ein Konzept mitteilen (vgl. Schmolke 2002: 1).

Schon 1976 brachte der Kunsthistoriker Detlev Hoffmann eine ähnliche Kritik an antiautoritären Museumskonzepten der 70er Jahre an, welche nach seinem Dafürhalten jede Form erklärender Vermittlung unter den Verdacht gestellt hätten, im Dienste »autoritärer Weltanschauungen« (Hoffmann 1976; 101) zu stehen. Hoffmann sieht hierin eine naive Einschätzung dessen, was Museumsdidaktik und -pädagogik tatsächlich leisten - nämlich eine Einordnung der Objekte in historische Kontexte. Gerade dieses Prinzip der >Historisierung « sei das, was die Dinge vor der »Interpretationswillkür« (Hoffmann 1976: 101) bewahre, indem es implizite Maßstäbe für die Zulässigkeit von Deutungen etabliere (vgl. ebd.).

Statt der Begriffe `Sender` und 〉Empfänger`, die ja eine klare Richtung des Kommunikationsvorganges und eine klare Begrenzung der Kommunikationsteilnehmer implizieren, verwendet Schmolke in seiner Vorstellung von musealem Informationsaustausch die Ausdrücke »Kommunikator« und »Rezipient« (Schmolke 2002: 2). Dinge, so stellt er fest, sind durchaus Kommunikatoren - aber sie können eine Botschaft immer nur so eindeutig vermitteln, wie es die Rezipienten zulassen. Weil eben 
der »ideale Rezipient« (ebd.), der jedes Objekt und dessen Rolle in der Ausstellung ohne weitere Erörterung verstehen könnte, in der Museumspraxis nicht auftaucht, müssen die Dinge epistemisch unterfüttert werden. Sie sprechen, so Schmolke, nicht »ohne Assistenz« (ebd.: 3) durch andere, inhaltlich eindeutiger bestimmte Kommunikatoren. Die üblichste Form dieser Assistenz ist die Beschriftung der Exponate mit erklärenden Tafeln (vgl. ebd.).

Diese Pluralität von Kommunikatoren, die ihre Botschaften mit variierender Klarheit an den Besucher bringen und die Erschließung der Museumsdinge erst ermöglichen, führt uns unweigerlich zurück zu Rheinbergers Experimentalsystemen. Was Schmolke hier beschreibt ist ja eben die Schärfung der Bedeutungen epistemischer Dinge durch ihre räumliche Einkreisung mithilfe technischer. Schmolke allerdings führt noch zwei Größen ein, die im musealen Raum immer mitkommunizieren und die das Rheinbergersche Modell an die Grenzen seiner Anwendbarkeit auf das Museum führen: nämlich die Besucher und die Kuratoren.

\subsubsection{Standpunkte und Blickwinkel}

Rheinberger ist zwar alles andere als blind für die Rolle des Experimentators als Subjekt der Laborarbeit, er beschreibt die Wissensproduktion der Naturwissenschaften aber in erste Linie von ihren Gegenständen ausgehend, die selbst keine Subjekte sind und mit denen der Forscher wiederum subjektiviert umgehen muss. Museen bringen im Gegensatz zu Experimentalanordnungen keine eindeutig reproduzierbaren Resultate hervor. Welches >Wissen nicht messen - tatsächlich darf man davon ausgehen, dass keine zwei verschiedenen Personen nach dem Besuch ein und derselben Ausstellung exakt dasselbe gelernt haben werden. Für Museumsbesucher gelten im Gegensatz zu Naturwissenschaftlern keine Verhaltens- und Diskursregeln, die ihren Wissenserwerb ordnen und vereinheitlichen. Dasselbe physikalische Experiment wird unter Laborbedingungen auch nach tausend Durchläufen noch dasselbe Ergebnis hervorbringen - aber dieselbe Ausstellung stößt bei tausend unterschiedlichen Besuchern ebenso viele verschiedene Effekte an.

Schmolke vergleicht das Museum daher mit einem »Rangierbahnhof von Kommunikation« (ebd.: 1). Seine Aufgabe sei es nicht vorrangig, konkretes Wissen zu vermitteln - dieses ist für Schmolke als »Inhalt der Waggons« (ebd.: 2) ein Phänomen zweiten Grades - sondern vielmehr, Kommunikationsprozesse anzustoßen. Museumskommunikation wird dabei nicht mehr als einseitiges Phänomen begriffen. Vielmehr spricht auch das Publikum in und über Ausstellungen. Wenn Museumsbesucher miteinander reden, dann diskutieren sie sowohl die von der gegenwärtigen Ausstellung angebotenen Wissensinhalte, als auch ein »Meta-Wissen« (ebd.) über Ausstel- 
lungen schlechthin - womit sie zugleich ständig den Horizont ihrer möglichen Museumserfahrungen neu verhandeln. Die Rollen von Kommunikator und Rezipient erscheinen vor diesem Hintergrund nicht als harte Kategorien der kommunikativen Situation >Museum`, sondern vielmehr als fließend ineinander übergehende Rollen, in welche Museumsbesucher je nach Situation schlüpfen. ${ }^{7}$ Es wird uns an anderer Stelle noch die Frage beschäftigen, wie es darüber hinaus gerade virtuelle Medien dem Publikum zunehmend ermöglichen, auch direkt mit den Museumsmachern zu kommunizieren.

Niemand geringerer als Franz Boas, der Vater der modernen Anthropologie, stellte 1907 in seinem Aufsatz Some Principles of Museum Administration ganz bewusst den Besucher in den Mittelpunkt der Gestaltung musealer Ausstellungen. Dabei beschrieb er die seiner Ansicht nach kaum zu unterschätzende Bedeutung der Perspektive und des Vorwissens der Besucher für die Vermittlung von Wissen im Museum mit dem Begriff des »point of view«. Dieser meint zugleich die vom Besucher mitgebrachten und kaum zu antizipierenden Vorbedingungen seiner Museumserfahrung als aber auch seine vom Kurator ermöglichten Verortungen im Raum. Tatsächlich sei, so Boas, die Jonglage mit den Blickpunkten der Besucher die eigentliche Königsdisziplin in der Ausrichtung von Museumsausstellungen:

The greater the number of people who desire to consult the museum in this manner, the more numerous will also be the points of view from which systematization will appear desirable. I think even to those not familiar with museum administration it will be at once apparent that the attempt to organize entire collections of a large museum from this point of view can have only one result. If every justifiable point of view is included, the complexity of the system will become so great that the usefulness of the whole series will become very doubtful. If, on the other hand, only a few points of view are selected, then all sciences as presented in that particular museum will appear in the strait-jacket into which they have been put by the narrowness of the selected view-points, while the material should rather be so arranged that it can be grasped from a multitude of points of view. (Boas 1907: 926)

7 Hier ist im Übrigen eine weitere Problematik bei der Übertragung von Rheinbergers Begriffssystem auf das Museum angezeigt: Der naturwissenschaftliche Experimentator hat im Kommunikationsgefüge des Museums keine eindeutige Entsprechung. Wer im Labor einen Versuch durchführt, möchte das Unbekannte in ein Bedeutungssystem zwingen und entwirft für diesen Zweck eine bestimmte räumliche Anordnung von Einzelelementen. Für Museumskuratoren sind ihre Objekte aber kein Unbekanntes - sonst ließen sie sich gar nicht museal verwenden. Die Tatsache, dass sie in eine Ausstellung aufgenommen wurden, setzt voraus, dass sie für die Schöpfer dieser Ausstellung bereits mit Bedeutungen belegt sind. Umgekehrt ist aber der Besucher, für den das Exponat tatsächlich noch nicht epistemisch erschlossen ist, im Gegensatz zum Laboranten nicht der Urheber des räumlichen Systems, das diese Erschließung ermöglichen soll. 
Bemerkenswert ist hier zweierlei: Erstens stellten diese Ausführungen die gängigen Museumskonzepte des frühen 20. Jahrhunderts buchstäblich vom Kopf auf die Füße. Zum Zeitpunkt der Veröffentlichung von Boas' Text waren gerade amerikanische Museen noch in hohem Maße als Forschungsinstitutionen angelegt, an denen vor allem in Disziplinen wie der Archäologie und Ethnologie mehr wissenschaftliche Arbeit geleistet wurde als an vielen Universitäten. Entsprechend wurden Ausstellungen im Allgemeinen von den Objekten her gedacht und das Museum selbst konstituierte sich fast ausschließlich über seine Sammlung - Besucher und der Umgang mit ihnen waren eher eine Randerscheinung (vgl. Redman 2010: 2).

Zweitens erkannte Boas das Problem der Besucherperspektive im Museum als ein räumliches: Exponate und Besucher sind für ihn Angelpunkte von Strategien semantischer Raumbewältigung. Dabei hat in seiner Konzeption des Museums aber gerade das Scheitern solcher kuratorischer Strategien didaktisch produktive Auswirkungen: Was das Museum als Vermittlungsinstitution auszeichnet ist eben gerade, dass seine Macher nur vage vorausahnen können, welche konkreten Inhalte die Besucher den Exponaten entnehmen werden (vgl. Boas 1907: 922). Die Konsequenz, die Boas daraus zieht, ähnelt der Absage, die Stefan Paul fast einhundert Jahre später dem »schmalen Gang« erteilt: Es sei ein zum Scheitern verurteiltes und der Beschaffenheit der Institution völlig widerläufiges Unterfangen, Ausstellungen um lineare Erzählungen herum zu konzipieren. Stattdessen gelte es, den goldenen Schnitt zu finden zwischen dem didaktischen sroten Faden`, der einer Ausstellung nachvollziehbare Zusammengehörigkeit verleiht, und den potenziell unzähligen >points of view` der Objektdeutung, die zwischen Exponaten und Besuchern entstehen. Je mehr unterschiedliche Blickwinkel ein museales Konzept bedienen kann, desto mehr schöpft es die medialen Möglichkeiten der Institution aus. Zugleich jedoch kann eine zu weitreichende epistemische Offenheit die Objekte unscharf und beliebig werden lassen. Die Herausforderung für den Ausstellungsmacher ist daher nach Boas die einer konzeptuellen Eingrenzung der Ausstellung auf eine Anzahl von Zugängen, welche die Vieldeutigkeit der Exponate zwar als Stärke ausspielt, dabei aber vermeidet, dass die Vielfalt möglicher Bedeutungen allen pädagogischen Anspruch unter sich begräbt (vgl. ebd.: 926).

Richard Saul Wurman behandelt in Information Anxiety ein ganz ähnliches Problem: Jede Form von Informationsverarbeitung hänge ganz entscheidend vom »vantage point « des Rezipienten ab - welcher wie Boas' »point of view« sowohl Kenntnisse und Vorannahmen beinhaltet, die von Rezipient zu Rezipient variieren, als aber auch die technische Beschaffenheit des Mediums, über welches die Informationen vermittelt werden. Die Art und Weise, wie Information situiert ist, entscheidet mit darüber, was ein Rezipient mit ihr tun kann: ob sie aus unterschiedlichen Perspektiven erfasst werden kann, ob man sich ihr nähern und von ihr entfernen, sie heranzoomen kann, ob Detailansichten möglich sind und ob sie für sich allein oder im Kontext weiterer Information präsentiert wird (vgl. Wurman 1989: 65). Als ein einfaches und 
prägnantes Beispiel für die Bedeutung des vantage point nennt Wurman hier den Effekt, den das bloße Umdrehen einer Weltkarte erzielt. Die Welt mit dem Süden aufwärts darzustellen ändert nichts am messbaren informationellen Gehalt einer Karte, aber der veränderte Blickwinkel legt offen, welche impliziten kulturellen Vor- und Werturteile sich mit der genordeten Darstellungsform verbinden (vgl. ebd.: 66).

Vantage points liegen dabei immer außerhalb der konkreten Informationsinhalte - gewissermaßen also in den Zwischenräumen (vgl. ebd.: 72). Diese Zwischenräume wiederum erhalten laut Wurman jedoch selbst Informationswert, insofern sie durch Informationseinheiten gegliedert und begrenzt sind (vgl. ebd.: 73). Ohne sich hier selbst in die Tiefen der Raumtheorie zu begeben, entwirft Wurman also ein Informationsmodell, das deutliche Parallelen aufweist zu Brigitte Scheers These, die Zeichensetzung im Raum mache den Raum schlechthin erst erfahrbar macht und ermögliche es, Räumen Bedeutungen zuzuschreiben. Wurmans Argumentation läuft jedoch in die genaue Gegenrichtung: Während für Scheer der leere Raum nur von jenen Punkten aus gedacht werden kann, an denen er mit Zeichen belegt ist, können für Wurman Informationsinhalte nur dann vermittelt werden, wenn man die Vermittlung aus dem Zustand der Informationsleere heraus konzipiert. Wissen vermitteln, so stellt Wurman fest, kann nur, wer sich in den Zustand des Nichtwissens zurückversetzen kann: »Communication equals remembering what it's like not to know.« (ebd.: 130).

Diese Feststellung mag auf den ersten Blick trivial erscheinen und deckt sich zweifelsohne mit den Erfahrungen eines jeden, der jemals gelehrt oder gelernt hat. Bemerkenswert ist hier jedoch zweierlei: Zum einen bedient sich Wurman in Information Anxiety laufend räumlicher Metaphern, um abstrakte Informations- und Kommunikationszusammenhänge zu beschreiben. Erst relativ spät kommt er in einem eingeschobenen Interview mit dem Ausstellungsdesigner Ed Schlossberg tatsächlich auch auf Mitteilungssysteme zu sprechen, die im physikalischen Raum ausgedehnt sind. ${ }^{8}$ Zweitens begreift er als Informationstheoretiker die Entstehung von Wissensgegenständen aus ihrem bedeutungsleeren Umfeld heraus, während der Museumspraktiker Paul und die Philosophin Scheer das Umfeld als Produkt seiner Inhalte verstehen. Dies wird uns später im Zusammenhang mit dem Begriff der >Information noch näher beschäftigen.

\subsubsection{Inszenierungen des Sozialen zwischen Ort und Raum}

Verweilen wir noch einige Seiten lang bei der Vorstellung vom Museum als einem Raum vielstimmiger Kommunikation. Im Jahre 1971 unterschied der damalige Direktor des Brooklyn Museum, Duncan F. Cameron, zwei kommunikative Formen,

8 Schlossberg unterstreicht hier übrigens wie Paul und Boas die Wichtigkeit der Offenheit von Ausstellungsräumen und die Gefahren zu enger Programmatiken (vgl. Wurman 1989: 133ff.). 
welche das Museum annehmen könne: einerseits jene des `Tempels`, andererseits jene des `Forums $\measuredangle$. In der hier schon mehrfach diskutierten Form des Tempels bleibt das Museum auch für Cameron seinen Ursprüngen im Museion verbunden: Es ist eine überwiegend von Machteliten gestiftete und erhaltene Einrichtung, die über das Bewahren von Objekten zugleich Wertvorstellungen und soziale Gefüge konserviert und der Etablierung von Idealen und Standards des gesellschaftlichen Lebens dient (vgl. Cameron 1972; 195, vgl. auch Morrissey u. Worts 1998: 149f.). Cameron bewertet diese Form von Museum durchaus nicht durchweg negativ, obwohl er zwei große Probleme identifiziert, an denen sie krankt: Erstens sei sie den didaktischen Intentionen kleiner und elitärer »club[s] of curators « (Cameron 1972: 194) unterworfen, welche diese der Gesellschaft gegenüber nicht immer rechtfertigen müssen. Zweitens unterwerfe das >Tempel<-Museum üblicherweise - und man erinnere sich hier an die >ästhetischen` Museen nach Korff - seine Objekte dem Narrativ der Ausstellung, anstatt es aus ihnen zu entwickeln (vgl. ebd.: 194f.).

Zugleich aber sei es gerade der Aspekt des Tempelhaften, auf den sich bis heute die kulturelle Autorität der Institution Museum gründe und aus dem heraus sie ihre kulturpolitische Relevanz behaupte. Trotz der autoritären Struktur solcher Museen sieht Cameron in ihnen ein notwendiges Werkzeug zivilisatorischer Identitätsstiftung: Um ihre Funktion in modernen Gesellschaften überhaupt erfüllen zu können, müssten Museen auf ihrer »proven excellence« (ebd.: 195) und unbedingten Interpretationshoheit über das von ihnen betreute materielle Kulturerbe bestehen (vgl. ebd.: 195f.).

Auf der anderen Seite aber müsse den >Tempeln « die museale Form des `Forums beigestellt werden (vgl. ebd.). Die Aufgabe des Forums sei es, kommunikative Brücken zwischen dem Mitteilungssystem der Ausstellungen und der Lebenswelt des Publikums zu bauen. Der Musentempel, so seine These, spreche nämlich allzu oft völlig an seinen Besuchern vorbei - mit weitreichenden Konsequenzen und ohne sich dessen je gewahr zu werden:

A very special task in reform for those museums concerned with alien, exotic or historic cultures is to relate those collections to contemporary life and society. Most museum directors would be shocked if they knew how their visitors interpret oriental collections or collections from the classical world when they are presented in the traditional fashion. By failing to provide meaningful interpretation of the collections museums are, by that omission, guilty of misrepresentation, distortion of fact and the encouragement of attitudes towards cultures other than our own which are dangerous and destructive in what McLuhan has called today's "global village«. (Ebd., 196)

Diese Verfehlungen klassischer Museen macht Cameron dafür mitverantwortlich, dass zum Zeitpunkt der Entstehung seines Textes im Rahmen der amerikanischen Bürgerrechtsbewegung ebenso wie europäischen Studentenproteste unlängst auch 
die Museen in den Fokus der Kritik gerückt waren: Als reine Kultstätten der gesellschaftlichen Führungsrollen von Aristokratie und Bürgertum hätten sie es verabsäumt, dieser die Errungenschaften und den historischen Werdegang der Arbeiterschaft gegenüberzustellen (vgl. ebd.: 197). Dass die Museumskultur beherrschende »Establishment« (ebd.) habe am Museum stets nur insofern ein Interesse gehabt, als dass sich in ihm Ewigkeitsansprüche für sein Gesellschaftsmodell formulieren ließen. Die Aufgabe des >Forums` hingegen sei es, die materiellen Zeugnisse dieses Gesellschaftsmodells der Diskussion durch eine möglichst breite Öffentlichkeit zugänglich und somit das Museum zu einem Raum der kritischen Reflexion über soziale $\mathrm{Zu}$ stände zu machen (vgl. ebd.: 197f.). Die hiermit angedeutete neue Funktion des Museums sei »the creation of an equality of cultural opportunity« (ebd.: 196).

Auch hier geht es also - wie immer man in der Rückschau Camerons linksliberalen politischen Impetus bewerten mag - um einen Wandel der musealen Kommunikationskonstellation von einem einfachen Sender-Empfänger-Verhältnis zu einer Polyphonie aller Beteiligten. Cameron äußert dabei große Zweifel daran, ob ein einziges Museum jemals zugleich Tempel und Forum sein könne. Schließlich sei das Wesen des Forums als Ort offener Kritik jenem des Tempels als Ort des autoritären Abschlusses von Sinnstrukturen und Deutungsmustern diametral entgegengesetzt. Die beste räumliche Lösung sieht Cameron in einem Kompromiss zwischen Nähe und Distanz: Forum und Tempel sollten baulich getrennt sein, damit das Forum nicht die Existenzberechtigung des Tempels in ständigen Zweifel ziehen kann, zugleich aber so nah beieinanderliegen, dass sie sich Anlagen, Dienste und vor allem ein gemeinsames Publikum teilen können. Für den Besucher müsse unbedingt ihre klare Unterscheidbarkeit gewährleistet bleiben (vgl. ebd.: 200). Die große Herausforderung einer zeitgemäßen Museumsreform sei es, neue kritische Dialogstrukturen im Museum zu ermöglichen ohne dabei seine Selbstverortung als das unzweifelhaft »objektive« Musterhaus des Realen preiszugeben, das über kulturelle Relevanz zu richten ermächtigt bleibt:

Museums must concern themselves with the reform and development of museums as museums. They must meet society's need for that unique institution which fulfills a timeless and universal function - the use of the structured sample of reality, not just as a reference but as an objective model against which to compare individual perceptions. (Ebd.: 201)

Damit plädiert Cameron also zugleich auch für die Koexistenz zweier völlig unterschiedlich angelegter musealer Raumkonzepte. Der Tempel etabliert in erster Linie eine Dichotomie des Innen und Außen: Die physische Museumswand stellt zugleich eine diskursive Grenze dar zwischen einerseits dem, was erhaltenswert und universell bedeutsam genug ist, um Gegenstand sanktionierter sozialer Erinnerungs- und Identitätsbildungsprozesse zu sein, und anderseits jenem, was der Sphäre des Alltagslebens, des Gebrauchs und des Warenverkehrs zugehörig bleibt. Das Forum dagegen 
steht im Zeichen räumlicher Offenheit und soll Diskussionen zwischen Museumsraum und Lebenswelt über die Museumswände hinweg ermöglichen.

Vierzig Jahre später ist die Diskussion über die Rolle des Besuchers im Museum so lebendig wie eh und je. Eine der jüngeren deutschsprachigen Veröffentlichungen zu diesem Problem- und Phänomenbereich erschien 2011 in Form des Sammelbandes Das partizipative Museum, herausgegeben von Susanne Gesser, Martin Handschin, Angela Jannelli und Sibylle Lichtensteiger, bei denen es sich durchweg um Museums- und Ausstellungspraktiker handelt.

Aus den Beiträgen dieses Sammelbandes sticht ein Aufsatz des Schweizer Kurators Beat Hächler heraus, der die Frage nach dem Museum als Einrichtung, die Besucher ins Gespräch bringen soll, nicht nur rein gestalterisch angeht, sondern sie auch raumphilosophisch kontextualisiert. Hächler bedient sich dabei des bereits im $\mathrm{Zu}$ sammenhang mit den Überlegungen Stefan Pauls gefallenen Begriffes der `Szenographieく, der er das Adjektiv 〉sozialく voranstellt. »Soziale Szenographie« ist für ihn eine Herangehensweise in der Ausstellungsgestaltung, die weniger darum kreist, mit Raumelementen ein bestimmtes narratives Konzept zu vermitteln, sondern über die Beschaffenheit von Ausstellungsräumen in erster Linie den Austausch unter den Besuchern anstoßen möchte. Diese sollen selbst zu einem Teil der Ausstellung werden und soziale Gefüge ausspielen, indem sie sich durch sie hindurchbewegen (vgl. Hächler 2011: 137f.).

Hächler beruft sich dabei auf die Raumtheorie des französischen Jesuitenpaters und Kulturphilosophen Michel de Certeau, wie dieser sie 1980 in seinem wichtigsten Werk Die Kunst des Handelns (Arts de Faire) dargelegt hat. Certeau unterscheidet darin kategorisch zwischen Raum (espace) und Ort (lieu). Der Ort ist für Certeau ein statisches Gebilde, das sich aus der gefügten Koexistenz von benenn- und lokalisierbaren Elementen ergibt. Räume dagegen sind zeitlich gebundene Zusammenkünfte von »Richtungsvektoren, Geschwindigkeitsgrößen und [der] Variabilität der Zeit« (Certeau 1988: 218). Der Raum ist also für Certeau nichts als fertiges Produkt Vorgefundenes, sondern etwas, das prozedural erst >gemacht $`$ werden muss. Er ergibt sich aus dem Umstand, dass in ihm gehandelt wird. Und weil er eben erst durch Handlungen geschaffen wird, ist der Raum im Gegensatz zum Ort nach Certeau kontinuierlich, fließend und veränderlich - er ist »ein Ort, mit dem man etwas macht» (ebd.) und existiert in seiner Wesensart nur innerhalb dieser Pragmatik, die nicht an den Raumbegriff der Physik gebunden ist:

So wird zum Beispiel die Straße, die der Urbanismus geometrisch festlegt, durch die Gehenden in einen Raum verwandelt. Ebenso ist die Lektüre ein Raum, der durch den praktischen Umgang mit einem Ort entsteht, den ein Zeichensystem - etwas Geschriebenes - bildet. (Ebd.) 
Texte sind für Certeau also Orte, geometrisch klar lokalisierbar in den Positionen von Buchstaben auf Papier, aus denen das Lesen einen Sinnraum entstehen lässt. Folgerichtig wäre auch das Museum ein Ort, der im Akt des Besuches zum Raum gemacht wird. Beat Hächler indes beobachtet im klassischen Museumskonzept (das in Camerons Diktion dem Modell >Tempel« entspricht) eine Überbetonung der Kategorie 〉ort $<$ bzw. ein kuratorisches Misstrauen gegenüber dem rezipientenseitigen Verräumlichungsvorgang. Die soziale Szenographie (welche nach Cameron unter die Modalitäten des >Forums〈 einzuordnen wäre) soll daher ausdrücklich ein Paradigma des \Raumes` stark machen, weil hier die Ausstellung prozesshaft von den Besuchern geschaffen werde, die sie erleben (vgl. Hächler 2011: 138f.).

Insofern ist soziale Szenographie ein Antizipieren von interpersonellen Prozessen, verbunden mit dem Versuch, sie über Raumkonzepte zu befördern und ihnen einen Kontext zu geben. Hächler nennt fünf Methoden, mit denen sie dies tut: »Personalisierung «, »Selbstbefragung «, »Partizipation«, »Dialogische Interaktion« und $»$ Exponierung« (ebd., 142ff.).

Personalisierung schafft laut Hächler die »Benutzeroberfläche für Identifikation« (ebd.: 142). Sie meint, den von der Ausstellung thematisierten Phänomenbereichen personale Qualitäten aufzuerlegen und es damit den Besuchern zu erlauben, sie auf sich selbst zu beziehen und als für ihr eigenes Leben bedeutsam zu erkennen (vgl. ebd.).

Unter dem Aspekt der Selbstbefragung wird verstanden, dass ein Museum laufend nachhalten solle, wie sein Publikum die Ausstellung erlebt - und zwar explizit indem es seine Besucher ermutigt, sich zu ihr zu äußern. Zugleich aber muss eine Selbstbefragung auch beim Publikum angestoßen werden: Die Ausstellung soll sie zwingen, ihre eigenen Prämissen zu hinterfragen und sich damit der Warte bewusst zu werden, aus der sie ihr gegenübertreten. Es gilt also in sozialen Szenographien stets, den Besucher herauszufordern und ihn über die Grenzen seiner üblichen Komfortzonen hinauszulocken (vgl. ebd.: 142f.).

Der Faktor Partizipation beschreibt eine Demokratisierung des Museumsbetriebes, indem Besucher bereits in die Gestaltung von Ausstellungen mit eingebunden werden. Dies könnte z.B. in Form eines Angebotes geschehen, dem Museum Ausstellungsstücke zukommen zu lassen, welche die Besucher für sich selbst als signifikant empfinden (vgl. ebd.: 143).

Unter >dialogische Interaktion ‘ fallen für Hächler all jene Gespräche, welche eine soziale Szenographie innerhalb eines Ausstellungsraumes anstößt. Das Museum soll Besucher dazu bringen, sowohl miteinander als auch mit dem Museumspersonal zu sprechen (vgl. ebd.: 144).

Mit dem Begriff der `Exponierung`schließlich beschreibt Hächler die bereits angesprochene Zielsetzung sozialer Szenographie, den Besucher selbst zum Teil der Ausstellung zu machen. Exponierung meint, dem Publikum und dem ganzen Spekt- 
rum seines Verhaltens in der musealen Anordnung selbst Exponatscharakter zu verleihen, oder kurz: die Besucher immer auch füreinander in Szene zu setzen (vgl. ebd.: 145).

Eine Extremform des Museums als Aushandlungs- und Etablierungsraum für soziale Gefüge und Verhältnisse beschreibt die Kuratorin Angela Jannelli mit jener des "wilden Museums « (Jannelli 2011: 165). Gemeint sind hiermit in erster Linie Amateurmuseen, wobei die Terminologie Claude Lévi-Strauss' Konzept des »wilden Denkens « aufgreift. Genau wie Strauss es ablehnte, die mentalen Weltordnungen von Naturvölkern als unterentwickelte Vorstufen des europäisch-modernen wissenschaftlichen Denkens zu begreifen, will Jannelli das Amateurmuseum nicht als Vulgärform des professionellen verstanden wissen, sondern als eine eigene und legitime Erscheinungsform dessen, was Museen sein können (vgl. ebd.).

Wilde Museen nach Jannelli zeichnen sich in erster Linie durch ihre sozialen Funktionen aus: Sie werden von freiwilligen Gemeinschaften getragen und sind damit zugleich die Fixsterne, um welche herum diese Gemeinschaften überhaupt erst entstehen. Ihre Sammlungen sind entsprechend nicht das Ergebnis eines geordneten Erwerbs von Exponaten im Sinne eines strukturierten thematischen Überentwurfs, sondern vielmehr Anhäufungen von Spenden ihrer Konstituenten, deren Zusammenhalt oberste Priorität ist. Wilde Museen nehmen Objekte zuerst einmal in die Sammlung auf, bevor nach ihrem Ausstellungswert gefragt wird - häufig auch einfach, um die Menschen, die sie vorbeibringen, nicht enttäuschen zu müssen. Die vom Exponat getragene Bedeutung ist entsprechend nicht zuvorderst eine didaktische. Objekte sind Träger von Beziehungen zwischen dem Museum und der Gemeinschaft, die es stützt (vgl. ebd.: 166). Für Jannelli manifestiert sich hier eine Form des vom französischen Soziologen und Anthropologen Marcel Mauss beschriebenen Rituals des `Gabentausches` (vgl. Mauss 1990). Die Schenkungen an das Museum, so ihre These, lassen in ihm soziale Räume entstehen und ermöglichen weitere Interaktionen zwischen den Spendern. Weil das Ablehnen eines Objektes zugleich der Negierung einer zwischenmenschlichen Beziehung entspricht, trennen wilde Museen ihren Fundus meist nicht von der Ausstellung: Um niemanden auszugrenzen, wird nach Möglichkeit die ganze Sammlung auf einmal präsentiert (vgl. Jannelli 2011: 167).

Hier sieht Jannelli zugleich auch das große Konfliktpotential zwischen Museumsamateuren und Museumsfachleuten. Letztere nämlich seien typischerweise dazu ausgebildet, Museumsdinge als konzise Sinnträger stark zu machen und sie (soweit eben möglich) aus personenbezogenen Kontexten herauszulösen. Das wilde Museum stellt dagegen gerade die Personen in den Mittelpunkt, welche die Ausstellung ermöglicht haben und deren Beziehungsgeflecht sie abbildet (vgl. ebd.). Im professionellen Museum werde das Objekt als Zeichen gedacht, im wilden dagegen als »Symbol« (ebd.: 168), das professionelle möchte seinen Exponaten möglichst eindeutige Verweisbeziehungen auferlegen, das wilde möglichst vielfältige (vgl. ebd.). Entspre- 
chend befinden sich wilde Museumsausstellungen auch ständig im Zustand der Veränderung und hören niemals auf, zu entstehen - sie wandeln sich mit jedem Eintrudeln eines neuen Exponates (vgl. ebd.: 170f.).

Damit sind wilde Museen auch immer von epistemischer Unschärfe gekennzeichnet. Die Frage nach einem für sich selbst stehenden Objekt stellt sich für sie gar nicht erst. Wilde Museen sind als soziale Orte meist darauf ausgelegt, unter der Anleitung ihrer Verantwortlichen in Führungen erlebt zu werden. Sie sind, so Jannelli, nicht etwa Orte, an denen Objekte sprechen, sondern Orte, die das Sprechen über Objekte, das »Erzählen über Dinge« (ebd.: 168) ermöglichen sollen.

Das Funktionieren musealer Ausstellungen beschreibt Jannelli interessanterweise mit den filmwissenschaftlichen Termini »Story« und »Plot ${ }^{9}$. In der Filmwissenschaft bezeichnen diese Begriffe zwei Ebenen, auf denen ein Film seine Handlung entfaltet. Seine Story ist die chronologische Abfolge der Ereignisse. Der Plot hingegen ist die Art, wie uns diese Ereignisse präsentiert werden und damit also die tatsächliche narrative Umsetzung der Story. Der Plot muss dabei nicht der Chronologie der Story folgen (ebd.: 170). Quentin Tarantinos Gangsterfilm Pulp Fiction beispielsweise spaltet seine Handlung in Einzelepisoden auf, welche dem Zuschauer in chaotischer Reihenfolge präsentiert werden und ihn vor die Herausforderung stellen, selbst herausfinden zu müssen, in welchem zeitlichen Verhältnis sie zueinander stehen. Der Plot von Orson Welles' Hauptwerk Citizen Kane beginnt kurz vor dem Ende seiner Story - nämlich mit dem Tod des Protagonisten, dessen Lebensgeschichte danach in Rückblenden erzählt wird. Um beim Schauen eines Filmes vom Plot zur Story zu gelangen, ist also mitunter eine intellektuelle Anstrengung des Rezipienten vonnöten - und ganz ähnlich verhält es sich in Museen, deren materielle Oberfläche ja immer erst durch Interpretation die ihr zugrunde gelegte Meistererzählung preisgibt.

Das häufig prekäre Verhältnis von Story und Plot werde laut Jannelli besonders deutlich in solchen Museen, welche wie eben die >wilden ihre soziale Komponente besonders in den Mittelpunkt stellen. Denn wenn eine Ausstellung in ihrem Objektbestand nicht scharf einzugrenzen ist, dann verschiebt sich das Plotting notwendigerweise immer weiter in den Bereich der Führung und Anleitung durch das Museumspersonal. Dies könne mitunter zu einer erheblichen Entkopplung zwischen derjenigen Story führen, welche sich die Besucher beim alleinigen Erforschen eines wilden Museums erschließen würden, und jener, welche aus dem Plot der Führung hervorgeht (vgl. Jannelli 2011: 170). Daraus lässt sich ableiten: Auf epistemischer Ebene werden Museen nicht notwendigerweise offener, nur weil ihrem Aufbau keine umfassende didaktische Konzeption zugrunde liegt. Vielmehr kann der Verlust konziser Interpretierbarkeit der Objekte dazu führen, dass die Ausstellung nur mehr sozial erfahrbar

9 Die Film- und Medienwissenschaft zieht diesen häufig die weitgehend gleichbedeutenden, dem russischen Formalismus entstammenden Begriffe `Fabel` und \Sujet` vor (vgl. Propp 1972: 27). 
ist und damit die Autorität der Museumsmacher hinterrücks wieder eingeführt wird, weil ihre Anleitung unentbehrlich ist.

\subsubsection{Authentizität, Aura, Atmosphäre}

Im laufenden Kapitel wurde das Museum bisher vor allem als eine Institution der Wissensvermittlung beschrieben. Dies ist freilich nur ein Teil ihres gesellschaftlichen Auftrages. Friedrich Waidacher sieht ihre Funktion als Lernort als ein zeitlich stets sehr eng begrenztes Überbauphänomen, welches in Abhängigkeit von dem Zeitgeist unterworfenen pädagogischen Maßstäben sehr unterschiedliche Gestalten annehmen kann. Als Ort der historischen Unterweisung ändert das Museum seinen Charakter mit den geltenden Maßstäben der historischen Forschung und Geschichtsdidaktik ebenso wie mit den wechselnden Ansprüchen und Erwartungen seines Publikums. Als die zeitübergreifend bestehenbleibende Aufgabe des Museums sieht Waidacher hingegen seine Funktion als Erinnerungsspeicher: Unabhängig von vorübergehenden Trends und Zielsetzungen des Museumsbetriebes bewahrt das Museum die materiellen Überreste der Vergangenheit und legt damit Zeugenschaft über bestimmte historische Wirklichkeiten ab (vgl. Waidacher 2000: 1ff.). Im Museum, so Waidacher, geht es nicht vorrangig darum, etwas Bestimmtes über die Vergangenheit zu lernen, sondern vielmehr darum, sich anhand der Evidenz der Exponate der Realität der Vergangenheit überhaupt zu vergewissern (vgl. ebd.: 6). Ihre Daseinsberechtigung bezögen die Museen dementsprechend in allererster Linie daraus, als einzige gesellschaftliche Einrichtungen materielle Kulturgüter professionell zu betreuen und immer wieder aufs Neue für die öffentliche Rezeption aufzubereiten (vgl. ebd.: 18). Eine ganz ähnliche Einschätzung des Museums und seines Auftrages findet sich auch bei Gottfried Korff:

Jede Zeit schafft sich ihre Museen neu, ordnet sie um, präsentiert deren Bestände in wechselnden Arrangements. So sind Museen gekennzeichnet durch die Historische Dialektik der Tätigkeiten Deponieren und Exponieren. Das Exponieren ist der Ort, an denen intellektuelle und ästhetische Vorstellungen der jeweiligen Zeit Bilder von Geschichte generieren, Bilder, die deswegen mit der Vergangenheit zu tun haben, weil das Museum Ort der Aufbewahrung von Relikten, survivals, Überresten (im Sinne Droysens) ist. (Korff 1999: 327)

Die in den Arbeiten Korffs immer wieder betonten Funktionen des Deponierens und Exponierens ranken sich, so fährt er fort, in erster Linie um eine ästhetische Kategorie - nämlich um jene der Authentizität:

Durch seinen Authentizitätsbezug ist das Museum eine Institution der sinnlich-ästhetischen Wahrnehmung. Eine Re-Dimensionierung, eine Kontextualisierung mit Mitteln der bildhaften 
Inszenierung ist dem Medium Museum deshalb angemessen, weil mit der Authentizität der Dinge eine ästhetische Erfahrungsform in Spiel kommt, deren Konsequenz eine ästhetische Präsentationsform ist. (Ebd., 332)

Das Museum ist demnach also eine Institution, die dem ästhetischen Erleben dient, was zugleich auch die Verwendung dramatisch-inszenatorischer Präsentationsformen legitimiert, welche einer reinen Lehrinstitution nicht angemessen wären. Dieses ästhetische Erleben wiederum benötigt Objekte, die nicht nur mit Sinn belegt, sondern eben vor allem auch authentisch sind.

Diese Argumentation erscheint auf den ersten Blick schlüssig - niemand, der einmal ein Museum besucht hat, wird abstreiten, dass gerade die affektive Anmutung der Objekte einen bedeutenden Teil des Reizes der Institution ausmacht. Das Erleben von Authentizität ist ein fester und dabei weitgehend intuitiver Bestandteil unserer kulturellen Welterfahrung - wir erkennen das >Authentischeく, wenn wir es vor uns haben, ohne dass wir genau benennen könnten, was es als solches ausmacht. Als ästhetischer Terminus ist die Authentizität dementsprechend alles andere als unproblematisch.

Die Literaturwissenschaftlerin Susanne Knaller verortet seinen Wortursprung im griechischen Adjektiv $\alpha v \theta \varepsilon v \tau \iota \kappa o ́ \varsigma$ (»zuverlässig, richtig«), das sich wiederum vom Substantiv $\alpha \dot{\theta} \theta \dot{v} v \tau \eta \varsigma$ (»Ausführer, Selbstherr, [...] auch Urheber«) ableitet (Knaller 2005: 18). Obwohl der Begriff schon in der griechischen Antike vor allem auf Schriftstücke bezogen wurde und hier deren Originalität bzw. Rückführbarkeit auf den Urheber beschrieb, konnte er auch Formen der Selbstermächtigung implizieren - so beschrieb er laut Knaller auch Selbst- und Verwandtenmörder (vgl. ebd.). Das Spätlateinische machte aus $\alpha v \theta \varepsilon v \tau$ เó $\varsigma$ authenticus und beschrieb hiermit ebenfalls vorrangig Schriftdokumente als »anerkannt, rechtmäßig, verbindlich« - jene Bedeutungen also, mit denen das Wort in variierenden Kontexten bis heute in den meisten europäischen Sprachen belegt ist (vgl. ebd.). Der Duden definiert das Adjektiv >authentisch gegenwärtig als »echt, den Tatsachen entsprechend und daher glaubwür$\operatorname{dig}{ }^{10}{ }^{10}$

Jedoch weist Knaller darauf hin, dass bereits in der latinisierten Form als authenticus keineswegs Eigenschaften beschrieben wurden, die einem Schriftstück selbst innewohnten. Authentizität war ein Begriff der kirchlichen Doktrin und meinte die Anerkennung der göttlichen Inspiriertheit von Texten durch die Autorität der Kirche selbst (vgl. ebd.). Seine weltliche Fortsetzung erfuhr diese Begriffsnutzung in der Juristerei des 18. Jahrhunderts, welche die Auslegung von Gesetzen in zwei Modi unterteilte: den Doktrinalen und den Authentischen, wobei doktrinale Gesetzesdeu-

$10 \mathrm{http} / /$ www.duden.de/rechtschreibung/authentisch vom 11.04.2018. 
tung die Domäne der Rechtgelehrten war, authentische hingegen jene des Gesetzgebers, welche sich in neuen Verwaltungsrichtlinien niederschlagen konnte (vgl. ebd.: 18f.).

In der frühen Neuzeit blieb der Authentizitätsbegriff in den meisten europäischen Sprachen zunächst autoritätsorientiert und beschrieb vor allem die Absegnung und Sanktion durch offizielle Instanzen. Erst im 20. Jahrhundert nahm er zunächst im Französischen und Italienischen die Bedeutung einer eigenbedingten Echtheit an, er wurde synonym mit Adjektiven wie »sincère, juste, naturel, vrai, non affecté, vero, genuino, schietto « (ebd.: 19). Knaller fährt fort, dass Authentizität als Begrifflichkeit der Kunsttheorie seit dem 20. Jahrhundert vor allem als »normativer Vermittlungsbegriff« (ebd.: 21) zwischen verschiedenen Disziplinen fungiere und eine Vielzahl von Eigenschaften sowohl von Subjekten wie von Objekten beschreibe (vgl. ebd.). Auf der Ebene des Subjekts meine Authentizität z.B. die Überwindung von individueller Entfremdung, eine Rückkehr zu Ursprung und Innerlichkeit und ein Zurückfinden zum »unkontaminierten Selbst« (ebd.: 22). Auf jener des Objekts hingegen manifestiere sich Authentizität oberflächlich in seiner Originalität (im Gegensatz zur Fälschung), fernerhin aber auch in seiner Verortbarkeit in bestimmten ästhetischen Traditionen wie z.B. einer kunsthistorischen Epoche und ihrer Stilistik (ebd.).

Knaller führt hier daher noch eine Unterscheidung zwischen reiner »Objektauthentizität« und »Kunstauthentizität« ein. Objektauthentizität gründet sich für Knaller üblicherweise auf eine Urheberschaft und Zugehörigkeit, die institutionellautoritär beglaubigt werden muss. Kunstobjekte hingegen bezögen ihre Authentizität aus einem Autorschaftskonzept, das weit über bloße Urheberschaft hinausgeht und in enger Verbindung mit dem System der Kunstkritik steht. In der Figur des Autors manifestiere sich die »der Künstlerperson immanente Schaffensqualität« (ebd.), während die Kunstkritik die Aufgabe übernehme, verbindliche (aber historisch flexible) Maßstäbe dafür auszuhandeln, wann genau Kunstwerke als authentisch gelten dürften. Gegenwärtig werde die Authentizität in der Kunst vor allem als »Synonym von Unmittelbarkeit« (ebd.) gedacht, womit zugleich angedeutet ist, dass Kunstwerke, wollen sie Authentizität beanspruchen, ihren medialen Charakter zu verschleiern haben. Damit werde, so Knallers These, Authentizität in erster Linie zum »Ergebnis von Strategien der Wiedererkennung«, sie ließe sich analytisch am besten »als Anerkennung, als Spiel oder als Medienpakt« greifen (ebd.).

Knallers Begriffsgeschichte folgend kann also zunächst festgehalten werden: Authentizität ist nicht vorrangig etwas, das einem Objekt anhaftet, sondern vielmehr eine kulturelle Größe, die vom Objekt lediglich mediiert bzw. anhand des Objektes sozial ausgehandelt wird. Im Lichte dieser Überlegung können wir museale Authentizitätserfahrungen auf zwei Ebenen verorten: Einmal auf jener der Exponate, welche das authentische Moment als dessen Trägermedium kommunizieren, und einmal auf jener der Institution Museum selbst, welche gewissermaßen den Rahmen und die 
Funktion jenes >Medienpaktes $`$ vorgibt, der die Museumsdinge überhaupt erst als authentisch erfahrbar kennzeichnet.

Dies wirft wiederum die Frage nach einer möglichen Beliebigkeit der Museumsdinge auf, welche vor allem die Notwendigkeit des >echten` Objektes berührt. Wenn Authentizität nicht etwa eine Eigenschaft von Objekten sondern vielmehr eine Kategorie der Verständigung über Objekte ist, könnte dann nicht eine Kopie ebenso authentisch sein wie ein Original? Tatsächlich haben in der Museumsgeschichte immer wieder in der einen oder anderen Form Reproduktionen ihren Platz in Ausstellungszusammenhängen gefunden, ohne dass damit eine Täuschung des Publikums oder eine Unterwanderung musealer Verhaltensrichtlinien intendiert oder auch nur verbunden gewesen wäre. Krzysztof Pomian sieht den frühesten Ursprung menschlicher Sammeltätigkeit tatsächlich in einer Abkehr von Originalgegenständen und führt als Beleg die Begräbnisriten altertümlicher Kulturen an: Von Europa bis nach China ließe sich fast überall eine Tendenz beobachten, Grabbeigaben in Form vom Gebrauchsobjekten nach und nach durch Modelle und Nachbildungen zu ersetzen. Als Beispiele nennt Pomian Beigaben von Tonfiguren anstelle einer Opferung von Sklaven und Tieren, die ihrem verstorbenen Herrn im Jenseits dienen sollten, oder die Fertigung rein ornamentaler Nachbildungen von Waffen und Werkzeugen, die häufig sehr viel wertvoller als die tatsächlich brauchbaren Originalobjekte und von vornherein offenbar nur als Sinnträger gedacht waren - eine Denkfigur, welche das (museale) Sammeln im neuzeitlichen Sinne erst ermöglicht habe (vgl. Pomian 2007: 22).

Auch die humboldtschen Kunstmuseen des 19. Jahrhunderts, welche durch und durch als Kultstätten des authentischen Originals konzipiert waren, erlaubten durchaus das Ausstellen von Reproduktionen. Zwar standen die von der Museumsarchitektur zu Kultgegenständen aufgewerteten Kunstwerke im Mittelpunkt dieser vorrangig ästhetischen Museumskonzeption, aber in weniger exponierten Winkeln der Gebäude waren durchaus auch ethnographische und historische Sektionen vorgesehen. Da den hier ausgestellten Exponaten nicht dieselbe inspiratorische und erzieherische Qualität beigemessen wurde wie den Kunstobjekten, wurde von ihnen auch keine Originalität verlangt - es genügten Nachbildungen, z.B. in Form von Abgüssen (vgl. Korff 2002a: 115).

Auch in der Gegenwart ist die Verwendung von Reproduktionen im Museum nicht unüblich. Sie vertreten z.B. Objekte, die im Ausstellungskontext wichtig, aber aus irgendwelchen Gründen nicht verfügbar sind - womöglich können sie nicht gefahrlos (oder gar nicht) transportiert werden, ihre Besitzerinstitution verleiht sie nicht, oder sie existieren schlicht nur noch in Form von Abbildungen (man denke hier an die enormen Zerstörungen von Kulturgütern in den Weltkriegen). Vielleicht befindet sich das Original auch durchaus im Besitz des Museums, aber es kann aufgrund seiner Empfindlichkeit oder eines schon fortgeschrittenen Verfalls nicht dem Publikum präsentiert werden, ohne seine Zerstörung zu riskieren. Die moderne Museums- 
praxis erachtet es dann üblicherweise als den didaktisch richtigen Weg, solche Platzhalter ausdrücklich als Kopien auszuweisen und transparent zu machen, warum das Original nicht ausgestellt werden kann (vgl. Beier-de Haan 2010: 2f.). Reproduktionen dürfen also durchaus Teil von Ausstellungen sein, solange ihr Dasein erstens im Ausstellungskontext als wichtig erachtet wird, zweitens plausible Gründe dafür vorliegen, nicht auf das Original zurückzugreifen und drittens der Besucher nicht in die Irre geführt und glauben gemacht wird, er habe ein Original vor sich. In diesem Sinne kann also offenbar auch Kopien durch Museen und ihre Kuratoren das Prädikat rauthentisch ` verliehen werden: Die Objekte sind keine tatsächlichen historischen Überreste, weisen aber zumindest augenscheinlich in der musealen Situation all deren ausstellungsrelevante Merkmale auf. Nichtsdestoweniger bleibt die Autorität und Notwendigkeit des Originals in der Museumsarbeit von der museologischen Fachliteratur weitgehend unangefochten.

Einer der zentralsten und meistzitierten Texte über die Affektqualität des Authentischen und das Verhältnis von Original und Kopie ist nach wie vor Walter Benjamins 1935 entstandener Aufsatz über Das Kunstwerk im Zeitalter seiner technischen Reproduzierbarkeit. In diesem Klassiker der Kunsttheorie diagnostiziert Benjamin zwei Phänomene, welche sich aus der massenhaften Reproduzierbarkeit von Kunstgegenständen ergeben: Auf der einen Seite steht die Auflösung der originären und überlieferten sozialen Kontexte, in welchen die Objekte ursprünglich zu rezipieren waren, auf der anderen der Verlust ihrer >Aurar. Beide Erscheinungen begreift Benjamin als ursächlich zusammenhängend.

Dabei ist Benjamins im Titel schon programmatisch vorgegebene Prämisse, dass sich das Wesen der Reproduktion von Kunstwerken mit ihrer Technisierung - Benjamin bezieht sich hier vornehmlich auf mechanisch-photographische Abbildungsverfahren und den modernen Druckereibetrieb - einschneidend verändert habe. Zwar seien Kunstwerke schon immer kopiert worden, aber im manuellen Nachvollzug der Entstehung des Originals durch den Kopisten habe das Original gleichsam immer seine Autorität bewahrt. Die manuelle Kopie sei entsprechend lediglich Vertreter des Originals und Verweis auf dasselbe. In der technischen Reproduktion hingegen verliere das Original seine Autonomie. Es ist nicht länger das `Eigentlicheく des Reproduktionsvorganges, sondern nur mehr eines unter vielen Funktionselementen innerhalb eines industriellen Apparates, der identische Abbilder in astronomischer Zahl ausspeit (vgl. Benjamin 2008: 12). Oder anders ausgedrückt: In technischen Reproduktionsverfahren sieht Benjamin den Subjektcharakter des Originals aufgehoben, den es in der manuellen Nachbildung noch besessen hat.

Originale besetzen für Benjamin einen bestimmten und bestimmbaren Ort sowohl in der sozialen als auch in der historischen Welt. Sie sind für soziale Räume und Zusammenhänge geschaffen worden, zu welcher sie eine repräsentative Referenz aufweisen. Das Ergebnis technischer Reproduktion ist laut Benjamin eine Loslösung der Originale von ihren Ursprungskontexten und damit zugleich der Verlust ihrer 
Verweisqualität (vgl. ebd.: 13). Dies wiederum führe zur Vernichtung der >Aura ‘, die als Begriff das vielleicht wichtigste Vermächtnis des Kunsttheoretikers Benjamin ist. Mit ihm bezeichnet er die Gesamtheit und Summe aller affektiven Wirkungen, welche das Betrachten eines Kunstwerkes beim Rezipienten hervorruft. Zugleich betrachtet er die Aura als eine Größe, in welcher das Zeitliche und das Zeitlose in Verbindung treten: Kunstwerke sind auratisch, weil sie historisch sind. Sie sind aus einer bestimmten geschichtlichen Situation entstanden, die sich in ihrer Materialität den Beleg ihrer Wirklichkeit geschaffen hat und die in der Gegenwart des Kunstwerks nahbar zu werden scheint, dem Betrachter zugleich jedoch fern und flüchtig bleibt. Andererseits behauptet sich die Aura bei Benjamin aber auch durch alle historischen Rezeptionserfahrungen hindurch und wird damit gewissermaßen übergeschichtlich. Die Aura verleiht dem Betrachter und seiner historisch gebundenen Erfahrung des Kunstwerks ein Moment des Ewigen (vgl. ebd.: 16). Technische Reproduktionen zerschlagen dementsprechend die Aura des Kunstwerkes vor allem dadurch, dass sie es aktuell und zeitgenössisch werden lassen, es in der Gegenwart neu beheimaten.

Gottfried Korff sieht in der auratischen Qualität des Orginals den raison d'être des Museums schlechthin (vgl. Korff 2002a: 120). Dabei weist er darauf hin, dass sie keinesfalls an die Schönheit des Objektes geknüpft ist. Entscheidend sei vielmehr seine Echtheit. Die auratische Funktion der Museumsdinge sei es nicht etwa, zu bezaubern, sondern vielmehr zu erschrecken. Affektivität und Narrativität des Museums greifen für Korff ineinander - die epistemische Unbestimmtheit des Museumsobjekts einerseits und seine Fähigkeit, emotional zu berühren andererseits lassen es zu einem Ort werden, der beim Besucher Fragen aufwerfen, nicht etwa geschlossene Geschichten erzählen soll. Das Mittel hierzu sei der `Schock ^ - ein Begriff, den Korff bewusst der Theorie Benjamins entlehnt (vgl. ebd.). Der Wert des Originals liegt demnach gerade darin, dass es durch seinen auratischen Nimbus auf eine Art und Weise sperrig ist, welche der von vornherein ortlosen Reproduktion abgeht, und nur hierdurch eine >Reibungsfläche ‘ für das Publikum darstellen kann.

Damit wäre ein erster Umriss des authentisch-auratischen Charakters der Exponate im Museum gezeichnet, aber wie verhält es sich mit dem Raum, dem dieses Unterkapitel ja gewidmet ist? Einen Zugang zu dieser Frage ermöglicht vielleicht die ästhetische Philosophie Gernot Böhmes - bzw. die Kategorie der >Atmosphäre`, welche in dieser eine entscheidende Rolle einnimmt. In seinen Essays zur neuen Ästhetik wendet sich Böhme gegen eine in Philosophie und Kunstgeschichte seiner Ansicht nach tonangebende »Beurteilungsästhetik« (Böhme 1995: 7) und meint hiermit die klassische ästhetische Kunstkritik, die sich normativ-hermeneutisch am Einzelkunstwerk abarbeitet und nach Böhmes Dafürhalten einer welthistorischen Situation nicht länger gerecht wird, deren entscheidendes Merkmal eine umfassende Ästhetisierung von Lebensrealitäten und Gesellschaftsordnungen ist. Seinen Gegenentwurf stellt Böhme unter das Vorzeichen einer Wiederentdeckung und Neubewertung des Menschen als leibliches Wesen: Es gelte, so Böhme, abzukommen von einer Ästhetik, die 
den Menschen vorrangig als reflektierendes Vernunftgeschöpf begreift, und sich stattdessen seiner körperlichen Verortung in seiner Umwelt bewusst zu werden. Die >Atmosphäre`stellt für Böhme das Kernkonzept dieser Ästhetik dar. Sie soll den ästhetischen Blick nicht auf das Erkannte, sondern auf das Empfundene scharf stellen (vgl. ebd.: 14f.).

Interessanterweise springt Böhme von diesen Vorüberlegungen direkt zur praktischen Raumsituation des Museums, welche er als eine Schule des Erlebens und Verstehens von Atmosphären begreift:

Die Kunst ermöglicht es uns, im Freiraum des Museums Atmosphären zu erfahren, ohne dass wir dabei in einem Handlungskontext stehen. (Ebd.: 16)

Die Kunst hat laut Böhme die Aufgabe, jene »Sinnlichkeit« (ebd.) beim Betrachter zu konditionieren, welche Voraussetzung ästhetischen Erlebens sei. Und weil diese Sinnlichkeit jedweder intellektuellen Auseinandersetzung mit Kunstwerken vorgeschaltet sei, könne sie nur im zweckfreien Erfahren atmosphärischer Situationen ohne Handlungsanweisung entwickelt werden (vgl. ebd.). Kurzum: Atmosphären sind das, was man erlebt, wenn man sich durch ästhetisch aufgeladene Räume bewegt und sie einfach auf sich wirken lässt.

Mit seinem nach eigenem Anspruch `neuen` Ästhetikbegriff plädiert Böhme zugleich für ein neues Wahrnehmungsparadigma. Ganz im Sinne der Raumkonzeption Brigitte Scheers und von Aleida Assmanns Semiose-Vorstellung sieht Böhme unsere Dingwahrnehmung in einem Zustand starker Funktionalisierung befangen: Wir seien, so seine Diagnose, kulturell darauf eingespielt, materielle Objekte nur noch als transitive »Signale« (ebd.: 17) für abstrakte Zusammenhänge zu lesen und damit als kulturelle Zeichen- und Bedeutungsträger zu interpretieren. Unsere Sensibilität für das Ding in seiner reinen, materiellen Anmutung (und damit also die Fähigkeit zu dem, was Assmann als den >langen Blick« bezeichnet) sei uns dabei zunehmend abhandengekommen, was sich besonders sinnfällig in unserem gesellschaftlichen Umgang mit der Kunst äußere: Böhme stellt in der professionellen Kunstkritik ebenso wie beim Laienpublikum eine völlige Fixierung auf das Kunstwerk als Zeichen und Verweis fest, in welcher es nur mehr auf seine Bedeutung befragt werde, nicht aber auf seine auratische Wirkung (vgl. ebd.: 23).

Diesem eindimensionalen Kunst- und Ästhetikverständnis möchte Böhme einen »ökologischen Zugang zu ästhetischen Fragen« (ebd.: 22) entgegensetzen, dessen zentraler Betrachtungsmodus eben die Kategorie der Atmosphäre ist. Ökologisch ist dieser Zugang insofern, als dass er das (jedweder Reflexion über irgendeine Form von `Sinn ২ vorgeschaltete) ästhetische Empfinden des leiblich anwesenden Menschen in einer komplexen Umwelt aus materiellen Entitäten verortet, die auf ihn einwirken. Er verhandelt das emotionale Erleben im Raum gewissermaßen als ein ma- 
schinelles Ineinandergreifen von Einzelkomponenten - ganz ähnlich, wie es Rheinbergers Modell des Experimentalsystems mit der Produktion von Wissen tut. Und ebenfalls ähnlich dem Rheinberger'schen Konzept lenkt auch der Atmosphärenbegriff den Blick unweigerlich vom Einzelobjekt auf das Gesamtarrangement, das über dessen Wirkung und Rolle mit- und vorentscheidet.

Böhmes ästhetischer Entwurf ist vor allen Dingen eine Raumästhetik, oder genauer noch: Eine Ästhetik des Zwischenraumes. Wie Richard Saul Wurman und Franz Boas die Herausforderung von Wissensvermittlung darin sehen, die den Inhalten gegenüberstehenden Blickwinkel der Lernenden vorauszuahnen, dreht sich für Böhme die Schaffung atmosphärischer Räume immer um die Verortung des empfindenden Betrachters zwischen den Dingen. Als den Gegenstand atmosphärischer Ästhetik bezeichnet er die »Beziehung zwischen Umgebungsqualitäten und menschlichem Befinden « (ebd.: 23) - »dieses Und, dieses zwischen Beidem [...], das sind die Atmosphären« (ebd.).

Weil die Atmosphäre für Böhme eben ins Befinden (und nicht etwa den Intellekt) mündet, verschließt sie sich der »Urteilsästhetik« (ebd.) der Kunstkritik. Ja mehr noch: Laut Böhme ist sogar deren mediales Äußerungsvermögen dem Phänomen >Atmosphäre` nicht angemessen, weil die beurteilende, interpretierende Ästhetik sich mit der Idee vom Zeichenhaften des Kunstwerkes auch der präzisen sprachlichen Ausformulierung von Bedeutungen verschrieben habe. Atmosphären hingegen seien in diesem Modus des Sprechens nicht abschließend zu erfassen, weil sie auf keine äußere Referenz verweisen. Böhme führt hier unter Rückgriff auf Umberto Ecos Einführung in die Semiotik (und zugleich in Abgrenzung zu dieser) das Beispiel der Mona Lisa an: Das Bild der Gioconda habe sich so tief in das kulturelle Bewusstsein der westlichen Welt eingegraben, dass die Person, deren ikonische Abbildung es ist, längst nicht mehr sein Signifikat darstelle. Vielmehr überlagere der Ruhm des Gemäldes als Gemälde seine Funktion als Abbildung von etwas so sehr, dass die Mona Lisa für die meisten Betrachter nur mehr sich selbst signifiziere:

Das Bild ist in gewisser Weise selbst, was es darstellt, d.h., das Dargestellte ist in und durch das Bild präsent. Natürlich kann man auch ein solches Bild lesen und deuten, aber das heißt die Erfahrung der Präsenz des dargestellten, nämlich die Atmosphäre des Bildes, überspringen oder gar verleugnen. (Ebd.: 24)

Böhme selbst diagnostiziert eine enge Verwandtschaft zwischen seiner Atmosphäre und Benjamins Aura und verwendet die Begriffe stellenweise sogar synonym (vgl. ebd.: 26f.). Ihnen beiden sei gemeinsam, dass sie eine schwer fassbare Qualität in der Dingwahrnehmung benennen wollen - ein kaum systematisierbares und nicht auf einfache Deutungen herunterzubrechendes »Mehr« (ebd.: 26), das keine klare Substanz besitze, zugleich aber doch »etwas räumlich Ergossenes« (ebd.: 27) sei, das vom Betrachter »geatmet«, ja »leiblich aufgenommen« werde (ebd.). In Abgrenzung 
zu Benjamin spielt für Böhme allerdings die Frage nach Original und Reproduktion keine herausragende Rolle. »Authentisch« ist hier die Atmosphäre bzw. das atmosphärische Erleben selbst, nicht das individuelle Objekt. Tatsächlich seien die Versuche der Avantgarde-Kunst des 20. Jahrhunderts, sich vom Element des Auratischen zu befreien, genau an den Atmosphären der Ausstellungsräume gescheitert: Indem man nicht-auratische Objekte als Kunstwerke präsentierte, habe man nicht etwa die Auren etablierter Kunstgegenstände dekonstruiert, sondern lediglich die entsprechenden Gegenstände auratisiert (vgl. ebd.: 26). Marcel Duchamps berühmtes Urinalkunstwerk Fountain war nicht imstande, den sozialen Stellenwert der Kunst jenem der Klempnerei anzugleichen. Es erhob vielmehr ein einziges, singuläres Pissoir in den Status eines authentischen Kunstwerkes. Die Werke der Avantgarde blieben in den »heiligen Hallen der Kunst « (ebd.) und ließen hier nur umso deutlicher die Macht von Aura und Atmosphäre sichtbar werden.

Die Beziehung zwischen Ding und Raum - die für das Museum ja relevant ist wie kaum eine andere - stellt Böhme über den Begriff der »Ekstase« (ebd.: 33) her. Als `Ekstasen < bezeichnet Böhme all jene wahrnehmbaren Zustände der Dinge, in welchen sie ihre räumliche Anwesenheit behaupten, so z.B. Form, Ausdehnung, Farbe und Klang. Atmosphäre und Ekstase befinden sich in einem symbiotischen Verhältnis, das sich im Raum vollzieht - Atmosphären sind Raumverhältnisse, welche von den Ekstasen der Dinge »tingiert « (ebd.) sind, sie seien damit »Sphären der Anwesenheit von Etwas « (ebd.), die über eine distinkt räumliche Wirklichkeit verfügen. Diese Wirklichkeit ist aber nicht als eine rein physikalische zu verstehen: Atmosphären werden real erst durch die Anwesenheit eines erlebenden, fühlenden, leiblichen Subjektes (vgl. ebd.: 34). Sie entstehen, wenn das menschliche Empfindungsvermögen einer Raumsituation ausgesetzt wird.

Man darf diesem ästhetischen Modell sicher skeptisch gegenüberstehen. Böhmes konsequente Ausarbeitung der Atmosphäre als eine bewusst nichtsystematische Annäherung an die Ästhetik materieller Dinge lässt sie für einen wissenschaftlich-analytischen Zugriff auf ästhetische Phänomene mindestens problematisch werden. Ihr Wert für die vorliegende Studie liegt daher eher in den von ihr ausgehenden Denkanstößen als in ihrem konkreten theoretischen Programm. Böhmes Atmosphärenbegriff erweitert in erster Linie die >Aura nach Walter Benjamin um eine räumliche Komponente: Während Benjamin das affektive Wirkungspotential der Kunst im Einzelobjekt verortet, richtet Böhme seinen Blick auf die Ästhetik von Umwelten sowie jene des Zusammenspiels von Objekten miteinander und einem Beobachter, der sich physisch in ihrer Präsenz aufhält. Der Ästhetik des individuellen Originalobjektes, an welcher sich Benjamin abarbeitet, setzt Böhme also eine Ästhetik von Raum und Körperlichkeit entgegen. Während für Benjamin die Aura das Resultat der Tatsache darstellt, dass das Kunstobjekt den Prozess der Geschichte durchlaufen hat und Referent einer historischen Situation ist, sieht Böhme in den Atmosphären das Produkt einer bestimmten Form von Anordnung im Jetzt, und das heißt auch: Während die 
Aura nur vorgefunden werden kann, sind Atmosphären machbar (vgl. ebd.: 34ff.). Übertragen wir diese Überlegung nun auf das Museum, dann präsentiert sich sein affektives Funktionieren als analog zu seinem epistemischen. Museen sind nicht nur Sinn-, sondern auch Atmosphärenmaschinen, in denen die von Rheinberger beschriebene Bricolage der Objekte nicht nur bestimmte Bedeutungen, sondern auch Anmutungen hervorbringt. Sie produziert nicht nur Wissensstrukturen, sondern auch Befindlichkeiten, die sich einem rein interpretatorischen Zugang widersetzen.

\subsection{STATT EINER DEFINITION: DAS MUSEUM ALS DISPOSITIV}

Weder die Museologie selbst, noch die sie umgebenden Rechtssysteme sind bis jetzt übereingekommen, was ein >Museums` im Wesentlichen ist oder zu sein habe, und entsprechend ist der Begriff auch nirgendwo geschützt. Dieses Fehlen eines definitorischen Schlusses führt unweigerlich dazu, dass jedes individuelle Museumskonzept zugleich eine Stellungnahme darüber ist, worin seine Kuratoren Rolle und Funktion der Institution Museum überhaupt sehen. Friedrich Waidacher erteilt dementsprechend jedem Versuch einer finalen Definition des Museumsbegriffs eine Absage und plädiert stattdessen in der Museumsforschung für eine Pluralität von Arbeitsdefinitionen, welche sich jeweils den akuten wissenschaftlichen Erkenntnisinteressen anpassen (vgl. Waidacher 2000: 1f.). Werner Schweibenz schlägt ähnliche Töne an und besteht zugleich darauf, solche Definitionen weit und offen zu halten, um der Vielgestaltigkeit ihres Gegenstandsbereiches gerecht zu werden. Er selbst verwendet ein von der United Kingdom Museums Association ausgelobtes mission statement, welches das Museum - wie es eben ist, wenn epistemische Dinge Form annehmen anhand einer Auflistung von Tätigkeiten beschreibt (vgl. Schweibenz 2001: 2):

Museums enable people to explore collections for inspiration, learning and enjoyment. They are institutions that collect, safeguard and make accessible artefacts and specimens, which they hold in trust for society. ${ }^{11}$

Minimalanforderung an ein Museum ist also, dass es erstens die materiellen Hinterlassenschaften unserer Vorzeit sammelt und diese zweitens einer wie auch immer beschaffenen Öffentlichkeit zur Rezeption anbietet. Gottfried Korff hat genau diesen Dualismus mit dem Begriffspaar des Deponierens und Exponierens belegt.

Erweitern müssen wir diese Definition hier zusammenfassend folgendermaßen: Indem Museen Objekte auf eine bestimmte Art im Raum anordnen, machen sie aus

$11 \mathrm{http} / /$ www.museumsassociation.org/about/frequently-asked-questions vom 12.04.2018, vgl. auch Schweibenz 2001: 3. 
diesen mediale Träger von Bedeutungsinhalten - nach Waidacher `Nouophoren <die für sich allein genommen meist unspezifisch sind und keine geschlossenen Aussagen formulieren. Darin unterscheidet sich das Museum grundlegend vom Archiv und der Bibliothek, die geschlossene Textkörper sammeln, welche sich auch außerhalb ihrer Räumlichkeiten rezipieren lassen. Die historischen Überreste, welche Museen sammeln, weisen hingegen (wie ‘authentisch « sie auch immer seien mögen) von sich aus meist keinen klaren epistemischen Charakter auf. Musealisierung ist jener Prozess, in welchem diese Objekte über kontextuelle Einbindungen in Ausstellungsund Verwaltungskontexte mit jenen Vermittlungs- und Anmutungsattributen belegt werden, welche das Museum zur Ausführung seines gesellschaftlichen Auftrages benötigt.

Gottfried Korff beschreibt diesen Auftrag als eine »Aufhebung« mit drei Ebenen: Die erste Aufhebung ist die Zerstörung jener Bedeutungszusammenhänge, in welchen die Objekte >ursprünglich`, also in ihrer historischen Entstehungs- und Gebrauchssituation, gestanden haben. Das zweite >Aufheben meint das Sammeln und Aufbewahren, eben das Deponieren der Exponate. Die dritte Aufhebung schließlich beschreibt die Erhöhung und Adelung der Dinge, die vom Museum als Träger kulturellen Sinns ausgezeichnet und in seine symbolische Ordnung aufgesogen worden sind (vgl. Korff 2005: 97).

Darüber hinaus ist das Museum auch eine Stätte des ästhetischen Erlebens. Museale Räume sind nicht nur mit intellektuell zu dechiffrierenden Bedeutungen und Narrativen aufgeladen, sondern auch mit den auratischen und atmosphärischen Qualitäten ihrer Exponate - die allerdings, so müssen wir uns vor Augen halten, in weiten Teilen selbst das Produkt des Musealisierungsprozesses und damit der Einbindung der Objekte in kulturelle Deutungsmuster sind. Authentizität und >Aurar sind keine Eigenschaften, welche dem Objekt physikalisch innewohnen. Sie werden im Museum deshalb erfahrbar, weil sich die Institution für die Authentizität ihrer Ausstellungsstücke verbürgt.

Für eine wissenschaftliche Arbeit drängt sich hiermit aber notwendigerweise auch die Frage nach einem brauchbaren analytischen Zugang zu einer auf diese Weise umrissenen Institution auf. Schließlich gilt es offenbar, nach sehr viel mehr als nur Museumpädagogik und Authentizität zu fragen: Im Museum wird Wissen geordnet und vermittelt, werden Erlebnis- und Gefühlswelten geschaffen, werden Menschen gebildet, belehrt und erzogen, werden aber auch (Gedächtnis-)Inhalte kanonisiert, die weit über die Museumswände hinauswirken und das kulturelle Bewusstsein und die Identitäten ganzer Gesellschaften mitinformieren. Das Museum äußert sich, gibt aber auch seinen Besuchern Gelegenheit zur Äußerung. Dabei existiert keiner dieser Wirkungsbereiche des Museums losgelöst von allen anderen. Wissen, Empfinden, Belehrung, Sinnstiftung usw. greifen vielmehr ineinander und sind funktional nicht zu trennen. Um das Museum und den medialen Wandel zu verstehen, den seine Virtualisierung darstellt, muss eine analytische Kategorie hinzugezogen werden, die 
gerade das Zusammenwirken seiner Funktionsebenen akzentuiert. Die vorliegende Studie wird zu diesem Zweck auf den in seiner heutigen Konnotation von Michel Foucault geprägten Begriff des Dispositivs zurückgreifen.

Das Dispositiv nach Foucault steht in enger Verbindung mit dem Konzept des Diskurses und verweist wie dieses nicht auf ein bestimmtes Repertoire methodischer Zugänge, sondern vor allem auf eine bestimmte Art, über soziokulturelle Phänomenbereiche bzw. die Schaffung dessen nachzudenken, was sich als ssoziale Tatsachen< oder umfassender noch >soziale Wirklichkeit` bezeichnen ließe. Und ebenfalls dem Diskurs ähnlich ist das Dispositiv eine sehr forschungspraktisch orientierte Begrifflichkeit, die Foucault aus gegenstandsbezogenen Arbeiten heraus entwickelt, anstatt sie ihnen programmatisch voranzustellen.

Die wohl meistzitierte Ausformulierung seiner Dispositiv-Vorstellung lieferte Foucault dementsprechend auch nicht in seinen Büchern, sondern 1977 in einem Gespräch über seine damals noch in der Entstehung begriffene dreibändige Histoire de la sexualité (im Deutschen erschienen als Sexualität und Wahrheit) mit dem Literaturhistoriker Alain Grosrichard. Das Dispositiv, so erklärt Foucault hier, sei vor allem dreierlei: Erstens sei es ein »entschieden heterogenes Ensemble« (Foucault 1978: 119), zu welchem »Diskurse, Institutionen, architekturale Einrichtungen, reglementierende Entscheidungen, Gesetze, administrative Maßnahmen, wissenschaftliche Aussagen, philosophische, moralische oder philanthropische Lehrsätze, kurz: Gesagtes ebenso wie Ungesagtes« (ebd.: 119f.) gehören. Zweitens aber erschöpfe sich das Dispositiv nicht in der bloßen Zusammenstellung dieser Einzelelemente. Der Begriff unterstreiche vielmehr die Beziehungen und Verbindungen zwischen ihnen - tatsächlich setzten Dispositive sich erst eigentlich aus diesen zusammen. Nicht statische und klar lokalisierbare Konstellationen von Einflüssen seien ihr Wesen, sondern bewegliche Allianzgefüge, deren »Positionswechsel und Funktionsveränderungen« (ebd.: 120) es zu erfassen heißt. Drittens und letztens sieht Foucault in Dispositiven zutiefst historische Erscheinungen. Sie seien »Formationen «, die in bestimmten geschichtlichen Situationen als Antworten auf »Notstände« (urgences) (ebd.) in Erscheinung treten: »Das Dispositiv hat eine vorwiegend strategische Funktion« (ebd.). Als sinnfälliges Beispiel hierfür nennt Foucault die Geburt der Psychiatrie und die ihr zugrundeliegenden, historisch wechselhaften Konzepte von Wahnsinn, Geisteskrankheit und schließlich Neurose. Die Psychiatrie sei, so seine These, als Dispositiv aus einem "strategischen Imperativ« (ebd.) hervorgegangen - nämlich jenem der »Resorption einer freigesetzten Volksmasse [...], die einer Gesellschaft mit einer Ökonomie wesentlich merkantilistischen Typs lästig erscheinen mußte« (ebd.).

Es fällt nicht schwer, das in diesem Sinne `Dispositivhafte` des Museums aufzuzeigen. Museen sind heterogene Gefüge aus Objekten, Architekturen, didaktischen Leitlinien und Vorstellungen, ästhetischen Prinzipien und Programmen, institutioneller Ein- und Anbindung, usw. Zugleich sind sie stets das Produkt von Wechselwirkungen zwischen diesen Elementen, das in der Weite seiner Effekte deren bloße 
Summe übertrifft und das in seiner Beschaffenheit historischen Veränderungen unterliegt. Nicht zuletzt sind natürlich auch Museen und ihre Vorgängerinstitutionen, vom antiken Tempel bis zur Wunderkammer, strategisch in soziale Unternehmungen wie z.B. die bürgerliche Aufklärung eingebunden gewesen und weiterhin eingebunden.

In den beinahe vier Jahrzehnten, die zwischen den obigen Ausführungen Foucaults und der Entstehung der vorliegenden Arbeit liegen, ist der Dispositivbegriff über seine ursprüngliche Konzeption hinaus erweitert und in modifizierten Formen in das Vokabular verschiedenster Forschungsgebiete importiert worden. Unter dem beiden Texten gemeinsamen Titel Was ist ein Dispositiv? verfassten mit Gilles Deleuze (1991) und Giorgio Agamben (2006) zwei zentrale Vertreter der zeitgenössischen kontinentalen Philosophie Versuche, aus den disparaten Äußerungen Foucaults über das Dispositiv verbindliche definitorische Kriterien herauszudestillieren, bzw. diese gleichzeitig zu erweitern und zu präzisieren.

Deleuze bedient sich in seinem Aufsatz einer geometrischen Metaphorik. Für ihn ist das Dispositiv zunächst ein »Durcheinander, ein multilineares Ensemble« (Deleuze 1991: 153), das sich aus »Linien verschiedener Natur« (ebd.) zusammensetzt. Diese `Linien a aber, so fährt Deleuze fort, seien nicht etwa die Umrisse statischer Systeme, »deren jedes für sich homogen wäre« (ebd.), sondern vielmehr die gedachten Abbilder gerichteter Prozesse: »Die sichtbaren Objekte, die formulierbaren Aussagen, die zur Ausübung kommenden Kräfte, die in Positionen befindlichen Subjekte sind wie Vektoren oder Tensoren « (ebd.). Deleuze legt dabei besonderen Wert auf die Beobachtung, dass diese Vektoren und Tensoren selten gradlinig sind, sondern meist »gebrochen und damit Richtungsänderungen « oder aber »verzweigt und gegabelt und damit Abweichungen unterworfen « seien (ebd.).

Das, was entlang der Vektorenlinien ausgerichtet wird, sind nach Deleuze die drei »großen Instanzen« Macht, Wissen und Subjektivität (ebd.), die Linien selbst verwendet er als Metaphern für »Ketten von Variablen, die sich voneinander ablösen« (ebd.). Die Erforschung von Dispositiven gleiche daher dem Erkunden neuer Länder, man könne sie nicht auf einfache Erklärungsmodelle reduzieren und definitorisch abschließen, sondern lediglich kartieren, vermessen und beschreiben (vgl. ebd.).

Für das, was Dispositive in der sozialen und kulturellen Welt tatsächlich leisten, verwendet Deleuze eine weitere Metapher - und zwar bezeichnenderweise jene der >Maschine . Dispositive sind für ihn maschinelle Anordnungen, die Sichtbarkeiten und Sagbarkeiten produzieren. Sie sollen Menschen dazu bringen, auf bestimmte Arten zu sehen und zu sprechen. Den Sichtbarkeitsaspekt verdeutlicht er naheliegenderweise mit dem von Foucault selbst in Überwachen und Strafen eingehend diskutierten Dispositiv des Panoptikons - jenes Gefängnistypus also, in welchem die latente Möglichkeit des Überwachtwerdens den Häftling zur Selbstdisziplinierung auch dann zwingt, wenn augenblicklich gar keine Überwachung stattfindet. Es entsteht so ein Machtsystem, in welchem die Macht selbst von keiner benennbaren Person mehr 
ausgeübt werden muss, um wirksam zu sein. Sie ergibt sich vielmehr virtuell aus einem bestimmten Arrangement von Sichtbarkeit (der Überwachten) und Unsichtbarkeit (der Überwacher). Der Faktor der Sagbarkeit wiederum manifestiert sich für Deleuze in Aussagevektoren, welche die verschiedenen Elemente von Äußerungsprozessen verbinden (also z.B. Personen, die sprechen, Orte, an denen gesprochen wird, Institutionen, welche die Modalitäten des Sprechens reglementieren, usw.).

Quer zu diesen Linien von Sichtbarkeit und Sagbarkeit laufen bei Deleuze »Kräftelinien«, entlang welcher »Macht« ausgeübt wird. Eine letzte Variante von Vektoren bilden für ihn jene, welche das Wirken der Subjektivität beschreiben (vgl. ebd.: 154ff.). Schon Foucault selbst hatte Subjektivierungsprozesse als eine der zentralen Funktionen von Dispositiven ausgemacht. Im Vorwort zur deutschen Ausgabe von Der Wille zum Wissen hebt Foucault ausdrücklich hervor, dass im Zentrum seiner Sexualitätsgeschichte die Frage stehe, welche diskursiven Praktiken innerhalb des Dispositivs `Sexualität den Sex zum konstitutiven Element von Selbstwahrnehmung und sozialer Verortung von Menschen werden ließen. Damit ist für Foucault zugleich die Frage aufgeworfen, wie der Mensch entlang seiner Sexualität als begehrendes Subjekt und damit als modernes Individuum schlechthin konstruiert wurde (vgl. Foucault 2012: 7f.). ${ }^{12}$ Deleuze sieht in den >Linien der Subjektivierung gewissermaßen jene Grenzen der Wirksamkeit des Dispositivs, die es aus sich selbst hervorbringt. Indem es eine bestimmte Form von Subjekten produziert, können seine Vektoren auch nur insoweit auf sie einwirken, wie es ihre spezifische Subjektivität erlaubt (Deleuze 1991: 156).

Übersetzen wir uns dies in einfachere Termini, so begreift Deleuze Dispositive als Ordnungsgefüge der kulturellen Welt. Dispositive sind in seiner Diktion komplexe Systeme aus Prozessen, die niemals vollkommen gradlinig verlaufen und stets unweigerlich im Fluss sind. Sie bestimmen darüber, was in sozialen Gefügen wahrgenommen werden kann und welche Aussagen aus ihnen heraus formulierbar sind. Diese Ausrichtungen von Sagbarkeit und Sichtbarkeit produzieren bestimmte Machtstrukturen, und diese wiederum soziale Verortungen von Menschen - eben >Subjektivierungen « - innerhalb derer sie beherrschbar sind. Am Museum lässt sich auch dies sehr gut nachvollziehen. Museumsausstellungen sind inszenatorische Sichtbarkeitsgefüge: Die Ausstellung kann nur auf bestimmten Pfaden erlebt werden, und auch die Kommunikationswege sind beschränkt. Der Museumsgänger kann zwar typischerweise mit seinesgleichen, selten aber mit den Ausstellungsmachern und Kuratoren sprechen. Damit wird ein bestimmtes Machtgefüge im Museum etabliert, und dieses wiederum schafft erst jene soziale Subjektrolle des >Besuchers`, in die man schlüpft, wenn man am Eingang seine Eintrittskarte erwirbt und sich in das Museumsdispositiv hineinbegibt. Als Forschungsperspektive greift das Dispositivkonzept damit

12 Vgl. für eine eingehendere Diskussion dieser Stelle Bührmann u. Schneider 2008: $29 f$. 
[...] die (begrifflich-theoretisch wie empirisch-forschungspraktisch vorzunehmende) Bestimmung des je über Wissen vermittelten Verhältnisses von Diskurs, Macht und dem gesellschaftlichen Sein. - >Das Sein ist hier zu verstehen als sinnlich-materiale gesellschaftliche Praxis, die die sozialen Beziehungen zwischen Menschen, ihren Umgang mit den sie umgebenden >Dingen` sowie ihre damit jeweils verbundenen (Selbst-)Erfahrungen - als Subjekte - konstituiert und formiert. (Bührmann u. Schneider 2008: 32f.)

Giorgio Agamben geht über Deleuzes Ausführungen hinaus und erläutert Foucaults Dispositiv-Vorstellung nicht nur, sondern unterzieht sie zugleich einer begriffsgeschichtlich-kritischen Revision. Er beobachtet, dass Foucault in seiner Archäologie des Wissens aus dem Jahre 1969 noch nicht von Dispositiven spricht, sondern vielmehr für dispositivartige Machtgefüge den Begriff der Positivitäten verwendet. Agamben führt diesen über einen von Focaults frühen Lehrern, den Philosophen Jean Hyppolite, auf die hegelianische Religionsphilosophie zurück. Hyppolite setzte sich in seinen Arbeiten ausführlich mit Hegels Unterscheidung zwischen »natürlicher« und »positiver« Religion auseinander, wobei die natürliche eine direkte, verinnerlichte Beziehung zwischen Mensch und Gottheit beschrieb, die positive hingegen den Ritenschatz, die abstrakten Glaubensgrundlagen, die Regelwerke der Glaubensgemeinschaft - die Gesamtheit der institutionalisierten Religionspraxis also, die durch zeremonielle Verrichtung und Gehorsam das soziale Bekenntnis zur Kultgemeinschaft erzwingen soll (vgl. Agamben 2008: 11ff.). Aber nicht nur den Positivitätsbegriff sieht Agamben ursprünglich in einem religiösen Kontext verortet. Auch der Begriff des Dispositivs selbst entstammt nach seinem Dafürhalten der Kirchensprache. Das Wort dispositio tauche nämlich erstmals in frühchristlichen lateinischen Texten als Übersetzung des griechischen oikonomia auf. Dieses wiederum sei nicht etwa als eine Entsprechung unserer modernen Vorstellung von >Ökonomieく zu lesen, sondern vielmehr als eine Metaphorik für die christliche Dreifaltigkeit, in welcher Gott der Vater Christus den Sohn als Verwalter seines irdischen Hauses oder oikos einsetzt (vgl. ebd.). Aus dieser begriffsgeschichtlichen Dimension leitet Agamben die Folgerung ab, dass Dispositive etwas seien, »in dem und durch das ein reines Regierungshandeln ohne jegliche Begründung im Sein realisiert wird « (ebd.: 23). Dies wiederum veranlasst ihn, eine erweiterte Definition des Dispositivs vorzuschlagen:

Als Dispositiv bezeichne ich alles, was irgendwie dazu imstande ist, die Gesten, das Betragen, die Meinungen und die Reden der Lebewesen zu ergreifen, zu lenken, zu bestimmen, zu hemmen, zu formen, zu kontrollieren und zu sichern. Also nicht nur die Gefängnisse, die Irrenanstalten, das Panoptikum, die Schulen, die Beichte, die Fabriken, die Disziplinen, die juristischen Maßnahmen etc., deren Zusammenhang mit der Macht in gewissem Sinne offensichtlich ist, sondern auch der Federhalter, die Schrift, die Literatur, die Philosophie, die Zigarette, die Schiffahrt, die Computer, die Mobiltelefone, und - warum nicht - die Sprache selbst, die das vielleicht älteste Dispositiv ist [...] (Ebd.: 26) 
Diese zugespitzte Verwendung des Begriffs, bei der plötzlich kein Element unseres sozialen Lebens mehr außerhalb von Dispositiven stattfindet, verweist auf den enormen >Boom<, den das Dispositiv seit seiner Entstehung als Denkfigur erlebt hat. Andrea Bührmann und Werner Schneider, die 2008 eine ausführliche Einführungsmonographie zur Dispositivanalyse vorgelegt haben, sehen vor allem seit den 1990er Jahren eine explosive Ausbreitung des Konzeptes in den verschiedensten Disziplinen der Geistes- und Kulturwissenschaften. Die Initialzündung dieser Entwicklung sei dabei von den Gender Studies ausgegangen: Besonders Judith Butlers Anknüpfen an das Foucaultsche Sexualitätsdispositiv als Beschreibungsmodell für geschlechtliche Körperlichkeit in ihrem Buch Bodies That Matter (erschienen 1993) habe dem Terminus zu neuer Aufmerksamkeit verholfen (vgl. Bührmann \& Schneider 2008: S. 11f.). Gerade die Medienwissenschaft habe ihn dankbar angenommen, um das »komplexe Zusammenspiel von technischer Apparatur, Medieninhalten sowie institutionellen Praktiken ihrer Produktion und vor allem ihrer Rezeption bzw. Nutzung « (ebd.: 12f.) greifbar zu machen, welches die zentrale Herausforderung für jeden kulturwissenschaftlichen Zugang zu Medienphänomenen darstellt.

$\mathrm{Zu}$ diesen ist eben auch das Museum zu rechnen. Die Frage, die sich die vorliegende Arbeit daher stellen muss, ist, ob und wie genau sich das Funktionieren des Museums als Dispositiv über unterschiedliche Medientechnologien hinweg reproduzieren lässt, und welche Rolle dabei insbesondere das Moment des `Virtuellen`spielt. Wenn wir in der gegenwärtigen medien- und technikgeschichtlichen Situation von Museumsvirtualisierung sprechen, dann bildet dabei fast immer implizit das Internet als Übertragungstechnologie für museale Inhalte die Szenerie der Diskussion. Es lässt sich trefflich darüber streiten, ob die Entwicklung zu irgendeinem Zeitpunkt eine andere Richtung hätte einschlagen können - verstanden sich doch die ersten selbsterklärten Online-Museen in den 1990er Jahren häufig noch als Gegenmodelle zur proprietären Museums-CD-ROM und damit auch zur Kontrolle von Kulturgütern durch Patente und Copyrights (vgl. Kac 1997: 295f.). Mit dem Internet (oder genauer dem World Wide Web, das für die überwältigende Mehrzahl der Nutzer dessen >Gesicht darstellt) hat sich nicht nur eine bestimmte technische Anordnung für die digitale Verbreitung musealer Inhalte durchgesetzt, sondern ein umfassendes mediales Dispositiv, das nun mit jenem des Museums zu konvergieren scheint. Dabei stößt uns schon die Metapher der >Vernetzung « unweigerlich auf die Tatsache, dass Dispositive eben mehr sind als bloße »Diskurs-Infrastrukturen« (Bührmann \& Schneider 2008: 51). Wären sie lediglich das mediale Gefüge hinter der stattfindenden Kommunikation, wäre ihre Analyse eine Angelegenheit für Systemingenieure. Dispositive sind vielmehr Analysemodelle, welche die Wechselwirkungen zwischen diesen Teilen in den Mittelpunkt der Betrachtung rücken:

Das Dispositiv selbst ist das Netz [Hervorhebung D.N.], das zwischen diesen Elementen geknüpft werden kann. (Foucault 1978: 120) 
Dispositive existieren damit also immer nur implizit innerhalb laufender Machtprozesse und sind nicht etwa die Plattformen, auf der solche stattfinden. Entsprechend entstehen sie weder zufällig oder chaotisch, noch sind sie aber das Produkt allgemeingültiger und überhistorischer sozialer Mechanismen. Sie gehen vielmehr aus zielgerichteten und immer historisch verorteten Diskursstrategien hervor, auf die sie zugleich formend und ordnend zurückwirken (vgl. ebd.: 132ff.; vgl. auch Bührmann \& Schneider 2008: 51ff.). Das Zusammenspiel von Museum und Computer lässt sich entsprechend nicht als ein reiner Medienwandel greifen - und aus diesem Grunde beschreibt auch der Begriff der >Digitalisierung` es nur unzureichend. Wir wollen uns daher im nächsten Kapitel dem Begriff der >Virtualität zuwenden und in den Blick nehmen, in welcher besonderen Beziehung dieser sowohl zum Museum als auch zu Computernetzwerken steht. 


\section{Netz und Virtualität}

Der Begriff des >Virtuellen` steht im Zentrum zahlreicher Debatten darüber, wie digitale Medien sowohl ontologisch (welche speziellen Formen und Spielarten des >Wirklichen bringen sie aus ihrer technischen Beschaffenheit hervor?) als auch psychologisch (in welchem Verhältnis stehen diese `künstlichen`Wirklichkeiten für die Rezipienten zur >tatsächlichen ?) und gesamtgesellschaftlich wirken und funktionieren. Dabei ist der Begriff im öffentlichen Diskurs mittlerweile so überstrapaziert, dass er in weiten Teilen nur mehr als Synonym für >irreal Anwendung findet und häufig die Implikation einer Täuschung mit sich führt - speziell einer Täuschung unter Einsatz computerbasierter Medientechnologien. Insofern ist das >Virtuelle auch zum Kampfbegriff für Kulturkritiker und besorgte Pädagogen geworden, die in Ego-Shooter und Facebook-Freundschaft bestenfalls Ablenkungen von und schlimmstenfalls Angriffe auf die vermeintlich >reale< Welt und ihre Gegebenheiten sehen.

Angesichts der problematischen Konnotiertheit des Virtualitätsbegriffs erscheint es verwunderlich, dass museale Angebote im Internet sich ganz unbefangen selbst als >virtuelle Museen $<$ bezeichnen - und noch verwunderlicher, dass auch die Museologie sich mittlerweile weitgehend auf diesen Terminus geeinigt zu haben scheint, nachdem in Veröffentlichungen der 1990er Jahre noch recht willkürlich und aus-

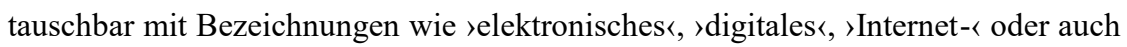
schlicht >Online-Museum` gearbeitet wurde. Mit der Entstehung des Begriffspaars >virtuelles Museum das dritte Kapitel dieser Arbeit noch eingehender beschäftigen - richten wir an dieser Stelle den Blick zunächst auf den Virtualitätsbegriff selbst. 


\section{1 \VIRTUALITÄT، ZWISCHEN ONTOLOGIE UND TECHNOLOGIE}

Werner Schweibenz, der als wohl erster deutschsprachiger Museumskundler den Begriff des > virtuellen Museums« nicht nur als Schlagwort, sondern als systematischkategoriale Beschreibung verwandt und damit den museologischen Diskurs entschieden geprägt hat, akzentuiert vor allem den antiken Wortursprung der >Virtualität (vgl. Schweibenz 2001: 7). Schweibenz orientiert sich dabei am Medienjournalisten Benjamin Woolley, der in seinem 1992 erschienen Buch Virtual Worlds: A Journey in Hype and Hyperreality der Konjunktur des Adjektivs >virtuell und dessen Verschränkung mit digitalen Medientechnologien auf den Grund geht. Woolley hält seine vormoderne Begriffsgeschichte dabei kurz: Nach einem Aufenthalt in der Wissenschaft der frühen Neuzeit, die als >virtuell vor allem optische Phänomene wie Brechungen und Spiegelungen bezeichnete (vgl. Woolley 1993: 60; vgl. Schweibenz 2001: 7) springt er mit einem großen Satz in die Antike und zum lateinischen Wort virtus, das Woolley und Schweibenz als >Tugend übersetzen (vgl. ebd.; vgl. ebd.). ${ }^{1}$ Für Woolley ist virtus vornehmlich an eine Teilhabe am Göttlichen gekoppelt, die der moderne Virtualitätsbegriff vor allem dadurch widerspiegle, dass mit ihm die Erschaffung neuer, künstlicher Welten verknüpft sei (vgl. Woolley: 60). Obgleich Woolleys historischer Abriss unvollständig ist, sind seine Schlussfolgerungen durchaus wegweisend: Er erkennt nämlich, dass >Virtualität eher ein philosophisch-ontologischer denn ein technischer Terminus ist (vgl. ebd.; vgl. Schweibenz 2001: 7).

Von diesen Überlegungen ausgehend sieht Schweibenz das Virtuelle am >virtuellen Museum vor allem in seiner Fähigkeit, neue (und dabei nicht minder >reale $\prec$ ) Ebenen der Auseinandersetzung mit dem Exponat zu ermöglichen sowie vielfältigere und -stimmigere Kommunikationsstrukturen im Museum zu etablieren. Er bezieht sich dabei auf seinen Fachkollegen Ben Howell Davis, der Mitte der 1990er Jahre in Digitalisierungsphänomenen zugleich die Entwicklung des Museums zu einem »transactional space« (Davis 1994) beobachtete.

Der Medienwissenschaftler Stefan Münker indes erzählt die Geschichte des Virtualitätsbegriffes vor allem aus seiner mittelalterlichen Verwendung heraus. Mit den Begriffen virtualis und virtualitas bezeichnete die Scholastik des Mittelalters Existenzzustände, die eindeutig weder dem >Realen` noch dem >Irrealen ren, sondern irgendwo dazwischen verblieben. Diese Verwendung ist eng verknüpft mit der aristotelischen Vorstellung, dass alles in der Welt Existierende eine Verwirklichung zuvor bereits bestehender Möglichkeiten darstellt - entsprechend war >virtuelk für die Scholastiker ein Synonym für implizit oder latent. Das Virtuelle ist im

1 Genauer meint dieses eine dezidiert männliche Tugend, die an die Figur des römischen Bürgers gekoppelt ist (vgl. Pertsch 2008: 671). 
Realen schon vorhanden, aber noch nicht zur physischen Ausformung gelangt (vgl. Münker 2005b: 244).

Während Woolleys und Schweibenz' Virtualitätsbegriff eher auf seine umgangssprachliche Verwendung abhebt, schreibt Münker eine Geistesgeschichte der Virtualität innerhalb philosophisch-akademischer Diskurse bis zu ihrer Wiederentdeckung in der Postmoderne. So war es in den 1960er Jahren zunächst Gilles Deleuze, der das Virtuelle als ontologische Kategorie erneut aufgriff und ganz im Sinne der Scholastiker des Mittelalters nicht der Realität als Kontrast gegenüberstellte, sondern vielmehr völlig im Realen verortete, wo »das Aktuelle« oder Aktualisierte - eben das reigentlich 'gewordene - seinen Widerpart bilden sollte (vgl. ebd..; vgl. Deleuze 1992: 264). Dem entspricht auch die fast drei Jahrzehnte später von Vilém Flusser gewählte Metapher vom Virtuellen als Wellenbewegung in einem »Ozean der Möglichkeiten« (vgl. Flusser 1993: 65). Jede Woge dieses Ozeans bildet hier für Flusser das Bestreben einer Möglichkeit ab, sich zu verwirklichen. Virtuell sind für ihn jene Wellen, die zwar hoch genug schlagen, um sich von der rein potenziell verbleibenden Masse ihrer Gefährten abzuheben, jedoch nicht ganz hoch genug, um tatsächlich in die Wirklichkeit hineinzuschwappen (vgl. ebd.: 65f.). Ähnlich verwendet die englische Sprache das Adverb virtually: Wenn ein Zustand virtually gegeben ist, dann ist er eben in allen seinen entscheidenden Merkmalen vorhanden, obwohl er der strengen Definition nach nicht vorliegen kann. Die Aussage »it was virtually night« (Weizenbaum 2006: 142) z.B. beschreibt, wie Joseph Weizenbaum feststellt, einen Zustand, in dem alle Merkmale der Nacht zwar vorhanden, der Uhrzeit nach die notwendigen Bedingungen der Nächtlichkeit aber noch nicht erfüllt waren (vgl. ebd.).

\subsubsection{Die Virtualität des Digitalen}

Die heute dominante Vorstellung von Virtualität als einem Phänomenbereich, der in erster Linie mit digitalen Technologien verbunden ist, geht laut Münker zurück auf eine vorwiegend im englischsprachigen Diskurs des 20. Jahrhunderts ausgebildete Lesart, welche von der weiteren Begriffsgeschichte und ihrer Rezeption in der kontinentalen Philosophie weitgehend unberührt geblieben ist (vgl. Münker 2005b: 244). Virtualität werde hier als die »(digital realisierte) Fähigkeit« verstanden, »etwas als etwas zu gebrauchen, was es (eigentlich) nicht ist « (ebd.). Die Virtualität des Computers wäre demnach in seiner Eigenschaft verortet, eine Maschine zu sein, auf der sich alle anderen symbolischen Maschinen simulieren lassen (vgl. Pias 2002: 256f.).

Tatsächlich fällt aber auch dieser technische Virtualitätsbegriff letztlich in den ontischen der Scholastiker und Postmodernisten zurück. Der Computer ist eben deshalb eine Meta-Maschine, weil er eine Aktualitätsmaschine ist. Wie Jens Schröter in einem Aufsatz über Die Ästhetik der virtuellen Welt betont, bedeutet »Pro-Gramm» 
wörtlich »Vor-Schrift« (Schröter 2009: 31): Wer programmiert, der gibt einem Computer vor, welche der unzähligen ihm potenziell möglichen Rechenoperationen er ausführen soll. Das Mittel hierzu ist der Code, der, wie der Jurist und Netzaktivist Lawrence Lessig festellt, für das Funktionieren von Computern einen eigenartigen Doppelcharakter aufweist. Er ist zugleich seine Substanz als auch sein Gesetz, er wird vom Computer nicht nur ausgelesen und ausgeführt, sondern bestimmt zugleich darüber, wie diese Operationen stattfinden (Lessig 2001: 24f.). Insofern belegt der Code ein virtuelles >Dazwischen ‘ von bloßer Möglichkeit und erfahrbarer Aktualität - er bildet >reale « (weil durchführbare) Rechenprozesse ab, die aber selbst noch nicht das >Eigentlicheく des Mediums darstellen. Dieses nämlich manifestiert sich, wie Sherry Turkle Mitte der 1990er Jahre in Life on the Screen diagnostiziert, erst auf der Ebene des Interfaces, welches die grafische Schnittstelle zwischen kultureller Lebenswelt des Menschen und formaler Logik des Rechners darstellt (Turkle 1998: 32f.). Wir interagieren im Alltag meist nicht mit Computern-als-Rechenmaschinen, sondern mit jenen impliziten Maschinen, die virtuell in ihrer Rechenkapazität bereits vorhanden sind und von einem entsprechenden Programm in die Aktualität des Interfaces gezogen werden:

Datenverarbeitung und Darstellung sind voneinander entkoppelt und beschreiben eine Grenze der wechselseitigen Kommensurabilität von Mensch und Maschine. »Interface« heißt fortan all das, was Datenverarbeitung in einer Doppelbewegung zugleich unsichtbar macht und auf andere Weise wieder erscheinen läßt, oder umgekehrt: das, was aus Eingaben Daten macht, und dabei bewirkt, daß die Eingaben nicht mehr die Daten sind. (Pias 2002: 253)

\subsubsection{Interfaces und die sKultur der Simulation`}

Die ontische Stellung von Interfaces ist in vielerlei Hinsicht die Gretchenfrage für einen kulturwissenschaftlichen Umgang mit digitalen Medien. Die parallel zu Heimund Personal-Computer entstandene Hacker-Szene beispielsweise gruppiert sich ja bis heute um die Idee, dass es durch die Interfaces hindurch auf die unanschauliche funktionale Logik des Apparates zu blicken gilt (vgl. ebd.: 252ff.). Auch in der Kulturkritik werden die medialen Entwicklungen der Interface-Kultur häufig pessimistisch und als Anzeichen schwindender Rezipientensouveränität in einem vorgeblichen >Spätkapitalismus` gelesen, der bei den ihn tragenden Konsumenten in erster Linie >Oberflächlichkeit` kultivieren möchte (vgl. Jameson 1984: 60ff.). Diese Lesart begreift das Interface als ein bloßes Trugbild - eine Täuschung, die vom Wesentlichen der Computertechnologien ablenkt. Wirkliche ১Demokratisierung \ des Computers würde demnach nicht etwa bedeuten, ihn durch grafische Benutzeroberflächen immer einfacher bedienbar zu machen, sondern vielmehr, die Anwender zu seiner Nutzung ohne derartige Krücken zu emanzipieren. Aus dieser Warte erscheint das 
Interface paradoxerweise als eine Virtualisierung des `Eigentlichen` der Rechenprozesse.

Für Turkle hingegen würde eine solche Deutung die alltägliche Erlebnisdimension unseres Umgangs mit Computern falsch abbilden. Die Art, wie wir an Interfaces herantreten, ist für sie nicht das Ergebnis eines geglückten Betruges des Anwenders durch die Entwickler schlimmstenfalls proprietärer Software, sondern vielmehr jenes einer »Gewöhnung« an eine »opake Technologie« (Turkle 1998: 32). Die überwiegend per Kommandozeile gesteuerten Betriebssysteme, die der Markteinführung des Apple Macintosh im Jahre 1984 vorausgegangen waren, hatten von ihren Nutzern noch die Einarbeitung in eine Befehls->Sprache` verlangt, welche in ihrem logischen Aufbau jenen der Rechnerarchitektur zumindest erahnen ließ. Der Mac hingegen konfrontierte seinen Nutzer erstmals mit einem Interface, das durchaus zur >Oberflächlichkeit im positiven Sinne ermutigte: Der Rechner musste als Rechner nicht mehr verstanden werden, um ihn für die verschiedensten anderen Zwecke zu verwenden (vgl. ebd.: 33; vgl. Pias 2002: 252). Am Mac und den ihm folgenden, von grafischen Interfaces gestützten Heim- und Personalcomputern vollzog sich laut Turkle ein Lernprozess, in dessen Zuge Computernutzer dazu übergingen, Interfaces als Teil ihrer alltäglichen Wirklichkeit hinzunehmen (vgl. Turkle 1998: 33).

In einer solchen »Kultur der Simulation« (ebd.) verschiebt sich die virtuelle Funktionalität des Computers: Es geht nun nicht mehr darum, über ein virtuelles Interface aktuelle Rechenoperationen anzustoßen, sondern vielmehr in einem Interface das zu aktualisieren, was in der Rechenfähigkeit des Computers virtuell bereits angelegt ist. Dies ist für Turkle kein in irgendeiner Form >irrealer« Vorgang:

Im Gegenteil, die Kultur der Simulation bestärkt mich darin, das, was ich auf dem Bildschirm sehe, »für bare Münze« zu nehmen. In der Kultur der Simulation gilt, daß etwas real ist, wenn es funktioniert. (Ebd.: 34)

Die Idee, dass Computer wirklichkeitserweiternd wirken können, weil sie Virtualitäten aktualisieren, findet u.a. ein Echo beim australischen Medientheoretiker und kritiker McKenzie Wark. In seinem 2004 entstandenen und seinem Titel entsprechend von revolutionärem Gestus getragenen Hacker Manifesto bezeichnet Wark das Hacking - in weiterem Sinne aber jedwede Form des Programmierens - als eine "production of production" (Wark 2004: 32). Weil Software nicht Produkt, sondern Prozess ist, schafft das Schreiben von Software nicht etwa Aktualität, sondern Virtualität - ein Programm kann ausgeführt und damit (vorübergehend) aktualisiert werden, kehrt aber mit seiner Beendigung wieder in den virtuellen Zustand zurück. Für Wark bildet das Virtuelle eine >dritte Natur - jenen Teil des Wirklichen, den wir bisher weder in die erste Natur des physikalischen Kosmos, noch die zweite der sozialen Welt integrieren konnten und der produktiv immer neue Wirklichkeitsoptionen 
hervorbringt (vgl. ebd.: 80): Softwareentwicklung mag die Musterdisziplin des Virtuellen sein, aber virtuell ist auch das Gebäude, das architektonisch bereits geplant ist und nur noch im Bau aktualisiert werden müsste, oder das Gesetz, dass erst in seiner Einhaltung durch den sich selbst disziplinierenden Bürger oder seiner polizeilichen Durchsetzung aktuell wird.

\subsubsection{Digitale Virtualität und kulturelle Kommunikation}

Steve Woolgar betont vor allem die enge Verworbenheit unseres vornehmlich an digitale Datenverarbeitung geknüpften Virtualitätsbegriffs mit der in den 1980er Jahren aufgeblühten Utopie vom Cyberspace, die nach Woolgar in erster Linie eine Utopie der Kommunikation ist: Das Wesen des Cyberspace liegt für ihn nicht in einer simulacrischen Erzeugung >künstlicher Welten, die in Konkurrenz zur `wirklichen ‘ treten, sondern in seiner Fähigkeit, die Beziehung der kulturellen Welt zu den Räumen, in denen sie sich entfaltet, zu verändern - ohne dabei aber selbst im physikalischen Sinne >räumlich zu sein. Der Cyberspace ist eine Metapher für von digitalen Medientechnologien getragene Kommunikationsstrukturen, welche die Verhältnisse des srealen` Raumes überschreiben können (vgl. Woolgar 2002: 2). ${ }^{2}$ Woolgars Virtualitätsvorstellung knüpft an dieses Konzept an und versteht Virtualität immer im Zusammenhang mit der Erwartung eines »death of distance« (ebd.: 19), welche sie zugleich relativiert.

Woolgar formuliert keine Definition oder Begriffsgeschichte der Virtualität. Vielmehr nimmt er unter die Lupe, welche Phänomene in öffentlichen Diskursen unter dieser Bezeichnung verhandelt werden und formuliert von diesen ausgehend seine Five Rules of Virtuality. Bei diesen >Regeln ' handelt es sich nicht um einen in Stein gemeißelten Kriterienkatalog für das, was als virtuell gelten darf, sondern um »Daumenregeln « und »Slogans" (ebd.: 14), die in erster Linie Landmarken für die Beschreibung von Virtualisierungserscheinungen darstellen sollen. Sie umreißen damit ein Feld, dass es nach Woolgar zum Zeitpunkt der Textentstehung erst noch zu erschließen galt: jenes der Auswirkungen von digitalen Medien auf die Grenzen und Beschaffenheiten der Lebensrealitäten ihrer Anwender (vgl. ebd.: 13f.).

Woolgars erste Regel besagt, dass neue Medientechnologien sich nicht etwa eigendynamisch und unaufhaltsam ausbreiten und dabei alle gesellschaftlichen Widerstände hinwegspülen, sondern dass Akzeptanz und Nutzungsgewohnheiten stark sozial situiert sind. Die Integration des digitalen Virtuellen in die Lebenspraxis kann auf sehr verschiedene Arten erfolgen und in unterschiedlichen sozialen Kontexten variierende Formen von Kompromissen und Zugeständnissen erforderlich machen. Die erste Regel besagt damit auch, dass die Vorstellungen, die Entwickler einer- und

2 Das Kapitel 3.3.3 dieser Studie wird sich der Geschichte und den Implikationen der Cyberspace-Metapher noch eingehender widmen. 
Endnutzer andererseits an neue Technologien herantragen, sehr weit auseinandergehen können (vgl. ebd.: 14f.).

Die zweite Regel erweitert die erste um die Feststellung, dass vor allem die Ängste und Gefahren, die mit Virtualisierung verbunden sind, ungleichmäßig über die Gesellschaft verteilt sind. Unterschiedliche soziale Gruppen und Institutionen fühlen sich von aufkommenden Technologien unterschiedlich stark bedroht (vgl. ebd.: 15f.) - man denke z.B. an Senioren, die fürchten, den Anschluss an ihre Umwelt zu verlieren, oder eben auch an Museen, denen der Virtualisierungsprozess aus genannten Gründen sehr viel schwerer von der Hand zu gehen scheint als Bibliotheken.

Die dritte Regel verbindet Woolgars sehr praktisches Virtualitätsverständnis mit der Virtualität als ontologischer Kategorie: Sie besagt, das virtuelle Technologien >reale< Tätigkeiten nicht etwa verdrängen, sondern funktional ergänzen bzw. die Modalitäten ihrer Durchführung verändern. Bürocomputer haben z.B. laut Woolgar nicht etwa das Papier überflüssig gemacht, sondern in Büros neue Kommunikationswege geschaffen, die sowohl von digitaler Datenübertragung, als aber auch von physischen Ausdrucken digitaler Information Gebrauch machen (vgl. ebd.: 16f.) Regel vier verdichtet diese Beobachtung auf die Formel »the more virtual, the more real« (ebd.: 17): Die Verfügbarkeit virtueller Angebote mache die entsprechenden physischen Tätigkeiten nicht etwa unattraktiv, sondern könne sogar zu ihrer Ausübung anregen. Bezeichnenderweise wählt Woolgar hier ausgerechnet das Beispiel, dass ein >Besuch ¿ in einem Online-Museum den in einem 〉Offline〈-Museum nicht notwendigerweise ablösen müsse, sondern letzteren gerade auch erst attraktiv machen könne. Etablierte Einrichtungen wie Geschäfte und Kulturinstitutionen können von der Existenz virtueller Entsprechungen demnach durchaus auch belebt werden (vgl. ebd.: 18f.).

Die fünfte Regel wird von Woolgar mit der Maxime »the more global, the more local« (ebd.: 19) zusammengefasst: Obwohl Virtualisierung immer zu einem gewissen Grad im Zeichen des >death of distance` stehe und ihre Trägertechnologien von der Entwicklerseite her zumeist global gedacht würden, hänge die Art, wie sich die Nutzer schließlich zur Globalität verhielten, stark von lokalen Voraussetzungen ab. Die Relevanzkriterien, aufgrund derer auf global verfügbare Informationen zugegriffen wird, seien - und damit mündet die letzte Regel der Virtualität zurück in die erste - eben in bestimmten gesellschaftlichen Gefügen positioniert, die sich von physikalischen Raumverhältnissen noch lange nicht unabhängig gemacht hätten (ebd.: 19ff.).

Zusammenfassend stellt Woolgar fest, dass >Virtualisierung als Prozess »counter-intuitive« (vgl. ebd.: 21) sei: Sie geschehe auf eine Art, die nicht immer unseren Erwartungen entspräche und nicht etwa von der vermeintlich folgerichtigen Logik der Technik vorgeschrieben sei, sondern in ihrem Vollzug laufend sozial neu verund ausgehandelt werde. Hiermit gesellt sich zur ontologischen und technischen Bedeutung des Virtualitätsbegriffs also eine soziale: Virtualität ist auch der Lebensmodus von Gesellschaften, die in zunehmendem Umfang Gebrauch von >virtuellen 
Technologien machen. Es sei in diesem Zusammenhang noch einmal an Lev Manovichs bereits erwähnte Beobachtung erinnert, dass sich der Computer ab den 1980er Jahren von einer Maschine mit begrenzten Anwendungsfeldern zu einem »filter for all culture« entwickelt habe (Manovich 2002: 64): Genau diese Entwicklung ist es, die in ihrer ganzen Vielgestaltigkeit das bildet, was Woolgar unter >Virtualisierung versteht. Mit einer solchen Einführung von Computern in kulturelle Kommunikationsstrukturen entsteht wiederum nach Joseph Weizenbaum eine Konfliktsituation zwischen dem formalen System der technischen Anordnung und der Lebenswelt der Menschen:

Nun zum Computer: Ich würde sagen, er kann nicht verstehen, weil er mit der Welt keine semantische Verbindung aufnimmt. Im Computer ist alles abstrakt, die Bits oder die Elektronen rasen herum und was sie bedeuten, kann der Computer nicht wissen, er kümmert sich nicht darum. Das ist sogar schon zuviel gesagt, er kann sich nämlich gar nicht »kümmern«. (Weizenbaum 2006: 135)

Hiermit ist wiederum angedeutet, dass Woolgars Virtualisierungsbegriff einer Erweiterung bedarf: Mit dem Eindringen von Computern in Abläufe der Aushandlung kultureller Kategorien und Inhalte geht die Notwendigkeit einher, diese Inhalte in Formalismen zu übersetzen, die der Computer wenn schon nicht verstehen, so doch zumindest prozessieren kann. Virtualisierung muss also auch als das Gegenteil der Aktualisierung verstanden werden, als die Verwandlung von etwas Konkretem in ein Abstraktes, von etwas Vorhandenem und Ausgeformten in ein Potenzielles, von Erscheinungen und Gegenständen der Kultur in die Mathematik des Codes.

Genau auf dieser Grenze zwischen kultureller Welt und selbstbezüglicher Kalkulation verortet auch Lev Manovich den Computer: Während er auf der Repräsentations- bzw. Interface-Ebene kulturelle Objekte entstehen lässt, die in kulturellen Kategorien verstanden und gedeutet werden können, ist der zugrundeliegende Code nur von Maschinen zu verwerten: Jede Datei besteht aus einem sog. Header, welcher ihre Art und Beschaffenheit kennzeichnet (und damit dem System zu erkennen gibt, wie genau mit ihr zu verfahren ist), und einer Folge von Ziffern, die ihren eigentlichen Inhalt darstellt (vgl. Manovich 2002: 45f.). Erst mit den Vor-Schriften entsprechender Software versehen kann ein Computer diese Ziffern ordnungsgemäß auslesen und in ein kulturell rezipierbares Objekt zurückverwandeln. Manovich sieht dabei den »culture layer« und den »computer layer« als völlig verschiedene »Kosmogonien« (ebd.: 46). Den Prozess, in welchem Inhalte zwischen diesen zwei Ebenen (und damit zwischen Virtualität und Aktualität) hin- und hergeschoben werden, bezeichnet Manovich als Transcoding (ebd.: 45).

Ein prägnantes Beispiel für Transcodierung liefert Friedrich Kittler (wohlgemerkt ohne selbst diesen Begriff zu verwenden) am auch für die Museumsvirtualisierung 
hochbrisanten Gegenstand der Computergrafik. Als Computergrafik ist hier im Gegensatz zum alltagssprachlichen Gebrauch nicht etwa das zu verstehen, was tatsächlich auf einem Bildschirm erscheint - dies sind Kittlers Diktion nach Computerbilder -, sondern das System von Softwareprogrammen, das für dessen Erzeugung verantwortlich ist (vgl. Kittler 2002: 178). Das Computerbild ist nach Kittler rein formal immer »eine zweidimensionale additive Mischung aus drei Grundfarben, die sich im Rahmen oder Parergon eines Monitorgehäuses zeigt« (ebd.). Während Manovich in dieser Einkreisung des Computerbildes durch den Rand des Bildschirms ein Vermächtnis des Kinodispositivs erkennt - eine diskrete simulierte Realität wird im Kader der Leinwand eingekapselt und vorgeführt (vgl. Manovich 2002: 80) - sieht Kittler den Vorgänger des Computermonitors vielmehr im Radarschirm: Anders als die analoge Projektion auf der Kinoleinwand oder auch das halbdigitale, aus Zeilen aufgebaute Fernsehbild bestehen Computerbilder aus einzelnen Punkten auf einem zweidimensionalen Raster, deren Positionen sich in cartesischen Koordinaten beschreiben und dementsprechend individuell adressieren lassen (vgl. Kittler 2002: 178f.). In dieser Adressierbarkeit ihrer Einzelelemente verkörpern Computerbilder laut Kittler »die Fälschbarkeit schlechthin« (ebd.: 179): Sie bestehen, soweit es den Computer betrifft, aus nichts weiterem als einer Auflistung von zweidimensionalen Koordinaten, denen jeweils ein Farbwert in Form einer Mischung aus den drei Grundfarben Rot, Grün und Blau (und damit einer dreidimensionalen Koordinate) zugeordnet ist. Jeder dieser Werte kann über eine einfache Manipulation der Zahlen verändert werden - Computergrafik, so Kittler, macht uns glauben, dass die von ihr auf den Schirm gebrachten Bilder kontinuierliche und abgeschlossene Objekte seien, während es sich bei ihnen in Wahrheit um einen aus diskreten und somit manipulierbaren Elementen zusammengesetzten Text handelt (vgl. ebd.). Dieser wird erst dann zum Bild, wenn eine mit entsprechenden programmatischen Vorgaben ausgestattete Software ihn ausliest und aktualisiert, indem sie nach seiner Anleitung tatsächlich Farben auf Pixel verteilt. Das von Lawrence Lessig beschriebene Zwitterdasein des Codes als Synthese von Substanz und Gesetz zeigt sich hier überaus schlüssig: Für den Computer, dessen Domäne (oder mit Manovich: dessen Kosmogonie) die zwingende Logik der Zahlen ist, sind Regeln Substanz. Alles, was wir am Computer als substantiell wahrnehmen und damit also als ein kulturelles `Etwas` reflektieren können - sei es nun das grafische Desktop-Interface eines Betriebssystems, die simulierte Umwelt eines Computerspiels oder ein digitales Abbild der Mona Lisa - ist das Ergebnis der Umsetzung bzw. Aktualisierung von Vor-Schriften, in denen das >Etwas« nur virtuell vorhanden ist. Manovich stellt aufgrund eben dieser Beobachtung fest, dass die auf einem Bildschirm erscheinenden Gegenstände keine >Dinge seien - sie besitzen nämlich keine singuläre Identität. Sie sind eher Signal als Objekt und dementsprechend nicht autonom. Zwei identische Instanzen desselben Signals sind funktional ununterscheidbar und dementsprechend auch nicht als diskrete Entitäten zu betrachten (Manovich 2002: 132ff.), auch wenn wir sie auf der Ebene des 
Interfaces aus unseren Wahrnehmungsgewohnheiten heraus als solche empfinden mögen.

Transcoding ist ferner immer auch ein Prozess der Entkopplung zwischen der (Bild-)Sprache der Nutzeroberfläche und den Formalien des Rechners: Das, was auf dem Bildschirm Gestalt annimmt, bildet nicht unbedingt das ab, was der Computer im selben Moment im engeren Sinne >tut «. So vermitteln z.B. die grafischen Oberflächen von Betriebssystemen wie Microsoft Windows oder MacOS (die ihrerseits ja selbst nichts anderes sind als Gefüge aus Computerbildern) eine bestimmte Logik der Dateien und des Computers insgesamt, die meist relativ wenig damit zu tun hat, wie er tatsächlich arbeitet. Unter Rückgriff auf die Sapir-Whorf-Hypothese, der zufolge die Sprache das Denken formt, charakterisiert Manovich Interfaces als Sprachsysteme, die eine bestimmte Vorstellung davon transportieren, was Computer sind und wie sie auf unterschiedlichen Ebenen (Prozessor, Speicher, Software, usw.) arbeiten (vgl. ebd.: 64f.). Solche Vorstellungen sind nicht etwa >falsch $<$ In den allermeisten Fällen sind die Interfaces ja hochgradig funktional und führen ihre Nutzer bei sachgemäßer Verwendung durchaus zum Ziel. Vielmehr unterstreicht Manovich mit dieser Feststellung die bei Turkle bereits angedeutete Idee von einer doppelten Wirklichkeit des Rechners: Interfaces sind nicht weniger real als die Maschinen, auf denen sie entstehen. Die elektronischen Abläufe im Rechner sind Teil der gleichen Wirklichkeit wie die Bildwelt, die auf dem Monitor erscheint. Es gibt hier keinen in Stein gemeißelten Dualismus von Realität und Irrealität, sondern lediglich einen fluktuierenden von Virtualität und Aktualität.

Wir wollen es für den Augenblick bei diesem ersten Umriss von >Virtualität « und >Virtualisierungく belassen. Es wird diese Begriffe im folgenden Kapitel noch auf die räumlichen und dinglichen Kategorien des Museums zu übertragen gelten. Konkretisiert werden sollen sie im Folgenden zunächst anhand einer technologischen Konfigurationsform, mit der sie in der Gegenwart wie mit kaum einer anderen verbunden sind: jener des Netzwerks.

\subsection{ZUM BEGRIFF DES INETZWERKS}

Im Laufe der vergangenen Jahrzehnte hat sich der Terminus des >Netzwerks` eng mit digitalen Medientechnologien verschränkt, ohne dabei notwendigerweise Computernetzwerke im engeren technischen Sinne zu meinen. Vielmehr scheint >Vernetzung〈, ganz ähnlich wie das bereits diskutierte Heideggersche `Bauen`, einen bestimmten Modus menschlicher Existenz zu beschreiben, der in vernetzten Rechnern lediglich seinen infrastrukturellen Unterbau und seine Metaphorik findet. Vernetzt sind nicht länger nur die Computer untereinander, sondern auch die von ihnen übertragenen Inhalte (in Form verlinkter Webseiten) und die Menschen, die sie benutzen. Das Wort 
netzwerken, welches der Duden mittlerweile immerhin als ein »schwaches Verb« der Umgangssprache einstuft und das »ein soziales Netzwerk aufbauen oder pflegen « ${ }^{3}$ meint, stellt gewissermaßen den Rückimport einer Versinnbildlichung dar. Nachdem die plastische Annahme von einem `Netz` einige Jahrzehnte lang unser Vorstellungsgebäude von der digitalisierten Gesellschaft geprägt hat, wird die digitale Vernetzung nun selbst zur Metapher für zwischenmenschliches Geschehen in der >analogen - womit, wie im Folgenden ausgeführt werden wird, eine unbeabsichtigte etymologische Rückbesinnung einhergeht.

Die ursprünglichen `Netzwerke` waren zunächst die Werkzeuge der Fischerei, ehe dieses Wort im Zeitalter der Industrialisierung zunehmend auch auf Elektrizitätsund Telegrafenleitungen, Schifffahrtskanäle und Bahngleise angewandt wurde (vgl. Stockhammer 2005: 200ff.). Im Zuge der Ökonomisierungs- und Industrialisierungsprozesse des 19. Jahrhunderts wuchs der Anwendungsbereich des Begriffs ins Abstrakte: Er konnte nun nicht nur eine Vielzahl konkreter, physischer Netze mit benennbaren räumlichen Abmessungen beschreiben, sondern auch die in ihnen stattfindenden prozeduralen Abläufe. Damit war ein Phänomenbereich benannt, der durchaus nicht neu war und u.a. im 1736 von Leonhard Euler als unauflösbar erkannten Königsberger Brückenproblem bereits vorweggenommen wurde: Nämlich die Pfade innerhalb geometrischer Systeme von Punkten und Linien mathematisier- und damit zugleich kommunizierbar zu machen. Das 19. Jahrhundert als Epoche sich rapide beschleunigender Güter- und Wissensproduktion benötigte Rechenmodelle, um die Bewegung sowohl von Waren als auch von Information innerhalb vernetzter Systeme beschreiben und beschleunigen zu können. Es prägte damit einen bis heute nachwirkenden Netzwerkbegriff, der nicht mehr nur Arrangements von Verbindungslinien und Umschlagspunkten beschreibt. Vielmehr gehörten zu seinem Gegenstand nun auch die dynamischen Bewegungsabläufe und die Gesamtheit all jener Beziehungskonstellationen, die sie bedingen. Hierin zeigt sich nicht nur eine Ausweitung des Netzwerkkonzeptes, sondern gewissermaßen eine Dopplung seines Bezeichneten: Zu jedem physischen, materiellen Netzwerk gehört ein gedachtes, das sich von diesem abhebt und in erster Linie eine Domäne des Planens und Simulierens bildet. Netzwerke werden zu einer Denkfigur, die zwar materielle Bezugspunkte, z.B. in Form von Schienen und Bahnhöfen oder Computern und Telefonleitungen hat, ihren besonderen Wert aber aus ihrer Fähigkeit zieht, von diesen zu abstrahieren (vgl. ebd.: 202ff.). Das 19. Jahrhundert entdeckte Netzwerke als Dispositive, ohne dass ihm dieser Begriff zur Verfügung gestanden hätte.

Der Entstehung eines Netzwerkkonzeptes, wie es seit dem ausgehenden 20. Jahrhundert mit den digitalen Medien konnotiert ist, mussten indes noch einige weitere Entwicklungen vorausgehen. Katja Mayer diagnostiziert in den Natur- und Gesellschaftswissenschaften des beginnenden 20. Jahrhunderts disziplinenübergreifend

3 http://www.duden.de/rechtschreibung/netzwerken vom 14.04.2018, Hervorhebung D.N. 
eine starke Tendenz zur Systemorientierung: Die Interessenlagen der Forschung verschoben sich, so Mayer, vom Verhalten bestimmbarer Einzelentitäten auf die nicht immer physikalisch sichtbaren Zusammenhänge und Verbindungen zwischen diesen. Die zahlreichen in der ersten Jahrhunderthälfte entstandenen Wissenschaftszweige wie Topologie, Spieltheorie, Mengenlehre, Biometrie und Ökonometrie seien hier nur die sichtbarsten Zeugnisse einer Prioritätenverschiebung in der Forschungskultur - weg von Auflistungen anekdotenhafter Individualerscheinungen, hin zu einem wissenschaftlichen Verständnis der Welt als ein systematisches Gefüge von Wechselwirkungen, für welche die individuellen Phänomene nur mehr Substrate und Grenzbedingungen darstellen (vgl. Mayer 2010: 67). Netzwerke sind also in der Form, wie wir sie heute verstehen, ein vergleichsweise junges Konzept - und Diskussionen darüber, was im medientheoretischen Sinne als Netzwerk gelten kann oder nicht, sind nach wie vor zu führen. In jedem Falle vereinigen sich aber auch in Mediennetzwerken sichtbare »materiell-technische Entitäten« (Stockhammer 2005: 200) mit Wissens-, Diskurs- und sozialen Konstellationen, die erst durch die Brille der NetzwerkKategorie betrachtet überhaupt in Erscheinung treten.

\subsection{1 (Ge-)Doppelte Netze}

Dieser Dualismus lässt sich an modernen Computernetzwerken sehr schön illustrieren. Auf der einen Seite sind diese natürlich immer materielle Gebilde: Sie bestehen aus individuellen Computern, die irgendwo auf der Welt eine Position im Raum belegen, und Datenleitungen, die diese miteinander verbinden und dabei eine vermessbare Distanz überbrücken. Die Computer bilden Knoten oder Nodes, von welchen Informationsströme ausgehen, in Empfang genommen und koordiniert werden; die Kabel zwischen ihnen Verknüpfungen oder Links, entlang welcher sich Information zwischen den Knotenpunkten bewegt (vgl. ebd.: 202). Funktional ähneln sie damit durchaus einem Eisenbahnnetz, in welchem Züge Fracht und Passagiere zwischen Bahnhöfen transportieren. Andererseits aber muss die Art, wie der Zugriff auf die im Netz verfügbar gemachten Daten organisiert wird, nicht unbedingt die Verschaltung des physischen Netzwerks von Server- und Client-Rechnern abbilden, auf dem diese gespeichert sind.

Das World Wide Web, in dem sich das überwältigende Gros der Internetnutzer üblicherweise bewegt, wenn es `surft<, ist nicht das `Internet` im physischen Sinne. Vielmehr handelt es sich bei ihm um ein System von Texteinheiten in Form von Webseiten, die über Hyperlinks miteinander verbunden sind. Diese Software-Verbindungen heben sich von ihrer Hardware weitgehend ab: Ein direkter Link zwischen zwei Webseiten kann es erforderlich machen, die entsprechenden Datensätze über Kontinente und Ozeane hinweg abzurufen. Zugleich können aber auch zwei Webseiten auf demselben Server liegen, ohne jemals miteinander in Verbindung gebracht zu 
werden. So ist z.B. die Wikipedia zum Zeitpunkt der Entstehung dieser Zeilen im Sommer 2013 in 286 Sprachen verfügbar und umfasst über 30 Millionen einzelne Artikel, von denen allein 4,2 Millionen auf die englische Version entfallen. Wikipedias Hardwareumfang lässt sich indes in deutliche kleineren Zahlen ausdrücken: Bis 2004 lief das ganze Projekt noch auf einem einzigen Computer, seit 2009 besteht der materielle Unterbau der freien Online-Enzyklopädie aus 344 Einzelservern. 44 hiervon stehen in Amsterdam, die übrigen 300 befinden sich in Florida. ${ }^{4}$

Beim Surfen ist der Nutzer also in der paradoxen Situation, dass ihm ein abstraktes Netz konkret gegenübertritt, während das konkrete Netz unsichtbar bleibt und im Grunde nur abstrakt zu erahnen ist. Dies unterstreicht abermals Sherry Turkles Bild vom PC als postmoderner Meta-Maschine: Das materielle ist das Un-Eigentliche und damit die Domäne der Virtualität, während Aktualitäten immer erst in der Simulation entstehen. Was für den einzelnen Rechner gilt, bleibt wahr für Agglomerationen von Computern in Netzwerken. Die kulturelle Wirkungs- und Rezeptionsdimension virtueller Medien ist auf der Ebene der Hardware ebenso wenig zu erklären wie auf jener des Codes allein. Wissen, Affekt und ästhetischer Eindruck entstehen eben auf der Ebene des Interfaces, welches die Schnittstelle zwischen kultureller Welt und unsichtbaren Rechenprozessen bildet. Uns wird im Folgenden daher die Vernetzung von Textfragmenten in Form von Webseiten interessieren, und nicht etwa die Architektur der darunterliegenden Hardware.

\subsection{HYPERTEXT}

Wer heute davon spricht, >im Internet` zu surfen, der meint damit im Allgemeinen das Anfang der 1990er Jahre vom englischen Computerwissenschaftler Tim BernersLee erfundene World Wide Web, dessen funktionale Grundlage von der Auszeichnungssprache HTML (Hypertext Markup Language) und dem Anwendungsprotokoll HTTP (Hypertext Transfer Protocol) gebildet wird. Während HTML das Erstellen verlinkter Websites ermöglicht, stellt HTTP die Schnittstelle dar, über welche diese Seiten von Client-Programmen (wie z.B. einem Browser) abgerufen, ıverstanden und ggfs. im Interface aktualisiert werden können. Der erste auf den Endnutzer zugeschnittene HTML-Editor wurde 1990 frei und unentgeltlich verfügbar gemacht (vgl. Krameritsch 2008: 119) und leitete nicht nur den Siegeszug des WWW ein, sondern mit ihm auch den einer Organisationsform von Wissen, deren Geistes- und Theoriegeschichte bis in die frühe Neuzeit zurückreicht und die schließlich zum bestimmenden Paradigma des Informationszeitalters werden sollte: jener des Hypertextes.

4 Vgl. http://en.wikipedia.org/wiki/Wikipedia\#Software_and_hardware vom 01.07.2013. 
Das Wort >Hypertext` wurde in den 1960er Jahren vom Soziologen Theodore Holm Nelson geprägt (vgl. ebd.: 117) und fällt in gedruckter Form erstmals in einem 1965 erschienenen Paper mit dem Titel A File Structure for the Complex, the Changing and the Indeterminate:

Let me introduce the word »hypertext« to mean a body of written or pictorial material interconnected in such a complex way that it could not conveniently be presented or represented on paper. It may contain summaries, or maps of its contents and their interrelations; it may contain annotations, additions and footnotes from scholars who have examined it. Let me suggest that such an object and system, properly designed and administered, could have great potential for education, increasing the student's range of choices, his sense of freedom, his motivation, and his intellectual grasp. Such a system could grow indefinitely, gradually including more and more of the world's written knowledge. However, its internal file structure would have to be built to accept growth, change and complex informational arrangements. (Nelson 2003: 144)

Hypertexte sind also modular aufgebaute Texte, die nicht etwa wie klassische literarische von vorne nach hinten zu lesen sind, sondern deren Einzelelemente weitgehend frei arrangiert und sequenziert werden können und ein dieser Eigenschaft entsprechendes technisches Fundament benötigen. Hintergrund für Nelsons Interesse an dieser medialen Form war eine Unternehmung, die zwar unverwirklicht bleiben sollte, dabei aber nichtsdestoweniger zukunftweisend war: Wenige Jahre zuvor hatte er das ambitionierte Project Xanadu begründet, dessen erklärtes Ziel die Schaffung eines universellen »Dokuversums« (Krameritsch 2007: 117) war. In diesem sollte die Gesamtheit der menschlichen Kulturgüter archiviert, hypertextuell verknüpft und nach Möglichkeit für jedermann abrufbar gemacht werden. Interessanterweise sah Nelson dabei Computer nicht als notwendige Bedingung für die Entstehung einer solchen universellen Datenbank an, sondern lediglich als das offensichtlichste und naheliegendste Instrument, um die physische Abwesenheit des ursprünglichen Materials zu überbrücken. Hierbei spielte gerade das Meta-Maschinelle und damit effektiv Multimediale des Rechners eine Rolle: Mit ihm sollten sich Text und Bild auf dynamische Weise miteinander kombinieren lassen, um der Vielgestaltigkeit des Materials gerecht zu werden (vgl. ebd.: 117f.).

\subsubsection{Frühe Formen}

Tatsächlich hatte der digitale Hypertext aber schon lange vor der Einführung des Begriffs analoge Vorgänger: Jakob Krameritsch verweist hier u.a. auf den Deutschen Victor Vogt, dessen 1922 erschienene Schrift Die Kartei, ihre Anlage und Führung die chronologische Linearität und Abgeschlossenheit schriftlicher Aufzeichnungen im Buchformat bemängelte und ihnen die Kartei als ein den physikalischen Raum 
umfassend ergreifendes System zur Verwaltung von Wissensinhalten gegenüberstellte. Information sollte nicht in geschlossene und eindimensional fortlaufende Narrative eingezwängt, sondern in kleine, disparate Teilbereiche und Themen aufgespalten werden, die dann wiederum mit Querverweisen auf verwandte Wissens->Einheiten` versehen werden können. Karteikästen sollten im Gegensatz zu Büchern interaktiv sein, Wissen nicht innerhalb eines festen Konzeptes, sondern pfadabhängig vermitteln und vor allem prozesshaften Charakter aufweisen, anstatt finalisierte und nicht mehr verhandelbare Endprodukte einer wissenserzeugenden Anstrengung zu sein. Eine Kartei lässt sich jederzeit erweitern, mit neuen Verweisen versehen, nötigenfalls auch neu sortieren. Der Argumentationsverlauf ist hier also in weiten Teilen schon derselbe wie jener der Hypertexttheorie: Das >Verzetteln` wird als dezidiert moderne epistemische Kulturtechnik vorgestellt, die einem immer rasanter anwachsenden Wissensfundus gerecht werden soll (vgl. ebd.: 109f.).

Die Ideengeschichte modularisierter und frei kombinierbarer Texte lässt sich indes noch weiter zurückverfolgen. Urahnen des Hypertextes erkennt Krameritsch auch in den vier Bänden der Bibliotheca Universalis Conrad Gessners, jener Ur-Bibliographie der dem Abendland bekannten Literatur, die 1549 zum Abschluss gelangte und alphabetische Autorenverzeichnisse mit thematischen Indizes und einem umfangreichen Anmerkungsapparat verband (vgl. ebd.: 111). Roberto Simanowski streicht vor allem die Bedeutung der kombinatorischen Poetik des Barock und die mit ihr verbundene Mathematisierung von Texten als ein frühes In-Erscheinung-Treten der späteren Hypertext-Idee heraus. Er verweist hier u.a. auf den Wechselsatz aus dem zwischen 1648 und 1653 entstandenen Poetischen Trichter Georg Philipp Harsdörffers (vgl. Simanowski 2002: 66) - einen zweizeiligen Reim im siebenhebigen Jambus, in welchem in jeder Zeile an jeweils einer Stelle eines von je 11 vorgegebenen Substantiven eingesetzt werden darf, so dass insgesamt fast 40 Millionen verschiedene Permutationen möglich sind (Martin 2011: 202):

Auf Angst / Noht / Leid / Haß / Schmach / Spott / Krieg / Sturm / Furcht / Streit / Müh' / und Fleiß folgt Lust / Raht / Trost / Gunst / Ruhm / Lob / Sieg / Ruh / Mut / Nutz / Lohn / und Preiß. (Harsdörffer 1648: 51; vgl. Martin 2011: 202.)

Die kombinatorische Logik hinter diesem Sprachspiel wurde den Barock hindurch immer wieder aufgegriffen (idealtypisch u.a. in Quirinus Kuhlmanns Libes-Kuß von 1671, vgl. Simanowksi 2002: 66; vgl. Martin 2011: 202f.). Die Begeisterung für Sprache als mathematisierbares funktionales System ist kaum überraschend, wenn wir uns an das erste Kapitel dieser Arbeit und das von Horst Bredekamp diagnostizierte mechanistische Weltmodell der Frühmoderne zurückerinnern, aus dem auch die Wunderkammer hervorgehen sollte: Wie die Welt als Ganzes wird auch die menschliche Kommunikation als ein Gefüge von Gefügen - von Buchstaben in Worten in Sätzen in Texten - begriffen, die einerseits variierbar und anderseits rigiden 
Gesetzmäßigkeiten unterworfen sind. Die Sprache definiert sich hier weniger über die Freiheitsgrade, die sie dem Sprechenden zur Verfügung stellt, als über ihre Reguliertheit, und erscheint damit ebenfalls als ein Machinamentum.

In der zweiten Hälfte des 20. Jahrhunderts sollte die kombinatorische Poetik eine Wiederbelebung erfahren, deren Triebkräfte zweierlei waren: Auf der einen Seite interessierten sich Kybernetik und Computerwissenschaft für die Regelhaftigkeit snatürlicher Sprachen und damit auch dafür, inwieweit man Computern beibringen könnte, diese zu >verstehen ‘ und zu produzieren. Auf der anderen Seite bot Permutationsdichtung Künstlern die Möglichkeit, die Grenzen ihrer eigenen Autorschaft auszuloten und Texte zu produzieren, die sich zu einem gewissen Grad `selbst schrieben. Als ein prominentes Beispiel eines entsprechenden Werkes führt Simanowski die 1961 erschienenen Cent mille milliards de poèmes des französischen Dichters Raymond Quesneau an. Quesneaus tatsächliche Schreibarbeit beschränkte sich bei diesem kleinen Gedichtband auf das Verfassen von zehn 14-zeiligen Sonetten mit jeweils identischem Versmaß und Reimschema. Einhunderttausend Milliarden Gedichte werden aus diesen erst dadurch, dass die einzelnen Seiten quer eingeschnitten sind - es kann also jede Zeile einzeln umgeblättert werden (vgl. Simanowksi 2002: 66). Im Ergebnis werden so aus gerade einmal 10 kurzen Einzeltexten mit einem klar benennbaren Autor eine Anzahl virtueller Texte, die so astronomisch groß ist, dass die meisten von Ihnen niemals zur Aktualisierung gelangen und mit großer Wahrscheinlichkeit keine zwei Leser jemals dieselbe Gedichtkonfiguration zu lesen bekommen werden. Kann Quesneau noch als Autor dieser Texte gelten? Und falls nicht: Geht die Autorschaft auf den Leser über, der zwischen Gedichtzeilen hin- und herblättert, oder geht sie auf in der Eigendynamik und Regelhaftigkeit des Systems >Sprache< selbst?

Die vorliegende Arbeit wird diesen Aspekt stochastisch-kombinatorischer Textproduktion an anderer Stelle noch genauer in den Blick nehmen und theoretisch kontextualisieren. Für den Augenblick soll dieser genealogische Exkurs nur verdeutlichen, warum die Hypertextidee besonders in ihrer Verbindung mit dem Meta-Medium Computer in den 1980er und 1990er Jahren ein so breites Echo auch in der akademischen Welt finden konnte: In Hypertexten schien sich die komplette Literaturtheorie der Postmoderne zu bestätigen, allem voran Roland Barthes 1968 formulierte These vom »Tod des Autors« (vgl. Simanowski 2002: 67, vgl. auch Barthes 2000).

\subsubsection{Vannevar Bush und die Memex-Maschine: Pfade des Wissens}

So bedeutend die Rolle von Literatur und Dichtung in der Ideengeschichte des Hypertextes gewesen ist, seine technische Entwicklung wurde weder von Literaten, 
noch von der Motivation künstlerischen Ausdrucks angetrieben. Vielmehr war es das Verlangen der Naturwissenschaften nach effizienteren Methoden zur Verwaltung ihres explosionsartig anwachsenden Kenntnisstandes, das den Anstoß zur Entwicklung hypertextueller Abrufsysteme lieferte. So erschien im Jahre 1945 im Atlantic Magazine ein Aufsatz mit dem Titel As We May Think aus der Feder des Leiters des amerikanischen Office of Scientific Research and Development, Vannevar Bush. Bush hatte als Chef jener Behörde, aus welcher wenige Jahre später die RAND-Corporation hervorgehen sollte, im zweiten Weltkrieg vor der Aufgabe gestanden, die Forschungstätigkeit hunderter über die gesamten USA verstreuter Forscherteams und Laboratorien koordinieren und dabei gleichzeitig für einen optimalen Austausch ihrer Forschungsergebnisse sorgen zu müssen (vgl. Krameritsch 2007: 114). Dies veranlasste ihn nach Kriegsende dazu, die üblichen Kanäle zur Verbreitung wissenschaftlicher Erkenntnisse über gedruckte Monographien und Zeitschriften für ebenso überkommen zu halten wie deren etablierte Verwaltung durch Kataloge und andere Ordnungssysteme, die über Kategorisierung und Systematisierung des Materials funktionierten. Angesichts eines immer schneller anwachsenden Wissenskorpus seien diese schlicht nicht intuitiv genug handhabbar und folgten zugleich einer Logik, die nicht jene des menschlichen Gehirns sei:

The human mind does not work that way. It operates by association. With one item in its grasp, it snaps instantly to the next that is suggested by the association of thoughts, in accordance with some intricate web of trails carried by the cells of the brain. It has other characteristics, of course; trails that are not frequently followed are prone to fade, items are not fully permanent, memory is transitory. Yet the speed of action, the intricacy of trails, the detail of mental pictures, is awe-inspiring beyond all else in nature. (Bush 1945)

Was Bush den alten Werkzeugen der Speicherung und des Abrufs von Forschungsdaten nun entgegensetzt ist eine niemals tatsächlich gebaute, für die Diskursgeschichte der modernen Informations- und Computerwissenschaft als Idee jedoch eminent wichtige Maschine namens $>$ Memex .

Ein Memex - seinerseits eine Wortschöpfung aus memory und index - sollte nach Bushs Vorstellung eine analoge Apparatur sein, mittels derer ihr Nutzer all sein schriftlich bezieh- und niederlegbares Wissen speichert und abruft. In seiner Funktionsweise und Abruflogik wiederum sollte dieses Gerät möglichst genau dem Modell des menschlichen Gedächtnisses als Netzwerks von Informationspartikeln entsprechen: »It is an enlarged intimate supplement to his memory. (Ebd.) Als eine >intim mit dem Geistesleben ihres Nutzers verwobene technische Vorrichtung sollte Memex sich auch in sein Wohnumfeld möglichst nahtlos einfügen und die Gestalt eines herkömmlichen Möbelstücks annehmen: In seiner äußeren Erscheinung hätte es idealerweise einem Schreibtisch geglichen, in dessen Oberfläche angewinkelte Projektions- 
schirme, eine Tastatur und eine Anzahl von Kontrollhebeln und -schaltern eingelassen gewesen wären (vgl. ebd.). Wie Jahrzehnte später die >Desktop<-Interfaces der Heim- und Personalcomputer sollte also schon Memex an ein etabliertes Dispositiv des Arbeitslebens anknüpfen.

Für die Speicherung und räumliche Kompression schriftlicher und bildlicher Inhalte war die Verwendung von Mikrofilmrollen vorgesehen. Bush ging davon aus, dass deren Kapazität zur fotografischen Verkleinerung bis zur praktischen Umsetzung von Memex soweit ausgereift sein würde, dass ein Nutzer selbst beim Abspeichern von 5.000 Seiten Text- und Bildmaterial am Tag hunderte von Jahren benötigen würde, um die Menge an Film zu füllen, die in einem der Geräte Platz fände (vgl. ebd.). Zusätzlich zur Anzeige fertig gekaufter Rollen, die z.B. Bücher und Zeitschriften enthalten hätten, sollte Memex auch die Speicherung auf leerem Film ermöglichen: Neben dem Projektionsschirm hätte sich eine Glasplatte mit einer Kamera darunter befunden, welche u.a. zum Abfotografieren von privater Korrespondenz und Notizen dienen sollte (vgl. ebd.).

Der Abruf bestimmter Inhalte sollte über Codes funktionieren, die über die Tastatur einzugeben gewesen wären - in einem Codebuch hätte der Nutzer die Kennziffern sämtlicher Bücher, Aufsätze, Artikel, Briefe usw. in seiner Mikrofilmbank verzeichnet, um diese dann direkt ansteuern zu können. `Geblättert` worden wäre, wie bei tatsächlich realisierten Mikrofilmlesegeräten, mit zwei kleinen Hebeln, welche den Film wahlweise vor- oder zurückspulen sollten. Ferner hätte Memex nach Bushs Entwurf über die Möglichkeit zum Setzen eigener elektronischer Lesezeichen verfügt, die das direkte hin- und herspulen zwischen mehreren markierten Stellen auf derselben Filmrolle ermöglichen sollten. Mit einem dem ursprünglich zur elektronischen Übertragung von Unterschriften konzipierten Telautographen verwandten System wäre es darüber hinaus möglich gewesen, handschriftliche Notizen und Anmerkungen auf dem Mikrofilm vorzunehmen (vgl. ebd.).

All diese angedachten Funktionen waren den technischen Möglichkeiten des Jahres 1945 nicht allzu weit voraus - auch wenn man sicherlich darüber spekulieren darf, wie Verschleiß- und Störungsanfällig eine Maschine gewesen wäre, die sie alle gleichzeitig auf mechanischem Wege bewältigt. Und obwohl Memex schon darin eine sehr andere Auseinandersetzung mit Texten ermöglicht hätte, als sie rein papierbasiert möglich ist, verdankt das Gerät seinen Platz in der Ideengeschichte der Hypertexttheorie vor allem einer geplanten Frühform von >Verlinkung`, deren technische Grundlage Bush zwar antizipieren, aber noch nicht zur Umsetzung anbieten konnte. Geplant war, dem Memex-Nutzer die Möglichkeit zum Anlegen von Wissens->Trails $\&$ zu geben, indem er diesen einfach eigene Kennziffern zuweist und diese wiederum in seinem Codebuch notiert. Hätte er zwei separate Wissenspartikel auf nebeneinanderliegenden Projektionsschirmen vor sich und wiese er mittels seiner Tastatur beiden dieselbe >Pfad «-Ziffer zu, so wären sie miteinander verknüpft und ein 
einfacher Knopfdruck würde es ermöglichen, zwischen den assoziierten Inhalten eines Text- oder Bildmoduls hin und her zu schalten. Abgespeichert werden sollten diese Trails dann wiederum in Form von Punkten auf dem Mikrofilm, die mit einer Fotozelle ausgelesen werden könnten. Im Ergebnis, so seine These, könne man unter der Kennziffer des Pfades quasi ein neues und ganz eigenes >Buch` einsehen, das so beschaffen sei, als wären aus zahllosen anderen Büchern Seiten herausgerissen und zu einem neuen gebunden worden, das einer sehr spezifischen Interessenlage entspricht und bei Bedarf auch mit abfotografierten Notizen des Nutzers selbst versehen werden kann (vgl. ebd.). Dieser Vergleich wird jedoch sofort wieder von einem Gedankenspiel zur Arbeit mit Memex widerlegt, welches Bush im nächsten Absatz ausführt:

The owner of the memex, let us say, is interested in the origin and properties of the bow and arrow. Specifically he is studying why the short Turkish bow was apparently superior to the English long bow in the skirmishes of the Crusades. He has dozens of possibly pertinent books and articles in his memex. First he runs through an encyclopedia, finds an interesting but sketchy article, leaves it projected. Next, in a history, he finds another pertinent item, and ties the two together. Thus he goes, building a trail of many items. Occasionally he inserts a comment of his own, either linking it into the main trail or joining it by a side trail to a particular item. When it becomes evident that the elastic properties of available materials had a great deal to do with the bow, he branches off on a side trail which takes him through textbooks on elasticity and tables of physical constants. He inserts a page of longhand analysis of his own. Thus he builds a trail of his interest through the maze of materials available to him. (Ebd.)

Was der Nutzer hier tut, gleicht eben gerade nicht dem Zerfleddern und Neuverkleben gedruckter Bücher, denn ein Druckwerk zu zerkleinern und neu zusammenzusetzen bedeutet zugleich, das vorherige Sinngefüge zu vernichten: Der Urtext wird der Bricolage geopfert und ist als solcher nicht länger rezipierbar. Memex hingegen sollte assoziative Pfade quer durch verschiedenste Texte stampfen, ohne dabei deren Integrität zu verletzen. Ferner wäre ein aus Fragmenten anderer Bücher zusammengefügter Band seiner Struktur nach immer noch ein eindimensionaler und damit linearer Text, könnte also immer nur einen einzigen möglichen Pfad durch den zugrundliegenden Wissensschatz abbilden. Memex hingegen war dazu konzipiert, Texte zweidimensional zu verschalten: Wissensmodule sollten nicht einfach nur nacheinander aufgefädelt werden wie Perlen auf einer Kette, sondern die Knotenpunkte eines Gewebes bilden, in welchem Fäden nach vielen Richtungen verlaufen können. So, wie in den 140 Gedichtzeilen Quesneaus hundert Milliarden virtuelle Sonette verborgen sind, verstecken sich in den Interdependenzen und Wechselbezüglichkeiten von Schriftstücken weitere Texte, die allerdings rein potenziell bleiben müssen, solange die diskreten Ursprungstexte nicht in einen gemeinsamen Rezeptionszusammenhang gebracht werden. Virtuell (und somit eben auch aktualisierbar) werden die von Bush 
ausgemachten >Trails` erst, wenn ein Abrufsystem wie Memex (oder in weniger raffinierter Form auch der Schlagwortkatalog einer Bibliothek) diesen Rahmen des Lesens und Querlesens herstellt. Welche impliziten Texte dann tatsächlich aktualisiert werden, hängt wiederum vom Leser $a b$.

\subsubsection{Das virtuelle Moment textueller Vernetzung}

Hypertexte sind also hochgradig virtuelle Erscheinungen, und zwar unabhängig davon, ob ihr technischer Unterbau von Zettelkästen, analogen Maschinen oder Auszeichnungssprachen gebildet wird, die Computerbrowsern den Aufbau von Webseiten diktieren. Und was für vernetzte Textfragmente gilt, lässt sich auf alle Netzwerke ausdehnen: Sie sind vor allem zweidimensionale Entfaltungsräume des Möglichen. Ein Schreibsystem wie der Hypertext schafft Virtualitäten, indem es Vektoren des Miteinanders zwischen Entitäten etabliert und das Nacheinander serialisierter Inhalte zu einem Nebeneinander auffächert. Ob dieses Neben- und Miteinander wiederum jemals zur Aktualität gelangt, steht auf einem anderen Blatt - das Format als solches schafft lediglich die Option zur Auslotung von Möglichkeiten (Moulthrop 1995: 302f.).

Wiewohl der Hypertext mittlerweile auch für die geistes- und kulturwissenschaftliche Auseinandersetzung mit den >neuen Medien` eine unerlässliche theoretische Kategorie geworden ist, blieb er noch bis in die 1980er Jahre vornehmlich ein Begriff der Computer- und Informationswissenschaft. Dass seine Entdeckung als >literarisches $<$ Konzept ausgerechnet in die Zeit der rasanten Ausbreitung von Personalcomputern in Büros und Privathaushalten fiel, ist durchaus kein Zufall: Computer mussten erst einmal das Alltagsleben und vor allem den akademischen Betrieb selbst durchdrungen haben, um als Kulturphänomene erkennbar zu werden (vgl. Aarseth 1995: 51f.).

Dabei macht der Gebrauch von Computern und Computernetzwerken als Technologie zu seiner Übertragung aus einem Text noch keinen Hypertext - wie andersherum Hypertexte ja auch durchaus außerhalb digitaler Medien in Erscheinung treten können. Viele über das World Wide Web verbreitete Schriften sind vielmehr das, was Jakob Krameritsch als »E-Texte« (Krameritsch 2007: 127) bezeichnet: Sie werden zwar in elektronisch-digitaler Form verbreitet, weisen aber ansonsten alle Merkmale klassischer, linearer Texte auf. ${ }^{5}$ Hypertexte sind hingegen, wie Roberto Simanowski betont, notwendigerweise multi- (und nicht etwa non-)linear: Sie sind zwar

5 Mike Sandbothe zufolge ist das Projekt >Hypertext « sogar so lange nicht wirklich abgeschlossen, wie es sich in der Modularisierung von Textkörpern erschöpft, die dann in der Rezeption doch wieder zu linearen Ketten arrangiert werden. Seiner Ansicht nach bräuchten wir zusätzlich zum Hypertext als Organisationsform für Schriftkörper auch eine ganz 
so angelegt, dass sie als fortlaufende und sich geradlinig entwickelte Textstränge rezipiert werden können, aber diese Stränge sind wiederum stets das Ergebnis eines Auswahlprozesses unter verschiedenen möglichen Sinnfragmenten (vgl. Simanowski 2002: 15f.). Hypertexte lassen ihre zweidimensionale Anlage bei nur einmaligem Lesen nicht sichtbar werden, bzw.: In ihrer Gänze als Textnetzwerke wären Hypertexte gar nicht sinnhaft zu rezipieren. >Sinn< entsteht im Hypertext vielmehr immer erst in der >Bewegung « des Rezipienten entlang eines strail of interest $`$, der den einzelnen Texteinheiten kontingente Zusammengehörigkeit verleiht und nur ganz bestimmte ihrer zahlreichen möglichen Bedeutungen aktualisiert, wobei >unpassende ২ Textbausteine ausgelassen werden. Im Ergebnis erlebt der Hypertext-Leser also durchaus die Entstehung eines linearen Textes, der allerdings immer anders hätte aussehen können.

Die digitalen Hypertexte des World Wide Web sind indes nicht nur multilinear, sondern obendrein auch noch intermedial: Sie bedienen sich nicht nur der Virtualität der Vernetzung, sondern auch jener des Computers als Meta-Maschine. Sie bestehen eben nicht nur aus vernetzten Textkomponenten, sondern auch aus Bildern, Videos, Klängen, Spielen, usw. Diese unterschiedlichen medialen Bausteine stehen nach Simanowski ausdrücklich nicht nur nebeneinander (weshalb er hier auch den Begriff der bloßen >Multimedialität zurückweist), sondern sie bilden für ihn »konzeptuelle Integrationen« (ebd.: 18) die innerhalb eines epistemischen und dramatischen Konstrukts ineinandergreifen. Hypertexte sind also die Summe ihrer Teile plus der Summe ihrer Virtualitäten, und Letztere steigt ungemein, wenn sich zum schriftlichen Text noch andere mediale Ausdrucksformen gesellen. ${ }^{6}$

\subsubsection{Die Grammatik der Verlinkung}

Jakob Krameritsch sieht auch im >Linkı eine Eigenart digitaler Hypertexte, welche sie von analogen unterscheidet. Natürlich arbeiten auch Zettelkästen mit Querverweisen. In der Textgattung der Enzyklopädie wird gar eine hypertextuelle Funktionalität mit dem gebundenen Buch zusammengeführt: Zwar sind die einzelnen Artikel

neue Sprache, die uns ein zweidimensionales, nonlineares Schreiben gestattet (vgl. Sandbothe 1997: 74f.).

6 Lev Manovich unterscheidet aus diesem Grund zwischen den Kategorien Hypertext und Hypermedia: Hypermedia bezeichnet hier eine flache Linkstruktur, die unterschiedliche Dokumentenformate assoziativ miteinander vernetzt, während Hypertext als eine bestimmte Untergattung von Hypermedia definiert ist, die sich einzig auf schriftliche Textbausteine stützt (vgl. Manovich 2002: 38). Manovichs herausragender Bedeutung als Theoretiker digitaler Medien zum Trotz hat diese Unterscheidung niemals allgemeine Gültigkeit beanspruchen können, und auch die vorliegende Arbeit meint mit Hypertext sowohl rein schriftbasierte als auch intermedial vernetzte Sinngefüge. 
alphabetisch sortiert, der Zugriff läuft aber quer zu dieser Sequenzierung, die lediglich der Auffindbarkeit einzelner Wissensinhalte dient. In jedem Falle jedoch bleiben, so Krameritsch, die individuellen Textbausteine beim bloßen Querverweis diskret und souverän: Dieser nämlich hält lediglich dazu an, mehrere in sich geschlossene Einzeltexte nacheinander zu lesen. In den Hyperlinks des World Wide Web prallen dagegen einzelne Textpartikel aufeinander und verbinden sich zu neuen Texten, die keinem derer gleichen, aus denen sie hervorgegangen sind. Links etablieren nicht nur die Zusammengehörigkeit von Texten, sie schaffen zugleich ein virtuelles $>$ Mehr . Dieses resultiert daraus, dass sie sich notwendigerweise immer an zwei Orten zugleich befinden: namentlich im Text, von dem sie ausgehen, und in jenem, auf den sie verweisen. Dabei heben Hyperlinks jede eventuelle räumliche Distanz zwischen diesen separaten Texten auf. Will man dem Querverweis einer Enzyklopädie folgen, so muss mindestens geblättert, eventuell sogar ein anderer Band aus dem Regal geholt werden. Auch jener des Zettelkastens kann nur dazu auffordern, eine andere Karteikarte physisch ausfindig zu machen. Der Hyperlink hingegen veranlasst einen nahtlosen Wechsel zwischen Texten. Er ist kein bloßer Verweis, sondern eine virtuelle Kopplung, die jederzeit aktualisiert werden kann und in dieser Eigenschaft eine eigene Poetik besitzt (vgl. Krameritsch 2007: 139).

Simanowski geht noch einen Schritt weiter und betrachtet Links nicht etwa nur als einen Modus der Textorganisation im Repräsentationssystem digitaler Medientechnologien, sondern als Bestandteile einer eigenen Grammatik digitalisierter Texte. Seiner Ansicht nach ziehen Links nicht nur einzelne Textelemente zu neuen Texten zusammen. Vielmehr seien sie »die Fortführung der Geschichte mit anderen Mitteln, sie verbinden nicht nur Text, sie sind Text« (Simanowski 2002: 64). Links sind demnach keine passiven Mechanismen zwischen den Texten, sie geben selbst Richtung und Grenze der Bedeutungsstrukturen vor. Sie vermitteln nicht zwischen aus sich heraus sinnvollen Inhalten, sondern verleihen diesen erst Sinn, indem sie sie mit den im Anklicken zum Ausdruck gekommenen Interessen des Rezipienten koppeln. Entsprechend haben sie selbst Inhaltscharakter - und die Möglichkeit zur sinnigen Erschließung eines Hypertextkörpers endet in jener medialen Sackgasse, in der es keine Links mehr gibt, denen man folgen könnte (vgl. ebd.).

\subsection{ZURECHTFINDUNG UND NAVIGATION IN VERNETZTEN TEXTEN}

Der Informatiker, Hypertexttheoretiker und Game Studies-Pionier Espen Aarseth befindet aufgrund ähnlicher Beobachtungen die klassischen grammatischen Struktureinheiten von Textkörpern wie Sätze, Worte und Buchstaben für unzureichend, um mit ihnen dem funktionalen Aufbau von Hypertexten gerecht zu werden. Anhand 
ihrer lässt sich ein Text zwar in seiner konkreten Verfasstheit vermessen, aber nicht in seiner prozeduralen Entstehung durch Erschließung aus dem Virtuellen. Aarseth setzt ihnen daher die Begriffe des Textons und des Scriptons entgegen: Textone bilden die Elementarteilchen des Hypertextes, also jene einzelnen und irreduziblen Textstücke, die selbst nicht mehr von Links unterteilt sind. Ihre Beschaffenheit und Begrenztheit ist damit immer nur im Zusammenhang des übergreifenden Netzwerks ersichtlich, sie bilden die Knoten zwischen den Sinnvektoren der Hyperlinks. Einfache Beispiele für Textone wären z.B. eine einzige Webseite ${ }^{7}$, eine einzelne Zeile aus Quesneaus permutativen Sonetten, oder ein einziges der wählbaren Worte aus Harsdörffers Wechselsatz. Scriptone werden im Gegensatz zu Textonen vom Leser nicht vorgefunden, sondern gemacht bzw. aktualisiert: Ein Scripton ist jede sinnvolle, aus dem Verfolgen von Links entstandene Kette von Textonen (vgl. Aarseth 1995: 60f.).

Aarseth entwickelt diese Begriffe wiederum im Rahmen einer nonlinearen Texttheorie, welche Mitte der 90er Jahre nach ganz neuen Beschreibungsmodellen für mutable und prozessorientierte Textformen verlangte, die vor allem von digitalen Medienformen getragen wurden und mit den Begrifflichkeiten der etablierten Literaturtheorie nur mehr bedingt greifbar schienen. Hypertexte sind unsichtbare Netzwerke, bzw. wird der Netzwerkbegriff im Zusammenhang mit ihnen zur Metapher: Anders als das physische Internet, das zwar in seiner schieren Ausdehnung kaum mehr zu (be-)greifen, aber dennoch als Gefüge von Computern und Leitungen in der physischen Welt zumindest vorstellbar ist, verfügen Hypertexte gerade aufgrund der zuvor identifizierten Entkopplung der Logik von Hard- und Software über keinen materiellen Unterbau, der ihre Vernetztheit abbildet. Sie können dementsprechend nur auf zwei Arten greifbar gemacht werden: Als rein bildhaftes Denkmodell, dass eben Textone als Knotenpunkte und Links als Vektoren der Erzeugung von Scriptonen in einem Netzgewebe der Sinnoptionen beschreibt und damit zumindest eine funktionale Verständigung darüber ermöglicht, was Hypertexte sind - oder aber mittels einer mathematischen Auswertung der Beziehungen der Textbausteine untereinander (vgl. ebd.: 60f.).

\subsubsection{Topologie und Textraum}

Der Ansatz, den Aarseth hierzu vorschlägt, stammt aus der Geometrie. Weil die Fülle der Linearitätsoptionen in komplexen Hypertexten es unmöglich mache, ihren Aufbau in simplen narrativen Kategorien zu verstehen, gelte es, ihre Gesamtgefüge in den Fokus zu rücken und in ihrer Topologie zu begreifen:

7 Gemeint ist hier tatsächlich eine einzelne Webseite - nicht etwa eine Ansammlung von Seiten unter einer gemeinsamen Domain, die man umgangssprachlich als website bezeichnen würde, wie z.B. de.wikipedia.org. 
For a formal definition of our concept, the mathematical branch of topology will suffice. According to my own copy of Webster's New Twentieth-Century Dictionary, this is the theory of »those properties of geometric figures that remain unchanged even when under distortion, so long as no surfaces are torn. « Without too much discordance, I hope, the textonomical version of topology may be described as »the study of the ways in which the various sections of a text are connected, disregarding the physical properties of the channel (paper, stone, electromagnetic and so on), by means of which the text is transmitted.« (Ebd.: 60)

Damit macht Aarseth interessanterweise das Problem der Sinnstiftung in Hypertexten zu einem räumlichen: Sie topologisch zu beschreiben und zu begreifen bedeutet, einen analytischen Standortwechsel vorzunehmen und sich vom Blickwinkel des >gewöhnlichen` Rezipienten zu lösen. Denn während dieser sich im Inneren des Labyrinthes befindet und seine Optionen und Freiheiten nur begrenzt voraussehen kann, ermöglicht der topologische Blick es gewissermaßen, >von oben Knotenpunkte und Verbindungslinien zu schauen. Dieser Blick wird dabei zugleich blind für das individuelle narrative Erlebnis, seine Aufmerksamkeit gilt der Fülle und Verwobenheit des Hypertextes, welche dem Leser als transversale Funktion der Textentwicklung im normalen Rezeptionsmodus verborgen bleiben muss (vgl. ebd.: 61): Hypertexte heben zwar die (Mono-)Linearität klassischer Texte auf, schaffen aber keine Simultaneität der Inhalte. Sie in ihrer Struktur zu betrachten, heißt, sie nicht länger lesen zu können - und sie zu lesen heißt, ihren Aufbau lediglich zu erahnen (vgl. Münker 1997: 125).

Katja Mayer zufolge verdanken wir unsere Fähigkeit, solche abstrakten Netze überhaupt denken zu können, vor allem der Sozialpsychologie und hier insbesondere der in den 1930er Jahren entstandenen `Soziometrieく des österreichisch-amerikanischen Psychiaters Jacob L. Moreno. Die Soziometrie befasste sich in erster Linie mit der Beschreibung und Quantifizierung zwischenmenschlicher Beziehungen unter Vermeidung kategorischer Vorannahmen über deren Natur und Beschaffenheit. Ihr wichtigstes mediales Werkzeug war dabei die Darstellungsform des Soziogramms gewissermaßen eine Landkarte bzw. ein Itinerar von Beziehungsverhältnissen in einem sozialen System. Dieses wurde nunmehr als Netzwerk begriffen, in welchem die sozialen Akteure als Knotenpunkte und ihre wechselseitigen Verhältnisse als Verbindungsvektoren erscheinen. Dieses völlig ohne Klassifizierungen auskommende Modell gesellschaftlicher Gruppen bricht den sozialen Status einzelner Personen auf mathematische Koeffizienten herunter, die sich aus der Anzahl der mit ihnen in Verbindung stehenden übrigen Akteure ergeben. Die Soziometrie nahm damit zugleich die Funktionsweise moderner Suchmaschinen vorweg (vgl. Mayer 2010: 68ff.): Will man sich in Hypertexten zurechtfinden, so muss man sie als etwas konzeptualisieren und darstellen, was sie eigentlich nicht sind - nämlich als tatsächliche $>$ Netze , in denen die Verknüpfungen zwischen einzelnen Punkten nicht nur formale, sondern tatsächlich räumliche Verhältnisse vorgeben. 
Insofern ist, wie Roberto Simanowski feststellt, das `Mapping`oder Kartieren die Paradedisziplin der kulturellen und künstlerischen Auseinandersetzung mit digitalen Medien (vgl. Simanowski 2008: 111). Als Beispiel führt er hier das zum Valentinstag 2006 von Golan Levin, Kamal Nigam und Jonathan Feinberg ins Leben gerufene Projekt The Dumpster an. The Dumpster (wörtlich: der Abfallcontainer, abgeleitet aber vom Verb to dump, das neben >wegwerfen` auch >Schluss machen` bedeuten kann) wird auf der zugehörigen Homepage ${ }^{8}$ als »a portrait of romantic breakups collected from blogs in 2005 « beschrieben: 20.000 aus privaten Blogs extrahierte Posts, welche die Worte >broke up oder >dumped me` enthielten, wurden ausgewählt und über ein animiertes Interface aus in Rottönen kodierten Punkten (die jeweils bestimmte Trennungs-Kategorien beschreiben) abrufbar gemacht (vgl. ebd.: 102). Simanowski sieht hierein eine mustergültige Auseinandersetzung mit dem Digitalen, weil das Projekt letztlich die weitgehend beliebige Übersetzbarkeit von allem in alles betont und diese Eigenschaft transcodierbarer Information ausnutzt, um im Internet publizierte Beziehungskisten zunächst in abstrakte Daten zu transformieren und diese wiederum über ein bildgebendes Verfahren ästhetisch rezipierbar zu machen. Unter Anspielung auf Duchamps Fountain nennt Simanowski dieses Spiel mit dem informationellen Detritus des World Wide Web »eine domestizierte Variante des Readymade, die statt auf den Skandal nun doch auf die Schönheit des Pissoirs setzt« (Simanowski 2008: 112).

\subsubsection{Anschluss statt Abschluss}

Man mag über Sinn und Unsinn solcher künstlerischer Auseinandersetzungen mit Hypertexten geteilter Meinung sein. In jedem Falle aber stellen Projekte, die sich mit der Visualisierung von Hypertextgefügen befassen (wie beliebig deren Inhalte auch sein mögen) implizit immer auch die Frage nach Bewältigungsstrategien für Textkörper, die sich jeder etablierten Vorstellung von literarischer Abschließbarkeit widersetzen. Obwohl das World Wide Web zweifelsohne das größte und kulturell einflussreichste existierende Hypertext-System darstellt, stammen viele der Theorien und Methoden, welche in den Geistes- und Kulturwissenschaften zum Umgang mit Hypertextphänomenen herangezogen werden, noch aus einer Zeit vor dem WWW und legen eine ganz andere Art von Hypertexten zugrunde. Die in den 1980er und 90er Jahren kurzzeitig aufgeblühte Hypertext-Literatur kam in Form zwar vernetzter und multilinearer, letztlich aber doch begrenzter Textgebäude daher, die zwecks Verbreitung auf physischen Datenträgern wie Disketten und CD-Roms abgespeichert und dementsprechend in einer bestimmten Verfasstheit finalisiert werden mussten. Das World Wide Web hingegen präsentiert sich als

8 http://artport.whitney.org/commissions/thedumpster/ vom 15.12.2015. 
[...] a hypertext corpus of enormous complexity, and it continues to expand at a phenomenal rate. Moreover, it can be viewed as an intricate form of populist hypermedia, in which millions of on-line participants, with diverse and often conflicting goals, are continuously crafting hyperlinked content. Thus, while individuals can impose order at an extremely local level, its global organization is utterly unplanned - high-level structure can emerge only through a posteriori analysis. (Kleinberg 1998: 1)

Das WWW ist also ständig im Werden begriffen und dementsprechend nicht einzugrenzen oder auch nur sinnvoll zu unterteilen - es ist schwierig geworden, von Hypertexten überhaupt noch im Plural zu sprechen, weil im Netz jeder Hypertext mit jedem anderen verbunden ist und ihre Peripherien kaum mehr zu bestimmen sind. Im Ergebnis erscheint das Netz als ein einziger, kolossaler Hypertext, der sich darüber hinaus laufend in Inhalt und Aufbau verändert. Auch längst >kartierte` Bereiche des Webs können sich beim nächsten Besuch schon wieder gewandelt haben. Krameritsch sieht aus diesem Grunde in digitalen Hypertexten eine Form von flüchtigen Medien: Sie kennen keine unveränderlichen Endprodukte und verteilen Autorschaft dezentral unter potenziell extrem großen und weit verstreuten Akteurskonstellationen (vgl. Krameritsch 2007: 38).

Dieses Zusammenspiel von verschwimmender personaler Autorenrolle einerseits und Verlust der Abschließbarkeit andererseits erscheint >postmodern auch insofern, als dass es jede zwingende Dramaturgie von Anfang, Mitte und Schluss verwirft und mit ihr die Idee, jede textuelle >Geschichte`müsse einem eindeutigen Ende entgegeneilen. Seit Aristoteles begreift die westliche Literaturtheorie das Ende als das eigentliche Moment literarischer Sinnstiftung: Der Anfang einer Geschichte sei frei wählbar und völlig der Willkür des Dichters unterworfen, das Ende aber die zwingende Kulmination all der Entwicklungen, die ihm vorangehen (vgl. Aristoteles 2014: 25). Insofern wirft das Ende stets den Schatten seines unausweichlichen Eintretens voraus, und unabhängig davon, ob es unsere Erwartungen bestätigt oder subvertiert, wird die Geschichte erst mit ihrem Abschluss interpretierbar (Douglas 1995: 160f.). In der postmodernen Literatur - wie z.B. den Werken Thomas Pynchons wurde mit dieser Tradition häufig insofern gebrochen, als dass man sich der Kontingenzbewältigung völlig verweigerte: Das `Ende` des Buches erschöpft sich hier oft in der profanen physischen Realität des Buchdeckels, der die einzige Schlussmarkierung darstellt. Narrative Geschlossenheit wird nicht angeboten, das Ende ist nur mehr der letzte Abschnitt eines linearen Textkörpers, dem keine herausgehobene Bedeutung gegenüber den ihm vorausgegangenen mehr zukommt (vgl. ebd. 1995: 164). Der konzeptionelle Ansatz des Hypertextes indes widersetzt sich auch diesem Paradigma der Sinnverweigerung. 


\subsection{3 'Navigation` als Kulturtechnik}

Was er ihr entgegensetzt ist die Idee der Navigation, mit der sich abermals ein räumliches Denkmuster verbindet und die zugleich frappierend mit Flussers Metapher vom `Ozean der Möglichkeiten` ineinandergreift. Konrad Becker spricht ferner von einem »Ozean der Information « (Becker 2010: 182) und sieht in den Meereskonzeptionen insbesondere der mediterranen Mythologien zugleich Äußerungen einer zivilisatorischen Urangst, sich in formlosen Wissenslandschaften zu verirren. Im Ursprungsnarrativ des hellenischen Pantheons entsteigt die Göttin Nyx als personifizierte Nacht als erste dem Chaos. Im babylonischen Mythos erhebt sich Tiamat aus der "großen und finsteren Leere« (ebd.), bevor aus ihrem Leib die Welt geschaffen wird. Für Becker sind diese Figuren Sinnbilder eines prärationalen Zustands des ImDunkeln-Tappens und Verlorenseins in einer Welt, die sich dem Verstandenwerden verweigert. Sie »spiegeln Ängste in Bezug auf die Abgründe chaotischer und unstrukturierter Information wider, unberührt von den logozentrischen Strahlen solarer Gottheiten und dem Licht der Vernunft« (ebd.).

In dieser Dunkelheit, in welche die Sonne der Rationalität und klassifizierenden Benennung noch nicht scheint, wird nun »die Navigation zur Wurzel moderner Wissenschaften « (ebd.): Der Navigator ist nicht der in der Sonne badende Gelehrte, der bereits weiß und versteht, sondern der Noch-Lernende, der sich an den verstreuten Lichtern vereinzelter Sterne orientiert und sichere Routen im »unüberschaubaren Meer des Wissens« (ebd.) absteckt. Wie der Navigator das räumliche Unbekannte kartiert, kartiert der Wissenschaftler das Abstrakte. Vor der Kategorisierung und Benennung erfolgt die Verzeichnung der Bezüglichkeiten von >Landmarken` untereinander - man erinnere sich hier an Rheinbergers Experimentalsysteme. Dass Navigation nun auch zum Leitprinzip des Umgangs mit digitalen Medien wird, ist für Becker nur folgerichtig, bezieht die Kybernetik als Wissenschaft selbstgeregelter Systeme ihren Namen doch von Odysseus' Steuermann Kybernos (ebd.: 182f.).

Freilich muss, so verführerisch diese Metaphorik in ihrer Schlüssigkeit auch sein mag, genauer betrachtet werden, in welcher Verbindung sie zu Hypertextsystemen steht. Alan Wexelblat greift hierzu wie Steve Woolgar auf den Begriff des Cyberspace zurück, und ebenfalls wie Woolgar betrachtet auch Wexelblat diesen als eine Metapher. Für ihn ist er kein >Raum<, der notwendigerweise als solcher erfahrbar sein müsste (auch wenn simulatorische Verfahren wie jene des Computerspiels ihn durchaus entsprechend visualisieren könnten). Vielmehr sei er ein »semantic space« (vgl. Wexelblat 1991: 256), dessen Dimensionsachsen in erster Linie als Bedeutungsachsen verstanden werden müssten: Der von ihnen aufgeschlossene $>$ Raum $<$ sei kein spatialer, in welchem Dinge körperliche Ausdehnung besitzen, sondern ein Sinn-Raum, in dem virtuelle Objekte Bedeutungsqualitäten entfalten können (vgl. ebd.: 256f.). Auch Wexelblat spricht von einer `Navigation` in solchen semantischen Räumen, bei 
der entlang jeder ihrer Achsen andere Inhalte zum Vorschein kommen (ebd.: 257). Er bleibt mit dem Begriff jedoch nicht auf metaphorischer Ebene. Sich im Cyberspace zu >bewegen < bedeutet in seiner Diktion, bestimmte Interaktionsprozesse hintereinander zu reihen und damit Sinnpotentiale aus der Rohmasse der vorhandenen Information herauszuschälen:

In an ordinary computer system, movement does not necessarily have the same societally constructed connotations. In most such systems, movement is merely a means of stopping interaction with one object and beginning interaction with another. Movement is necessary because objects are at some distance from one another, but the act of movement itself has no meaning. However, this loss of meaning need not happen in a semantic cyberspace. An effect of constructing cyberspace along semantic dimensions is to render the actions of motion meaningful in and of themselves. This is so because, as discussed above, the space itself has meaning, possibly even when no objects are present. (Ebd.: 264f.)

》Constructing cyberspace along semantic dimensions« beschreibt hier einen Vorsatz, der recht genau dem bereits ausgemachten Anspruch digitaler Hypertexte entspricht: Links lassen zwischen einzelnen Textonen einen informationellen `Zwischenraum entstehen, der selbst informativen Mehrwert besitzt und diesen den Navigationsentscheidungen des Rezipienten entsprechend in unterschiedlicher Form und variierendem Umfang offenlegt. Seine zwei Dimensionen sind dabei die des Aktuellen und die des Virtuellen, des linearen Ausgewählten und des nonlinearen zur Auswahl stehenden. Dies bedeutet aber paradoxerweise auch, dass Navigation in Hypertextsystemen Reduktion der vorgefundenen Komplexität bedeuten muss und nach der Auswahl einiger weniger Optionen aus dem Netz der Potentialitäten zwecks ihrer Serialisierung verlangt. Die Prozeduralität der Hypertextrezeption liegt darin begründet, dass das bestimmende Strukturmerkmal des Mediums immer wieder aufs Neue ausgeschaltet werden muss.

\subsection{4 \Connectedness}

Voraussetzung für das Funktionieren dieses Selektionsprozesses ist in der Diktion des amerikanischen Medienpädagogen Glen Hoptman das Vorhandensein einer Connectedness der Textfragmente untereinander - ein Begriff, der aus zweierlei Gründen hier interessant ist: zum einen, weil Hoptman ihn in unmittelbarem Zusammenhang mit jenem des virtual museum entwickelt (Hoptman 1995: 141), auf den sich auch Werner Schweibenz stützt (vgl. Schweibenz 2001: 11), zum anderen, weil er auch in der Topologie gebräuchlich ist. Hier beschreibt er den Zustand separater geometrischer Punkte, die sich innerhalb eines gemeinsamen, begrenzten Bereichs oder Sets befinden und damit connected sind (vgl. Mendelson 1990: 112ff.). 
Connectedness im Sinne Hoptmans überträgt also abermals eine räumliche Metaphorik auf abstrakte Konstellationen von Textmodulen: Sie legt die Vorstellung eines Netzes zugrunde, das in einem zweidimensionalen Raum ausgebreitet ist und in dem die Kognition des Lesers nicht nur, wie im linearen literarischen Text, dem Verlauf der Schrift und damit der Zeitachse folgt, sondern zugleich ständig Richtungswechsel ins >Stattdessen< vornimmt (vgl. Hoptman 1995: 141f.). Connectedness meint, ganz im Sinne der topologischen Bedeutung, die Zusammengehörigkeit von Textfragmenten in einem gemeinsamen Set - >connected s sind zwei Textone dann, wenn ein virtueller Pfad zwischen ihnen existiert, wenn sie sich also durch das Verfolgen von Links (und ggfs. auch auf Umwegen) innerhalb eines Scriptons zusammenführen lassen. Insofern ist diese Form der Verbundenheit immer sowohl eine Eigenschaft der einzelnen Knotenpunkte, als aber auch des Netzwerks insgesamt, wobei Hoptman besonderen Wert auf die intermedialen Überschneidungen legt, die gerade im Web ihre notwendige Konsequenz sind (vgl. ebd.: 142f.). Auch hier wird also der virtuelle epistemische Mehrwert eines >Dazwischen $<$ und eines $>$ Rundherum akzentuiert:

By applying the concept of connectedness throughout the editorial and production process, digital integrated mixed media publications can better represent the broad contexts from which information is reduced as a natural part of its capture and in all forms of its being »told « Thus, the user of these publications will have available information that has not, by necessity or habit, been filtered through the narrow funnels of traditional media. (Ebd., 142).

Wer sich also bei der Navigation in Hypertexten verirrt, hat weder als Rezipient versagt, noch liegt eine Dysfunktionalität des Mediums vor - solange Connectedness weiterhin gegeben ist. Umweg und Abschweifung sind gewollte und gewinnbringende Rezeptionsformen, weil sie Kontexte aufdecken und Zusammengehörigkeiten transparent werden lassen. Ganz grundlegend und alltagsnah zeigt sich dies zum Beispiel beim Surfen auf den Seiten von Netz-Enzyklopädien wie Wikipedia, wo Querverweise in Form von Links die Gestalt blau unterlegter Worte in Artikeltexten annehmen, von denen man direkt zum nächsten Texton gelangt. Eine kurze und ohne weitere Erklärung nachvollziehbare Verkettung von Artikeln könnte sich z.B. folgendermaßen darstellen:

Deutschland $\rightarrow$ Deutsch-Französischer Krieg $\rightarrow$ Otto von Bismarck $\rightarrow$ Wilhelm II. (Deutsches Reich) $\rightarrow$ Militarismus ${ }^{9}$

9 Hier wurde schlicht den entsprechenden Links auf der deutschen Ausgabe von Wikipedia gefolgt, vgl. www.wikipedia.de vom 17.04.2018. 
Jeder dieser Artikel ist hier doppelt sinnvoll: einmal für sich genommen als Sachtext über sein jeweiliges Thema, zugleich aber auch als Element einer assoziativen Kette. Und diese Kette ist wiederum abermals doppelt kontingent: Sie kontextualisiert jedes einzelne ihrer Glieder in Bezug auf jedes andere, zugleich aber reflektiert sie auch die Verlaufsgeschichte der Evolution einer Interessenlage. Die Navigation selbst ließe sich entsprechend ohne weiteres als eine Abfolge von Entscheidungssituationen narrativieren. Die Connectedness gewährleistet, dass jeder einzelne Textbaustein allermindestens mit dem ihm vorausgegangenen in direktem Zusammenhang steht und dementsprechend die Sinnhaftigkeit der Navigation zu keinem Zeitpunk abreißt. Im obenstehenden Beispiel ist die Assoziationsabfolge schon auf den ersten Blick relativ schlüssig und auch ohne besonderes Expertenwissen zu verstehen. Schauen wir uns im Gegensatz dazu nun das folgende Beispiel an:

Napoleon Bonaparte $\rightarrow$ Arthur Wellesley (1st Duke of Wellington) $\rightarrow$ Gummistiefel $\rightarrow$ Chloropren-Kautschuk $\rightarrow$ Tauchanzug ${ }^{10}$

Die Connectedness äußert sich hier folgendermaßen: Napoleon Bonaparte verlor am 18. Juni 1815 die Schlacht bei Waterloo gegen den Herzog von Wellington. Auf diesen geht auch ein bestimmtes Schnittmuster für Militärstiefel zurück, welches heute überwiegend für die Herstellung einer in Großbritannien populären Form von Gummistiefeln verwendet wird. Hochwertige Gummistiefel wiederum werden heutzutage oft aus Chloropren-Kautschuk hergestellt, der umgangssprachlich besser unter der Bezeichnung >Neopren` bekannt und seinerseits das übliche Material für die Fertigung von Tauchanzügen ist. Die topologische Beschaffenheit Wikipedias erlaubt es uns also, eine völlig kontingente Assoziationskette vom Kaiser der Franzosen zu zeitgenössischer Sportbekleidung zu ziehen, die kein bisschen weniger valide ist als jene, die Deutschland mit dem Militarismus verbindet.

Uwe Wirth betrachtet angesichts solch extremer Beispiele von assoziativer Textnavigation nicht etwa die Kontinuität des Lesevorgangs als das Kernmerkmal der Rezeption von Internet-Texten, sondern vielmehr die Unterbrechung: Links lassen nach seinem Dafürhalten eben nicht separate Texte zu einem verschmelzen, sondern vielmehr den Leser ständig aus dem vorigen heraus- und in den folgenden hineinspringen. Hypertextleser werden seiner Deutung zufolge laufend aus dem narrativen Strom der individuellen Textone herausgerissen (vgl. Wirth 1997: 319). Damit verwischt das Innen und Außen einzelner Texte - während der Einband physischer Bücher stets auch eine scharfe »Grenze zwischen Text und Kontext« zieht (ebd.: 324), löst sich die ganze literarische Kategorie des Einzelwerkes im Netz auf und macht damit eine Form des Lesens erforderlich, die einen krassen Gegensatz zur klassischen, ästhetisch orientierten Textrezeption bildet.

10 S.o. 
Dabei ist aber in Wirths Deutung Hypertextualität keine vorgeschichtslose Erfindung der Moderne, sondern eine Fortsetzung von Intertextualität mit digitalen Mitteln: Texte nämlich, so seine Feststellung, haben sich nicht nur schon immer aufeinander bezogen, sie sind in dieser wechselseitigen Verbundenheit auch schon immer mental modularisiert worden. Intertextualität sei kein Dialog zwischen Texten im Ganzen, sondern »zwischen Textstellen, also aufgeschlagenen Büchern« (ebd.: 325). Genuin neu an digitalen Hypertexten sei, dass sie Intertextualitäten eine mediale Tatsächlichkeit verleihen, weil der Link eben nicht nur verweist, sondern einen »wirklichen Sprung« (ebd.) vollziehe. Damit wird hier also im Gegensatz zu den meisten anderen gängigen Theorien des Hypertextes nicht etwa Virtualität, sondern Aktualität als sein entscheidendes Wesensmerkmal ausgemacht.

Diese technisch unterbaute Aktualität jedes möglichen Sinnzusammenhangs verleiht, so Wirth weiter, dem assoziativen Spiel der Leseerfahrung durchaus ernstzunehmenden subversiven Charakter. Er verweist hierbei auf eine dem obigen Wikipedia-Beispiel sehr ähnliche Textstelle aus Umberto Ecos Roman Das Foucaultsche Pendel:

Das Gestrüpp der vernetzten und verlinkten Querverweise entspräche dann jenem Spiel, »bei dem man durch Assoziationen in fünf Schritten von Würstchen zu Platon gelangen soll«. ${ }^{11}$ Man stellt sprunghafte Kontinguitäts- und Assoziationsbeziehungen an und gelangt so von »Würstchen« zu »Schwein«, von »Schwein« zu »Borste«, von »Borste« zu »Pinsel«, von »Pinsel« $\mathrm{zu} »$ Manierismus «, von »Manierismus « zu »Idee« und von dort zu »Plato«. Das Prinzip der universellen Anschließbarkeit karnevalisiert alle pragmatischen Relevanzsysteme. (Ebd.: 329)

Hypertexte implizieren damit eine »Poetik des Transports« (ebd.: 325), in welcher Verlinkung wiederum zu einer »Spur, ein[em] Abdruck einer diskursiven Strategie» werde: »Hier zeigt sich, ob die 〉Ökonomie des Diskurses` bestimmten Relevanz- und Kohärenzkriterien folgt oder rein willkürlich den Leser in die Irre leitet« (ebd.: 326).

\subsubsection{Detektive und Dandies}

Dementsprechend schaffe sich, so Wirth weiter, das digital-hypertextuelle Dispositiv zwei mit dieser Vermittlungslogik korrespondierende Lesertypen, die beide zwar auch im Umgang mit linearen Texten in Erscheinung treten können, bei jenem mit navigablen jedoch besondere Brisanz entwickeln. Auch hier bezieht er sich auf Überlegungen Umberto Ecos, in diesem Falle aus der Nachschrift zum Namen der Rose: Der Leser sei einerseits Detektiv und Fährtenleser (vgl. Eco 2012: 63ff.), der sich gewitzt im Labyrinth des Textes orientieren und zurechtfinden müsse, zugleich aber

11 Für die ursprüngliche Textstelle siehe Eco 2015: 293. 
auch Dandy, der sich von den Eigendynamiken von Narrativ und Medium gleichermaßen mitreißen und treiben lässt (vgl. Wirth 1997: 326). Dabei unterstreicht Wirth jedoch auch die von Eco an anderer Stelle gemachte Feststellung, dass letztlich kein Lesen ein passives sei: Vielmehr sei es in seiner produktiven Hervorbringung von Sinn eine Form der »Mittäterschaft« (ebd.) - und die große noch zu schreibende Kriminalgeschichte wohl jene, in welcher die detektivischen Bemühungen des Lesers ihn letztlich zu der Einsicht führen, dass er selbst der Täter war (vgl. ebd., vgl. Eco 2011: 200).

Auch Lev Manovich und Roberto Simanowksi bedienen sich dieser Metaphern, um zu beschreiben, was genau der Hypertextleser eigentlich leistet, wenn er sich im Netz der Bedeutungspartikel orientiert. Simanowski sieht hier gerade in der Figur des Dandys - für die er den Baudelaire'schen Begriff des Flaneurs vorzieht - eine Umwendung der postmodernen emanzipatorischen Hoffnungen, die sich einst mit dem Hypertext verbunden haben. Mit dieser gekoppelt sei nämlich nicht nur die Idee einer Befreiung des Lesers aus dem Käfig des semantischen Gebäudes, in das ihn der Autor linearer Texte vorgeblich eingesperrt hat, sondern auch die Angst vor einer Kultur informativer Beliebigkeit. Solche vornehmlich von linksliberalen Intellektuellen getragenen Diskurse spielen laut Simanowski Detektiv und Flaneur gegeneinander aus: Während der Detektiv als denkender Nutzer die den Text untermauernde Logik des Mediums zu decodieren versucht, um gezielt bestimmte Inhalte zum Vorschein zu bringen, überlässt der Dandy die Steuerung und Lenkung seiner Aufmerksamkeit ganz der architektonischen Beschaffenheit des Netzwerks selbst. Dementsprechend wandle er nur mehr auf längst ausgetretenen Pfaden und konsumiere Wissen in Form von >Häppchen<, die im Vorbeigehen mitgenommen und unbesehen verschlungen werden. Hier erscheint der Flaneur also als Symptom einer Wissenskultur, welche die aufgeklärte Modernität, in deren Zeichen der Hypertext als Medium einst zu stehen schien, einem oberflächlichen Belustigungsprinzip unterordnet. Wissen wird nicht mehr gesucht, erarbeitet, verinnerlicht und hinterfragt, sondern von einer auf Unterhaltungswert ausgerichteten Informationsindustrie als Ware und Spektakel inszeniert (vgl. Simanowski 2002: 70).

Manovich hingegen sieht den Flaneur in digitalen Netzen in sehr viel deutlicherer Kontinuität zum großstädtischen Spaziergänger des 19. Jahrhunderts, an dem sich die Metapher festmacht: Der Flaneur ist für ihn verkörperte Subjektivität in einem sozialen Rahmen, der gleichwohl anonym ist - und entsprechend sei er gerade aus dieser Position des Nichtbetroffenseins und der Naivität seiner Umwelt gegenüber zu Formen der Subversion und Kritik imstande, welche dem involvierten und bewusst die Logik des medialen Systems durchdringen wollenden Leser nicht offen stünden. Der Netz-Flaneur nach Manovich ist ein unfrei-, indes jedoch durchaus nicht widerwilliger Entdecker, der wie Mark Twains Romanheld Huckleberry Finn gerade deshalb 
laufend in informatives Neuland vorstößt, weil er vorurteilsfrei, absichtslos und ergebnisoffen ins Unbekannte hineinspaziert und die mediale >Landschaft einfach auf sich wirken lässt (vgl. Manovich 2002: 268ff.).

Der Detektiv dagegen müsse, wie Wirth abermals mit Eco feststellt, immer Vorurteile an den Text herantragen, um ihn ergründen zu können. Diese seien nicht notwendigerweise in Stein gemeißelt und könnten im Laufe der Lektüre durchaus eine Revision erforderlich machen und erleben, sie seien aber eine zwingende Voraussetzung allen detektivischen (und auch wissenschaftlichen) Denkens. Er verwendet hier einen Begriff, den Eco den Collected Papers des amerikanischen Philosophen Charles Sanders Peirce entleiht: jenen der Abduktion (vgl. Wirth 1997: 328, vgl. Eco 2011: 205ff.). Abduktion schießt in der Produktion von Erkenntnis quer zu Induktion und Deduktion: Während Induktion begründete und wahrscheinliche Schlussfolgerungen aus Beobachtungen zieht und Deduktion zwingende Aussagen aus gegebenen Prämissen extrapoliert, ${ }^{12}$ beschreibt Abduktion das Formulieren der Annahme, dass es überhaupt Zusammenhänge zwischen Einzelbeobachtungen und damit etwas zu erkennen gibt. Peirce verwendet aus diesem Grunde in seinen früheren Schriften auch den Begriff der Retroduktion für dasselbe Stadium der Produktion von Erkenntnis: Gemeint ist die Entwicklung der Annahme, das separate Phänomene sich auf gemeinsame Ursachen zurückführen lassen. Die Methode dieser Annahmenentwicklung ist dabei eine der Plausibilisierung aus der kursorischen Beobachtung von Umständen heraus. Peirce schreibt:

The inquiry begins with pondering these phenomena in all their aspects, in the search of some point of view whence the wonder shall be resolved. At length a conjecture arises that furnishes a possible Explanation, by which I mean a syllogism exhibiting the surprising fact as necessarily consequent upon the circumstances of its occurrence together with the truth of the credible conjecture, as premisses. On account of this Explanation, the inquirer is led to regard his conjecture, or hypothesis, with favor. As I phrase it, he provisionally holds it to be »Plausible«; this acceptance ranges in different cases - and reasonably so - from a mere expression of it in the interrogative mood as a question meriting attention and reply, up through all appraisals of Plausibility, to an uncontrollable inclination to believe. [...] the final estimation of its Plausibility, I reckon as composing the first stage of inquiry. Its characteristic formula of reasoning I term Retroduction. [...] In short, it is a form of Argument rather than of Argumentation. Retroduction does not afford security. The hypothesis must be tested. (Peirce 1966: 367f.)

Eco beschreibt die Abduktion am Beispiel eines Säckchens voller weißer Bohnen. Habe ich ein Säckchen vor mir und weiß, dass es weiße Bohnen enthält, so kann ich Voraussagen, dass bei einem blinden Griff in den Beutel alle Bohnen in meiner Hand

12 In Kapitel 3.2.3 werden diese beiden Begriffe im Zusammenhang mit Gilbert Simondons Begriff der Transduktion noch einmal genauer diskutiert. 
weiß sein werden. Dies wäre deduktives Denken. Habe ich ein Säckchen vor mir, dessen Inhalt ich nicht kenne, so kann ich immer wieder hineingreifen - die erste Handvoll wird beweisen, dass es weiße Bohnen enthält, und jede weitere Hand mich in der Überzeugung bestärken, dass es nur diese und nichts anderes (z.B. schwarze Bohnen) enthält. Dies wäre ein induktives Vorgehen. Eco hält den Leser nun an, sich vorzustellen, er fände auf einem Tisch ein geschlossenes Säckchen unbekannten Inhalts und daneben ein Häufchen weißer Bohnen. Das Vorhandensein der Bohnen in räumlicher Nähe des Säckchens gilt es, sinnhaft zu machen - und zwar mittels einer Konjektur. Diese ist bei Eco das »hypothetische Gesetz« (Eco 2011: 207), dass erstens das Säckchen Bohnen enthalte und dass zweitens diese Bohnen weiß seien. Wenn nun ein Ausleeren des Säckchens zu einem Vorhandensein von Bohnen auf dem Tisch führt, dann ist damit die Annahme plausibel gemacht, dass auch die ursprünglich lose vorgefundenen Bohnen aus dem Säckchen stammen. Dies ist Abduktion (vgl. ebd.).

Im Hinblick auf das Lesen von Texten bzw. den Leser als detektivische Figur meint Abduktion speziell die Bildung der Annahme, dass sinnhaftes Lesen und Verstehen überhaupt möglich sei. Wer eine Botschaft zu entschlüsseln sucht, der setzt voraus, dass eine solche überhaupt existiert und wird meistens auch eine bestimmte, aus Erfahrung resultierende Vorstellung davon haben, was sie uns wahrscheinlich sagen will. Abduktion ist also auch hier eine Form intelligenten Ratens und bedeutet in Bezug auf Hypertexte speziell, zunächst einmal eine hypothetische Ordnung bzw. die Annahme auf sie zu projizieren, dass sie einer bestimmten sinnbildenden Struktur unterliegen müssen. Auf der Basis dieser angenommenen inneren Logik lassen sich dann erst jene bewussten Navigationsentscheidungen treffen, die das Wesen detektivischer Hypertextrezeption ausmachen (vgl. Wirth 1997: 328f.).

Beide Metaphern, Detektiv und Dandy, stellen bestimmte Formen von >Navigation und damit abermals die topologische Räumlichkeit des Hypertextes in den Mittelpunkt: Detektive suchen in der physikalischen Welt nach im Raum verteilten Sinnbausteinen, aus denen sich der Narrativ eines Tathergangs konstruieren lässt - ja womöglich ließen sich Tatorte auch als hypertextuelle Systeme von Spuren beschreiben, in deren Arrangement all jene Abläufe latent codiert sind, von denen sie hinterlassen worden sein könnten. Flaneure wandeln durch belebte Straßenzüge und entscheiden über die Richtung ihrer Bewegung aus spontanen, intuitiven und häufig durch das Strömen der sie umgebenden sozialen Welt mitbedingten Eingebungen heraus. Was die Übertragung dieser Bilder auf das Phänomen modularer und digital vernetzter Texte so attraktiv und schlüssig macht ist das sie verbindende Element des Relationalen, das zugleich die Bedeutung dieser Überlegungen für das Museum deutlich werden lässt: Hypertexte funktionieren über Beziehungen, die sich quantifizieren und somit in räumlichen Verhältnismäßigkeiten nicht nur metaphorisch visualisieren, sondern durchaus mathematisch übersetzen lassen. 
Nicht umsonst sieht Richard Saul Wurman in der Landkarte die Schlüsseltechnologie zu den Wissenkulturen der Moderne: Sie erst ermögliche es, disparate und kulturell völlig verschieden besetzte Punkte in der physischen Welt innerhalb eines geteilten Raumsystems zusammenzudenken und so innerhalb einer gemeinsamen mentalen Ordnung vergleichbar zu machen (vgl. Wurman 1989: 262f.). In diesem Sinne reiche ihre medientechnologische Implikation weit über die Darstellung spatialer Räume hinaus und schließe auch jene rein epistemischer mit ein: Auch in Verlaufs-, Balken und Tortendiagrammen sieht Wurman Formen von kartographischer Darstellung, die hier aber nicht räumliche Verhältnisse in reduziertem Maßstab abbilden, sondern gänzlich andere quantitative Beziehungen in eine räumliche Bildsprache übertragen (vgl. ebd.: 271ff.). Den didaktischen Nutzen solcher räumlicher Darstellungen sieht Wurman wiederum darin begründet, dass - und diese sich in weiten Teilen mit Rheinbergers Modell wissenschaftlicher Erkenntnis deckende Beobachtung stellt für ihn die Grundlage aller information architecture dar - Wissen immer nur in Verhältnis zu anderem Wissen überhaupt existieren, bzw. Lernen immer nur als vernetzter Prozess zwischen Gelerntem und noch zu Lernendem funktionieren kann: »You can only learn something relative to something you understand.« (Ebd.: 168, Hervorhebung D.N.)

Dabei bilden die Metaphern von Detektiv und Dandy die genaue Beschaffenheit dieser Relationalität, die im Hypertext eben die Form einer Connectedness durch Hyperlinks annimmt, deutlich akkurater ab als jene vom Navigator: Denn während der Seefahrer sich auf einer offenen, zweidimensionalen Fläche bewegt, in der grundsätzlich unendlich viele Punkte angesteuert werden können, sind Detektive an das Vorhandensein von Spuren und Flaneure an das von Straßenzügen gebunden - also Vektoren, die sich als eindimensionale Linien beschreiben lassen, die einzelne Punkte miteinander verbinden. Zugleich zeigt sich hier auch die Grenze dieser Versinnbildlichung: Denn während es zwischen den Straßen einer Stadt und den Spuren eines Verbrechens eine ganze ihrerseits selbst semantisch belegte Welt zu entdecken gibt, kennen Links und Nodes im Netz kein >Außen torschaft und Rezipientenrolle bedeutet, wollen wir später noch in den Blick nehmen - wenn es im vierten Kapitel darum geht, wie sich virtuell vernetztes Wissen ganz praktisch vermessen, kartieren und erschließbar machen lässt. Für den Moment wollen wir das in diesem Kapitel gepackte medientheoretische Bündel erst einmal zuschnüren und uns mit ihm im Gepäck wieder der Institution Museum und ihrer Virtualisierung zuwenden. 



\section{3 sVirtuelle Museens: Medienwechsel und Kontinuität}

Dabei muss uns mit Rückblick auf die beiden Einführungskapitel das Projekt einer >Virtualisierung des Musealen $>$ zunächst wie eine redundante Unternehmung erscheinen. Denn natürlich sind Museen im Sinne des hier zugrunde gelegten Virtualitätsbegriffes zutiefst virtuelle Dispositive: Das Museum lebt von der Unabschließbarkeit der Bedeutungsinhalte seiner Exponate. Ausstellungen sind keine räumlich ausformulierten Texte, sondern Netzwerke von Sinnträgern, in deren wechselseitigen Bezüglichkeiten die verschiedensten Deutungsmöglichkeiten latent vorhanden sind. Was der Hypertextleser im übertragenen Sinne tut, das leistet der Museumsbesucher im wörtlichen: Seine Navigation nimmt die Gestalt tatsächlicher, physischer Bewegung an und der semantische Raum, in welchem sie stattfindet, ist zugleich ein physikalischer. Der monumentale und immer das Ding in seiner Körperlichkeit und Materialität ins Zentrum rückende Bewahrungsauftrag des Museums verstellt allzu leicht den Blick darauf, dass Museen in ihren Vermittlungsmodalitäten prozedural angelegt sind: Erst die rezipierende Bewegung durch den musealen Raum und entlang der Objekte belegt sowohl Raum als auch Objekte mit Bedeutungen (vgl. Grossarth 2005: 47f.).

Im Jahre 2006 veröffentlichte der britische Museologe Ross Parry mit seiner Monographie Recoding the Museum nicht nur eine sehr positive Einschätzung der Möglichkeiten, welche sich für die Institution Museum aus Digitalisierungsprojekten ergeben. Vielmehr handelt es sich bei seinem Buch um die wohl erste museumswissenschaftliche Auseinandersetzung mit diesem Thema, die nicht vorrangig den Bruch problematisiert, der sich aus dem Wegfall des materiellen Objektes ergibt, sondern die eine Kontinuität der Vermittlungslogik zwischen Museum und Web in den Mittelpunkt stellt und das Museum zugleich zu einem mediengeschichtlichen Vorgänger moderner Netzwerkarchitekturen erklärt: »Simply put, before computing came along, museums had already been performing many of the functions of computers.« (Parry 2006: 81) 
Diese steile These bildet die Realität sicher nur begrenzt ab. So frappierend die Parallelen zwischen musealer und web-basierter Wissensorganisation und -kommunikation sein mögen, die Hypertexttheorie und -praxis hat dem Museum bisher keine besondere Aufmerksamkeit gezollt. Insofern stößt uns Parry hier also weniger auf eine tatsächliche Evolution der Hypertextidee aus dem Erbe des Museums, als auf einen Treppenwitz in der Theoriegeschichte des Hypertextes. So entwickelte schon Vannevar Bush seine Memex-Idee vor allem entlang einer Metakritik an der Bibliothek bzw. dem alphabetischen Katalog (vgl. Bush 1945). Hätte er seinen Blick auf das Museum gerichtet, so wäre ihm kaum entgangen, dass dieses seine Forderung nach einem navigationsoffenen »web of trails « zwischen assoziativ arrangierten Wissensbausteinen durchaus einlöst. Franz Boas' im zweiten Kapitel dieser Arbeit diskutierter Text Some Principles of Museum Administration nimmt seinerseits 1907 bereits einen bedeutenden Teil jener Probleme vorweg, die Bush fast vier Jahrzehnte später in As We May Think umtreiben sollten: Beide Texte betonen die assoziative Offenheit und Unbestimmtheit von Wissensinhalten nicht etwa als ein didaktisches Problem, sondern als einen potenziell hochgradig produktiven Anknüpfungspunkt für einen ermächtigten Rezipienten. Damit sind sowohl Boas' als auch Bushs Texte Traktate gegen die Linearität und die kategorialen Ordnungssysteme in der Wissensvermittlung.

Vielleicht ist es bereits der Begriff des `Hypertextes`, der einen Anhaltspunkt dafür liefert, warum seine Theoretiker und Praktiker dem Museum keine oder kaum Aufmerksamkeit gewidmet haben. Bush interessierte sich als Wissenschafts-Manager ganz konkret für Speicherung und Abruf schriftlich niedergelegter Forschungsergebnisse. Ted Nelson antizipierte als Erfinder des Begriffs zwar bereits die Intermedialität digitaler Hypertexte, dachte selbst jedoch noch vorrangig in Kategorien von Text- und Bildmaterial (vgl. Nelson 2003: 144). Auch das World Wide Web begann seine rasante Karriere als ein Schriftmedium, das es in weiten Teilen immer noch ist: Schnellere Internetanschlüsse haben die Übertragung von statischen Bildern, Ton und Videos einfacher gemacht, >geschrieben` werden müssen HTML-Seiten indes nach wie vor in Buchstaben und Zahlen - auch wenn Editor-Programme mit grafischer Oberfläche dem User diese Aufgabe weitgehend abnehmen können. Das Museum mag eine dem Hypertext-Prinzip ähnliche Struktur vernetzter Informationseinheiten aufweisen, aber seine überwiegend nicht-schriftliche, auf dreidimensionale Objekte ausgerichtete Funktionalität wäre gerade in der Anfangsphase der Geschichte des Hypertextes kaum in ein computergestütztes System adaptierbar gewesen. Zugleich verbindet sich mit dem Museum ein ganz eigenes Expertensystem, das sich personell nur sehr begrenzt mit jenem überschneidet, in welchem die Hypertext-Idee zur Reife gelangt ist: Museumsleute sind üblicherweise keine Computerexperten. Ihre Arbeit spielt sich, um mit Manovich zu sprechen, gänzlich auf dem culture layer ab, während ihr Ausbildungshintergrund üblicherweise - sofern sie nicht tatsächlich ein ausgewiesenes, praxisorientiertes Studium der Museumswissenschaft 
absolviert haben - in den Disziplinen der Kultur-, Geistes- und Geschichtswissenschaften verortet werden kann. So kam eine zwischen 1998 und 2008 im Auftrag des Deutschen Archäologen-Verbands durchgeführte Verbleibstudie über Museumsvolontäre zu dem Ergebnis, dass über $40 \%$ der Berufseinsteiger im Museumsbetrieb aus den Bereichen Kunst und Kunstgeschichte stammten, weitere 15,8 \% aus der Geschichtswissenschaft und abermals ca. 6,3 \% aus der Archäologie. Naturwissenschaftler waren nur in Form von Biologen (ca. 5,7 \%) und Geologen (ca. 1,5 \%) in nennenswerter Zahl vertreten, und als einzige dezidiert ausgewiesene Absolventen technischer Studiengänge schlugen die Architekten mit ungefähr 2,4 \% zu Buche (vgl. Volk 2009: 120). Computerwissenschaftler und Informatiker tauchen in der Statistik ebenso wenig auf wie Medienwissenschaftler - und das, obwohl der zehnjährige Erhebungszeitraum genau in eine Zeit fiel, in der sich der Anteil der Internetnutzer an der Bevölkerung in Deutschland von $37 \%$ auf annähernd $70 \%$ nahezu verdoppelte $^{1}$, und, wie im sechsten Kapitel dieser Studie noch dargelegt werden wird, die Ausweitung des Angebotes ins WWW zu einem zentralen Aufgabenbereich musealer Öffentlichkeitsarbeit werden sollte.

Wie Museumsleute aus ihrem akademischen Hintergrund heraus meist keine ausgewiesene Kompetenz für den Umgang mit digitalen Medientechnologien mitbringen, so sind andererseits auch kulturaffine Programmierer ein rares Gut. Die Frühphase der Computerisierung der Museumsarbeit, die Ross Parry in den 1970er und 80er Jahren verortet und die vor allem von der internen Computerisierung der Sammlungsverwaltung gekennzeichnet war, sei daher in erster Linie eine Zeit personeller Krisen und disziplinären Aneinander-Vorbeiredens gewesen: Die Entwicklung benutzerfreundlicher Interfaces für Kuratoren scheiterte immer wieder daran, dass den Softwareentwicklern die Ansprüche und Erfordernisse der Institution ebenso fremd waren wie den Museumsschaffenden die funktionalen Eigenarten und Einschränkungen von Computern. So seien sich beispielsweise viele Entscheidungsträger für Personalfragen an den Museen der 1980er Jahren gar nicht darüber im Klaren gewesen, was für eine Art von Programmierer man für welche spezifische Aufgabe benötigte (vgl. Parry: 123f.). Mit diesem Problemfeld disparater Kompetenzverteilungen verbanden sich laut Parry gerade auf der Museumsseite sehr grundsätzliche Vorbehalte gegen die Digitalisierung: Klassisch geschulte Ausstellungsmacher empfanden die Logik und den Jargon elektronischer Datenverarbeitung nicht selten als verstörend und befürchteten das Untergehen ihres traditionellen Tätigkeitsfeldes in einer »factory culture« (ebd.: 126) - war es doch letztlich digitale Fließbandarbeit, einem Fundus aus materiellen Objekten Stück für Stück eine Datenbank aus ephemeren Datensätzen gegenüberzustellen (vgl. ebd.: 126f.).

1 Vgl. http://de.statista.com/statistik/daten/studie/13070/umfrage/entwicklung-der-internet nutzung-in-deutschland-seit-2001 vom 18.04.2018. 
Während im Museum Narrative über vergangene Wirklichkeiten aus Objekten aktualisiert werden, die materiellen Dinge also die Oberfläche eines kulturellen Diskurses bilden, ist die Virtualität digitaler Medien immer eine doppelte: Das Interface aktualisiert kulturell interpretierbare Zeichensysteme aus dem abstrakten Code, und der Rezipient aktualisiert aus diesen seinerseits Bedeutungen. Kuratoren, die mit digitalen Medien arbeiten, sprechen meist nur die Sprache einer dieser Schichten - und damit übertragen sie einen Teil ihrer Souveränität in der >Ausstellungs<-Gestaltung an ein formallogisches System, das selbst zur Autorschaft unfähig ist und das Manovich als den computer layer charakterisiert hat. Wolfgang Ernst beschreibt das hiermit auftretende Qualifikationsproblem - wohlgemerkt nicht im Hinblick auf das Museum im Speziellen, sondern auf Geschichtsvermittlung im Allgemeinen - folgendermaßen:

Datenverarbeitung operiert nicht auf der Basis von Sprachen, sondern von Algorithmen und zeigt deshalb Effekte, die keine Rede zureichend beschreiben kann. Bleibt das Projekt einer »History of the Computer in its own medium«. Diese history aber wäre keine Erzählung mehr, sondern Berechnung (computing) [...] Klassische Geschichtswissenschaftler mußten noch lediglich über alphabetische Kompetenz verfügen. Mediengeschichtswissen aber bedarf der Programmierkompetenz, und einmal mehr taucht die Rätselfrage auf, in welchem Verhältnis bei Medien Programm und Narrativität stehen. (Ernst 1997: 700)

Suzanne Keene, deren Buch Digital Collections aus dem Jahre 1998 ein umfassendes Resümee über die Erfolge und Fehlschläge musealer Digitalisierungbestrebungen in den 1990er Jahren darstellt, geht vor diesem Hintergrund davon aus, dass sich im Zuge der Digitalisierung nicht nur Funktion und sozialer Ort des Museums selbst ändern würden, sondern auch die Berufsbilder der Museumsmitarbeiter. Digitale Medien, so ihre Feststellung, nehmen diesen nämlich nicht nur Arbeit ab (z.B. bei der Verwaltung und Katalogisierung von Objektbeständen), sondern generieren auch ganz neue Aufgabenfelder, die unter vordigitalen Bedingungen niemals zu ihrem Qualifikationsprofil gehört haben: Die technischen Entscheidungen, die mit der Einbindung von Computern in Arbeitsprozesse verbunden sind, dürften Keene zufolge eigentlich nur von Experten auf den entsprechenden Gebieten gefällt werden (vgl. Keene 1998: 78ff.).

Der Phänomenbereich einer >Museumsdigitalisierung (im weitesten Sinne ist indes nicht gleichbedeutend mit der konkreten Idee eines >virtuellen Museums`, deren Implikationen im Laufe dieses Kapitels noch zu erörtern sein werden und die in Diskursen über das Zusammenwirken von Museum und Computertechnologien sowohl eine Tatsächlichkeit als auch eine Utopie beschreibt: Auf individueller Ebene sind virtuelle Museen Web-Angebote, welche den Anspruch erheben, nicht nur MuseumsHomepages zu sein, sondern ein zum physischen Museumsbesuch äquivalentes, telepräsentes Erleben einer Sammlung zu ermöglichen. Auf der über solche einzelnen 
Projekte ausgreifenden Bedeutungsebene hingegen beschreibt das virtuelle Museum einen schlechthin veränderten Modus des Musealen, der uns zugleich ein neues und vieler Hinsicht möglicherweise unmittelbareres Verhältnis zur Masse der materiellen Kulturgüter in Aussicht stellt.

Diesem utopischen Moment einer großflächigen Digitalisierung von Museumsbeständen wird von Vertretern einer traditionalistischen Museumsphilosophie und Pädagogik vor allem der Wert des Authentischen entgegengehalten. Friedrich Waidachers Position darf hier als durchaus exemplarisch gelten: Waidacher hält es schlechterdings für unmöglich, eine Sammlung als solche zu digitalisieren. Weil Museumsdinge ihren Wert eben aus ihrer indexikalischen Verweisqualität auf jene Vergangenheit beziehen, die sie hervorgebracht hat, lassen sich nach seiner Ansicht ihre Bedeutungsinhalte nicht einfach auf jene Abbildungen übertragen, auf die sich ein >virtuelles Museum Waidacher 2000: 7). Was Digitalisierung in musealen Kontexten dieser Lesart zufolge also produziert, sind nicht etwa Ausweitungen musealer Erlebnisdimensionen auf die Sphäre des digitalen, sondern lediglich Festplatten voller Abbilder musealer Objekte, die aber selbst keine museale Qualität mehr aufzuweisen imstande sind.

Dieses Kapitel wird - wie die Arbeit im Ganzen - keinen Versuch unternehmen, die kommunikativen Gemeinsamkeiten von Museum und Web gegen das Materialitätsparadigma der etablierten Institution auszuspielen und damit die Frage zu beantworten, ob >virtuelle Museen denn nun Museen im eigentlichen Sinne seien. Vielmehr sollen uns im Folgenden die Dynamiken dieses Zwiespalts beschäftigen, der ja letztlich auch auf das Verhältnis von Botschaft und Medium im physischen Museum zurückverweist: Es soll vor allem die Frage behandelt werden, was eine virtuelle Musealität überhaupt sein könnte.

\subsection{ZUM BEGRIFF DES ,VIRTUELLEN MUSEUMS、}

Dabei ist der Begriff > virtuelles Museum`selbst ein relativ junger: Als er in der Fachliteratur aufzutauchen begann, diskutierten Museumskundler und Museumsmacher schon seit fast dreißig Jahren über die Implikationen des Computereinsatzes in ihrer Institution und bedienten sich dabei einer Vielzahl von Termini. So verwandte die in der Einleitung angeführte, 1968 vom Metropolitan Museum of Art ausgerichtete Tagung über Computers and Their Potential Applications in Museums vornehmlich die Bezeichnung relektronisches Museum keine abstrakten ontologischen oder didaktischen Aspekte dieser neuen Entfaltungsebene musealer Tätigkeit, sondern vielmehr ihre Technizität (vgl. Schweibenz 2001: 6). Damit wird hier begrifflich also noch kein Graben zwischen digital vermittelten 
und physisch präsenten Erscheinungsformen des Museums gezogen, weil die Technik ja selbst notwendigerweise Material ist: Klassisches und elektronisches Museum finden in derselben physikalischen Wirklichkeit statt. In der Fachliteratur der darauffolgenden Jahrzehnte und insbesondere der 1980er und 1990er Jahre lässt sich hingegen eine Tendenz zu Adjektiven beobachten, welche diese beiden Formen von Musealität einerseits kategorial voneinander trennen, zugleich aber auch ein bestimmtes Beziehungsgefüge zwischen ihnen behaupten.

Die Bezeichnung digital museum, die sich exemplarisch z.B. bei den kanadischen Museologen Gorge MacDonald und Stephen Alsford findet (vgl. MacDonald u. Alsford: 1997), stellt ebenfalls einen technischen Aspekt in den Mittelpunkt - jedoch einen, der für den Betrachter des Mediums meist unsichtbar (weil hinter Interfaces verborgen) bleibt. Während im >elektronischen Museum` das Vorhandensein eines technischen Apparates im Prozess musealen Erlebens schlechthin als Unterscheidungsmerkmal zum >normalen` Museumsbesuch gekennzeichnet ist, insinuiert das >digitale Museum < eine kategorische Abgrenzung von einem implizierten >analogen<, die eben nicht entlang der Technik per se verläuft, sondern vielmehr entlang einer bestimmten Form von technischer Funktionalität. Begriffsgeschichtlich leitet sich das Adjektiv >digital vom lateinischen digitus (Finger, Zehe) ab, bzw. dem im Mittelalter daraus abgeleiteten Konzept der sog. >Fingerzahlen` 1-9: Digital ist, was in diskreten Werten ohne fließende Übergänge funktioniert, während das >Analoge< (von lat. analogia: ähnlich, übereinstimmend) in einem Kontinuum existiert. Digitalität kann in Ziffern ausgedrückt werden, während analoge Gefüge über physikalische Größen und Verhältnismäßigkeiten beschrieben werden müssen (vgl. Dotzler 2005: 9f.). Die auf Claude Shannon zurückgehende Trennung zwischen Analogität und Digitalität (vgl. Shannon 1948) antizipiert damit in technisch-funktionaler Form bereits die ontologische Verwerfung zwischen den >Kosmogonien` von culture und computer layer, die Lev Manovich ein halbes Jahrhundert später feststellen sollte - und der Begriff des digitalen Museums verortet seinen Gegenstand zwar noch nicht im Gegenüber der Realität, wohl aber in Modalitäten und Voraussetzungen kultureller Entfaltung, die kategorisch andere sein müssen als jene der analogen Institution.

Der 1997 von Katherine Jones-Garmil herausgegebene Sammelband The Wired Museum setzt wiederum einen ganz anderen Akzent und rückt, indem von >verkabelten` Museen gesprochen wird, einerseits das World Wide Web und das Phänomen Vernetzung ins Rampenlicht, betont andererseits aber auch die Bedeutung des Museums in seiner etablierten physischen Form: Das Museum löst sich nicht auf, wird nicht irreal und produziert auch keine digitalen Ableger, die ein Eigenleben zu führen imstande wären. Vielmehr wird das bestehende Museum an eine neue Kommunikationsstruktur angeschlossen, in der es ein souveräner Akteur bleibt.

Ausgerechnet Ross Parry, der den Netzwerkcharakter des Museums als wohl erster und bislang einziger publizierter Museologe erkannt hat, wählt mit der Bezeichnung »media museum« (Parry 2006: 136) einen im Grunde nichtssagenden Begriff: 
Mediale Anordnungen sind Museen schließlich unweigerlich. Zwar macht Parry deutlich, dass er hiermit eine völlig auf digitale Vermittlung beschränkte und in Form von Computerdaten über ein Netzwerk distribuierte Erscheinungsform von Museum meint (vgl. ebd.), aber das Wort media allein sagt über Art und Richtung der Vermittlung noch nichts aus. Ohne Parrys mitgelieferte Spezifizierung zeigt es lediglich an, dass offenbar eine Medialität zum Einsatz kommen soll, die über jene der Museumsdinge und ihrer üblichen Begleitmedien wie Erklärungstafeln und Ausstellungskataloge hinausgeht. Es wird weder deutlich, ob dieser zusätzliche Medieneinsatz inoder außerhalb des Museumsgebäudes stattfinden soll, noch in welcher Beziehung er sich zur eigentlichen Ausstellung befindet.

Bis weit in die 1990er Jahre hinein lässt sich eine große Beliebigkeit im Sprachgebrauch der museologischen Fachliteratur feststellen, wenn es um die Verfügbarmachung von Museumsinhalten im Netz geht, und nicht selten findet man auch ganz pragmatische Lösungen, wenn z.B. einfach vom `Online $<-$, , Netz<-, >Web $<-$ oder >Internet<-Museum gesprochen wird. Glen Hoptman legte 1995 eine erste systematische Ausarbeitung zum Begriff des virtual museum vor, den er nach eigener Darstellung als Medienberater für Museen schon seit 1983 verwandte (vgl. Hoptman 1995: 141). Für Hoptman ist das virtuelle Museum, wie ja zuvor bereits ausgeführt wurde, als Dispositiv eng verbunden mit seinem Connectedness-Konzept:

Basic to the Virtual Museum is the term connectedness. Connectedness enriches information sources and publications as educational learning resources. Connectedness is a basic manner of referring to the interrelated or interdisciplinary as well as the integrated media nature of information. (Ebd.)

Damit legt er zugleich einen sehr umfassenden Virtualitätsbegriff zugrunde, der sowohl die klassische ontologisch-philosophische Bedeutungsebene einbezieht (Virtualität als ein Implizites und Latentes, das der Aktualisierung bedarf, sich also aus der hypertextuellen Vernetzung ergibt) als auch die moderne technische (Virtualität als die Fähigkeit digitaler Medien, simulatorisch zu etwas zu werden, was sie im engeren Sinne nicht sind - diese resultiert hier aus der Intermedialität des Computers). Das Wort >virtuell impliziert aus seiner alltagssprachlichen Verwendung heraus das Vorhandensein des Computers, setzt ihn aber nicht zwingend voraus. Zugleich sucht Hoptman mit einer Virtualität, die von digitaler Connectedness getragen wird, den Anschluss an Vannevar Bushs und Ted Nelsons Vorstellung vom Mehrwert des Assoziativen (vgl. ebd.: 155): Viele museale Online-Angebote sind nach seinem Dafürhalten ausdrücklich keine virtuellen Museen, weil sie die Vorteile und spezifischen Eigenarten ihres Mediums verschleuderten und in ihrem organisatorischen Aufbau zu sehr über redaktionelle Relevanzkriterien gesiebt seien. So sei es (und es sei hier daran erinnert, dass der Text aus dem Jahre 1995 stammt) die gängige Methode, um 
Sammlungen und Ausstellungen online abrufbar zu machen, die Exponate kategorisch zu unterscheiden - z.B. in Skulpturen, Gemälde, ethnografische Objekte, usw. - und dann über entsprechende subject headers zum Abruf bereitzustellen, die letztlich dem Inhaltsverzeichnis eines Buches gleichen (vgl. ebd.: 142). Hier wird natürlich im Grunde, ohne dass es dezidiert ausgewiesen würde, jener Gedankengang nachvollzogen, der Bush überhaupt erst zum Nachdenken über assoziative Vernetzung von Informationseinheiten veranlasste: Auch Hoptman beruft sich auf neurowissenschaftliche Modelle, welche den Umgang des menschlichen Gehirns mit Wissensinhalten als einen assoziativen und relationalen beschreiben (vgl. ebd.: 144). Seine Vision für das virtuelle Museum entspricht wiederum dem, was Franz Boas zum didaktischen Ziel des physischen erklärt: Nämlich Wissen multiperspektivisch zugänglich zu machen und Vieldeutigkeiten bewusst als Stärke auszuspielen. Während Boas allerdings noch die Notwendigkeit eines Kompromisses zwischen assoziativer Offenheit und kuratorischer Vermittlungsabsicht betonte, um die Ausstellung nicht beliebig werden zu lassen, sieht Hoptman hierzu im Kontext der Digitalisierung keine Veranlassung mehr: Im virtuellen Museum soll es seiner Ansicht nach potenziell möglich sein, jeden nur möglichen Blickwinkel auf die Objekte zuzulassen, ohne dass der Besucher jemals die Orientierung verliert (vgl. ebd.: 146f.).

Dass die hypertextuelle und intermediale Funktionalität, in der Hoptman die große epistemische Chance des virtuellen Museums erkennt, auch im physischen Museum schon vorhanden ist, erwähnt Hoptman nicht. Ob es ihm entgangen ist oder ob er diese Beobachtung im Rahmen seiner Ausführungen schlicht nicht für relevant befunden hat, können wir nicht wissen. Auch Hoptman diskutiert damit den digitalen Medienwandel im Museum in erster Linie als einen Bruch mit der Materialität des physischen Museums, nicht als eine kontinuierliche Fortsetzung seiner Kommunikationsstrukturen auf einer veränderten medialen Grundlage.

Nichtsdestoweniger brachte es Hoptmans Terminologie als erste Bezeichnung für das Phänomen von Internetangeboten, die als >Museen umshomepages auftreten, zu einem gewissen Maß an Allgemeingültigkeit. Dies dürfte eher an einer generellen Inflation im Gebrauch des Virtualitätsbegriffes gelegen haben denn an Hoptmans theoretischer Unterbauung seines Konzeptes, welche im breiteren Diskurs über das virtuelle Museum kaum mitrezipiert wurde. So nahm 1996 die Online-Ausgabe der Encyclopaedia Britannica einen von Joffrey Lewis verfassten Artikel über das virtual museum auf, in welchem dieses lediglich definiert wurde als

[...] a collection of digitally recorded images, sound files, text documents, and other data of historical, scientific, or cultural interest that are accessed through electronic media. A virtual 
museum does not house actual objects and therefore lacks the permanence and unique qualities of a museum in the institutional definition of the term. ${ }^{2}$

Hiermit sind freilich nur die absoluten Minimalanforderungen dessen benannt, was ein virtuelles Museum ausmachen könnte - legt man einzig die obigen Kriterien zugrunde, so gäbe es eigentlich keinen Grund, es nicht bei den Begriffen >elektronisch oder >digital zu belassen. Ja selbst die Bezeichnung >Museum tisch, denn wenn neben der Materialität auch noch das Element assoziativer Navigation zwischen Wissenselementen wegfällt - und die Definition der Britannica fordert diese nicht ein -, dann bliebe als letzter, dünner Faden, der das virtuelle Museum mit dem physischen verknüpft, nur mehr die genaue Natur der Inhalte, die gesammelt werden. Ein virtuelles Museum unterscheidet sich dann von einer beliebigen Datenbank nur noch darin, dass die in ihm gesammelten Dateien Abbilder von und Metadaten über Objekte sind, die sich in Museen befinden bzw. die als materielle Dinge unter den Bewahrungsauftrag des Museums fallen könnten. Es ist ferner bezeichnend, dass auch dieser Artikel nach einem kurzen definitorischen Umriss sofort zu einer Herabqualifizierung des virtuellen Museums gegenüber dem physischen übergeht: Ihm fehle eben dessen Permanenz ebenso wie seine >unique qualities $\triangleleft$, und wir können wohl mit gutem Grund annehmen, dass mit diesen Qualitäten eben die Dimensionen von Anmutung und Auratizität des authentischen, materiellen Objekts gemeint sein werden.

\subsection{MUSEEN OHNE DINGE}

Insofern sind Walter Benjamins Überlegungen zum Status des Originals und seiner Beziehung zu seinen Reproduktionen immer noch zentral für den Umgang der Museologie mit der Digitalisierung (bzw. Virtualisierung) von kulturellem Erbe (vgl. Schweibenz 2001: 8f.). Dabei kann sie Benjamins Theoriegebäude allerdings nicht in allen Details anerkennen: Täte sie dies, so wäre das Museum als kommemorative Einrichtung schon mit dem Aufkommen analoger technischer Reproduktionsverfahren obsolet geworden. Vielmehr muss die Museumswissenschaft Benjamins Thesen umformulieren, um an sie anknüpfen zu können: Statt von einer Zerschlagung der Aura und damit im weiteren Sinne auch jener Kategorie des >Originals`auszugehen, um die sich das Museum formiert hat, wird das Museum als jene Einrichtung begriffen, welche eben die Zerschlagung der Aura verhindert und das Original unmissverständlich als solches ausweist:

2 Hier zitiert nach Schweibenz 2001: 7. Der Absatz findet sich immer noch unverändert im zwischenzeitlich aktualisierten Artikel unter http://www.britannica.com/EBchecked/ topic/630177/virtual-museum vom 18.04.2018. 
Virtualisierung aber bedeutet Verschiebung aus dem Sein in den Schein, und gerade in einer Zeit, in der eine einst unvorstellbare Flut von visueller und akustischer Information über die Menschheit hereinbricht, ist es umso wichtiger, darauf zu achten, daß »Visionen nicht durch Televisionen« ersetzt werden. (Waidacher 2000: 7)

Was hier bei Waidacher anklingt wäre also die Position, dass dem Museum gerade in Zeiten von Digitalisierung und Virtualisierung eine besondere Rolle als Anwalt und Beschützer des authentischen Originalobjektes zukomme. Damit ist zugleich impliziert, dass die Aura des musealen Objektes immer aus einer doppelten Situiertheit hervorgeht - nämlich einerseits aus jener in der historischen Welt, die es erst musealisierbar macht, andererseits aus jener in der musealen Ausstellung, welche ihre Exponate als Sinnträger historischer Zeugenschaft kennzeichnet. Howard Besser sieht aus diesem Grunde das auratische Erlebnis nicht nur als eine Reaktion des Rezipienten auf die Konfrontation mit dem Museumsding, sondern auch als eine auf die soziale Situation des Museums, in der man das Objekt in einem sehr bestimmten räumlichen und epistemischen Kontext erlebt, den man zu jeder Zeit mit anderen Besuchern teilt. Demgegenüber sei der Besuch im virtuellen Museum - der ja letztlich nichts anderes sei als ein Anschauen von Abbildungen auf einem Bildschirm - ein bequemer, aber tückischer Prozess: Die einschränkungslose Verfügbarkeit digitalisierter Exponate schalte nicht nur die pädagogisch-didaktische Funktion des Kurators weitgehend aus, sondern auch jenes Moment musealer Andacht, das sich eben gerade auf das Wechselspiel von Präsenz und Unnahbarkeit der Objekte gründe (vgl. Besser 1997: 120).

Auch Stefanie Samida, die der Idee virtueller Museen durchaus positiv gegenübersteht, sieht im Begriff selbst lediglich eine Metapher: Ein virtuelles Museum sei zunächst immer nur eine endliche Anzahl von Dateien, die museale Inhalte lediglich abbilden und über eine Struktur von Links miteinander verbunden und abrufbar sind (vgl. Samida 2002: 16). Eine Aura sei anhand dieser nicht erfahrbar, was allerdings kein Nachteil gegenüber dem physischen Museum sein müsse: Vielmehr akzentuiere die digitale Reproduktion andere Aspekte des Objektes, indem sie seine epistemischen Eigenschaften über seine materielle Präsenz und damit Reflexion über Anmutung stelle. Die Kopie ermögliche vielfältigere und unbefangenere Formen der Auseinandersetzung mit dem Gegenstand als das Original, gerade weil sie nicht dieselbe Ehrfurcht einfordere (vgl. ebd.: 19). In diesem Sinne stelle das virtuelle Museum eine Auseinandersetzung mit der Frage nach dem Verhältnis von Erlebnisqualität und Vermittlungsanspruch im Museum dar und könne die physische Institution durchaus herausfordern (vgl. ebd.: 20). 


\subsubsection{Ding und Information}

Werner Schweibenz denkt in eine ähnliche Richtung und hält es angesichts der Entstehung virtueller Museen für geboten, auch über die ökonomische Verortung von Museen zu diskutieren. Seiner Ansicht nach unterstreichen museale Präsenzen im Netz eine grundsätzliche Zugehörigkeit der Museen zur Informations- und Kommunikationswirtschaft: In letzter Konsequenz seien sie eine Form von Massenmedium, womit notwendigerweise auch einherginge, dass sie mit anderen massenmedialen Angeboten in Konkurrenz stünden (vgl. Schweibenz 1998: 186f.). Diese Einschätzung findet Schweibenz bestätigt in einer These des serbischen Museumswissenschaftlers Ivo Maroevic, der zufolge die Museologie als eine Teildisziplin der Informationswissenschaft verstanden werden müsse, ob sie sich dessen nun selbst bewusst sei oder nicht (vgl. Schweibenz 2001: 1; vgl. Maroevic 1998: 88). Stefanie Samida sieht eine entscheidende psychologische Hürde für Museumsschaffende darin, sich diesen Sachverhalt tatsächlich einzugestehen: Mit der Digitalisierung verbände sich für sie allzu häufig zugleich die Idee von einer Anbiederung des Museums an die Populärkultur, einer Abkehr vom didaktischen Auftrag der Institution und eine Hinwendung zu unreflektiertem 〉Edutainment $\iota$, mit dem man langfristig die Daseinsberechtigung des Museums aushebeln müsse (vgl. Samida 2002: 5). Diese Einschätzung wird von Ann Mintz unterstrichen, der zufolge Museen und Kuratoren zwar genau auf der Grenze von materieller Kultur und Wissenswirtschaft operieren, die materielle Komponente ihnen im Arbeitsalltag jedoch sehr viel präsenter sei:

The Age of Information raises especially interesting issues for museums. On the one hand, museums are part of the information economy. By the current definition, museum professionals are $»$ knowledge workers«, engaged in the creation and transfer of information. On the other hand, it's a very special kind of information, based not on pure data but on real things. (Mintz 1998: 20)

Richtig ist sicherlich Folgendes: Ein virtuelles Museum kann nichts ausstellen, was sich im strengen ontologischen Sinne als ein 〉Ding〈, geschweige denn als ein 〉Original bezeichnen ließe. Alle Software ist nämlich zuallererst und wesentlich Kopie, bzw.: Bei digitalen Entitäten wie Programmen und Dateien gibt es keine Möglichkeit, Kopien kategorisch als solche zu erkennen, weil sich ihnen kein Original gegenüberstellen lässt. Digitale Technologie funktioniert in diskreten Werten - auf grundlegendster Ebene jenen der Bits, die als binäre Signale immer nur die Zustände 0 (〉Ausく, >Nein`) oder 1 (〉Ein〈, >Jaく) aufweisen können. Daraus folgt, dass es so etwas wie eine verlustfreie Digitalisierung eines analogen Objektes nicht geben kann (vgl. Manovich 2002: 49). Wie bereits diskutiert wurde, ist z.B. eine Bilddatei ja nichts anderes als eine Zuweisung diskreter Farbwerte zu diskreten Koordinaten auf dem 
Raster eines Computerbildschirmes. Auf der Oberfläche eines Gemäldes aber lassen sich grundsätzlich unendlich viele einzelne Punkte bestimmen - und unendlich viele Farbwerte unendlich vielen Pixeln zuzuweisen würde logischerweise auch eine unendliche Anzahl von Bits und damit eine unendlich große Datei erfordern. Ein analoges Objekt zu digitalisieren heißt also, zunächst eine sehr offensichtliche Kopie entstehen zu lassen, die von ihrer Vorlage nicht nur verschieden ist, sondern eine klare Reduktion derselben darstellt. Beim oben gewählten Beispiel der Digitalisierung eines analogen Bildes wird das Objekt auf eine endliche Anzahl von diskreten Werten reduziert, deren genaue Höhe wiederum abhängig ist vom Auflösungsvermögen der Apparatur (also des Scanners oder der Digitalkamera) und der angestrebten Dateigröße. Während der Informationsgehalt eines analogen Objektes also prinzipiell unbegrenzt ist, ist jener einer digitalen Reproduktion auf eine genau benennbare Anzahl von Bits beschränkt (vgl. ebd.).

Dies bedeutet aber zugleich auch, dass digitale Information im Gegensatz zu analoger prinzipiell perfekt reproduzierbar ist. Kein Fälscher der Welt, sei er auch noch so kunstfertig, kann eine im mathematisch-informationstheoretischen Sinne perfekte Kopie eines Gemäldes anfertigen, weil dies erfordern würde, jede der unendlich vielen Positionen, die auf einer Leinwand bestimmbar sind, mit einem genau identischen Farbwert auf eine andere zu übertragen. Auch die mechanisch-fotografischen Reproduktionsverfahren, die für Walter Benjamin noch im Mittelpunkt der Betrachtung standen, waren hierzu nicht imstande. Analoge Kopierverfahren weisen notwendigerweise immer kleine Abweichungen vom Original auf. Und diese wiederum beginnen sich zu summieren, sobald Kopien nicht mehr vom Original, sondern von früheren Kopien erstellt werden. Im Qualitätsverfall der Abbildung äußern sich die Grade oder Generationen der Reproduktion, welche die Kopie vom Original trennen. Wohlgemerkt enthält die analoge Reproduktion dabei nicht weniger Information als das Original, das ihr vorausging. Auf dem Foto lassen sich ebenso wie auf der bemalten Leinwand beliebig viele Punkte benennen. Aber sie sind informationell nicht länger identisch, die Abweichungen vom Original sind Artefakte des Reproduktionsapparates (vgl. ebd.).

Ein digitales Bild hingegen besteht aus einer endlichen Zahl von Werten, die bereits in diskreten Ziffern vorliegen. Entsprechend können diese auch unverändert kopiert bzw. beim Kopiervorgang laufend mit dem relativen >Original abgeglichen werden, sodass sich eventuell auftretende Abweichungen sofort berichtigen lassen. Im Ergebnis sind die bitperfekten Kopien dann (außer über Metadaten) weder voneinander, noch vom ihnen zugrundliegenden Ursprungs-Datensatz zu unterscheiden (vgl. ebd.). Die Kategorie des Originals ist digitalen Mediensystemen also völlig fremd. Die >Authentizität $<$ digitaler Daten kann nur auf zweierlei Arten etabliert werden: Entweder über den Abgleich mit einer als solchen ausgewiesenen >Mastercopy< (die, wie der Name schon sagt, kein Original, sondern lediglich eine Referenz- oder 
Musterkopie darstellt), oder über eine aus den Daten selbst ausgelagerte Herkunftsdokumentation (vgl. Lynch 2000: online).

Die Frage nach digital-virtuellen >Dingen $`$ ist wiederum mindestens ebenso problematisch wie die nach digitaler Authentizität und Originalität. Im physischen $\mathrm{Mu}-$ seum sind die Ausstellungsgegenstände ja immer zwingend aktuell: Während der Raum zwischen ihnen das Entfaltungsmedium des Virtuellen darstellt, in dem der Besucher die Ausstellung wahrnimmt, navigiert und potenzielle Deutungen aktualisiert, stellen die Dinge in ihrer Materialität die Leuchttürme und Landmarken des unzweifelhaft >Wirklichen $<$ dar. Ihr Sinn ist verhandelbar, aber nicht ihr physisches Vorhandensein. Ein Museumsding kann unzählige mögliche Bedeutungen in sich vereinen, aber sein Platz im Raum ist unteilbar und kann nicht zur gleichen Zeit von einem anderen Objekt belegt werden. Es schafft also durch seine Präsenz im Raum Sinnpotentiale, während es zugleich die Anwesenheit anderer Nouophoren am selben Ort ausschließt. Digital simulierte Dinge hingegen können durchaus denselben 〉Ort belegen, weil ihr >Raum sich zwei semantisch identische virtuelle Objekte auch an derselben Position des Sinngefüges. Wer zwei gleiche Dateien als distinkte Entitäten betrachten möchte, der wird nicht umhinkommen, sie künstlich verschieden zu machen, indem er z.B. eine von ihnen mit einem global identifier versieht (vgl. Wexelblat 1991: 262f.)

\subsubsection{Stetigkeit vs. Prozeduralität}

Erschwert wird diese Problematik abermals dadurch, dass es in digital-virtuellen Umgebungen keine persistenten Dinge gibt, wie wir sie aus der physikalischen Welt kennen:

There are no objects in cyberspace, only collections of attributes given names by travellers, and thus assembled for temporary use, only to be automatically dismantled again when their usefulness is over, unless they are used again within a short time-span. Thus useful or valued objects remain, while others simply decay. These collections of attributes are assembled around nameless nodes in information spaces. (Novak 1991: 235)

Die Objekte, welche in und von digitalen Medien dargestellt werden, sind also ihrer technologischen Unterlage entsprechend keine abgeschlossenen Produkte, sondern dynamische Prozesse, die erst in ihrer Rezeption aus >Attributen werden. Insofern erleben wir hier gewissermaßen eine Umkehr des Experimentalsystems nach Rheinberger: Während dort ein gegebenes Objekt nach und nach seine Eigenschaften preisgibt, sind hier die Eigenschaften das Gegebene, und in der Betrachtung setzt der Nutzer sie zu etwas zusammen, das als ein singuläres funktionales 
Ganzes begriffen werden kann. Solche positiven Einheiten simulierter Erfahrungswirklichkeit nennt Novak »attribute objects« (ebd.: 236). Das virtuelle Element liegt bei ihnen gerade darin, dass sie nichts >Eigentliches` an sich haben. Sie sind keine sperrigen, vorgefundenen Entitäten, die man verhandelbar zu machen versucht, indem man sie beschreibt, sie sind vielmehr ganz das Produkt der sie beschreibenden Attribute (vgl. ebd.). Ein einfaches und einprägsames Beispiel für diesen vielleicht etwas abstrakt erscheinenden Sachverhalt findet sich in Friedrich Kittlers Ausführungen zur dreidimensionalen Computergrafik. Dreidimensionale Gegenstände, wie sie uns z.B. in Computerspielen begegnen, bestehen grundsätzlich immer nur aus Oberflächen in Form von Vektoren, die eine sichtbare Peripherie beschreiben, welche dann von einer Renderer-Software mit zweidimensionalen Texturen überzogen werden kann (vgl. Kittler 2002: 184). Jedes dreidimensionale, von einem Computer auf einen Bildschirm gebrachte Objekt besteht also aus einem >Drahtgerüst $<$ eindimensionaler Linien und einem >Bezug « in Form einer zweidimensionalen Bilddatei. Die geometrische Beschreibung geht dem Ding damit nicht nur voraus - dies ließe sich durchaus auch bei virtuellen Erscheinungen der physikalischen Welt beobachten, so z.B. bei der bereits erwähnten Architekturskizze -, sie ist vielmehr im Wesentlichen das Ding, das ansonsten selbst im höchsten ihm möglichen Zustand der Physikalität, dem Erscheinen als Bild auf dem Monitor nämlich, flüchtig bleibt.

Der brasilianisch-amerikanische Multimediakünstler Eduardo Kac sieht daher bei digital mediierten Kunstobjekten eine kategorische Verschiedenheit zwischen einerseits solchen, die lediglich Digitalisate eines zuvor existierenden Dinges aus der analogen Welt darstellen, und andererseits jenen, die von Grund auf am Computer bzw. in grafischen Interfaces entstehen. Diese Verschiedenheit ist für Kac keine vorrangig ontologische, sondern vielmehr eine, die sich in diskrepanten Rezeptionssituationen äußert. Das analoge Kunstwerk werde - außer in Projekten, die Performance-Elemente mit einschließen - im Zustand seiner Entstehung bzw. seiner Unfertigkeit nur vom Autor selbst erlebt. Der Betrachter, der dem Objekt dann in Museum oder Galerie begegnet, wird es nur in abgeschlossener Form kennenlernen, also niemals die weiße Leinwand, den unbehauenen Marmor zu sehen bekommen. Digitale Erscheinungen hingegen entstehen in ihrer Aktualisierung über das Interface erst vor den Augen des Rezipienten - und vergehen zugleich wieder, wenn dieser Aktualisierungsprozess beendet wird (vgl. Kac 1997: 300). Damit fehlt digitalen >Dingen die entscheidende Charakteristik physikalisch-analoger, welche das Museum als Erinnerungsdispositiv erst entstehen lassen konnte: jene nämlich, den Moment ihres Zustandekommens zu überdauern.

Hannah Arendt sieht in ihrer Vita Activa in der Dauerhaftigkeit von materiellen Dingen den Schlüssel zur Verankerung kultureller Formen in der menschlichen Lebenswelt und verbindet damit zugleich eine Kritik an Karl Marx' Begriff der Produktivität. Marx definiert die produktive Tätigkeit grundsätzlich nur als jenen Teil der 
Arbeit, den ein Mensch über die bloße Erfüllung seiner Grundbedürfnisse hinaus leistet, wobei Beschaffenheit und Ergebnis dieser Arbeit unerheblich sind: Nach Marx ist das Backen eines Brotes, das wenige Tage nach seiner Herstellung entweder gegessen oder ungenießbar geworden sein wird, nicht fundamental verschieden von der Herstellung eines Möbelstücks, das Generationen zu überdauern imstande ist (vgl. Arendt 2013: 111f.). Arendt sieht darin ein Versäumnis, das bloße »Arbeiten« vom »Herstellen « zu unterscheiden - die Arbeitstheorie des Marxismus koppelt den Arbeitenden von der kulturellen Welt ab, in der er arbeitet und ermittelt den Wert seiner Tätigkeiten nach reinen Subjektvariablen wie z.B. der in die Arbeit investierten Lebenszeit. Wenn Menschen aber über ihre eigene Arbeit oder die anderer sprechen, so tun sie dies meist in Verbindung mit den Effekten und den Unterschieden, welche diese Arbeit in ihre Lebenswelt einbringt: Marx' Vorstellung von Arbeit und Produktivität wird also, so Arendt, nicht der Tatsache gerecht, dass in der menschlichen Erfahrung verschiedene Arten von Arbeit und ihre Ergebnisse auch grundverschiedene »Wesensarten« aufweisen (vgl. ebd.: 112). Für sie ist Arbeit nämlich erst dort produktiv, wo sie herstellt: Produktive Arbeit heißt, Veränderungen in der äußeren Welt zu bewirken, die den Moment ihrer Entstehung signifikant überleben - und dies wiederum geschieht nach Arendt nur dort, wo »Gebrauchsgegenstände« (vgl. ebd.: 112f.) geschaffen werden. Gebrauchsgüter unterscheiden sich nach Arendt von Verbrauchs- oder Konsumgütern darin, dass sie von unserem Umgang mit ihnen nicht oder nur sehr langsam verzehrt werden und uns somit »vertraut« werden können:

Aus ihnen erwächst uns die Vertrautheit der Welt, ihrer Sitten und Gebräuche, die den Umgang von Mensch und Ding wie den zwischen Menschen regeln. Was die Verbrauchsgüter für das Leben des Menschen bedeuten, bedeuten die Gebrauchsgegenstände für seine Welt. (Ebd.: 112)

Das Herstellen ist also für Arendt die einzig produktive und langfristig kulturstiftende Äußerung seines Daseins, zu welcher der Mensch imstande ist. Freilich äußert der Mensch sein Dasein auch, wenn er »denkt«, »spricht« oder im weitesten Sinne des Wortes »handelt« - aber diese Äußerungen sind nicht produktiv, solange sie kein Ergebnis hervorbringen, das in der Welt bestand hat: Menschliche Kultur als Phänomenbereich ist erst das Produkt von Verdinglichungen und Ausmaterialisierungen dessen, was sonst Rede, Gedanke, Geste oder singuläre Handlung bleiben müsste (vgl. ebd.: 114). Wer also ein produktiver Denker sein will, der muss seine Gedanken materiell in die Welt projizieren, indem er sie z.B. niederschreibt:

Die Faktizität des gesamten Bereichs menschlicher Angelegenheiten hängt davon ab, einmal daß Menschen zugegen sind, die gesehen und gehört haben und darum erinnert werden, und zum anderen davon, daß eine Verwandlung in die Handgreiflichkeit eines Dinghaften gelingt. Ohne Erinnerung und die Verdinglichung, die aus der Erinnerung selbst entspringt, weil die 
Erinnerung der Verdinglichung für ihr eigenes Erinnern bedarf [...], würde das lebendig Gehandelte, das gesprochene Wort, der gedachte Gedanke spurlos verschwinden, sobald der Akt des Handeln, Sprechens oder Denkens an sein Ende gekommen ist; es würde sein, als hätte es sie nie gegeben. Die verwandelnde Vergegenständlichung ist der Preis, den das Lebendige zahlt, um nur überhaupt in der Welt bleiben zu dürfen; und der Preis ist sehr hoch, da immer ein »toter Buchstabe« an die Stelle dessen tritt, was einen flüchtigen Augenblick lang ein »lebendiger Geist« war. (Ebd.: 113f.)

Die Medialität ist demnach die Tochter der Materialität und das Medium immer eine Form von Ding - genauso, wie ja auch alle von Menschen geschaffenen Dinge irgendwo immer Medien sind, die eine kulturelle Bedeutung in sich tragen, auch wenn diese Funktionalität nicht immer ihre wichtigste ist. Dinge, die vorrangig medialen Charakter haben (und damit eben auch Kunstwerke und andere Museumsdinge), zählen im arendtschen Duktus dementsprechend zu den Gebrauchsgütern. Natürlich sind auch diese Objekte zeitlichen Veränderungen und dem Verfall unterworfen - aber das Schicksal des Verzehrtwerdens ist den Gebrauchsgegenständen Tisch, Buch oder Gemälde nicht auf dieselbe Art eingeschrieben wie den Verbrauchsgegenständen Brot, Wein oder Toilettenpapier. Die Dauerhaftigkeit von Gebrauchsgütern muss keine ewigwährende sein, geht aber meist doch deutlich über die individuelle menschliche Lebenszeit hinaus. In dieser Fähigkeit, uns zu überleben, erhalten diese Dinge eine gewisse »Unabhängigkeit« (ebd.: 161) von den Menschen: Sie existieren zwar, weil wir sie zu irgendeinem Zeitpunkt einmal hergestellt haben, aber nach dieser Herstellung benötigen sie uns nicht mehr, um in der Welt aktualisiert zu sein. Aus diesem Grunde »stabilisieren« die Dinge nach Arendt unser Leben (ebd.: 162). Während wir Subjekte uns sowohl körperlich als auch in unseren kulturell erlernten Verhaltensweisen laufend ändern, begegnen uns die Objekte mit scheinbar völlig stabilen Identitäten (vgl. ebd.). Zugleich bestimmt das materielle Produkt einer Herstellungstätigkeit schon vor seiner Fertigstellung den Prozess der produktiven Arbeit, indem es ihm einen Endpunkt setzt: Das Herstellen endet immer im fertigen Ding, das abgeschlossen bleibt, auch wenn der Arbeitsprozess zur Herstellung identischer Dinge wiederholt wird (vgl. ebd.: 169f.).

In fast allen diesen von Hannah Arendt beschriebenen Aspekten kultureller Verstetigung durch Materialisierung und Verdinglichung unterscheiden sich digital-virtuelle Objekte von materiellen. Zwar steht auch hinter jeder Bilddatei und jedem simulierten Ding im Computerspiel eine bestimmte Materialität - in Form der Datenträger, des Rechners selbst, des Bildschirms, usw. - aber das, was sich auf der Interfaceebene als ein abgeschlossenes Objekt präsentiert, ist eben in seiner Existenz auf die Dauer seiner Aktualisierung beschränkt. Der Computer kann arbeiten, ist aber aus sich heraus zum >Herstellen` unfähig - er kann Virtualitäten in Form von Programmen und Dateien speichern, seine Aktualitäten lassen sich allerdings äußerstenfalls über Peripheriegeräte wie z.B. einen Drucker verstetigen. Darüber hinaus haben die 
simulativen Aktualisierungsprozesse des Computers im Gegensatz zur materialen Herstellungstätigkeit des Menschen keinen klaren Endpunkt: Der Computer, der Programmvorgaben ausführt, interessiert sich nicht für das, was wir kulturell und lebensweltlich mit den Objekten anstellen, die in seinem Interface erscheinen, ja die ganze menschliche Vorstellung eines \Zwecks` dieser Objekte ist ihm schlechthin fremd. Am Ende der Herstellung eines Tisches steht das Abstellen anderer Dinge auf seiner Oberfläche, am Ende jener eines Brotes sein Verzehr, am Ende jener eines Gemäldes seine Zurschaustellung in einem kulturellen Raum. Am Ende der Anzeige einer Bilddatei auf einem Monitor mag für den Nutzer die Befriedigung eines bestimmten Schaubedürfnisses stehen, für den Computer aber geht das Rechnen weiter: Weil das Bild für ihn eben Code ist, unterscheidet es sich erstens qualitativ nicht fundamental von den zigtausenden anderen digitalen Entitäten, mit denen ein gewöhnlicher PC in jedem Augenblick seines Betriebes umzugehen hat, und weil reine Zahlen keine singuläre, raumzeitlich gebundene Existenz aufweisen, ist zweitens jeder zukünftige Aufruf des digitalen Bildes für ihn nicht verschieden vom gegenwärtigen. Das materielle Objekt macht sich mit Abschluss seines Herstellungsprozesses von seinem Hersteller unabhängig und verfügt über ein von ihm losgelöstes Dasein, das sich auch dann noch behauptet, wenn nach ihm noch zahlreiche ihm gleichende Dinge hergestellt werden. Das simulierte Objekt hingegen existiert erstens immer nur im Zustand seiner gerade jetzt stattfindenden Herstellung (die, weil sie keine stetige Veränderung in der Welt hervorbringt, nach Arendt ja eigentlich keine ist) und verfügt dabei zweitens über keinerlei Autonomie - weder vom technischen Apparat, der es erzeugt, noch von seinen zahlreichen Kopien, von denen es ontisch nicht verschieden ist.

\subsection{3 \Digitale Objekteı als semantische Konstrukte}

Yuk Hui setzt sich in einem jüngeren Paper genauer mit der Frage auseinander, was ein »digitales Objekt« (vgl. Hui 2013) überhaupt sein könnte, bzw. wie wir aus der Kontinuierlichkeit und Nichtabschließbarkeit des digitalen Codes und seiner Verarbeitung durch eine CPU zu einer Vorstellung von diskreten und begrenzten `Objekten< gelangen. Hui stellt dabei den >Daten`-Begriff besonders heraus, und zwar sowohl in seiner in den 1940er Jahren entstandenen Bedeutung als Bezeichnung für Information, die von Computern verarbeitet werden kann (bzw. für die Verarbeitung durch Computer formatiert ist) als auch im Sinne seines lateinischen Wortursprungs - das datum ist ja zunächst einmal nur ein 〉Gegebenes〈, ohne dass ein bestimmter Gebender angezeigt wäre (vgl. ebd.: 103).

Dieses generische Gegebensein digitaler Daten ist für Hui eines, das wir immer nur mittelbar wahrnehmen können. Als rein formale Abfolgen von binären Zuständen weisen sie für uns keine erkennbare Dingqualität auf. Entsprechend sieht auch Hui 
die Notwendigkeit einer vermittelnden Instanz zwischen Code und Kulturwelt, wenngleich er hierbei nicht ausdrücklich vom >Interface〈 spricht. Das >digitale Objekt ist bei ihm die Oberfläche eines digitalen Systems, das den ihm zugrundeliegenden Daten sinnliche und kulturelle Wahrnehmbarkeit verleiht. Digitale Objekte entstehen dementsprechend aus der eindimensional-prozeduralen Verarbeitung von Daten ebenso wie aus deren zweidimensionaler Verknüpfung untereinander (vgl. ebd.). Entlang dieser Überlegung gelangt Hui interessanterweise zu einer ähnlichen Konzeption von digitalen >Dingen` wie Novak mit seiner Vorstellung von Attributobjekten. Auch Huis digitale Objekte sind netzartig arrangierte Gefüge von Eigenschaften, welche die Grenze zwischen dem Gegenstand und seiner Beschreibung verwischen:

Was ich im Einzelnen mit Objekten meine, sind Begriff gewordene oder strukturelle Daten. So hat zum Beispiel ein Stuhl vier Beine, ist aus Holz gebaut und so fort, und diese Beschreibungsmerkmale konstituieren die Identität des Objekts. Die Beschreibung von Objekten wird üblicherweise unter dem Begriff der »Metadaten « gefasst. Werden diese Daten als vereinheitlichtes Objekt digitalisiert, wie dies beim objektorientierten Programmieren geschieht, dann wird daraus ein digitales Objekt. (Ebd.: 104)

Digitale Objekte erscheinen hier also in erster Linie als semantische Konstrukte: Sie werden artikuliert, indem für den Computer verständliche Attribute zu Gefügen arrangiert werden. Diese Verständlichkeit für das formallogische System des Computers wiederum gründet sich nach Huis Ansicht auf eine doppelte >Objektivität der Beziehungen von Daten untereinander: Erstens nämlich weisen sie keine Subjektqualitäten und damit auch keine eigene Mitteilungsabsicht auf, und zweitens sind sie »objektbezogen « (ebd.: 104) insofern, als dass ihr funktionaler Apparat eben darauf ausgerichtet ist, digitale Daten zu digitalen Objekten zu arrangieren. Als Paradebeispiel für ein solches Bezugssystem führt Hui das sog. »semantic web« (Berners-Lee, Handler u. Lassila 2001) an, das in einem vom WWW-Erfinder Tim Berners-Lee 2001 mitverfassten Artikel im Scientific American als logischer Nachfolger des ursprünglichen, auf HTML und HTTP basierenden Webs in Aussicht gestellt wurde.

Zum Zeitpunkt seiner Benennung stellte das Semantic Web also noch eine Zukunftsvision dar, die erst in Ansätzen existierte, und auch jetzt noch kann es bestenfalls als in funktionalen Teilaspekten verwirklicht gelten. Der Begriff bezeichnet die Idee, dem Web als einem von Menschen für Menschen arrangierten Hypertextsystem ein zweites Netz aufzusetzen, das für Maschinen lesbar ist. Dieses soll »SoftwareAgenten« (ebd.) ein >Verstehen « von Webseiteninhalten ermöglichen, das mit dem der menschlichen User zwar nicht identisch, jedoch funktional gekoppelt ist. Die >Agenten sollen Seiten auf eine Weise miteinander assoziieren, die auf kulturelle Zusammenhänge zurückverweist - bzw. so auf diese zurückverweist, dass die Software den Menschen bei der Navigation des Netzwerks unterstützen kann. BernersLee und seine Co-Autoren verdeutlichen diese Idee in Form eines kurzen (und Züge 
der Science Fiction tragenden) Narrativs, in dem >Pete ( und seine Schwester `Lucy einen Arztbesuch mit ihrer kranken Mutter komplett von Softwareprogrammen organisieren lassen: Petes Agent findet über das Web nicht nur das nächstgelegene und von der Versicherung seiner Mutter abgedeckte Krankenhaus - er berücksichtigt zugleich, dass Pete es vermeiden möchte, zur Stoßzeit nach Hause zurückfahren, schlägt ihm Abkürzungen und Schleichwege vor und stellt in Petes Terminkalender eigenständig Termine zurück, deren Priorität geringer ist als der Arztbesuch mit seiner Mutter. Zugleich synchronisiert sich Petes Agent mit dem Lucys, der für sie wiederum ähnliche Planungen vornimmt, und stellt damit sicher, dass sie beide zeitgleich mit ihrer Mutter am gewählten Krankenhaus eintreffen - die Wahl fällt hier letztlich auf eine Klinik, die auf der Webseite der Versicherung irrtümlich nicht als abgedeckt angegeben wurde, vom Programm aber auf anderem Wege als mögliche Option verifiziert werden konnte (vgl. ebd.).

Dabei hat die Software als rein funktionales System ohne kulturelles Bewusstsein natürlich keinerlei Konzept davon, wer Pete, Lucy oder ihre Mutter >als Menschen sind, was eine Versicherung oder ein Krankenhaus als Einrichtungen ihrer Lebenswelt leisten oder warum Pete z.B. einer Verabredung zum Tennis eine geringere Priorität beimessen würde als der Behandlung seiner Mutter. Das Semantic Web soll vielmehr über eine Art unsichtbares und gewissermaßen >umgekehrtes` Interface für Maschinen verfügen: Während HTML und HTTP es Menschen ermöglichen, auf Computern gespeicherte Information auf eine Art anzusehen, die sie in kulturelle Objekte verwandelt, soll das Semantic Web es Maschinen ermöglichen, mit den kulturellen Inhalten von Webseiten zu interagieren:

Pete and Lucy could use their agents to carry out all these tasks thanks not to the World Wide Web of today but rather the Semantic Web that it will evolve into tomorrow. Most of the Web's content today is designed for humans to read, not for computer programs to manipulate meaningfully. Computers can adeptly parse Web pages for layout and routine processing - here a header, there a link to another page - but in general, computers have no reliable way to process the semantics: [...] The Semantic Web will bring structure to the meaningful content of Web pages, creating an environment where software agents roaming from page to page can readily carry out sophisticated tasks for users. Such an agent coming to the clinic's Web page will know not just that the page has keywords such as »treatment, medicine, physical, therapy« (as might be encoded today) but also that Dr. Hartman works at this clinic on Mondays, Wednesdays and Fridays and that the script takes a date range in yyyy-mm-dd format and returns appointment times. And it will »know« all this without needing artificial intelligence on the scale of 2001's Hal or Star Wars's C-3PO. Instead these semantics were encoded into the Web page when the clinic's office manager (who never took Comp Sci 101) massaged it into shape using off-the-shelf software for writing Semantic Web pages along with resources listed on the Physical Therapy Association's site. (Ebd.) 
Das digitale Objekt >Arztbesuch « entsteht hier also nicht etwa aus den an Menschen gerichteten Daten auf der Webseite des Krankenhauses, sondern vielmehr aus MetaDaten, die diese zum Abruf durch Softwareagenten konnotieren und indexieren. Es genügt zur Erzeugung digitaler Objekte nicht, einfach Attribute zusammenzuführen - vielmehr müssen diese Attribute nochmals mit weiteren Attributen versehen werden, die ihrerseits einem digitalen System zu verstehen geben, wie mit den Daten zu verfahren ist. In Huis Beispiel vom Stuhl - und natürlich ließe sich hier auch jedes andere Objekt einfügen - bleiben wir komplett auf der Ebene des Kulturellen, auf welcher wir mit zwei Datenschichten umzugehen haben: Nämlich erstens jener des Stuhls als Datum, also einem gegebenen Ding, das uns im Raum gegenübertritt, und zweitens jener seiner Beschreibung als einer Ansammlung von Metadaten, die gewissermaßen das kulturell etablierte Konzept `Stuhl abbilden, anhand dessen wir uns zum materiellen Gegenstand verhalten können. Ein Stuhl hat vier Beine, ist aus Holz, hat eine Lehne, man sitzt darauf, usw. Im Semantic Web nach Berners-Lee et. al. entfällt das eigentliche Datum, bzw. verschmilzt es mit seinen Metadaten: Der >digitale Stuhl wäre nunmehr nur eine Ansammlung von Attributen, die zusammengenommen das kulturelle Objekt `Stuhl entstehen lassen. Die ursprünglichen Metadaten verlieren ihren Charakter als solche und werden ersetzt von einer zweiten Schicht von Metadaten, die sich nunmehr an den Computer selbst richtet und diesem mitteilt, wie genau die Einzeldaten aufeinander zu beziehen sind.

Hui bezeichnet digitale Objekte aus diesem Grunde als »indexierte Relationen « (Hui 2013: 105) innerhalb einer Ansammlung von Daten, die einerseits vom Computer funktional `verstehbar`sein müssen, um überhaupt auf Softwarebasis produziert werden zu können, andererseits aber in ihrer rein formalen Funktionalität an die kulturelle Erfahrungswelt des Users zurückgekoppelt werden müssen. Im Vollzug dieses doppelten Interfacings, bei dem Mensch und Maschine einander paradoxerweise zu verstehen imstande sind, obwohl sie eigentlich völlig aneinander vorbeikommunizieren, kommen erfahrbare Objekte Hui zufolge auf eine ganz andere Art zustande, als dies in Abwesenheit digitaler Medien der Fall wäre. Um sie ontologisch greifbar zu machen, schlägt er vor, drei Mechanismen ihrer Entstehung in den Blick zu nehmen: zum Ersten den induktiven, den er aus David Humes Überlegungen zum Induktionsproblem ableitet, zum Zweiten den deduktiven, den er vor allem aus dem Schematismus Immanuel Kants heraus beschreibt, und schließlich den Transduktiven, bei dem sich Hui vor allem an Theorien Gilbert Simondons anlehnt.

Auf der Induktionsebene beschreibt Hui die Entstehung digitaler Objekte als das Ergebnis bestimmter \Erfahrungswerte<, und zwar sowohl auf Seiten des Nutzers wie auch der Maschine. Die Induktion (die ja im Zusammenhang mit Charles Peirces Abduktionsbegriff und Umberto Ecos Bohnen-Beispiel im zweiten Kapitel dieser Studie kurz angerissen wurde) beschreibt eine empirische Erkenntnisproduktion, in welcher die Regel aus der Beobachtung abgeleitet wird. David Hume hat die Induktion 1738 in A Treatise of Human Nature als ungeeignet dazu identifiziert, finale 
Schlussfolgerungen herbeizuführen: Weil sie letztlich nur Einzelbeobachtungen hintereinander reihe, könne sie niemals den abschließenden Beweis für eine Regelhaftigkeit liefern (vgl. Hume 2011a: 86f.). Trotzdem ist natürlich ein großer Teil unserer Annahmen über die uns umgebende Welt das Ergebnis von induktiven Schlüssen in Form von Folgerungen aus wiederholten Beobachtungen. Hui verweist hier insbesondere auf Humes Ausführungen zum Billardspiel aus dem Enquiry Concerning Human Understanding von 1748, in denen dieser als tragendes Element induktiver Erkenntnis die Beobachtung von Relationen bzw. Zusammenhängen zwischen Objekten und Ereignissen ausmacht. Ein Mensch, der das erste Mal und ohne Vorkenntnis zwei Billardkugeln zusammenstoßen sieht, wird nach Hume nicht imstande sein, die Bewegung der angestoßenen Kugel auf jene der stoßenden zurückzuführen. Beobachtet er denselben Vorgang jedoch ein weiteres Mal und dann noch einige Male, so wird sich in seiner Vorstellung zunehmend die Annahme ausbilden, dass es eine Beziehung zwischen den beiden Kugeln gibt, und dass diese Beziehung der Grund für ihre jeweiligen Bewegungen ist. Die Beobachtung aber hat Hume zufolge noch keinen Kausalitätsbeweis erbracht - sie hat lediglich in der Imagination des Beobachters eine Relation entstehen lassen (vgl. Hume 1748/2011: 595f.; vgl. Hui 2013: 106f.). Einen ganz ähnlichen Mechanismus wähnt Hui bei der Entstehung digitaler Objekte am Werk: Die Relationen, aus denen sie hervorgehen, müssen zunächst einmal imaginiert werden.

In redaktionell entstehenden Hypertextanordnungen wie der Wikipedia ist dieser Prozess nicht schwer nachzuvollziehen: Die Links zwischen einzelnen Artikeln werden von menschlichen Redakteuren gesetzt und auch von Menschen in Anspruch genommen, die gemeinsame Vorstellung von Autoren und Rezipienten verknüpft also Daten zu Wissensgegenständen. Computer haben indes keine Phantasie, mit der sie digitale Objekte zusammenführen könnten. Sie verfügen jedoch bereits über Agentensysteme, die zwar noch nicht die volle Funktionalität derer des von Berner-Lee antizipierten Semantic Web aufweisen, aber durchaus bereits in der Lage sind, Beziehungen zwischen ansonsten unverbundenen Daten herzustellen. Wenn z.B. eine Webseite wie Youtube dem Nutzer auf Basis seiner bisher angeschauten Videos eine Reihe anderer empfiehlt, die ihn auch interessieren könnten, sieht Hui in der dahinterstehenden Software eine Form von Einbildungs-Ersatz, der es dem System ermöglicht, induktive Mutmaßungen anzustellen - auch wenn hier lediglich die Zugriffsmuster von Anwendern mathematisch ausgewertet werden. An die Stelle des wiederholten Kugelstoßes tritt der wiederholte Klick von Nutzern auf ähnliche Angebote (vgl. Hui 2013: 107).

Die Deduktion führt Hui in die Diskussion ein, weil mit der Induktion allein zwar die Entstehung von Zusammenhängen in Datenansammlungen erklärbar wird, nicht aber, warum diese Zusammenhangsgefüge als diskrete `Objekte ` in Erscheinung treten. Hui greift hier auf Immanuel Kants Konzept des \Schemas`zurück, das bei Kant 
selbst ein Zwischenstadium der Erkenntnis zwischen der Anschauung und der kategorialen Begriffsbildung einnimmt und den auf notwendige Identitätsbedingungen reduzierten 〉Standard darstellt, mit dem Anschauungen abgeglichen und Begriffen zugeordnet werden. Hui sieht in den Schemata eine Wendung, mit der Kant den schwammigeren Begriff der `Einbildung « umgeht und den Prozess der Welterkenntnis »maschinistischer« (ebd.: 108) beschreibt als Hume: In der Herstellung mentaler Relationen und Zusammenhänge ist der Geist nicht frei, sondern an vorgefasste Konzepte gebunden. Die Entsprechung zum Schema im Universum des Computers erkennt Hui dabei in den Ontologien der Informationswissenschaft (vgl. ebd.).

Der Begriff der Ontologie bedarf hier zweifelsohne einer grundlegenden Klärung. Obwohl Informatiker mit ihm nicht dasselbe meinen wie Philosophen - was sich schon darin äußert, dass sie ihn im Gegensatz zu Geisteswissenschaftlern auch und gerade im Plural verwenden - besteht eine Verwandtschaft zwischen den Ontologievorstellungen beider Disziplinen, und die Informatik borgt sich den Begriff ganz explizit aus der Philosophie. Thomas R. Gruber beschreibt Ontologien als formalisierte Repräsentationen von Wissen, die es für und über Computer handhabbar machen sollen. Am Anfang jeder Ontologie steht eine Konzeptualisierung als »an abstract, simplified view of the world that we wish to represent for some purpose " (Gruber 1993: 2): Ein Interessengebiet wird als eine Ansammlung von Gegenständen und Konzepten angenommen, die in bestimmten Beziehungsverhältnissen zueinander stehen (vgl. Gruber 1993: 2, vgl. auch Hui 2013: 108). Eine Ontologie ist wiederum eine »explicit specification « (Gruber 1993: 2) einer solchen Konzeptualisierung - und ihre Verbindung zum philosophischen Mutterbegriff liegt gerade darin begründet, dass im Digitalen Beschreibung und Gegenstand zusammenfallen. Während sich die klassische Ontologie nämlich mit »systematic accounts of existence« (ebd.: 3) befasst, sind digitale Systeme in Grubers Diktion rein »knowledge-based « (ebd.: 2) und das \Seiende ist damit in ihnen schlechthin das Beschriebene (vgl. ebd: 3). Eine Ontologie stellt einen Benennungsschatz für Phänomene innerhalb eines Wissensgebietes zur Verfügung und schafft damit den Rahmen für die Entstehung von Wissensobjekten - oder um abermals auf Grubers Begriffe zurückzugreifen: Eine Ontologie ist ein »declarative formalism « (ebd.), und die Objekte, die aus diesem Formalismus heraus formuliert und somit erzeugt werden können, bilden ein »universe of discourse $\ll$ (ebd.):

This set of objects, and the describable relationships among them, are reflected in the representational vocabulary with which a knowledge-based program represents knowledge. Thus, we can describe the ontology of a program by defining a set of representational terms. In such an ontology, definitions associate the names of entities in the universe of discourse (e.g., classes, relations, functions, or other objects) with human-readable text describing what the names are meant to denote, and formal axioms that constrain the interpretation and well-formed use of these terms. (Ebd.) 
Ontologien sind also Repräsentationssysteme des Realen, die, soweit es den Computer betrifft, die Realität sind und die Virtualitäten schaffen, aus denen sich Objekte des Wissens aktualisieren lassen - wie eben Kants Schemata die Schablonen bilden, mit denen Anschauungen des Realen abgeglichen, zu Begriffen ins Verhältnis gesetzt und somit Gegenstände der Erkenntnis aus den physischen Gegebenheiten der Welt abgeleitet werden. Insofern sind Ontologien natürlich auch, wie Hui feststellt, jene »Strukturen«, die digitale Objekte "produzieren, reproduzieren und modellieren« (Hui 2013: 108). Als spezifizierte und formalisierte Konzeptualisierungen von Wissensgebieten und Wissensobjekten brechen sie diese auf eine kleine Anzahl von Kerneigenschaften herunter, anhand derer sie eine "wiedererkennbare Identität« (ebd.) aufweisen. Während in der Induktion die Identitäten von Objekten das Produkt wiederholter Erfahrung sind, wird in der schematischen Deduktion die Erfahrbarkeit von Objekten durch die vom Schema eröffneten und verschlossenen Möglichkeitspotentiale schon vorab bedingt und eingeschränkt (ebd.: 109). Wir erkennen Objekte demnach nicht einfach aus einer ihnen innewohnenden Eigenqualität heraus, die in der Wiederholung der Beobachtung zunehmend offenbar wird, sondern wir tragen bestimmte mehr oder weniger systematische Vorstellungen von Objekten an sie heran, die darüber bestimmen, was wir wie als ein diskretes und distinktes >Ding erkennen können. Und weil diese Vor-Stellungen meist nicht individuell-subjektiv sind, sondern von mehreren Agenten geteilt werden (schließlich sind mehrere Menschen unabhängig voneinander imstande, einen Stuhl als solchen zu erkennen), wirft uns diese Feststellung wieder auf die Frage einer gemeinsamen Semantik zurück und zwar nicht nur zwischen einzelnen Menschen, sondern eben auch zwischen Menschen und Maschinen (vgl. ebd.: 109).

Hier führt Hui nun mit der Transduktion die dritte Größe ein, die seiner Ansicht nach die Objekterfahrung bestimmt. Hui entleiht diesen Begriff der Individuationstheorie Gilbert Simondons und fasst ihn als eine Ansammlung von Effekten des synthetischen Zusammenwirkens von Induktion und Deduktion auf (vgl. ebd.: 110):

Transduktion setzt sich aus dem Präfix trans- (über-, hinaus-) und dem Wort ducere (führen) zusammen und bedeutet also so viel wie »weiter- oder hindurchführen, übertragen«. Transduktion bezeichnet einen Prozess oder eine Handlung, die über verschiedene Bereiche hinweg zur Transformation führt. (Ebd.)

Hui hält sich mit seinem Transduktionsbegriff an die Lesart Simondons, die ihn als technisch-naturwissenschaftlichen Terminus voraussetzt und auf Übertragungsphänomene bezieht, mit ihm aber zugleich eine erkenntnistheoretische Alternative zu Induktion und Deduktion stark zu machen versucht: Während die Induktion von außen nach innen denkt (aus dem Gegenstand der Beobachtung also die Regel herleiten will) und die Deduktion die Welt von innen nach außen verstehen will (die schema- 
tische Regel bringt die Welt hervor), will Simondon mit seiner Transduktionsvorstellung ein Erkenntnismodell anbieten, das nicht nur in eine Richtung funktioniert (vgl. ebd.: 110f.; vgl. Simondon 2007: 39f.). Hui nennt die Transduktion dementsprechend einen »empirischen Prozess der Umwandlung von Formen und Strukturen« (Hui 2013: 111) und verdeutlicht diese Funktionalität anhand des auch von Simondon selbst angeführten Beispiels des Kristallwachstums: Wird eine gesättigte Lösung (d.h. eine Flüssigkeit, in der so viel eines festen Stoffes gelöst ist, wie diese aufnehmen kann, ohne dass sich ein Bodensatz bildet) erhitzt, so bilden sich in ihr Kristalle nicht blindlings überall, sondern ausgehend von sog. `Kristallisationskeimen ২ - Feststoffpartikeln, die bereits die notwendige kritische Größe aufweisen, um sich nicht wieder auflösen zu können und die Schicht um Schicht von Molekülen an sich zu binden imstande sind. Insofern geben die Keime die Form der Kristalle vor, die um sie herum entstehen können - und deren finale Form ist wiederum das Ergebnis sowohl des ihnen von ihren Keimen eingeimpften >Genotyps`, als auch das der Interaktionsvorgänge, die in Gang kommen, wenn die von einzelnen Keimen ausgehend wachsenden Kristalle ineinander zu wuchern beginnen. Simondon schreibt (und das Zitat wird auch bei Hui wiedergegeben):

Unter Transduktion verstehen wir einen physikalischen, biologischen, mentalen, sozialen Vorgang, durch den sich eine Aktivität im inneren eines Bereiches nach und nach ausbreitet. Diese Ausbreitung beruht auf einer allmählich fortschreitenden Strukturierung des betroffenen Bereichs: Jede Region der gebildeten Struktur dient der folgenden Region als Konstitutionsprinzip, so dass sich zugleich mit diesem strukturierenden Vorgang eine Modifikation immer weiter ausbreitet. Ein Kristall, der ausgehend von einem sehr kleinen Keim wächst und sich in seiner Mutterlösung in alle Richtungen ausbreitet, liefert das einfachste Bild für den transduktiven Vorgang: Jede Molekulare Schicht, die bereits gebildet ist, dient der sich gerade bildenden Schicht als strukturierende Grundlage. Das Ergebnis ist eine netzartige Struktur, die sich erweitert. Der transduktive Vorgang ist eine fortschreitende Individuation. (Simondon 2007: 40f.)

Eine solche Emergenz von Struktur aus Interaktionsprozessen erscheint angesichts der zuvor attestierten Einheit von Gegenstand und Beschreibung bei digitalen Objekten sicherlich zunächst konterintuitiv - denn mit letzterer wäre ja zunächst impliziert, dass dem Objekt schon vor seinem Erscheinen auf der Interface-Ebene eine bestimmte Identität zugeordnet sein müsse (vgl. Hui 2013: 111). Hui sieht indes gerade in dieser Eigenschaft digitaler Objekte ihr Potential begründet, in assoziativen Sinngefügen zusammenzufinden: Die identische Festgeschriebenheit des digitalen Objektes nämlich mache es erst möglich, es sowohl zwischen Menschen als auch zwischen Mensch und Maschine zu verhandeln. Sie schaffe vor allem »Bilder« und »Symbole« (ebd.: 112), die nicht nur in der Einbildung bzw. als schematischer Satz von Identitätsbedingungen im Kopf des menschlichen Betrachters existieren, sondern die auch 
in der äußeren Welt Bestand haben und damit eine materielle Qualität aufweisen (vgl. ebd.). Zwischen diesen sowohl für den Menschen als auch für den Computer eindeutig existierenden Entitäten lassen sich dann mittels Ontologien Beziehungen etablieren, die ebenfalls sowohl für den Rechner als auch für den menschlichen Rezipienten existent sind - allerdings in sehr verschiedener Form und mit sehr verschiedenem Bedeutungsinhalt. Nach Hui liefern die Identitätsmerkmale digitaler Objekte keine stranszendentalen Bedingungen, die einen Rahmen bilden, durch den sich Daten begrifflich subsumieren lassen « (ebd.) - und dementsprechend erschöpfe sich ihre Bedeutung nicht darin, Funktionselement von Ontologien (also deduktiven Systemen, die einen Gegenstand top-down aus vorgefassten Begriffen erzeugen) oder Folksonomien (induktiven Systemen, in denen die Identität bestehender Gegenstände bottom-up durch Kategorisierung oder tagging gefestigt wird) zu sein. Vielmehr müssten wir sie, wie die Kristallkeime, als »Quellen von Beziehungen « (ebd.: 113) verstehen, zwischen denen Netzwerke entstehen können. Die Entstehung digitaler Objekte ist dann weder rein induktiv-empirisch noch rein deduktiv-transzendental zu begreifen, vielmehr erscheinen Induktion und Deduktion als funktionale Komponenten, die auf derselben Stufe der Objekterkenntnis wirksam werden: namentlich jener der Herstellung vom Beziehungen von Objektattributen untereinander (vgl. ebd.). Digitale Objekte entstehen unter dem Einfluss deduktiver Vorannahmen darüber, wie sie beschaffen sein könnten und sollten, zugleich aber auch aus der induktiven Beobachtung von Nichtvergleichbarkeiten zwischen Schema und Anschauung. Auch hier ähnelt nach Hui die kognitiv-technische Entstehung digitaler Objekte jener von Kristallen in einer Nährlösung. Genau wie Kristalle immer nur aus einer Verschiedenheit zwischen ihrer Substanz (dem Feststoff) und ihrem Milieu (der Flüssigkeit) heraus entstehen können, so können auch digitale Objekte nur dort entstehen, wo neben Phänomenen, die deren jeweilige Identitätsbedingungen erfüllen, auch solche auftreten, die dem jeweiligen Objekt nicht entsprechen und somit seine >Umwelt konstituieren (die ihrerseits eben sowohl aus anderen Objekten, als auch aus $\triangleright$ Zwischenraum < bestehen kann) (vgl. ebd.). Insofern greift also auch hier wieder die raumtheoretische Feststellung Scheers, das `Ding und $>$ Raum nur in Relation zueinander denkbar sind. Objektwahrnehmung bedeutet, Unvereinbarkeiten bzw. »Inkompatibilität« (ebd.) wahrzunehmen.

Hui beschreibt die Entstehung diskreter Objekte also auf drei Ebenen: Induktiv erkennen wir ihr Vorhandensein aus der wiederholten Beobachtung von funktionalen Wechselwirkungen. Deduktiv ordnen wir diese Beobachtungen in bestimmte Ordnungsgefüge oder Schemata ein und erlegen ihnen damit eine vorab schon existierende Identität auf. Auf der transduktiven Ebene schließlich erkennen wir sowohl die Beziehungen zwischen Einzelobjekten untereinander als auch ihr Voneinander-Geschieden-Sein und ihre Verortung in einem wie auch immer gearteten Raum oder Milieu, das ihr Existieren erst möglich macht. Dabei bezieht sich Huis Objektbegriff ausdrücklich nicht auf konkrete Dinge der physischen Welt, sondern auf Gegenstände 
der menschlichen Wahrnehmung und Welterfahrung - eben solche, die uns als geschlossene, von ihrer Umgebung und allen anderen Objekten abgesonderte Entitäten erscheinen. Das Objekt ist ein Gegenüber des Subjektes, um das wir eine verhältnismäßig klare kognitive Grenze gezogen haben.

Das, was Hui ein Objekt nennt, ist weniger ein dem Menschen gegenüberstehender Gegenstand der Erkenntnis als eine bestimmte Funktionalität des menschlichen Erkenntnisapparates selbst: Objekte werden hier nicht als vorgefundene Tatsachen und Gegebenheit der äußeren Welt aufgefasst, sondern als ordnende Kategorien unserer Erfahrung, deren Konstruiertheit besonders dort augenfällig wird, wo ihnen wie im Falle digitaler Objekte - jedwede Anbindung an ein wie auch immer beschaffenes physisches Substrat abgeht, welches das bloße Objekt zum 〉Ding ‘ werden lässt und es schon a priori von allem anderen absondert. Für die Exponate des physischen Museums bedeutet dies, dass sie nicht nur in ihrer Eigenschaft als Sinnträger das Produkt einer zeitlich ausgedehnten semantischen Fügung sind, sondern dass sie auch als singuläre physische Objekte im Wahrnehmungs- und Erkenntnisapparat ihres Beschauers erst `gemacht` werden müssen.

\subsubsection{Das `Objektı als Bewusstseinsgröße}

Von dieser Warte aus verwischen nicht nur die Grenzen zwischen physischen Dingen und deren digitaler Simulation, sondern schlechthin jene zwischen Objekten im materiellen, dinghaften Sinne einer- und Objekten der Vorstellung, der Kommunikation und des Diskurses andererseits. Objekte sind nicht per Definition abgeschlossen oder vollständig, sondern werden prozedural von einem Bewusstsein erzeugt, das sich seine physische Umwelt handhabbar macht, indem es sie nicht nur in physikalische, sondern auch semantische und semiotische Funktionselemente zerlegt - welche es sich dann wiederum sinnhaft erschließen und in kontingenten Bezug zueinander setzen kann.

In seinen Texten zur Phänomenologie des inneren Zeitbewusstseins identifiziert Edmund Husserl eine Kategorie von Gegenständen der menschlichen Erfahrung, die er als »Zeitobjekte« bezeichnet. Zeitobjekte unterscheiden sich von materiellen Dingen darin, dass sie nicht in jedem Augenblick ihrer Existenz in ihrer Gänze im Raum vorhanden sind. Vielmehr können Zeitobjekte, wie der Name schon sagt, nur im Zustand ihres zeitlichen Vorüberziehens erlebt werden, also eines Erscheinens und Verschwindens aufeinander folgender Einzelelemente: Idealtypische Zeitobjekte wären z.B. ein Musikstück, eine Sprachsequenz oder ein Filmausschnitt (vgl. Husserl 1985: 125ff.). Zeitobjekte können wir erleben, weil unsere Kognition selbst sich nicht nur im Verhältnis zum physikalischen Raum, sondern eben auch und vor allem entlang der Zeitachse entfaltet. Nach Bernard Stiegler ist unser Bewusstsein »wesentlich Dauer, und somit verfließen« (Stiegler 2009: 71). 
Spitzfindiger Weise könnte man hieraus schließen, dass damit natürlich alle Objekte Zeitobjekte sind, ist doch das Vergehen der Zeit zwingende Voraussetzung aller Wahrnehmung und allen Denkens. Nichtsdestoweniger erleben wir natürlich in unserem alltäglichen Umgang mit der uns umgebenden Welt durchaus jene kategorische Verschiedenheit von flüchtigen Zeitobjekten und sperrigen Dingen. Das Bild auf dem Fernsehschirm ändert sich unter unserem Blick etwa zwei Dutzend Mal in der Sekunde, während das Sofa, von dem aus wir es betrachten, uns Tag für Tag in kontinuierlicher Gleichförmigkeit begegnet - dies ist eben jene Dauerhaftigkeit, aus der sich nach Arendt das kulturstiftende und -festigende Moment der Verdinglichung ableitet, und aus der heraus sich das Museum legitimiert. Das Zeitobjekt hingegen besteht aus vergänglichen Einzelphänomenen, denen unser Bewusstsein mit Verzögerung Zusammengehörigkeit verleiht - im Falle der Musik nimmt diese Zusammengehörigkeit z.B. die Gestalt der Harmonie an. Wir erkennen, dass die von Instrumenten und Gesang erzeugten Töne zusammen ein Objekt bilden - ein Lied, eine Symphonie, eine Sonate - welches in sich geschlossen ist und welches wir klar von allen anderen Geräuschen trennen können, die womöglich zeitgleich in unsere Wahrnehmung eindringen.

Die bildgebenden Verfahren, derer sich Computerinterfaces bedienen, erzeugen indes Sichtbarkeiten, die weder im ontischen Sinne als »Dinge« zu begreifen, noch einwandfrei unter Husserls Zeitobjektbegriff zu subsumieren sind. Dabei sind freilich die tatsächlichen Rechenvorgänge bzw. die sie tragenden technischen Abläufe Zeitobjekte par excellence - handelt es sich bei ihnen doch um einen Strom diskreter Signale, die nur als Sequenz interpretiert werden können. Zugleich aber verschleiert das Interface diesen Prozesscharakter, indem es die digitalen Objekte nicht als solche in Erscheinung treten lässt: Ein Bild steht auf dem Monitor nicht anders als auf der Leinwand in räumlicher Gänze vor seinem Beschauer, auch wenn der Text, der jeder $\mathrm{X} / \mathrm{Y}$-Koordinate auf dem zweidimensionalen Bildschirm eine X/Y/Z-Koordinate aus dem dreidimensionalen RGB-Farbkubus zuordnet (vgl. Kittler 2002: 179) zeitlich sequenziert verarbeitet werden muss. Und natürlich sind digitale Daten nicht völlig körperlos: Dass wir uns dieselbe Bilddatei immer wieder anschauen, dieselbe MP3Datei immer wieder hören, in Computerspielen dort weitermachen können, wo wir am Vorabend unseren Spielstand gespeichert haben - all das liegt natürlich darin begründet, dass digitale Speicher eine zwar unanschauliche, aber doch völlig materielle Grundlage in der physikalischen Welt haben. Der Computer ist ein prozedurales, aber auch in Zeiten von cloud computing und Tablet-Rechnern noch kein ephemeres Medium (und deshalb ist auch das Programmieren eine im Sinne Arendts >herstellender Tätigkeit). Dass Interfaces als ein positives Etwas im Raum in Erscheinung treten können, hängt nicht zuletzt ursächlich damit zusammen, dass sie auf Geräten sichtbar werden, die materiell sind und im Sinne Gernot Böhmes `ekstatisch` ihr Vorhanden- 
sein im Raum behaupten. Wie die Leinwand, auf der die Farbe eines Gemäldes aufgebracht ist, ist auch der Monitor ein positiver, materieller Träger einer Bildinformation.

\subsubsection{Materialität und Digitalität}

Die von Friedrich Kittler betonte und im zweiten Kapitel dieser Arbeit bereits angerissene Abstammung der Computeranzeige vom Radarschirm führt indes auch dazu, dass Computermonitore ihre Digitalität bzw. jene der Bildinformation immer noch nicht völlig verschleiern können. Weil digitale Bilder eben aus irreduziblen, rechtwinkligen Elementarteilchen in Form von Pixeln bestehen, deren Anzahl endlich ist und auch bei modernen Monitoren immer noch deutlich unterhalb der Wahrnehmungsschwelle des menschlichen Auges liegt, können wir die Textualität des Computerbildes bei genauem Hinsehen durchaus ausmachen, so z.B. an Treppeneffekten oder unweichen Farbübergängen (vgl. ebd.: 180). Nach Kittler ist es gerade die Materialität des Rechners, die der digitalen Bilderzeugung ästhetische Grenzen setzt. Die physikalischen Vorgänge, die in der analogen Welt unsere Wahrnehmung bedingen und ermöglichen, können allesamt mathematisch beschrieben werden und ließen sich deshalb auch in Software übersetzen. Einem »optimalen Algorithmus« (vgl. ebd.: 183), der schlicht alle mathematischen Variablen der physikalischen Welt einbezieht und somit eine völlig perfekte Bildgebung auf dem Bildschirm ermöglicht, steht demnach keine unumgängliche formale Hürde im Weg:

[Ein solcher Algorithmus] müßte einfach alle optischen und d.h. elektromagnetischen Gleichungen, die die Quantenelektrodynamik für meßbare Räume kennt, auch für virtuelle Räume durchrechnen, schlichter gesagt also die drei Bände von Richard Feynmans Lectures on Physics in Software gießen. (Ebd.: 183)

Beschränkt werden die Möglichkeiten von Computergrafik vielmehr durch die technischen Grenzen und natürlich immer auch die Bezahlbarkeit von Hardware. Der optimale Algorithmus mag grundsätzlich denkbar sein, könnte aber auf keinem Rechner der Welt ausgeführt werden - insbesondere nicht, wenn die hierbei erzeugten Computerbilder zu einem Interface gehören sollen, mit dem der Nutzer in Echtzeit interagiert (vgl. ebd.).

Computergrafik benötigt also »Idealisierungen« bzw. nicht selten auch »Vulgarisierungen« (ebd.): Was auf einem Computerbildschirm in Erscheinung tritt, existiert nicht nur immer im Zustand der Prozeduralität und Vergänglichkeit, sondern auch auf halben Wege zwischen einer ästhetischen Zielsetzung und technischer Machbarkeit. So ist z.B. der besagte R/G/B-Würfel, dessen drei Dimensionsachsen 
jeweils einer der Grundfarben rot, grün und blau zugeordnet sind, nur eine zweckmäBige und technisch vergleichsweise einfach umsetzbare Annäherung an das tatsächlich vom menschlichen Auge wahrnehmbare Lichtspektrum - Kittler spricht hier von einem der »üblichen Kompromisse zwischen Ingenieuren und Betriebswirten« (ebd., 179).

Die Tatsache, dass Computergrafik eben Prozess und nicht Produkt und in ihrer Prozesshaftigkeit wiederum von physikalischen Voraussetzungen der Computerhardware abhängig ist, führt Kittler zu der hier bisher nur touchierten Frage, welcher Domäne der menschlichen Lebenswelt Computerbilder eigentlich zugehörig sind. Novaks Vorstellung von >Attributobjekten $<$ rückt die semantische Ebene in den Vordergrund und verortet die von Computerinterfaces erzeugten Objekte damit im kulturellen Bereich der Sprache und der Kommunikation, während Huis digitale Objekte vor allem in einem vorsprachlichen Bereich der menschlichen Kognition entstehen, in welchem akute Beobachtung, bekanntes Schema und `Mustererkennung/ zusammentreten. Beide Ansätze verorten das Objekt aber beim Menschen, dem das Medium lediglich zuarbeitet. Für Kittler hingegen steht alles, was Computer auf einen Bildschirm zu bringen imstande sind, grundsätzlich außerhalb der Kulturwelt.

In seinem 1990 erschienen Aufsatz über Fiktion und Simulation führt er diesen Gedankengang am Beispiel der fraktalen Geometrie genauer aus: Die endlos verschachtelten 〉Mandelbrot-Bäumchen〈, in welchen sich dieselben komplexen geometrischen Figuren laufend wiederholen, sind laut Kittler eine Methode der Sichtbarmachung einer mathematischen Funktion, die sich im Grunde nur auf sich selbst bezieht und gar keine $>$ Welt $<$ außerhalb jenes formallogischen Systems kennt, innerhalb dessen sie formuliert und aufgelöst werden kann. Weil Computergrafik Software und daher notwendigerweise Mathematik ist, sind Computerbilder eben keine Zeugnisse einer freien und kreativen Willensanstrengung, sondern ganz im Gegenteil: Das Funktionieren von Software setzt eine zwingende Logik der Zahlen voraus, die vor allem zweierlei ist - nämlich selbstbezüglich und eigendynamisch. Damit sind die Interface-Erscheinungen von Computern weder Produkte des menschlichen Geistes noch physischer menschlicher Schaffenskraft - vielmehr haben sie den Charakter von Naturphänomenen, die grundsätzlich weder auf Absichten zurückzuführen sind noch aus sich selbst heraus in kulturellen Kategorien interpretierbar sind. Sie sind schlicht das Ergebnis unverhandelbarer mathematischer Zusammenhänge und folgerichtiger Notwendigkeiten (vgl. Kittler 1990: 202f.).

Stefanie Samida unterscheidet zur Abgrenzung des Museums von anderen Erinnerungs- und Vermittlungsdispositiven kategorisch zwischen zweierlei Formen von Kulturgütern. Auf der einen Seite stehen die »Mentefakte«, zu denen z.B. Texte und Musikstücke gehören und die vor allem von Institutionen wie dem Archiv und der Bibliothek gesammelt und gepflegt werden. Mentefakte sind, wie der Name schon sagt, das Ergebnis vornehmlich mentaler Anstrengungen und zeichnen sich dadurch aus, dass sie nicht fest an einen einzigen materiellen Träger gebunden sind, sie sind 
also eher Botschaft als Medium. »Artefakte« hingegen sind all jene materiellen Objekte, die aus >Herstellungs`-Prozessen im Sinne Hannah Arendts hervorgehen und die die Zeit nicht als immer wieder tradierter Inhalt, sondern in ihrer konkreten räumlichen und körperlichen Verfasstheit überdauern (vgl. Samida 2002: 20). Diese Unterscheidung ist natürlich implizit abermals eine zwischen finiten und permanenten materiellen Dingen einer- und Zeitobjekten andererseits, die nun aber vor allem unterschiedliche Ursprünge des Objektes in den Fokus rückt: Während Mentefakte eben dem Geist entspringen, setzen Artefakte ein kunsthandwerkliches Tätigwerden ihrer Erzeuger voraus.

Digitale Interface-Erscheinungen, wie Kittler sie konzeptualisiert, wollen aber so recht unter keine dieser Kategorien passen, weil sie eben letztlich weder aus den Händen noch aus den Hirnen menschlicher Agenten hervorgehen. Kittler verortet die Tatsächlichkeiten der Bilderzeugung am Computer in einer Seinsdimension, die er als »Hypernatur « (Kittler 2002: 180) bezeichnet, und die eben weder der relativen Willkürlichkeit kultureller Formen und Zuschreibungen unterworfen ist, noch dem entspricht, was wir umgangssprachlich als `die Natur` bezeichnen würden. Die Hypernatur nach Kittler ist vielmehr die Domäne der logischen Formalismen und der mathematischen Ausdrücke, die zwingend und unverhandelbar (und damit eben auch kulturresistent) sind, wenn sie auch nicht von sich aus sichtbar in der Natur in Erscheinung treten (vgl. ebd.).

Nun wäre es natürlich patent absurd, die Ergebnisse digitaler Bildgebung tatsächlich als Naturafakte abzuhandeln. Computer sind in kulturelle Kommunikationsprozesse eingebunden, ihre grafischen Oberflächen werden in kulturellen Kontexten genutzt und gedeutet, und obwohl Software von Computern nach mathematischen Gesetzmäßigkeiten aktualisiert werden muss, liegt ihr üblicherweise doch eine menschliche Geistesanstrengung zugrunde: Die Vor-Schrift, nach der Computer rechnen, wird ihnen von Menschen eingeimpft, die mit ihnen umgehen können.

Zugleich deutet die Endung >-fakt « eine `Gemachtheit` an, und zwar eine solche, die bereits abgeschlossen ist. Factum ist im Lateinischen die »vollendete Tat«, die ihren Weg in unseren heutigen Sprachgebrauch vor allem als »Tatsache« (vgl. Pertsch 2008: 240) gefunden hat - >-fakte< haben also ihren Herstellungsprozess definitionsgemäß bereits durchlaufen und sind in einem unverhandelbaren Endzustand angekommen. Darin stellen sie geradezu die Antithese von `Daten` dar, die ja gemäß Hui als ein noch zu erschließendes `Gegebenes` die funktionale Grundlage digitaler Informationstechnik bilden. Digitale Objekte erreichen niemals die formale Abgeschlossenheit, die das -fakt als solches auszeichnet. Vielmehr verbleiben sie stets im Zustand des Gemacht-Werdens, der laufenden, kontextabhängigen Aktualisierung und Transformation zwischen Rohdaten und Interface und damit auch zwischen Computer- und Kulturebene. Die Vermittlung zwischen Abstraktem und Konkretem, die von Benutzeroberflächen geleistet wird, ist vor allem auch eine zwischen der na- 
turgesetzartigen Logik der technischen Datenverarbeitung einerseits und der Offenheit und den Freiheitsgeraden kulturellen Ausdrucks andererseits. Die von Simanowski diagnostizierte >Übersetzbarkeit von Allem in Alles` (vgl. Simanowski 2008: 112 ) ist weniger eine Potentialität digitaler Medien, als ihr ständiger modus operandi: Sich digitalen Objekten adäquat nähern zu wollen, setzt möglicherweise gerade voraus, sie nicht in rigiden ontischen Kategorien greifen zu wollen und sie stattdessen als fluide und transformative Objekte zu begreifen, die als das in Erscheinung treten können, was Rezipient und technischer Apparat aus der Situation heraus aus ihnen machen.

\subsubsection{Verkehrsformen}

Anke te Heesen führt aus dem Kontext der Museumswissenschaft und -praxis einen sehr interessanten Begriff in das Nachdenken über Objekte ein, den sie der marxistischen Wirtschaftstheorie entleiht: jenen der Verkehrsform. In seiner ursprünglichen Bedeutung ist dieser Terminus ein Sammelbegriff für die Gepflogenheiten und Modalitäten zwischenmenschlicher Austauschprozesse: Verkehrsformen sind Arten und Formen des Sich-Gegenübertretens, die im Marx'schen Duktus selbstverständlich von ökonomischen Umständen determiniert sind - so sei die übliche Verkehrsform des Kapitalismus z.B. die des Austauschs von Tauschwerten zwischen Eigentümern (vgl. Marx u. Engels 1953: 70ff.). Nach te Heesen gingen aus derselben wirtschaftsgeschichtlichen Situation, welche diese menschliche Verkehrsform hervorbringen konnte, auch neue »Verkehrsform[en] des Objekts« (Heesen 2005: 60) hervor. Während die Verkehrsform in Bezug auf den Menschen in erster Linie die Beziehungen zwischen Einzelpersonen beschreibt, meint die Verkehrsform des Objekts hier eine spezifische Beschaffenheit der Objekte selbst. Te Heesens Einschätzung nach tritt dem Menschen seit der Industrialisierung zunehmend nicht mehr das abgeschlossene und mit klarer Identität versehene Einzelobjekt gegenüber, sondern eine ständig anschwellende Fülle von Massenprodukten, die im Einzelnen kaum mehr voneinander zu unterscheiden sind und die darüber hinaus immer schneller von neuen Objekten ersetzt werden (vgl. ebd.: 60f.).

Der Umgang mit diesen Gütern erfordert nach te Heesen neue Formen der Auseinandersetzung, die der erdrückenden Schwemme immer beliebiger werdender Objekte Spezifizierung und Handhabbarkeit gegenüberstellen. Als ein einfaches Beispiel für eine solche Transformation nennt sie den Zeitungsausschnitt. Die vollmaschinell gedruckte Tageszeitung erscheint als idealtypisches Beispiel für ein Verkehrsobjekt der industriellen Moderne: Sie wird in Massen kaum unterscheidbarer Einzelexemplare hergestellt, hat eine sehr begrenzte Aktualitätsdauer von nur einem einzigen Tag, wird dementsprechend mit sehr schneller Frequenz von >Folgemodellen` abgelöst, und sie ist nahezu überall für einen geringen Preis erhältlich, was sie 
zu einem selbstverständlichen Bestandteil moderner Lebenswirklichkeiten werden lässt.

Will man Zeitungen über ihre extrem begrenzte historische Situation hinaus anschlussfähig machen, so muss man sie in eine andere Verkehrsform überführen - und diese ist nach te Heesen eben jene des Ausschnitts (vgl. ebd.: 61). Das Zerschneiden von Zeitungen in kleine Versatzstücke wird hier nicht als eine »Potenzierung« (ebd.) des Objektes verstanden, sondern vielmehr als der Versuch, »gerade der Fülle und Geschwindigkeit der Zeitung Herr zu werden« (ebd.). Das industriell fabrizierte und individuell beliebige Zeitungsblatt erhält eine distinkte Autorität eben durch die Autorschaft der Schere: Ausschnittsammlungen erzeugen aus zuvor nur durch ihre Gleichzeitigkeit miteinander assoziierten Kurztexten neue Textgebäude mit neuen Kriterien der Zusammengehörigkeit ihrer Einzelelemente. Der Zeitungsausschnitt »aktualisiert « (ebd.) - man beachte diese Begriffswahl! - in te Heesens Interpretation damit Bedeutsamkeiten innerhalb der Zeitungsartikel, die in ihrem ursprünglichen Veröffentlichungszusammenhang nicht zum Tragen kommen konnten.

Das Zerteilen von Zeitungen und das Anlegen von Ausschnittsammlungen ist also ein durch und durch transduktiver Prozess, indem aus Kristallisationskeimen von Bedeutungen ganz wie in digitalen Hypertextsystemen und ganz wie in musealen Ausstellungen neue Objekte und neue Systeme von Objekten entstehen. Unter Rückgriff auf Michel de Certeau spricht te Heesen hier von einer »zweiten Produktion«, die sich aus dem zentralen »Alltagsritual« (ebd.: 62) des Kapitalismus, nämlich dem Konsum, ergibt. Diese zweite Produktion ist ausdrücklich nicht auf die Herstellung eines neuen oder anderen Produktes ausgerichtet, sondern auf eine Veränderung des Umgangs mit bereits bestehenden, die durch diesen neuen Umgang ihrerseits transformiert werden (vgl. ebd.). Der Zeitungsausschnitt ist die »Verdinglichung der ephemeren Zeitung und der durch einen schnellen Rhytmus geprägten Lektürepraxis« (ebd.):

Aus einem Serienprodukt entwickelte sich ein Verkehrsobjekt, das Mensch und Objekt, vergehende Lektüre und Speicherung, Abfall und Dauer verband, ohne sich auf eine Seite zu schlagen. Aus einem Warenprozess stammend und doch nicht seinen Grenzen unterliegend, steht es zwischen Reproduktion und Einmaligkeit, zwischen Ware und Kunst, Anonymität und Auktorialität, zwischen dem »schlechthin Dauernden« und dem »schlechthin Nicht-Dauernden«, zwischen Medium und Objekt. (Ebd.: 63)

Die Verkehrsform verwandelt also das Objekt nicht durch eine physische Veränderung seiner selbst, sondern indem sie dasselbe Etwas an einen anderen sozialen Ort transponiert und es damit als etwas anderes rezipierbar macht als das, was es zuvor scheinbar offensichtlich gewesen ist. Damit sind natürlich in gewisser Art alle Reproduktionen Verkehrsformen der Objekte, die sie abbilden. Beziehen wir den Begriff allerdings auf digitale Bilderzeugung, dann erscheint die Verkehrsform zugleich 
als ein überaus hilfreicher Terminus, um über die kategoriale Verschiedenheit von culture und computer layer hinweg das Zustandekommen von virtuellen, digitalen oder auch schlicht Interface-Objekten zu operationalisieren.

Die von Eduardo Kac festgestellte Verschiedenheit von originär digitalen Objekten und solchen, die Reproduktionen physischer Dinge darstellen, verweist hier zugleich auf ein paralleles Wirken zweier unterschiedlicher Verkehrsformen. Lässt man den Aspekt der Reproduktion zunächst außen vor, so sind digitale Objekte ganz grundsätzlich Verkehrsformen des digitalen Codes, zu dem wir uns als Kulturwesen eigentlich nicht verhalten können. Nicht nur, dass er wie die industriell hergestellte und marktwirtschaftlich vertriebene Zeitung mit überwältigend hoher Frequenz an uns vorbeirauscht - er ist darüber hinaus auch, im Gegensatz zur Zeitung, in den Begrifflichkeiten und Sinnstrukturen unserer Alltagswelt nicht zu deuten. Interfaces verleihen dem Code auf dem Bildschirm zumindest eine Illusion von Stetigkeit, während sie ihm zugleich eine Bildlichkeit auferlegen, zu der wir in Beziehung treten können. Stefan Münkers Feststellung, dass > Virtualität ` im Hinblick auf den Computer meist seine Fähigkeit beschreibt, simulatorisch zu etwas zu werden, das er eigentlich nicht ist, lässt sich in te Heesens Sinne also durchaus so interpretieren, dass digitale Virtualität schlechterdings das Prinzip der technischen Erzeugung von kulturellen Verkehrsformen aus abstrakten numerischen Werten ist. Beziehen wir nun digitale Objekte in die Betrachtung mit ein, die ihren Ursprung in der Digitalisierung physischer Gegenstände haben, so legt sich über die Verkehrsform des Codes die Verkehrsform eines präexistenten kulturellen Sinnträgers, deren Funktionalität jener des Codes genau gegenläufig ist. Während digitale Objekte den verfließenden Bits nämlich eine temporäre Stabilität auf dem Bildschirm verleihen, ist ihre Lebensdauer gegenüber materiellen Dingen massiv reduziert. Die Bildlichkeit von Digitalisaten verschleiert die Prozeduralität des Codes ebenso, wie sie die Permanenz des Originals unterläuft.

Der große Nutzen des Verkehrsform-Begriffes ist in diesem Zusammenhang, dass er ein Beiseitestellen der Frage nach einem ontisch-technisch `Eigentlichen $<$ digitaler Objekte ermöglicht, ohne dass man diese völlig ausblenden müsste. Tatsächlich ist es eben gerade die Uneigentlichkeit von Verkehrsformen, die ihren begrifflichen Wert ausmacht: Verkehrsformen der Objekte beschreiben ein situatives, kulturelles `Sein`, das an räumliche, zeitliche und vor allem auch diskursive Orte gebunden ist. Zugleich verweisen diese situierten Objektidentitäten immer auf ihr Substrat zurück: ohne Zeitung kein Zeitungsausschnitt, ohne historischen Überrest kein Museumsding, ohne Code kein digitales Objekt, ohne Original keine Reproduktion. Die Frage nach der Dinghaftigkeit digitaler Objekte bleibt also relevant, ist aber nicht die einzige und - so soll hier für den Augenblick postuliert werden - auch nicht die entscheidende, was die Möglichkeit virtueller Museumsdinge anbelangt. Vielmehr gilt es auch nach den Modalitäten (sofern es sie denn gibt - und mit Sicherheit wird auch die vorliegende Studie nicht jeden Vertreter einer konservativen Museologie hiervon 
überzeugen können) zu fragen, unter welchen Computerbilder eine museale Verkehrsform annehmen können.

Dieser Problemkomplex ist wiederum von der `hypernatürlichen $<$ Fundierung der Computerbilder insofern gar nicht abzukoppeln, als dass deren Präsentation (bzw.: deren Präsentierbarkeit schlechthin) den Voraussetzungen, Grenzen und Standards digitaler Technik unterworfen ist. Während das physische Museum den \Zugriffı auf seine Objekte und damit deren Rezipierbarkeit über eine bestimmte Raumsituation ermöglicht und reglementiert, bestimmen bei digitalen Objekten die Methoden des Datenabrufs über ihre Anschlussfähigkeiten und damit eben auch über die konkreten Ausprägungen ihrer Verkehrsform. Wie im physischen Museum ist auch im virtuellen das Funktionieren der Objekte als Medien nicht zu verstehen, wenn man es nicht im sie umgebenden $>$ Raum $<$ kontextualisiert.

\subsection{MUSEEN OHNE RAUM}

Museale Räume sind Orte der Abduktion, und zwar in einem pointierten, doppelten Sinne. Zum einen meint die Abduktion in diesem Kontext jene bereits im ersten Kapitel erwähnte Erkenntnisebene, die nach Umberto Eco aller Induktion und Deduktion (ebenso wie wohl aller Transduktion) vorausgeht: Der museale Raum weist die in ihm enthaltenen Dinge überhaupt erst als Träger einer Botschaft aus und gibt uns Anlass zu der Annahme, dass es in seinem Inneren etwas zu verstehen gibt. Die harte Innen-/Außen-Trennung zwischen Ausstellungsfläche und Rest der Welt, die im und vom Museum etabliert wird, kennzeichnet die in ihm enthaltenen Dinge als Semiophoren, an denen kulturelle Inhalte und Zusammenhänge abgelesen werden sollen und dies gilt auch und oft sogar umso mehr, wenn sich außerhalb des Museums vergleichbare Objekte im alltäglichen Gebrauch befinden. Nicht umsonst geschah der legendär gewordene Kunstfrevel an Jospeh Beuys' Badewannen-Kunstwerk im Jahre 1973 nicht in einem Ausstellungskontext, sondern zu einem Zeitpunkt, an dem sich die künstlerisch verdreckte Kinderwanne in einem Lagerraum des Leverkusener Schlosses Morsbroich befand und der lokale SPD-Ortsverein ein Spülbehältnis für das bei einer Veranstaltung anfallende Schmutzgeschirr benötigte (vgl. Lutteroth 2011).

Zum anderen sind Museen aber auch Orte der >Abduktion $<$ im allerwörtlichsten Sinne. Das lateinische Verb abduco meint zunächst nur ein weg- oder entführen (Pertsch 2008: 14) und auch das aus ihm hervorgegangene englische to abduct bzw. das Substantiv abduction beschreiben einen Akt der Entführung und damit der Verlegung von etwas oder jemandem aus einem Kontext, in den es, sie oder er shineingehört in einen solchen, der ihm oder ihr fremd ist. Im Museum gehen diese beiden Ebenen der Abduktion notwendigerweise miteinander einher: Der Standortwechsel 
der Dinge hinaus aus der belebten Welt und hinein in die symbolische Ordnung der Erinnerungseinrichtung ist eben jene Abduktion als `Entführung \der Dinge aus ihren Ursprungszusammenhängen, welche zugleich die epistemische Abduktion nach Eco erst ermöglicht. Um die Dinge als Medien lesen zu können, müssen sie dem Alltag entrissen werden. Im ersten Kapitel dieser Arbeit wurde dieser Vorgang mit Korffs »dreifacher Aufhebung« (Korff 2005: 97), beschrieben, und auch in Grütters These vom Objekt, das im Musealisierungsprozess zwar »real«, jedoch nicht »im Realen« verbleibe (Grütter 1997: 671), klingen ähnliche Überlegungen an.

Bevor der museale Raum also irgendwelche konkreten epistemischen Funktionalitäten in Bezug auf individuelle Ausstellungen und Ausstellungsgegenstände entfalten kann, ist er ein Medium, auf das eine Kulturinstitution ihren Vermittlungsanspruch projiziert. Ein Schild mit der Aufschrift `Museum` an einem Gebäude anzubringen, heißt, dem Raum innerhalb des Gebäudes ein bestimmtes kulturelles Programm aufzuerlegen. Zu diesem gehört eben nicht nur die von Paul Valéry diagnostizierte Justierung der Besucherlautstärke auf ein Niveau zwischen Alltagsleben und Kirchbesuch, sondern auch eine bestimmte Art, sich zu dem zu verhalten, was hier zuvor mit Brigitte Scheer als die räumliche Zeichensetzung durch Architekturen und Dinge identifiziert wurde.

Die Frage nach virtuellen Museums->Räumlichkeiten` muss dementsprechend unter zweierlei Aspekten abgehandelt werden: Auf der einen Seite steht eben die Frage nach dem Innen und Außen, nach der Peripherie zwischen Außenwelt und Ausstellung und damit eben auch nach der Abduktion, in welcher das Museum als Mitteilungssystem überhaupt erst erkannt bzw. vorausgesetzt wird. Hier wird es also in den Blick zu nehmen gelten, inwiefern sich das Dispositiv >virtuelles Museum< von nicht-musealen virtuellen Angeboten abzusetzen vermag. Auf der anderen Seite wird es um die konkreten Modalitäten gehen müssen, unter denen digitale Medien Wissensfragmente zu einander ins Verhältnis setzen können, und inwiefern diese Relationen überhaupt räumlich in Erscheinung treten bzw. in räumlichen Kategorien beschreibbar sind. Die Brücke zwischen diesen beiden Ebenen wird dann abermals der Rezipient bilden - und mit ihm die Frage nach seiner räumlichen Verortung innerhalb des bzw. gegenüber dem digitalen Mediendispositiv.

\subsubsection{Museale Entführungen}

In seinem vielzitierten Text Über den Begriff der Geschichte beschreibt Walter Benjamin ausgehend von Paul Klees Gemälde Angelus Novus die Geschichte als einen »Engel«, welcher vom »Sturm« des Fortschritts immer weiter vom Paradies fortgetrieben wird, und dabei - unfähig, sich zurück zu kämpfen und die Fehler der Vergangenheit zu korrigieren - nur verzweifelt die Anhäufung der »Trümmer« betrachten kann, welche das Fortschreiten der Zeit ihm hinterlässt (Benjamin 2007: 133). 
Paul Valérys anderthalb Jahrzehnte zuvor entstandener Text über das Museum lässt sich durchaus als eine Antizipation der Benjamin'schen Metaphorik lesen, die für Valéry allerdings ausdrücklich nicht metaphorisch ist. Denn während Benjamin mit seinem Bild von Engel, Sturm und Trümmern allgemein bleibt und vor allem die schwierige Position des Gegenwartsmenschen im Schatten verfehlter geschichtlicher Entwicklung unterstreichen will, betrachtet Valéry die Anhäufung historischer Trümmer vor der Bugwelle des Fortschritts ganz konkret in Form von Dingen, die in Museen landen. Während Benjamins Engel seine Trümmer nur in der Rückschau betrachten und selbst nicht zurückkehren kann, um sie wiederaufzurichten, drängen sich Valéry die Bruchstücke der Vergangenheit regelrecht auf. Wo Benjamins Trümmer unberührbar und irreparabel hinter dem Betrachter zurückbleiben, wird für das $\mathrm{Mu}-$ seum nach Valéry gerade die Persistenz und Präsenz der Überreste zum Problem. Engel dürfen die Vergangenheit offenbar verzweifelnd hinter sich zurücklassen, während wir sie einlagern, verwalten und präsentieren müssen - und das Wort >präsentieren lässt sich ja durchaus auch lesen als: ins Präsens entführen und damit vergegenwärtigen.

Dabei ist, sofern die ausgestellten Objekte nicht zeitgenössisch sind, diese Abduktion der Objekte aus ihrem historischen Ursprungszusammenhang immer auch ein Stück weit Adoption. Folgt man Valérys Plot von der sozialen Aufgabe des Museums, so fängt es ja gerade jene Objekte auf, die »ihre Mutter die Architektur« (Valéry 1958: 7) verloren haben. Der historische Bruch, der nach Pierre Nora erst den Gedächtnisort ermöglicht, muss also vollzogen sein, bevor sich das Museum für einen Gegenstand zu interessieren beginnt, oder genauer: Die Attribute jener historischen Lebenswelt, aus welcher das Objekt hervorgegangen ist, müssen in ausreichendem Maße aus unserer Erfahrungswirklichkeit verschwunden sein, bevor das Objekt von uns als Verkörperung einer Differenz wahrgenommen werden kann. Das >Problem` der Museen, wie Valéry es diagnostiziert, lässt sich aus dieser Warte auch so lesen, dass zu viele wahllos nebeneinander gestellte Differenzen am Ende kein konkretes >Anderes` mehr zu bezeichnen imstande sind, sondern sich in völlig beliebiger Alterität um ihrer selbst willen verlieren:

Das Ohr würde es nicht ertragen, zehn Orchester auf einmal anhören zu müssen... Der Geist vermag nicht, mehrere unterschiedene Unternehmungen auf einmal zu verfolgen oder durchzuführen, und gleichzeitige Gedankengänge gibt es nicht. Den Augen aber wird bei jedem Aufwinkeln ihrer Pforten und im Augenblick selbst, da sie wahrnehmen, zugemutet, ein Porträt, ein Sehstück, ein Kücheninneres und einen Triumphzug einzulassen, Gestalten verschiedenster Zuständlichkeit und Größenordnungen - mehr noch: Sie sollen in einem und demselben Schauen Harmonien und Malweisen aufnehmen, die nichts miteinander zu tun haben. (Ebd.) 
Das Ergebnis ist dann für Valéry ein »Mißbrauch des Raumes«, der sowohl »Gesichtssinn« als auch »Erkenntnisvermögen« überfordere (Ebd.). Das Museum scheitere nicht an seinem Sammlungsanspruch per se, sondern an einem falschen Umgang mit dem ihm zur Verfügung stehenden Raum - die epistemische Abduktionsfunktion des musealen Raumes wird also gewissermaßen von seiner wörtlichen untergraben. Gerade weil wir im Museum davon ausgehen, dass erstens die ausgestellten Objekte Träger von Bedeutungen sind und dass zweitens die Art, wie diese Bedeutungsträger im Raum angeordnet sind, ebenfalls Mitteilungscharakter hat, ist seine Fähigkeit, Dinge in sich aufzunehmen, beschränkt. Es ist sicherlich keine steile These zu behaupten, dass sich in einem durchschnittlichen Einfamilienhaus ebenso viele oder gar mehr Bilder befinden als in mancher Kunstausstellung. Im Gegensatz zur Kunstausstellung müssen wir diese Bilder aber nicht gleichzeitig und vor allem nicht in ihren Bezügen aufeinander erfassen. Der Kunstdruck an der Wohnzimmerwand, die Illustration auf der Cornflakeschachtel, das Foto auf dem Titelblatt der Tageszeitung bilden in unserem Alltag kein spezifisches Sinnsystem, dessen wir gewahr wären. Sie finden vielmehr zufällig als Nebeneffekt unserer Lebensäußerungen in unseren Lebensräumen zusammen. Freilich haben auch sie Zeichenfunktionen und stellen komplexe Verweise auf kulturelle Muster da - womöglich werden in zweihundert Jahren unsere Nachkommen in ihren Museen durch Nachbauten unserer heutigen Wohnungen spazieren können - aber wir sind an diese Dinge so sehr gewöhnt, dass wir sie völlig transitiv begreifen und sie in den Praktiken unseres täglichen Umgangs mit ihnen völlig verschwinden. Die von Hannah Arendt betonte Rolle materieller Dinge als Kulturstifter, die Zeitläufe überdauern und uns >vertraut` werden, erklärt also die Funktion des Museums nur halb: Vertrautheit und Musealisierbarkeit der Dinge gehen gleichermaßen auf ihre materielle Permanenz zurück, aber die museale Situation lebt davon, dass uns die ausgestellten Objekte eben gerade nicht vertraut sind bzw. andernfalls ihre Vertrautheit durch den Ausstellungskontext von ihnen abgetragen wird.

Eine der interessantesten - wenngleich mit Vorsicht zu genießenden - Abhandlungen zu dieser Transformation der Objekte im Museum stammt aus der Feder von André Malraux. Der französische Schriftsteller, Abenteurer und spätere Kulturminister im Kabinett Charles de Gaulles verfasste in den 1940er Jahren eine Anzahl von Abhandlungen zur Kunsttheorie, welche in den 1950ern die Form des Bandes Les voix du silence annahmen. Was Malraux in seinen Ausführungen unternimmt ist einerseits eine historische Dekonstruktion des Museums als Institution und des mit ihm verbundenen Authentizitätsversprechens, andererseits aber auch eine gleichermaßen hellsichtige wie visionär überzeichnete Neubewertung der technischen Reproduktionstechnologien, die sich gleichzeitig an Benjamin anlehnt und vollends gegen ihn wendet. 
Dabei ist für Malraux zunächst wie für Benjamin das `Kunstwerk` Dreh- und Angelpunkt allen Nachdenkens sowohl über das Museum als auch über die Reproduktionen musealer Objekte. Unter Ausblendung anderer materieller Kulturgegenstände (die z.B. technischer oder ethnographischer Natur sein könnten) kapriziert sich Malraux bei seinen Betrachtungen auf Dinge, die kategorisch der Domäne der Kunst zugehörig sind. Zugleich aber relativiert Malraux deren Monumentalität: Seine Ausgangsüberlegung ist, dass unsere zeitgenössischen Vorstellungen davon, was Kunstwerke sind, bereits vollends das Produkt musealer Anschauungsmodalitäten sei. Ursprünglich, so Malraux, waren Kunstwerke wie Gemälde und Skulpturen in erster Linie Abbilder eines bestimmten äußeren Gegenstandes. Solche Gegenstände konnten ebenso >realer` (z.B. Porträtkunst, Landschaftsmalerei) wie fiktiver Art (z.B. Statuengruppen mit mythologischen Motiven) sein - in jedem Fall bezog das Kunstwerk vor der Erfindung des Museums seinen Wert vorrangig aus seiner Fähigkeit zum Verweis über sich selbst hinaus auf ein Objekt der Abbildung. Das Museum hingegen hat in der Lesart Malrauxs diese Verweisstruktur mit einer anderen überschrieben. Anstatt auf ein Abgebildetes zu deuten, seien die Werke nun in erster Linie Zeugnisse der Fähigkeiten und Schaffenskraft eines Abbildenden, und damit verwiesen sie nicht mehr auf den Gegenstand ihrer medialen Vermittlungsfähigkeit als Objekt, sondern auf die Figur des Künstlers als Subjekt. Das Porträt beispielsweise bilde nun nicht mehr vorrangig den Adligen ab, der es in Auftrag gab, sondern sei vor allen Dingen ein Rembrandt oder ein Tizian (vgl. Malraux 1960: 10). Diese Bedeutungsverschiebung ist für Malraux ebenso wenig Zufall, wie sie das Produkt durchdachter musealer Strategien ist - vielmehr sei sie die folgerichtige Konsequenz der Tatsache, dass dort, wo das Museum und sein Bewahrungsauftrag auf den Plan treten, ein aus sich heraus >authentisches` Ding gar nicht mehr vorliegen könne. Ganz ähnlich wie Benjamin sieht auch Malraux das historische Werden von Kunstwerken im Dualismus materieller Dauerhaftigkeit auf der Seite des Werkes selbst und transitiver Vergänglichkeit auf jener der historischen Welt begründet. Und genau wie Valéry sieht auch Malraux in der Musealisierung einen massiven Eingriff in die inhaltliche Integrität des Kunstwerks:

Jedes Kunstwerk hatte in irgendeiner Bindung gelebt, eine gotische Statue zu einer Kathedrale gehört, ein Bild der Klassik in den seiner eigenen Zeit dekorativen Zusammenhang; niemals traf das Werk zusammen mit anderen, die aus anderem Geist entstanden waren. Von solchen blieb es im Gegenteil isoliert, um desto besser genossen werden zu können. Das 17. Jahrhundert besaß zwar Antikenkabinette, und Sammlungen, doch blieben diese ohne Einfluss auf eine Haltung dem Kunstwerk gegenüber, für die uns Versailles zum Symbol geworden ist. Das Museum aber enthebt das Kunstwerk der »profanen« Welt, um es mit Werken entweder gegensätzlicher oder gleicher Richtung zusammenzubringen. Es konfrontiert Metamorphosen miteinander. (Ebd.) 
In anderen Worten: Die Idee, man könne in einer Speicherinstitution wie dem Museum Dinge als Bedeutungsträger in ihrer originären Verfasstheit erhalten, indem man ihre physische Unversehrtheit gewährleistet, ist für Malraux nicht haltbar. Dinge existieren als kulturelle Größen immer nur in >Bindungen` an andere Dinge, an bestimmte Raumstrukturen und soziale Gefüge, innerhalb derer sie gelesen und verstanden werden können. Weil sich der Auftrag des Museums auf die Dinge selbst richtet und nicht auf die komplexe soziale und physikalische Umwelt, die sie umgibt, kann es ursprüngliche Bedeutungen gar nicht konservieren. Malraux schreibt an anderer Stelle:

Jedes überlebende Kunstwerk ist verstümmelt, hat vor allem seine Zeit eingebüßt. Die Skulptur, wo war sie einst? In einem Tempel, in einer Straße, in einem Salon. Sie hat Tempel, Straße oder Salon verloren. Wenn der Salon im Museum wieder aufgebaut wird, wenn die Statue noch am Portal der Kathedrale steht, so hat sich doch die Stadt, welche Salon oder Kathedrale einschloss, verändert. Nichts kann die banale Behauptung entkräften, dass daß die Gotik für einen Menschen des 13. Jahrhunderts die Moderne war. Und die Welt der Gotik war eine Gegenwart, keine Epoche der Geschichte; setzen wir Kunstgenuß an die Stelle des Glaubens, so macht es wenig aus, wenn ein Museum eine Kapelle rekonstruiert, denn wir haben schon vorher unsere Kathedralen zu Museen gemacht. Gelänge es uns, vor einer ägyptischen Statue oder einem romanischen Kruzifix das gleiche zu empfinden wie dessen erste Beschauer, wir dürften diese Werke nicht mehr im Louvre lassen. (Ebd.: 59f.)

Eine Legitimation des Museums über die Kategorie der Authentizität wäre mit Malraux dementsprechend, wenn nicht rundheraus abzulehnen, so doch zumindest der Erweiterung bedürftig. Natürlich leben Museen von Authentizität im Sinne einer Beglaubigung der kulturellen Relevanz ihrer Ausstellungsstücke. Aber diese institutionelle, den Objekten durch Museen und ihnen vor- oder zugeschalteten Expertensysteme von außen auferlegte Authentizität kann nur greifen bzw. auf die Dinge projiziert werden, weil diese aus eigener Kraft keine Authentizität für sich in Anspruch zu nehmen imstande sind. Entsprechend sind es für Malraux auch nicht die weitgehend abstrakten, >gedachten` Originalzustände der Exponate, aus denen unser kulturelles Bewusstsein sich ein bestimmtes Bild der Vergangenheit oder Vorstellungen von ästhetischer Kanonizität ableitet. Vielmehr schauen wir beim Blick ins Gestern stets auf die Ausstellungspraktiken des Heute. Ein plakatives, auch von Malraux gewähltes Beispiel hierfür ist die griechische Skulpturenkunst: Die bunten Farben, mit denen Statuen und Gebäude der griechischen Antike bemalt waren, haben sich nicht erhalten - und die Museen der Neuzeit haben aus dieser Verstümmelung der Kunstwerke ästhetische Programme für ihre jeweiligen Gegenwarten entwickelt, welche die Fantasie vom weißen Athen normativ aufluden und zum Sinnbild schlichter Größe werden ließen (vgl. ebd.: 43). 
Authentizität ist also weniger in den Dingen selbst verortet als im Museumsraum, der sie umfängt, oder genauer: Der Museumsraum ist die Voraussetzung für das Alsauthentisch-Erleben der Exponate, und die Authentizität selbst wiederum entsteht im Gegensatz zum konkreten, von der Ausstellung vermittelten Wissen - weder induktiv noch deduktiv, sondern in allererster Linie abduktiv. Im Museum nämlich stellt sich die Frage, ob etwas authentisch ist, idealerweise gar nicht erst. Authentizität im Sinne einer äußeren Beglaubigung darf schlicht vorausgesetzt werden, weil ja die Musealisierung selbst jener Prozess ist, in welchem materielle Gegenstände als mediale Träger kulturell bedeutsamer Inhalte institutionell beglaubigt werden. Indem Museen Dinge aus einer Alltagswelt entführen, in welcher durch ihre Physiognomie hindurch direkt auf ihre rohe Funktionalität geblickt wird, weist es diese zugleich als Signifikanten in einem kommunikativen System aus. Für den Museumsbesucher heißt dies, dass er bei Betreten eines Ausstellungsraumes gar nicht mehr darüber sinnieren muss, ob sich in seiner Umwelt Spuren womöglich an ihn gerichteter Mitteilungen befinden könnten. Vielmehr versteht sich in der musealen Situation die Bedeutsamkeit der Dinge von selbst. Gerade deshalb ist es womöglich so schwierig, Museen als >Foren sätzlichste Funktion - nämlich jene, materielle Dinge als Träger historischer Bedeutsamkeit zu sammeln und auszustellen - können Museen nur dann ausüben, wenn die von ihrem Vermittlungsauftrag anvisierte Öffentlichkeit ihnen die Autorität zugesteht, diese Bedeutsamkeit ohne vorgeschaltete Diskussion mit dem Publikum erst einmal zu setzen. Duncan Camerons Metapher vom Museum als >Tempel « wird hier überaus sinnfällig: Auch Gotteshäuser können eben keine Grundsatzdiskussion darüber zulassen, ob das vermeintlich höhere Wesen, zu dessen Ehren sie erbaut wurden, tatsächlich wirklich und heilig ist. Museen und Kirchen leisten gleichermaßen jene Realisierung eines »Regierungshandeln[s] ohne jegliche Begründung im Sein«, welche Giorgio Agamben als das definitorische Kriterium eines Dispositivs ausmacht (Agamben 2008: 23).

\subsubsection{Raum als Metapher und Programm}

Nun sind digital-virtuelle Medientechnologien, wie bereits dargestellt wurde, zwar durchaus Techniken der >Realisierung bzw. der Aktualisierung von Objekten aus dem augenscheinlichen >Nichts $<$, aber das sich mit ihnen verbindende kommunikativkulturelle Paradigma steht unter ganz anderen Vorzeichen als jenen institutioneller Autorität und räumlicher Abgeschlossenheit. 2002 veranstaltete die Nobel-Stiftung in Stockholm ein Symposium über Virtual Museums and Public Understanding of Science and Culture, in dessen Rahmen David Filkin das zentrale Problem bei digitalen Museumsprojekten in einer für den etablierten Museumsbetrieb schwer verdaulichen Machtverschiebung hin $\mathrm{zu}$ den Rezipienten verortete. »They have all the 
power « (Filkin 2002: 6), lautet Filkins These - und alle Macht verleiht ihnen nicht nur die Geschwindigkeit und Einfachheit des Zugriffs, sondern vor allem auch die kolossale Fülle des Abrufbaren. Im Internet verbinde sich eine astronomisch große Zahl konkurrierender informativer Angebote mit extrem niedrigen Zugangshürden, und für die jeweiligen Anbieter bedeute dies vor allem eines: dass es zunehmend unmöglich werde, den Usern noch in irgendeiner Form Bedingungen zu stellen. Die Entscheidung, was ein Nutzer wann sehen möchte, sei von ihrer Umsetzung stets nur einen Mausklick entfernt - und Information ohne ein aufwändiges Schmackhaft-Machen durch klare und gezielte Publikumsorientierung kaum mehr an den Empfänger zu bringen (vgl. ebd.: 6). Filkin wählt interessanterweise - ohne zuvor vom >Tempel gesprochen zu haben - ebenfalls eine kirchliche Metapher, um die Rolle von Museen im Umgang mit digitalen Medien zu beschreiben: jene der Mission. Das WWW müsse als ein Neuland begriffen werden, in welchem das klassische Museum Anhänger erst noch gewinnen müsse. Dementsprechend genüge es nicht, einfach eine Kirche zu errichten und zu hoffen, dass die Konvertiten schon den Weg zum Altar finden werden. Vielmehr gelte es für die Museumsschaffenden, der Netzbevölkerung im Web entgegenzukommen - und sie also dort zu ımissionieren`, wo sie sich befinden (vgl. ebd.: 7).

Diese Wortwahl stößt uns auf dreierlei: Der Vergleich mit dem sakralen Raum des Gottesdienstes betont abermals die schon bei Valéry diskutierte Situiertheit des Museums außerhalb (und oberhalb) der unmittelbaren Alltagswelt. Mit der Mission verbindet sich die Vorstellung einer Neuheit und Unerforschtheit digitaler Kommunikation, in der zugleich eine zivilisatorische Rückständigkeit und Erziehungsbedürftigkeit ihrer menschlichen Nutzer mit anklingt. ${ }^{3}$ Vor allem aber bedient Filkin sich abermals jener diskursiven Technik, welche das kulturelle Sprechen über virtuelle Medien erst zu ermöglichen scheint: der metaphorischen Verräumlichung ihrer Funktionalität.

Die Notwendigkeit derartiger sinnbildlicher Übertragungen liegt eben darin begründet, dass computer layer und culture layer nicht innerhalb derselben Sprachsysteme zu beschreiben sind. Lawrence Lessig unterscheidet hier drei Arten bzw. geschichtete Ebenen von Code, die zu jeweils unterschiedlichen Graden von Menschen und Computern verstanden werden können: den Quellcode, den Assemblercode und den Objektcode. Quellcode ist typischerweise das, womit der Berufsstand der Programmierer im Alltag am häufigsten umgeht. Quellcodes sind ihrem Aufbau nach formallogische Sprachen, die es Menschen ermöglichen, Befehle an den Computer

3 Diese Neulands-Metapher, die zu Beginn der 2000er Jahre noch zutreffend gewesen sein mag, hat verblüffenderweise die tatsächliche Neuheit des World Wide Web bei Weitem überlebt und stellt bis in die Gegenwart einen immer wiederkehrenden Topos in tagespolitischen Diskussionen über das Netz und seine mögliche Reglementierung dar, der sich am deutlichsten wohl im Begriff der >digital natives` zeigt. 
zu formulieren, ohne sich dabei in Einsen und Nullen ausdrücken zu müssen. Die einfachen Befehlszeilen der Basic-Programmiersprache sind hierfür ein anschauliches Beispiel. Diese von Menschen aufgesetzten Befehle können dann von Compilersoftware zunächst in Assemblercode übertragen werden, der nurmehr aus Zahlen besteht und nur für sehr wenige menschliche Nutzer noch Aussagekraft besitzt. Soll das Programm tatsächlich ausgeführt werden, bedarf es schließlich der Übersetzung in den ausschließlich für Maschinen verständlichen Objektcode, bei dem es sich um eine binäre Abfolge von Ein/Aus-Signalen handelt (vgl. Lessig 2001: 185f.).

Das technisch `Eigentlicheく digitaler Datenverarbeitung ist diese serielle Folge von diskreten Signalen, die sich akkurat nur mathematisch beschreiben ließe. Doch selbst wenn jeder von uns der höheren Mathematik in ausreichendem Maße mächtig wäre um auch nur den Assemblercode zu verstehen, so sagt der bloße Code noch rein gar nichts darüber aus, welche kulturelle Information der Rechner tatsächlich transportiert und in welcher Beziehung diese zum lebensweltlichen Alltag des Nutzers steht. Das Medium ist hier, soweit es den menschlichen Anwender betrifft, ausdrücklich nicht die Nachricht - ja tatsächlich lässt sich die Nachricht in der Sprache des Mediums nicht einmal formulieren, sondern bedarf eben eines Interfaces, auf Basis dessen wir mit Schriftsprache agieren können. Das technische Funktionieren von Computern spielt sich zwar durchaus in derselben materiell-physikalischen Wirklichkeit ab wie unser Alltagsleben, ist aber in seiner Logik kategorisch verschieden von all jenen Kontingenzsystemen, in denen wir uns die Welt erklären. Metaphern überbrücken diese kategoriale Kluft und sind insofern völlig unabdingbar, um als Mensch mit Computern umgehen zu können (vgl. Niewerth 2013: 1).

Dies gilt nicht nur im Sinne einer sprachlichen Reflexion über das Wirken digitaler Technologien in der kulturellen Welt, sondern auch in jenem konkreter Eingabesysteme: Die meisten Computerinterfaces sind nichts anderes als bildliche Metaphern, die bekannte Arbeitsdispositive der physischen Welt auf einem Bildschirm nachbilden. Der Computer ist kein Schreibtisch, aber der Desktop koppelt abstrakte Datenverarbeitung an konkrete Symbole aus dem Büroalltag: Auf einer >Oberflächeく lassen sich Dokumente lesen und bearbeiten, Daten befinden sich in leicht auffindbaren 〉Ordnern`, nicht mehr benötigtes verschwindet im >Papierkorb` (vgl. Carlson 1995: 70f.).

So notwendig Metaphoriken sind, um Computer in unsere Alltagswelt einzubinden, so sehr verstellen sie in ihrer Schlüssigkeit zuweilen den Blick auf ihre eigene Uneigentlichkeit und Gemachtheit. Metaphern sind niemals objektiv oder zwingend und dementsprechend auch nicht von Werturteilen und politischen Programmatiken zu trennen. Werden kulturelle Raumkategorien als Sinnbilder für die Modalitäten computergestützter Informationsvermittlung herangezogen, so wird nicht nur eine Analogie bezüglich der Beschaffenheit des kommunikativen Systems unterstellt, sondern auch eine Vergleichbarkeit im politischen und ideologischen Sinne, die unausweichlich auch die >Bewohner`solcher metaphorischer Räume berühren muss. So 
ist Filkins Netzbewohner gewissermaßen ein >Wilder`, der in den noch hierarchiefreien Ebenen des Webs umhernomadiert und dem die >frohe Botschaft Expertensysteme erst noch verkündet werden muss. Der Memex-Nutzer, wie Vannevar Bush ihn 1945 in Aussicht stellte, erscheint hingegen als entdeckender Pionier, der sich Schneisen durch einen dichten Dschungel der Information schlägt: Die Pfade des Wissens, welche durch Memex erschließbar werden sollen, sind nicht präexistent, sondern müssen manuell geschaffen werden. Zwei Texte verschalten zu können, erfordert zunächst einmal, sie beide gelesen zu haben. Während die nautische Metapher von der Navigation, wie sie sich vor allem mit digitalen Hypertexten verbindet, eine Offenheit des Wissens->Raumes`nach allen Richtungen impliziert, unter denen nur die richtige ausgewählt werden muss, deutet sich in den >trails of interest $८$ Bushs eben eine Epistemologie des Pfadfindens und damit eine widerständige Dichte des Wissens an. Man treibt nicht auf einem Meer der Einsichten, sondern muss erst das Gestrüpp unnützer Nebensachen niederstampfen, um an relevante Information zu gelangen. Raummetaphern sind nicht bloß neutrale Beschreibungen von Organisationsstrukturen in digitalen Datenanhäufungen, sie sind immer auch normative Aussagen darüber, wie solche Datenanhäufungen organisiert sein sollten, bzw. welche Verortung des Rezipienten im Verhältnis zum Medium als wünschenswert erachtet wird. Wie Architektur und Ausstellungsaufbau im Museum, so bilden Ab- und Aufrufmodalitäten im Netz immer auch didaktische Entscheidungen ab.

\subsubsection{Cyberspace(s)}

Auf diese Tatsache verweist schon der Umstand, dass der >Cyberspace` als wohl meistgebrauchte räumliche Metapher für das digitale Kommunikationsmilieu eben nicht Offenheit und Freiheit akzentuiert, sondern die Möglichkeit der Steuerung und Lenkung. Kybernos leiht seinen Namen der Wissenschaft der Kybernetik nicht aus seiner Eigenschaft als ein auf dem Meer Treibender heraus, sondern aus jener als Führer seines Schiffes. Das griechische Verb $\kappa v \beta \varepsilon \rho v \alpha \omega$ und seine lateinische Entsprechung guberno meinen gleichermaßen das `Steuern »das Steuerruder führen« (Pertsch 2008: 276), ferner aber auch das `Leiten` im Allgemeinen und in bestimmten Kontexten auch das >Regieren ( (vgl. ebd.). Das Substantiv gubernaculum wiederum meint ursprünglich das Schiffsruder, aber eben auch die >Leitung « oder >Regierung « als soziale Einrichtung - und der gubernator ist eben nicht nur der Steuermann, sondern auch der $>$ Leiter $<$ und $\gg$ Lenker $<$ im nicht-maritimen Sinne (vgl. ebd.).

Der Begriff des >Cyber -Raumes impliziert also zunächst weniger navigatorische Offenheit als zielführende Steuerung - ohne allerdings Steuernde und Gesteuerte zu benennen. So uneindeutig der Begriff schon im Wortsinne ist, als so wenig hilfreich erweist sich auch der Blick in seine Geschichte, denn 〉Cyberspaceく ist zu keiner Zeit 
ein analytischer oder gar wissenschaftlicher Terminus gewesen. Als sein Urheber wird für gewöhnlich der kanadisch-amerikanische Schriftsteller William Gibson, Pionier des Cyberpunk-Genres ${ }^{4}$ innerhalb der Science Fiction-Literatur, angeführt (vgl. Münker 2005b: 245). Gibson verwendet das Wort erstmals Anfang der 1980er Jahre in der Kurzgeschichte Burning Chrome (vgl. Gibson 2003: 179), seinen entscheidenden Popularitätsschub erfuhr es allerdings erst 1984 durch Gibsons wegweisenden Roman Neuromancer.

Neuromancer erzählt die Geschichte des verkrüppelten und drogenabhängigen Hackers Henry Dorsett Case, der in der Tokioter Unterwelt einer nicht allzu fernen Zukunft von einem mysteriösen Auftraggeber namens Henry Armitage angeheuert wird, um sich einer künstlichen Intelligenz namens Wintermute entgegenzustellen. Das Medium, durch das sich Gibsons Romanhelden dabei bewegen, ist die sogenannte >Matrix : Eine Visualisierung globaler Datennetze, in welche sich Hacker direkt über ihr Nervensystem einklinken und wie körperlich anwesend bewegen können. Gibson beschreibt diese simulierte Umwelt eben als `Cyberspace` und extrapoliert ihr Erscheinungsbild aus Militärtechnologien und den zeitgenössischen Computerspielen der 1980er Jahre:

»The matrix has its roots in primitive arcade games, « said the voice-over, »in early graphics programs and military experimentation with cranial jacks.« $[\ldots] »$ Cyberspace. A consensual hallucination experienced daily by billions of legitimate operators, in every nation, by children being taught mathematical concepts... A graphic representation of data abstracted from the banks of every computer in the human system. Unthinkable complexity. Lines of light ranged in the nonspace of the mind, clusters and constellations of data. Like city lights, receding... « (Gibson 1984: 51)

Der Cyberspace erscheint also schon bei Gibson in erster Linie als eine metaphorische Interface-Struktur, welche Interaktionen mit einem abstrakten formallogischen Computersystem ermöglicht. >Lichtlinien`, die sich im `Nichtraum des Geistes` erstrecken, >Datenkonstellationen $<$ wie >schwindende Stadtlichter - Gibson selbst sah gerade in dieser fast lyrischen Vagheit der Beschreibung wenige Jahre später ihren eigentlichen Wert: jenen nämlich, einen noch der Füllung harrenden Rahmen für eine eigentlich noch nicht formulierbare Zukunftserwartung zu bilden. So schreibt er 1991 für den von Michael Benedikt herausgegebenen Sammelband Cyberspace. First Steps in einem Text, der halb expressionistische Kurzgeschichte und halb technikphilosophisches Traktat ist:

4 Der Begriff des `Cyberpunk dem das Genre seinen Reiz bezieht, bilden doch die Steuerungsziele und -phantasmen der wissenschaftlichen Kybernetik und der `Punk « im Sinne von Auflehnung und Subversion gänzlich gegensätzliche kulturelle Positionen. 
Assembled word cyberspace from small and readily available components of language. Neologic spasm: the primal act of pop poetics. Preceded any concepts whatever. Slick and hollow - awaiting received meaning. All I did: folded words as taught. Now other words accrete in the interstices. (Gibson 1991: 27)

Demnach war das Wort >Cyberspace` für Gibson also zunächst nur eine poetische Konstruktion, die ihm die Andeutung einer Erfahrung von Technologie ermöglichte, ohne sie präzise auszudefinieren. Gibson >faltet die Worte, wie es ihm beigebracht wurde $\prec$, und nicht etwa die Worte selbst sind es, welche die Bedeutung tragen, sondern wieder einmal die `Zwischenräume ২. Gibson selbst verband mit dem Cyberspace nach eigener Aussage eine bestimmte Bilderwelt von der abgerissenen, neonlichtgefluteten Zukunft, in welcher die Handlung des Romans angesiedelt ist:

I work the angle of transit. Vectors of neon plaza, licensed consumers, acts primal and undreamed of... The architecture of virtual reality imagined as an accretion of dreams: tattoo parlors, shooting galleries, pinball arcades, dimly lit stalls stacked with damp-stained years of men's magazines, chili joints, premises of unlicensed denturists, of fireworks and cut bait, betting shops, sushi bars, purveyors of sexual appliances, pawnbrokers, wonton counters, love hotels, hotdog stands, tortilla factories, Chinese greengrocers, liquor stores, herbalists, chiropractors, barbers, bars. These are dreams of commerce. Above them rise intricate barrios, zones of more private fantasy. (Ebd.: 28)

Der Begriff präsentiert sich im Lichte seiner Entstehung also zunächst als ein seiner Zeit vorauseilendes Stück Science-Fiction-Poesie, das weniger signifiziert, als es evoziert - und zwar die Vorstellung von einer verrucht-faszinierenden >Gegenwelt der digitalen Simulation, in die man eintauchen und in der man sich verlieren kann. Der von Jennifer Bussell verfasste Eintrag zum Cyberspace in der Onlineversion der Britannica traut sich angesichts dieser Vagheit nicht, eine kurze und eindeutige Definition des Gegenstandes auch nur zu versuchen. Stattdessen wird eine Beschreibung von sichtbaren und sinnfälligen Cyberspace-Phänomenen versucht, wobei Bussell in ihrem Sprachgebrauch sichtlich mit der Tatsache zu kämpfen hat, dass der Cyberspace einerseits >Raum`sein soll, andererseits aber eben nicht in räumlichen Kategorien existiert, also weder in seiner Ausdehnung vermessen, noch punktuell lokalisiert werden kann. Cyberspace sei dementsprechend zunächst einmal eine »amorphous, supposedly >virtual world created by links between computers, Internet-enabled devices, servers, routers, and other components of the Internet's infrastructure « (Bussel 2014). Diese Kriterien bilden allerdings allein noch keine gangbare Eingrenzung des Phänomens, denn wie Bussell fortfährt, müsse der Cyberspace zugleich kategorisch vom Internet selbst unterschieden werden: »As opposed to the Internet itself, however, cyberspace is the place produced by these links« (ebd.). Die Unterscheidung zwischen Cyberspace und Internet ist hier dieselbe wie jene in dieser Studie bereits 
festgestellte zwischen Internet und World Wide Web. Als Cyberspace ist nicht die Summe und Ausdehnung der Technik zu verstehen, welche digitale Kommunikation ermöglicht (also der Computer, der Modems, der Telefonleitungen usw.), sondern der aus dem Umgang mit digitaler Information entstehende Eindruck, man bewege sich zwischen Orten. Anstatt hier abstrakt zu bleiben, fährt Bussell - sicher auch dem enzyklopädischen Format der Britannica geschuldet, das ja nach Praxisbezug und Alltagsrelevanz für einen Leser ohne speziellen fachlichen Hintergrund verlangt mit naheliegenden Beispielen dafür fort, wie der Cyberspace seinem gegenwärtigen Nutzer gegenübertreten könne: Cyberspace sei die Domäne der Onlinespiele gleichermaßen wie jene der Chatrooms, das Milieu von Messenger-Diensten ebenso wie jenes der Blogs (vgl. ebd.). Der Cyberspace definiert sich aus dieser Perspektive also über das, was er in sich beherbergt - und vor allem dadurch, dass dieses Beherbergte keine Existenzmerkmale außerhalb des Cyberspace aufweist (vgl. ebd.). Zwei Menschen mögen sich samt ihrer Computer an zwei anhand von Längen- und Breitengraden genau benennbaren Punkten der Erdoberfläche aufhalten, aber der Chatroom (abermals eine Verräumlichung!) in dem Sie sich unterhalten, befindet sich in einem >Dazwischen ‘, das - ganz anders als z.B. der Raum zwischen Museumsexponaten weder wahrnehmbar noch vermessbar ist. Dieses Dazwischen sträubt sich damit notwendigerweise auch gegen jede klare Einordnung in die Zuständigkeiten nationaler Jurisdiktionen. Die immer wieder bemühte Rede vom Cyberspace als `Neuland $\$ hat, folgen wir Bussells Ausführungen, ihren Ursprung eben gerade darin, dass er zwar einen Eindruck von Räumlichkeit vermittelt, zugleich aber als $\gg$ Non-Space $\triangleleft$ im Sinne Gibsons keinen Raum in der >realen` Welt belegt, an dem er von irgendeiner politischen Kraft territorial beansprucht werden könnte. Hieraus erklären sich nach Bussell auch diverse in den 1990er Jahren von Computeraktivisten unternommene Versuche, den Cyberspace als eine Sphäre abseits der physischen Welt und damit auch jenseits des Zugriffs jener Autoritäten zu behaupten, welche diese unter sich aufgeteilt haben (vgl. ebd.).

Die Onlineversion des Oxford Dictionary, das sich als Wörterbuch solch weitschweifige Ausführungen natürlich nicht leisten kann, wartet hingegen mit einer geradezu minimalistischen Definition des Cyberspace auf, welche es vermeidet, ihm irgendwelche spezifischen Eigenschaften, Ästhetiken oder Funktionsprinzipien zuzuschreiben. Stattdessen wird der Cyberspace schlicht als »the notional environment in which communication over computer networks occurs $~^{5}$ definiert und damit nicht etwa in der Technik, sondern gänzlich in der Imagination seiner Anwender verortet. Er wird eben als eine notion begriffen - als eine Annahme oder Auffassung darüber, wie sich digitale Kommunikation abspielt. Als solche muss er nicht notwendigerweise etwas mit tatsächlichen funktionalen Prinzipien oder technischen Abläufen zu tun haben. Der Cyberspace-Begriff wäre damit gewissermaßen eine Proto-Metapher,

5 http://www.oxforddictionaries.com/de/definition/englisch/cyberspace vom 13.05.2018. 
die selbst außer einer scheinbaren Räumlichkeit noch nichts impliziert, aber den Weg bereitet für eine Anzahl sehr viel konkreterer Raum-Metaphern, wie eben z.B. den Chatroom oder den Desktop.

Für Marcos Novak indes schließen sich Cyberspace als Metapher und Cyberspace als technische Realität nicht aus. Vielmehr, so seine These, beschreibt der Begriff eine Verschmelzung von Sinnbild und medialer Funktionalität in einem Interface, welches die Funktion der Vorstellung unterwirft. Der Cyberspace wäre hier weder in den Formalismen des Rechners, noch in der Imagination des Anwenders verortet. Stattdessen erscheint er als eine bestimmte Strategie der Bildgebung, welche den Umgang mit digitaler Kommunikationstechnik anhand von Erfahrungswerten der analogen Alltagswelt ermöglichen soll:

Cyberspace is a completely spatialized visualization of all information in global information processing systems, along pathways provided by present and future communications networks, enabling full copresence and interaction of multiple users, allowing input and output from and to the full human sensorium, permitting simulations of real and virtual realities, remote data collection and control through telepresence, and total integration and intercommunication with a full range of intelligent products and environments in real space. (Novak 1991: 225)

Mit der Wortwahl der > verräumlichten Visualisierung ‘ charakterisiert Novak den digitalen Informationsraum nicht als eine vorgefundene Ordnung, sondern vielmehr als etwas, das aus >Kopräsenz und Interaktion ২ laufend hervorgebracht wird. Damit ist sein Cyberspace-Konzept eng verbunden mit dem der Attributobjekte - was nur folgerichtig ist, wenn wir uns an Brigitte Scheers Feststellung erinnern, dass Raum und Ding als notwendige Gegenstücke ihre wechselseitige Existenzbedingung bilden. Der Cyberspace, wie Novak ihn begreift, ist vor allem die Bedingung der Möglichkeit für die Existenz digitaler Attributobjekte (bzw. deren Wahrnehmung durch den Nutzer, was letztlich auf dasselbe hinausläuft). Er ist das Milieu, in dem die Auswahl und >Bewegung ¿ zwischen Objekteigenschaften möglich ist.

Damit ist Novak schon ganz nah an Alan Wexelblats Modell vom Cyberspace als semantischem Raum, dessen dimensionale >Achsen` Potenziale und Möglichkeiten der Sinnproduktion beschreiben. Auch Wexelblat bleibt hier nicht metaphorisch, sondern betont die Wichtigkeit von Visualisierungssystemen, die seiner Ansicht nach nicht zuletzt ergonomische Kriterien zu erfüllen haben:

One of the most important features of any visualization system is the placement, or location, and arrangement of the represented objects. A well-structured view can make things obvious to the viewer and can empower interaction. Similarly, a badly constructed view can obfuscate and impede. A well-strctured view has internal consistency and logic, and can be easily understood. In addition, the structure can convey an underlying mental model and can indicate possibilities for interaction. (Wexelblat 1991: 255) 
Zur Vermittlung eines schlüssigen >zugrundeliegenden mentalen Modells` schlägt Wexelblat vor allem solche Visualisierungen vor, die den Eindruck einer körperlichen Bewegung in einem unserer lebensweltlichen Alltagserfahrung entsprechend ausgedehnten Raum zu vermitteln suchen. Der Mehrwert dieses visuellen Programmes ist für ihn vor allem der, dass es an basalste und intuitivste Fähigkeiten anknüpft, anhand derer wir uns in der Welt zurechtfinden:

The ability to traverse areas is a fundamental human ability: it is one of the first things we look for in a child's development; it is the first thing we take away from someone who has violated society's law. In a cyberspace that corresponds to a physical terrain, navigation, or movement, has meaning by virtue of its analogy with physical action. Movement from one room to another within an imaginary building is meaningful by virtue of the fact that we have been doing it since childhood and have learned where to go at what times. (Ebd.: 264)

Zugleich stellt Wexelblat aber - wie in Abschnitt 2.4.3 dieser Arbeit bereits ausgeführt wurde - fest, dass es kontinuierliche Bewegung in digitalen Sinnräumen klassischerweise nicht gibt. Positionsveränderungen bedeuten das Ende einer Interaktion mit einem Objekt und den Beginn einer Interaktion mit einem anderen, ohne dass dabei ein kontinuierlicher Zwischenraum zu durchqueren wäre. Der >Raum` wird als Vorstellung zwar benötigt, um Objekte voneinander zu trennen, ist selbst aber sinnentleert, womit auch die Bewegung zum semantisch qualitätslosen Prozess wird dies ist jene Form unverzögerten Transfers, die mit Uwe Wirth im zweiten Kapitel der vorliegenden Studie als > wirklicher Sprung « umschrieben wurde. Die >Topologie verlinkter Hypertextsysteme ist eine solche im allzu wörtlichen Sinne, bestehen Hypertexte doch gänzlich aus diskreten >Orten` der Information. Der Begriff des >Netzes` evoziert eine Gleichberechtigung der Knotenpunkte und Verdichtungen mit den >Fäden`, die zwischen ihnen gespannt sind. Tatsächlich aber dürften, wollte man einen beliebigen Ausschnitt des WWW grafisch abbilden, die Link-Fäden überhaupt keine Ausdehnung aufweisen, existieren sie doch eigentlich nur in den jeweiligen Textmodulen, von denen sie ausgehen und jenen, auf die sie verweisen. Zumindest müsste man in einer halbwegs akkuraten Visualisierung von Hypertexten alle Links in Form gleich langer Linien darstellen, denn Hyperlinks kennen keine semantischen >Entfernungen zwischen zwei Textonen. Sie sind entweder verbunden oder nicht. >Intensitäten` oder >Stärken` von Zusammengehörigkeit ließen sich allenfalls in längeren Scriptonen ausmachen, und zwar als Separierungsgrade in Form ganzer Sprünge, die z.B. in der Abfolge von Napoleon hin zum Taucheranzug benötigt werden. Ein Zustand, in welchem sich der Rezipient tatsächlich `zwischen ২ Bedeutungsbausteinen verortet findet, ist in der Logik digitaler Hypertexte nicht vorgesehen: Schon Memex war ja nicht zuletzt als eine Vorrichtung der Ausblendung konzipiert - nämlich jener ganzer Bücher, welche den >Raum`zwischen für relevant befundenen Textstellen ausfüllen. 
Der Cyberspace als semantic space soll nach Wexelblat in erster Linie die Schaffung eines sinnhaften Zwischenraumes bewerkstelligen, der nicht nur diskrete Objekte erkennbar werden lässt, sondern vor allem auch die Positionierung der Objekte zueinander bzw. die des Rezipienten in Relation zu den Objekten gestattet. Er soll auf der Ebene des Interfaces die Kontinuität ins Digitale bringen. Er entsteht demnach also nicht nur aus der relativen Anordnung von Objekten in Bezüglichkeiten auf einander, sondern vor allem aus der Einordnung von Information in ein semantisches Positions- oder Koordinatensystem, in dem Beziehungen zwischen Objekten nicht nur als geschlossene qualitative Zustände bestimmbar sind, sondern quantitative Unterschiede in Form von >Abständen` nach unterschiedlichen Richtungen aufweisen. Im Cyberspace können digitale Objekte bzw. die Daten und Attribute, aus denen sie entstehen, nicht nur zusammengehörig oder voneinander geschieden, sie können einander vor allem auch unterschiedlich nah oder fern sein. Cyberspaces finden wir nach Wexelblat also überall dort, wo digitale Medien nicht einfach nur diskrete Informationspartikel verschalten, sondern ihren Rezipienten zugleich die Möglichkeit eröffnen, sich zwischen diesen objekthaft-diskreten Wissensbausteinen zu positionieren und sie aus unterschiedlichen Warten zu betrachten. Dies wiederum verweist uns zurück auf die vantage points aus Richard Saul Wurmans Informationsarchitektur. Der Begriff der >Architektur « nämlich leistet für Wurman im Großen und Ganzen dasselbe wie jener des Raumes für Wexelblat: Räumlichkeit ist nicht nur eine der Veranschaulichung von abstrakter Funktionalität dienliches Bild, sie ist ein didaktisches Programm, in dessen Zentrum einerseits die Relativität von Bedeutungen zueinander und zum Rezipienten steht, andererseits aber auch die Kontinuität von Sinn über unterschiedliche Standorte hinweg. Es gibt keine endliche Anzahl von Blickwinkeln, aus denen sich das Wissen betrachten lässt, sondern ein Kontinuum, in welchem der Rezipient idealerweise jede beliebige Position einnehmen kann, während sich der tatsächliche Informationsgehalt der Objekte aus jedem Blickwinkel anders darstellt.

Wexelblat legt dabei besonderen Wert darauf, dass es neben einer Bewegung entlang semantischer Dimensionsachsen auch die Möglichkeit zu einer »orthognalen« (ebd.: 268) Verschiebung der Rezipientenperspektive aus dem Cyberspace sheraus geben soll. Dieser Blick soll es ermöglichen, sowohl die konkrete Ordnung, als auch die grundlegende Funktionsweise des Wissensraumes in den Blick zu nehmen. So gleicht Wexelblats Vorstellung von einem visualisierten Cyberspace einem Blick in einen sternenklaren Nachthimmel: Semantische Objekte erscheinen als helle Lichtlein, die je nach sinnhafter Zusammengehörigkeit in Anhäufungen und Konstellationen arrangiert sind. >Zoomt man jedoch einzelne Objekte heran, so stellt man fest, dass auch diese vermeintlichen `Sternchen` tatsächlich nur Agglomerationen kleinerer Lichter sind und ihrerseits aus semantischen Attributen bestehen. Andersherum können distinkte >kleine` Objekte aber auch zu übergeordneten >größeren` verschmelzen, wenn der Betrachter sich von ihnen entfernt. Was zusammengehört und 
was nicht, was also als distinktes Etwas erscheint und was in Strukturen höherer Ordnung aufgeht, ist letztlich eine Frage der Perspektive und Verortung des Rezipienten (vgl. ebd.).

Nun kann man einwenden, dass klassische Katalog- und Karteisysteme grundsätzlich durchaus ähnliches zu leisten imstande sind. So könnte man das Wissensobjekt `Napoleon` mit zahlreichen anderen in das übergeordnete Objekt `Frankreich einordnen, dieses wiederum unter ein abermals übergreifendes Objekt wie `Nation< oder `Europar subsumieren, usw. Allerdings liegen die Objekte im Wexelblatschen Cyberspace nicht in wie Matrjoschka-Puppen ineinandersteckenden Schachteln herum, sondern sie schweben durch einen offenen Bedeutungsraum, in welchem sie von einander angezogen und abgestoßen werden, sich gegenseitig umkreisen und an einander vorbeischießen. Insofern denkt Wexelblat Objekte im Cyberspace tatsächlich eher wie Himmelskörper am Firmament, oder Elementarteilchen in einer Nebelkammer. Mit dieser Vorstellung geht einher, dass der Cyberspace grafisch nur unvollkommen zu visualisieren ist, weil jede topografische Abbildung nur eine Momentaufnahme aus einem Raum darstellen kann, der in ständiger Bewegung begriffen ist (vgl. ebd.: 268f.).

Während Wexelblat in seinen Ausführungen eher auf der Ebene einer Vision dessen bleibt, was der Cyberspace seiner Ansicht nach leisten sollte, geht Marcos Novak sehr viel expliziter darauf ein, wie sich der Umgang mit dem Cyberspace praktisch gestaltet und was seine technischen Voraussetzungen sind. Vorbedingung eines >Eintretens` des Users >in « den Cyberspace ist für Novak dabei die Möglichkeit, den Nutzer selbst in Information zu transformieren, bzw. auf technischer Ebene die Trennung zwischen Rezipient und Rezeptionsgegenstand zu überbrücken oder aufzuheben (vgl. Novak 1991: 225). Obwohl der Cyberspace häufig in den Kategorien physischer Räumlichkeit beschrieben und diskutiert wird, sieht Novak in ihm vor allem eine ephemer-poetische Aufhebung des Dualismus von individueller Person und Umwelt, der unsere physische Raumerfahrung prägt: Sein kulturelles Versprechen ist die Vermengung des Betrachters mit dem Raum, in dem er sich bewegt, und damit eine grundsätzliche Neuverhandlung der Rollen und Bedeutungen von Subjekt und Objekt (vgl. ebd.: 226).

Die technischen Voraussetzungen für diese Neuverhandlung sind laut Novak zweierlei: Der Nutzer muss erstens über ein »deck« und zweitens über ein »protocol« verfügen (ebd.: 233). Das `deck oder der »synthesizer « (ebd.) ist die technische Anordnung, die den Cyberspace in Form eines Interfaces visualisiert. Typischerweise ist es also der physische Computer - sei er nun Desktop, Laptop oder Tablet - mit dem der Nutzer interagiert. Das >Protokolk hingegen ist der Kommunikationsstandard, welcher die Kommunikation sowohl mit dem Cyberspace selbst, als auch mit allen anderen Decks ermöglicht, die mit ihm verbunden sind. Das Protokoll nach Novak meint damit nicht nur Netzwerkprotokolle im engeren Sinne, sondern auch Auszeichnungssprachen, gemeinsame Interface-Standards und die komplette formale, 
immaterielle Infrastruktur, die sich außerhalb der Decks individueller Kommunikationsteilnehmer befindet (vgl. ebd.).

Entscheidend für Novaks Vorstellung vom Cyberspace ist zunächst der Begriff des »Hypermediums « - der in seiner Diktion all jene Medientechnologien beschreibt, die unterschiedliche mediale Formen wie Bild, Video, Schrift und Tonwiedergabe miteinander verbinden - und die an diesen anknüpfende Unterscheidung zwischen spassiven ‘ und raktiven ‘ Hypermedien (ebd.: 230). Passiv sind für Novak Hypermedien, die in ihrer Entstehung ein einziges Mal in einer endgültig bleibenden Form verfasst werden und zwar rezipiert, aber nicht mehr verändert werden können. Aktiv sind solche, die über ihre ursprüngliche Entstehung hinaus veränderlich bleiben bzw. die bereits aus ihrer Entstehungssituation heraus mit Mechanismen versehen sind, die Veränderungen begünstigen oder veranlassen (vgl. ebd.). Darüber hinaus akzentuiert Novak den Aspekt der Intermedialität als einen abermals räumlichen: Während bei Wexelblat die `Dimensionen` des Cyberspace semantische sind (Bewegung im Cyberspace bedeutet für ihn eine Aktualisierung von Sinnpotentialen, deren mediale Erscheinungsform sekundär ist), ergibt sich seine Räumlichkeit für Novak aus seiner Eigenschaft, Information nicht nur in einer medialen Erscheinungsform wie dem schriftlichen Text abzubilden, sondern vielmehr unterschiedliche Vermittlungsformen einander ergänzen zu lassen. Die Anzahl der Raumachsen des Cyberspace resultiert demnach aus den medialen Formen, welche Deck und Protokoll dem Nutzer abzurufen gestatten. Die semantischen Bedeutungen hingegen bestimmen selbst nicht die Räumlichkeit des Cyberspace, sie füllen vielmehr den Raum aus, der vom Medium umrissen und definiert wird:

Every node in a hypermedium has a dimensionality. Hypertext, for example, occurs in a onedimensional space, but we can easily envision hypermedia with higher dimensions. While the dimensionality of a node is fixed, the dimensionality between nodes need not be: a word in a text can open to a hologram, a point within the hologram can open to an animation, a frame in the animation can return to a text. Every node in a hypermedium is therefore an information space, a space of potential information, and the »text « of the node is the actual information within that space. (Ebd.: 230f.)

Während Wexelblat also die McLuhansche Losung vom Medium als Nachricht gewissermaßen dahingehend umdreht, dass die Nachricht das Medium ist (denn erst der Sinngehalt der Information bestimmt hier die Struktur des Abrufs), sind Botschaft und Medium in der Cyberspace-Konzeption Novaks zunächst einmal kategorisch getrennt: Der >Raum « ist hier nicht Information, sondern die Bedingung der Möglichkeit von Kommunikation. Seine Dimensionen sind Potentiale medialen Ausdrucks, entlang derer Information wandern kann. Dabei ist diese intermediale Räumlichkeit für sich genommen aber noch kein Cyberspace, denn dieser ist ja nach Novaks Definition 
eine >verräumlichte Visualisierung` von Information, die sich innerhalb eines technischen Kommunikationsapparates in Bewegung befindet. Genauso, wie ein leeres Gebäude zwar den Raum eines Geschehens vorgibt, aus sich heraus aber noch kein Museum, Supermarkt oder Finanzamt ist, muss auch ein Cyberspace erst durch einen bestimmten Umgang mit der vom Medium geschaffenen >Raum`-Situation zu einem solchen gemacht werden.

Ähnlich wie Brigitte Scheers Konzeption vom physischen Raum entsteht auch Novaks Cyberspace aus einer Unterscheidung zwischen Raum und Objekt, bzw. aus der Tatsache, dass der Rezipient einen Unterschied wahrnimmt zwischen funktional abschließbaren Attributobjekten und einem medialen Milieu, das sie umgibt. Um diese Unterscheidung plausibel zu machen, greift Novak bezeichnenderweise auf genau jenes Areal menschlicher Tätigkeit zurück, das auch Scheer umtreibt: nämlich die Modulation des Raumes durch gestalterische Arbeit. Er identifiziert dabei zwei Techniken der Raum-Formung durch den Menschen, die seines Erachtens eine andauernde Konstante in der Kulturgeschichte bilden. Auf der einen Seite steht die Skulptur als positive Form des Umgangs mit dem Raum, die einem bestimmten Raumabschnitt Gestalt und Sichtbarkeit verleiht, ihn gleichzeitig für den Betrachter aber unokkupierbar macht. Ihr gegenüber verortet er die Architektur, die einen leeren Raum umfasst, begrenzt und damit Räume als solche erlebbar werden lässt (vgl. ebd.: 243). Raum ist also dort, wo wir uns frei bewegen können, Ding dort, wo wir Widerstand verspüren. Im Umgang mit den virtuellen Quasi-Räumen digitaler Medien haben für Novak Interfaces Skulpturcharakter, weil sie dem Nutzer als eine Oberfläche gegenübertreten, mit der zwar interagiert werden kann, die aber nicht zu penetrieren ist. Der navigierbare `Cyberspace〈, wie er sich z.B. in Form eines Hypertext-Systems manifestieren kann, entspricht für ihn hingegen einer architektonischen Konstellation (vgl. ebd.: 243).

Bei der Bewegung >im< Cyberspace agieren wir demnach immer nur mit Objekten, die vom Interface unseres Decks aktualisiert werden, während der $>$ Raum $<$ hinter den Dingen höchstens erahnt werden kann. Dies widerspricht augenscheinlich der von Novak ausgegebenen Zielsetzung des Cyberspace, die Subjekt-Objekt-Trennung zwischen Rezipient, Medium und Inhalt aufzuheben. Die Auflösung dieses Widerspruchs erfolgt durch ein funktionales Element innerhalb des Cyberspace, welches Novak als den »Navigator (ebd.: 231) bezeichnet. Der Navigator ist in Novaks Diktion vielleicht am ehesten als ein Stellvertreter des Nutzers zu verstehen - ein über das Interface ferngesteuerter virtueller `Roboter〈, der sich innerhalb der räumlichen Dimensionen des Cyberspace bewegt und durch dessen Augen der Anwender ihn er>fahren` kann. Dabei ist die Bezeichnung `Navigator` hier irreführend, wenn man sie allzu wörtlich nimmt. Der Navigator eines Schiffes hat selbst die Macht der Lenkung inne. Er führt also selbst das Ruder, während der Navigator nach Novak von außen gesteuert wird. Zugleich ist der Navigator der physischen Seefahrt in seiner Len- 
kungsmacht auf sein Schiff beschränkt. Er kann die Oberfläche des Meeres navigieren und sich nach dem Stand der Sterne orientieren, aber weder der Ozean noch das Firmament folgen seinen Anweisungen oder haben das geringste Interesse daran, ihm seine Arbeit zu erleichtern. Der virtuelle Navigator soll sich dagegen nach Novaks Vorstellung nicht nur im Cyberspace bewegen, sondern auch mit ihm interagieren und ihn auf eine Art gestalten, die es dem Nutzer erleichtert, an jene Information zu gelangen, die ihn interessiert:

My point in space is given by my navigator. Its forms can vary but the idea remains the same: I control a point in an n-dimensional space, say a cube. I assign meaning to each of the axes, and to any rotational parameters, material parameters, shape parameters, color and transparency parameters, and so on, that describe the »reality« of my icon. By moving my icon in this abstract space I alter the cyberspace I occupy. My navigator follows me at all times, and my position within it is fixed while I move within the cyberspace I have defined. Should I decide to search through a slightly different »reality« all I need to do is reach out for my navigator and alter a parameter. Otherwise, for more drastic navigation, I can alter a dimension, or even the number of dimensions. Finally, I may choose an entirely different coordinate system. In every case my deck is responsible for synthesizing the requested information in a new cyberspace. (Ebd.: 231)

Der Cyberspace ist in seiner Struktur und Erscheinung das Produkt des Wirkens virtueller Stellvertreter, über welche seine menschlichen Nutzer sich zu ihm verhalten. Er ist damit faktum und nicht etwa datum - wie die digitalen (Attribut-)Objekte, die ihn bewohnen, muss er laufend aktualisiert werden, um sein Vorhandensein behaupten zu können. Medialität und Inhalt bilden als Raum und Ding zwar kategorisch verschiedene Bezugsgrößen innerhalb des kommunikativen Systems, beide existieren aber in Abhängigkeit voneinander und entstehen aus der Ordnung einer virtuellen informationellen $\gg$ Rohmasse $<$ durch ein Interface-System, das Zentrum und Peripherie erst unterscheidbar macht. Dieser Vorgang lässt es im Grunde notwendig werden, von multiplen `Cyberspaces〈 statt einem gemeinsamen `Cyberspace zu sprechen, in welchem sich alle Nutzer gleichzeitig und gemeinsam bewegen. Denn weil seine Aktualisierung (bzw. im Novak'schen Duktus seine `Synthetisierung $`$ ) auf der Ebene des einzelnen Decks stattfindet, können unterschiedliche Nutzer zum gleichen Zeitpunkt sehr verschiedene Erscheinungsbilder des Cyberspace erleben, ohne dass seine `Substanz` davon betroffen wäre. `Cyberspace` als Terminus beschreibt hier weniger einen absoluten Raum, in dem alle Kommunikation in Computernetzwerken stattfindet, als vielmehr eine Pluralität kommunikativer Situationen, die auf Basis einer gemeinsamen technischen Grundlage möglich und von ihren Teilnehmern - die ihrerseits selbst in Informationsentitäten in Form von >Navigatoren « transformiert sind in ihrer Beschaffenheit laufend neu ausgehandelt werden. Dinge und Räume des Wissens werden dabei erst durch den Akt der Kommunikation selbst voneinander geschieden und mit Identitäten versehen, die zwar aus der jeweiligen Konstellation von 
Kommunizierenden und Information heraus weitgehend klar differenzierbar, jedoch keiner Kategorisierung a priori zu unterwerfen sind. Der Akt der prozeduralen, heuristischen Unterscheidung von Gegenständen und ihren Zwischenräumen ist für Novak genau das, was wir im Umgang mit dem Web als das `browsen` bezeichnen:

Furthermore, if these objects are not placed in any permanent system of categorization, that is, if as few assumptions are made about what these objects are, beyond their collection of attributes, then it becomes possible to envision cyberspaces created along the parameters of user's needs. Attribute-objects can be gathered and sorted by attributes or combinations of attributes, and these sorted collections can then be mapped onto coordinate axes. An information space can thus be formed, and motion through that space can imply »browsing.« (Ebd.: 236)

\subsubsection{Anschauung, Handlung, Raum und Räumlichkeit}

Wie im ersten Kapitel dieser Studie bereits angeklungen ist, waren solche Überlegungen zum Raum zum Zeitpunkt der Entstehung von Novaks Cyberspace-Theorie Anfang der 1990er Jahre durchaus nicht neu, und ebenso wenig wurden sie erst mit dem Aufkommen digital-virtueller Medien denkbar. Vielmehr lohnt hier abermals der Blick in die in Michel de Certeaus Kunst des Handelns ausgearbeitete Raumphilosophie, welche die Räume des kulturellen Handelns ja ebenfalls nicht als vorgefundene Settings begreift, die unser Agieren diktieren, sondern sie vielmehr gerade als die impliziten Resultate menschlicher Daseinsäußerungen auffasst: Räume entstehen aus dem Umgang mit und der Bewegung zwischen präexistenten Orten (vgl. Certeau 1988: 217ff.). Übertragen wir diese Kategorien auf den Cyberspace, wie Novak ihn definiert, so stellt sein von den Optionen medialen Ausdrucks aufgeschlossenes Koordinatensystem zunächst nur eine Ansammlung von lokalisierbaren Orten zur Verfügung, aus denen Raum erst durch menschlichen Verkehr geschaffen werden kann. Zwei weitere Begrifflichkeiten, mit denen Certeau die Schaffung kultureller Räume beschreibbar zu machen sucht, knüpfen unmittelbar an die Unterscheidung zwischen lieu und espace an und beschreiben Erfahrungsdimensionen des Raumes: auf der einen Seite die »Karte« (carte), auf der anderen die »Strecke« (parcours) (Certeau 1988: 220ff.; vgl. Olek u. Piepiorka 2012: 86f.).

Die `Karte stellt für Certeau einen alle kulturellen Praktiken der Raumstiftung zu umgehen trachtenden Umgang mit nackten, vorgefundenen Orten dar. Karten streben nach einem objektivierten Blick auf räumliche Verhältnismäßigkeiten wie Größe und Distanz von Erscheinungen innerhalb eines gemeinsamen Positionssystems (vgl. Certeau 1988: 222). Karten fallen damit also in die Domäne einer reinen Topologie - wobei natürlich bemerkt werden muss, dass jeder Abbildung eine Intention vorausgeht, und dass im Falle von Karten bereits die Entscheidung zur Abbildung sowie die 
Auswahl des Abzubildenden implizite kulturelle Botschaften, Wertungen und Relevanzaussagen beinhaltet (vgl. Olek u. Piepiorka 2012: 86f.). Die `Streckeく hingegen beschreibt das handelnde Sich-Bewegen im Raum, in dessen Zuge Orte zur kulturellen Verwendung gelangen und sich Räume zwischen ihnen ausbilden können (vgl. Certeau 1988: 221f.). Während Wexelblat den Cyberspace also aus der Perspektive der Karte konzipiert, denkt ihn Novak vor allem aus jener der Strecke heraus. Novak interessiert sich nicht vorrangig für abstrakte topografische Ordnungen in einem Datenraum, den der Nutzer in seiner >eigentlichen` Beschaffenheit weder zu sehen imstande noch zu sehen interessiert ist, sondern für die Praktiken des Umgangs mit verräumlichter Information, die in der Hypernatur des technischen Simulacrums Räume der Kultur entstehen lassen. Beide Autoren aber verstehen den Cyberspace nicht als eine im Voraus bestehende, räumliche Infrastruktur von Informationen und ihrer Vermittlung, sondern als Spatialisierungen von Beziehungen zwischen Informationsbausteinen im Vollzug ihres Abrufs durch einen Nutzer. Der Unterschied zwischen den beiden Cyberspace-Modellen liegt vor allem darin, wo genau diese Rezipientenfigur räumlich (und damit zugleich epistemisch) im Verhältnis zu den Informationsobjekten positioniert wird.

Novak erkennt interessanterweise die Ahnen des Cyberspace nicht etwa in Systemen der Informationsverwaltung - und damit eben auch nicht in den Vorgängern und Frühformen der Hypertexttheorie - sondern vielmehr in der abstrakten Kunst des 19. und 20. Jahrhunderts. Künstler wie Paul Klee, Piet Mondrian, Kazimir Malevich und Wassily Kadinsky nahmen, so Novaks These, die Erfahrungsdimensionen des Cyberspace insofern vorweg, als dass sie nicht etwa nach ordnender Abbildung einer präexistenten Wirklichkeit strebten, sondern vielmehr Attribute einer erfahrbaren Welt zu Objekten der Anschauung, des Verstehens und des Empfindens zusammenführten, die so zuvor nicht existiert hatten (vgl. Novak 1991: 244f.). Die abstrakte Malerei schafft, indem sie Farbe, Form, Textur usw. ohne direkte Abbildungsintentionen zusammenführt, originär neue Modi der Wahrnehmung und des Erlebens. Der Cyberspace definiert sich für Novak demnach weniger darüber, ein neues und womöglich besonders intuitives Abrufsystem für Gegenstände des Wissens zu sein, die schon vor der Digitalisierung und Vernetzung unserer kulturellen Kommunikation bestanden hatten. Stattdessen schöpft er seine lebensweltliche Relevanz für uns gerade aus seiner Fähigkeit, originär neue Wissensobjekte entstehen zu lassen, die außerhalb seiner medialen und semantischen Dimensionen so nicht existieren könnten.

Der Medien- und Kulturwissenschaftler Richard Rogers rückt den Cyberspace in einem Aufsatz aus dem Jahre 2011 in eine historische Perspektive und charakterisiert ihn dabei als eine überholte Begrifflichkeit. Er hält ihn in erster Linie für eine Verlegenheitsbezeichnung, mittels welcher man sich in den 1980er und frühen 1990er Jahren eine neue Medientechnologie zu erklären versuchte, die in den Alltag der breiten Öffentlichkeit noch überhaupt nicht vorgedrungen war. Das Netz erschien noch nicht als selbstverständlicher Bestandteil der sozialen Welt des Durchschnittsverbrauchers. 
Stattdessen sei es entweder in der Domäne jener Sub- und Konterkulturen verortet gewesen, welchen >virtuelle Welten Rückzug aus und Zuflucht vor der Mehrheitsgesellschaft zu versprechen schienen, oder aber in jene akademischer Expertendiskurse (vgl. Rogers 2011: 61). Für Rogers bestärkt die Vorstellung vom Cyberspace damit zugleich jene von einer harten Trennung zwischen >realer und > virtueller Welt - und diese wiederum besäße keinerlei analytischen Wert mehr in einer Alltagswelt, die von digitaler Technik ebenso durchdrungen ist wie von einer Selbstverständlichkeit des Umgangs mit derselben (vgl. ebd.: 64). Rogers hat hiermit sicherlich nicht ganz unrecht. Kulturwissenschaftliche (und gerade auch die sich auf sie beziehenden politischen) Diskurse über Digitalität und Virtualität scheinen allzu oft betriebsblind zu sein für die längst eingetretene Normalität des Virtuellen, anstelle derer sie sich an einer längst nicht mehr real gegebenen Neuheit der Technologien und der mit ihnen verbundenen medialen Erlebnisqualitäten abarbeiten.

Indes hält gerade der anhaltende Diskurs über die vorgebliche Ver- und Geschiedenheit der physisch-analogen Welt von der angenommenen informationellen Räumlichkeit digitaler Kommunikationssysteme diese als eine soziale >Tatsache〈 lebendig. Als solche bestimmt sie weiterhin mit darüber, wie sich Individuen, Gruppen und eben auch Institutionen in diesem Zwiespalt positionieren. Zugleich aber sind auch in einer Welt, in der Virtualität zur Normalität geworden ist, Widersprüchlichkeiten zwischen etablierten Dispositiven der sozialen Ordnung und den epistemischen, pädagogischen, affektiven oder politischen Programmatiken einer immer noch von rasanten Entwicklungen gekennzeichneten Medientechnik keineswegs ausgeschlossen. Dies gilt umso mehr, als dass der Computer als Meta-Maschine laufend neue Funktionalitäten hervorbringt, die immer wieder aufs Neue gesellschaftlich normalisiert werden müssen.

Insofern kann der Begriff des Cyberspace - insbesondere, wenn man ihn nicht nur als Schlagwort verwendet, sondern durch die Brille seiner Theoretiker und Propheten betrachtet - speziell im Zusammenhang mit solchen gesellschaftlichen und kulturellen Systemen wertvoll sein, in denen Digitalisierung und Virtualisierung nicht reibungslos und kontinuierlich ablaufen, sondern sich sperrig verhalten und als Bruch empfunden werden. Steve Woolgars zweite Regel der Virtualität ${ }^{6}$ impliziert auch, dass unsere Erklärungsmodelle und Metaphoriken für Virtualisierungsphänomene nicht überall gleichmäßig schnell verfallen und veralten. So mag der Cyberspace als virtuelle Gegenwelt und kategorisch >Anderes` nicht mehr akkurat den längst völlig ins realweltliche Leben der digital natives integrierten Umgang mit digitaler Technik beschreiben - im Hinblick auf die Museumsvirtualisierung erscheint

6 Die ja besagt, dass die mit Virtualisierungprozessen verbundenen Ängste und Risiken nicht gleichmäßig über Gesellschaften verteilt sind, sondern sich in bestimmten sozialen Systemen und Bereichen verdichten - siehe Kapitel 2.1.3 dieser Arbeit. 
er als Konzept jedoch überaus nützlich. Dies liegt zum einen daran, dass die Vorstellung einer Räumlichkeit von Information es in besonderem Maße ermöglicht, die Dispositive des Museums mit jenen digitaler Mediennutzung zu konfrontieren und auf funktionale Parallelen und Unterschiede hin zu untersuchen. Zugleich aber entsprechen die zum Cyberspace gehörigen kulturellen Konnotationen von Exotik, Neuheit, Fremdartigkeit und Unbeherrschbarkeit genau jenen Ängsten, die sich für das Museum mit digitalen Medien verbinden.

Gemein ist Museum und Cyberspace also vornehmlich die Idee eines Arrangements von Information im Raum, und damit verbunden das virtuelle Element einer Vieldeutigkeit der vermittelten Inhalte aus unterschiedlichen Perspektiven der Betrachtung. Gemein ist ihnen ferner auch, dass sie das, was sie beinhalten, als informativ und bezeichnend ausweisen. Der Zweck von Dingen, die im Museum stehen, wird von der Institution selbst als ein kommunikativer und medialer gekennzeichnet. Der Cyberspace wiederum ist eine Visualisierung von Information und besteht überhaupt nur aus der Tatsache heraus, dass er etwas mitzuteilen hat. In beiden Fällen müssen Bedeutungen aktualisiert werden - wobei im Falle des Cyberspace die Aktualisierung in zwei Schritten erfolgen muss, da die Ebene des Decks und seines Interfaces zwischengeschaltet ist. Schließlich und endlich verbindet Museums und Cyberspace paradoxerweise gerade ihre Verortung im `Außer- $\prec$ oder Gegenweltlichen .

Das Museum ist, wie es ja schon bei Valéry so nachdrücklich und emphatisch betont wird, eben kein Raum des `Lebens « im Sinne von Verrichtungen des Alltags. Es steht außerhalb der Normalität und kann, wie man mit Malraux und Theodor Grütters These vom >realen Objekt außerhalb des Realen` weiter ausführen kann, seine Funktion als Bildungsdispositiv überhaupt nur aus dieser Außeralltäglichkeit heraus erfüllen. Brigitte Scheer unterscheidet hier unter Rückgriff auf die Raumtheorie Elisabeth Stökers zwei Typen von Räumlichkeit, in denen sich zwei unterschiedliche kulturelle Programmatiken abspielen. Die Idee eines Raumes, der als natürliche Konstante vorgegeben ist und nur durch bildnerische und architektonische Maßnahmen verändert werden kann, fällt laut Scheer unter das Paradigma eines reinen »Anschauungsraumes «, in welchem sich das schauende Subjekt als passiver Betrachter der ihm gegenüberstehenden Objekte erlebt (vgl. Scheer 2000: 239). Diese Ebene der Raumerfahrung kontrastiert Scheer mit jener des »Aktionsraumes« (ebd.), die Certeaus Vorstellung von im Zuge menschlicher Tätigkeit erst prozesshaft /gemachten Raumordnungen durchaus verwandt ist: In unserem Umgang mit der physischen Welt interagieren wir mit Räumen nicht immer als unverhandelbaren, vorgefundenen Handlungsdeterminanten und -eingrenzungen. Vielmehr ziehen wir beim Handeln im Raum laufend mentale Grenzen durch unsere Erfahrungswelt (ebd.) - Aktionsräume sind damit also im besten Sinne des Wortes `Arbeitsplätzeく. Während im Anschauungsraum Dinge vor allem in ihrer räumlichen Ausformung von Interesse sind (also darin, wie sie den Raum ausfüllen oder begrenzen), geht es in Aktionsräumen eher um ihr generelles Vorhandensein innerhalb der unmittelbaren Interaktionsreichweite 
eines Subjekts - oder wie Scheer es mit Heidegger nennt, um ihre »Zuhandenheit« (ebd.). Im Anschauungsraum wollen die Dinge betrachtet und im räumlichen Kontext begriffen werden - Scheer spricht hier mit begrifflicher Nähe zu Aleida Assmann von einem »physiognomischen Verstehen « (ebd.), das sich bei Scheer allerdings anders als bei Assmann weniger auf das individuelle Ding als auf die räumliche Gesamtsituation bezieht. Im Aktionsraum sind die Dinge dagegen bereits verstanden und können verwendet werden, ohne dass sie zuvor einer Semiose unterzogen werden müssten. Während der Mensch im Anschauungsraum eine rigide Subjekt-ObjektTrennung erfährt, in welcher die physikalischen Dinge in all ihrer Tiefe als sein nicht zu durchdringendes Gegenüber auftreten, werden die Dinge im Aktionsraum zu Werkzeugen und Erweiterungen seiner Subjektivität bzw. seines Handlungspotentials als Subjekt (vgl. ebd.). Insofern sind Anschauungs- und Aktionsräume gleichermaßen Dispositivgefüge: Sie etablieren Ordnungen der Sichtbarkeit und produzieren aus diesen Ordnungen heraus Subjektrollen für die Menschen, die sich in ihnen bewegen und mit ihnen umgehen.

\subsubsection{Flüssige Architekturen}

In gewisser Weise lässt sich damit die Musealisierung von materiellen Gegenständen als deren Überführung aus einem Handlungs- in einen Anschauungsraum und damit als ein Dispositivwechsel beschreiben: Die antike Amphore, die ein Gebrauchsgegenstand war, hatte in ihrer Ursprungssituation ihren Verwendern nichts mitzuteilen. Ihre Funktion war es nicht, Bedeutungen zu speichern und zu transportieren, sondern Flüssigkeiten. Sie war eben für ihren Gebrauch im Alltag >zuhanden $<$ - zwar war ihre Präsenz im Raum im streng physikalischen Sinne keine andere als jene, die sie heute als Museumsding aufweist, aber in der Praxis des Umgangs mit Objekten des Aktionsraumes bleiben diese sunsichtbar` oder werden zumindest nicht dezidiert angeschaut. Zwar wird ihre Rolle in räumlichen Arbeitsprozessen nach wie vor von ihrer Materialität und Physikalität bestimmt (die Amphore z.B. konnte eben nur so benutzt werden, wie sie benutzt wurde, weil sie zwei Griffhenkel und einen Hohlraum aufweist, der sich befüllen lässt), diese Materialität jedoch wird im Aktionsraum nicht als Physiognomie, sondern als Funktionalität wahrgenommen. In der Musealisierung wiederum wird das Zuhandensein der Objekte durch ihre Sichtbarkeit abgelöst: Die Amphore bleibt nun zwar im physischen Sinne ১leer`, wird aber zugleich mit Bedeutungen gefüllt. Sie kann uns jetzt etwas mitteilen, jedoch nur, weil sie eben nicht länger `benutzt` wird und dementsprechend als materielles Ding nicht mehr in ihrer eigenen Zweckdienlichkeit untergeht. Museen sind also notwendigerweise Anschauungsräume, und als solche wiederum Räume des Außergewöhnlichen. 
Dennoch ist das Museum als völlig statischer und dem Besucher in abgeschlossener Gänze gegenübertretender Raum der Anschauung nur unzureichend beschrieben. Zwar definiert es sich erstens darüber, dass es von der umgebenden Außenwelt erkennbar abgetrennt, und zweitens darüber, dass es mit durch diese Trennung als museal ausgewiesenen Gegenständen ausgestattet ist. Dabei befindet der museale Raum sich jedoch stets in einem reziproken Verhältnis sowohl zur Arbeit der Museumsschaffenden, als auch zu seinen Besuchern. Als kulturelles Dispositiv entsteht das Milieu Museum erst aus den sich in ihm abspielenden Sinnbildungsprozessen, welche sowohl die Ausstellungstätigkeit, als auch die Rezeptionserfahrung und das zu ihr gehörende Wohlverhalten beinhalten. Das Museum ruft nicht nur einseitig den von Paul Valéry beschriebenen Andachtsgestus zwischen Alltag und Kirchgang bei seinen Besuchern hervor, sondern es entsteht als soziale und kulturelle Erfahrungsgröße nicht zuletzt auch aus den mit dem Museumsbesuch verbundenen sozialen Skripten, die von den Besuchern performativ ausgespielt und somit affirmiert werden. Stefan Pauls Vorstellung vom Museum als einer Umkehr des Theaterdispositivs, in welchem die darbietenden Objekte auf ihrem Platz bleiben und das Publikum sich im Raum bewegt (vgl. Paul 2005: 354f.), sollte den Blick auf die kreative Mittäterschaft der Besucher nicht verstellen: Im Museum wie im Theater wirken Besucher bzw. Zuschauer an der Darbietung mit, indem sie sich in bestimmte soziale Rollen begeben und bestimmten sozialen Drehbüchern folgen. Diese Drehbücher wiederum bringen die Dispositive >Museum` und `Theater` ebenso sehr hervor, wie sie von ihnen hervorgebracht werden. Auch das Schauen des Rezipienten wird im Museum zu aktivem Handeln: Wie im ersten Kapitel dieser Arbeit ja bereits herausgearbeitet wurde, setzen museale Inszenierungen das Gesehenwerden voraus, bzw. existieren Museen immer nur im Kontext einer `Öffentlichkeit`, die sie besucht. Insofern zeigt sich hier eine weitere Parallele zwischen Museum und Cyberspace, die im Kontext der Museumsvirtualisierung brisant werden muss: Beide sind räumliche Systeme, die von Visualität abhängig sind und somit nur dort existieren, wo sie in ihrer Räumlichkeit von Betrachtern wahrgenommen werden. Insofern ist diese Räumlichkeit immer performanzabhängig. Das Museum ist als Gebäude und als Anordnung materieller Dinge eine Infrastruktur für bestimmte soziale Situationen, zum Dispositiv wird es aber erst im Parcours seiner Besucher, die seine einzelnen 〉Orte ২ (die man z.B. in den einzelnen Exponaten erkennen kann) zu sinnhaft gefügten >Räumen`verbinden. Auch im Cyberspace muss dies vom Rezipienten geleistet werden, jedoch findet diese semantische Gemachtheit eine Entsprechung in der Prozesshaftigkeit digitaler Bilderzeugung selbst.

Certeaus Raumphilosophie soll uns hier nicht zu unkritischem Konstruktivismus verleiten. So richtig es natürlich ist, dass wir in kulturellen Kontexten weniger mit Räumen in ihrer reinen Physikalität interagieren als mit gemachten Bedeutungssystemen, die wir auf Räume projizieren und die dann wiederum unsere Erfahrung des physischen Raumes entscheidend beeinflussen, so unumstößlich ist wiederum auch 
die Tatsache, dass die harten physikalischen Realitäten des Raumes zugleich auch die Grenzen seiner Erlebbarkeit bestimmen. Es gibt keinen unendlich weit ausgedehnten Ausstellungsraum - und gäbe es ihn, so ist überaus fraglich, ob dieser etwas beherbergen könnte, was wir als ein Museum zu erleben imstande wären. Wie Andreas Urban anmerkt, existiert keine Form absoluter musealer Darstellung. Was Museen anbieten, ist nicht etwa >die Vergangenheit< oder auch nur >die Geschichte im Sinne einer Auseinandersetzung mit der Vergangenheit, sondern jeweils nur ein schlaglichtartiges »Geschichtsbild« (Urban 2009: 75). Diese Beschränktheit der musealen Perspektive ist für Urban wiederum ein konstitutives Merkmal der Institution: Wenn Museen ihre Exponate als Träger von zu empfangenden Botschaften für den Besucher ausweisen, so verbriefen sie damit zugleich eine Autorschaft der Kuratoren (vgl. ebd.). Kuratorische Autorschaft wiederum manifestiert sich in der Auswahl von Objekten und ihrer Positionierung im Raum - und diese Auswahl und Positionierung trägt die Züge von Autorschaft und Handlungsabsicht eben deshalb, weil sie in begrenzten und physisch fest strukturierten Räumen stattfindet. Ein Museum, das keine Objekte ausschließt, wäre ebenso wenig zu verstehen wie ein Text, der keine Worte ausschließt. Das einzelne Objekt wäre beliebig und die Institution nicht länger imstande, sich für die Sinn- und Zeichenhaftigkeit der Ausstellungsstücke zu verbürgen. Insofern ist die Abgeschlossen- und Begrenztheit des Museums kein Defizit, sondern eine Eigenschaft, die seine Existenz als gesellschaftliches Dispositiv erst ermöglicht. Museen sprechen nicht nur vermittels der Dinge, die sie uns zeigen, sondern auch vermittels jener, die sie uns vorenthalten.

Die sich mit dem Cyberspace verbindende Erwartung an eine von digitalen Medien getragene Informationsgesellschaft hingegen lebt vom Versprechen der völligen semantischen Offenheit eines Wissens-Raumes, der ohne die Hierarchie individueller Autorenschaften auskommen soll. Zugleich aber sollen Cyberspaces auch imstande sein, die Signifikanz aller in ihnen enthaltenen Information zu bewahren und eben nicht beliebig werden zu lassen. Zum Garanten der Sinnhaftigkeit wird eben der >Cyber-Aspekt selbst als jenes Element der Steuerung und Rückkopplung, welches dafür sorgen soll, dass der Rezipient im Cyberspace nicht einfach auf einem Ozean der Information treibt, sondern vielmehr laufend gelenkt und angeleitet wird. Diese Lenkung und Anleitung findet aber nicht in einem Raum statt, der sich in einer bestimmten, endgültigen Verfassung präsentiert und nach kultureller Deutung verlangt, sondern in einem, dessen Struktur vom Rezeptionsverhalten seiner Besucher tatsächlich beeinflusst und geformt wird. Insofern will der Cyberspace sowohl Handlungs- als auch Aktionsraum sein, oder genauer noch: Indem der Rezipient sich im Cyberspace nur als digitale Doublette seiner selbst bewegt - genau dies beschreibt Novak ja mit dem >Navigator<-Konzept - verwandelt er sich selbst in ein Informationsobjekt. Dieses wiederum kann (man denke an Berners-Lees semantic web) nicht nur Informationsfragmente oder Attribute zu von Menschen rezipierbaren digitalen Objekten zusammenfügen, sondern es kann vor allem auch seinerseits von Computern als eine 
funktionale Einheit erkannt und verstanden werden. Insofern ist in der Navigation digital-virtueller Räume die Trennung zwischen Rezeption und Aktion aufgehoben: Jeder Abruf von Information stellt eine Aussage gegenüber dem Computernetzwerk dar, die ihrerseits informativen Charakter hat. Die Information darüber, dass und was ich rezipiere, ist für einen Computer qualitativ nicht fundamental verschieden von der Information, die ich rezipiere. ${ }^{?}$

Um nun der Prozeduralität solcher virtueller Räume gerecht zu werden, erweitert Novak den Begriff der Architektur als Modus der Raumgestaltung um ein Adjektiv, das abermals eine bestimmte Materialität evoziert: Er spricht bei der Praxis der Strukturierung des Cyberspace von einer »liquid architecture (Novak 1991: 251), die im Gegensatz zu physikalischen Architekturen eben keine feste und unveränderliche Ordnung in einen vorgefundenen Raum stellt, sondern die Räume um denjenigen herum laufend neu entstehen lässt, der sich durch sie hindurchbewegt. ${ }^{8}$ Die Kommunikation schafft sich also nicht nur ihre Gegenstände, sondern auch die Referenzgrößen ihrer Umwelt:

I look to my left, and I am in one city; I look to my right, and I am in another. My friends in one can wave to my friends in the other, through my having brought them together. (Ebd.: 249)

Wenn wir den Cyberspace als funktionales Modell für den Ablauf kultureller Kommunikation in und über digitale Medien voraussetzen oder auch nur Züge liquider Architekturen im World Wide Web erkennen wollen, dann erscheint der Begriff des >virtuellen Museums` zunächst einmal als eine überaus problematische Bezeichnung für digitale Angebote. Wenn Räume in den flüssigen Architekturen digitaler Medien laufend neu verhandelt werden, dann ist es schwierig, in ihnen eine Institution zu etablieren, die sich ja gerade durch ihre bauliche Trennung von der sie umgebenden Welt auszeichnet. Museum und Cyberspace mögen beide als Gegenwelten zu unserem gewohnten Lebensmilieu erscheinen und dabei beide die Merkmale des Certeauschen Handlungsraumes aufweisen, im Gegensatz zum Museum aber ist der Cyberspace keine singuläre Institution mit einem klaren Auftrag. Er erscheint nicht als Gegenstück eines bestimmten sozialen Settings, wie das Museum z.B. dem heimischen Wohnzimmer gegenübersteht, sondern schlechthin als eine Antithese zur materiellen Welt. Wir können das Museum dementsprechend nicht schlechthin dem Cyberspace gegenüberstellen, sondern allerhöchstens bestimmten Zusammenkünften digitaler Objekte im Cyberspace, die Züge des Musealen aufweisen oder emulieren.

7 Kapitel 5 dieser Studie wird sich diesem Aspekt der Lenkung und Analyse von Nutzerverhalten noch eingehender widmen.

8 Zum Gebrauch von Flüssigkeitsmetaphern im Zusammenhang mit digitaler Medientechnik vgl. Niewerth 2013: 1ff. sowie Niewerth 2014. 
Solche >Gebäudeく im Cyberspace sind aber keine gesetzten institutionalisierten Raumsysteme, die als Dispositive ein bestimmtes Wohlverhalten von ihren Besuchern einfordern. Vielmehr sind sie Muster, die sich aus den Navigationsentscheidungen der Nutzer erst herauskristallisieren und dann zugleich - wie in einem Experimentalsystem epistemische Dinge schließlich zu technischen werden können - den Bezugsrahmen aller weiteren Orientierung bilden. In den physischen Museen der Belle Époque, die Paul Valéry mit solchem Unbehagen durchwandern musste, ist es die Institution Museum in ihrer ganzen kulturellen Geltung und Schwere, die ihm ein Betragen irgendwo zwischen alltäglicher Gelassenheit und sakraler Andacht aufzwingt. In digitalen Medien kehrt sich dieses Verhältnis um: Hier kann das Museum sich nur um den Nutzer herum konstituieren, wird von seinem Verhalten gewissermaßen erst heraufbeschworen. Virtuelle Museen entstehen überall dort, wo Computer und Web gemeinsam als Museum verwendet werden - nicht der >Raum` des virtuellen Museumsbesuchs ist Träger der Musealität, sondern vielmehr der >Besucher in seinem Benehmen und Erkenntnisinteresse (das freilich wiederum beeinflusst werden kann durch die Selbstbeschreibungen von Webangeboten und die Strukturen ihrer Verlinkung). Auf dieselbe Art können so auch virtuelle Kathedralen, Kaufhäuser, Bibliotheken usw. als flüssige Architekturen um die Bedürfnisse der Nutzer entstehen und wieder vergehen, wenn der Bedarf nach ihnen erloschen ist (vgl. ebd.: 249). >Liquid architecture ‘ ist also einerseits veränderlich, reaktiv und >lebendig`, dabei aber niemals eigendynamisch, weil sie stets den Menschen als intendierendes Subjekt benötigt. Während das Selbst sich in der Architektur der physikalischen Welt im Prozess des Bauens Räume schafft, in denen es sein kann, wird es sich in den liquiden Architekturen digitaler Medien selbst zum Raum (vgl. ebd.: 250f.).

\subsubsection{IVirtuelle Realitätı und Grenzen der Raum-Metaphorik}

In diesem Sinne ist, wie Stefan Münker bereits Ende der 1990er Jahre beobachtet, der Cyberspace eben keine Gegen-Realität außerhalb der physikalischen, sondern fällt vielmehr in die Domäne dessen, was seit den 1980er Jahren mit dem Begriff der virtual reality überschrieben wird: Der Cyberspace, so fährt Münker fort, ist weder irreal noch surreal, sondern schlicht ein von vernetzten Computern getragenes mediales System, in welchem sich Produzenten und Rezipienten gleichermaßen artikulieren - und diese Artikulationen wiederum sind nicht mehr oder weniger real als jede andere Form kultureller Äußerungen (vgl. Münker 1997: 126f.).

Die Prägung des Begriffes der >virtuellen Realität « wird meist dem Computerwissenschaftler, Künstler und Komponisten Jaron Lanier zugeschrieben, dessen zu Beginn der 1980er Jahre gegründete Firma VPL Research als einer der ersten Fabrikanten VR-Utensilien wie head-mounted displays und Datenhandschuhe am Markt zu 
etablieren versuchte. Da sich eine erste Nennung des Begriffes im Druck nicht datieren lässt, nimmt Lanier selbst für sich allerdings lediglich in Anspruch, ihn »geprägt oder popularisiert « zu haben. ${ }^{9}$ Dass dieser Terminus etwa zur gleichen Zeit in den öffentlichen Diskurs eintritt wie jener des Cyberspace ist kein Zufall: Das bis ins Mittelalter zurückreichende Denken in und über Virtualitäten als eine erst durch das verwirklichende Handeln in die Erfahrbarkeit überführbare Erscheinungsform des Wirklichen bleibe nämlich, so Münker, unter den Voraussetzungen der physischen Wirklichkeit meist ein rein philosophisches. Zwar werden auch in unserer materiellen Umwelt ständig Dinge `verwirklicht $\iota$, die zuvor nur als Potentialität existiert haben, aber ihre physikalischen Gesetzmäßigkeiten setzen dem, was grundsätzlich aktualisierbar ist und den Arten, wie diese Aktualisierung stattfinden kann, sehr konkrete Grenzen. Darüber hinaus erleben wir Virtualitäten üblicherweise nicht im Zustand ihrer Virtualität, sondern nur in fortschreitenden Zuständen ihrer Verwirklichung (vgl. ebd.: 112ff.). Der einem Hausbau vorausgehende architektonische Entwurf ist ein virtuelles Phänomen, aber alle Erscheinungsformen des Hauses auf dem Weg zu seiner Aktualität als Raum des Wohnens sind ihrerseits materiell präsent - von der Architekturzeichnung über die Baugrube und alle darauffolgenden Stadien der Fertigstellung begegnet uns das werdende Haus als eine positive, materielle Erscheinung. Sein virtueller Zustand der Vollendung bleibt ein imaginärer bis zu jenem Augenblick, in dem er zur Aktualität wird. Ähnliches gilt für das Erleben von Museumsausstellungen: Die im Gefüge der Sinnträger implizit angelegten Narrative und Deutungsmöglichkeiten werden erst dann wahrnehmbar, wenn sie aktuell geworden sind, wenn also beim Rezipienten bereits eine oder mehrere Deutungen Gestalt angenommen und alle anderen möglichen Lesarten ausgeklammert haben. Digitale Medientechnologien und ihre Interfaces hingegen ermöglichen uns laut Münker ein sehr viel intensiveres und bewussteres Erleben virtueller Seinszustände von Gegenständen des Wissens.

Dies liege zum einen daran, dass im Cyberspace das `Mögliche`sehr viel weiter bemessen ist als im physikalischen Universum. Zwar unterliegt der Cyberspace als Produkt digital arbeitender Hard- und Software den Gesetzen des mathematischen Codes und damit der Tatsache, dass er nur das visualisieren kann, was sich mathematisch beschreiben lässt - aber während die Mathematik in der physikalischen Welt beschreibend wirkt, hat sie im Cyberspace vor-schreibende, eben: pro-grammatische Funktion. Der Physiker artikuliert in der Sprache der Mathematik ein formales Abbild der Welt, deren Funktionalität er beobachten kann, überträgt also Aktualität in Virtualität. ${ }^{10}$ Der Programmierer hingegen arbeitet in einem formalen mathematischen System, in dem Ding und Beschreibung nicht unterscheidbar sind. Den von

9 http://www.jaronlanier.com/general.html vom 13.05.2018, Hervorhebung D.N.

10 Dabei ist es freilich verblüffend, dass der Kosmos immer wieder der zwingenden Logik unserer Beschreibungssprache zu folgen scheint - deswegen kann die theoretische Physik 
ihm geschaffenen Virtualitäten geht keine Aktualität voraus, an deren Beschaffenheit er gebunden wäre - er kann also ermöglichen, was er will, solange es sich algorithmisch ausdrücken lässt.

Zum anderen diagnostiziert Münker in den Interfaces digitaler Medien einen schnelleren und sichtbareren Übergang zwischen Virtualität und Aktualität, der sich auf das »utopische« Moment virtueller Räume gründet (ebd.: 126). Dabei meint er »Utopie« wortwörtlich: Virtuelle Orte und Raumgefüge sind `U-Topoi < im Sinne von >Nicht-Orten`, die zwar im kulturellen Sinne durchaus `real sind, aber eben kein permanentes Substrat besitzen. Vielmehr müssen sie diskursiv und aktiv >beschworen< werden und haben Bestand nur durch jene Handlungen und Kommunikationen, deren Rahmen sie bilden. Vor diesem Hintergrund ist der Cyberspace für Münker schlicht die sinnfälligste denkbare Ausprägung von virtueller Realität: Er ist die auf ein technisches Fundament gestellte Möglichkeit des Entstehens und der Veränderung kultureller Sachverhalte vermittels einer Schnittstelle, die visuell funktioniert und daher mit der physikalischen Erfahrungswelt sichtbar verbunden ist (vgl. ebd.). Dabei erleben wir das Erscheinen, Verschwinden und Einander-Ablösen von Tatsächlichkeiten hier in sehr viel rapiderer Abfolge, als dies in der physikalischen Realität möglich wäre.

\subsubsection{Räumlichkeit und Raumlosigkeit virtueller Museen}

Insofern ist es vielleicht nur folgerichtig, dass derzeit nur wenige als > virtuelle Museen auftretende Web-Angebote sich tatsächlich einer Computergrafik bedienen, welche die Räumlichkeit unserer körperlichen Erfahrungswelt nachzubilden imstande wäre. Stattdessen begegnen uns die meisten solcher Internetauftritte unverblümt als eben solche, nämlich als gewöhnliche hypertextuell verlinkte Webseiten, deren gemeinsame Beschaffenheit als virtuelles Museum ausgewiesen ist durch ihr Abrufbar-Sein unter einer gemeinsamen Domain, die mit den technischen Auszeichnungen $h t t p: / / w w w$. beginnt und mit einem Länderkürzel endet, sowie eine die >eigentlichen Wissensinhalte begleitende Dokumentation der dem Hypertextgefüge zugrundeliegenden Autorschaft (wie sie sich z.B. in Front- und Impressumsseiten ausdrückt, aber auch im die einzelnen Webseiten ästhetisch verbindenden Webdesign). Dies hat sicher zunächst ökonomische Gründe: Sollen Computerbilder heutzutage routinierte Nutzer noch beeindrucken, so müssen sie sich an den bereits auf unseren Bildschirmen präsenten Bilderwelten messen lassen. In einer Zeit, in der Computerspiele nicht selten mit den Budgets von Hollywoodfilmen produziert werden und

ihre Formalismen über das hinaus weiterdenken, was augenblicklich zu beobachten ist und aus der zwingenden Logik der Mathematik heraus immer wieder akkurate Voraussagen über das Eintreten und Ausbleiben von Phänomenen machen. 
Endnutzer-Grafikhardware zunehmend digitale Bildgebungen ermöglicht, die einem >Photorealismus« schon recht nahekommen, liegt hier die Messlatte denkbar hoch.

Womöglich jedoch steckt hinter dem weitgehenden Verbleib der virtuellen Museen im Hypertext-Format der HTML-Seiten jedoch mehr als nur ein Problem der technischen und damit auch finanziellen Machbarkeit von computergrafisch umgesetzten virtual reality-Umgebungen. Hypertexte, so stellt Roberto Simanowski fest, sind eine mediale Erscheinung, bei der kulturelle Erwartungshaltung und tatsächliche Funktionalität weit auseinanderdriften. Das vermeintliche Versprechen vom (nun nicht einmal mehr metaphorischen, sondern wortwörtlich zu verstehenden) >Tod des Autors im Spiel der Assoziationen von Textpartikeln sei von ihnen niemals eingelöst worden. Vielmehr, so Simanowskis These, suggerieren uns Hypertexte Freiheitsgrade der Bedeutung und Sinnhaftigkeit, die sie tatsächlich nicht aufweisen. Er diagnostiziert hier im Besonderen eine Verwechslung der kombinatorischen Offenheit von Hypertexten mit ihrer konnotativen: Die Rolle des Rezipienten bei der Erzeugung einer bestimmten strukturell-semantischen Verfasstheit des Textes (die aus dem Akt des Verfolgens von Links resultiert) wird verwechselt mit seiner Rolle in der transitiven Erzeugung der Bedeutung von Text (vgl. Simanowski 2002: 68). Eine Freiheit bei der Kombination vorgefundener Textbausteine impliziert aus sich heraus noch keine Freiheit im Verständnis oder in der Interpretation der so entstehenden Textsequenzen, und damit auch keine gesteigerte Souveränität des Lesers im Umgang mit dem Text. Insofern sei das Hypertext-Format in vielerlei Hinsicht zu Unrecht als eine emanzipatorische Form des Schreibens idealisiert worden. Auch in Hypertexten überschreibe der Annotationskosmos des Autors stets den Konnotationskosmos des Rezipienten - letztlich beinhalten Hypertexte eben nur jene konkreten Textelemente und Links, die ihnen von ihren Autoren eingestiftet worden sind (vgl. ebd.). Mit dem Element der Verlinkung wiederum werde den Autoren ihre Kontrolle über den Text nicht etwa entzogen, sondern vielmehr um eine ganz neue Ebene erweitert, die nun nicht mehr nur den Inhalt, sondern schlechterdings die Funktionalität von Texten und die Beschaffenheit der Texterfahrung insgesamt berühre. Verlinkung, davon ist Simanowski überzeugt, generiere einen Zustand ständiger, unweigerlich erkundender Bewegung des Rezipienten, der ständig nach dem nächsten assoziativen Sprung verlangt, anstatt zur Reflexion über das bereits gelesene einzuladen (vgl. Simanowski 2008: 49). Dies führe nicht etwa zum Tod des Autors, sondern vielmehr zu jenem des Lesers: Es werde nicht mehr reflektiert, überdacht und verstanden, sondern nur mehr an bestehenden Textpfaden entlanggestampft, die aus ihrem virtuellen Vorhandensein heraus nach Aktualisierung verlangen (vgl. ebd.).

In diesem Sinne sind verlinkte Hypertexte per se noch keine Cyberspaces, auch wenn sie in ihrer Funktionalität die Züge einer zweidimensionalen Räumlichkeit aufweisen. Verlinkung, wie sie das Merkmal von HTML-Seiten ist, trägt gemeinhin die Züge einer Autorschaft, auch wenn diese nicht notwendigerweise die einer Einzel- 
person sein muss (man denke nur an die Wikipedia, die ja die kollaborative Errungenschaft zigtausender Mitwirkender darstellt). Mit Rückblick auf die in diesem Kapitel zu kuratorischer Arbeit getroffenen Aussagen müssen wir uns sogar fragen, ob nicht die Verständlichkeit eines Hypertextes ebenso wie jene einer Museumsausstellung gerade darauf basiert, dass eine ausgewiesene Autorschaft uns die grundsätzliche Sinnhaftigkeit der präsentierten Inhalte garantiert und damit die Abduktion vorwegnimmt. Hypertexte im WWW kennen zwar keine so klare Trennung von ihrer >Umwelt`, wie sie sich in den Mauern eines Museumsgebäudes manifestiert, jedoch weisen auch sie topologische Verdichtungen und Ausdünnungen auf, die auf Zusammengehörigkeiten und Verschiedenheiten schließen lassen. Beim Surfen auf Wikipedia erleben wir uns ganz unzweifelhaft als Leser der Wikipedia und keiner anderen Webseite, auch wenn zwischen der freien Enzyklopädie und dem Rest des Webs keine Mauern oder Gräben gezogen sind. Ein Dienst wie Youtube ist recht klar von anderen Webseiten zu unterscheiden - selbst von solchen, die tatsächlich ganz ähnliche Funktionalitäten anbieten. Die Mechanismen dieser hohen Identifizierbarkeit diskreter Einheiten im Web wurden bereits genannt: Ein Wikipedia-Artikel oder ein Youtube-Video sind im Sinne Yuk Huis und Marcos Novaks digitale bzw. AttributObjekte, deren innere Zusammengehörigkeit und äußere Geschiedenheit vom Rest der Welt ein Produkt der Rezeption sind - nur findet die Rezeption von Web-Inhalten niemals im luftleeren Raum statt. Während Vannevar Bushs Memex-Nutzer noch ein wahrer Info-Pionier war und in der Maschine lediglich das Werkzeug zur Erschließung von Texten vorfand, deren wechselseitige Bezüglichkeiten er selbst ausarbeiten musste, tritt uns das Web bereits vernetzt und strukturiert gegenüber.

Die Frage nach dem virtuellen Museum kann daher nicht nur als eine theoretische nach den grundsätzlichen Potentialen und Implikationen digitaler Medientechnik gestellt werden, wie sie in diesem Kapitel stattgefunden hat - obschon eine solche unumgänglich ist, um sich der Entstehung von Dinghaftigkeit und Räumlichkeit und dem Verhältnis zwischen der Funktionalität und der Metaphorik des Mediums anzunähern. Es gilt nunmehr, hier anzuknüpfen und das virtuelle Museum unter den konkreten und tatsächlichen technischen Voraussetzungen des World Wide Web ins Zentrum der Betrachtung zu stellen. 


\section{Das Museum von Babel?}

Wenn man in zeitlicher Nähe zum Informationszeitalter nach Texten sucht, welche mustergültig jene Informationsangst zum Ausdruck bringen, die nach Konrad Becker die abendländische Geschichte durchdringt, so wird man fast unweigerlich auf Jorge Luis Borges' 1941 entstandene Kurzgeschichte Die Bibliothek von Babel stoßen und, wenn man etwas weiter gräbt, vielleicht auch auf den ihr bereits 1904 vorausgegangenen und weniger bekannten Text Die Universalbibliothek aus der Feder des deutschen Science-Fiction-Pioniers Kurd Laßwitz. In Die Universalbibliothek entwirft Laßwitz als Gedankenexperiment eine Bibliothek, die in ihren Büchern jede mögliche Permutation des lateinischen Alphabetes beinhaltet - also jede mathematisch mögliche Zusammenstellung der uns zur Verfügung stehenden Buchstaben und damit notwendigerweise auch jeden Text, der sich mit diesen schreiben lässt. Eine solche Bibliothek würde, so Laßwitz, tatsächlich alles menschliche Wissen enthalten, das sich sprachlich und schriftlich artikulieren lässt - und für uns als Kulturwesen doch vollkommen nutzlos bleiben, denn: Die sinnvollen und in unseren Lebenskontexten interpretierbaren Texte würden versinken in Bergen von Kauderwelsch und sinnlosen Zeichenfolgen, und es gäbe für die menschlichen Nutzer der Universalbibliothek praktisch keine Möglichkeit, aus der aberwitzig großen Anzahl ihrer Bände jene herauszusuchen, die sich tatsächlich im Sinne eines transitiven Verstehens >lesen lassen (vgl. Laßwitz 1998). Damit bezieht Laßwitz ganz ausdrücklich Stellung zum virtuellen Moment der Schrift: Im Codesystem der Buchstaben und Satzzeichen ist implizit eine unvorstellbar große Zahl von Texten bereits vorhanden - und der Nutzen der Schrift als Trägermedium von Wissen und kulturell-historischer Kontinuität ist gerade davon abhängig, dass wir nicht jeden dieser virtuellen Texte aktualisieren, sondern nur jene, die wir sinnhaft in Bezug zu unserer Erfahrungs- und Vorstellungswelt setzen können.

Während Laßwitz die Universalbibliothek als ein amüsantes statistisches Gedankenspiel abhandelt und dieses verwendet, um modernen Informationsutopismen eine wohlwollend-humorvolle Absage zu erteilen, ist die Vorstellung von der absoluten Bibliothek für Borges eine zutiefst tragische. Seine Bibliothek von Babel wird uns als 
ein »Universum « (Borges 2010: 146) der Information vorgestellt, das die Gestalt einer möglicherweise endlos übereinander gereihten und von einer Wendeltreppe miteinander verbundenen Abfolge sechseckiger Räume annimmt. An je vieren dieser Wände befinden sich jeweils fünf Bücherregale, während die beiden übrigen Seiten von einer Toilette und einem Schlafplatz eingenommen werden, die das Überleben im Universum der Bibliothek möglich machen sollen (vgl. ebd.: 146ff.). Jede Etage der Bibliothek beherbergt also 20 Regale. In jedem Regal befinden sich genau 32 Bücher, von denen jedes exakt 410 Seiten stark ist. Jede einzelne Buchseite wiederum ist beschrieben mit exakt 40 Zeilen, von denen jede genau 80 Zeichen enthält. Die Zeichen, die in den Bändern der Bibliothek auftauchen, sind schließlich 25 an der Zahl - nämlich die ursprünglichen 22 Buchstaben des lateinischen Alphabetes sowie der Punkt, das Komma und das Leerzeichen (vgl. ebd.: 148f.).

Borges erläutert uns nicht die Umstände der Entdeckung oder Entstehung dieser bemerkenswerten Bibliothek. Der Erzähler - selbst ein Bibliothekar ${ }^{1}$, der in jungen Jahren als Pilger in die Welt der Bücher und Sechsecke eingewandert ist - lässt uns nur wissen, dass sie bereits seit Jahrhunderten oder Jahrtausenden existiert, und dass ihr Wesen fünfhundert Jahre zuvor von einem anderen Bibliothekar entschlüsselt worden ist. Diesem war nicht nur aufgefallen, dass sich in den Büchern immer wieder dieselben 25 Zeichen wiederholen, sondern auch, dass in den bekannten Sechsecken noch niemand auf zwei Kopien desselben Textes gestoßen war:

Auch führte er einen Umstand an, den alle Reisenden bestätigt haben: In der ungeheuren Bibliothek gibt es nicht zwei identische Bücher. Aus diesen unwiderleglichen Prämissen folgert er, daß die Bibliothek total ist, und daß ihre Regale alle nur möglichen Kombinationen der zwanzig und soviel orthographischen Zeichen (deren Zahl, wenn auch außerordentlich groß, nicht unendlich ist) verzeichnen, mithin alles, was sich irgend ausdrücken läßt: in sämtlichen Sprachen. (Ebd.: 151f.)

Diese überwältigende Einsicht in die Natur der Bibliothek von Babel ${ }^{2}$ wurde, so lässt uns der Erzähler wissen, zunächst mit allgemeiner Euphorie aufgenommen - ist ihre Implikation doch keine geringere als jene, dass alles, was die Menschheit jemals zu wissen imstande sein wird, irgendwo in den Büchern der Bibliothek schon niedergeschrieben sein muss:

1 Ursprünglich, so erfahren wir, betreute in den erforschten Bereichen der Bibliothek jeweils ein Bibliothekar drei Sechsecke, jedoch sei dieses Verhältnis im Laufe der Jahre durch »Selbstmord und Lungenkrankheit« (vgl. Borges 2010: 151) zunichtegemacht worden.

2 Deren tatsächliche geographische Position uns im Übrigen ebenso wenig mitgeteilt wird wie die Umstände ihrer Entstehung - der Erzähler postuliert lediglich seine Theorie, dass die Bibliothek »ab aeterno« existiere (ebd.: 148) und damit dem physikalischen Kosmos und der Menschheit möglicherweise sogar vorausgegangen sei. 
Alles: die minutiöse Geschichte der Zukunft, die Autobiographien der Erzengel, den getreuen Katalog der Bibliothek, Tausende und Abertausende falscher Kataloge, den Nachweis ihrer Falschheit, den Nachweis der Falschheit des echten Katalogs, das gnostische Evangelium des Basilides, den Kommentar zu diesem Evangelium, den Kommentar zum Kommentar dieses Evangeliums, die wahrheitsgetreue Darstellung deines Todes, die Übertragung jeden Buches in sämtliche Sprachen, die Interpolationen jeden Buches in allen Büchern, den Traktat, den Beda hätte schreiben können (und nicht schrieb), über die Mythologie der Angelsachsen, die verlorenen Bücher des Tacitus. Als verkündet wurde, die Bibliothek umfasse alle Bücher, war der erste Eindruck ein überwältigendes Glücksgefühl. Alle Menschen fühlten sich als Herren über einen unversehrten und geheimen Schatz. Es gab kein persönliches, kein Weltproblem, dessen beredte Lösung nicht existierte: in irgendeinem Sechseck. (Ebd.: 152)

Diese Entzückung über die Fülle der auf den Buchseiten verborgenen Einsichten weicht jedoch schnell einem horror vacui angesichts der Tatsache, dass das vollkommene Informationsuniversum der Bibliothek letztlich von einer völligen Informationsleere nicht fundamental verschieden ist. Nicht nur, dass auf jedes grundsätzlich semantisch verständliche Buch zahllose kommen, die nur wirre Zeichenfolgen enthalten - ja selbst die sprachlich sinnvollen Texte erweisen sich als unnütz, weil es keine Kriterien gibt, anhand derer sich ihr bestehender oder fehlender Bezug zur Welt außerhalb der Bibliothek klären und damit die Wahrheit von der Fiktion scheiden ließe. Auch wenn sich unter den zahllosen Bänden ein Katalog der gesamten Sammlung fände, ließe sich sein Wahrheitsgehalt kaum ermitteln. Selbst wenn man auf die verlorenen Bücher des Tacitus stoßen würde, ließe sich ihre `Echtheit nicht bestätigen oder widerlegen. Weil die Bibliothek jede nur mögliche Permutation des ihr zugrundeliegenden Zeichensystems enthält, ist das in ihr gespeicherte Wissen nicht länger sozial oder kulturell situiert und kreist damit nicht mehr um eine Welt, die es sprachlich ab- oder nachzubilden gilt, sondern nur mehr um die statistisch-mathematischen Eigenheiten seiner medialen Verfasstheit. Autorschaft gibt es hier nicht, bzw. falls doch, so wäre es eine völlig beliebige, der kein Verlangen nach Mitteilung zugrunde liegt, sondern nur danach, die Möglichkeiten eines Codierungssystems auszuschöpfen. So enthält die Bibliothek von Babel zwar alle Fragen und alle Antworten, die sich in Schriftsprache ausdrücken lassen, bietet aber zugleich keine Möglichkeit, sie zusammenzuführen.

Die Bewohner der Bibliothek sind dementsprechend in Borges' Erzählung nicht die erleuchteten Verwalter eines wundervollen Wissensschatzes, sondern vielmehr ziellose und zunehmend verzweifelte Nomaden in einer Wüste von Information - die eigentlich keine solche ist, weil sich aus ihr nichts lernen lässt. Begreift man Information im Sinne Gregory Batesons als »Unterschied, der einen Unterschied ausmacht« (Münker 2005a: 99; vgl. Bateson 1972: 452ff.), so wäre das, was in der Bibliothek von Babel angehäuft ist, eine Ansammlung von Unterschieden, die überhaupt 
keinen Unterschied machen. Zwar ist jeder Text formal einmalig - aus einer Perspektive, die nach kulturellem Sinn Ausschau hält, sind sie jedoch alle gleichermaßen wertlos. Diese Wertlosigkeit jedoch verbindet sich für Borges mit einer existenziellen Verzweiflung. Denn weil Texte im Gegensatz zu materiellen Dingen keine Arte-, sondern Mentefakte sind, sind zwei identische Texte keine separaten Objekte - auch wenn der eine in der Außenwelt aus einem kreativen menschlichen Schöpfungsakt des Schreibens hervorgegangen ist, während sein Doppelgänger in der Bibliothek einfach deshalb existiert, weil er statistisch existieren muss. Welchen Sinn kann es also noch haben, zu denken und zu schreiben? Die albtraumhafte Implikation der Universalbibliothek ist für Borges, dass sie uns überflüssig macht und all unsere Geistesanstrengungen ad absurdum führt. Ihr Schrecken liegt nicht nur darin begründet, dass sie uns mit einer nicht handhabbaren Fülle von Information überwältigt, sondern vor allem auch darin, dass dieses Universum des Wissens uns als Subjekte gar nicht mehr benötigt. In seiner Codierung perpetuiert sich das Wissen einfach selbst.

Entsprechend wird die Suche nach kulturell anschlussfähigen Texten in der Bibliothek für ihre Bewohner zu einem verzweifelten Ringen um Belege für die Sinnhaftigkeit ihrer menschlichen Existenz - und bleiben diese aus, so bleibt nur der Wahnsinn. In ihrer Verzweiflung flüchten sich zahlreiche Bibliothekspilger in Biblioklasmen und vernichten massenhaft Bücher, die sie für sinnlos befinden. Aber obwohl jedes der Bücher ein unersetzliches Einzelstück ist, kann angesichts der enormen Größe der Bibliothek alle menschliche Zerstörungswut doch nur unmerklichen Schaden am Gesamtumfang der Sammlung anrichten. Zugleich verfügt jedes Buch, wenn auch über keinen perfekten Zwilling, so doch über zigtausende nahezu identische Geschwister, die lediglich in wenigen Zeichen von ihm abweichen (vgl. ebd.: 154f.).

Auch flüchten sich die Bewohner des Buch-Universums in diverse Spielarten des Aberglaubens. So suchen zahlreiche Pilger nach einem legendären »scharlachroten Sechseck « (ebd.: 155) auf irgendeiner Ebene der Bibliothek, das angeblich Bücher beherbergen soll, die in ihrem Format von denen aller anderen Sechsecke abweichen und das Mysterium der Bibliothek aufzulösen imstande sind. Eine andere Legende betrifft »Den Mann Des Buches« (ebd.) - einen mythischen Bibliothekar, der angeblich in irgendeinem Regal zufällig auf das tatsächliche Kompendium aller Bücher in der Bibliothek gestoßen und durch seine Lektüre zu gottgleicher Weisheit gelangt ist. Der Erzähler selbst hat sein Leben in der Bibliothek mit der Jagd nach solchen Mythen verbracht, ohne den Geheimnissen des ihn umgebenden Informationsuniversums jemals auf die Spur zu kommen. Er scheint jedoch einen gewissen Frieden in der Gewissheit gefunden zu haben, dass jeder Gedanke und jedes Wort, zu dem Menschen imstande sind, irgendwo in der Bibliothek bereits vorweggenommen und damit unser Dasein letztlich redundant geworden ist (vgl. ebd.: 157f.). Den meisten ihrer Bewohner ist die Bibliothek indes ein Ort der Verzweiflung, an welchem rasende 
Sinnsucher den möglicherweise unmittelbar bevorstehenden Totentanz der Menschheit vorwegnehmen, den indes die Bibliothek selbst - die uns eben nicht braucht gleichgültig überstehen wird:

Die Gewißheit, daß alles geschrieben ist, macht uns zunichte oder zu Phantasmen. Ich kenne Bezirke, in denen die Jungen sich vor den Büchern niederwerfen und in barbarischer Weise die Seiten küssen, aber keinen Buchstaben entziffern können. Die Epidemien, die ketzerischen Zwistigkeiten, die Pilgerzüge, die unvermeidlich zu Banditentum ausarten, haben die Bevölkerung dezimiert. Ich glaube, ich sprach schon von den Selbstmorden, die jedes Jahr häufiger werden. Vielleicht trügen mich Alter und Ängstlichkeit, aber ich argwöhne, daß die Gattung Mensch - die einzige - bald erlöschen und daß die Bibliothek fortdauern wird: erleuchtet, einsam, unendlich, vollkommen unbeweglich, gewappnet mit kostbaren Bänden, nutzlos, unverweslich, geheim. (Ebd., 158f.)

Der einzige fahle Lichtblick, den der Erzähler erkennt, ist, dass die Unendlichkeit der Bibliothek wohl keine gradlinige sein kann (schließlich gebietet ja auch die Mathematik, dass die Anzahl von Texten in der Bibliothek zwar ungemein hoch, aber endlich ist) - wer also immer weiter emporsteigt, wird nicht ewig neue Sechsecke vorfinden. Zugleich jedoch glaubt der Erzähler nicht daran, dass man jemals die Decke der Bibliothek zu Gesicht bekommen wird. Seine Theorie ist vielmehr jene, dass die Bibliothek »unbegrenzt und zyklisch« (ebd.: 159) ist - und dass ein hypothetischer Wanderer mit ausreichend langer Lebensspanne nach Jahrhunderten des Aufstieges schließlich wieder vor jenen Regalen stehen würde, vor welchen seine Reise begonnen hat. Die scheinbar beliebige Anordnung der Texte in der Bibliothek wäre dann keine offene Unordnung, die uns mit der Aussicht quält, sie ließe sich ergründen sie wäre vielmehr »Die Ordnung« (ebd.), die einzig mögliche und geschlossene Beschaffenheit des Universums, mit deren Sinnlosigkeit wir uns abfinden können. Die Erzählung endet mit dem Satz: »Meine Einsamkeit erfreut sich an dieser eleganten Hoffnung.« (Ebd.)

\subsection{VIRTUELLE TEXTE: DIE EIGENDYNAMIK DES CODES}

Diese >elegante Hoffnung` des Erzählers lässt sich also als jene lesen, dem Sog der Virtualität schließlich doch noch entrinnen zu können. Sollte die Bibliothek unbegrenzt und zyklisch sein, so stünde am Ende einer nur theoretisch möglichen, jahrhundertelangen Pilgerreise zwar keine Erleuchtung, aber doch ein Abschluss, der als ein >heilsgeschichtlicher` verstanden werden kann. Wer aufwärts oder abwärts die volle >Runde ( durch die Bibliothek absolviert, der hat den vollen Umfang dessen durchmessen, was es an Wahrheiten, Fiktionen und Nonsens zu wissen gibt und lebt 
damit in einem vollständig aktualisierten Universum. Wäre die Bibliothek hingegen endlos in eine Richtung ausgedehnt, so würde der ewige Pilger für immer einem Abschluss nachjagen, der niemals eintreten wird und wäre damit bis in alle Ewigkeit in Virtualitäten befangen.

Die Universalbibliothek ist also in erster Linie ein Gedankenspiel, das unser Verhältnis zur Schrift und das Verhältnis der Schrift zu unserer Existenz als Kulturwesen exploriert. Nach Hannah Arendt ist das Schreiben eine jener produktiven Tätigkeiten, in denen wir erstens unser Dasein behaupten (das bloße Vorliegen eines Textes weist auf eine Autorschaft zurück, die ihn hervorgebracht haben muss) und zweitens den Fortbestand unserer Erfahrungswelt über unsere eigene Existenz hinaus gewährleisten (der Text ist qua seiner Autorschaft als sinnhafte Zusammenstellung von Information ausgewiesen und adressiert damit einen Rezipienten). Borges hingegen konfrontiert uns mit der Tatsache, dass die probabilistischen Eigenschaften des Alphabets, mittels dessen wir schreibend unser Dasein äußern, die Rollen von Autor und Rezipient völlig unterlaufen oder gar vernichten. Das Schreiben erscheint weniger als ein willentlicher und kreativer Akt der Sinnstiftung, sondern vielmehr als ein >Würfeln` mit Variablen, das am Ende einen von Myriaden möglichen Texten aus der virtuell im Code vorhandenen Universalbibliothek zum Vorschein bringt.

Ein vielleicht noch prägnanteres Bild für diesen statistischen Albtraum liefert ein als infinite monkey theorem bekanntes Gedankenexperiment (vgl. Gibbons 2009: 1). Dieses wurde wohl erstmals im Jahre 1913 vom französischen Mathematiker Émile Borel ausformuliert, der das folgende Szenario ersann: Man stelle sich eine Million Affen vor, die jeden Tag zehn Stunden lang auf eine Million Schreibmaschinen einhämmern. Lässt man genügend solcher Affen-Arbeitstage verstreichen, dann gebietet die statistische Wahrscheinlichkeit, dass die Primaten irgendwann exakte Kopien aller Bücher in allen Bibliotheken der Welt produziert haben werden. Oder genauer: Während natürlich an jedem einzelnen Tag die Chance für die Entstehung jedes individuellen Buches verschwindend gering ist und die zum Abschluss des Vorhabens notwendige Anzahl von Tagen enorm hoch sein dürfte (möglicherweise ein Vielfaches der zu erwartenden Lebenszeit des physikalischen Kosmos), übersteige doch die Wahrscheinlichkeit eines letztendlichen Erfolges der Affen jene einer Verletzung der Gesetze der statistischen Mechanik und eines völligen Ausbleibens der Texte (vgl. Borel 1913: 194f.; vgl. Gibbons 2009: 1). ${ }^{3}$

Wenn Affen grundsätzlich imstande sind, jeden Text der Weltliteratur zu produzieren ohne dabei die Bedeutung der Worte überhaupt zu erfassen, dann erscheinen

3 Angemerkt sei, dass 2003 von der University of Plymouth ein Feldversuch im Affenhaus des Paignton Zoo im englischen Devon durchgeführt wurde, bei dem sechs indonesische Schopfaffen Zugriff auf eine Computertastatur erhielten. In einem ganzen Monat produzierten die Affen lediglich fünf Seiten sinnlosen Textes und nutzten die Tastatur wiederholt als Toilette (vgl. http://news.bbc.co.uk/2/hi/3013959.stm, vom 15.05.2018). 
literarische ebenso wie Sachtexte weniger als etwas Gemachtes denn als etwas Gefundenes. Für jede beliebige Schriftsequenz ließe sich grundsätzlich in jeder beliebigen Schreibsituation eine bestimmte Wahrscheinlichkeit ihres In-Erscheinung-Tretens benennen - wären uns nur all die unzähligen Variablen bekannt, die den Schreibenden dazu anleiten, bestimmte Buchstaben an bestimmte Positionen im entstehenden Text zu setzen. Wer schreibt, schafft also nicht ex nihilo Sinn, sondern navigiert abermals einen Möglichkeitsraum und trifft Entscheidungen zwischen einer endlichen Zahl von präexistenten Optionen.

Von vergleichbaren Überlegungen ausgehend entwickelte in den 1960er Jahren der deutsche Philosoph Max Bense eine `Informationsästhetik , die auf die statistische Beschreibung von Texten im engeren, aber auch Kunstwerken im weiteren Sinne abzielt. Bense sieht Kunstwerke als Ansammlungen von diskreten Zeichen, und jedes dieser Zeichen wiederum als das Resultat einer Abfolge von Auswahl- und Entscheidungssituationen, die anders hätten verlaufen und ausgehen können (vgl. Bense 1960: 42f.). So, wie jeder Text ein Fundstück aus der absoluten Bibliothek abbildet, ist demnach jedes Gemälde und jede Skulptur also ein aus einem absoluten Museum geborgener Schatz. Während sich die »statistische Ästhetik« (ebd.: 28) von Texten aber relativ leicht erheben lässt, weil diese eben von vorneherein aus klar diskreten Zeichen bestehen, müssen Objekte der bildenden Kunst zunächst einmal analytisch in einzelne Zeichen >zerlegt werden (ebd.: 28f.) - wobei die Frage, was diskrete Zeichen sind bzw. wo ein einzelnes Zeichen anfängt und aufhört freilich weitgehend im Ermessen des jeweiligen Analytikers liegen müsste.

In digitalen Medien indes erübrigt sich dieses Element der Willkür, weil - wie zuvor bereits mit Friedrich Kittler festgestellt wurde - aufgrund der spezifischen technischen Eigenart des Computerbildschirms die aus einzelnen Bildpunkten zusammengesetzten Computerbilder Texte sind. Und: Auch nicht-bildliche Attributobjekte sind aus Einzelmerkmalen zusammengesetzt, die im semantischen Koordinatensystem des Cyberspace diskret verortbar sind. Die Virtualität des Computers - die ja genau darin besteht, dass alle seine Applikationen latent in seiner Fähigkeit enthalten sind, zu Rechnen bzw. abstrakte Signale zu prozessieren - lässt ihn potenziell zu einer digitalen Universalbibliothek werden. Freilich wird man vergeblich nach einer Festplatte suchen, auf der sich sämtliche aus Einsen und Nullen arrangierbaren Dateien befinden. Dies ist jedoch auch gar nicht erforderlich. Denn während eine Universalbibliothek des gedruckten Wortes tatsächlich alle möglichen Kombinationen des Alphabets in aktualisierter Form beinhalten müsste und damit überhaupt erst in Erscheinung treten könnte, wenn die Affen ihre Jahrmillionen an der Schreibmaschine bereits abgesessen haben, sind die Affen im Rechner gewissermaßen permanent am Werke. In einer Bibliothek ohne Autorschaften, ohne kulturellen Bezug und ohne für den Menschen wahrnehmbare Begrenzung spielt es keine Rolle, ob die gleichermaßen zahl- wie sinnlosen Texte bereits in den Regalen vorhanden sind oder ob sich die Regale unermüdlich füllen, während wir uns an ihnen entlang bewegen. 
Nun tut der Computer natürlich grundsätzlich nichts anderes als das, was auch ein Mensch tut, wenn er Texte erzeugt: Er reiht einzelne Zeichen hintereinander. Dabei ist er zwar sehr viel schneller als ein menschlicher Schreiber, in ihrer äußeren Beschaffenheit aber ist die Tätigkeit dieselbe. Der qualitative Unterschied von menschlicher und digital-maschineller Textproduktion liegt vielmehr in den Sinnsystemen, die hinter dem Umgang mit dem Code stehen. Denn während ein menschlicher Schreiber den unermesslichen Raum der möglichen Texte innerhalb eines Gefüges kultureller Bezüglichkeiten navigiert und Texte erzeugt, die eben verständlich und anschlussfähig (oder kurz: für andere Menschen lesbar) sein sollen, arbeitet sich der Rechner an mathematischen Verhältnismäßigkeiten und logischen Zusammenhängen ab, die zunächst einmal keine äußere Referenz besitzen oder benötigen - der computer layer gleicht tatsächlich in gewisser Weise Borels tippenden Schimpansen. Damit einher geht jene zweite, im Laufe dieser Studie bereits mehrfach diskutierte Eigenart digitaler Medien, dass dieselben Daten vom selben Computer auf ganz unterschiedliche Weisen verarbeitet werden können, dass eben alles in alles übersetzbar ist, solange es sich in Algorithmen ausdrücken lässt. Zwischen den Bänden der absoluten Bibliothek und den Bildern eines absoluten Museums gibt es also in digitalen Medien keine kategorische Verschiedenheit. Jedes Bild ist Text, und jeder Text potenziell Bild (oder auch Klang oder Video).

\subsubsection{Die Suche als Ohnmachtserfahrung}

Im Jahre 1995, also kurz vor Beginn der Internet-Revolution in Privathaushalten, erschien im britischen Science-Fiction-Magazin Interzone unter dem vielsagenden Titel The Net of Babel eine Kurzgeschichte des Schriftstellers David Langford, die sich ganz offen als Fortsetzung zu Borges' über ein halbes Jahrhundert zuvor entstandenen Erzählung über die papierne Universalbibliothek versteht. Die Prämisse von Langfords Text ist dabei, dass die Bibliothek von Babel ihre Digitalisierung erfahren hat. Uns wird nicht mitgeteilt, wie genau diese abgelaufen ist, ob also tatsächlich alle Bände erfasst und digital dupliziert wurden, oder ob womöglich einfach - eben im computerisierten Affensystem - noch eine zweite, bereits originär digitale Bibliothek erzeugt wurde. Zu Beginn von Langfords Narrativ befinden sich alle Bände aus Borges’ >Universum ‘ auf Microchips, die entlang der Wände eines einzigen Sechsecks aufgereiht sind. Der Erzähler, abermals ein Bibliothekar, berichtet:

The Library is both exhaustive and exhausting. But now it has been transfigured. Observe: in place of the old days' interminable weary lattice of hexagonal chambers, I and my colleagues inhabit a single, vast, crimson-walled hexagon. Instead of the long bookshelves there are desks arrayed against each wall, and on each desk that many-keyed device which places all the Library's volumes under my hand. (Langford 1995/1997: 451f.) 
Das einst mythische scharlachrote Sechseck ist also Wirklichkeit geworden - von hier aus hat man tatsächlich Zugriff auf die Gesamtheit aller in der ursprünglichen Bibliothek enthaltenen Texte, die nun nicht länger in körperlicher Person bepilgert werden müssen, sondern über ein elegantes Computerinterface ganz unkompliziert aufgerufen werden können. Ja mehr noch: Nun, da die Bibliothek auch maschinenlesbar geworden ist - jedes einzelne für Menschen verständliche alphabetische Zeichen also übersetzt werden kann in für den Computer verständliche Zahlenwerte sind ihre menschlichen Besucher nicht länger von ihrer eigenen, ebenfalls durch ihre Körperlichkeit begrenzten Fähigkeit zur Textlektüre abhängig. Die Bibliothek besitzt nun eine Suchfunktion:

The golden or leaden key that unlocks the Library is the inbuilt search facility. One prepares a text of any length, sets the searching into motion, and the Library's own devices will swiftly trawl that sea of data. A glad chime sounds when the sought words are found. (Ebd.: 452).

Das Problem mit diesem `goldenen oder bleiernen`Schlüssel zur Bibliothek ist allerdings gerade die Tatsache, dass ihre Sammlung absolut ist. Weil jede mögliche Kombination alphabetischer Zeichen in der Bibliothek meist nicht nur einmal, sondern sogar mehrfach vorhanden ist, führt auch jede Suche unweigerlich zu einer Vielzahl von Treffern:

Since it is an article of faith that the Library truly is exhaustive, all these text searches should necessarily succeed no matter what is searched for ... as indeed they do. Every find is a sacrament and a vindication. (Ebd.)

Dieses Sakrament der erfolgreichen Suche verliert sich notwendigerweise in Bedeutungslosigkeit, wenn zwar jede Suchanfrage Treffer produziert, diese Treffer jedoch abermals nur zu Büchern führen, die über den gesuchten Satz hinaus nur kulturloses Kauderwelsch beinhalten. Die Ironie der Textsuche ist, dass sie letztlich einzig das bestätigen kann, was man ohnehin bereits weiß, nämlich dass eine eingetippte Suchanfrage aus alphabetischen Zeichen arrangierbar und damit notwendigerweise auch in der Bibliothek vorhanden ist. Wollte man mittels der Textsuche ein komplett sinnvolles und kulturell verwertbares Buch finden, so müsste man es schlicht selbst schreiben und in Gänze in die Suchmaske eintragen, womit die Suche ihren Gegenstand bereits überflüssig machen würde - schreiben ist eben nicht länger kreative Schöpfung, sondern Würfeln im Absoluten. Weil Suche nach und Schöpfung von Texten letztlich dasselbe sind, bleibt die unendliche Bibliothek auch in digitaler Form unergründlich und unbrauchbar - ja tatsächlich führt die Technik den Bibliothekaren nur noch deutlicher vor Augen, wie vollends zum Scheitern verurteilt jede Bestrebung ist, der formlosen Information irgendwelches Wissen entlocken zu wollen. Während der Erzähler der ursprünglichen Kurzgeschichte sich noch der >eleganten 
Hoffnung hingeben konnte, dass es eine Grenze des Virtuellen in der Bibliothek geben könnte, ist für Langfords Techno-Bibliothekar das Ausmaß der völlig ungefilterten Beliebigkeit aller gespeicherten Texte buchstäblich nur einen Tastendruck entfernt. Im Ergebnis gibt es für ihn keine eleganten Hoffnungen mehr, sondern nur die Nostalgie und Sehnsucht nach einer Zeit, als man sich der eigenen Ohnmacht zumindest noch nicht in solchem Ausmaß bewusst gewesen ist:

Thus it may be seen what advantages we enjoy over the past librarians whose entire lives might be spent in traversing the hexagonal cells of their conjectural, physical Library, without ever encountering a book that held a single intelligible sentence. As my own long span of Librarysearching ticks to its close, I think again and again of those times when so little could be found. Now every volume lies instantly within our grasp, and we possess a far greater understanding of our identical impotence. I would that I lived in the old days. (Ebd.: 454)

Der absolute Informationsfundus, wie Borges ihn beschrieb, treibt seine Rezipienten in den Wahnsinn, weil er sie mit einer Hoffnung auf Einsicht und Erleuchtung peinigt, die er nicht zu erfüllen imstande ist. Die absolute Verfügbarkeit dieses Fundus hingegen, wie sie uns in Langfords Szenario begegnet, gewährleistet nicht etwa die Nutzbarkeit der enthaltenen Information, sondern gebiert lediglich eine dumpfe Resignation angesichts der Tatsache, dass es keine Urheberschaft und keinen Entstehungskontext gibt, der die rein kombinatorisch entstandenen Texte mit der Welt verbindet.

Nichtsdestotrotz hat die Digitalisierung uns bisher kein solches Szenario beschert. In unserem tatsächlichen kulturellen Umgang mit schriftlichen Texten ebenso wie mit digitalen Medien sind wir zwar mitunter frustriert von schlechter Abrufbarkeit und unvollständiger Katalogisierung, unverständlicher Sprache oder mangelnder Transparenz von Bezügen und Zusammenhängen, dies aber sind Momente der Verirrung, und Verirrung setzt voraus, dass zielgerichtete Bewegung zumindest grundsätzlich möglich wäre. In der Universalbibliothek ist daran von vorneherein nicht zu denken, weil ihr keine Sinnstrukturen aufzuerlegen sind, innerhalb derer Navigation stattfinden könnte. Man verirrt sich in ihr nicht, man ist in ihr von vorneherein verloren.

Langfords im Computerzeitalter verfasste Hommage an Borges' informationsapokalyptisches Gedankenspiel ist eine offensichtliche Absage an die sich mit dem Hypertext-Prinzip und der Cyberspace-Vorstellung verbindenden Vorstellungen, eine Totalität der Speicherung mit einer problemlosen, unmittelbaren Verfügbarkeit des Gespeicherten für jede individuelle Interessenlage verbinden zu können. Allerdings unterscheidet sich Langfords Szenario noch in zwei entscheidenden Punkten von der Realität des Webs, wie wir es im zweiten Jahrzehnt des 21. Jahrhunderts kennen. Der erste Punkt ist, dass das Net of Babel tatsächlich gar kein Netz ist. Denn 
ganz wie die ursprüngliche Bibliothek von Babel besteht es nur aus souveränen, völlig für sich allein stehenden Texten, die sich in Ermangelung menschlicher Autorschaft ebenso wenig aufeinander wie auf irgendetwas anderes beziehen können. Daraus ergibt sich unmittelbar der zweite Punkt: Langfords Bibliothekar kann die Bibliothek nur auf der Ebene des nackten Codes durchsuchen, weil es eine andere schlechterdings nicht gibt. Entsprechend ist die ihm zur Verfügung stehende Suchfunktion auch eine reine Volltextsuche: Sie gleicht eine eingegebene Sequenz von Zeichen mit dem ihr vorliegenden, gespeicherten Textkörper ab und wird dabei, weil dieser eben absolut ist, notwendigerweise auch fündig. Im World Wide Web hingegen sind Texte erstens überwiegend autorschaftlich an den culture layer rückgekoppelt, und zweitens untereinander verlinkt. Dieses assoziative Element, das in der Frühphase der Hypertexttheorie noch als Garant universeller Verständlichkeit und Zugänglichkeit verhandelt wurde, hat sich tatsächlich mit der Entwicklung des Webs als ein zweischneidiges Schwert erwiesen. Denn während die Bezüglichkeiten zwischen Einzeltexten und Einzeltextfragmenten einerseits deren sinnhafte Rezeption erst ermöglichen, schafft andererseits die Verlinkung selbst eine neue Ebene der Komplexität, innerhalb derer man sich verirren kann. Nicht anders verhält es sich ja im Museum.

Weil aber das Netz im Gegensatz zum Museum weder eine Trennung zwischen Innen und Außen noch ein institutionell abgesegnetes Kuratorium kennt, bei welchem sich die Gestaltungshoheit zumindest formal konzentriert, potenziert sich das Problem hier natürlich. Veränderlichkeit ist ja, wie Lev Manovich betont, ein zentrales definitorisches Merkmal der >neuen Medien` (vgl. Manovich 2002: 36ff.), und die gesamte Programmatik des Hypertextes als Organisationsform von Wissensgefügen stand im Zeichen der Absicht, diese aus dem Korsett vorgefertigter und statischer Ordnungs- und Relevanzsysteme zu befreien. Es sei an Jon Kleinberg erinnert, der als Besonderheit und Kernproblem bei der Erschließung des Meta-Hypertextes WWW gerade das dreifache Faktum ausmacht, dass das Web erstens bereits aus enorm vielen Webseiten und Verlinkungen besteht, zweitens immer weiter wächst, und sich drittens in seiner inneren Struktur laufend verändert (vgl. Kleinberg 1998: 1). Das WWW mag (noch, müsste man einschieben, denn die Primaten tippen hier mit weit größerer Zielstrebigkeit als jene in Borels Gedankenspiel) keine Universalbibliothek sein, kämpft aber mit einem ähnlichen Problem: Die in ihm enthaltene Textmenge wächst kontinuierlich, und mit ihr die Wahrscheinlichkeit jeder beliebigen Volltext-Suchanfrage, Übereinstimmungen zu finden. 


\subsection{NAHES UND FERNES WISSEN}

Zum Glück jedoch folgt das WWW nur örtlich begrenzt der Logik der inventarisierten Bibliothek, deren Bände miteinander unverbunden sind. Weil ihre Einzelelemente miteinander verwoben sind, lassen sich in Hypertexten nicht nur die Textfragmente selbst als Ansammlungen von Codezeichen vermessen. Auch die zwischen ihnen bestehenden Verstrebungen lassen sich unter bestimmten Bedingungen auf ihre respektive `Näheく und 〉Distanz $\prec$ hin untersuchen. Stellen wir uns z.B. idealisiert ein virtuelles Museum vor, das eine Anzahl von digitalisierten Werken der abendländischen Kunst ausstellt. Die Sammlung sei um unseres Beispiels willen ein Querschnitt von der Renaissance bis ins 20. Jahrhundert. Organisiert sei dieses Museum als ein relativ konventioneller Hypertext, der jedem Ausstellungsstück genau eine Webseite widmet, welche Abbildungen, beschreibenden Text, vielleicht Videos und Tonmaterial zum Exponat enthält. Jede dieser Webseiten wäre also ein digitales Objekt im Sinne Yuk Huis.

Stellen wir uns nun weiter vor, diese einzelnen Webseiten wären untereinander verlinkt. Dies könnte auf verschiedene Arten geschehen, die es alle erforderlich machen, bestimmte diskrete Zeichen aus dem digitalen Gesamtobjekt hervorzuheben. So könnten z.B. ganz nach dem Wikipedia-Prinzip Worte im Beschreibungstext markiert werden, die direkt zu anderen Objekten oder Inventarseiten weiterleiten. Klickte man z.B. im Beschreibungstext eines Gemäldes auf den Namen eines anderen Gemäldes desselben Malers, würde man direkt zu diesem Werk weitergeleitet. Klickt man hingegen auf den Namen des Malers, würde man womöglich zu einer Übersichtsseite mit dessen Werken in chronologischer Reihenfolge gelangen. Ein Klick

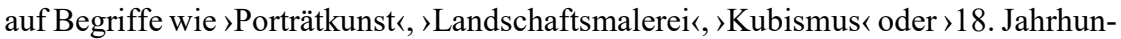
dert würde andere solche Überblicksseiten öffnen und somit eine assoziative Erschließung der Sammlung ganz im Sinne Vannevar Bushs ermöglichen - freilich mit dem Abstrich, dass die trails of interest hier nicht vom Nutzer erst geschlagen und ausgetrampelt werden müssten, sondern als virtuelles Straßennetz bereits vorhanden wären.

Auch auf Bildebene wäre eine solche Verlinkung durchaus denkbar - hier wäre es dann nötig, innerhalb der Abbildungen (den Ideen der Bense'schen Informationsästhetik folgend) diskrete Zeichen zu definieren und diese zueinander ins hypertextuelle Verhältnis zu setzen. So könnte z.B. die Auswahl eines Schädels oder einer Laute in einem Gemälde der altniederländischen Malerei zu Werken der selben Epoche weiterleiten, die das gleiche Symbol aufweisen, oder der Klick auf ein Christusmotiv epochenübergreifend Werke abrufen, welche die christliche Heilerzählung thematisieren. In diesem hypothetischen - von tatsächlich existierenden Angeboten aber durchaus nicht weit entfernten - virtuellen Museum ließe sich natürlich ganz leicht 
topographisch vermessen, wie >weit` einzelne Wissensgegenstände voneinander entfernt sind. Man könnte den Hypertext einfach als eine Landkarte oder ein Itinerar der Verlinkung darstellen.

Allerdings ließe sich dabei natürlich keiner Verbindungslinie eine klare Länge zuweisen, weil zwischen zwei Webseiten jeweils nur erhoben werden könnte, ob diese verbunden oder unverbunden sind, bzw. wie viele assoziative $>$ Schritte $<$ unternommen werden müssen, um von Seite A zu Seite B zu gelangen. So ließen sich z.B. Aussagen treffen wie: >Die kürzeste Verbindung zwischen Leonardo DaVinci und Jackson Pollock führt über sieben individuelle Links`, oder: `Es gibt keinen direkten Zusammenhang zwischen Norman Rockwells The Problem We All Live With und Caspar David Friedrichs Wanderer über dem Nebelmeer . Eine solche Topologie würde also die spezifische connectedness dieses bestimmten Hypertextes beschreiben und damit letztlich nur auf die kunstpädagogischen Prämissen und Intentionen schließen lassen, welche die Kuratoren bzw. Webdesigner zugrunde gelegt haben. Über die Interessenlagen der virtuellen ,Besucher ${ }^{\circ}$, oder gar die weiteren kulturellen Zusammenhänge, aus welchen diese hervorgehen, verrät eine solche Analyse wenig, weil sie die Perspektive der Karte, nicht die der Strecke einnimmt.

\subsubsection{Soziometrie und Science Citation Index: Vorspiel zur Suchmaschine}

Will man ein Netzwerk erfolgreich navigieren, so genügt es nicht, zu wissen, wo sich Querverbindungen befinden - wichtig ist darüber hinaus auch, zu wissen, wie diese beschaffen sind. Dies führt uns zurück zur bereits erwähnten Soziometrie Jakob L. Morenos. Morenos Versuch, soziale Beziehung kartier- und quantifizierbar zu machen, führte relativ schnell zu der Erkenntnis, dass die Netzwerkstruktur sozialer Gruppen zumeist keine gleichmäßige Verteilung von Personen und Beziehungen ist. Vielmehr finden sich in jedem Soziogramm Punkte (und damit Personen), um die herum sich die Beziehungsvektoren in besonderem Maße verdichten, die also ein besonderes soziales Kapital auf sich vereinen und die Moreno - in Anspielung sowohl auf ihre offensichtliche Popularität als auch auf das Aussehen der so vernetzten Punkte in der graphischen Darstellung - als stars bezeichnete (vgl. Mayer 2010: 68ff.). In den 1940er Jahren wandte sich die Soziometrie von der unübersichtlichen und potenziell verwirrenden Abbildungsform des Soziogramms zunehmend ab und ersetzte es durch Matrizen, welche den Vernetzungskoeffizienten einzelner Personen als diskreten numerischen Wert ausdrückten. Dabei entschied nicht nur die individuelle Vernetzung der betreffenden Person über ihren sozialen >Wert all jener Gruppenmitglieder, mit denen sie direkt oder indirekt verbunden war. Der Status eines Menschen in einem sozialen Gefüge ergibt sich demnach nicht nur aus 
der reinen Anzahl seiner Bekanntschaften, sondern wiederum auch aus deren Gewichtung innerhalb der Gruppe (vgl. Mayer 2010: 71).

1964 schlug der amerikanische Linguist Eugene Garfield vor, diese Einsichten über die Natur von Netzwerken auf ein anderes Feld zu übertragen: Das der wissenschaftlichen Forschung bzw. genauer jenes der einander zitierenden wissenschaftlichen Veröffentlichungen. Garfield ging dabei von ganz ähnlichen Prämissen aus wie keine zwanzig Jahre zuvor Vannevar Bush in seiner Kritik an der Bibliothek: Angesichts unserer ständig und rasant schnell wachsenden Wissensbestände ließe sich die Forschungsliteratur unmöglich so schnell erschließen, wie sie gedruckt wird - unserem »scientific wealth« stehe, so Garfield, eine »bibliographic poverty« (Garfield 1984a: 525) gegenüber. Dies sei, so fährt Garfield fort, nicht zuletzt ein ganz schlichtes Problem der Forschungsökonomie: Jeder Index publizierter Forschungsarbeit sei in seiner Anlage mit einem erheblichen Arbeitsaufwand verbunden, und dieser sei nur zu rechtfertigen, wenn sein Nutzen seine Kosten überwiegt. Als eine naheliegende Gefahr schlechter Auffindbarkeit von Forschungsergebnissen nennt Garfield die Doppelforschung - also die unnötige Forschung an einem Gegenstand, zu dem bereits Untersuchungen vorliegen.

Allerdings seien in vielen Fällen die an redundante Forschung verschwendeten Ressourcen immer noch günstiger als die Kosten einer zentralisierten Erfassung aller Forschungsliteratur. Eine sinnvolle Indexierung wissenschaftlicher Veröffentlichungen müsse daher in erster Linie kostengünstig funktionieren - an eine tatsächlich beim Inhalt ansetzende Erschließung sei somit nicht zu denken (vgl. ebd.: 526). Stattdessen schlägt Garfield vor, sich den schon von Vannevar Bush diagnostizierten Netzwerkcharakter akademischer Literatur zunutze zu machen, um die Auffindbarkeit relevanter Schriftstücke zu gewährleisten. Sein bis heute in Gebrauch befindlicher (und in zahlreichen Forschungszweigen über Karrieren bestimmender) Science Citation Index nahm sich den existierenden juristischen Zitationsindex Shepard's zum Vorbild und sollte die Wichtigkeit von Büchern und Aufsätzen auf ähnliche Weise als mathematischen Wert ausdrücken, wie es in der Soziometrie mit dem sozialen Status von Menschen geschieht (vgl. Mayer 2010: 74f.).

Weil wissenschaftliche Publikationen sich laufend aufeinander beziehen und sich gegenseitig zitieren, lassen sie sich grundsätzlich genau so behandeln wie Menschen, die sich untereinander `kennen - und genau wie man in einer Gruppe von Menschen besonders beliebte Mitglieder ausfindig machen kann, welche im Zentrum weitreichender Beziehungsgefüge stehen, findet man auch in Netzwerken von aufeinander Bezug nehmenden Schriftstücken solche, die für ihren Einzugsbereich zentral sind und hier das bilden, was wir umgangssprachlich ,Standardwerke ${ }^{e}$ nennen würden. Diese Werke, die innerhalb des Literaturnetzwerkes einen hohen Status aufweisen, bilden gewissermaßen Schlüsseltexte, denen zum einen ein hoher inhaltlicher Wert beigemessen wird und die dementsprechend oft zitiert werden, und die zum anderen 
aus ihrer besonderen fachlichen Geltung heraus imstande sind, über ihre Literaturverzeichnisse und Fußnotenapparate als Wegweiser zu anderer wichtiger Literatur zu gelten (vgl. ebd.). Um diese Geltung als einen konkreten Zahlenwert ermittelbar zu machen, muss der Index nach Garfield aus zwei Listen bestehen: einer, die zitierende und einer, die zitierte Werke aufführt. Derselbe Text kann durchaus auf beiden Listen auftauchen - die Unterscheidung zwischen Zitieren und Zitiert-Werden ermöglicht es, Zitations->Vektoren` zu bestimmen, entlang derer Veröffentlichungen einander Relevanz verleihen. So könnte ein Paper, das eine sehr große Zahl von Titeln zitiert, in einer topographischen Darstellung wie der des Soziogrammes durchaus wie ein star aussehen, tatsächlich aber völlig irrelevant sein, wenn es seinerseits in wichtigen Publikationen nicht als Referenz angegeben wird. Umgekehrt könnte ein Text, der für ein Forschungsgebiet Pionierqualitäten aufweist (wie dies z.B. für Vannevar Bushs As We May Think der Fall ist) einen enorm hohen Zitationsquotienten aufweisen, ohne selbst viele oder überhaupt irgendwelche Werke zu zitieren (vgl. Garfield 1984a: 528f.). Der SCI macht die Zentren und Peripherien wissenschaftlicher Diskurse anhand ihres Niederschlages in der Veröffentlichungspraxis ausfindig. Dabei sind nach Garfields Einschätzung ausdrücklich nicht nur die Zentren von Interesse. Ein Mangel an Zitationen deute nämlich nicht immer auf ein schlechtes Paper hin manchmal könne er auch ein Zeichen für Forschungsarbeit sein, die ihrer Zeit zu weit voraus und bei ihrem Erscheinen schlicht noch nicht anschlussfähig war. In Verbindung mit inhaltlichen Analysen könne die Wichtigkeitsvermessung, die der SCI vornimmt, dazu beitragen, unterbewerteten und zu Unrecht marginalisierten Arbeiten zur verdienten Aufmerksamkeit zu verhelfen (vgl. ebd.: 532).

Garfield selbst prägte den Begriff der Hypersearch als Bezeichnung für das Vorgehen, statt einer großflächigen Erschließung von Einzeltiteln jene zentralen Schlüsseltexte ausfindig zu machen, über welche man zu den relevantesten Titeln im betreffenden Themenfeld gelangt (vgl. Mayer 2010: 74f.). Und so revolutionär dieser Ansatz für die Wissenschaftsökonomie und -soziologie bereits gewesen sein mochte sein eigentlicher, die gesamte Kultur der neuen Medien durchdringender Siegeszug sollte erst Ende der 1990er Jahre, mitten in der take-off-Phase des World Wide Web, beginnen.

\subsubsection{Google: Kulturelle Relevanz als statistische Korrelation}

Angesichts der Fülle der bereits existierenden und leicht verfügbaren Literatur zum Aufstieg des Google-Imperiums scheint es hier wenig sinnvoll, die Geschichte des Unternehmens im Detail zu rekapitulieren. Vielmehr soll im Folgenden am Beispiel Googles abgehandelt werden, wie das Suchparadigma der Hypersearch zu einer entscheidenden Kulturtechnik der virtualisierten Welt werden konnte - und wie sich diese Kulturtechnik auf die Inhalte auswirkt, die mit ihrer Hilfe organisiert, gefunden 
und rezipiert werden. Im weiteren Verlauf der Arbeit wird dann der Blick auf die Frage zu richten sein, was genau dies für das mögliche Funktionieren und NichtFunktionieren musealer Angebote im Netz bedeutet.

Im Jahre 1998 veröffentlichten die an der Universität Stanford tätigen Computerwissenschaftler Sergey Brin und Larry Page ein Paper mit dem recht spröden Titel The Anatomy of a Large-Scale Hypertextual Web Search Engine. Die von Brin und Page darin in Aussicht gestellte Suchmaschine trug zu diesem Zeitpunkt bereits den Namen Google und bekannte sich damit unmissverständlich zu einer Programmatik der großen Zahlen: Der Name ist eine Verzerrung des Wortes Googol, welches die Zahl $10^{100}$ bezeichnet (vgl. Brin u. Page 1998: 1). Eine wirklich funktionale Suchmaschine, so lautet dementsprechend auch gleich die erste Feststellung des Aufsatzes, müsse über Mechanismen verfügen, die es ihr erlauben, mit dem Web zu wachsen. Als im Jahre 1994 in Gestalt des World Wide Web Worm $(W W W W)$ die erste InternetSuchmaschine für den Massengebrauch online ging, indexierten die von ihr verwendeten Webcrawler (also Programme, die eigenständig Hyperlinks verfolgen und Seiteninhalte verzeichnen) etwa 110.000 Webseiten. Schon 1997 gaben die Suchmaschinenbetreiber dagegen Millionenwerte an - die an der University of Washington beheimatete Metasuchmaschine WebCrawler kannte allein zwei Millionen individuelle Seiten, das Portal Seach Engine Watch machte über sämtliche Suchdienste hinweg sogar rund 100 Millionen aus. Der $W W W W$ erhielt im Frühsommer 1994 im Schnitt bescheidene 1.500 Anfragen am Tag, während Altavista Ende 1997 angab, ca. 20 Millionen Suchoperationen täglich durchzuführen. Eine Suchmaschine, die angesichts dieser Entwicklung auch nur ansatzweise zukunftsfähig sein wollte, müsse laut Brin und Page dreierlei leisten: Erstens müsse sie neue Webseiten effizient verzeichnen bzw. ihre Kenntnisse über existierende regelmäßig eigenständig erneuern, zweitens müsse sie den ihr zur Verfügung stehenden Speicherplatz auf ihren Heimatservern intelligent und sparsam ausnutzen, und drittens müsse sie ihren Endnutzern ein simples, schnelles und intuitives Interface zur Verfügung stellen, welches die individuelle Suche möglichst zügig zum Erfolg führt (vgl. ebd.: 2). Im Hinblick auf das Web stellen die Autoren nämlich eine ganz ähnliche Diagnose wie Vannevar Bush und Eugene Garfield Mitte der 1940er und 60er Jahre für die Wissenschaft: Während das Informationsvolumen des Netzes seit seiner Entstehung laufend angewachsen war, sei die Fähigkeit seiner Nutzer, es zu durchsuchen und zu navigieren, konstant geblieben. Weil die existierenden Suchdienste lediglich Textsuchen betrieben, also nach bestimmten Zeichenfolgen auf Webseitentexten suchten, waren sie nicht imstande, diese in irgendeiner Form nach ihrer tatsächlichen Relevanz zu sortieren und wurden tatsächlich immer weniger nützlich, je mehr das Web anschwoll. In der Welt vor Google war jede Internetsuche von einer hohen Menge sogenannter junk results bestimmt, durch welche sich die Nutzer schlicht mit Geduld hindurchzugraben hatten, um sinnvolle Ergebnisse ausfindig zu machen. Als sinnfälligstes Armutszeugnis dieser Form von Websuche führen Brin und Page hier die Beobachtung an, dass Ende 
1997 nur die vier marktführenden Suchmaschinen imstande waren, ihre eigenen Webseiten zu finden. Google sollte aus diesem Grunde die bloße Textsuche um ein Verfahren erweitern, das die relative Relevanz von Webseiten beurteilen und seine Treffer danach ordnen konnte (vgl. ebd.: 2f.).

Dieses Verfahren bildete das Herz der Google-Websuche und wurde auf den Namen PageRank getauft - wobei das Wort Page sich hier nicht etwa auf Webseiten, sondern auf die Person Larry Page bezieht. Ganz ähnlich wie der Science Citation Index die Verweisstruktur von wissenschaftlichen Texten auswertet, sollte PageRank die Relevanz von Webseiten aus ihrer Verlinkung herausrechnen. Auch hier galt es, Seiten von hoher Geltung ausfindig zu machen, die ihre Popularität an verlinkte Seiten weitergeben (vgl. ebd.: 3f.). Das Gegenstück zum star der Soziometrie bildet in Hypertextgefügen dabei der sogenannte $h u b$ - wörtlich eigentlich der >Verkehrsumschlagplatzı - als eine Seite von hoher Autorität mit vielen ein- und ausgehenden Links (vgl. Mayer 2010: 71). Während in der Soziometrie und beim SCI jedoch ein relativ klares Verständnis davon vorausgesetzt werden konnte, was eine beliebte Person oder eine wichtige Veröffentlichung ausmacht, stand Google zunächst vor dem Problem, dass abhängig von den Interessenlagen seiner Nutzer die tatsächliche Relevanz einer Webseite stark variieren konnte, selbst wenn diese nach ihrem Verlinkungsgefüge eigentlich von hoher Wichtigkeit hätte sein müssen. Die funktionale Logik von PageRank sollte aus diesem Grund das Surfverhalten eines angenommenen Standard-Users abbilden, der mehr Flaneur als Detektiv war: Google sollte sich, so Brin und Page, wie ein »random surfer« betragen, der ohne ein klar gesetztes Ziel einfach Webseiten ansurft, die ihm gerade interessant erscheinen. PageRank erhebt entsprechend keinen Anspruch darauf, den Verlauf einer längeren Recherche oder einer ausgedehnten Auseinandersetzung mit einem bestimmten Thema antizipieren zu können. Für seine Schöpfer fungiert es vielmehr als ein auf die individuelle Suchsituation eingegrenztes »model of user behavior«, welches die unmittelbar naheliegendsten Surfentscheidungen identifiziert und anbietet (vgl. Brin \& Page 1998: 4).

Über das PageRank-Verfahren hinaus sollte sich Google noch einer Anzahl anderer Tricks bedienen, um junk-Resultate so weit wie möglich zu unterdrücken und Seiten von hoher Relevanz an die Spitze seiner Trefferlisten zu setzen. Eines davon ist der sogenannte anchor text. >Ankertexte` sind der Teil eines in natürlicher Sprache verfassten Webseitentextes, der als Hyperlink fungiert. Eine der Grundfunktionen von HTML ist die Möglichkeit, mittels eines einfachen Skriptbefehls eine Webadresse gewissermaßen in einer Textpassage zu >verstecken`, die dann einfach angeklickt werden kann und die entsprechende Webseite öffnet. Auf diese Art ist es nicht nur möglich, Hyperlinks in Webseiten einzubauen, ohne den Fließtext zu unterbrechen oder sie in einen separaten Verweisapparat auszulagern. Es kann darüber hinaus einem Link direkt eine bestimmte kulturell lesbare Bedeutung in Schriftsprache zugewiesen werden. Das komplette System der Querverweise auf Wikipedia 
funktioniert beispielsweise nach diesem System. Dass eine solche unmittelbare Verknüpfung von culture und computer layer für ein Suchmaschinen-Ranking eine sehr aussagekräftige Quelle darstellt, ist naheliegend. Der besondere Wert, den Brin und Page ihm beimessen, gründet sich auf den Sachverhalt, dass er meist die Fremdbeschreibung einer Webseite darstellt und damit abbildet, aus welchen Interessen heraus ein Nutzer diese möglicherweise anklicken könnte (vgl. ebd.: 5). Ein weiteres Novum, mit dem Google gegenüber konkurrierenden Suchmaschinen auftrumpfen sollte, war die Einbeziehung geographischer Größen beim Ranking von Webseiten. Über IP-Adressen lassen sich sowohl die Standorte der Server bestimmen, auf denen Web-Inhalte gespeichert sind, als auch jene der Nutzer, die nach diesen suchen. Die räumliche Distanz kann somit ebenfalls zu einem Faktor werden, anhand dessen über die Wichtigkeit einer Webseite im Hinblick auf eine individuelle Suchanfrage entschieden werden kann (vgl. ebd.).

Wie die ihm vorausgegangenen Suchmaschinen wertet auch Google die Texte seiner indexierten Webseiten aus und erhebt dabei insbesondere die Häufigkeit des Auftauchens bestimmter Wörter, die in sogenannten hit lists verzeichnet werden. Hier unterscheiden Brin und Page allerdings abermals zwischen plain hits und fancy hits. Es kommt für die Suche nicht nur darauf an, $o b$ ein Wort auf einer Seite auftaucht, sondern auch darauf, wie und wo es genau in Erscheinung tritt. Ein plain hit bedeutet lediglich, dass das Wort im Fließtext der Seite gefunden wurde. Ein fancy hit hingegen beschreibt einen Treffer an besonders exponierter Stelle auf der Webseite oder sogar im HTML-Code selbst. Ein fancy hit kann z.B. bedeuten, dass das gesuchte Wort im Titel einer Webseite oder in einer Überschrift fällt - im Gegensatz zu älteren Suchmaschinen sollte Google nämlich auch erkennen können, ob Textpassagen durch Fett-, Kursivsatz oder Unterstreichung hervorgehoben sind (vgl. ebd.: 5). Ein fancy hit wäre aber auch ein Auftauchen des Wortes in einer URL, einem Ankertext oder in mit der Webseite assoziierten Metadaten (vgl. ebd.: 9).

Kurzum: Google, wie Brin und Page es 1998 in Aussicht stellten, war zunächst nichts anderes als ein Bündel von Algorithmen, die Muster und Zusammenhänge erkennen und operationalisieren sollten, ohne dabei auch nur im Ansatz imstande zu sein, sie inhaltlich zu begreifen. Suchmaschinen verstehen keine kulturellen Inhalte, aber sie können unseren Umgang mit kulturellem Wissen unter ganz bestimmten Aspekten mathematisch auswerten. Die Schrift allein verbürgt - wie Laßwitz, Borges und vier Jahre vor Google schließlich noch Langford demonstrieren - für sich allein genommen keinen hinter den Worten wirkenden Geist, und dementsprechend führt die reine Textsuche meist nicht zum benötigten Wissen. Sie kann den Text nicht an die Welt zurückbinden, in welcher er gelesen wird. Erst im Zwischenraum der Intertextualität - dies ist eben der >museale< Charakter des Netzes - werden Texte bedeutsam. Google kann diesen Zwischenraum nicht lesen, ihn wohl aber nach rein funktionalen Maßstäben vermessen. 
Bevor diese Vermessung aber stattfinden kann, müssen die einzelnen Webseiten erst einmal erhoben werden, und nach Brin und Page ist dies der schwierigste Teil des gesamten Indexierungsprozesses. Die Webcrawler-Programme, deren Aufgabe es ja ist, systematisch so viele Links wie möglich zu verfolgen und Daten zu den so gefundenen Seiten zu erheben, müssen mit einem riesigen, nur begrenzt standardisierten digitalen Hypertextsystem umgehen, das sich der Kontrolle der Suchmaschinenbetreiber in weitesten Teilen entzieht. Sowohl die Seiten selbst als auch die Server, auf denen sie gespeichert sind, unterscheiden sich in Standards, Formaten und allgemeinem Aufbau mitunter erheblich. 1997 konnte ein Crawler ca. 300 simultane Verbindungen offenhalten und ein übliches System von vier gleichzeitig koordiniert operierenden Crawlern etwa 100 Seiten pro Sekunde indexieren. Bei derart großen Zahlen und einer solchen Geschwindigkeit liegt auf der Hand, dass eine Suchmaschine von der Größe Googles im laufenden Erhebungsverfahren nicht zwischen Webseiten differenzieren oder diskriminieren kann. Wer seine Seite nicht indexiert sehen möchte, der kann dies nur sicherstellen, indem er sie technisch so anlegt, dass sie von Webcrawlern nicht erfasst werden kann oder ihre Zugriffsversuche von vorneherein abgeblockt werden. Der Crawler selbst ist nicht imstande, ein sprachliches Statement auf der Webseite zu verstehen - und die Datenmenge wiederum viel zu groß, als dass sie jemals sinnvoll von Menschen gesichtet werden könnte (vgl. ebd.: 10).

Die Frage nach der Legitimität einer solch großflächigen und für die einzelnen Webangebote sowie ihre Inhalte weitgehend blinden Datenerhebung verschärfte sich im Jahre 2005, als Google, nunmehr bereits der unumstrittene Marktführer auf dem Gebiet der Websuchen, die Firma Urchin Software Corp. und mit ihr die Rechte an der Software Urchin aufkaufte. Bei Urchin - was wörtlich etwa >Straßenkind ২ bedeutet - handelte es sich wie bei PageRank um ein Programm, welches das Web zwischen den eigentlichen Webseiten zu vermessen trachtet. Während PageRank allerdings die Verlinkung und damit gewissermaßen die Architektur des semantischen Netz-Raumes ausmisst, hatte Urchin nun die Aufgabe, nicht etwa die Seiten, sondern die Nutzer zu beobachten - bzw. die Fußspuren ihrer digitalen Dubletten, welche Marcos Novak mit dem Begriff des >Navigators` belegt hat. Urchin leistet dies, indem es die Log-Dateien von Webservern ausliest, jene Dateien also, in welchen die Verbindungen verzeichnet sind, die von anderen Computern zu diesem Server aufgenommen wurden. Urchin Software Corp. wurde zur Keimzelle von Googles 2006 geformtem Firmenzweig Google Analytics, der heute zu den wichtigsten Pfeilern des Geschäftsmodells gehört. Google Analytics bietet Webseitenbetreibern die Möglichkeit, detaillierte Informationen über die Nutzer ihrer Seiten zu erhalten - im Austausch dafür, dass Google selbst diese Daten natürlich ebenso zur Verfügung stehen. Die einzelnen Webmaster müssen hierzu lediglich einen Account anlegen und ein paar Zeilen Javascript in den Code ihrer Webseite einfügen. Google kann dann jeden 
Nutzer >tracken`, der sich auf vom Analytics-System indexierten Seiten bewegt. ${ }^{4} \mathrm{Im}$ Jahre 2010 waren dies nach Angaben der Amazon.com-Tochter Alexa Internet immerhin allein die Hälfte der 1.000.000 meistbesuchten Seiten im WWW. ${ }^{5}$ Die Identifikation der User kann auf verschiedenem Wege erfolgen, so z.B. anhand der IPAdresse oder durch `Cookies〈, welche Google Analytics auf den Rechnern der Endnutzer ablegt. Theoretisch kann ein bestimmter Computer sogar anhand der Browsereinstellungen erkannt werden. Im Idealfall besitzt der Nutzer auch noch einen mit seinen persönlichen Daten versehenen Googlemail-Account. Sein komplettes Surfverhalten, alle seine Suchanfragen und alle von ihm auf Google Search angeklickten Treffer sind dann zentral an einer Stelle gespeichert und mit seiner individuellen Person identifizierbar ${ }^{6}$ - was es Google wiederum ermöglicht, noch genauer personalisierte Navigationshilfen im Web bereitzustellen und zukünftige Entscheidungen für und gegen das Anklicken bestimmter Links noch akkurater zu antizipieren.

In seinem Text über das virtuelle Museum als neue kulturelle Ausdrucksform identifizierte Werner Schweibenz schon 2001 - als der Siegeszug von Google gerade erst Fahrt aufnahm - als eine entscheidende und für jede Form von Kulturvermittlung in Netz prägende Eigenart digital-virtueller Massenmedien ein ihnen ganz eigenes Zusammenspiel von broadcasting und narrowcasting: Sie verteilen große Mengen von Information an große Massen von Menschen, sind aber gleichzeitig imstande, der Einzelperson ein sehr stark auf sie zugeschnittenes und personalisiertes Angebot aus ihrem Datenfundus zu machen (vgl. Schweibenz 2001: 12). Google ist für diese Tendenz innerhalb der digitalen Medienkultur und -wirtschaft nur das größte und sinnfälligste Beispiel. Nahezu alle noch existierenden Suchmaschinen arbeiten heute mit Rankingverfahren, und ihnen allen ist gemein, dass deren grundsätzliche Funktionsprinzipien zwar bekannt, die konkret zum Einsatz kommenden Algorithmen aber Betriebsgeheimnisse sind. Neben Google Analytics sind inzwischen noch hunderte weiterer Tracking-Dienste im Netz unterwegs, die häufig Daten für sehr spezielle und begrenzte Brancheninteressen sammeln. Und nicht nur die abstrakten Daten werden von dieser Kybernetisierung ergriffen, sondern auch konkrete Dinge. Jeder Nutzer von Amazon kennt jenen Startbildschirm, der ihn auf Produkte aufmerksam macht,

4 Angemerkt sei, dass der Endnutzer sich dem Tracking durchaus verweigern kann, indem er entweder ein entsprechendes Plugin in seinem Browser installiert (Google bietet ein eigenes an, es stehen aber auch diverse von Drittanbietern zur Verfügung) oder das Javascript insgesamt ausschaltet.

5 Vgl. http://s3.amazonaws.com/alexa-static/top-1m.csv.zip vom 15.05.2018.

6 Google bietet zwar ein Löschen dieser Daten an, dies jedoch bezieht sich nur auf das für den Benutzer sichtbare >Logbuch` seiner Google History - Google selbst behält eine Logdatei, versichert jedoch, die gesammelten Daten nach 18 Monaten zu anonymisieren, vgl. http://support.google.com/accounts/answer/54068?hl=en vom 23.01.2015. 
die dem System im Hinblick auf sein bisheriges Konsumverhalten relevant erscheinen. Diese Relevanzeinschätzung wiederum basiert logischerweise auf der Beobachtung des Kaufverhaltens der breiten Masse der Kunden. ${ }^{7}$ Dabei werden einzelne Artikel im Sortiment zugleich dynamisch mit anderen verlinkt, welche oft zusammen mit diesem bestellt werden. Amazon besitzt zwar auch ein System von Produktkategorien, mit dem sich z.B. direkt die romantischen Vampir-Romane oder die Komödien-DVDs aufrufen lassen, sein eigentliches Herz ist aber das assoziativ angelegte Navigationssystem.

Überhaupt präsentieren sich Auswertungsalgorithmen wie jene von Google oder die Amazon-Produktempfehlung zunächst einmal als logische Weiterentwicklungen des Assoziationsparadigmas, das Vannevar Bush der Memex-Maschine zugrunde gelegt hat. War es dort noch der individuelle Nutzer, der einer individuellen Maschine seine eigenen Assoziationsmuster einimpfen und sie damit außerhalb seines eigenen und notwendigerweise vergesslichen Verstandes verstetigen sollte, sind es nun Kollektive von Nutzern, die einer zumindest in unserem Nutzungserleben weitgehend ortlosen bzw. kaum lokalisierbaren Software-Zentralinstanz ihre Assoziationen nur mehr ganz implizit mitteilen - indem sie eben suchen, anklicken, womöglich bestellen oder herunterladen. Das ganze vernetzte Gefüge unserer kulturellen Wirklichkeit, aller unserer Zeichen, aller unserer Texte und aller ihrer Bedeutungen scheint virtuell (und vor allem: vermessbar!) verborgen zu sein in der Architektur des Hypertextes und der Art, wie individuelle Nutzer einzelne Webseiten abrufen. Der Code allein spricht nicht über die Welt, aber die Art und Weise, wie er gelesen wird, sehr wohl und diese ist, so lautet die dem Google-Prinzip zugrundeliegende Annahme, eben kein aller Technik entrücktes Gemauschel im Raum des Geistes und der Emotion, sondern ein in seinem großen Umriss durchaus statistisch modellierbares Gewebe von Zugehörigkeiten und Abgeschiedenheiten, von Nähen und Distanzen, über welches letztlich nicht die Netz-Detektive, sondern die Netz-Flaneure abstimmen. Dies tun sie mit den metaphorischen Füßen: Das Besondere am Hypertext ist eben, dass der Text nicht mehr nur die Entscheidungen des Autors abbildet, sondern zugleich jene des Lesers einfordert, und jede dieser Leserentscheidungen muss dem System in Form einer klaren Auswahl dieses oder jenes Hyperlinks mitgeteilt werden, womit sie unweigerlich serverseitig erfassbar wird. Das Web steht nicht immer und überall im direkten >Dialog $<$ mit seinen Nutzern, aber wir erklären ihm grundsätzlich mit jedem Klick aufs Neue unsere Absichten.

7 Amazon.com nutzt dabei ein kompliziertes System, das `Cluster`von Zugriffen auf Artikel auswertet und hierbei sowohl Nutzer- als auch Artikelgruppen einbezieht (vgl. Linden, Smith u. York 2003: 76f.; 78f.). 


\subsubsection{Das gezähmte Netz: Vom Flanieren zum Finden}

Der Erfolg sowohl des Hypertext-Formates als auch jener des Nutzer-Trackings ist sicherlich auch siebzig Jahre nach As We May Think noch im Kontext einer evidenten Unfähigkeit klassischer Wissensordnungs- und Abrufsysteme zu lesen, mit rasanten Informationsexplosionen mitzuhalten. Die institutionelle und personelle Autorität, die sich mit der Idee der Autorschaft verbindet und die in einem Bibliothekskatalog ebenso präsent ist wie in einer Museumsausstellung, hat grundsätzlich nur eine begrenzte Reichweite, die sich aus den Einschränkungen des menschlichen Organismus ergibt: Eine Gruppe von Bibliotheksmitarbeitern kann nur eine begrenzte Zahl von Büchern bibliographisch erschließen, eine Gruppe Kuratoren nur eine bestimmte Menge von Exponaten verwalten und eine noch kleinere in die Ausstellung aufnehmen. Dabei sind solche Expertensysteme, wie Konrad Becker feststellt, stets befangen in ihren jeweiligen disziplinären Vorurteilen, die nicht immer das Ergebnis kritischer Reflexion und Auseinandersetzung sind, sondern allzu oft quasi-religiöse Züge aufweisen:

Professionelle Kategorisierungsexperten bemühen sich, das Kontextabhängige und Temporäre um jeden Preis zu meiden, und enden doch immer mittendrin. [...] Fast zwangsläufig dominieren eigene Interessen und Anforderungen der Katalogproduzenten über objektivere Bedürfnisse von Navigation in komplexen Welten. Sie züchten kognitive Verwaltungstechnologien, die kulturelle und subjektive Vieldeutigkeit und das Schillern kontextabhängiger Aussagen nicht erkennen. Vorstellungen einer objektiven Ordnung des abstrakten Raumes entstehen auf Grundlage religiöser Ideen von makelloser Reinheit. Solche Illusionen werden von gefährlichen Ideologien kybernetischer Kontrolle genährt und vom Glauben, dass die manifeste Welt auf einen einzigen Standpunkt zu reduzieren wäre. (Becker 2010: 185)

Damit möchte Becker aber keineswegs ein Loblied auf die völlige Kontextabhängigkeit anstimmen: Vielmehr, so seine These, gibt es derzeit schlicht keine ideale Form der Zurechtfindung in komplexen Wissensräumen von der Größe des WWW. Zwar sei eine kategoriale Ordnung seiner Inhalte weder machbar noch für die Masse der Nutzer in irgendeiner Form zielführend, zugleich jedoch vermittle eine rein assoziative Zugriffsform allzu leicht falsche Vorstellungen von Verfügbarkeit und schaffe sich darüber hinaus immer auch ihre ganz eigenen Irrwege:

Der Versuch der elektronischen Aufbereitung von Informationen und Ressourcen kann durch überkommene Gewohnheiten und veraltete Strategien aus vorangegangenen Ansätzen der Strukturierung von Wissen sehr unzureichend ausfallen. Digitale Information braucht kein Regal, und es stellt sich die Frage, inwieweit vordefinierte Kategorisierung überhaupt eine gute Idee ist. Ein Hauptgrund für den Erfolg von Google war das Fehlen virtueller Regale, von im 
Voraus konstruierten und immer auch eigenartigen Dateistrukturen. Aber bei Regalflächen, auch wenn sie den Wissensraum seltsam verzerren, ist zumindest einfach zu sehen, ob sie voll oder leer sind. (Ebd.)

Das Heimtückische an der Assoziation im näherungsweise Absoluten ist also, dass ganz ähnlich wie die Textsuche in Langfords Net of Babel immer zum Erfolg führen wird - uns die Assoziation in einem ausreichend großen und vernetzten Hypertextsystem letztlich fast immer in irgendeiner Form zum nächsten Textsegment führen wird. Ein schwarzer Bildschirm, der uns sagt >Du, Nutzer, hast die Grenze sinnvoller Assoziierbarkeit erreicht, ab hier gibt es nichts mehr zu lernen ‘ ist in der Konzeption des Webs nicht vorgesehen. Während die Bibliothek von Babel irgendwann durchschaut und der Umstand, dass ein Text in überhaupt keinem kulturellen Bezug zur Außenwelt steht, als Normalzustand erkannt wird, lädt das Netz uns immer wieder zum abduktiven Trugschluss ein: Die statistische Kontingenz der Zugriffsmuster erzeugt eine kulturell-narrative Kontingenz der Sinnzusammenhänge, aber diese entsteht selbst nicht in der Domäne des Kulturellen. Bevor unsere kulturellen Schemata das digitale Objekt nach Hui aus den Relationen zwischen digitalen Informationspartikeln entstehen lassen können, nehmen solche Navigationswerkzeuge die gemittelten Mechanismen unserer kollektiven Kognition vorweg und präsentieren uns das, was sie als wahrscheinlich kommensurabel für uns identifiziert haben.

Die Vorstellung vom völlig emergenten und gänzlich situativ um unsere eigenen Interessenspfade herum entstehenden Cyberspace ist, wie 2012 der weißrussische Publizist Evgeny Morozov feststellt, in erster Linie Leitbild und frommer Wunsch der Advokaten einer emanzipatorischen Netzkultur, die möglicherweise längst technisch unmöglich geworden ist. Morozov sieht darin keinen Sieg des Flaneur-Paradigmas über jenes des kritischen Detektivs - sein Text The Death of the Cyberflâneur sieht den Flaneur (offensichtlich) vielmehr als das erste und bedeutendste Opfer eines nach statistisch ausgewertetem Massenverhalten geordneten Webs (vgl. Morozov 2012).

Der Flaneur nämlich, so Morozov, ist originär eine Figur, die sich zwar mit großer Selbstverständlichkeit in der Masse bewegt, sich aber zu keiner Zeit von ihr vereinnahmen lässt. Sein Begriff vom Flaneur im Datenraum ist also sehr viel näher jenem Lev Manovichs verbunden als jenem Roberto Simanowskis. Der Flaneur nach Morozov zeichnet sich dadurch aus, dass er zwar gern durch die Einkaufsstraße tändelt, niemals jedoch der Versuchung des unreflektierten Konsums erliegt. Der Flaneur im Baudelaire'schen Sinne wolle am städtischen Leben nicht funktional teilnehmen, sondern schauen, beobachten, verinnerlichen und - selbstverständlich - darüber erzählen und schreiben. Die Stadt war für ihn also eher Anschauungs- als Handlungsraum. Der Flaneur sei daher immer Kulturkritiker - allerdings einer, der sich nicht etwa vom Feldherrenhügel einer wie auch immer definierten Hochkultur herab äußert, sondern aus dem kulturellen Milieu der Straße heraus über die Straße und die 
sich in ihr bewegenden (und für sich selbst blinden) Massen schreibt. Dieses Bild vom Internetnutzer als einem lustwandlerischen, zugleich aber auch nachdenklichen und kritischen `Entdecker〈schlägt sich nach Morozovs Lesart schon in den Namen der ersten Browsersoftwares nieder: Bezeichnungen wie Internet Explorer und Netscape Navigator waren in der Frühzeit des WWW attraktive und affirmative Metaphern für eine mündige Internetnutzung (vgl. ebd.).

Von diesem Nutzerbild zieht Morozov eine interessante Parallele zum Schicksal des historischen (Straßen-)Flaneurs: Dieser nämlich sei an einer Veränderung seiner Umwelt zugrunde gegangen, die er nicht zu kompensieren imstande war. Beginnend im Frankreich des Louis Napoleon und seines Pariser Stadtplaners Georges-Eugène Baron Haussmann hätten Neuordnungen des urbanen Raumes ihm seine wichtigste Lebensgrundlage entzogen: die verwinkelten, labyrinthischen Seitenstraßen, die das Mittelalter den europäischen Metropolen hinterlassen hatte und die dem Flaneur sowohl das äußere Verlorengehen im öffentlichen Raum, als auch das innere im Privaten der Gedanken ermöglicht hatten. An ihre Stelle traten weite, begradigte Boulevards, die nicht nur dem Fußgänger, sondern wenige Jahrzehnte später gerade auch dem Automobil ein schnelles und zielführendes Vorwärtskommen ermöglichen sollten, dabei aber zugleich leichter sauber zu halten und - nach 1848 nicht mehr nur in Frankreich ein entscheidender Faktor - schwerer zu verbarrikadieren waren. Mit den Boulevards kam die Gasbeleuchtung, welche die Stadt zunehmend auch als Raum der abendlichen Freizeitgestaltung interessant werden ließ. Die Nacht gehörte nicht länger Flaneuren und Halbweltlern, sondern wurde vom Bürgertum und seinen Zerstreuungen erobert. Viele klassische Einkaufsstraßen mit kleinen Einzelgeschäften fielen der Konkurrenz kompakter Kaufhäuser zum Opfer, in denen nicht mehr gebummelt, sondern zügig, effizient und verkaufsorientiert bedient wurde. Und nicht zuletzt wurde das Flanieren immer gefährlicher: Der zunehmende (und vor allem auch: zunehmend motorisierte) Verkehr machte das versonnene Spazieren zu einem Unterfangen, das durchaus im Krankenhaus oder auf dem Friedhof enden konnte. Nach Morozov waren es eben diese Entwicklungen im räumlichen Gefüge der Stadt, die schließlich auch die größten Flaneure - Proust, Baudelaire, Sainte-Beuve - ins innere Exil ihrer Wohnungen trieben (vgl. ebd.).

Im World Wide Web der Gegenwart sieht Morozov ganz ähnliche Mechanismen am Werk wie in der zweiten Hälfte des 19. Jahrhunderts in den Großstädten Europas: Der Cyberflaneur existierte, so seine These, in einem Web, das noch keine (oder nur relativ ineffiziente) Suchmaschinen kannte und noch nicht durchgreifend von kommerziellen Akteuren erobert worden war. Das Netz-Äquivalent zu den mittelalterlichen Sträßchen und Gassen des städtebaulich noch nicht modernisierten Paris sieht er dabei in den »Arkaden« der bunten Geocities-Seiten der frühen 1990er Jahre, die inzwischen griffigeren Interfaces und Abrufmechanismen gewichen seien. Im Netz gäbe es keinen Raum mehr zum Flanieren, weil sich alles viel zu leicht finden lasse (vgl. ebd.). 
Den Baron Haussmann des Netzes erkennt er dabei interessanterweise aber nicht etwa in Sergey Brin und Larry Page, sondern im Facebook-Gründer Mark Zuckerberg. Nicht nur die bis zur Trivialität vereinfachte Auffindbarkeit von Daten sei der Todesstoß für den Cyberflaneur, sondern vielmehr auch eine »Tyrannei des Sozialen« (ebd.), die auf das Herz des flanierenden Erfahrungsmodus ziele. Dienste wie Facebook wollen, so schreibt Morozov, jede Erfahrung im Netz zu einer sozialen machen und damit jene Anonymität und Ambivalenz vernichten, auf die der Flaneur existenziell angewiesen ist. Die Einsamkeit, die in definiert, soll schlicht nicht mehr möglich sein.

Indes sind die hinter der Suchmaschine Google und dem social network Facebook stehenden Absichten und Geschäftsmodelle natürlich ohnehin ganz ähnliche: Ihre Ware und Währung sind die Nutzungsprofile derer, die ihnen mehr oder weniger bewusst und willig Informationen über sich selbst zur Verfügung stellen und damit eine Optimierung von Online-Angeboten auf ihre Interessenlagen hin ermöglichen. Dass hier natürlich der Weg für allerhand selbsterfüllende Prophezeiungen geebnet ist, muss kaum hervorgehoben werden. Google kann auf die Bedürfnisse und die Lebensweise des Flaneurs gar keine Rücksicht nehmen, weil seine epistemischen Spaziergänge statistisch kaum zu erfassen sind - um seinen assoziativen Gedankenketten zu folgen, müsste man sie eben inhaltlich verstehen. Google kann einzig die Bewegungen von Massen verfolgen und anhand derer zwar nicht die Natur von connectedness vermessen, wohl aber ein mathematisches Modell ihrer relativen Stärke zeichnen. Weil Google aber nicht nur passiv beobachtet, sondern aufgrund seiner Auswertungen die `Relevanz` von Wissensinhalten unmittelbar an seine Nutzer zurückspielt, gewichtet die Software die Autorität bestimmter Webseiten unweigerlich immer weiter zu einem bestimmten »Gondelende« (vgl. Jeanneney 2007: 44) hin: Eine Seite steht hoch oben in der Google-Trefferliste, weil sie oft angeklickt wird - und sie wird oft angeklickt, weil sie hoch oben in der Google-Trefferliste steht. Der Historiker Jean Noël Jeanneney spricht hier im Jahre 2007 - unmittelbar nach dem Ende seiner Dienstzeit als Direktor der französischen Nationalbibliothek - unter dem Eindruck von Googles großangelegtem Bücherdigitalisierungsprojekt Google Books von einer »natürlichen Kybernetik« (ebd.), die nunmehr mit der Suchmaschine ihre technische Untermauerung und Vollendung erfahren habe: Kulturelle Wissensbestände neigen zur rekursiven Selbstbestärkung und damit zur Privilegierung von Wissen, das sich leicht an etablierte Kenntnisschätze anschließt. Diesen »epistemischen Selbstläufern $\aleph^{8}$ gegenüber stehen unweigerlich ausgedehnte Landschaften $>$ schwierigen $<$ Wissens, das nicht den Majoritäts-Lesarten entspricht und am fernen Ende der Gondel marginalisiert wird (vgl. Jeanneney 2007: 44). Die Verfolgung solch randständigen

8 Stefan Rieger entwickelt den Begriff des »epistemischen Selbstläufers« bezeichnenderweise an den technischen Apparaturen physiologischer Experimentalsysteme des 19. Jahrhunderts (vgl. Rieger 2012). 
Spezialwissens ist das Privileg individualisierter Rezeption - der Flaneur lässt es lustwandelnd auf sich zukommen, der Detektiv stellt ihm angestrengt nach, aber beide Figuren scheinen keinen rechten Platz mehr zu haben in einer Informationswelt, die auf schnellste Verfügbarkeit und umweglosen Abruf ausgerichtet ist.

Jeanneney sorgt sich mit Blick auf Google Books ganz konkret um die Geltung der frankophonen Literatur in der globalisierten Welt. Weil Google erstens zugleich das Mess- und Etablierungswerkzeug einer hierarchischen Ordnung unter kulturellen Inhalten sei und zweitens die Popularität des Populären bestärke, begünstige sein Ausgreifen in die Welt der gedruckten Bücher im kolossalen Maße die Verbreitung englischsprachiger Texte, und damit letztlich auch die der englischen Sprache schlechthin (vgl. ebd.: 6ff.). Da Suchmaschinen durch geschickte mathematische Tricks die Grenze zwischen computer und culture layer überbrücken, müssen sich ihre eigentlich völlig kulturfremden Algorithmen unweigerlich Debatten über ihre kulturellen Implikationen stellen - und damit auch über ihre Rolle in Auseinandersetzungen zwischen privilegiertem und marginalisiertem Wissen sowie den Identitäten und Lebensentwürfen, die sich mit diesem verbinden. Letztlich aus reiner Mathematik bestehende Software wird zum Abbild von Ideologien und damit implizit politisch: In einer Welt, in der Information längst überwiegend digital gespeichert, verbreitet und abgerufen wird, programmieren Programmierer eben nicht mehr nur Computer, sondern auch die Kulturen, die sich ihrer bedienen. Damit stehen etablierte Kulturinstitutionen vor ganz neuen Herausforderungen - und sehen sich mit ganz neuer Konkurrenz konfrontiert.

\subsection{ANDRÉ MALRAUX: DAS IMAGINÄRE MUSEUM}

Die Geschichte des Museums ist, wie das erste Kapitel dieser Arbeit abrissartig darstellen konnte, eng verwoben mit gesellschaftspolitischen Visionen und Utopien, die sich durchaus als Programme begreifen lassen: Vor-Schriften des Denkens und der Welterfahrung, die sowohl deren Inhalt als auch ihren Modus betreffen und die das Museum bei seinen Besuchern anregen, kultivieren, verfestigen soll. Von der Vermittlung einer vermeintlich göttlichen Ordnung in den Wunderkammern der Frühneuzeit über die Humbold'tschen Musentempel zu den >emanzipatorischen`Ausstellungskonzepten der Nachkriegszeit wollten Museen nicht nur ein spezifisches Wissen, sondern auch bestimmte Formen und Philosophien des Lernens transportieren. Eine Kontinuität der Museumsgeschichte, die sie nun mit jener der digitalen Medien verbindet, war dabei das Netzwerk als funktionales Leitprinzip. Eine andere, die immer noch als Barriere zwischen dem Museum und dem Web steht, ist die Innen-/Außen-Trennung und mit ihr die naturgemäße Beschränktheit aller Sammlungen und 
aller auf ihnen gründenden Ausstellungen. Während das Web und seine ideengeschichtlichen Vorläufer auf das Bestreben zurückzuführen sind, Grenzen und Abschlüsse in Wissensräumen zu überwinden, braucht das Museum in seiner klassischen Erscheinungsform den inneren Abschluss des Präsentierten und den äußeren der Institution, weil eben nur so die Autorschaft des Kuratoriums und die Bedeutsamkeit der Objekte im physikalischen Raum nachzuweisen sind. Paul Valérys Museumskritik lässt sich letztlich leicht als eine lesen, die von den Museen vor allem mehr Abschluss, mehr Selbstbescheidung und mehr Fokussierung auf das Einzelobjekt verlangt.

André Malraux indes, jener Staatsmann und Kulturtheoretiker, der dem Museum ja ohnehin jede Fähigkeit zum historisch sauthentischen` Ausstellen abspricht, sieht in ihm eine gerade aus ihrem vergeblichen Streben nach der Rekonstruktion historischer Wirklichkeiten heraus verfehlte (oder zumindest immer defizitäre) Institution. Authentische Abbildung nämlich müsste nach Malraux die Wiederherstellung des Gesamtzusammenhanges beinhalten, und in dessen Ermangelung bleibt jedes $\mathrm{Mu}-$ seum letztlich unvollständig. Was Andreas Urban >Geschichtsbild ^nennt - eben das souveräne, schlaglichtartige und in sich geschlossene Deutungsangebot, in dem die Ausstellung vollständig und vollendet erscheint - ist für Malraux immer nur der annäherungsmäßige und letztlich zum Scheitern verurteilte Versuch einer Rekonstruktion von Zusammenhängen, die in der weiten Welt menschlichen Lebens und Handelns nun einmal verloren sind. Sie alle wiederherzustellen wäre nicht einmal möglich, wenn wir tatsächlich die ganze Welt zum Museum machten. So schreibt Malraux über die Unvollkommenheit des Museums als Ort der Erinnerung:

Was muß dem Museum unvermeidlich fehlen? Alles, was an ein Ganzes gebunden ist, wie Glasfenster oder Fresken; was sich nicht transportieren oder was sich nur unter Schwierigkeiten ausbreiten läßt, wie etwa Folgen von Wandteppichen; was nicht zu erwerben ist. Selbst wenn ständig immense Mittel zur Verfügung ständen, bleibt ein Museum doch nur das Ergebnis vieler glücklicher Zufälle. Trotz all seiner Siege ist es Napoleon nicht geglückt, die Sixtina dem Louvre einzuverleiben, und kein Mäzen wird je das Königsportal von Chartres oder Piero della Francescas Fresken in Arezzo in das Metropolitan Museum verbringen können. [...] So ist das Museum, entstanden zu einer Zeit, da das Staffeleibild die einzige noch lebendige Form der Malerei war, heute wohl eine Bildergalerie geworden, nicht aber ein Museum der Farbe, eine Sammlung plastischer Einzelwerke, nicht der Skulptur schlechthin. (Malraux 1960: 11)

Malrauxs Antwort auf diese Unfähigkeit des Museums, die versatzstückhaften Ausstellungsobjekte in die Totalität ihrer historischen Umwelten einzuordnen und damit die Gesamtheit der Stile in ihrer geschichtlichen Kontinuität abzubilden (es sei daran erinnert, dass Malraux sich in seinen Ausführungen vorrangig auf das Kunstmuseum als Träger kulturellen bzw. kulturhistorischen Bewusstseins kapriziert) ist eine Medientechnologie - nämlich die Fotografie. Tatsächlich begegnet uns bei Malraux im 
Kontext musealer Ausstellungen mit nur geringer zeitlicher Distanz zur Veröffentlichung von As We May Think eine ganz ähnliche Abfolge von Gedankengängen, wie Vannevar Bush sie im Hinblick auf die Bibliothek entwickelt. Weil das Museum seinen gesellschaftlichen Auftrag nur suboptimal zu erfüllen imstande sei, sollen technische Apparaturen sich seine Inhalte aneignen und den Zugriff auf eine Art neu organisieren, welche das physische Objekt verbietet. Malraux führt aus:

Heute stehen dem, der sich mit der Kunst beschäftigt, farbige Reproduktionen der meisten Hauptwerke zur Verfügung, dazu eine Fülle zweitrangiger Bilder, die Kunst archaischer Epochen, die indische, chinesische und präkolumbische Bildnerei in ihrer Blütezeit, ein Teil der byzantinischen Kunst, die romanischen Fresken, die Kunst der Naturvölker und die Volkskunst. Wie viele Plastiken waren 1850 schon reproduziert? Unsere Bildwerke hingegen finden ihr bevorzugtes Thema in der Skulptur, die sich im Schwarz-Weiß getreuer als ein Gemälde wiedergeben lässt. Einst kannte man den Louvre (und einige kleinere Sammlungen, die zu diesem gehören), und an ihn erinnerte man sich, soweit das Erinnerungsvermögen eben reichte. Heute dagegen stehen unserem lückenhaften Gedächtnis als Ergänzung mehr wichtige und bedeutsame Werke zur Verfügung, als das größte Museum je in sich zu fassen vermöchte. (Ebd.: 12)

Mit der Rede von der >Ergänzung « des >lückenhaften Gedächtnisses` mittels der Fotografie ist bei Malraux natürlich genau jene Wendung angezeigt, die Bush unternimmt, wenn er das (ja ebenfalls fotografisch arbeitende) Memex-System als »an enlarged and intimate support to his [des Nutzers] memory« (Bush 1945) bezeichnet - und ganz wie Bush akzentuiert Malraux die Fülle des im Medium aus dem Geist ausgelagerten Wissens. Die frappierendste Parallele zwischen Bush und Malraux ist aber, dass der französische Schöngeist und der amerikanische Ingenieur aus völlig unterschiedlichen Problemstellungen und Interessenlagen heraus fast zeitgleich kurz vor der Jahrhundertmitte das Assoziative als den Schlüssel zum Umgang mit der Informationsflut der Moderne entdecken. Für Malraux führt dieser Gedankengang uns paradoxerweise zunächst aus den Museen als Einzelorganisationen hinaus, dann jedoch unmittelbar wieder in die Institution zurück:

Denn ein Imaginäres Museum hat seine Pforten aufgetan, das die unvollständige Gegenüberstellung, wie sie nun einmal in der Natur der wirklichen Museen liegt, bis zum äußersten erweitert. Was die Museen angeregt hatten, ist Wirklichkeit geworden: Die bildende Kunst hat ihre Vervielfältigung durch den Druck gefunden. (Ebd.: 12)

Malraux, für den die Zerschlagung der Aura durch die Reproduktion mangels Authentizität der Originalobjekte ohnehin kein Problem darstellt, kann die Auswirkungen technischer Reproduzierbarkeit im Gegensatz zu Benjamin völlig abseits des jeweiligen Originals denken und ins Auge fassen, wie kulturelles Bewusstsein mit den 
medialen Voraussetzungen der Verbreitung von Kulturgütern zusammenhängt. Interessant ist dabei die Wortwahl vom >Imaginären Museum`: Während, wie bereits ausgearbeitet wurde, die zeitgenössische Museumswissenschaft das virtuelle Museum gern als einen mangelhaften Abglanz der physischen Einrichtung begreift, versteht Malraux die `wirklichen $<$ Museen als eine bloße Vorwegnahme eines erst von industriellen Vervielfältigungstechniken ermöglichten Bilderuniversums, in dem jedes Objekt grundsätzlich jedem anderen zu begegnen imstande wäre. Die Reproduktionen sind nicht der Schatten des Museums, sondern seine Vollendung. Die Bilder existieren nicht, um auf das Museum zurückzuverweisen, sondern das Museum existiert, um Bilder in die Außenwelt hinauszustrahlen. Damit knüpft Malraux nicht nur an Walter Benjamins Überlegungen aus dem Reproduzierbarkeitsaufsatz an, sondern auch an Fotografiediskurse der französischen Kunstwelt, die bereits in der ersten Hälfte des 19. Jahrhunderts nachzuweisen sind. Der Kurator und Museumshistoriker Ulfert Tschirner verweist hier beispielhaft auf den Pariser Feuilletonisten Jules Janin, der 1839 das Museum vor allem als ein »Reservoir latenter Daguerreotypien« beschrieb (Tschirner 2011: 32).

\subsubsection{Im Universum der Abbilder: Museum und Fotografie}

Im Malraux'schen Blick auf das Museum dient also nicht etwa die Kopie dem Original als Referent, sondern vielmehr das Original der Kopie als Referenz. Indes zeigt der Begriff des musée imaginaire aber auch an, dass Malraux in dieser Entwicklung durchaus keine Auflösung des Museums sieht - weder des individuellen Ausstellungsgefüges, noch der Institution als Bezugsgröße. Tschirner, der Malraux im Zusammenhang mit der Rolle der Fotografie in der Museumsgeschichte sehr ausgiebig behandelt, vergleicht das Verhältnis zwischen Imaginärem und physischem Museum mit dem eines Konzertbesuches zum Anhören einer Schallplatte (vgl. ebd.: 220f.). Eine Aura des Originalobjektes gibt es für Malraux sehr wohl, aber der öffentliche Diskurs über die Kunst und ihre Rolle in der Welt findet seines Erachtens ganz überwiegend auf der Basis von Abbildungen statt - und: Weil es für ihn eben keine immanente und autonome Authentizität der Kunstwerke an sich gibt, ist jedes auratische Erleben im Museum das Produkt von Ausstellungskonstellationen und genau jenen Auseinandersetzungen über die Kunst, die ohne Reproduktionen gar nicht stattfinden könnten (vgl. ebd.).

In diesem Sinne also erfüllt das Original für André Malraux eine ähnliche Funktion wie die Buchseite für Vannevar Bush: Es ist ein vergleichsweise ineffizientes Medium, das seinen Inhalt zu stark an einen bestimmten Standort bindet und ihn somit auch zu rigide von anderen Inhalten getrennt hält. Aus diesem Grunde verlangt es stumm nach deren Übertragung in ein >mobileres« Mediensystem. Tschirner, der 
sich in seiner Dissertationsschrift mit der Mediengeschichte des Germanischen Nationalmuseums befasst, weist in diesem Zusammenhang auf eine interessante Tatsache hin: Die Koevolution von Hypertext und Museum lässt sich tatsächlich bis in die Mitte des 19. Jahrhunderts zurückverfolgen, und die Brücke zwischen den beiden Wissensformen ist die Fotografie.

Tschirner macht dabei den Liegnitzer Freiherrn Alexander von Minutoli als einen entscheidenden Pionier aus: Um 1845 legte dieser eine umfangreiche Sammlung historischen Kunsthandwerks an, die als ein Musterrepertorium für das fertigende Gewerbe dienen sollte. Um seiner Sammlung in dieser Funktion zu größerer Reichweite zu verhelfen, ließ von Minutoli ab etwa 1847 Daguerreotypien seiner Schaustücke anfertigen und diese an Gewerbeverbände verschicken, ab 1854 kamen Papierfotos hinzu, die auch mit großem Erfolg in Bildbänden publiziert wurden (ebd.: 10 f.).

Obwohl das Wiener Museum für Kunst und Industrie erst 1864 als erstes europäisches Museum ein eigenes Foto-Atelier einrichten sollte, bemühte sich das 1852 eröffnete GNM unter seinem Gründer Hans von Aufseß bereits ca. 1855 um die Einrichtung einer sogenannten Photographischen Anstalt, die sich in den Jahren 1859/60 sowie zwischen 1862 und 1867 in aktivem Betrieb befand (vgl. ebd.: 12). Das GNM wird von Tschirner als besonders interessant eingeschätzt, da es als Idealtypus eines kulturhistorischen Museums vom in Kunstmuseen des 19. Jahrhunderts üblichen Selbstbegrenzungsparadigma abweicht und den Anspruch formuliert, eine möglichst universelle und abgeschlossene Zusammenstellung des deutschen Kulturerbes zu präsentieren. Weil aber - wie Malraux ja so plastisch schildert - jede Sammlung immer auch das Ergebnis von Zufällen ist und ein individuelles Originalobjekt sich nicht an zwei Orten zugleich befinden kann, wird die Reproduktion zu einem notwendigen Behelf, um eine solche Universaldarstellung auch nur Ansatzweise leisten zu können (vgl. ebd.: 14f.). In fotografischer Abbildung können Objekte vorhanden sein, ohne sich physisch im Raum zu befinden. Auch mit analogen Fotografien lässt sich also durchaus virtuell ausstellen. Johannes Müller, erster Sekretär des GNM, erklärte 1855 die »Gesammtrepräsentation in effige« (ebd.: 82) zum Daseinsgrund des Museums und stellte damit die herkömmliche und bis heute überwiegend maßgebliche Museumsphilosophie auf den Kopf, welche Echtheit und Anmutungsqualität der Sammlungsgegenstände über eine ohnehin nicht zu erreichende Abgeschlossenheit der Darstellung erhob. Mit der Fotografie verband sich, so Tschirner weiter, in besonderem Maße eine Utopie von annähernd idealer und verlustfreier Reproduktion, sie war allerdings nur die Leittechnologie unter einer Anzahl von Nachbildungsverfahren, zu denen u.a. auch klassische Gipsabgüsse oder Galvanoplastiken zählten (vgl. ebd.: 82f.).

Das Universalmuseum, wie es das GNM als Sammlungsfernziel anstrebte, hat der Laßwitz'schen und Borges'schen Universalbibliothek gegenüber einen entscheidenden Vorteil: Während der schriftliche Code dem kulturellen Inhalt vorausgeht und in ihm aus diesem Grunde eine astronomische Anzahl von Texten vorhanden sind, die 
für uns weder verständlich noch anschlussfähig sind, kann das Museumsding nur dort in Erscheinung treten, wo kulturelle Prozesse bereits stattgefunden haben. Die Komplexität entfaltet sich daher nicht im Einzelobjekt, sondern in den Relationen zwischen ihnen, die ja das Wesen des Museums ausmachen. Bei Hans von Aufseß und dem GNM mit seiner schwierigen Kollision von musealer Ausstellungspraxis und Totalitätsanspruch wird daher in der Lesart Tschirners bereits das deutlich, was man mit Rückgriff auf Ross Parrys Recoding the Museum womöglich als den besonderen >Datenbank«-Charakter des Museums beschreiben könnte. Das GNM war, so Tschirners These (die uns unweigerlich an Vannevar Bushs Analyse der wissenschaftlichen Veröffentlichungsschwemme im 20. Jahrhundert denken lassen muss), ein »Sammelkasten« von Sinnmodulen, der sich aufgrund seines Umfangs mittels klassischer Register und Kataloge zwar grundsätzlich noch verzeichnen, nicht aber sinnvoll dynamisch verwalten ließ. Von Aufseß habe sich daher bezeichnenderweise dem Zettelkasten als Werkzeug zur Organisation seiner Sammlung zugewandt (vgl. ebd.: 52ff.) und damit eben jener Urform modularer Wissensorganisation, aus deren Tradition das Medium Hypertext auch nach seiner Digitalisierung nicht zu lösen ist. Die besonderen Vermittlungseigenarten des Museums jedoch ermöglichten eine besonders innige Integration des Zettelsystems in die kuratorische Arbeit: Für die Ausstellungsmacher des GNM wurde, so schreibt Tschirner, die Karteikarte gewissermaßen zur virtuellen Dublette des Objektes, das sie beschrieb. Ausstellungen ließen sich mit den Karten, die auf individuelle Schaustücke verwiesen, vorab modellieren. Sammlung und Verwaltungsapparat erschienen als ihre jeweils wechselseitigen Spiegelbilder, und das GNM selbst als Versuch eines »Generalrepertoriums« der deutschen Geschichte sowohl in Form materieller Objekte, als auch der schriftlich niedergelegten Sprachfetzen, die sie identisch ausweisen und somit unabdingbar für den informierten Umgang mit ihnen sind (vgl. ebd.). Die Sinnhaftigkeit einer Sammlung hängt aufgrund der epistemischen Unschärfe von Museumsdingen von ihrer Inventarisierung $a b$ - und die Art der Inventarisierung wiederum bestimmt entscheidend die Möglichkeiten musealer Gestaltung mit (vgl. ebd.: 186f.).

\subsubsection{Das Museum ohne Wände und das transformative Objekt}

Das Imaginäre Museum nach Malraux entfernt das Originalobjekt zwar nicht komplett aus dieser Gleichung, aber als Konzept postuliert es eine Bedeutungsverschiebung der materiellen Kulturgüter von Gegenständen der subjektivierten Anmutung hin zu Gegenständen objektivierten Wissens:

Eine serienmäßig hergestellte Reproduktion dient mehr der Bereicherung unserer Kenntnisse, als daß sie unser betrachtendes Auge befriedigt; immerhin bereichert sie unsere Kenntnisse, wie es ehemals durch die Erfindung des Kupferstichs geschehen war. (Malraux 1960: 26) 
Malraux stellt im Hinblick auf das Imaginäre Museum also ähnliches fest wie Schweibenz im Hinblick auf das virtuelle: Die auratischen Aspekte werden dem Informationswert notwendigerweise untergeordnet. Der informative Stellvertreter wird zur eigentlichen kulturellen Größe, das Originalobjekt bleibt als Referenz im Hintergrund - Konkretes und Abstraktes tauschen die Plätze. Insofern ist natürlich auch die technische Reproduktion musealer Objekte eine Erzeugung von Verkehrsformen. Sie bildet gewissermaßen eine Umkehrung dessen, was Anke te Heesen in der Herstellung von Zeitungsausschnitten beobachtet: Während der Zeitungsausschnitt die Verstetigung eines industriell erzeugten, schnell verfallenden Massenmediums durch die Autorschaft des Schnittes ist, ist die fotografische Reproduktion vielmehr eine Mobilisierung eines einmaligen, raumzeitlich gebundenen und auratisch höchst aufgeladenen Kulturgegenstandes aus der Autorschaft eines Museumskuratoriums hinaus.

Schweibenz, der sich stark auf Malraux bezieht (und dabei übrigens mit einer amerikanischen Übersetzung arbeitet, die das Imaginäre Museum in das museum without walls verwandelt - also bewusst sein Nicht-Abgetrennt-Sein sowohl von der Außenwelt, als auch von einzelnen Sammlungen thematisiert), sieht gerade in dieser 〉Entzauberung ‘ des Materials die Voraussetzung für die Universalität des Imaginären Museums. Schweibenz interpretiert die Rolle des Museums bei Malraux vor allem dergestalt, dass es den Erhalt der Kunstobjekte gewährleistet - und für diesen Erhalt ist die Ablösung der Dinge aus den historischen Zusammenhängen, die ihren Ursprung bilden, nicht etwa ein zu kaschierendes Manko, sondern vielmehr eine entscheidende Voraussetzung. Indem das Museum originäre soziale Verortungen des Ausgestellten aufhebt und die Kunstwerke in Räumen miteinander konkurrieren lässt, die letztlich den Gewohnheiten und Erfordernissen der Gegenwart genügen müssen, schafft es erst die Voraussetzungen zu deren Neuinterpretation. Das $\mathrm{Mu}-$ seum lässt die raumzeitlichen Distanzen zwischen historischen Einzelsituationen schrumpfen und ermöglicht damit deren (assoziatives) In-Beziehung-Setzen zueinander und zu unserer Gegenwart (vgl. Schweibenz 2001: 4f.). Derartige Funktionalitäten des Museums sind in der vorliegenden Studie ja bereits herausgearbeitet worden, allerdings sieht Malraux in diesen Darstellungs-Transformationen nicht nur eine spezifische Eigenart musealen Präsentierens, sondern summa summarum die entscheidende Voraussetzung für die historische Beständigkeit der Kunst schlechthin. Das Kunstwerk nach Malraux ist eben nicht zeitlos, sondern lebt - darin liegt die Radikalität der Malraux'schen Kunsttheorie - gerade von seiner ständigen Erneuerung in der Deutung und somit auch von seiner ständigen Loslösung aus Kontexten, die dem gegenwärtigen Publikum fremd geworden sind. Das revolutionäre Potential der Reproduktion in diesem Kulturverständnis ist nach Schweibenz vor allem, dass sie (und hierin mag man eine Unterstreichung der Benjamin'schen Thesen von der Zerschlagung der Aura erkennen) den mystisch-verklärten Historizismus vom Objekt abfallen lässt, der dem Original innerhalb aller Ausstellungskonzepte noch anhaftet, wie semanzipatorisch`sie auch immer gedacht sein mögen. Die Funktion der Fotografie 
bei Malraux sieht Schweibenz von daher als die der Schaffung von >reinen< Kunstwerken, denen die >Aura keine Grenzen der Assoziierbarkeit mehr zu setzen vermag: Sie lege den »Sinngehalt der Stile« offen und intellektualisiere die Kunst. Für Schweibenz ist die Entstehung virtueller Museen lediglich die logische Fortsetzung dieser im 19. Jahrhundert einsetzenden Entwicklung auf der Basis neuer medialer Möglichkeiten (vgl. ebd.).

Dass Malraux im Zusammenhang mit dem virtuellen Museum immer wieder auftaucht und hier tatsächlich als einer der wenigen kanonischen Autoren zu gelten hat - vielleicht gar als der einzige - ist also keineswegs verwunderlich. Auch die Verbindung zur Ideengeschichte der Hypertexttheorie ist hier bisweilen angeklungen Ross Parry These vom Museum als eigentlichem Vorläufer der Datenbank wurde ja bereits erwähnt, und Erkki Huhtamo bemerkt in einem 2002 für das Nobel-Symposium über virtuelle Museen entstandenen Text ebenfalls die kuriose und zunächst noch nach beiden Seiten völlig folgenlose Zeitgenossenschaft von Vannevar Bush und André Malraux. Diese verleitet ihn gar zu der These, dass die kombinierten Ideen dieser beiden Figuren bereits die Wegweiser seien, die uns »an die Pforten des virtuellen Museums« (vgl. Huhtamo 2002: 3) führen. Huhtamo lässt es sich dabei nicht nehmen, diese Vermählung direkt in noch größere Gedankentraditionen einzureihen - vor allem in jene des in den 1930er Jahren von H.G. Wells geprägten Konzeptes vom World Brain. Wells projizierte mit diesem Begriff das Bild eines absoluten Speichers, der nicht nur alles Wissen der Menschheit aufnehmen, sondern auf den darüber hinaus von überallher mittels technischer Apparate zuzugreifen möglich sein sollte (vgl. Huhtamo 2002: 2). So naheliegend diese Einordnungen zu sein scheinen, sie verfehlen doch die jeweiligen Eigenheiten sowohl des Imaginären Museums als auch des Memex-Konzeptes.

Natürlich muss eine Idee wie das World Brain im Internet-Zeitalter prophetisch erscheinen, und der Anspruch, ein absolutes Speicher- und Abrufsystem für die Gesamtheit des Weltwissens zu konstruieren, erhält spätestens mit Ted Nelsons Project Xanadu in den 1960er Jahren Einzug in die Hypertexttheorie. Auch Eugene Garfield, der Vater des Science Citation Index, verortete seine Arbeit Mitte der 1970er Jahre als Beitrag zum Großprojekt der Schaffung des World Brain. Garfield sah in der Ökonomisierung und Entschlackung von Kommunikationsprozessen nicht nur eine Überlebensfrage für die Wissenschaft, sondern auch eine wichtige Voraussetzung dafür, das entstehende Weltgehirn für jedermann offen und verfügbar zu halten und damit seinem Missbrauch durch totalitäre Zentralgewalten vorzubeugen (vgl. Garfield 1984b: 8).

Obwohl insbesondere Vannevar Bush aus dieser speziellen utopischen Ideentradition nicht hinwegzudenken ist, zielen seine Ideen und die André Malrauxs für sich genommen und aus ihrer historischen Situation heraus doch in unterschiedliche Richtungen. Bushs Memex ist kein Netzwerk-Terminal, das Information von einem räumlich weit entfernten >Server aufruft, sondern es ist selbst sowohl Speicher als auch 
Abruf-Interface. Das von ihm verfügbar gemachte Wissen ist nicht das Ergebnis sozialer Aushandlungsprozesse mit dem Anspruch der Allgemeingültigkeit, sondern das Ergebnis individueller Assoziationen des Einzelnutzers, die so nur innerhalb seines eigenen Memex-Gerätes Bestand haben. Memex war niemals als Weltgehirn angelegt, sondern als Erweiterung des Erinnerungsvermögens einer bestimmten Einzelperson. Das Imaginäre Museum wiederum trägt zwar in seiner abstrakten Konzeption die Züge eines ‘absoluten` Museums, tritt jedoch im Alltag nicht als solches in Erscheinung.

Zunächst gibt es im Imaginären Museum keine Zentralisierung, wie sie das >World Brain als Idee ja impliziert. Das Imaginäre Museum ist eben imaginär und damit an einen imaginierenden Geist gebunden. Es existiert nur implizit innerhalb der ungleichmäßig über unsere kulturelle Lebenswelt verteilten Reproduktionen und muss durch einen bestimmten, letztlich assoziativen Umgang mit diesen verwirklicht werden. Wie es im physischen Museum einen Dualismus von Potentialität und Aktualität in der Trennung von Fundus und Ausstellung gibt, so gibt es auch im Imaginären ein Gegenüber von Präsenz und Latenz, denn auch hier kann nicht alles zugleich >ausgestellt $`$ werden. Niemand ist imstande, gleichzeitig die Gesamtheit aller Museumsdinge zu rezipieren - Paul Valéry waren ja bereits die Pariser Museen zu voll. Der Latenzraum des Imaginären Museums ist die Fülle der Kulturgüter mit den zahllosen virtuell in ihr angelegten Konstellationen, in denen die Objekte zu einander in Beziehung gebracht werden könnten. Tatsächlich aktualisiert werden kann indes immer nur ein musealer \Pfad des Interesses $<$ - das 〉babelhafte $<$ am imaginären Museum ist, dass es grundsätzlich unzählige Ausstellungen beherbergt, von denen viele unter kulturellen Gesichtspunkten völlig absurd wären und dementsprechend niemals zur Aktualität gelangen werden (vgl. Tschirner 2011: 222f.). Tschirner schlägt vor diesem Hintergrund sinnvollerweise vor, zwei Ebenen des Imaginären Museums zu unterscheiden: Das Imaginäre Museum mit großem >I meint hier den gesamten Fundus von in Form von Reproduktionen grundsätzlich verfügbaren Kulturgütern, während ein imaginäres Museum mit kleinem >i< jede individuelle Assoziationskette meint, die aus einem Auswahlprozess hervorgegangen ist (vgl. ebd.: 223f.).

Dabei sind beide Ebenen - Imaginäres wie imaginäres Museum - zunächst rein mediale Virtualitäten innerhalb unserer kulturellen Kommunikation, und sie treten nur dort in Erscheinung, wo Reproduktionen musealer Gegenstände auf eine Art miteinander zusammengeführt, konfrontiert und gedeutet werden, die musealen Charakter hat. In diesem Sinne könnte man also durchaus sagen, dass das Imaginäre Museum, wie Malraux es in den 1940er Jahren beschreibt, weniger ein World Brain denn einen vordigitalen Cyberspace beschreibt. Im Umgang mit fotografischen Abbildungen fallen die Rollen von Kurator und Rezipient weitgehend zusammen und imaginäre Museen entstehen und vergehen im Augenblick assoziativen Springens von Objekt zu Objekt. Während das Imaginäre Museum allerdings immer prozeduraler, 
ephemerer und letztlich virtueller Natur ist, können imaginäre Museen durchaus materiell in Erscheinung treten und in einer bestimmten Konfiguration verfestigt werden. Das Mittel imaginären Kuratierens, das Malraux sich selbst wählte, war dabei paradoxerweise das Kunstbuch bzw. der Bildband - die Stimmen der Stille selbst präsentieren sich dem Leser als eine Mischung aus kunstphilosophischer Abhandlung und quer durch Stile, Provenienzen und Epochen galoppierender Sammlung fotografischer Abbildungen von Kunstwerken. Für Malraux sind Bildbände imaginäre $\mathrm{Mu}-$ seen - was aus der Perspektive dieser Abhandlung natürlich zunächst paradox erscheinen muss, wurde doch die Linearität und Sequenziertheit des gedruckten Wortes als das genaue Gegenteil der mehrdimensionalen, räumlichen Vermittlungslogik des Museums ausgemacht. Die Auflösung dieses Widerspruches liegt für Tschirner darin, dass Malraux den Bildband eben nicht als eine eindimensionale Abfolge von Fotografien anlegt, sondern ihn als ein Mittel der Konfrontation zwischen Objekten versteht. Grundsätzlich leisten imaginäre Museen ähnliches wie physische und sind ähnlichen Beschränkungen unterworfen: Sie assoziieren Kulturgüter miteinander und müssen dabei immer auch aus- und abschließen - sie sind zwar nicht räumlich begrenzt, wohl aber durch die Aufnahmefähigkeit ihrer Rezipienten. In imaginären Museen entfällt allerdings eine Beschränkung, die für physische unumgänglich ist: die Singularität der Exponate.

In der Reproduktion brechen Kunstwerke nicht nur aus den Stätten aus, an denen die Originale verwahrt und präsentiert werden, sondern sie durchleben zugleich eine potenziell unüberschaubare Multiplikation ihrer selbst. Semiotisch bedeutet dies, so Tschirners Deutung, dass nun dasselbe Zeichen in unterschiedliche Signifikanten aufgespalten werden kann, und diese Aufspaltung liegt nicht nur in der Vervielfältigung begründet, sondern gerade auch in der Neukontextualisierbarkeit der Kopien. Die von Malraux selbst in den Nachkriegsjahren mitherausgegebenen Bildbände seien hierfür exzellente Fallbeispiele: Malraux verwendet darin unterschiedliche fotografische Ansichten derselben Kunstobjekte, um das singuläre Original in eine Anzahl unterschiedlicher Bedeutungsträger aufzufächern. Im Ergebnis konfrontiert das Kunstbuch als imaginäres Museum nicht nur - wie es das physische Museum tut zeitgenössische Metamorphosen unterschiedlicher historischer Objekte miteinander, sondern auch das Einzelobjekt mit Metamorphosen seiner selbst und damit seiner eigenen Vieldeutigkeit. Das epistemische Ergebnis dieser Rekursion der Ausstellungsgegenstände auf sich selbst beschreibt Tschirner mit dem Konzept der »zirkulierenden Referenz«, das auf den Wissenschaftstheoretiker Bruno Latour zurückgeht: In der technischen Reproduktion von Kunstobjekten wird nicht etwa eine SignifikantSignifikat-Beziehung zwischen Kopie und Original etabliert, sondern das Originalobjekt wird durch die Offenlegung seiner Stilistik in seiner fotografischen Abbildung selbst zum Zeichenträger für dieselbe. Die bei Benjamin in ihrer tatsächlichen Funktionalität noch schwammig gebliebene Zerschlagung der Aura erklärt Tschirner aus dem Malraux'schen Konzept des Imaginären Museums heraus als eine Verschiebung 
semiotischer Verweisstrukturen, in welchem die Kette der Bedeutungen nicht mehr beim konkreten Material endet, sondern im abstrakten Historischen oder Stilistischen. Die Intellektualisierung der Kunst, bzw. die Herabstufung des affektiven zugunsten des informativen Wertes der Dinge, ist dabei gleichermaßen Mittel wie Ergebnis dieser Transformation (vgl. ebd.: 234 f.).

Das Imaginäre Museum ist folglich eine Vision vom Universalmuseum, die nicht nur aus ganz praktischen Erwägungen an die Reproduktion gebunden ist, sondern vielmehr eine mediale Funktionalität voraussetzt, die das Original gar nicht erfüllen kann: jene der Beweglichkeit. Ein wirkliches Universalmuseum im Sinne Malrauxs darf nicht einfach nur Objekte anhäufen, es muss sie zugleich epistemisch offenhalten, weil es ansonsten das Gros ihrer potenziellen Bedeutungen unterschlägt. Als der Louvre 1803 zum Musée Napoleon wurde und mit den triumphalen Feldzügen Bonapartes zugleich die Hoffnung unter Pariser Museumsdirektoren aufflammte, die wichtigsten europäischen Kunstschätze in ihrer Gänze in der französischen Hauptstadt zusammenführen zu können, war damit eher ein Gefängnis der materiellen Kulturgüter angezeigt denn ein totales Museum des Abendlandes (vgl. ebd.: 229f.). Erst mit der fotografischen Verkehrsform ist es möglich geworden, nicht nur die Dinge, sondern auch die Vielfalt ihrer möglichen Beziehungen zueinander imaginär-museal zusammenzuführen.

Insofern ist das Imaginäre Museum, wie der argentinische Museumswissenschaftler Antonio Battro 1999 bemerkt, als Idee nicht aus dem politischen Kontext seiner Entstehungszeit zu lösen. Die Stimmen der Stille wurden im Umriss schon konzipiert, bevor der Zweite Weltkrieg ausbrach und die Bewegungen der Beutekunst das materielle Erbe Europas nicht nur geographisch völlig umverteilen, sondern auch in signifikanten Teilen vernichten sollten. In den 1940er Jahren wurde das Imaginäre Museum für Malraux zunehmend auch zu einem Ort, an dem Kulturgüter durch ihre Trennung vom ortsgebundenen Original sowohl vor der Kontrolle durch politische Mächte, als auch vor der physischen Vernichtung in den Wirrungen der Machtgeschichte geschützt sein sollten. Das Imaginäre Museum ist insofern eine hoffnungsvolle Zielsetzung wider die Traumata des 20. Jahrhunderts - es ist unbeherrschbar, steht jedermann offen, lässt nichts verlorengehen und verabsolutiert weder Deutung noch Didaktik (vgl. Battro 1999).

Auch Battro betont dabei die Rolle des Kunstbuches und betrachtet die Stimmen der Stille selbst nicht nur als eine Abhandlung über Malrauxs Vorstellungen von materieller Kultur und Kunsttheorie, sondern zugleich als eine Demonstration dessen, was ein imaginäres Museum zu leisten imstande ist. Mit seiner reich illustrierten Abhandlung bewegt sich Malraux an der Grenze zwischen Schrift- und Bildkultur - er führt Kunstwerke zusammen, die geographisch disparat sind und ordnet sie damit sowohl einander zu, als auch in den Kontext seiner schriftlich ausgeführten Theorien ein. Malraux kuratiert kommentierte Abbildungen ganz so, wie das Museum kommentierte Objekte kuratiert, und lässt in einer Zusammenführung, die so physisch 
unmöglich wäre, Bedeutungen sichtbar werden, die ohne das Medium Fotografie unsichtbar bleiben müssten (vgl. ebd.).

Die Fotografie nivelliert Hierarchien indes nicht nur im Hinblick auf menschliche Akteure im Museumsdispositiv, sondern auch zwischen den Objekten selbst. Battro verweist hier ganz grundlegend auf Größenverhältnisse: Im physischen Museum kann bereits die räumliche Ausdehnung der Exponate über ihre Stellung und Geltung in der Aufmerksamkeitsökonomie des Museums entscheiden. Die Fotografie kann diese völlig verschieben (vgl. ebd.). In Nahaufnahme mag selbst eine Scherbe oder ein Fingerknochen gigantisch erscheinen, im Weitwinkel eine Statuengruppe oder ein Dinosaurierskelett hingegen winzig. Durch diese Verzerrung entwickelt die fotografische Abbildung aus dem Originalobjekt dementsprechend nicht nur Kopien, sondern originär neue Kunstwerke, die sich zueinander völlig anders verhalten als die Originale (vgl. ebd.). Die Reproduktion werde in diesem Sinne bei Malraux zur Vollendung der Kunst, deren Erleben für ihn (ohne, dass Malraux selbst diesen spezifischen Begriff jemals systematisch gebraucht hätte) wiederum die vollendete Erfahrung von Virtualität darstellt: Kunst, so Battro, werde von Malraux zum buchstäblichen »Anti-Schicksal« der Menschheit erhoben, zum humanisierenden Universum des Möglichen und Potenziellen, in welchem sich der Mensch mit dem Menschen anfreunden kann. Das Kunstwerk ist Kommunikation, weil es eine Auswahl aus dem Möglichkeitsraum ist und eben - im Gegensatz zu den Bänden der Bibliothek von Babel, die aus statistischer Notwendigkeit heraus existieren - auch gar nicht vorhanden sein bzw. ein anderes Objekt an seiner Stelle stehen könnte. Grundsätzlich wäre es DaVinci durchaus möglich gewesen, statt der Mona Lisa ein Männerporträt zu malen, und in dem Marmorblock, aus dem Michelangelo seinen David schlug, war virtuell auch Goliath vorhanden. Jedes materielle Erzeugnis menschlichen Schöpfungsvermögens stellt implizit eine Entscheidung gegen jedes mögliche Stattdessen dar, und diese Eigenschaft verleiht ihm eine kulturelle Bedeutsamkeit auch dann noch, wenn die Beweggründe dieser Entscheidung längst nicht mehr zu rekonstruieren sind. Friedrich Waidachers Feststellung, dass man sich im Museum vor allem anderen der Tatsache versichere, dass die Vergangenheit realen Bestand gehabt hat (vgl. Waidacher 2000: 6), bedeutet für das Einzelobjekt: Das Mindeste, was es dem Besucher mitteilt, ist, dass zu irgendeinem Zeitpunkt in der Vergangenheit von Menschen die Entscheidung gefällt wurde, es zu erschaffen - und diese Entscheidung muss im weiteren Kontext einer sozialen Wirklichkeit stattgefunden haben, in der einem solchen Gegenstand aus irgendeinem Grund ein Wert beigemessen wurde. Battro indes verweist darauf, dass der Umgang des Menschen mit Dingen immer in beide Richtungen wirkt - und dass auch das bloße Schauen keine passive Begegnung von Subjekt und Objekt ist. So, wie sich das Kunstwerk seinem Beschauer mitteilt, trägt der Rezipient die ganze Summe seines Wissens und seiner Vorannahmen an das Werk heran und verwandelt es in deren Licht in etwas, dass es jetzt erstmals werden 
kann (vgl. Battro 1999). Genau dies ist ja die Kernthese der Malraux'schen Kunstphilosophie: dass das Objekt in der Rezeption wieder und wieder transformiert werden muss, um als kultureller Sinnträger überleben zu können. In seiner tatsächlichen Aktualisierung als Nouophor jedoch verschwimmt jede klare Richtung der Sinnstiftung in einem regelrechten `Huhn/Ei<-Szenario: Das Ding kann als Bedeutungsträger interpretiert werden, weil es sich als solcher zu erkennen gibt, und zugleich kann es nur als solcher erkannt werden, weil es in der Interpretation immer wieder aufs Neue anschlussfähig gemacht wird. In den Worten Battros findet daher zwischen uns und den Dingen (bzw. speziell den Kunstwerken) ständig eine »virtuelle Interaktion « statt (ebd.). Zugleich greife dieser Interaktionsprozess weit über den Augenblick der individuellen Konfrontation von Rezipient und Werk in unser kulturelles Bewusstsein aus: Das Kunstwerk begegnet niemals nur dem Betrachter mit seinem individuellen ästhetischen Empfinden, sondern es wird in seiner Wahrnehmung und Reflexion auch mit all den anderen Kunstobjekten konfrontiert, welche die Fixsterne seines Kunstverständnisses bilden und den Kontext, in dem er neu wahrgenommene Gegenstände deutet. Jedes Kunstwerk stellt einen Knotenpunkt dar im Netzwerk komplexer Diskurse über sich und andere Objekte, und somit auch einen Knotenpunkt für die Kommunikation zwischen Betrachtern. Oder einfacher gesagt: Über Kunstwerke interagieren laufend Betrachter miteinander, und über Betrachter Kunstwerke. Hieraus resultiert eine regelrechte Flut von Virtualitäten der Kunst, die es laufend neu zu bewältigen gilt und die womöglich den Umfang der Universalbibliothek noch bei weitem übertrifft. Der Bewahrungs- und Präsentationsauftrag des Museums bedeutet vor allem auch, immer wieder in die Tiefen explodierender Virtualitäten hinabzusteigen und die Vergangenheit ständig aufs Neue zu erobern (vgl. ebd.).

\subsection{PFADE DURCH DAS WELTMUSEUM}

Nun sind aber virtuelle Museen, wie zu Beginn des vorigen Kapitels dieser Arbeit deutlich gemacht wurde, weder abstrakte und utopische Konzepte von Kulturvermittlung, die sich den Anspruch der Universalität auf die Fahnen geschrieben hätten, noch treten sie üblicherweise als mediale Dispositive mit einer souveränen technischen Infrastruktur in Erscheinung, wie es klassischerweise das physische Museum tut. Noch 1998 nannte Suzanne Keene drei entscheidende Kanäle für digitale Multimedia-Angebote im Museumsbetrieb, und bei keinem davon spielte zu diesem Zeitpunkt die Veräußerung der eigenen Inhalte in eine wie auch immer geartete virtuelle Meta-Ausstellung eine Rolle: Keenes drei Vektoren der Museumsvirtualisierung sind die Homepage im World Wide Web, das Computerterminal im Museumsraum selbst, und die Museums-CD-ROM (vgl. Keene 1998: 52). Keene behandelt diese drei Op- 
tionen noch weitgehend als gleichwertig und erkennt bei ihnen allen ein ausgewogenes Für und Wider. Eine Museums-Webseite, so befürchtet sie, erreiche zwar für einen überschaubaren finanziellen Aufwand ein relativ großes Publikum, erfordere aber auch laufend intensive Betreuung, weil sich die Standards und Ansprüche an Web-Angebote laufend ändern. Vor allem aber gebe das Museum mit der Öffnung zum Internet die Kontrolle über die Abbildungen seiner Ausstellungsobjekte und damit seine Deutungshoheit preis. Computerterminals in den Ausstellungsräumen selbst ermöglichten hingegen eine Individualisierung und inhaltliche Ausweitung der Besuchererfahrung unter kontrollierten Bedingungen, deren einzige Schattenseite hohe Anschaffungskosten seien. Ein solches Terminalsystem nämlich müsse für jedes Museum gesondert entwickelt werden, und weil jedes Terminal stets immer nur von einem Besucher genutzt werden kann, benötige man eine entsprechend hohe Anzahl, um Wartezeiten kurz zu halten. CD-ROMs hätten dagegen den großen Vorteil, monetarisierbar zu sein und Mobilität mit kuratorischer Kontrolle zu verbinden. Eine $\mathrm{CD}$, für die Besucher tatsächlich Geld auszugeben bereit seien, müsse jedoch ausgesprochen gut produziert sein und eine Menge Inhalt anzubieten haben. Dies mache es unwahrscheinlich, dass eine solche CD-ROM ihre Produktionskosten wieder einspielt - und zwinge Museen zugleich dazu, Verbindlichkeiten mit Verlagen einzugehen, weil sie meist selbst meist nicht über die Voraussetzungen zur Produktion solcher Software verfügten (vgl. ebd.: 52ff.).

Das WWW sollte nicht einmal ein Jahrzehnt benötigen, um sich zum dominanten digitalen Kommunikationskanal für Museen zu entwickeln. Die typische MuseumsCD-ROM sei, wie der Kurator Jay Levenson schon zeitgleich mit Keene feststellte, in ihrem Aufbau ohnehin nie strukturell verschieden gewesen vom gedruckten Ausstellungskatalog, und entbehre dabei dessen bibliophiler Anmut (vgl. Levenson 1998: 96f.). Darüber hinaus ist auch in Zeiten von DVDs und Bluray-Discs der Speicherplatz eines physischen Datenträgers stark beschränkt gegenüber der Datenmenge, die über das Internet schnell und einfach an die Zielgruppe gebracht werden kann - und während der Silberling im Museumsshop nur jene Menschen zu erreichen vermag, die ohnehin schon den Weg ins Museum gefunden haben, lassen sich über die OnlinePräsenz auch jene ansprechen, die bis dato noch nicht zum Besucher geworden sind. Das Computerpult im Ausstellungsraum auf der anderen Seite hat zwar seit den 1990er Jahren einen soliden Platz in zahlreichen mehr oder minder >modernen $<\mathrm{Mu}-$ seumskonzepten erringen können, jedoch gerät jüngst auch diese Form musealen Computereinsatzes unter Beschuss, und zwar durch jene Geräte, die Besucher heutzutage ohnehin mit ins Museum bringen - Mobiltelefone und Tablet-Computer. Die letzte Fallstudie im siebten Kapitel dieser Arbeit wird noch genauer ausführen, wie solche Kompaktcomputer gerade im Begriff sind, den physischen Museumsraum mit virtuellen Wissensräumen zu verknüpfen.

Für den Augenblick sei festgestellt: Der derzeitige und wohl auch zukünftige Trend in der Museumsvirtualisierung läuft wie bei fast allen derzeit unsere soziale 
Wirklichkeit ergreifenden Virtualisierungsvorgängen nicht auf eine Abschottung von Soft- und Hardwaresystemen hinaus, sondern auf deren Anbindung an das Internet. Und das heißt auch: Virtuelle Museumsangebote können nicht die Gesamtheit der technischen Architektur kontrollieren, innerhalb derer sie sich entfalten, sondern müssen den Anschluss an bestehende Standards und Formate suchen. Und weil, wie ja bereits ausgeführt wurde, die meisten existierenden virtuellen Museen ganz normale Gefüge von vernetzten HTML-Webseiten sind, sind diese damit unweigerlich all jenen Ordnungs- und Zugriffsmechanismen unterworfen, mit denen auch das restliche Netz erschließbar gemacht wird.

Das bedeutet zunächst einmal, dass kein virtuelles Museum die Bewegungen seiner telepräsenten Besucher in derselben Art antizipieren kann, wie dies einem physischen möglich ist. Selbst in den räumlich offensten Ausstellungskonzepten können sich die Kuratoren physischer Museen auf eines verlassen: Alle Besucher überschreiten die Peripherie zwischen Aktions- und Anschauungsraum an einer (oder einigen wenigen) ganz bestimmten Stelle. Die Eingänge erzeugen für alle Besucher gleichermaßen einen bewusst erlebbaren Moment des Überganges bzw. des Ankommens, der meist mit der konkreten und expliziten Entscheidung einhergeht, nun das Museum zu besuchen. In den allermeisten Fällen wird diese Entscheidung durch die ökonomische Handlung punktiert, welche der Erwerb der Eintrittskarte ist. Und auch nach der Ankunft sind bestimmte Eigenheiten des physikalischen Raumes durch keine Museumspädagogik zu negieren: Bei allem Bemühen um Offenheit und Nonlinearität einer Ausstellung ist nichts daran zu ändern, dass bestimmte Teile der Ausstellung nun einmal weiter vom Eingang entfernt sein müssen als andere und damit im zeitlichen Verlauf der Rezeption an eine spätere Position verbannt sind. Das virtuelle Museum als multimediales Hypertextsystem kann zwar seine Zugriffsinterfaces so gestalten, dass seinen digitalen Exponaten eine ähnliche Ordnung auferlegt wird, aber es hat keine Kontrolle darüber, wie die nichtmenschlichen Mitspieler im System World Wide Web sich zu dieser Ordnung verhalten. Jede einzelne Seite eines in HTML angelegten virtuellen Museums lässt sich per URL individuell adressieren. Entsprechend kann sie von einem Webcrawler erfasst und von einer Suchmaschine als Treffer ausgegeben werden - ohne, dass die sie umgebende Webpräsenz eine signifikante Rolle spielen würde. Für die Auswirkung, die dies auf die Rezeptionssituation hat, gibt es im physischen Museum keine Entsprechung. Bildlich könnte man sich höchstens vorstellen, dass Menschen plötzlich durch Fenster und Luftschächte in das Museum einsteigen oder gar aus der dünnen Luft wie von Zauberhand im Ausstellungsraum erscheinen - und sich dabei mangels eines bewussten Augenblickes der Ankunft nicht einmal bewusst sind, nun Museumsbesucher zu sein. Was immer die Kuratoren virtueller Museen in ihre Ausstellungen aufnehmen wird automatisch auch Teil einer virtuellen Meta->Sammlung`digitaler Daten, deren `Kuratoren`keine individuellen Personen mehr sind, sondern Dispositivgefüge von Menschenmassen, 
Elektronik und Software, die kulturelle Bedeutsamkeiten auf mathematische Koeffizienten herunterbrechen und sie nach deren Maßstab in die Kulturwelt zurückspeisen.

Insofern ist das >Wesen « des virtuellen Museums ein prekäres. Es bildet gewissermaßen immer eine Schnittmenge aus imaginärem Museum und Bibliothek von Babel ab, in welcher das Spiel der informierten Assoziation von Kulturgegenständen in Reproduktion sich mit der statistischen Mechanik großer Datenmengen und der generativen Eigendynamik des Computercodes überlagert. Das Netz - oder genauer die vielen, oft miteinander konkurrierenden Ordnungsmechanismen, mit denen wir es erschließbar zu machen versuchen - kann kulturelle Inhalte überhaupt nur als etwas >verwalten<, was sie im Eigentlichen nicht sind: nämlich als rein formallogisch prozessierbare Bitsequenzen, die mit bestimmten nur in der Semantik des Computers überhaupt verständlichen Eigenschaften versehen sind. Zwischen diesen rein numerischen Werten und den kulturellen Zusammenhängen zu vermitteln, die sie abbilden sollen, erfordert nicht nur ganz eigene Formen der Autorschaft, sondern womöglich gar eine ganz neue Grammatik der Darbietung. 



\section{Gelenkte Rhizome: Kulturelles Erbe und kulturelle Kybernetik}

In der 1976 vorab gedruckten Einleitung zu ihrem 1980 erschienenen Buch Mille Plateaux (das gemeinsam mit seinem 1972 veröffentlichten Vorgänger L'anti-Oedipe das Gesamtwerk Capitalisme et Schizophrénie bildet) entwickeln Gilles Deleuze und Félix Guattari ein Wissens- (und im weiteren Sinne Gesellschafts-)Modell, das sich aller Hierarchisierung und stratifizierten Machtausübung entziehen sollte und das - obwohl die Autoren keinerlei Bezug auf ihn, seine Theoriegeschichte oder digitale Medien nehmen - in vielerlei Hinsicht die Funktionalität, Ästhetik und soziale Programmatik des Hypertextes unterstreicht. Deleuze und Guattari bedienen sich dabei einer Metaphorik, die der Biologie bzw. genauer der Botanik entlehnt ist: Sie sprechen vom Rhizom - ein Wort, das typischerweise das netzartige unterirdische Sprosssystem beschreibt, das bestimmte niedrigwachsende Pflanzen wie Gräser, Moose oder Lotusblumen ausbilden.

Die Stoßrichtung dieser Metapher wird für den mit Hypertextsystemen vertrauten Leser der Gegenwart bereits zu erahnen sein - die Medientheoretikerin Janet Murray zieht diese Verbindung ganz ausdrücklich in ihrer einflussreichen, 1997 erschienenen Monographie Hamlet on the Holodeck (vgl. Murray 1997: 134) - interessant ist aber nicht nur die Metapher selbst, sondern auch die Art des Schreibens und der Wissensvermittlung, gegen die Deleuze und Guattari sich mit ihr positionieren. Während Vannevar Bush das Memex-System aus der Perspektive der Bibliothek heraus konzipiert, blicken Deleuze und Guattari bei der Ausarbeitung des Modells auf individuelle Bücher bzw. Texte und nähern es damit als ungewollten Nebeneffekt auch dem Museumsdispositiv an, in dem das Wissensgefüge ja ebenfalls aus Fragmenten besteht, die individuell nicht abzuschließen sind. Die prototypische Form von Wissensvermittlung im abendländischen Denken sei, so stellen sie fest, das »Wurzelbuch» (Deleuze u. Guattari 1997: 8). Dieses zeichne sich dadurch aus, dass es eine an einen Baum erinnernde, von unten nach oben reichende Hierarchie des Sinns etabliere: Aus

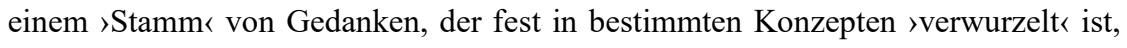
entwickelt das Wurzelbuch ein >Geäst`von Ideen, das zwar sehr komplex und weit 
ausladend gedeihen könne, in dem sich aber letztlich jede Sinn-Verästelung geradewegs zu den ihr zugrundeliegenden Vorannahmen zurückverfolgen lasse (vgl. ebd.: 8f.). Interessanterweise erscheint diese Textform nicht etwa stringent linear, sondern ist durchaus zweidimensional organisiert - nur so lassen sich >Wurzeln $<$ und >Ästeく ja denken. Allerdings ist ihre Organisation nicht flach, sondern getragen eben von der Autorität von Ideen übereinander bzw. der Abhängigkeit allen Wissens von Prämissen, die ihnen als Wahrheitsbedingungen vorangestellt sind.

\subsection{VERWURZELTE UND VERTEILTE TEXTE}

Das Rhizom bzw. der rhizomatische Text wird dagegen als eine entschieden moderne, völlig flache und egalitäre Bühne des Wissens gedacht. Ganz in Übereinstimmung mit der Hypertexttheorie entwerfen Deleuze und Guattari hier das Bild von Texten, die zerstückelt und zerkleinert sind und deren Fragmente ihren Sinngehalt nicht etwa aus der Rückbindung an `Stamm〈 oder >Wurzel «-Konzepte beziehen, sondern aus der machtfreien Interaktion miteinander. Dabei können einzelne dieser Bausteinchen durchaus miteinander verbunden sein, aber diese Verbundenheit impliziert keine Hierarchie in irgendeiner Richtung, und die >Wurzeln « innerhalb des Rhizoms sollen viel kürzer und chaotischer verstrebt sein als jene des Wurzelbuches (vgl. ebd.: 9ff.). Während im Wurzelbuch Sinn (wie Flüssigkeit und Nährstoffe im tatsächlichen Baum) von den Wurzeln durch den Stamm ins Geäst geleitet wird, impliziert das Rhizom als Begriff eine Heterogenität semiotischer Einzelelemente, die ihre Bedeutung temporär aus einem variierenden Machtgefüge erhalten, anstatt sie in Form ihrer eigenen Genealogie mit sich herumzutragen:

Ein Rhizom verknüpft unaufhörlich semiotische Kettenteile, Machtorganisationen, Ereignisse in Kunst, Wissenschaft und gesellschaftlichen Kämpfen. Ein semiotisches Kettenglied gleicht einem Tuberkel, einer Agglomeration von mimischen und gestischen, Sprech-, Wahrnehmungs- und Denkakten: es gibt keine Sprache an sich, keine Universalität der Sprache, sondern einen Wettstreit von Dialekten, Mundarten, Jargons und Fachsprachen. Es gibt keinen idealen Sprecher-Hörer, ebensowenig eine homogene Sprachgemeinschaft. Die Sprache ist nach einer Formulierung von Weinreich »eine wesentlich heterogene Wirklichkeit«. Es gibt keine Muttersprache, sondern die Machtergreifung einer beherrschenden Sprache in einer politischen Vielheit. (Ebd.: 12)

Rhizome sind also im Gegensatz zum Wurzelbuch nicht 'gewachsen<, sondern permanent im Zustand des Wachstums (und damit natürlich auch des partiellen Absterbens und Neugedeihens) befangen. Während Inhalte im Wurzelbuch punktuell lokalisierbar sind, funktioniert das Rhizom über Linien und Vektoren (vgl. ebd.: 14f.). 
Das bedeutet zugleich, dass das Rhizom Sinnbrüche verkraften und auffangen kann, die dem Wurzelbuch seine Wahrheitsfähigkeit rauben würden. Erweist sich eine Wurzel-Prämisse oder ein Stamm-Gedanke im Wurzelbuch als Irrtum, gerät aus der Mode oder verliert schlicht aus irgendeinem Grunde die soziale Akzeptanz, dann kann damit das Buch als Ganzes hinfällig werden. Der Tod der Wurzel zieht den des ganzen Baumes nach sich. Das Rhizom hingegen soll als lebendiges Textsystem um solche >Löcher herumwuchern, oder sie mit neuen Inhalten in Form neuer Bindungen auffüllen (vgl. ebd.: 16f.). In Rhizomen könne es nach Deleuze und Guattari keine eindeutigen Urheberschaften geben (die ja ihrerseits selbst ein >Wurzel<-Phänomen wären), sondern nur Fluktuationen in den Verhältnissen zwischen Inhalten und Sich-Mitteilenden.

Das Wurzelbuch entstehe außerdem immer innerhalb eines Paradigmas der Kopie: Wurzelbücher zu schreiben - und die Zitationskultur in der Wissenschaft führt dies sehr plastisch vor Augen - heißt zwingend, aus anderen Büchern abzuschreiben. Wurzelbücher müssen in weiten Teilen als Reiterationen bereits bestehenden Wissens angelegt werden und bauen insofern aufeinander auf: Jedes Wurzelbuch kann seinerseits Wurzel von anderen werden. Entsprechend lässt sich der Zusammenhang zwischen solchen Texten als eine Genealogie von Ideen beschreiben. Das Rhizom soll dagegen keine solchen Gleichförmigkeiten aufweisen. Während Wurzelbücher sich entlang von Ähnlichkeiten und über Generationen von Texten andauernde Transformationserscheinungen in einen Stammbaum eingliedern lassen, ist die Wesensart des Rhizoms Originalität und Alterität, die sich nicht im Verhältnis zu einer ihr zeitlich vorangestellten Geschichte definieren, sondern aus den sich laufend verändernden Beziehungen zwischen Textfragmenten in der Gegenwart. Deleuze und Guattari erkennen daher die entscheidende Darstellungsform für rhizomatische Sinngefüge (ohne jede Bezugnahme auf Michel de Certeau) in einer Karte, die ständig neu gezeichnet werden muss, die also mit dem Territorium wächst, das sie beschreibt (vgl. ebd.: 20f.). Damit ist der Leser bei ihnen weder Flaneur noch Detektiv, sondern Entdecker und Kartograph einer sich rasant verändernden Landschaft kultureller ÄuBerungen:

Fassen wir die wichtigsten Merkmale eines Rhizoms zusammen: im Unterschied zu den Bäumen und ihren Wurzeln verbindet das Rhizom einen beliebigen Punkt mit einem anderen; jede seiner Linien verweist nicht zwangsläufig auf gleichartige Linien, sondern bringt sehr verschiedene Zeichensysteme ins Spiel und sogar nicht signifikante Zustände (états de non-signes). Das Rhizom läßt sich weder auf das Eine noch das Viele zurückführen. [...] Eine Struktur ist durch ein Ensemble von Punkten und Positionen definiert, durch binäre Relationen zwischen diesen Punkten und biunivoke Relationen zwischen diesen Positionen; das Rhizom dagegen besteht nur aus Linien: den Dimensionen der Segmentierungs- und Schichtungslinien, aber auch der Maximaldimension der Flucht- und Deterritorialiserungslinie, auf der die Vielheit abfährt und sich verwandelt. (Ebd.: 34) 
Der Entdecker einer solchen Landschaft ist insofern grundverschieden von Umberto Ecos Detektiv, als dass dieser immer in einer historischen Welt beheimatet ist, in der alles Geschehen auf eine `Ahnenreihe` von kausal gestaffelten Vorgängerereignissen zurückblicken kann. Er lebt gewissermaßen in derselben >Wurzelwelt $\iota$, in der sich auch das Museum konstituiert, in der nämlich vergangene Tatbestände uns Spuren hinterlassen, zwischen denen wir den Umriss einer historischen Welt zu zeichnen vermögen. Der Entdecker im Rhizom hingegen findet die sich ihm darbietende SinnWelt immer wieder wie neu geboren vor - nicht umsonst denken Deleuze und Guattari das Rhizom vor allem aus der Perspektive von Mentefakten (nämlich Textsystemen), die im Gegensatz zu Artefakten nicht in der penetranten, Arendt'schen Dauerhaftigkeit des Materiellen ihre Ursprungssituation referieren. Das Rhizom soll dem Entwurf seiner Definitoren folgend überhaupt keine punktuellen Landmarken mehr aufweisen. Orientierung soll nicht mehr über klare semiotische Zuordnung von Signifikant und Signifikat funktionieren, sondern über die Interrelationen der Signifikanten zwischeneinander. Das Nächstbeste zu einem tatsächlichen Orientierungspunkt sollen Text->Orte< sein, an denen sich Signifikanten besonders engmaschig verdichten. Diese Orte leihen dem zweiten Band von Capitalisme et Schizophrénie ihren Namen: Deleuze und Guattari nennen sie Plateaus (vgl. ebd.: 35).

\subsection{PARTIZIPATION ALS RHIZOMATISCHES PHÄNOMEN}

Diese Arbeit will überhaupt nicht versuchen, abschließend zu klären, inwiefern das WWW oder das Museum tatsächlich als rhizomatische Kulturerscheinungen betrachtet werden könnten. Sicherlich erfüllen beide eine Anzahl der genannten Kriterien: Beide weisen eine netzartige Organisation von Zeichen auf, die eben nicht nur Text sind, beide verbinden diese vernetzte Anordnung von Inhalten mit einer Vernetzung von Rezipienten und Produzenten, beide vermitteln Wissen eher in zweidimensional modularisierter denn in eindimensional sequenzierter Form, beide ordnen ihre Sinnbausteine eher horizontal in der Ebene als vertikal hierarchisiert an, beide stellen also ihren Rezipienten Virtualitäten des Wissens zur Verfügung und lassen ihnen einigen Spielraum bei deren Aktualisierung. Allerdings legen sowohl Netz als auch Museum darüber hinaus weitere Eigenschaften an den Tag, die entschieden unrhizomatisch sind: Beide bestehen eben nicht nur aus dynamischen Vektoren des Wissens, sondern auch aus Knotenpunkten. Im Museum sind diese als materielle Dinge in ihrer Verfasstheit nahezu unveränderlich, während digitale Objekte im Netz zwar prozedural entstehen, dabei aber Identitätsbedingungen unterworfen sind, die auf die spezifische Beschaffenheit von Verlinkungsgefügen und die Architekturen von Softwares zurückverweisen. Das Web besteht nicht aus Vektoren in Relation zueinander, sondern 
aus Pfaden zwischen Punkten. Im Museum ist dies ähnlich, und in seiner ganzen institutionellen Anlage steht es darüber hinaus im Widerspruch zur rhizomatischen Enthierarchisierung, weil sich sein Anspruch als Dispositiv pädagogisch legitimierter Kulturvermittlung ja gerade aus seiner Wechselwirkung mit Expertensystemen wie z.B. den historischen Wissenschaften ergibt. Und auch das Web überschreibt als Hypertextsystem die Geschichtlichkeit des Wurzelbuches nicht rundheraus mit der Situativität des Assoziativen: Schon in Vannevar Bushs Metapher von den Pfaden des Interesses ist ja eine historische Zielrichtung der Texterschließung angezeigt, eine Bewegung von der Abreise in Richtung einer wie auch immer beschaffenen Ankunft. Trails of interest bilden mindestens eine Genealogie der Interessen des Lesers ab, hinter der sich in den meisten Fällen ja gerade der Wunsch verbergen wird, Wissen zu ordnen. Tatsächlich kann Memex durchaus als eine Maschine beschrieben werden, die Wissen hierarchisiert und >verwurzelt $\iota$, die weniger die Wurzelbücher in ein Rhizom auffächern sondern aus disparaten Textstellen neue, virtuelle Wurzelbücher entstehen, neue Stämme aus alten Wurzelwerken sprießen lassen soll.

Indes ist das Rhizom sicherlich ein durchaus tragfähiges metaphorisches Modell für die Utopien von Sinnstiftung und die Beziehung zwischen Autoren und Rezipienten, die sich mit dem Cyberspace verbinden, wie er in den 1980er und 1990er Jahren ersonnen wurde - und gezähmt mit der Vorstellung vom Web 2.0, die ja zentral in Aussicht stellte, den User selbst zum wichtigsten Produzenten von Inhalten zu machen, die Intelligenz der Masse über die Vermittlungsabsichten irgendwelcher Urheber zu stellen und Software vom Produkt, das fertig und abgeschlossen im Regal eines Elektromarktes steht, zu einem Prozess zu machen, der sich im Zustand seiner Nutzung erst funktional entwickelt (vgl. O’Reilly 2005). Zugleich lassen sich auch die in der Museumspädagogik stattfindenden Debatten über Tempel- und Forenprinzip letztlich als eine Diskussion darüber lesen, inwieweit Museen imstande sind, rhizomatisch zu funktionieren - und zwar sowohl innerhalb ihrer Wände, als auch in ihrer Beziehung zur Außenwelt. Innerlich würde eine `Rhizomatisierung〈 des Museums wohl am ehesten darauf hinauslaufen, sich im von Franz Boas diagnostizierten Balanceakt von perspektivisch-interpretativer Offenheit und didaktischer Eingrenzung verstärkt in Richtung Offenheit zu bewegen, bzw. nicht nur einer Offenheit der Rezeptionsmöglichkeiten und Interpretationsspielräume, sondern schlechthin der Kommunikation zwischen Besuchern und Kuratoren. Es würde bedeuten, die >Wurzeln< der kuratorischen Autorschaft sowie der Anbindung an wissenschaftliche, politisch institutionalisierte Expertensysteme wenn nicht zu kappen, so doch der emergenten Kommunikation innerhalb des Museums unterzuordnen. Es hieße also, darauf zu vertrauen, dass die Auseinandersetzung der Besucher mit der Ausstellung und miteinander letztlich ein sinnhaft erfahrbares Gesamtgefüge entstehen lassen wird - und dass der rhizomatische Umgang mit musealen Inhalten mögliche Unverständlichkeiten einfach >umwuchern und anderweitig auszufüllen imstande ist. 
Insofern darf auch Aleida Assmanns >wilde Semiose` als eine Form der rhizomatischen Sinnstiftung angesehen werden, weil sie eben nicht ein Verstehen vom >Ast zur >Wurzel ist, sondern der Versuch des Füllens einer Verständnislücke mit situativem Wissen: Rhizomatisch zu kuratieren, sofern dies überhaupt möglich ist, würde gerade nicht bedeuten, das museale Objekt >für sich selbst sprechen $<$ zu lassen, was Detlev Hoffmann ja sicherlich nicht zu Unrecht als einen nur vermeintlich emanzipatorischen Irrweg in der Museumspädagogik der 1970er Jahre anprangert (vgl. Hoffmann 1976: 114). Dies würde das definitorische Kriterium des Rhizoms verletzen, dem zufolge Rhizome ja keine in cartesischen Koordinaten benennbare Knotenstruktur aufweisen sollen. Rhizomatisches Ausstellen würde es vielmehr erfordern, zwischen Objekten und Museumswänden die Möglichkeit zur Entstehung kommunikativer Vektoren zu schaffen, also nicht etwa das Objekt sprechen zu lassen, sondern im »gestimmten Raum« (Korff 2005: 102) die Besucher selbst zum Sprechen zu bringen. Es ginge also darum, nicht länger die individuellen Objekte als Sinnträger der Ausstellung aufzufassen, sondern die Plateaus, die nur implizit in laufenden Sprachhandlungen existieren.

Wenn aber Besucher dazu aufgerufen würden, einander die Ausstellung zu erklären, dann würden sie damit bereits ein Stück weit in die Schuhe der Kuratoren schlüpfen, denn deren Aufgabe ist nicht nur das Arrangement von Dingen im Raum, sondern auch das Entwickeln von Sinnzusammenhängen und nicht selten sehr linearen Erzählungen. Die Relevanz des Rhizoms als Programm für das World Wide Web ergibt sich nicht zuletzt aus der ihm eingeschriebenen Idee und Ideologie einer Teilhabe am Möglichen - nicht umsonst war Gilles Deleuze sowohl Mit-Definator des Rhizoms, als auch der zentrale postmoderne Denker der Virtualität.

Damit spielt der Begriff, sowie man ihn auf das Museum bezieht, unweigerlich in einen Bereich, den die Museologie (u.a. im bereits erwähnten Sammelband von Gesser, Hanschin, Jannelli und Lichtensteiger) gemeinhin mit dem Begriff der >Partizipation $<$ überschreibt. Partizipation ist, wie Sabine Jank feststellt, immer der Prozess, indem sich die Macht im Museumsdispositiv vom Kurator zum Rezipienten verschiebt (vgl. Jank 2001: 148). Diese Feststellung zielt indes in eine ganz andere Richtung als jene David Filkins, dass mit der Museumsvirtualisierung jetzt alle Macht beim User liege (vgl. Filkin 2002: 6). Denn während Filkin vor allem auf die Vielfalt der Angebote blickt, zwischen denen der Nutzer mit wenigen Mausklicks wechseln kann, wenn ihm Inhalte oder Darstellungsformen nicht zusagen, schaut Jank auf Strategien der Publikumsbeteiligung innerhalb individueller, physischer Museen. Sie kommt dabei zu dem einleuchtenden Schluss, dass Kuratorium und Institution unweigerlich Kontrolle einbüßen müssen, wenn das Publikum in die Gestaltung von Ausstellungen eingebunden werden soll (vgl. Jank 2011: 148). Wie Claudia Glass und Beat Gugger anmerken, muss es dabei gar nicht um tatsächliche, physische Mitwirkung gehen. Bei den meisten Debatten über Partizipation im Museum gehe es tatsächlich zunächst einmal um Deutungshoheiten und damit um die Frage, wem es 
gestattet ist und gestattet sein sollte, Objekte und Objektkonstellationen mit Bedeutungen aufzuladen. Im Begriff der Partizipation manifestiere sich sowohl das ehrliche Bemühen der Fachleute darum, als aber auch ihr Unwohlsein dabei, dem Laienpublikum ein Mitspracherecht einzuräumen (vgl. Glass u. Gugger 2011: 176f.). Nina Simon erkennt im Partizipationsgedanken im Museum nicht das ideologische Fundament, das er für den Cyberspace oder das Web 2.0 bildet, sondern eher eine Strategie zum Umgang mit einer Kulturwelt, die gerade unter dem Einfluss digitaler Medien ganz neue Forderungen an Kulturinstitutionen stellt. So verweist sie auf einen 2009 veröffentlichten Bericht das amerikanischen National Endowment for the Arts, welchem zufolge einerseits die Besucherzahlen in amerikanischen Museen insgesamt rückläufig sind und das Publikum immer älter wird, während andererseits ein deutlich gestiegenes kulturelles Interesse in der Bevölkerung festgestellt wird. Kulturelle Internetangebote würden immer stärker in Anspruch genommen, immer mehr Menschen engagierten sich ehrenamtlich im Kulturbereich, und im Schnitt werde viel mehr gelesen als noch wenige Jahre zuvor. Es könne also, so folgert Simon, keine Rede von einem generellen Verfall des kulturellen Lebens in den USA sein (vgl. Simon 2011: 95). Vielmehr zeige der Bericht, dass sich das Publikum von Kulturangeboten abwende, die auf passive Rezeption ausgerichtet sind, und sich zu solchen hin orientiere, die ihm Mitwirkung anbieten und auf seine Bedürfnisse und Wünsche eingehen. Die Öffentlichkeit, so Simons These, wolle offenbar eine größere Rolle in den Kulturinstitutionen spielen. Ein wichtiger Schritt in diese Richtung sei es, auf Seiten der Museen Partizipation nicht nur als eine zweckdienliche Strategie zu denken, um Besucher anzulocken, sondern sie als ein eigenes und zukunftsträchtiges Museumsprinzip zu umarmen, in dem das Museum nicht als Umgebung zur Präsentation auratischer Dinge auftritt, sondern als eine »Plattform« zur kreativen Interaktion von Menschen in Gegenwart dieser Dinge:

In traditionellen Ausstellungen und Veranstaltungen werden den Besuchern Inhalte geboten, die sie konsumieren sollen. In diesem Fall konzentrieren sich die Gestalter darauf, solide Inhalte von hoher Qualität zu schaffen, sodass jeder Besucher, unabhängig von seinem Hintergrund oder seinen Interessen, ein positives Ausstellungserlebnis hat. Bei partizipativen Projekten dagegen bietet die Institution mehrdimensionale Erfahrungen rund um Inhalte. Die Institution dient hier als »Plattform«, die verschiedene Nutzer verbindet, sie in die Rolle von Schaffenden, Vertreibern, Konsumenten, Kritikern und Mitarbeitern schlüpfen lässt. Das bedeutet, dass eine Institution keine einheitlichen Ausstellungserlebnisse mehr garantieren kann. Dafür ermöglicht sie vielfältige, gemeinsam mit dem Publikum erzeugte Erlebnisse. (Ebd.: 96)

Simon sieht also - ähnlich wie Beat Hächler, der im selben Sammelband ja Partizipation und Dialog als entscheidende Bestandteile seiner `sozialen Szenographie〈 anführt - die Aufgabe einer auf Partizipation ausgerichteten Ausstellungsgestaltung im Schaffen der Voraussetzungen für Momente des Dialoges zwischen Vertretern aller 
sozialer Gruppen und Rollen, die in irgendeiner Weise mit dem Museum verbunden sind. Dabei sind diese dialogischen Prozesse kein bloßes diskursives Anknüpfen an museale Inhalte und Szenerien, sondern sie sind selbst musealer Inhalt und Bestandteil der Szene. User generated content muss in musealen Kontext also nicht zwangsläufig heißen, dass Besucher Dinge ins Museum bringen oder die physische Beschaffenheit von Ausstellungen mitgestalten - ihr bloßes Sprechen ist bereits ein Mehrwert, mit dem sie den musealen Raum sinnhaft bereichern.

\subsection{DAS VERMESSENE PUBLIKUM}

Mit einer Offenheit der Kuratoren für den Austausch mit dem Publikum allein ist natürlich noch längst keine museale Selbstorganisation >von unten` (oder vielleicht eher noch: >aus der Ebene $)$ ) angezeigt, wie sie sich mit dem Rhizom verbindet. Das virtuelle Museum existiert zwischen zwei Mediendispositiven, die sich gerade aus ihren Ursprungszuständen in sehr unterschiedliche Richtungen und dabei ironischerweise aufeinander zu bewegen. Während das WWW aus der Tradition des Hypertextes kommt und all die mit diesem verbundenen Utopien von Weltgehirn, Dokuversum und Tod des Autors mit sich herum trug, bevor es von Webcrawlern, Suchmaschinen und Empfehlungssystemen gebändigt wurde, begann das Museum erst in den letzten zwei bis drei Jahrzehnten wirklich, sich als mediales Angebot zu verstehen, das seine Zielgruppe nicht nur bespielen, sondern tatsächlich einbinden kann. Eilean HooperGreenhill beobachtet Mitte der 1990er Jahre einen Wandel in der Vorstellung, welche die Museumszunft bisher von ihrer Zielgruppe hatte: Ging man zuvor üblicherweise vom "visitor « aus - also jenem Menschen, der das Museum bereits betreten hat und dem gegenüber es nun Aussagen zu machen gilt - wurde nun zunehmend die »audience« als Summe all jener Menschen zum Gegenstand des Interesses, die sich möglicherweise für das Museum begeistern lassen könnten. Etwa zeitgleich, so fährt sie fort, begannen britische Museen in großem Stil damit, hauseigene Marketing-Abteilungen einzurichten (vgl. Hooper-Greenhill 1995: 2).

Traditionell nämlich tauche, wie Samuel Redman schreibt, das Publikum in den historischen Plots der Museumsgeschichte vor allem in zwei Formen auf: entweder als eine kleine bourgeoise Elite, die im Museum schöngeistigen Leidenschaften frönt, oder als eine gesichtslose, kulturell vernachlässigte `Masse`, die im Museum der sozialen Kontrolle solcher Eliten unterworfen wird. Bis weit ins 20. Jahrhundert hinein blieb der Blick auf den Besucher ein oberflächlicher - und in einer Institution, welche die Spuren der Geschichte für die Öffentlichkeit aufbereiten sollte, durfte die Öffentlichkeit selbst weder ihre Spuren noch ihre Geschichten hinterlassen. Als Franz Boas 1901 seinen Text über das Kuratieren als ein Spiel mit Mehrdeutigkeiten zugunsten 
eines durchaus interpretationsfähigen Besuchers schrieb, waren Museen noch im hohen Maße Forschungseinrichtungen und wurden von ihren Kuratoren vor allem als Repertorien für die Wissenschaften geführt (vgl. Redman 2010: 1). Eine der ersten demographischen Besucherstudien entstand 1929 am Pennsylvania Museum (heute das Philadelphia Museum of Art) und erhob für eine Stichprobe von 1.000 Besuchern jeweils Beruf, Wohnort, Anreisemethode, Anlass des Besuches, Lieblingsaspekte der Ausstellung und solche, die als verbesserungswürdig empfunden wurden. Das Publikum erwies sich dabei in seiner Komposition als deutlich komplexer, als es die Forscher erwartet hatten: Zwar stellten Studenten, wie vorhergesehen, den Großteil der Besucherschaft, ein Viertel aber entfiel auf Hausfrauen ohne höhere Bildung. Auch Fabrikarbeiter waren signifikant repräsentiert, während kaum mehr Anwälte als Bauern ins Museum kamen. Geschlechtlich war das Publikum fast ausgeglichen. Hausfrauen und Farmer zeigten eine besondere Vorliebe für kulturhistorische Ausstellungsräume, während Studenten und Fabrikarbeiter gleichermaßen Gemälde favorisierten. Besonderes Interesse am Museumsgebäude selbst zeigten Ingenieure und Architekten. Die am häufigsten auftauchenden Verbesserungsvorschläge betrafen nicht die Ausstellungen selbst, sondern die das Museum umgebende Infrastruktur: Besucher wünschten sich ein Café, regelmäßige Vorlesungsveranstaltungen und einen Ausbau von Anreisemöglichkeiten (vgl. ebd.: 3f.).

In Großbritannien wurden in den 1980er Jahren sogenannte sparticipation studies` durchgeführt, in diesen wurde aber tatsächlich nur über Zeiträume von meist 12 bis 24 Monaten hinweg erhoben, wie groß der Anteil von Museumsgängern an der Gesamtbevölkerung war und wie sie sich als Gruppe demographisch zusammensetzten. Dabei kam man zu stark variierenden Befunden, denen zufolge der Anteil der Briten, die einigermaßen regelmäßig Museumsangebote in Anspruch nahmen, an der Gesamtbevölkerung zwischen einem Viertel und etwas mehr als der Hälfte lag. Darüber hinaus waren diese Studien sich untereinander nie recht einig darüber, was genau unter einem Museum zu verstehen sei. Einige von ihnen bezogen auch Kunstgalerien und Gedenkstätten mit in die Betrachtung ein, während andere sich auf Museen im engsten Sinne beschränkten (vgl. Hooper-Greenhill 1995: 3f.). Unabhängig von genauer Methodik und jeweiligem Gegenstandsumriss wurden solche Erhebungen von der britischen Museumswissenschaft der 1990er Jahre zunehmend verworfen: Die Gesamtheit der Museumsbesucher einfach als \Masse $\triangleleft$ zu operationalisieren, hatte ungeachtet der tatsächlichen Aussagekraft der Studien schlicht zu keinen Einsichten geführt, die museumspraktisch anwendbar gewesen wären. Sie bestätigte letztlich nur den Gemeinplatz, dass die Zielgruppe der Institution Museum schwammig und damit eben »the general public« sei (vgl. ebd.: 5). Es galt nun vielmehr, die Besucherforschung zu nutzen, um ein virtuelles Publikum zu aktualisieren, das bisher noch nicht für die Institution aktiviert worden war. Eine neue britische Museumsforschung wollte nicht mehr nur nach den demographischen Daten der Besucher fragen, sondern vielmehr nach ihren Wünschen, Motivationen, Interessen und der sozialen 
Situiertheit des Museumsbesuches überhaupt: Das Publikum nimmt nicht nur Vorwissen, Interessenlagen und Meinungen mit ins Museum, sondern, wie HooperGreenhill es zuspitzt, »the rest of their lives« (vgl. ebd.).

Partizipativ zu kuratieren würde daher für den menschlichen Kurator aus Fleisch und Blut auch beinhalten müssen, dass seine Arbeit nun nicht mehr nur um die Materialität der Dinge und die ihnen von Experten zugeschriebenen Bedeutungen kreist, sondern auch um eine Größe, die in weiten Teilen weder bekannt noch messbar ist: nämlich das `kulturelle Bewusstsein`, das die Besucher als Masse und als Individuen an und in jede Ausstellung heran- und hereintragen - und damit, um die Konfusion komplett zu machen, auch aneinander. Mit dieser Gemengelage in ihrer vollen Komplexität umzugehen, ist natürlich von menschlichen Museumsschaffenden in physischen Museumsräumen überhaupt nicht zu leisten. Franz Boas identifizierte die Arbeit von Kuratoren ja bereits als die ewige Suche nach Kompromissen zwischen den Bedeutungspotentialen von Dingen und der Aufnahmefähigkeit eines angedachten Publikums. Nicht nur die Fähigkeit der Besucher zur Sinnstiftung ist begrenzt, sondern auch die der Kuratoren, diese Sinnstiftung zu antizipieren. Insofern suchen Museen in ihrer Ausstellungspraxis gemeinsame (wenn auch nicht unbedingt kleinste gemeinsame) Nenner nicht nur zwischen der größtmöglichen Zahl ihrer gedachten Besucherschaft, sondern auch zwischen dieser Besucherschaft und ihrem eigenen Kuratorium. So besteht in jeder musealen Ausstellungspraxis - ob sie sich nun die Partizipation konzeptuell auf die Fahnen schreibt oder nicht - ein implizites, reziprokes Verhältnis zwischen Machern und Betrachtern. Weil das Museum eben keine geschlossene Schatzkammer ist und die Darbietungstätigkeit definitorisch zu ihm gehört, können Kuratoren gar nicht umhin, den Besucher in jedem Aspekt ihrer Arbeit mitzudenken. Hierbei ist >der Besucher aber unweigerlich ein imaginärer Idealtypus, dessen Realitätsbezug diskursiv erst hergestellt werden muss. Dies kann eben beispielsweise durch demographische Besucherforschung geschehen. In vielen (wahrscheinlich gar den meisten) Fällen wird `der Besucher` als Vorstellung aber im Wissensstand und der Psychologie ganz individueller Kuratoren und Kuratorenteams beheimatet sein und sich aus deren Erfahrungswerten, Hoffnungen, Wünschen, Idealen, Ängsten, Vorbehalten usw. zusammensetzen. Kurzum: Es gibt keinen Grund anzunehmen, dass das Publikum aus der Sicht der Kuratoren mit weniger Deutungspotentialen versehen ist, als Museumsdinge und Ausstellungen es aus der Sicht der Besucher sind.

Nun sind mit Software-Infrastrukturen wie Suchmaschinen und Empfehlungssystemen im Web Mechanismen am Werke, die eben gerade Muster und Bewegungen von Bedeutung und Bezüglichkeit numerisch nachvollziehbar machen sollen, und für die zwischen erwartbarer Masse und vermeintlich unvorhersehbarer Einzelperson keine Kluft, sondern eine Kopplung besteht. Für Google erhalten einzelne Webseiten Relevanz eben gerade aus der Beschaffenheit ihrer Anbindung ans restliche Web. 
Individuelle Navigationsentscheidungen sind nicht individuell interpretierbar, sondern nur innerhalb enorm großer Datensätze, in denen der einzelne Zugriff in Beziehung gesetzt wird zu Millionen von anderen. Dabei interessiert sich das System nicht für die Wünsche kultureller Eliten und Experten bezüglich der Frage, wie mit kulturellen Inhalten umgegangen werden sollte, sondern wie mit ihnen laufend umgegangen wird - um so Regelmäßigkeiten auszumachen, die man an das Publikum zurückspielen kann. Damit scheinen Suchmaschinen natürlich zunächst einmal ganz dem Geiste des Rhizoms verpflichtet zu sein: Sie haben keine Ambition dazu, der Informationswelt, für die sie den Zugang bilden, irgendeine systematische oder kategoriale Ordnung mit Ewigkeitsanspruch aufzusetzen, sondern sie sind Instrumente, die >Plateaus im Sinne Deleuzes und Guattaris sowohl ausfindig machen, als auch formen. Waren Suchmaschinen vor Google lediglich Garanten dafür, dass eine Webseite eine bestimmte Folge von Zeichen enthielt, wurden sie nach Page Rank und mit dem Aufkommen von Analytics-Systemen zum Bürgen tatsächlicher Sinnhaftigkeit und Anschlussfähigkeit auf dem culture layer. Dabei bildet Google aber keine bestimmte Pädagogik oder Philosophie kultureller Vermittlung ab außer jener, dass sich irgendwo in den großen Zahlen ein virtueller Konsens des Massenpublikums verbirgt, den es nicht zu hinterfragen oder herauszufordern, sondern zu vermessen und weiterzutragen gilt. In diesem Sinne >partizipiert ^ natürlich jeder Nutzer zu einem gewissen Grade an der Abruf-Architektur, welche die Suchmaschine dem Web aufsetzt.

\subsection{CYBERTEXT: EMANZIPATION UND FREMDBESTIMMUNG IM GERANKTEN WEB}

Es liegt intuitiv nahe, in den Algorithmen der Suchmaschinen ein plebiszitäres Moment auszumachen: Nicht nur, dass sie das Urteil über die Relevanz von Webinhalten scheinbar völlig paritätisch über ihre Nutzermassen verteilen, sie sind dabei auch blind für abstrakte Kategorien von kultureller Wertigkeit. Geert Lovink schreibt dazu noch im Jahre 2010 (und das Zitat wurde in der Einleitung dieser Arbeit ja bereits paraphrasiert):

Ein Gespenst geht um unter den intellektuellen Eliten der Welt: Informationsüberlastung. Das gemeine Volk hat sich strategische Ressourcen unter den Nagel gerissen und verstopft einst sorgfältig überwachte Medienkanäle. Vor dem Internet beruhte die Macht der Mandarinklasse auf der Idee, dass man »Geschwätz« von »Wissen« trennen könne. Mit dem Aufstieg der Internetsuchmaschine ist es jedoch nicht mehr möglich, zwischen patrizischen Einsichten und plebejischem Tratsch zu unterscheiden. Die Trennung von high und low, dem Ernsten und dem Trivialen, und ihre Vermischung zu Zeiten des Karnevals stammt aus vergangenen Zeiten. (Lovink 2010: 53) 
Für Suchmaschinen gibt also es keine Höhenkamm-, sondern nur eine Populärkultur: Über Geltung und Rang von Inhalten entscheidet kein institutionalisierter Richtstuhl und keine Akademie, sondern nur die relative Popularität. Und damit, so fährt Lovink fort, ändert sich die gesamte Rezeptionserfahrung: Der Computer sei keine Maschine, die mit Informationen umgeht, sondern lediglich ein Signalprozessor, der es Menschen ermöglicht, aus seinen Signalen qua kultureller Deutung Information entstehen zu lassen. Sei es in der klassischen, literarischen Schriftkultur noch darum gegangen, Lesekompetenz für das Verstehen individuell bedeutungsvoller Texte zu kultivieren, benötigten wir heute vor allem eine Medienerziehung, die uns lehrt, wie man Computern gegenüber klare und verständliche Suchanfragen formuliert. Lovinks These lautet, dass das Internet eben kein Orakel und keine Wunschmaschine des Wissens ist, sondern vielmehr ein Mediendispositiv mit sehr komplexen Machtstrukturen, das von uns nicht nur ein funktionales Wohlverhalten im Umgang mit seinen Interfaces, sondern eine Anpassung unserer kulturellen Lese- und Lerngewohnheiten an sein technisch-formallogisches System einfordert (vgl. ebd.: 57). Wir partizipieren also nicht nur am System, sondern das System partizipiert ständig auch an uns, schreibt sich unserem Kulturverständnis ein, erzieht uns zu seinen idealen Anwendern, indem es uns mit anschlussfähigen Suchtreffern belohnt.

Espen Aarseth prägte in den 1990er Jahren den Begriff des »Cybertext« als Bezeichnung für eine Form der Literatur, in der nicht nur (wie im konventionellen Hypertext) eine zweidimensionale Navigierbarkeit zwischen Textbausteinen vorliegt, sondern in der die strukturelle Beschaffenheit von Texten sich unter den Augen des Lesers entsprechend seiner Navigationsentscheidungen verändert (vgl. Aarseth 1997: 1). Damit evoziert das Kompositum 〉Cybertext $<$ den Cyberspace nicht nur begrifflich, sondern auch konzeptuell: Wo der Cyberspace einen sich um das Verhalten des Nutzers herum konstituierenden und verändernden $>$ Raum $<$ in Aussicht stellt, da verspricht der Cybertext eben einen Text, der sich prozedural auf persönliche Interessenlagen und Entscheidungen hin organisiert. Während der Cyberspace aber eine Metapher ist, die eine abstrakte Kommunikationssituation verräumlicht und damit vorstellbar macht, ist der Cybertext genau das, was er zu sein vorgibt - nämlich ein Text, der von Rückkopplungsmechanismen zusammengesetzt wird.

Aarseth bezeichnet diese Eigenschaft von Cybertexten als »Ergodizität« - eine Wortschöpfung aus den griechischen Substantiven ergon und hodos, Arbeit und Pfad (ebd. 1997: 1). Leser stiften im Cybertext also nicht nur - wie im Hypertext - pfadabhängig Sinn zwischen Einzelbausteinen, sondern sie wirken auf die tatsächliche Verfasstheit des Textsystems in Gänze ein, und diese Einwirkung wird als >Arbeit<, als Veräußerung von Energie, klassifiziert. Auf der Leserseite unterscheidet Aarseth hier `trvialen und `nontrivialen` Aufwand. Trivialer Aufwand ist für ihn all das, was jeder Leser bei der Rezeption klassischer linearer Texte leisten muss: Dazu gehören z.B. Augenbewegungen, das Umblättern, aber auch das grundsätzliche sprachliche Verstehen der Worte und Satzstrukturen. Nontrivialer Aufwand bezeichnet dagegen 
das navigatorische Element und vor allem das Treffen von Entscheidungen über die Bewegung im Textraum. Beides findet natürlich auch im konventionellen Hypertext statt. Was Aarseth aber mit seinem Cybertext-Konzept bezwecken will, ist eine Verschiebung der Betrachtungsebene fort von Ergebnissen und hin zu Mitteln. Obwohl das gesamte Hypertext-Konzept von seinen Anfängen im Memex-Gedankenspiel bis zum WWW eng mit technischen Entwicklungen verbunden war, sieht er die Hypertexttheorie befangen in der Frage, was gelesen wird, und nicht etwa, wovon abgelesen wird (vgl. ebd.: 3). Damit rückt er das Problem der konkreten Technizität des Mediums in den Brennpunkt des Interesses, und mit ihm das Dispositiv der Lesesituation.

Aarseth vergleicht das Lesen klassischer literarischer Narrative mit dem Besuch einer Sportveranstaltung, oder dem Beobachten einer vorbeiziehenden Landschaft aus einem Zugfenster. Der Leser kann natürlich sehr intensiv vereinnahmt werden ergriffen oder gerührt sein, mitfiebern - aber er bleibt auf eine rein voyeuristische Rolle beschränkt. Seine Teilhabe reicht nicht über seine emotionale Involviertheit hinaus und zugleich kann er sich in seinem Rezeptionsverhalten im Grunde nicht falsch betragen, so lange er nur dem gradlinigen Textfluss folgt. Er ist, in Aarseths Worten, »safe, but impotent« (ebd.: 4) - zwar kann er den Text auf unzählige Arten interpretieren, reflektieren, über ihn nachdenken, ihn gutheißen oder ablehnen, aber keine dieser Reaktionen kann auch nur ansatzweise auf den Text in seiner medialen Beschaffenheit zurückwirken. Der Cybertextleser setze sich dagegen stets dem Risiko aus, am Text bzw. an den Modalitäten des Lesens zu scheitern. Er ist niemals >sicher und damit laut Aarseth auch gar kein `Leser im klassischen Sinne, sondern vielmehr ein Spieler. Im Cybertext stellt unsere nontriviale Arbeit gewissermaßen einen `Einsatz $\triangleleft$ dar, mit dem wir auf eine positive Rezeptionserfahrung setzen. Diese >Spielsituation< impliziert unweigerlich die Möglichkeit einer Niederlage und damit auch die des Verlustes unseres Einsatzes. Im Cybertext ringen wir, so fährt Aarseth fort, nicht nur um Vergnügen an einem Narrativ, sondern um Kontrolle über die konkrete Erscheinungsform des Textes: Wir wollen nicht nur eine Geschichte erfahren, sondern unsere Geschichte bzw. eine Geschichte, die ohne uns gar nicht existieren könnte. Während sich beim Lesen klassischer linearer Texte das virtuelle Moment in der Interpretation durch den Leser manifestiert und der Hypertext eine zweite Virtualitätsebene in Form der Navigation einführt, erzeugen Cybertexte also eine dritte Schicht des Virtuellen in Form der Möglichkeit zur Intervention (vgl. ebd.: 4). Der Rezipient deutet nicht nur Individualtexte oder sucht Sinnpfade durch Text-Topologien, sondern er wird selbst zum Architekten möglicherweise überaus kurzlebiger Bedeutungsgefüge. Die von Aarsetz beschriebene Möglichkeit des Scheiterns ergibt sich dann daraus, dass im Cybertext Rezeption und Autorschaft zusammenfallen und der sinnhafte Abschluss der Lesesituation eben nicht mehr durch eine vorgeschaltete Schreibsituation garantiert ist. Trotzdem entgeht der Cybertextrezipient dem BabelSzenario, denn während die Bibliothekare der Universalbibliothek auf die Rolle einer 
Leserschaft von Texten ohne Autoren reduziert sind, wird das Cybertextsystem laufend durch die Entscheidungen seines Lesers mit dessen kulturellem Verständnis verkoppelt und ist so in einen andauernden Prozess der Kontingenzbewältigung eingebunden. 〉Erfolgreicher< Umgang mit einem Cybertext resultiert für Aarseth in »Intimität« zwischen Leser und Gelesenem, in einem sinnhaften Abschluss nicht nur eines literarischen Textes, sondern einer ganzen Rezeptionssituation, die vor allem auch den Rezipienten in seiner Wirkmächtigkeit bestätigt, während `Scheitern ‘ einem Verlaufen, einer narrative Sackgasse, einer Erfahrung ergodischer Ohnmacht entspricht (vgl. ebd.: 4).

Die gesamte Idee und Absicht hinter Cybertextsystemen zielt also in eine der pädagogischen Programmatik des klassischen Museums völlig entgegengesetzte Richtung. Selbst wenn partizipative Ansätze im Zentrum einer Museumskonzeption stehen, kann sich eine materielle Ausstellung in einem physischen Gebäude unmöglich spontan um einzelne Besucher herum neu aufstellen. Veränderungen an der physischen Beschaffenheit eines Museums sind natürlich möglich - Objekte können umgestellt werden, aus der Ausstellung in den Fundus oder aus dem Fundus in die Ausstellung wandern, ja sogar Gebäude lassen sich umbauen - aber derartige Neuaufstellungen müssen nach den Öffnungszeiten in Abwesenheit der Besucher erfolgen, können eventuell gar längere Schließungen erfordern. Museen können ihre Besucher einbinden und auf sie reagieren, aber ihre Reaktion muss eine verzögerte sein, weil sie voraussetzt, dass Menschen einander verstehen und dieses virtuelle Verständnis dann durch produktive Tätigkeit in der Ausstellung aktualisieren. Auch eine Aufweichung der Trennung zwischen Kuratorium und Publikum kann dieser Trennung von Autorschafts- und Rezeptionsmoment keinen Abbruch tun. Der Cybertext nach Aarseth hingegen greift zwar nicht die Raummetapher des Cyberspace auf, wohl aber seinen zentralen Gedanken: den von einem medialen Milieu, das auf seine >Bewohner (d.h. die Software-Doppelgänger von Rezipienten) entsprechend ihrer kulturellen Erwartungen reagiert, ohne dass es dabei von einer menschlichen Autorenpersönlichkeit betreut werden müsste.

Zwei Jahre nach der Veröffentlichung von Aarseths Monographie sollten Brin und Page ihr Paper über die Funktionsprinzipien von Google veröffentlichen und damit den Weg dahin ebnen, auch das Web als Cybertext rezipierbar zu machen. Denn diese Feststellung muss natürlich vorausgeschickt werden: Per se ist das World Wide Web erst einmal kein solcher. In seiner Infrastruktur aus Hard- und Software ist es zwar ebenso hoch veränderlich wie in seinem logischen Aufbau - genau deshalb benötigen wir ja dynamische Such- und Indexierungssysteme wie Google, um es navigierbar zu machen - aber seine spezifische und zeitlich wechselhafte Verfasstheit von Inhalten und Verlinkungen wird üblicherweise auf der Produzentenseite generiert, also von jenen Akteuren, die Webseiten und ihre Verknüpfungen untereinander tatsächlich in HTML und verwandten Auszeichnungssprachen erstellen. Das Web ist in 
ständigem Wandel begriffen und technisch genau darauf ausgerichtet, diesen zu ermöglichen, allerdings ändert die bloße Rezeption erst einmal rein gar nichts daran, wie Webseiten beschaffen und miteinander verschaltet sind. Page Rank adressierte als Dienstleistung 1999 zwar bereits den Endnutzer, stellte diesen aber nicht in den Mittelpunkt seiner Datenerhebung. Auch die erste Version von Google blickte in erster Linie auf jene Netzakteure, die unzweifelhaft auf der Autorenseite standen. Zwar konnte sie ihre Relevanzbewertung von Webseiten mittels unermüdlicher Webcrawler dynamisch an sich verändernde Verlinkungskonstellationen anpassen, aber über Wichtigkeit und Unwichtigkeit einzelner Angebote entschieden letztlich die Webmaster selbst, die sich über die Entscheidung zur Verlinkung oder Nichtverlinkung Relevanz zusprechen oder vorenthalten konnten.

Der \User« als Leser wurde erst mit Analytics-Diensten zum Referenzpunkt der Kulturtechnologie Suchmaschine, und erst mit dieser Entwicklung beginnt das WWW, im Sinne Aarseths, echte Cybertext-Züge aufzuweisen. Obwohl Aarseth selbst seinen Betrachtungsschwerpunkt noch auf narrative Cybertexte setzt und sich vor allem für Formen (nicht zwingend computergestützter) interaktiver Literatur interessiert, bringt er entsprechende Überlegungen bereits in Anschlag. Cybertext ist für ihn kein spezifisches literarisches Genre, sondern eine Organisationform für alle nur denkbaren Arten von Information und eine mediale Kategorie, die sich nicht über Inhalte, sondern über Funktionalität definiert (vgl. ebd.). Diese Funktionalität ist eben die prozedurale Umstrukturierung des Textkörpers anhand von Rückkopplungsschleifen mit dem Leser (vgl. ebd.: 19). Dass diese Rückkopplungsschleifen im WWW nicht das Web selbst um unsere Surfentscheidungen herum neu aufstellen, sondern vielmehr Bestandteil von >Navigator/-Programmen sind und damit nicht am eigentlichen Text, sondern innerhalb eines aufgesetzten Abruf-Interfaces arbeiten, tut unserem Erleben dabei keinen Abbruch: Broad- und narrowcasting greifen zwar unmittelbar und notwendig ineinander, aber für den Nutzer von Suchmaschinen verschwindet der Breit- weitgehend im Schmalfunk.

\subsection{ALGORITHMISCHE AUTORSCHAFTEN}

Daher werden wir auch allzu leicht blind für die Tatsache, dass hinter dem Ranking von Suchergebnissen auf Google-Trefferseiten ebenso wenig eine natürliche Folgerichtigkeit steht wie hinter den Kaufempfehlungen, die uns Amazon feilbietet. Aarseth stellt mit seiner Begrifflichkeit vom Cybertext zwar keinen vollendeten Tod des Autors in Aussicht, wohl aber sein Aufgehen in einer cyborghaften »Literaturmaschine«, in welcher der Computer kein passives Schreibwerkzeug ist, sondern ein verinnerlichter Teil der Entstehung des Textes sowohl vor als auch in der Rezeption (vgl. ebd.: 129ff.). Damit einher geht eben eine besondere Form der Aneignung durch 
den Leser, der den Text nicht mehr im Vorbeiziehen erlebt, sondern Arbeit in ihn investiert und ihn damit gewissermaßen >besiedelt . Der Cybertext fließt nicht einfach vom Autor durch das Medium abwärts zum Leser, sondern entsteht in einem deutlich verflachten netzhaften Dispositivgefüge, in dem Produzenten und Rezipienten miteinander und mit einer medientechnischen Anordnung in Rückkopplung treten. Wie Google Analytics im Speziellen scheint das Prinzip Cybertext im Allgemeinen einem rhizomatischen Paradigma zu folgen, das keine institutionalisierten oder von Experten sanktionierten Lesarten und Wissensordnungen privilegiert, sondern sich >von unten`, oder zumindest in der Ebene, organisiert.

Nun wurde allerdings zuvor bereits ausgeführt, dass der Mensch mit Computern immer im Imperativ kommuniziert. Pro-Gramme sind Vor-Schriften, also Regelsysteme, und damit unweigerlich hierarchisch angelegt. Cybertexte setzen Programmierung voraus, und Programmierung wiederum eine kulturelle Absicht. Googles Suchalgorithmen sind nicht aus kosmischer Notwendigkeit heraus entstanden, sondern aus der Intention, eine Auffindbarkeit kultureller Inhalte in einer ganz bestimmten Form der Textorganisation mit einer ganz bestimmten Infrastruktur zu gewährleisten. Page Rank und Google Analytics bilden einerseits eine Reaktion auf existierende technische Gegebenheiten ab - nämlich auf das Internet und das WWW in ihrer konkreten funktionalen Verfasstheit -, zugleich aber auch ein Modell kultureller Relevanz und Autorität, das gewählt ist und durchaus anders aussehen könnte, so nützlich und intuitiv einleuchtend es auch sein mag.

Insofern teilt das Web ein weiteres zentrales Charakteristikum klassischer Museumsausstellungen: Es gaukelt uns zuweilen natürliche Folgerichtigkeit vor, wo wir tatsächlich auf kulturelle Programmatiken blicken. Anders als die meisten Museen gehören die Anbieter von Navigationssoftware im Web allerdings üblicherweise zur Privatwirtschaft und verfolgen ein Ziel, das für öffentliche Bildungseinrichtungen meist sekundär ist: Profitmaximierung. Google ist nicht nur ein Werkzeug für die Suche nach Webinhalten, und auch nicht >nur ein mächtiges Interface, das mittlerweile über den Zugriff auf weite Teile unserer kulturellen Welt mitbestimmt, sondern es ist vor allem auch ein Dienstleistungsunternehmen mit einem spezifischen Geschäftsmodell. Dieses kreist nicht vorrangig um Suchtreffer, sondern um Nutzerdaten. Wer von Google kulturelle Ausgewogenheit oder gar ein Bewahrungsinteresse für Kulturgüter erwartet, der versteht laut Geert Lovink schlechterdings nicht, wie Google technisch und wirtschaftlich funktioniert. Zum schon von Jeanneney kritisierten Bibliothekprojekt Google Books merkt er an:

Google leidet an Datenfettsucht und ist gegenüber Aufforderungen zu sorgfältiger Aufbewahrung von Daten indifferent. Es wäre naiv, von Google kulturelles Bewusstsein zu erwarten. Das primäre Interesse Googles an diesem zynischen Unternehmen besteht darin, das Verhalten 
von Nutzern zu beobachten, um Verbindungsdaten und -profile an interessierte Dritte zu verkaufen. Google geht es nicht um das Eigentum an Émile Zola. Seine Absicht besteht eher darin, den Proust-Fan vom Archiv wegzulocken. (Lovink 2010: 59)

Die Suche und die Inhalte, die sie uns erschließen soll, sind also nicht Googles eigentliches Geschäft, sondern nur ein Zwischenprodukt, dass es in metrisch auswertund monetarisierbare Nutzerentscheidungen zu übersetzen gilt. Google (und natürlich auch jeder andere Suchmaschinenbetreiber) trachtet letztlich danach, das kostbarste Gut der Netzökonomie in bare Münze umzuwandeln - nämlich die Aufmerksamkeit der Nutzer. Es geht darum, Modelle ihrer >Persönlichkeit $<$ zu entwickeln, mit deren Hilfe sie sich optimal ansprechen lassen (vgl. ebd.: 60f.). Insofern kann Google sich ebenso wenig pädagogischen Idealen verschreiben wie einer Logik des Rhizoms. Suchmaschinenanbietern geht es nicht darum und kann es nicht darum gehen, der >breiten Masse` die Deutungshoheit über kulturelle Inhalte zu übertragen. Vielmehr ist es ihr Ziel, dem individuellen Nutzer so präzise wie möglich genau das zuzuführen, was er haben möchte, damit er möglichst in Zukunft wieder denselben Dienst nutzt und dabei noch mehr über sich preisgibt. Entsprechend muss ihnen daran gelegen sein, das Rhizom auf die dichtesten, höchsten Plateaus zusammenzustutzen. Aus ihrer logischen Anlage heraus begünstigen sie peripheres Wissen zunächst keineswegs. Genau dies meint Jean Jeanneney ja mit seiner Kritik an der Gewichtung von Suchergebnissen in Richtung des >Gondelendes $২$. Zugleich sind Suchmaschinen und Empfehlungssysteme aber natürlich längst nicht mehr aus dem WWW fortzudenken, und wenn eine klassische Kulturinstitution wie das Museum ins Web ausgreifen möchte, dann muss sie sich zu dieser Tatsache in irgendeiner Form verhalten. Dies kann, wie der Museumswissenschaftler Jon Pratty anmerkt, schmerzhafte Kompromisse erforderlich machen.

Museale Web-Präsenzen können es sich seiner Einschätzung nach nicht nur nicht leisten, sich von Auffind-Mechanismen abzugrenzen, sondern sie müssten sich diesen vielmehr sogar explizit anpassen (vgl. Pratty 2006) - und sich damit in einen Trend einreihen, der nach Roberto Simanowski längst für Design und Ausrichtung von Webseiten jeder Couleur tonangebend geworden ist. Das Netz nämlich ist bereits mit Webseiten überschwemmt, deren einzige Funktion es nicht etwa ist, irgendwelche eigenen Inhalte zu übermitteln, sondern vielmehr, Suchmaschinentreffer zu erzeugen. Diese sogenannten made for adsense- (oder kurz $M F A$-)Seiten dienen in erster Linie als Plattformen für Werbung und sollten idealerweise (oder treffender vielleicht: schlimmstenfalls) Worte oder Wortfolgen enthalten, die eine maximale Anzahl von Suchtreffern für eine maximale Anzahl von Anfragen produzieren. Längst ist auch eine eigene Subökonomie von Internetfirmen entstanden, die Unmengen billiger Arbeitskräfte für nichts anderes bezahlen, als unsinnige Texte für solche Webseiten zu schreiben. Während Suchmaschinen also über trickreiche Rankingsysteme versuchen, die Bibliothek von Babel zu bändigen, sind solche Netz-Hasardeure eifrig 
damit beschäftigt, sie zu verwirklichen - und über Schlupflöcher in der Logik von Suchmaschinenrankings deren Sinn und Funktion auszuhebeln, um parasitär von ihnen zu profitieren. Die Suchmaschinenbetreiber wiederum haben natülich ein Interesse daran, dass ihre Nutzer hilfreiche Trefferlisten zu sehen bekommen und auch in Zukunft ihrer Dienstleistung die Treue halten. Entsprechend gibt es auch Firmen, die MFA-Seiten aufspüren und abschalten - und zwar sowohl im Auftrag von Suchmaschinenbetreibern, als auch in jenem von Internet-Werbeträgern. $M F A$-Seiten generieren nämlich erfahrungsgemäß extrem hohe Ansichtszahlen für Internetwerbung, aber so gut wie keine neuen Kunden und beschädigen darüber hinaus das Firmenimage. Sie nutzen also tatsächlich nur ihren eigenen Betreibern und schädigen werbende Firmen ebenso wie Suchmaschinen und suchende Nutzer (vgl. Simanowski 2008: 69f.).

Indes verweist die Prävalenz von $M F A$-Seiten darauf, wie sehr die Suchmaschine als Portaltechnologie längst unseren Internetkonsum bestimmt. War die Frage Ende der 1990er Jahre noch, wie eine Suchmaschine beschaffen sein müsste, um sich dem Web anzupassen, gilt es nun für die Gestalter von Webseiten, Mittel und Wege zu finden, um Ranking-Algorithmen zu bedienen und sich opportun in Trefferlisten zu platzieren. Laut Pratty bedeutet aus diesem Grunde Virtualisierung für Museen nicht nur eine Transformation in ein \Museum ohne Wändeく, sondern vielmehr eine Umstülpung des Museumsdispositivs von innen nach außen. Soll ein virtuelles Museumsangebot tatsächlich ein Publikum erreichen, dann muss es Prattys Ansicht nach ganz bewusst und gezielt genau diesen Anschluss an eine bestehende und mächtige Infrastruktur suchen. Das virtuelle Museum ist im Gegensatz zum physischen keine souveräne und diskrete Sinnmaschine mehr, sondern ein Subsystem innerhalb eines sehr viel größeren Machinamentums. Natürlich hat auch das Museum immer innerhalb urbaner Landschaften existiert, zu denen es in mehr oder minder ausdrücklichen Beziehungsgefügen steht - André Malraux hat dies ja in seinen Betrachtungen zur Authentizität des Museums herausgestellt - aber als Dispositiv hat es die Abgrenzung von der Außenwelt zu einem seiner Leitprinzipien gemacht. Das virtuelle Museum hingegen müsse, so Pratty, sein Inneres nach außen kehren und seine Sinnstiftung an Suchmaschinen veräußern - oder vielleicht auch: Die Modalitäten der Sinnstiftung durch Suchmaschinen verinnerlichen, indem es seinen inneren Aufbau auf die Suchmuster zuschneidet, die Google und Co. ihm zuführen (vgl. Pratty 2006). 


\subsection{CULTURAL ANALYTICS: DIE QUANTIFIZIERUNG KULTURELLER PHÄNOMENE}

Im Jahre 2007 beantwortete Lev Manovich die Geburt von Google Analytics mit einem gleichermaßen ambitionierten wie streitbaren Text, den er programmatisch mit Cultural Analytics betitelte und in dem er nicht weniger einfordert als eine fundamentale Reform im Umgang der Kulturvermittlung und Kulturwissenschaften mit dem Wissen über die Welt, in der wir leben. Es gelte, so seine These, sich hier Technologien zu öffnen, die in anderen Bereichen - wie den >harten Wirtschaft und diversen Regierungsagenturen - längst essentiell geworden seien. Er meint damit nicht etwa nur die >neuen Medien` als Präsentationsplattform, sondern mit ihnen einhergehend vor allem jene häufig unter dem Begriff big data gehandelten Methoden des data mining, der statistischen Auswertung und der simulatorischen Visualisierung, mit denen Muster, Regelmäßigkeiten und Anomalien in extrem großen Datensätzen ausfindig gemacht werden sollen. Der Kulturbetrieb, ob er nun profitorientiert sei oder nicht, komme nach Manovichs Dafürhalten nicht länger umhin, sich diese Werkzeuge ebenfalls zu eigen zu machen - schließlich fände bereits ein Großteil (wenn nicht gar der größte Teil) unserer Auseinandersetzung mit kulturellen Inhalten in digitaler und vernetzter Form statt. Zum Zeitpunkt der Entstehung seines Textes hatten allein Google und Amazon bereits zehntausende von Büchern eingescannt und im Netz abrufbar gemacht, und zur Illustration der schieren Datenmasse verweist Manovich auf die Fotoplattform Flickr, auf der im Juni 2007 nicht weniger als 560 Millionen Bilder samt Metadaten abrufbar waren. Das Ziel, das Manovich mit den Cultural Analytics verfolgt, erscheint dabei als eine extrem konsequente technische Umsetzung dessen, was Friedrich Kittler 1980 folgenreich die »Austreibung des Geistes aus den Geisteswissenschaften« (vgl. Kittler 1980: 8ff.) nannte: nämlich die Ablösung der Kulturarbeit von dem, was man klassischerweise den >Inhalt $\iota$ nennen würde, und eine Hinwendung zu den situativ-medialen Umständen seiner Rezeption. Gegenstand von Cultural Analytics sind für Manovich nicht Inhalte, sondern die Daten, die im Zuge ihrer Verwendung generiert werden. Das System soll dreierlei in den Fokus rücken: Erstens die existierenden Metadaten, mit denen kulturelle Inhalte ins Netz hochgeladen werden, zweitens die neuen Metadaten, die aus dem Umgang mit im Netz verfügbaren Inhalten entstehen (ein einfaches Beispiel wären hier z.B. Bildanalysen, die sich auf digital abrufbare Bilder beziehen und ihrerseits im Web publiziert sind), und drittens schließlich die virtuellen Spuren von Netz-Nutzern, die kulturelle Inhalte online produzieren, veröffentlichen, anschauen, verändern, diskutieren, konsumieren usw. Die so gewonnene Datenflut gilt es dann laut Manovich nicht etwa unters metaphorische Mikroskop zu legen und im hermeneutischen Detail zu untersuchen - dies liefe den Implikationen des Mediums völlig zuwider -, sondern 
vielmehr je nach Interessenlage der jeweiligen Untersuchung auf zweckdienliche Art zu visualisieren (vgl. Manovich 2007: 1f.).

Es geht Manovich also um eine neue Form der Geisteswissenschaften und der kulturellen Vermittlung, die sich nicht länger am vermeintlich >Wesentlichen $<$ kultureller Gegenstände abarbeitet, sondern vielmehr nach ihrer Verbundenheit - oder eben connectedness - in Massenbewegungen des Wissens fragt, die womöglich rein gar nichts Wesentliches mehr an sich haben. Was dahinter steht ist eben die McLuhansche Erkenntnis, dass das Medium die Botschaft ist, oder in diesem Falle präzisiert: Dass Such- und Abrufsysteme für Information Determinanten sind für deren Wirken in unserer sozialen Umwelt. Die Suchmaschine ist für Manovich ausdrücklich kein indexikalisches Auffindewerkzeug, dessen Wirkung und Anwendbarkeit sich auf das spezifische technische System beschränkt, in dem es als Software ausgeführt wird. Weil der Computer nach Manovich ja ein Filter für die Gesamtheit aller Kultur geworden ist, wird die Suchmaschine unweigerlich zu einem ihrer zentralen Interfaces. Und auch wenn Empfehlungssysteme überwiegend noch die Domäne von kommerziellen Dienstleistern wie eben Internet-Kaufhäusern sind, so werden doch auch sie zunehmend zu maßgeblichen Navigatoren, die uns im Dschungel der Virtualitäten zu dem führen, was uns interessiert und gefällt (oder die - das wäre die kulturpessimistischere Lesart - womöglich aus der assoziativen Logik des Webs heraus unsere Interessen nicht etwa abbilden, sondern überhaupt erst produzieren). Kultur, davon ist Manovich überzeugt, ist letztlich keine Ansammlung dezidiert gemachter Fakten, sondern vielmehr data - das gefundene (und somit gegebene) Ergebnis des Umgangs mit Gegenständen und ihren Bedeutungen, die in der Rezeption erst aktualisiert werden. Das revolutionäre Potential digitaler Medien besteht nun darin, dass diese Aktualisierungsprozesse nicht mehr nur in den uneinsehbaren Köpfen von Rezipienten ablaufen, sondern messbare Spuren hinterlassen, weil jeder Abruf von Information dem Netzwerk und seinen Abrufsystemen gegenüber eine Aussage darstellt und somit selbst data wird, die in großem Stil >gemined « werden kann. Naturwissenschaftliches, kommerzielles und gouvernementales Wissen wird längst auf diese Art produziert - und wenn sich die Kultur- und Geisteswissenschaften solche Methoden nicht ebenfalls aneignen, dann laufen sie nach Manovich Gefahr, über kurz oder lang hoffnungslos hinter ihre eigenen Untersuchungsgegenstände zurückzufallen (vgl. ebd.: 2f.).

Damit will Manovich zugleich eine Kulturpädagogik und -wissenschaft anstoßen, die ihren Blick anstatt auf die Geschichte auf die Gegenwart richtet. Jede wissenschaftliche Auseinandersetzung mit der kulturellen Welt hat ja unweigerlich mit ihrer eigenen Nachträglichkeit zu kämpfen. Wer kulturelle Trends an Inhalten ablesen will, der kann dies immer nur im Nachhinein tun, wenn die entsprechenden Diskurse und die mit ihnen einhergehenden Bedeutungsverschiebungen längst stattgefunden und mediale Zeugnisse in genügendem Ausmaß hinterlassen haben. Manovich sieht die Attraktivität von Cultural Analytics nicht zuletzt darin begründet, dass sich mit ihnen 
kulturelle Prozesse in Echtzeit beobachten und beschreiben lassen sollen - und mit diesem Umstand verbinden sich für ihn auch ganz neue Bilder von den Dispositiven der Geisteswissenschaften und der Kulturvermittlung. Die Zukunft der humanities ist seines Erachtens nicht der individuelle Forscher, der in einer Bibliothek über einzelnen Büchern oder in einem Museum über einzelnen Kulturgegenständen brütet. Stattdessen soll unser Verständnis davon, was unsere Kultur ist und wie sie funktioniert, bald in riesigen Datenzentren produziert werden, die laufend ein unvorstellbar großes Kommunikationsvolumen erfassen und auswerten. Der Geisteswissenschaftler der Zukunft sitzt nach Manovichs Vorstellung in einer Kommandozentrale vor riesigen Bildschirmen, auf welchen ständig sekundenaktuelle Visualisierungen von Entwicklungen innerhalb großer Datenmengen ablaufen, und er illustriert diese Vision mit dem Foto einer Verkehrsüberwachungszentrale in Florida (vgl. ebd.: 3).

Dabei sind diese Ideen nicht vollkommen neu. Bereits recht früh in der zweiten Hälfte des zwanzigsten Jahrhunderts entstand innerhalb der Geisteswissenschaften ein Forschungszweig, der zunächst den Namen Humanities Computing trug und in den 1990er Jahren zunehmend unter der Bezeichnung Digital Humanities firmieren sollte. Als Initialzündung wird hier meist das Mitte der 1940er Jahre (und damit abermals zeitgenössisch zu Vannevar Bush und André Malraux) vom italienischen Jesuitenpater Roberto Busa angestoßene Projekt genannt, einen vollständigen Index sämtlicher Worte in den mittellateinischen Originaltexten des Thomas von Aquin anzulegen. Busa war offenbar nur allzu bewusst, dass dieses Vorhaben in rein menschlicher Kopf- und Handarbeit kaum zu bewältigen sein würde, was ihn dazu veranlasste, sich 1949 um die Unterstützung des damaligen IBM-Geschäftsführers Thomas J. Watson zu bemühen. Mit der Schützenhilfe des bereits seit 1911 in der Herstellung von Rechenmaschinen tätigen Konzerns wurde in den folgenden Jahren und Jahrzehnten das gesamte zu erschließende Textvolumen auf Lochkarten übertragen, die sich anschließend maschinell auswerten ließen. Der Index Thomisticus erschien ab 1974 zunächst in gedruckter Form, bevor er 1992 erstmals digital aufCD-ROM veröffentlicht wurde (vgl. Hockey 2004; vgl. Niewerth 2013: 4).

Die Institutionalisierung dieser Form statistischer Texterschließung mit maschinellen Hilfsmitteln als legitimer disziplinärer Zugang der Geisteswissenschaften geschah 1987 mit der Gründung der Text Encoding Initiative. Diese Interessengruppe von Wissenschaftlern war geographisch wie fachlich gleichermaßen weit verstreut, kommunizierte vorwiegend über Mailinglisten miteinander und hatte sich zunächst ein wenig utopisch klingendes Ziel gesetzt: Es ging ihr darum, ein Standardformat für die digitale Codierung von geistes-, sozial- und kulturwissenschaftlichen Texten auszuarbeiten, das elektronische Forschungsressourcen für Wissenschaftler in den entsprechenden Disziplinen leichter verfügbar werden lassen sollte. Die 1994 erstmals vorgestellten TEI Guidelines besitzen bis heute Gültigkeit (vgl. Text Encoding Initiative 2014; vgl. Niewerth 2013: 4). Der Begriffswechsel vom Humanities Computing zu den Digital Humanities, der zum Ende der 1990er Jahre einsetzte, war vor 
allem in einer ausgeweiteten Perspektive und einem gewachsenen Selbstbewusstsein dieses Forschungsansatzes begründet: Während Humanities Computing noch weitgehend als ein weiteres Werkzeug unter vielen im bestehenden Repertoire der Geisteswissenschaften konzipiert war und sich im Ansatz sehr bestimmt auf die Nutzung des Computers zur Beherrschbarmachung von Texten konzentrierte, wollten die $\mathrm{Di}$ gital Humanities das Potential des Computereinsatzes in der geisteswissenschaftlichen Forschung sehr viel umfassender in Augenschein nehmen - gegebenenfalls bis hin zum völligen Umdenken über Funktion, Rolle und Auftrag der eigenen Disziplin in der digitalisierten Welt (vgl. Schreibman, Siemens u. Unsworth 2004; vgl. Niewerth 2013: 4).

Dementsprechend sind die Digital Humanities getragen von einer doppelten Einsicht: Nämlich erstens jener, dass der wissenschaftliche Umgang mit einer digitalisierten Kultur auch digitaler Methoden bedarf, und zweitens jener, dass die Methoden einer Wissenschaft niemals nur Werkzeuge sind, die nicht auf ihren Nutzer zurückwirken, sondern vielmehr die Struktur jedweder wissenschaftlichen Erkenntnis vorab mitbestimmen. Diese beiden Einsichten erschöpfen sich indes nicht in ihrer Bedeutung für die geisteswissenschaftliche Forschung, weil sie darüber hinaus auf einen Tatbestand von noch umfassenderer Bedeutung verweisen, welcher in Malrauxs Konzeption des Imaginären Museum bereits anklingt: Die Reproduktion kultureller Inhalte ist niemals nur ein Prozess der Vervielfältigung und Kopistik, sondern notwendigerweise immer auch einer der Transformation. Der transformative Charakter der Reproduktionen liegt darin begründet, dass anhand ihrer andere Formen der Rezeption möglich werden, als die Originale sie erlauben. Der Buchdruck befreite die Literatur aus den Bibliotheken von Adel und Klerus und ermöglichte ihre Rezeption in bürgerlichen Settings, die mechanische Fotografie nach Malraux befreite die Kunst aus den Museen und Galerien, durchspülte die Alltagswelt mit ihr und hob virtuell die Voneinander-Geschiedenheit der Einzelobjekte auf. In beiden Fällen >verändern< sich die kulturellen Ursprungsobjekte unwiederbringlich. Die von neuen Medientechniken ermöglichten Verkehrsformen bereits bestehender kultureller Inhalte operieren nicht folgenlos innerhalb bestehender Dispositive, sondern verändern das Gefüge kulturellen Verstehens insgesamt: Nie wieder wird ein Mensch das Alte Testament so lesen können, wie es ein katholischer Geistlicher vor Luther und Gutenberg vermochte, und nie wieder werden wir die Mona Lisa mit den Augen eines Menschen sehen können, für den sie nur im Louvre existierte. Jedoch hat die analoge Reproduktion eines niemals angetastet: Die völlige Verortung kultureller Objekte innerhalb der Kulturwelt. Ein Foto der Erschaffung Adams aus dem Deckenfresko der Sixtinischen Kapelle ist natürlich nicht identisch mit dem Deckenfresko selbst, aber auch auf der glänzenden Oberfläche eines Polaroids bleibt es ein Bild, das nur in kulturellen $\mathrm{Zu}-$ sammenhängen gelesen werden kann - nämlich zum einen als das Abbild eines berühmten Kunstwerkes, und zum anderen als eine Darstellung der biblischen Schöpfungsgeschichte. Unser erlerntes Sehen und Deuten erlaubt es uns überhaupt nicht, 
die Darstellungsfunktion des Objektes und seiner Reproduktionen infrage zu stellen. Auch die Wilde Semiose nach Aleida Assmann bricht nicht aus der Kulturwelt aus sie setzt ja gerade voraus, dass in den Dingen eine Lesbarkeit vermutet wird, eine Verweisstruktur, die das Gesehene mit dem Gewussten verbindet (vgl. Assmann 1988: 240). In der digitalen Reproduktion hingegen verlassen die Dinge den culture layer und werden nicht nur in etwas transformiert, was sie eben eigentlich nicht sind (das gilt im strengen Sinne ja auch für die Fotografie), sondern in etwas, das für uns ohne den strategischen Einsatz von Interfacetechnologien wie eben dem Computerbildschirm überhaupt nicht mehr als ein `Etwas` zu erkennen ist.

Was sich in den Digital Humanities also andeutet und was Manovich mit den Cultural Analytics aufgreifen und im großen Maßstab weiterdenken will, ist nicht nur eine Erschließung neuer Analysemethoden für veränderte Arbeits- und Rezeptionssituationen. Vielmehr wird hier ein fundamentaler Wandel im Wesen kultureller Objekte und Äußerungen thematisiert, welcher sich eben im Prozess der Digitalisierung vollzieht und dessen Analyse in einen völlig neuen Kontext stellt: Kulturelle Phänomene sind im Digitalen nicht länger nur interpretier-, sondern nunmehr auch quantifizierbar, bzw. vielmehr noch: In ihrer Aufbereitung als digitaler Code sind sie bereits quantifiziert, denn nur so können sie auf dem computer layer überhaupt gespeichert, prozessiert und transcodiert werden. Ein Text ist nicht länger >nurく eine sprachliche Äußerung, die gelesen und verstanden werden kann, sondern repräsentiert eine genau vermessbare Menge an Information, die sich wiederum statistisch beschreiben lässt. Ein Gemälde ist nicht länger einfach Farbe auf Leinwand, die kulturell als eine Anhäufung von bedeutsamen Zeichen verstanden werden kann, sondern eine mathematisch aufschlüsselbare Verteilung von Farbwerten über ein Raster. Kulturelle Objekte, die sich zuvor scheinbar nur qualitativ und sprachlich verhandeln ließen, können nunmehr auch quantitativ und somit in Zahlen beschrieben und verarbeitet werden - und der Modus dieser Beschreibung ist die von Manovich geforderte zweckorientierte Visualisierung, die jeden beliebigen Aspekt der zugrundeliegenden Datenmenge hervorheben und verbildlichen kann.

Dies eben ist der Verlust des `Eigentlichen zahlreichen Arten, auf welche sich digitale Information visualisieren lässt, ist keine besonders privilegiert. Eine Bilddatei der Mona Lisa als Mona Lisa in Form bunter Pixel auf einen Bildschirm zu projizieren ist grundsätzlich keine >richtigere` Form ihrer Darstellung als jede andere. Insofern entstehen die trails of interest nicht nur im Hypertext zwischen mehr oder weniger diskreten digitalen Objekten. Vielmehr sind die digitalen Objekte Huis und die Attributobjekte Novaks selber Produkte strategischer Visualisierung von Daten, die man sich auch ganz anders erschließen könnte. Für virtuelle Museen bedeutet dies ganz konkret, dass sie ihre epistemische Architektur auf zwei Etagen entfalten müssen: auf dem culture und dem computer layer. Soll so etwas wie museales Erleben im Web überhaupt möglich sein, dann müssen erstens abstrakte digitale Daten auf eine Art und Weise auf dem Monitor visualisiert 
werden, die sie als kulturelle Objekte erkennbar werden lässt (und in vielen Fällen wird das heißen: als Abbildungen von physisch existierenden Dingen), und zweitens diese digitalen Objekte auf eine Art zueinander in Beziehung gesetzt und mit einem Abrufinterface versehen werden, das einen ähnlichen Kompromiss von didaktischer Führung und navigatorischer Assoziierbarkeit ermöglicht, wie es der physische $\mathrm{Mu}-$ seumsraum tut.

Lev Manovichs Hauptmotivation für die Konzeption der Cultural Analytics als Alternative zu den Digital Humanities ist dabei seine Beobachtung, dass letztere immer noch allzu befangen seien in klassischen, analogen Vorstellungen von Kultur, und damit auch in praxis- und lebensfernen Expertendiskursen. Das offensichtlichste Symptom dafür sieht er darin, dass existierende Analysesoftware für digitale Kulturgüter diese vornehmlich über Meta-Daten erschließbar zu machen trachtet: Sie blickt, so stellt Manovich fest, nicht in die eigentlichen Daten und auch nicht auf die Nutzungsmuster, in welche sie eingebunden sind, sondern auf ein die Daten umgebendes, von Menschen katalogisiertes Verwaltungswissen. Insofern füge sie den bestehenden Zugängen nur ein etwas schnelleres Abrufsystem hinzu (vgl. Manovich 2007: 6). Darüber hinaus erschöpften sich abseits aller visionären Vorstellungen von einer neuen Form der Kulturwissenschaft die tatsächlich Anwendungen der Digital Humanities in der statistische Analyse von Texten - und zwar vor allem von hochkulturellen Texten, deren Auswahl immer noch nach den bestehenden Vorurteilen und Relevanzvorstellungen einer Wissenschaft stattfinde, die dem gedruckten Wort verhaftet sei. Die Digital Humanities tun sich, so moniert Manovich, schwer mit all jenen digitalen Datenformen, die keine Schriftsprache abbilden - und mit der gesamten Fülle kultureller Artikulationen, die überhaupt erst aus digital-vernetzter Kommunikation heraus entstehen können (vgl. ebd.: 10). In anderen Worten: Die Digital Humanities wollen klassische geisteswissenschaftliche Zugänge um digitale Erschließungsmethoden erweitern, deren Nutzen aber unweigerlich in die etablierte Domäne der Geistes- und Kulturwissenschaften zurück münden muss, nämlich den culture layer. Paradoxerweise entstehen neue kulturelle Artikulationsmöglichkeiten aber gerade dort, wo kulturelle Kommunikation die Sphäre der Kultur verlässt und als digitaler Code eben in alles transformierbar wird. In der Digitalität können kulturelle Praktiken entstehen, welche den etablierten und didaktisch legitimierten Umgang mit Inhalten unterlaufen, gerade weil diese Inhalte als etwas anderes visualisiert, rezipiert und genutzt werden können, als das, was sie >eigentlich zu sein scheinen. Das mag nun tatsächlich das Bild eines >Museums von Babel evozieren, und mit ihm die Dystopie von der Beliebigkeit allen medial codierbaren Wissens. Laut Manovich ist dies jedoch gerade nicht der Fall.

Denn während die Bibliothek von Babel das furchteinflößende Produkt einer Aktualisierung all dessen ist, was ihr Codesystem virtuell-kombinatorisch hergibt, ist das Web eben kein Produkt, sondern Prozess. Zwar sind kombinatorisches Compu- 
ter-Kauderwelsch und von menschlichen Absichten bedingte und geleitete Programmiertätigkeit ontisch nicht voneinander zu unterscheiden, funktional lässt sich aber sehr wohl differenzieren zwischen dem, was ein Computer aus seinem formallogischen Aufbau heraus gewissermaßen >für sich selbst $`$ tut, und dem, was er für die kulturelle Rezeption durch Menschen über Interface-Systeme visualisiert. Manovich möchte seinen analytischen Blick nicht auf die Masse der Virtualitäten des Webs und der vernetzten Computer richten, sondern auf die Aktualitäten dessen, was Menschen mit Computern machen. Der Zugang dieser Analyse ist dabei kurioserweise gerade doch das virtuelle Element digitaler Systeme, aus dem heraus Aktualisierung erst möglich wird: Cultural Analytics reißen, indem sie sich der Visualisierung digitaler Daten als Werkzeug zur Erforschung digital mediierter Kulturphänomene bedienen, die Grenze zwischen Methode und Untersuchungsgegenstand völlig ein.

Im und um das World Wide Web hat sich längst eine ganze Industrie entlang der Notwendigkeit konstituiert, die digital-formalen Abbilder kulturell motivierter Entscheidungsprozesse vermessbar und aufeinander beziehbar zu machen, um sie dann wieder in kulturelle Zusammenhänge zurück zu überführen. Die Cultural Analytics greifen die unleugbare Tatsache auf, dass dynamische >Navigatoren` wie Suchmaschinen und Empfehlungssysteme längst zu Architekten von Sinngefügen im Netz geworden sind, und dass es damit keine feststehende `Ontologie $<$ mehr gibt, innerhalb derer sich digitale Objekte konstituieren und deren einmalige Entschlüsselung die Gesamtheit aller Modalitäten der Sinnproduktion im World Wide Web offenlegen könnte. Stattdessen ändern sich mit den Objekten des Wissens auch laufend die Umstände und Richtlinien ihrer Hervorbringung. 



\section{Virtualisierung und Musealisierung: Skizze eines Spannungsfeldes}

Die zentrale Herausforderung für die kuratorische Arbeit in virtuellen Museen ist also noch vor den klassischen Problemstellungen allen Kuratierens - der Ausarbeitung von Ausstellungskonzepten und Zielsetzungen, der Auswahl von Exponaten, ihrer Anordnung in einem bereits existierenden Museumraum - das Finden zweckdienlicher strategischer Umgangsformen mit der virtuellen Wesensart des Mediums Computer. Die zuvor diagnostizierte Einbindung des virtuellen Museums als Konzept in die übergreifende Idee vom > Weltmuseum der Medienlandschaft unserer Gegenwart regelrecht anachronistisch und der Vorstellung verhaftet, dass das `Museum von Babel< Architekten und Baumeister benötigen würde, die es mit voller Absicht und klaren Zielkonditionen errichten. Tatsächlich scheint es stattdessen so zu sein, dass die zunehmende >Verbabelung ‘ aus den technischen und sozialen Eigendynamiken des Mediums heraus ganz von allein stattfindet. Als Problem präsentiert es sich dabei weniger, Inhalte ins Netz zu bringen und sie prinzipiell auffindbar zu halten. Schwierig ist es vielmehr, der Emergenz von Zugriffsmustern und den Sinngefügen, welche die `natürliche Kybernetikı der Navigatorensoftwares aus ihnen entstehen lässt, noch Didaktiken aufzusetzen, die in irgendeinem Expertenwissen fundiert sind. Die Frage danach, wie man das Universalmuseum errichtet und ordnet, ist technisch und informationstheoretisch längst beantwortet. Brisant wird hingegen jene danach, wie man sich als virtuelles Museum (oder auch als Onlineauftritt eines physischen) noch abschirmen kann vor Ordnungsmechanismen, die letztlich alle von ihnen erfassten Inhalte einem einzigen Relevanzsystem unterwerfen, in welchem für die Wesensart des Museums kein Platz mehr ist in der nämlich die Idee einer Aufwertung durch Abgrenzung und institutionelle Auszeichnung nicht mehr auftaucht.

Das Museum bedient sich zwar auf der Ebene struktureller Wissensorganisation rhizomatischer Prinzipien - Dinge stehen einander >flach $`$ im Raum gegenüber und geben dem Besucher die Chance zur Sinnbildung abseits einer eindimensionalen, linearen Erzählung - will aber in seiner didaktischen Architektur weiterhin von der 
Wurzel zum Geäst funktionieren. Dabei wäre das Geäst die fertige Ausstellung, in der sich die Besucher bewegen, das Wurzelwerk aber das System von Spezialistenkenntnissen, aus dem sich die Ausstellung konzeptionell speist und institutionell legitimiert. Insofern arbeitet das Museum also mit Rhizomstrukturen, die hierarchisch übereinandergeschichtet werden, und die Kompetenz des Kurators zieht sich gewissermaßen als verbindender `Stamm 〈 durch sie hindurch. Kuratoren müssen das Netz wissenschaftlicher Erkenntnisse über Gemengelagen der Vergangenheit ebenso zu navigieren imstande sein wie jenes der pädagogischen Einsichten und Positionen zu Strategien der Kulturvermittlung, und sie müssen sich natürlich in ihrem eigenen Fundus zurechtfinden, bevor aus diesem eine Ausstellung hervorgehen kann. Der Kurator ist also ein Experte, der unterschiedliche Expertensysteme verbindet und zuweilen miteinander verfließen lässt, aber letztlich in seiner Arbeit auch eine Rangordnung unter ihnen affirmiert: Die Produktion von Wissen muss seiner Vermittlung vorangehen. Das Museum existiert unter den Vorzeichen einer Kulturauffassung, in der eben nicht allen Arten und Resultaten menschlicher Betätigung dieselbe Geltung beigemessen wird, sondern in der die Hierarchisierung durch den Kenner der Rezeption durch den Laien vorausgeht. Das Museum macht Dinge zu Museumsdingen, aber damit es diese Transformation vollziehen kann, muss zunächst die Vorstellung etabliert sein, dass a priori alle Dinge gerade nicht gleich sind, dass bestimmten materiellen Gegenständen eine Qualität anhaftet, die sie von anderen Dingen abhebt und ihre Musealisierung ermöglicht und rechtfertigt. Diese virtus ist ihr Charakter als Überrest einer Vergangenheit, die selbst per Definition keinen Bestand mehr haben und nur als \Geschichte〈 fortbestehen kann, die laufend produziert und zukunftsfähig gemacht werden muss. Das Museum verbürgt zwar als Asservatenkammer der Geschichte die Tatsache, dass es eine Vergangenheit gab, aber weil es keine Universaldarstellung leisten kann, muss es sich in eine kontinuierliche und kontingente historische Wirklichkeit eingliedern, die es nicht aus sich selbst heraus erzeugen kann.

Ranking- und Empfehlungsalgorithmen stellen dagegen die Rezeptionssituation allen Relevanzurteilen voran und schalten jedweder Hierarchisierung eine grundsätzliche Nivellierung vor. Diese besteht darin, dass sie jedes kulturelle Vorurteil von Informationen hinwegwaschen: Für eine Suchmaschine ist kein digitales Objekt aus sich heraus >besser< oder >schlechter als ein anderes. Das Geschirr, das man im Onlinekaufhaus bestellen kann, besitzt keinen ausgewiesenermaßen höheren Stellenwert als das, das es im Antikenmuseum zu besichtigen gibt, das Facebookposting über die Party am vergangenen Wochenende ist für sie von keiner Instanz mit größerer Bedeutung ausgestattet als das Goethe-Gedicht, das ulkige Youtube-Video nicht wichtiger als Citizen Kane, der Webcomic nicht mehr oder weniger schön als die Gemälde der flämischen Meister. Was die Suchmaschine uns anbietet, ist eben niemals eine im klassischen Sinne des Wortes kuratierte Auswahl. 
Virtuelle Museen müssen also idealerweise Web-Architekturen ausbilden, die sie von Auffind- und Ordnungssoftwares soweit abtrennen, dass sie ein Modicum an inhaltlicher und pädagogischer Souveränität zu bewahren imstande sind. Zugleich aber gilt es auch, zumindest so viel Anbindung an diese zu ermöglichen, dass ihre Auffindbarkeit gewährleistet ist - und damit ihre Fähigkeit, in der Aufmerksamkeitsökonomie des Webs zu bestehen. Ist diese Voraussetzung nämlich nicht erfüllt, dann steht infrage, inwiefern der finanzielle und personelle Aufwand für ein Digitalisierungsprojekt überhaupt zu rechtfertigen wäre. Museen müssen also mediale Strategien für den Umgang mit dem Web entwickeln, die beiderlei ermöglichen: einerseits die Schaffung eines virtuellen `Raumes`, in dem sich kuratorische Autorschaft in der Gestaltung von Webseiten ebenso manifestieren und mitteilen kann wie in der Topologie ihrer Verlinkung untereinander, andererseits die Öffnung dieses Raumes hin zu bestehenden Mechanismen, die über Relevanz, Marginalität und schlicht Sichtbarkeit im Web entscheiden. Indes verstecken sich die neuen Akteurskonstellationen der Museumsvirtualisierung nicht nur in den Zugriffsmustern und Auswertungsalgorithmen von Suchmaschinen. Sie treten auch ganz offen in Erscheinung: nämlich in den zahllosen Laien-Projekten ohne jede institutionelle Anbindung, die im Netz als >virtuelle Museen auftreten.

Ende der 1990er Jahre betreuten Werner Schweibenz und James Andrews an der Universität von Missouri das sogenannte Kress Study Collection Project, das im Ansatz die Schaffung eines imaginären Museums in bester Manier Malrauxs mit digitalen Mitteln zum Ziel hatte. Dreh- und Angelpunkt dieser Unternehmung war die Sammlung des 1955 verstorbenen amerikanischen Unternehmers Samuel H. Kress, der zu Lebzeiten mehr als 3.000 italienische Kunstwerke angehäuft und diese verschiedenen Museen vermacht hatte. Andrews' und Schweibenz' Projekt befasste sich spezifisch mit einen Kernbestand von 224 Gemälden, die als für Museen ungeeignet befunden worden und im Besitz der Kress Foundation verblieben waren. Diese den Kress'schen Nachlass verwaltende Stiftung wiederum hatte die Gemälde auf Schausammlungen an Universitäten in 19 amerikanischen Bundesstaaten und auf Puerto Rico verteilt, die als Kress Collections bezeichnet wurden. Das Kress Study Collection Project sollte nun die Aufgabe haben, diese geographisch weit verteilte Sammlung virtuell wieder zusammenzuführen und in einer gemeinsamen Datenbank online als Ganzes erfahrbar zu machen (vgl. Andrews u. Schweibenz 1998: 5f.).

Andrews und Schweibenz zeigten bei der Durchführung dieses Virtualisierungsvorhabens beeindruckt davon, wie niedrig die Zugangshürden für die Schaffung eines musealen Webauftrittes tatsächlich sein können. Die Umsetzung des Kress-Projektes gelang mit einer durchaus haushaltsüblichen Hard- und Softwareausstattung, verbunden mit der Arbeitskraft einiger engagierter Freiwilliger. Es zeigte daher gerade in seiner Konfrontation musealer Inhalte mit der Funktionalität des WWW die Weite der Diskrepanz zwischen der Offenheit des Netzes und der Abgeschlossenheit des klassischen Museumsdispositivs auf. Diese enorme Zugänglichkeit auf technischer 
und personeller Ebene birgt für Andrews und Schweibenz das eigentlich revolutionäre Potential des Virtuellen Museums, das nicht in der Aussicht auf Universaldarstellung in Abbildung, sondern in jener auf eine Demokratisierung der Museumslandschaft liege. Und wenn grundsätzlich jede Privatperson ein Angebot ins Netz stellen und dieses als >virtuelles Museum < bezeichnen kann, dann müsse dies nach Andrews und Schweibenz in irgendeiner Form eine Aufweichung des Museumsbegriffes schlechthin nach sich ziehen (vgl. ebd.: 10f.). Insofern ist das Web also kein Phänomenbereich, dessen Auswirkungen sich in jenen auf einzelne Museen im Hinblick auf ihre individuellen Vermittlungsabsichten erschöpfen würden. Vielmehr verhandelt jeder Museumsauftritt im Web implizit mit, was ein Museum ist, sein könnte und sein sollte. Das virtuelle Museum lehnt sich begrifflich an die Autorität einer Institution an, welche es zugleich durch seine bloße Existenz zur Disposition stellt.

Diese Feststellung führt uns zurück zu Steve Woolgars erster Regel der Virtualität, der zufolge Ablauf und Akzeptanz von Virtualisierungsvorgängen stark sozial situiert sind. Andrews und Schweibenz unterstreichen diese Einschätzung mit der bezeichnenden Beobachtung, dass es aus der breiten Mitte der Gesellschaft und damit dem von der Institution Museum anvisierten Publikum heraus keine vehemente Kritik an der Museumsvirtualisierung gebe. Zweifel und Vorbehalte gegen die Ausweitung musealer Präsentationsbestrebungen in den Cyberspace kämen vielmehr aus den Reihen der Vertreter und Bediensteten existierender physischer Museen (vgl. ebd.: 21). Wiederkehrende Motive sind dabei in der museumspraktischen und -wissenschaftlichen Fachliteratur eben der Verlust des Materiellen und damit der Authentizität (vgl. Waidacher 2000: 7) und die Besorgnis um eine Autorschaft, die erstens in der kulturellen Welt und zweitens speziell in der Expertise von Kuratoren verortet ist, welche sowohl in der Thematik der Ausstellung als auch in der Museumspädagogik formal ausgebildet sind (vgl. Parry 2006: 52ff.).

Im Folgenden wird der Blick darauf gerichtet werden, welche technisch-medialen Strategien virtuelle Museen tatsächlich anwenden (und anwenden können), um die Attribute physischer musealer Ausstellungen - Authentizität, auratische Anmutung, kuratorische Autorschaft, Abgrenzung von der sprofanen Welt‘, usw. - im Web zur Geltung zu bringen. Dabei wird ein besonderes Augenmerk zu einen darauf liegen müssen, wo hier Potentiale zur `Aneignung` der Qualität des Musealen durch Akteure liegen, die selbst außerhalb der klassischen Institution und des klassischen Dispositivs `Museum $`$ agieren. Zum anderen wird es aber auch erforderlich sein, die Grenzen, Brüche und Dysfunktionalitäten des Unterfangens aufzuzeigen, dem Netz museale Paradigmen der Vermittlung von Wissen und `Erlebnissen` aufzusetzen. Es wird also um die Beantwortung der Frage gehen, was genau im Diskurs der Museumsvirtualisierung als $>$ Musealität $\iota$ verhandelt wird bzw. inwiefern die Eigenlogik des digitalen Mediendispositivs eine solche zu tragen imstande ist - und damit natürlich auch darum, ob und wo in diesem Grenzbereich die Rolle und Funktionalität des Museums womöglich komplett neu gedacht werden müssen. 


\subsection{MUSEUM UND WEB: ZWEI ABDUKTIVE PARADIGMEN}

Als eine (wenn nicht gar die) zentrale Herausforderung an ein virtuelles Museum muss dabei wohl das Bestreben gelten, dem User innerhalb seiner >Grenzen ২ die Abduktionsbedingungen des Web abzugewöhnen und ihn wieder zum Flaneur und Detektiv, ihn also zu einem bewussten Betrachter werden zu lassen. Das Web mit seiner Fülle digitaler Bildwelten und seinen hocheffizienten Navigationswerkzeugen habe, so eine These Anette Spohns aus den frühen 2000er Jahren, in den Nutzern einen Habitus des Sehens (oder genauer: des Übersehens) kultiviert, der ganz anders funktioniert als jener, den das Museum bei seinen Besuchern anzustoßen versucht: Das Überangebot von Reizen habe den >langen Blickı und die Suche nach dem »optisch Unbewußten« Walter Benjamins (Benjamin 2008/1935: 36) zu einem Luxus werden lassen, den wir uns im alltäglichen Umgang mit Informationstechnologien kaum mehr leisten könnten. Stattdessen ginge es vor allem darum, in der Rezeption laufend all das auszusieben, was für uns nicht unmittelbar anschlussfähig ist (vgl. Spohn 2002: 268f.).

In ihrem 1994 - fünf Jahre vor Google - erschienenen Buch Data Trash identifizieren Arthur Kroker und Michael A. Weinstein narrowcasting (ohne selbst diesen Begriff zu benutzen) als eine Verführungsstrategie des Netzes, die den Rezipienten zum Konsumenten mache. Im Web, so ihre These, vervollkommne sich das aus dem Konsumentenkapitalismus geborene »possessive individual«: Alle nur vorstellbare Information scheint dem Anwender zur Verfügung zu stehen und nur darauf zu warten, von ihm ergriffen und in Besitz genommen zu werden. Dabei werde er aber zugleich ganz unmerklich seinerseits von Information besessen (vgl. Kroker u. Weinstein 1994: 9). Der Computer, so postulieren Weinstein und Kroker, ist in dieser Situation nicht nur ein Instrument zur Nutzung des Netzes und zur Visualisierung von Interfaces, sondern er nimmt die Funktion eines medizinischen Messgerätes an, das ständig die Befindlichkeiten seines Anwenders protokolliert und an bestimmte, ihm übergeordnete Autoritäten weiterleitet. Den bereits diskutierten Nutzerrollen von Flaneur und Detektiv fügen Kroker und Weinstein damit eine dritte, weniger positiv belegte hinzu: die des Patienten, dem laufend das zugeführt wird, von dem die technische Anordnung annimmt, er bräuchte es. Gottfried Korff hat bei seinem Versuch einer Übertragung der Experimentalsystem-Vorstellung Hans Jörg Rheinbergers auf das Museum ja bereits die Problematik des unscharfen Übergangs zwischen epistemischen und technischen Dingen in die Museologie eingeführt. Im Netz gehen nun nicht mehr nur technische und epistemische Dinge prozesshaft ineinander über, sondern die technischen Dinge verschmelzen nicht selten mit der Figur des Experimentators - oder eben des Kurators.

Unter diesen Voraussetzungen präsentiert sich das Moment der Abduktion im Web als eine Umkehrung seiner Entsprechung im Museum. Museen existieren als 
Anschauungs- in einer Welt der Aktionsräume: Sie differieren von anderen, sie umgebenden sozialen Räumen also darin, dass sie die in ihnen enthaltenen Dinge als Objekte der Betrachtung und damit auch der Bedeutung ausweisen - im Gegensatz zu Objekten der Nutzung und der Arbeit, wie sie unsere Alltagswelt belegen. Das virtuelle Museum dagegen existiert in einem Milieu, in dem grundsätzlich alles Information, alles also Nachricht ist. Entsprechend dürfen wir davon ausgehen, dass das Netz uns immer etwas mitzuteilen hat. Dies ist in seiner assoziativ-navigierbaren Verfasstheit bereits angelegt und wird verschärft durch die (den kulturellen Inhalten selbst völlig indifferent gegenüberstehenden) Navigatoren, wie etwa den Suchmaschinen. Das Erscheinen einer Seite von Google-Treffern auf einem Monitor ist ein Abduktionsmoment par excellence, denn es garantiert dem User nicht nur, dass die untenstehenden Seiten ihm etwas Verständliches zu kommunizieren haben, sondern auch, dass dieser Inhalt in direktem Zusammenhang mit einer dem System gegenüber geäußerten Interessenlage steht.

Damit geht es also abermals um den musealen Raum und die Möglichkeit oder Unmöglichkeit, ihm im Cyberspace eine Entsprechung zu schaffen - in Form einer kommunikativen Situation, die eben nicht das komplette restliche Web mitbeinhaltet, sondern Grenzen wahrt, in denen kuratorische Gemachtheit erkennbar und interpretierbar ist, von wem sie auch immer ausgehen mag. Die Abduktion darf daher nicht nur darin bestehen, dass dem Rezipienten klar ist, dass Kommunikation stattfindet, sondern dass es innerhalb eines bestimmten Gefüges von Webseiten eine Vermittlungsabsicht gibt, die sich zwar an ihn richtet und ihn zu ihrer Deutung ermutigt, jedoch ausdrücklich keine Wunscherfüllung sein will. Die Idee des virtuellen Universalmuseums krankt letztlich daran, dass sie tatsächlich die Logik des Museums jener des Archivs unterordnet. Nach Gottfried Korff ist neben der Natur der gesammelten Objekte der entscheidende Unterschied zwischen Museen und Archiven nämlich jener, dass das Archiv eine Vollständigkeit anstrebt, die vom Museum weder zu bewerkstelligen noch seinem gesellschaftlichen Auftrag zuträglich wäre. Wie im ersten Kapitel der Studie ja bereits dargestellt wurde, verortet Korff den Wert des Museums nicht in seiner Fähigkeit zur umfassenden Darstellung, sondern in seinem Vermögen, zu >schocken < - und damit eben die historische Vorstellungskraft seiner Besucher auf Arten anzuregen und herauszufordern, auf die sie außerhalb der Ausstellungssituation nicht herausgefordert werden würde (vgl. Korff 2007: 120). Die vorliegende Studie hat verschiedene Ansätze vorgestellt, um den in der museologischen Literatur ubiquitär diagnostizierten Bruch zwischen physischem und virtuellem Museum, der im Verlust des materiellen Originals besteht, ins Verhältnis zu setzen zu einer meist übersehenen Kontinuität von Vernetzung, Navigation und Kontextabhängigkeit, die das Museum und das Web in Geschichte und Gegenwart teilen. Mit Rückblick auf die bisherigen Ausführungen zur Geschichte des Museums und des Webs drängt sich nun folgende Hypothese darüber auf, warum diese ominösen Parallelen 
zwischen der medialen Logik der beiden Dispositive bisher so hartnäckig übersehen wurden: Web und Museum gehen genau gegensätzlich mit ihnen um.

\subsubsection{Das Museum der Fragen und das Web der Antworten}

Museen sind in ihrer Existenz natürlich davon abhängig, dass Besucher sich für ihre Ausstellungen interessieren - aber ihr gesellschaftlicher Auftrag besteht eben gerade nicht darin, die naheliegendsten Antworten auf die Fragen ihres Publikums zu liefern und ihm bestehende Annahmen über die Vergangenheit zu bestätigen. Die museale Abduktion, welche durch die in der räumlichen Trennung von der Außenwelt abgebildete Institutionalisierung gewährleistet wird, schafft zugleich die Voraussetzungen für Unverständnis und Irritation überall dort, wo das Authentizitätsversprechen des Museums mit dem kollidiert, was der Besucher über die historische Welt zu wissen glaubt. Das Web und die Hypertextsysteme, die ihm vorangegangen sind, stehen hingegen in einer Ideengeschichte des unbedingten Anschlusses. Von den Zettelkästen des 19. Jahrhunderts über Vannevar Bushs und Ted Nelsons gleichermaßen im Ideenstadium verbliebene >Memex «- und `Xanadu<-Projekte bis hin zu Googles immer noch andauerndem Siegeszug über alle konkurrierenden Suchtechnologien hat hier immer ein Paradigma der Auffindbarkeit und der Folgerichtigkeit im Mittelpunkt gestanden. Zwar hat künstlerisch intendierte Hypertext-Literatur immer wieder Möglichkeiten ausgelotet, mittels modular vernetzter Texte Leser irrezuführen und mit der Möglichkeit des \Scheiterns am Versuch der Sinnstiftung zu konfrontieren (vgl. Aarseth 1995; vgl. Douglas 1995), aber in der Geschichte der wissenschaftlichen, didaktischen und kommerziellen Nutzung von Hypertextsystemen ist das gegenteilige Bestreben tonangebend. Daraus ergibt sich auch ein ganz bestimmtes Rezipientenbild, welches möglicherweise daraus resultiert, dass diese Systeme vor dem takeoff des World Wide Web in den 1990er Jahren überwiegend von Experten für andere Experten gedacht wurden: Sie setzen meist einen souveränen und gebildeten Nutzer voraus, der recht gute Vorstellungen davon hat, was er braucht - und wollen ihn dabei unterstützen, es zu finden und verfügbar zu halten. Auch wenn das WWW heute Massenmedium ist und der User, der ein Thema googelt, in den meisten Fällen wohl gerade kein Experte für selbiges sein (oder werden wollen) wird, klingt diese Vorstellung immer noch nach. Man mag in Googles kultureller und technischer Programmatik, entsprechend der Lesart Weinsteins und Krokers, eine Degradierung des Nutzers zum invaliden Patienten sehen, der an ihrem informativen Tropf hängt - man kann in Google Search aber auch eine Technologie erkennen, die ihren Nutzer als einen Kunden respektiert, dessen Motivationen und Interessenlagen zu hinterfragen sie sich überhaupt nicht anmaßt.

Das Museum hingegen ist seinem Selbstverständnis nach eine Bildungsstätte und muss didaktische Programme nicht für Einzelpersonen, sondern für ein extrem weit 
gedachtes Publikum entwickeln. Dabei gründen sich diese Programme seit seines institutionellen Kindesalters auf die Annahme, dass es dem Besucher etwas beizubringen gilt - über Kultur, Natur, Geschichte, Gegenwart, womöglich gar über sich selbst -, das er erstens noch nicht weiß und von dem er zweitens möglicherweise auch noch gar nicht weiß, dass man es wissen könnte. Genau an dieser Stelle kann der von Korff beschriebene \Schock` eintreten, der im Idealfall natürlich ein heilsamer wäre: Die von Korff propagierte Museumspädagogik will dem Besucher nicht das geben, was er will, sondern das, was er (zumindest ihrer Ansicht nach) braucht - unter der Annahme, dass er sich über Letzteres selbst weder im Klaren ist noch sein kann (vgl. Korff 2007: 120).

$\mathrm{Zu}$ diesem Bildungs- und Erziehungsauftrag gesellt sich im Museum eine affektorientierte Performanz, die Gottfried Korff und Heinrich Theodor Grütter mit ihrer Analogsetzung des Kurators zum Theaterregisseur scharfstellen: Inszenierungen beziehen ihren Wert ja gerade aus ihrer spezifischen Beschaffenheit, ihrem >So-UndNicht-Anders $ৎ$, in der sich ein ganz bestimmtes Verhältnis von Aktualität zu Virtualität manifestiert. Das Theater bietet seinem Publikum nicht einfach Goethes Faust, sondern Faust gefiltert durch die Interpretation dieses oder jenes Regisseurs, unter Mitwirkung dieser oder jener Schauspieler, dieser oder jener Bühnen- und Maskenbildner, usw. Diese Form der Autorschaft ist hier kein notwendiges Übel, keine bloße Verwaltung von Möglichkeitspotenzialen für begrenzte (Zeit-)Räume der Darbietung. Sie ist vielmehr die Bedingung aktuellen Erlebens: Das Theaterstück existiert ja als solches erst, wenn es gespielt oder aufgeführt wird, seine Niederschrift stellt lediglich die virtuelle Voraussetzung seiner Wiedergabe als Zeitobjekt dar. Im Museum manifestiert sich eine solche Autorschaft notwendigerweise in einer Verweigerung von Verfügbarkeit, und diese Verweigerung soll nicht nur erzieherischen Mehrwert haben, sondern macht womöglich auch einen erheblichen Teil des ästhetischen und dramatischen Reizes einer Museumsausstellung aus. Den Erfolg einer solchen Ausstellungsphilosophie unterstreichen Ergebnisse aus der amerikanischen Besucherforschung der 1950er Jahre: So stellte die LA Times 1957 fest, dass nach explizit in Besucherbefragungen geäußerten Wünschen angelegte Ausstellungen vom Publikum tatsächlich nicht positiv aufgenommen, ja bisweilen als langweilig und uninteressant erlebt wurden (vgl. Redman 2010: 4).

\subsubsection{Die Individualisierung der Dinge im Museum}

Indes kann gerade dieses affektive Moment auch eine Überschreibung aller Reflexionspotentiale bewirken. Paradoxerweise neigen gerade konservative Museumskonzepte mit straffer kuratorischer Programmatik und hoher Betonung von Authentizität und auratischem Erlebniswert dazu, die Gemachtheit der Ausstellung zu verschleiern - und damit auch den virtuellen Charakter der Ausstellungsstücke. Ulfert Tschirner 
sieht hier eine Fetischisierung der Dinge durch die Kuratoren am Werk, welche an die Besucher weitertradiert wird, und im Zuge dieser Fetischisierung kommt es seines Erachtens zu einer Verwechslung von Medium und Nachricht: Wo das Museum sich darauf kapriziert, über Originalgegenstände auratische Erfahrungen vermitteln zu wollen, da sind die Exponate eben nicht länger Medium einer differenzierten und womöglich gezielt desorientierenden Auseinandersetzung mit abstraktem Wissen, sondern werden selbst zur Botschaft - und zwar zu einer Botschaft, die sich unverhandelbar auf das beschränkt, was im Augenblick der Konfrontation mit dem Gegenstand erlebt und empfunden wird (vgl. Tschirner 2011: 15). Die kuratorische Autorschaft macht sich so gewissermaßen selbst überflüssig, weil sie das Objekt zu etwas erhebt, das ihrer nicht länger bedarf. Die komplexen Abhängigkeitsgefüge einer kuratierten Ausstellung können eigenartigerweise Exponate entstehen lassen, die gerade aus ihren musealen Bindungen heraus autonom erscheinen.

Tschirner sieht in Gottfried Korffs Begriff des >Museumsdings` und seiner großflächigen Verwendung in der deutschen Museumswissenschaft ein Symptom dieser Art, Ausstellungsstücken gegenüber zu treten. Das Museumsding beziehe als Konzept zwar die Medialität der Objekte durchaus ein, begreife diese aber vorrangig als ein Vehikel für das emotional ergreifende Erleben von materieller Echtheit und Authentizität - womit das Korffsche Museumsbild sich logischerweise selbst untergraben müsse. Tschirner setzt dem Museumsding daher seinen eigenen Begriff des »MedienObjekts « (ebd.: 16) entgegen, mit dem er gerade das transformative Element des Wechselspiels von Ding und Ausstellung greifbar machen möchte und das Museumsexponat als eine Projektionsfläche für Kuratoren- und Rezipientendiskurse ins Zentrum der Analyse stellt, gerade aber auch die von Reproduktionen gewährleistete Präsenz des Objektes in der Außenwelt als konstitutiven Bestandteil seiner musealen Existenz begreift. Bezeichnenderweise ist es für Tschirner dabei der Blick über die konkrete Ausstellungssituation hinaus auf die medialen Bedingungen der Verwaltung von Sammlungen und auf den Umgang mit Reproduktionen in der Alltagswelt, unter dem diese inneren Widersprüche musealer Präsentationspraktiken erkennbar werden.

Wenn eine rigide, inszenatorische Ausstellungspraxis kulturelle Sinnmodule entstehen lässt, welche die Bedingungen der Abduktion schon aus sich selbst heraus erfüllen und nicht länger durchblicken lassen, wie sehr sie das Produkt von Darbietungsmodalitäten sind, dann schafft sie entgegen aller Intuition womöglich auch gerade die Voraussetzungen für eine Verwaltung kultureller Inhalte durch völlig kulturfremde Computersysteme. Sie definiert gewissermaßen a priori, welches die Knotenpunkte im Netzwerk des Museums sind - ohne deutlich werden zu lassen, dass die Exponate tatsächlich ihrerseits abermals Netzwerk-Merkmale aufweisen, dass sie das Produkt möglicher Deutungszugänge und Präsentationsmodalitäten sind, ja dass ihr >inneres Netz der Sinnzuschreibungen tatsächlich eng verwoben ist mit dem >äußeren der Ausstellung. Die Mona Lisa ist nicht aus ihrer materiellen Wesensart als 
bemalter Leinwand heraus die Ikone der abendländischen Kultur, als die wir sie typischerweise verhandeln, sondern sie wird im Gefüge einer performativen Medienpraxis dazu gemacht. Sie ist nicht nur das Gemälde an der Wand, sondern sie ist die sie umgebende Ausstellungssituation des Louvre und darüber hinaus auch das Ergebnis ihrer massenmedialen Präsenz im Imaginären Museum - und damit das Produkt der Erwartungshaltung von Millionen Besuchern, die sich das Original in Paris anschauen. \Die Mona Lisa< im Sinne des Originalwerkes ist gewissermaßen der materielle Sockel eines komplexen Phänomens, das sich ganz überwiegend in völliger Abwesenheit des Originals konstituiert. Dennoch wird man kaum eine lexikalische Definition der Mona Lisa finden, die sie als etwas anderes erfasst als eben eines der zentralen Werke der Malerei der italienischen Renaissance.

So entstehen >Kulturbausteine`, die sich hervorragend zur Transposition in digitale Attributobjekte eignen. Um zum vorherigen Beispiel zurückzukehren: In absehbarer Zeit wird kein Computer ein Theaterstück inszenieren können, weil ein Theaterstück nur sehr begrenzt in Einzelelemente diskretierbar ist. Natürlich lassen sich in Narrativen funktionale Einheiten bestimmen - z.B. Charaktere, Handlungsorte und -zeiträume oder Ereignisse - aber diese gehen üblicherweise auf Arten ineinander über und auseinander hervor, die nach menschlicher Sinnstiftung verlangen. Unser materielles Kulturerbe hingegen ist schon aus dem Museumsdiskurs heraus weitgehend diskretiert - in singuläre, monumentale Einzelgegenstände, deren materielle Abgeschlossenheit und Begrenztheit die ihnen inhärente Beweisführung für das zu sein scheint, als was wir sie wahrzunehmen gelernt haben.

\subsection{IKURZER KOPF، UND ,LANGER SCHWANZ، DES KULTURELLEN BEWUSSTSEINS}

Wollten virtuelle Museen dementsprechend lediglich Deutungen und Verständnisse von Kulturgegenständen perpetuieren, die ohnehin bereits als fest im kulturellen Bewusstsein ihrer Zielgruppen vorausgesetzt werden dürfen, würden sie sich in letzter Konsequenz per ihrer Redundanz zu bestehenden Navigationswerkzeugen im Web obsolet machen. Wenn es nur darum ginge, innerhalb einer bestehenden Interessenlage Erwartungshaltungen zu erfüllen, dann wäre jede Bemühung um ein museales Moment im Web letztlich eine personell extrem aufwändige Wiederholung dessen, was Analytics-Dienste ganz ohne menschliches Eingreifen zu leisten imstande sind: Nämlich einen in relativen Zahlenwerten erfassbaren `Konsens` eines völlig ungefilterten Publikums darüber abzubilden, was kulturell in welchem Maße zusammengehört.

Das folgende Beispiel mag dies veranschaulichen: Der Verfasser dieser Studie googelt am Abend des 26. Juli 2015 den Begriff Mona Lisa. Die ersten zehn ihm 
gezeigten Suchergebnisse sind in der Reihenfolge absteigender Relevanz: erstens der deutsche Wikipedia-Artikel über die Mona Lisa; zweitens die Homepage des ZDFMagazins Mona Lisa; drittens die vom Berliner Turandot-Verlag betriebene Webseite $w w w$.die-mona-lisa.de; viertens ein auf www.ruhrnachrichten.de veröffentlichter Artikel über die Ausstellung eines Faksimiles der Mona Lisa im Oberhausener Gasometer; fünftens die Homepage des ebenfalls in Oberhausen ansässigen Fliesenlegerbetriebes Mona Fliesa; sechstens ein auf www.bild.de veröffentlichter Artikel darüber, ob das berühmte Gemälde möglicherweise ein außerirdisches Wesen zeigt; siebtens ein weiterer, der postuliert, die Dargestellte sei DaVincis Mutter; achtens die Homepage des Modehändlers www.interchic.de, der unter dem Label Mona Lisa Damenmode in Übergröße vertreibt; neuntens ein Beitrag auf www.focus.de über die mögliche (nicht-außerirdische) Identität der Gioconda und zehntens schließlich ein kurzer Artikel auf der Seite www.medienwerkstatt-online.de, welche sich vor allem an Schüler richtet. Obwohl der Louvre selbst eine Homepage mit virtueller Sammlung betreibt, taucht die dort der Mona Lisa gewidmete Seite ${ }^{1}$ erst auf der fünften Seite der Trefferliste auf. Ändert man die Suchanfrage in Mona Lisa Louvre, so rückt diese Seite zwar auf die zweite Position, erreicht aber immer noch nicht die Relevanz des Wikipedia-Artikels.

Das Museum, das das Original besitzt und obendrein auch noch im Web präsentiert, steht mit seiner Webseite also nicht allzu hoch in der Gunst des Publikums. Dies mag auf den ersten Blick überraschen, wird allerdings nachvollziehbar, wenn man sich die der Mona Lisa gewidmete Seite der Louvre-Homepage genauer ansieht: Sie besteht aus einer kurzen technischen Beschreibung des Werkes (Titel, Entstehungszeitraum, Abmessungen und Standort im physischen Louvre), drei kurzen Absätzen zu Geschichte und Rezeption, eine Auflistung gedruckter Referenzliteratur und eine per Flash-Applikation eingebundene Zusammenstellung von Bildmaterial, bestehend aus einer Gesamtdarstellung und einigen Detailansichten. Das Textvolumen der Beschreibung nimmt sich ähnlich klein aus wie die niedrig aufgelösten Bilder, die aufgrund ihrer Einbindung via Flash auch nicht ohne weiteres vom Nutzer heruntergeladen werden können. Die Homepage des Louvre verzeichnet darüber hinaus die verfügbaren Werke lediglich nach Sammlungen (z.B. Gemälde, Skulpturen, Drucke, Antiquitäten ${ }^{2}$ ), ohne sie untereinander zu verlinken. Die Mona Lisa steht hier also in sehr kleiner Abbildung mit sehr begrenzter Erläuterung völlig für sich allein. Der die Google-Trefferliste für die Suche nach Mona Lisa anführende Wikipedia-Artikel allein überbietet das Angebot des Louvre um ein Vielfaches: Er enthält umfassende Informationen über Geschichte und Rezeption des Kunstwerkes, einen Verweiskatalog, der nicht nur auf gedruckte Literatur verweist, sondern auch eine Anzahl von

1 http://www.louvre.fr/en/oeuvre-notices/mona-lisa-portrait-lisa-gherardini-wife-francescodel-giocondo vom 19.05.2018.

2 http://www.louvre.fr/en/departements vom 19.05.2018. 
Links enthält, mittels derer der Nutzer sofort auf andere Webseiten springen kann, ist mit der auf Wikipedia üblichen Querverweisstruktur versehen und beinhaltet nicht zuletzt eine Abbildung des Werkes in einer Auflösung von stolzen 7.479x11.146 Pixeln, die von jedermann heruntergeladen werden kann und darf. ${ }^{3}$ Die anderen Google-Treffer mögen hierzu bisweilen redundant oder gar absurd erscheinen, weiten aber immerhin den Blick auf die ganze Breite kultureller Reaktionen auf die Mona Lisa. Das Feedback-Feld, dass zu jeder Google-Suche nach populären Begriffen neben der Trefferliste erscheint, zeigt zugleich wichtige Ergebnisse aus der Bildersuche an und weist darauf hin, dass Suchen nach der Mona Lisa häufig mit Suchen nach DaVincis Abendmahl, der Dame mit dem Hermelin, dem Vitruvianischen Menschen, der Felsgrottenmadonna, aber auch mit Edvard Munchs Schrei einhergehen. Verblüffender- (und für den Louvre womöglich blamabler-)weise leistet die Software hier also etwas, was die menschlichen Webmaster auf der Louvre-Homepage nicht zu leisten imstande waren, sie ordnet die Mona Lisa nämlich in kulturell völlig plausible und nachvollziehbare Zusammenhänge ein - und der Besuch auf der von Menschen kuratierten Museums-Webseite hat tatsächlich keinerlei Mehrwert gegenüber der maschinellen Suche.

\subsubsection{Chris Andersons /Long Taik-Theorie}

Entsprechend ist die von Korff geforderte Schockfunktion des Museums für virtuelle Museen möglicherweise mehr als nur eine didaktische Philosophie unter vielen, sondern eine notwendige Modalität der Abgrenzung gegenüber all dem, was im Web längst >von allein ‘ geschieht. Wenn Computersoftware imstande ist, für Menschen verständliche kulturelle Zusammenhänge aus massenhaft erhobenen Zugriffsmustern herauszurechnen und an die Nutzer zurückzuspielen, dann müsste sich menschliche Autorschaft im Cyberspace eben gerade darin manifestieren, dass sie Inhalte >gegen den Strich einer solchen mechanischen Sinnstiftung bürstet. In einem Web, in dem die problemlose Anschlussfähigkeit alles Gefundenen an beim User bereits vorhandene Wissensbestände als Normalzustand vorausgesetzt werden kann, wäre gerade das Auftreten von Sinnstrukturen jenseits des Erwartbaren eine deutliche Indikation für das Wirken einer personellen Autorschaft und ein Argument für den Blick über den Tellerrand der ersten Google-Treffer.

Die entscheidende Frage wäre hier natürlich, wo im Web solche Freiräume für Irritationen und Überraschungsmomente noch bestehen, wenn - so lautet ja Yevgeny Morozovs Diagnose unserer digitalen Befindlichkeit - die Informationskanäle des Webs bereits in ähnlicher Weise begradigt sind wie die Boulevards im Paris Napoleons III. und alles, was uns online widerfährt, längst sozialisiertes Erleben ist ohne Raum für das Private und Verinnerlichte. Eine Antwort hierauf liefert womöglich

3 https://de.wikipedia.org/wiki/Mona_Lisa vom 18.05.2018. 
gerade jenes ökonomisierte und an Marktprozessen orientierte Verständnis von den Funktionalitäten des WWW, in welchem Morozov die Ursache seiner Kolonisierung durch privatwirtschaftliche Kräfte und der Nivellierung seiner ehemals fein nuancierten Kommunikationslandschaften ausmacht. In seinem 2006 erschienen Buch The Long Tail entwirft der ehemalige WIRED-Redakteur Chris Anderson ein Bild von der Ökonomie des Webs, das ganz gezielt all jene Angebote in den Mittelpunkt des Interesses stellt, die nicht im Brennpunkt kybernetisch fokussierter Nutzeraufmerksamkeit stehen. Anderson spricht hier vom »long tail« und benennt damit eine bestimmte Form von Pareto-Verteilung, die er erstmals 2004 in den monatlichen Verkaufszahlen des Musikportals Rhapsody beobachtete: Während eine relativ kleine Zahl hochaktueller und akut populärer Titel eine überproportional große Zahl von MP3-Verkäufen auf sich vereinte und damit den >kurzen Kopf ^ der Verteilung bildete, zeigte sich hinter dieser Ballung ein stetiger Abfall der Absätze über hunderttausende von Musiktiteln hinweg, der aber - und das ist entscheidend - kaum jemals tatsächlich die Nulllinie berührte. Anderson folgert aus dieser Beobachtung, dass es im WWW zwar eine Marginalität in Nischenmärkten, selten aber eine tatsächliche Obskurität gäbe. Auch die unpopulärsten Inhalte finden noch einen Rezipienten und der Grund hierfür ist seiner Einschätzung nach eben die schon mit Konrad Becker festgestellte Abwesenheit von >Regalen` im Web (vgl. Anderson 2007: 11). Ein Wirtschaftssystem, das auf »Hits« (nicht nur musikalischer Art) basiert, verdanke sich weitgehend der Tatsache, dass in der analogen Welt die Vermarktbarkeit von Gütern durch physikalische Größen eingeschränkt ist: Ein Supermarkt ist ein Gebäude mit begrenztem Rauminhalt und ebenso begrenzter Regalfläche, auf welcher entsprechend auch nur eine begrenzte Anzahl räumlich ausgedehnter Produkte angeboten werden kann. In einer materiellen Warenökonomie ist deshalb das, was nicht den Sprung in die Regale der Geschäfte schafft, unter Umständen überhaupt nicht zu erstehen. Ein Produkt, das nicht die notwendige kritische Masse erreicht, um sich aus der Marginalität zu erheben, ist wirtschaftlich allzu häufig schlicht nicht existenzfähig.

Das Internet hat diese Einschränkung Andersons Einschätzung nach weitgehend aufgehoben, und zwar nicht nur für Informationsgüter (die zuvor den Weg vom Produzenten zum Kunden auf materiellen Datenträgern zurücklegen mussten), sondern auch für klassische, dinghafte Waren, die nun in digitaler Effigie ausgestellt werden können und beim Händler nur mehr gelagert, nicht präsentiert werden müssen (so funktionieren ja sämtliche Internetkaufhäuser). Im Web steht nicht nur nahezu unbegrenzt >Platz`zur Verfügung - es verfügt darüber hinaus auch über Werkzeuge, um potenziell alle in ihm vorhandenen Informationen auffindbar zu halten, auch wenn sie nicht in den oberen Rängen von Suchmaschinen-Trefferlisten auftauchen (vgl. ebd.: 20). Das Problem aller physischen Ladengeschäfte ist ja nicht nur, dass sie nicht endlos viele Produkte in ihre Regale quetschen können, sondern auch, dass in diesen 
Regalen nicht alles vorn und auf Augenhöhe stehen kann. Nicht anders als das Museum ist der Supermarkt ein Dispositiv, das Sichtbarkeiten organisiert und Aufmerksamkeit kanalisiert. Mit dem Web tauchen Anderson zufolge nun nicht nur zuvor marginalisierte Waren und Inhalte auf dem metaphorischen >Radarı der Konsumenten auf, sondern es verändere schlechterdings das Wesen ganzer Marktwirtschaften. Im profitorientierten physischen Warenhandel wird der >lange Schwanz` vernachlässigt, weil man sich von ihm keinen Mehrwert verspricht. Ähnlich wie das Museum muss ein Geschäft Kompromisse im Hinblick auf die Gefälligkeit seines Angebotes für ein möglichst breites Publikum machen, anders als das Museum steht es dabei jedoch in keiner didaktischen Verantwortung. Es gilt, Verkaufsfläche optimal auszunutzen - und das heißt, sie möglichst mit Waren zu füllen, die vom Kunden schnell aufgekauft werden und ihren Platz wieder zur Neubefüllung freigeben. Unpopuläre Waren verwandeln die Regalfläche dagegen in toten Raum, long tail-Produkte stören den Warenumschlag. Normalerweise finden sie ihren Lebensraum daher vorrangig in kleineren, spezialisierten Geschäften, die sich bewusst abseits des Massenmarktes einnischen und in ihrer Rentabilität davon abhängig sind, ob sich ein ausreichend großes Publikum für ihre sehr speziellen Angebote in ihrem Einzugsgebiet befindet (vgl. ebd.: 192f.). Im Web hingegen verlieren nach Anderson solche Waren ihre prekäre Stellung. Zwar ist der potenzielle Markt für jedes individuelle Nischenprodukt sehr klein, aber in seiner Gesamtheit beschreibt der long tail ein enormes Absatzpotential, das womöglich jenes des short head noch übertrifft (vgl. ebd.: 24).

Mit diesem Wandel in den Voraussetzungen marktwirtschaftlicher Wertschöpfung sei über Kurz oder lang auch ein Wandel in der Art impliziert, wie wir uns zwischen kulturellen Angeboten zurechtfinden. Andersons Ansicht nach sind wir in unserer Wahrnehmung der uns umgebenden Welt durchdrungen von einem Dualismus aus »Hits« und »Flops« und damit der Vorstellung, dass letztlich kommerzieller Erfolg und Popularität kulturellen Wert abbildeten (vgl. ebd.: 46f.). Dieser Dualismus, der ursprünglich nur die Produzentenseite dahingehend betroffen habe, ob eine wirtschaftliche Unternehmung mehr oder weniger eingebracht als gekostet hat, sei über die medialen Kanäle der Vermarktung in unsere Alltagsbegrifflichkeiten eingesickert und entscheide nun darüber, worauf wir überhaupt noch unsere Aufmerksamkeit zu richten bereit sind. Die sich mit dem Web verbindende long tail-Ökonomie verfüge dementsprechend über das Potential, die wirtschaftliche Grundlage unseres kulturellen Erfahrungshorizontes komplett neu aufzustellen: weg von der Navigation zwischen Leuchttürmen des Interesses in einem Ozean des zu Vernachlässigenden, hin zur Zurechtfindung in einer rhizomatisierten Hügel- (oder eben: Plateau-)Landschaft der Optionen, die zwar nicht alle die gleiche Popularität genießen, aber alle sichtbar und erreichbar sind.

Das Web, so lässt sich damit Andersons These auf die vorliegende Studie übertragen, biete eben doch Räume für das Marginale, und damit auch für die Flanerie und zwar umso mehr, je weiter man sich von der kybernetisierten Verdichtung von 
Massenaufmerksamkeit im short head entfernt. Seine Navigationswerkzeuge und Ordnungsmechanismen neigen zwar dazu, Aufmerksamkeit auf bestimmte Brennpunkte hin zu bündeln, zugleich aber schafft das schiere Ausmaß der Möglichkeiten zur virtuellen Darstellung und Präsentation die Voraussetzungen für eine Sichtbarkeit von Inhalten, die in der physischen Welt gar nicht herzustellen wäre. Im narrowcasting sieht Anderson im Gegensatz zu Jeanneney nicht nur einen Mechanismus der Aussonderung und Verschleierung, sondern einen der Auffindbarmachung auch des Obskuren: Long tail-Inhalte sind im Netz nicht nur vorhanden, sondern potenziell immer auch für Suchmaschinen registrier- und innerhalb ihrer Auswertungsmaßstäbe anschließbar - was aufmerksamkeitsökonomisch womöglich immer noch günstiger ist als jede Form der Präsentation, die ihnen ohne Google zuteilwerden würde. Morozovs These von Tod des Cyberflaneurs liegt aus dieser Warte der Fehler zugrunde, dass sie in ihrer Vorstellung vom WWW die Raum-Metaphorik zu wörtlich nimmt. Das Web ist keine Stadt, der begrenzter Boden für ihr Wachstum zur Verfügung steht und in der die Seitenstraßen weichen müssten, um Platz für die Boulevards zu schaffen. Tatsächlich sind, wenn man Andersons Argumentation folgt, sowohl die Boulevard als auch die Seitenstraßen so gut besucht wie nie - worauf uns allerdings ein Fahrstuhleffekt den Blick verstellt. Besonderen Wert legt er hier darauf, festzustellen, dass die long tail-Theorie nicht nur für monetarisierbare Produkte und Dienstleistungen gilt, sondern grundsätzlich für alles, was im Internet angeboten und kommuniziert wird.

Dementsprechend erkennt er den long tail auch bei nicht profitorientierten Bildungs- und Kulturangeboten - so z.B. auf Wikipedia. Der lange Schwanz des Wissens besteht hier aus den tausenden von (teils überaus ausführlichen) Artikeln über randständige und obskure Themen, deren Relevanz sich auf sehr kleine Interessengruppen beschränkt und deren Aufnahme in eine gedruckte Enzyklopädie weder wirtschaftlich noch didaktisch zu rechtfertigen wäre. Auf Wikipedia indes ist für nahezu jeden Wissensgegenstand Platz - und eine Kombination aus >von Hand erstellten Querverweis-Links und guter Anbindung an die gängigen Suchmaschinen gewährleistet, dass auch diese Einträge gelesen werden, sei es vom etablierten, >detektivisch eingestellten Interessentenkreis, der bewusst nach ihnen sucht, oder von Web-Flaneuren, die schlicht beim Spiel der Assoziationen über sie stolpern. Dabei bedingt die grundsätzliche Offenheit Wikipedias, dass der long tail der freien Enzyklopädie laufend länger wird: Denn wer einen Eintrag zu seinem jeweiligen Steckenpferd vermisst, der kann ihn ohne weiteres selbst schreiben (vgl. ebd.: 78f.). Insofern sind die diversen long tails im Web immer auch Räume des Wachstums und Wandels, während die kurzen Köpfe als >Gondelenden` im Sinne Jeanneneys zur Selbststabilisierung neigen.

So schaffen sich long tail-Erscheinungen nach Anderson sowohl eigene Communities, als auch eigene Systeme der Belohnung und Vergütung, die oft gerade nicht über Geld funktionieren. Wikipedianer werden als freiwillige Helfer und Hobbyisten 
nicht finanziell entlohnt, ziehen aber dennoch einen Mehrwert aus ihrem Einsatz: Sie handeln Reputation und Aufmerksamkeit als immaterielle Währung. Damit bewegen sie sich gewissermaßen in einer Anerkennungs-Ökonomie, die sie wie eine Geldwirtschaft zur Anpassung an Angebot und Nachfrage zwingt. Das Prestige wird zum diskursiven Mittel der Verlinkung von Akteuren und gewährleistet, dass sie dort tätig werden, wo ihre Arbeitskraft gefragt ist (vgl. ebd.: 86f.). Die »Zuverlässigkeit«Wikipedias hängt nach Andersons Einschätzung von einer komplexen, kollektiven Intelligenz ab, welche aus diesem Dispositiv hervorgeht und die eben nicht mehr in klassischen Kategorien intentionalen Intellektes zu verstehen ist, sondern nur in Form statistischer Mustererkennung. Wikipedia lässt keine »Gewissheiten« im Sinne klassischer Enzyklopädien entstehen, die sich auf die Expertise benennbarer Autoren zurückführen ließen, sondern validiert Geltungsansprüche aus der auf Adam Smith zurückgehenden Vorstellung heraus, dass Kollektive in ihrer (ökonomischen) Verschaltung zwischen Individuen eine ganz eigene Intelligenz entwickeln (vgl. ebd.: 80f.). Obwohl die Wikipedia keinem individuell benennbaren Autor die Verantwortung für die innere Authentizität im Sinne einer >Wahrheit` zuweist, funktionieren ihre Kontrollmechanismen überraschend gut: Im Jahre 2007, als Anderson sein Buch über den long tail schrieb, betrug die durchschnittliche Korrekturzeit für Vandalismus an populären Artikeln etwa vier Minuten - und schon damals war Wikipedia der Britannica in Artikelzahl und durchschnittlicher Länge von Einzelbeiträgen etwa um ein Zehnfaches überlegen (vgl. ebd.: 83).

\subsubsection{Der slange Schwanzı als Problem und Chance für Museen}

Obwohl der Begriff des long tail Suzanne Keene 1998 noch nicht zur Verfügung stand, benennt sie aus ihren Beobachtungen zur Museumsvirtualisierung heraus zwei zentrale, von der Digitalisierung angestoßene Wandlungen in den Grundlagen der Kulturwirtschaft, welche Andersons Theorie schon antizipieren: sie spricht von mass customization und disintermediation. Mass customization beschreibt dabei nicht etwa das narrowcasting der Suchmaschinen und das Diktat ihrer sich selbst verstärkenden 》Cyber-Kaskaden « (Metahaven 2010: 211), sondern eine diesen gegenüberstehende Auswirkung veränderter Produktionsbedingungen: Virtuelle Güter lassen sich in viel kleineren Chargen kostengünstig herstellen als materielle, und müssen dementsprechend für den Markteintritt eine viel niedrigere finanzielle Zugangshürde überwinden. Das Angebot wird also breiter - während es für Konsumenten zugleich einfacher wird, sehr genau zu spezifizieren, was sie eigentlich haben möchten. Disintermediation wiederum meint einen zunehmenden Wegfall von Mittelsmännern, die in der physischen Warenwirtschaft notwendig sind, um Güter räumlich und rechtlich vom Produzenten zum Verbraucher zu bringen (vgl. Keene 1998: 111). Wenn z.B. eine Band ihre Musik als Download direkt über die eigene Webseite vertreibt, dann 
braucht sie weder einen Vertrag mit einem Label, noch Plattenläden, die physische Datenträger verkaufen. Große Warenhändler wie Amazon sparen sich mit dem digitalen Vertrieb den Druck von Katalogen oder das Betreiben von Ladengeschäften. Beide Phänomene, so stellt Keene fest, betreffen ganz unmittelbar auch das Museum, allerdings nicht nur im Hinblick auf seine Wirtschaftlichkeit, sondern auch bezüglich seiner ganzen institutionellen Festigung und personellen Ausformung (vgl. ebd.).

Der long tail scheint natürlich zunächst einmal genau jener Sektor der Informationswirtschaft im WWW zu sein, in welchem sich eine pädagogisch orientierte Autorschaft wie jene von Museumskuratoren sowohl epistemisch als auch ökonomisch behaupten könnte. Seine Inhalte sind zu weit von der Popularitätsballung im short head entfernt, um vom Sog der Cyberkaskaden ergriffen und auf die ersten Seiten einer Google-Suche katapultiert zu werden - und entsprechend ist sein Publikum es noch gewohnt, sowohl gezielt und detektivisch entlang von Verlinkungsstrukturen nach interessanten Inhalten zu suchen, als aber auch abseits der von Expertenprogrammen geschlagenen Wissensbreschen auf assoziative Erkundungstouren zu gehen.

Für virtuelle Museen, die in der Trägerschaft von Hobbyisten entstehen und bewusst sehr begrenzte und spezielle Interessenlagen bedienen, ist die long tail-Theorie damit natürlich eine Bestätigung für Zeit, Geld und Arbeit, die in die Pflege solcher Angebote investiert werden: Sie verbrieft das Vorhandensein eines Publikums, wie klein es auch immer sein mag, für die obskursten denkbaren Phänomenbereiche. Der diesem Kapitel folgende Fallstudienabschnitt der vorliegenden Arbeit wird einige solcher Projekte näher unter die Lupe nehmen. Für virtuelle Museen, die indes als Ableger und Vorhöfe etablierter Institutionen existieren, wäre die gezielte Ansprache eines solchen Publikums von Cyber->Hipstern` eine völlige Abkehr von jenem Bildungsauftrag, dem das Museum seit seiner Entstehung in der frühen Neuzeit verpflichtet ist: nämlich jenem, >die breite Öffentlichkeit $z u$ bespielen, und nicht etwa hochspezialisierte Partikularöffentlichkeiten. Nicht umsonst stellt Jon Pratty die These auf, das virtuelle Museum müsse im Vergleich zum physischen sein Innerstes nach außen wenden und den Anschluss an existierende Suchmaschinen anstreben. Ein professionell angelegtes und entsprechend kostspieliges, ja womöglich aus öffentlichen Geldern gefördertes virtuelles Museumsprojekt kann sich nicht damit begnügen, unter dem long tail kleine Enthusiastenzirkel zu bedienen. Vielmehr muss es - ganz wie das physische Museum - eine Maximierung seiner Besucherzahlen anstreben, soweit dies mit seinem didaktischen Anspruch zu vereinbaren ist. Wird das virtuelle Angebot von der Betreiberinstitution als Teil der Öffentlichkeitsarbeit verstanden (und damit als ein Mittel, um Menschen ins physische Museum zu locken), greifen die beiden Ebenen sogar ineinander. 


\subsubsection{Der Kurator als Techniker?}

Idealerweise müsste eine virtuelle Museumspräsenz im WWW also nach außen hin die Erscheinung eines short head-Angebotes haben, das es in die Spitzenpositionen der Trefferlisten möglichst vieler relevanter Suchanfragen schafft, im Innern aber imstande sein, long tail-Inhalte zu vermitteln, die nicht nur bereits bestehende Erwartungshaltungen befriedigen. Da die Systeme, die im Web über Sichtbarkeit und Unsichtbarkeit entscheiden, kulturelle Inhalte aber nicht verstehen können, ist dieser Spagat im Rahmen klassischer kuratorischer Arbeit kaum zu bewerkstelligen. Das virtuelle Museum sieht sich mit dem Problem konfrontiert, dass seine soziale Wirksamkeit und Reichweite nicht in der Sphäre der Kultur allein determiniert wird, sondern zu einem bedeutenden Teil innerhalb von formallogischen technischen Systemen. Damit reiht sich die Museumsvirtualiserung gerade in Deutschland ein in eine Konfrontationsgeschichte von humanistischem Bildungsideal und technischen Realitäten, die nach Günter Ropohl letztlich auf die Humboldt'schen Bildungsreformen und damit eben jene Epoche zurückverweist, in der auch die neuzeitliche deutsche Museumsgeschichte ihren Anfang nimmt. Der Bildungskanon Wilhelm von Humbolds hat, so Ropohl, die Technik nie einzuschließen vermocht, weil er sich wesentlich auf den menschlichen `Geist « und damit das Innere richtet, während die Technik notwendigerweise immer in der Außenwelt ansetzt. Diese kategorische Trennung von Bildung und Technik sei niemals ganz aus der deutschen Geistesgeschichte verschwunden, auch wenn ein halbes Jahrhundert nach Humbold Karl Marx für eine Gleichbewertung und -behandlung von geistig-ästhetischer und pragmatischer Bildung warb (vgl. Ropohl 1999: 218f.). Günther Gottmann sah Mitte der 1970er Jahre den Auftrag von Technikmuseen gar nicht vorrangig darin, über konkrete technikgeschichtliche Entwicklungen zu informieren, sondern vielmehr in der konzeptuellen Zusammenführung des Gegenstandes Technik mit der Institution Museum deutlich werden zu lassen, dass Technologien unhintergehbarer Bestandteil der kulturellen Welt sind:

Will ein Technikmuseum teilnehmen am zeitgenössischen Dialog und nicht nur in der Vergangenheit gegebene Antworten registrieren, muß es immer wieder die Objektivität der Technik in der Subjektivität des Menschen spiegeln. (Gottmann 1976: 34) 


\subsection{DATENBANK UND NETZWERK: ARCHITEKTUREN DES VIRTUELLEN MUSEUMS}

Indes geht es im Falle des Technikmuseums natürlich darum, die Technik ins $\mathrm{Mu}-$ seum zu holen und damit in ein kuratorisch beherrschtes Dispositiv. Das virtuelle Museum dreht diese Sachlage ins Gegenteil: Hier geht es nun darum, die Institution Museum der Technik anzuvertrauen. Wie Suzanne Keene darlegt, haben in den vergangenen Jahrzehnten eigentlich zwei Museumsvirtualisierungen stattgefunden: Bevor nämlich zum Ende der 1990er Jahre die Idee einer Ausweitung musealen Präsentierens in den Cyberspace wirkmächtig wurde, hatten (vernetzte) Computer bereits weite Teile der musealen Verwaltung durchdrungen - nicht nur auf der Ebene der Objekte, sondern in allen Aspekten des Museums als wirtschaftlicher, sozialer und pädagogischer Einrichtung. Hatten im Aufseßschen Registerkartensystem des GNM nur die Museumsdinge virtuelle Dubletten innerhalb des Zettelkastens erhalten, erfassten die Datenbanken der Museen nun auch Mitarbeiter, Partnerorganisationen, Veranstaltungen, Ideen und Konzepte, usw. Während analoge Registersysteme nur die Sammlung >gedoppelt $<$ hatten, existierte nun fast zur ganzen Institution ein virtuelles Gegenstück innerhalb ihrer eigenen, technisch vereinheitlichten Verwaltungsinfrastruktur (vgl. Keene 1998: 16). Obwohl die innere Virtualisierung des Museums nicht ansatzweise dieselbe Problematisierung durch die Museumswissenschaft erfahren hat wie seine äußere, bedingte sie eine grundsätzliche Neubewertung musealer Sammlungsbestände - und vor allem auch: eine Funktionalisierung der Museumsdinge, die so zuvor nicht stattgefunden hatte.

\subsubsection{Computer als Werkzeuge musealer Sammlungsverwaltung}

Wie Ross Parry darlegt, lässt sich der Computereinsatz in Museen mittlerweile über fünfzig Jahre zurückverfolgen. Als William Paisley 1968 auf der im Metropolitan Museum of Art ausgerichteten Tagung zu den Perspektiven der Computernutzung in Museen seine Vision vom digitalisierten Meta-Museum entwickelte, war das Thema durchaus schon seit einigen Jahren im Gespräch. Fünf Jahre zuvor hatte das Washingtoner Museum of National History ein Komitee ins Leben gerufen, welches die Möglichkeiten der Nutzung von Computern für die Sammlungsverwaltung evaluieren sollte. 1965 führte die Firma Peat, Marwick, Mitchell \& Co. für das Smithsonian eine Studie zur Anwendbarkeit von Computerdatenbanken in dessen zahlreichen Tochterinstitutionen durch. Dieser folgte 1967 ein Projekt zu automatisierten Dokumentationsvorgängen, und in den Jahren 1969 und 1970 wiederum Prototypen einer Katalogisierungs-Software, die eine hochstandardisierte Verzeichnung von Exponaten ermöglichen sollte (vgl. Parry 2006: 15f.). Ende 1974 benutzten 50 Museen innerhalb der USA dieses sog. SELGEM (SELf GEnerating Master)-System, das aus über 40 
Einzelprogrammen bestand und es ermöglichte, zu individuellen Ausstellungsstücken >Masterdateien anzulegen, auf deren Basis die Software dann allerlei Verwaltungsdokumente automatisch erstellen konnte: von Vorlagen für Arbeitsberichte über Klebeetiketten, Karteikarten und Seiten für gebundene Kataloge oder Handbücher bis hin zu nach beliebigen Kriterien sortierten Sammlungslisten und Indizes (vgl. Gautier 1986: 50). Parallel dazu wurde Ende der 1960er Jahre in New York vom 1963 gegründeten Institute for Computer Research in the Humanities (einer Institution, die selbst zu den Ahnherren der Digital Humanities zu zählen ist) das Museum Computer Network konzipiert, das nicht nur den Museen selbst nützlich sein, sondern auch museale Wissensresourcen für die Kultur- und Geisteswissenschaften erschließen sollte. Sein Leiter Jack Heller sah das $M C N$ als ein Netzwerk, das die bedeutendsten Kunstmuseen der Welt mit den bedeutendsten wissenschaftlichen Lehr- und Forschungseinrichtungen zusammenführen und damit eine neue Form computergestützter Kulturwissenschaft ermöglichen würde (vgl. Parry 2006: 16f.).

In Großbritannien fand 1971 das erste große museale Computerisierungsprojekt Europas statt. John Cutbill von der Universität Cambridge, der mit dem $M C N$ assoziiert war und 1968 eine Session auf der wegweisenden Tagung im Metropolitan Museum of Art geleitet hatte, wurde von der Museums Association mit der Aufgabe betraut, die Fossiliensammlung des Sedgwick Museum of Earth Sciences digital zu katalogisieren. Um diesen etwa 40.000 Stücke beinhaltenden Fundus zu erfassen, wurden zunächst klassisch kategorisierte und hierarchisierte Katalogdaten als Lochcodes auf Papiertapes übertragen, diese dann in einen Computer eingelesen und anschließend so aufbereitet, dass sie variabel für die Erstellung anderer Dokumente herangezogen und statistisch ausgewertet werden konnten. Diese Unternehmung war zugleich die Initialzündung für die Entstehung der Information Retrieval Group of the Museums Association, die Ende der 1960er und Anfang der 1970er Jahre vor allem darum bemüht war, das Museums Communication Format (MCF) als gemeinsamen Datenstandard für Museumscomputer auszuarbeiten (vgl. Parry 2006: 18f.). Dieses Projekt knüpfte wiederum seinerseits an Vorarbeiten an, die in den Bibliothekswissenschaften geleistet worden waren. Der Machine-Readable Catalogue (MaRC) der amerikanischen Library of Congress hatte als Pilotprojekt zur Verwaltung bibliographischer Daten fast alle frühen Ansätze zur Anlage und Betreuung musealer Datenbanken beeinflusst - und hier zugleich seine Unzulänglichkeiten offengelegt. Denn während für die Verwaltungsmaschinerien von Bibliotheken lediglich die Angaben auf der jeweils ersten Seite von Büchern von Interesse waren, galt es in Museen, der Unabschließbarkeit der Exponate gerecht zu werden und prinzipiell das gesamte sich prozedural immer noch entwickelnde Wissen über individuelle Objekte zu bewältigen (vgl. ebd.: 22 f.). 


\subsubsection{Digitalisierung und Professionalisierung}

Diese Suche nach einheitlichen Datenstandards zog Parry zufolge einen Problembereich ins Rampenlicht, der seit der frühesten Geschichte des Museums als Bildungseinrichtung bestanden hat, jedoch vor der Einführung digitaler Technik und ihrer medialen Eigenheiten in das museale Tagesgeschäft niemals als solcher wahrgenommen worden war: Für die Verwaltung von Museumsdingen hatten die Institutionen, die sich über ihre fachgerechte Betreuung legitimieren, niemals verbindliche Richtlinien geschaffen. Den Mittelpunkt allen administrativen Umgangs mit Museumsdingen bildeten in der angelsächsischen Welt seit dem 19. Jahrhundert vor allem zwei Arten von Büchern: Auf der einen Seite standen große und im Gebrauch häufig regelrecht fetischisierte Registerbände, in denen die vorhandenen Schaustücke - dem Buchformat entsprechend - in jener Reihenfolge verzeichnet wurden, in der sie in die Sammlung aufgenommen worden waren, versehen mit all jenen Daten, die vom jeweiligen Haus als wichtig für den Gebrauch der Objekte in Ausstellungskontexten erachtet wurden. Auf der anderen Seite standen die sogenannten day books, die von einzelnen Kuratoren individuell geführt wurden und die teils Tage-, teils Notiz- und teils Logbuch waren (vgl. ebd.: 102f.). Day books waren ein notwendiges Hilfsmittel, weil die Registerbände aufgrund ihrer Anlage nach dem chronologischen Eintreffen der Gegenstände im Sammlungsbestand keine Ordnung aufwiesen, die in irgendeiner Form der Konzeption von Ausstellungen entgegenkam. Ihre Funktion war vielmehr die bloße Verzeichnung als eine Technik der Herstellung musealer Autorität: Ross Parry beschreibt als das Fundament der gesellschaftlichen Geltung des Museums dessen Fähigkeit, eine »kontrollierte Umwelt« (ebd.: 102) herzustellen - und der erste Schritt zur Herstellung dieser Kontrolle sei es logischerweise, Dinge rechtlich, institutionell und epistemisch zu vereinnahmen, indem man sie schriftlich katalogisiert und somit als Eigentum registriert. Im Experimentalsystem Museum ist ein solches Register demnach das erste aller technischen Dinge und Voraussetzung dafür, dass es epistemische überhaupt geben kann. Day books übten hingegen eine Anzahl nachgeschalteter Funktionen aus. Vor allem enthielten sie verkürzte Listen von Objekten, die tatsächlich im Bezug aufeinander für konkrete Ausstellungssituationen ausgewählt oder in Erwägung gezogen wurden, stellten also (ganz nach dem Memex-Prinzip) >Pfade des Interesses $\triangleleft$ durch die großen Kataloge dar. Day books waren aber auch prozedural gedeihende Abbilder (und Bausteine) des gesamten Museumsbetriebes. Notizen über individuelle Ausstellungsstücke konnten in ihnen ebenso abgelegt werden wie z.B. Anmerkungen zu Arbeitsabläufen, dokumentarische Aufzeichnungen zu prominenten Besuchern, Korrespondenzen der Kuratoren untereinander und mit Personen außerhalb des Museums, usw. Solche Kladden waren hochgradig unsystematisch angelegte Hilfsmittel zur Verwaltung und Präsentation der Sammlung, die im Grunde nur für jene Kuratoren wirklich zu verstehen waren, die sie auch angelegt 
hatten. Das höchste Ideal und die ordnende Instanz blieb das Wissen des einzelnen Kurators um >sein` Museum (vgl. ebd.: 104f.).

Als sich in der ersten Hälfte des 20. Jahrhunderts die Kartei zu den gängigen Werkzeugen des Museumsalltags gesellte, änderte sich hieran nur wenig. Karteien funktionieren zwar modular und lassen sich beliebig rearrangieren, jedoch ist auch die einzelne Karteikarte ein individuelles materielles Artefakt, das immer nur in einem Karteikasten liegen und zur gleichen Zeit nur in einem Verwaltungsablauf genutzt werden kann. Bevor Karteikarten am Computer erstellt werden konnten (und damit faktisch zu Ausdrucken von digital codierten Datensätzen aus Datenbanken wurden) mussten sie von Hand produziert werden - und zwar nach den Maßstäben und Bedürfnissen individueller Kuratoren und ihrer Arbeitsweisen. Insofern blieb auch die Kartei zunächst gleichermaßen Bestätigung wie Werkzeug kuratorischer Autorität. Die Verwaltung von Museumsdingen war vor ihrer Computerisierung eine hochgradig individualisierte Arbeit, die wohl von keinen zwei Verantwortlichen exakt gleich ausgeübt wurde, und darin war sie ein Produkt der Medien, derer sie sich bediente (vgl. ebd.: 105ff.).

Der Einzug von Computern in die Arbeitsabläufe von Kuratoren legte erstmals offen, wie lücken- und bisweilen amateurhaft die museale Sammlungsdokumentation vielerorts betrieben wurde und wie sehr sie auf die Bedürfnisse einzelner Ausstellungsmacher zugeschnitten war. Projekte wie SELGEM standen dementsprechend nicht nur im Zeichen der Schaffung einer Schnittstelle zwischen kuratorischer Kultur- und computerisierter Rechenarbeit, sondern auch in jenem eines »new professionalism« an den Museen (vgl. ebd.: 27f.). Digitale Technik kann sich nicht in die kulturellen Sensibilitäten von Museumsleuten einfühlen - sie verlangt nach klar definierten und mit unmissverständlichen Eigenschaften ausgezeichneten Objektgefügen, wenn sie Kuratoren bei ihrer Arbeit unterstützen soll. Entsprechend ließen sich die existierenden Registrationssysteme nicht einfach in Datenbanken übertragen Sammlungen mussten komplett neu erschlossen werden, und zwar mit Blick auf die Ansprüche der Software, die zukünftig zu ihrer Verwaltung herangezogen werden sollte. Dieses neue Konzept von Museumsverwaltung fand auch in der zeitgenössischen Philosophie einen fruchtbaren Nährboden: Insbesondere der Strukturalismus mit seinem besonderen Interesse an der Rolle von Ordnung und Operationalisierung bei der Produktion von Wissen übte einen Einfluss auf das Bestreben von Museen aus, ihre eigene Funktionsweise bewusst zu reflektieren und ihre Buchführung darauf hin zu optimieren (vgl. ebd.: 29ff.).

Zugleich aber brachen diese neuen Ordnungssysteme in vielerlei Hinsicht mit klassischen Modellen kuratorischer Souveränität. Hatten Kuratoren zuvor Exponate so beschrieben, wie sie es im Hinblick auf ihre Ausstellungsarbeit für richtig und sinnvoll hielten, wurde ihnen der Informationswert von Objekten nun gewissermaßen Präskriptiv vorgegeben - von Datenbanksoftwares, die nur sehr begrenzte und hochstandardisierte Datensätze zu erfassen vermochten. Das MODES-System, das 1987 
erstmals im vereinigten Königreich eingeführt und aufgrund seiner niedrigen Kosten innerhalb eines Jahres an über 100 Museen in Betrieb genommen wurde, ließ innerhalb seiner Datenstruktur nur 254 Eintragsfelder zu. Diese Zahl orientierte sich weder an den Bedürfnissen von Kuratoren, noch war sie ein funktionaler Kompromiss seitens der Programmierer. Vielmehr war sie die Ausreizung der Möglichkeiten einer 8Bit-Prozessorarchitektur, deren formales System nur $2^{8}=256$ Zustände darstellen kann. Die Software orientierte sich also nicht vorrangig am musealen Betrieb, für den sie gemacht war, sondern an den harten, technischen Grenzen, die ihr von der Hardware gesetzt wurden - und die menschlichen Museumsschaffenden mussten ihr Bild von den eigenen Exponaten letztlich dem anpassen, was das neue System ihnen von deren Eigenschaften zu erfassen und zu verzeichnen gestattete (vgl. ebd.: 46ff.).

\subsubsection{Grenzen der Kategorisierbarkeit}

Kurz nach der Markteinführung von MODES schrieb David W. Scott vom Washingtoner National Museum of American History einen Bericht über den Einsatz von digitalen Datenbanken in Museen und stellte dabei die Kategorisierung als eines der größten Probleme bei der Erfassung von Sammlungen in den Vordergrund. Sein Text, der bezeichnenderweise im bibliothekswissenschaftlichen Fachjournal Library Trends erschien, betont wie Parry das Problem, dass Museumsdinge (und insbesondere Kunstgegenstände) sich nur sehr schwer klassifizieren ließen. Zwar könne man sie nach Entstehungsort, Epoche, Künstler und anderen Faktoren erfassen, doch dies sei letztlich nur eine Ausschilderung des Datensatzes mit äußeren Merkmalen, die am `Eigentlichen` des Gegenstandes vorbeigehe (vgl. Scott 1988: 132). Die von William Paisley 1968 ersonnene Zukunftsvision von einer musealen Universaldatenbank, in der man nur nach dem Wort `Segelschiff` suchen müssen sollte, um alle auf Segelschiffe beziehbaren Objekte in allen Sammlungen der Welt auszuspüren, forderte hingegen etwas sehr viel Spezifischeres ein: Nämlich eine Klassifizierung und Kategorisierung der Darstellungsebene, die letztlich nicht weniger bedeuten müsste als die Diskretierung von kontinuierlichen, materiellen Gegenständen in eine Art \Zeichen-Sprache`, wie sie als Vorstellung im Zentrum der Bense'schen Informationsästhetik steht. Dass Paisleys Idee trotz mittlerweile ubiquitärer Verwendung digitaler Verwaltungstechnologien im Museumsalltag auch zwanzig Jahre später noch ihrer Verwirklichung harrte, schreibt Scott vor diesem Hintergrund gleichermaßen logistischen wie methodischen Faktoren zu. Klassische Registereinträge wie eben Autor, Entstehungsdatum, Größe, Material usw. sind relativ leicht auf eine einheitliche Formatierung zu fixieren - und zugleich nicht ungemein hilfreich bei der Suche nach konkreten Objekten. Innere Merkmale sind hierzu hingegen enorm nützlich aber kaum zu standardisieren (vgl. ebd.: 137). Bei Kunstwerken dürfte es wohl noch am einfachsten sein, auf der Darstellungsebene konkrete Sujets zu beschreiben. So 
könnte ein Datenbankeintrag z.B. erfassen, dass ein Gemälde ein Segelschiff, den blauen Ozean und einen Leuchtturm zeigt, und eine Begriffssuche nach diesen Gegenständen der Darstellung würde zu entsprechenden Treffern führen. Was aber, wenn man statt der reinen Gegenständlichkeit von Museumsdingen an ihrer Deutungsebene, an ihrer kulturellen Symbolik, oder ihren Beziehungen zu anderen Objekten interessiert ist? Oder gar an ästhetischen Kategorien wie ihrem atmosphärischen Wirken? Schon die Gegenstandsebene auf eine Art und Weise zu vereinheitlichen, die den Transfer von Datensätzen zwischen den Systemen unterschiedlicher Museen (und damit als Fernziel ihre Zusammenführung in einer Meta-Datenbank) erlauben würde, wäre eine große Herausforderung, die weitreichende Kooperation zwischen den Einzelinstitutionen erfordern würde. Es fällt nicht schwer, sich auszumalen, wie ungleich komplizierter sich das Problem noch gestalten würde, wollte die Datenbank z.B. erfassen, dass der Leuchtturm, das Meer und das Segelschiff Symbole für menschliche Lebensgestaltung sein könnten, oder dass das Gemälde Gefühle von Einsamkeit und Verlorenheit im Betrachter evoziert.

Das Problem ist hier nicht nur die Standardisierung der Formate, sondern vielmehr auch der Umstand, dass `Fakten $<$ als soziale Aktualitäten des Wissens ein Mindestmaß an Verbindlichkeit aufweisen, Interpretationen als Virtualitäten einer Rezeptionssituation aber nicht. Die Abmessungen eines Gemäldes oder das Gewicht einer Skulptur sind in den meisten Fällen keine streitbaren Größen und etwas, dass jeder Dokumentar gleichermaßen in den Eigenschaftskatalog des Exponats aufnehmen würde. Dagegen sind Bedeutungen und ästhetische Effekte auch für den Experten nicht nur eine ausgesprochene Ermessenangelegenheit, sondern auch hochgradig davon abhängig, was und wie ein Museum insgesamt ausstellt. Eine Objekteigenschaft, die in der einen Ausstellung zentral ist, kann in der anderen völlig irrelevant sein - oder umgekehrt. In manchen Fällen mag ein Objekt in eine Ausstellung geraten sein, in der eine überaus unwahrscheinliche Deutungsmöglichkeit zur Geltung kommt, während viel offensichtlichere auf der Strecke bleiben. Überhaupt werden wohl die allermeisten möglichen Bedeutungsebenen eines beliebigen Museumsdings überhaupt niemals >entdeckt $`$ werden - zu begrenzt ist die Anzahl der Ausstellungskontexte, die es je durchlaufen wird. Seit den 1960er Jahren hatte die Digitalisierung der Museumsinventare vor allem darin bestanden, bestehende Registerdaten zu digitalisieren. Inhaltliche Angaben waren Gegenstand von day books und lagen entsprechend nicht in einer Form vor, die man ohne weiteres in Felder in einer SoftwareMaske hätte übertragen können. Wollten Museen inhaltliche oder gar interpretatorische Aspekte in ihre Datenbanken aufnehmen, so müssten sie laut David Scott ihre Sammlungen komplett neu erschließen (vgl. ebd.), was offensichtlich erstens je nach Größe des Fundus eine kolossale Aufgabe sein kann, und zweitens nach wie vor nur vereinzelte Schlaglichter auf die zahllosen möglichen Bedeutungen der Objekte werfen würde. Die große Gefahr bei der Kategorisierung von Deutungen wäre, dass die Kategorien letztlich nur für die eigene Perspektive und die eigenen Arbeitsabläufe 
anschlussfähig sein könnten. Scott nennt als ganz konkretes Beispiel für ein schwer zu klassifizierendes Museumsding Picassos berühmtes Gemälde Drei Musikanten aus dem Jahre 1921, das im New Yorker Museum of Modern Art zu besichtigen ist. Scott verweist darauf, dass die drei Figuren auf dem Bild - der Harlekin, der Pierrot und der Mönch - überhaupt nicht zwingend als Musikanten gedeutet werden müssten, sondern auch Schauspieler sein könnten, bzw. von Kennern häufig als Repräsentanten Picassos selbst sowie seiner Freunde Max Jacob und Guillaume Apollinaire gedeutet würden. Darüber hinaus seien die Objekte in ihren Händen und auf dem Tisch vor ihnen vieldeutig genug, als dass sie nicht zwingend als Musikinstrumente verstanden werden müssten (vgl. ebd.: 131). Aber selbst wenn man die Ebene der Deutungen und Zuschreibungen außen vor lässt, scheitert die Idee von einer musealen Universaldatenbank, wie sie von Paisley ersonnen wurde, schlicht an der ungeheuer großen Bandbreite dessen, was in Museen gesammelt wird. Die Standards einer solchen Datenbank müssten auf Kunstgegenstände ebenso anzuwenden sein wie auf technik- und naturgeschichtliche oder ethnographische Exponate. Sie müssten Picassos Musiker also ebenso umfassen können wie ein Mammutskelett, einen brocken Mondgestein oder Charles Lindberghs im Smithsonian ausgestellte Spirit of Saint Louis. Will man Paisleys eigenes Beispiel weiterdenken, dann müssten sie unter dem Schlagwort \Segelschiff « auch Museumsschiffe wie die in Portsmouth vor Anker liegende HMS Victory verzeichnen, die zugleich Exponat als auch Museum sind.

Das Problem bei der Verwaltung von Museumsdingen durch Datenbanken ist also ein doppeltes: Zum einen wird Museumssoftware typischerweise nicht von $\mathrm{Mu}-$ seumsleuten programmiert, sondern von Softwareentwicklern, welche mit den Bedürfnissen von Kuratoren im Alltag musealen Arbeitens meist nicht aus erster Hand vertraut und außerdem bestimmten technischen Limitierungen unterworfen sind, um die es sich nicht immer herumprogrammieren lässt. Die Karteikarten und day books der Vergangenheit waren hingegen der Arbeit der Kuratoren nicht vorgeschaltet, sondern gingen unmittelbar aus ihr hervor und entsprachen den Vorgehensweisen und Denkmustern derjenigen, die sie anlegten. Zum anderen verlangen digitale Datenbanken nach systematischen Klassifizierungen, die für Museumsdinge nicht nur schwierig zu bewerkstelligen sind, sondern einem klassischen, affektorientierten $\mathrm{Mu}-$ seumsverständnis womöglich völlig zuwiderlaufen. In einem 2011 erschienenen Aufsatz über Versuche zur Quantifizierung ästhetischer Phänomene betont Barbara Flückiger, dass es hier nicht nur um Machbarkeitsfragen gehe, sondern um stark normativ geführte Debatten darüber, wie man sich zu Objekten künstlerischen Ausdrucks in Beziehung setzen darf und wie nicht:

»Wer die eigentümliche Unschärfe, die allen künstlerischen Werken eignet, in messbare Einheiten zerlegen will, der setzt sich leicht dem Verdacht des reduktionistischen Positivismus aus.« (Flückiger 2011: 44) 
Auf der anderen Seite gründet sich die herausgehobene Rolle des Museums schon immer auf die Anbindung all seiner Vermittlungstätigkeit an ein wissenschaftlich validiertes Fachwissen, das unweigerlich systematisiert ist. Die Geschichtswissenschaft, die Archäologie, die Kunstgeschichte schaffen sich epochale, stilistische oder methodische Unterscheidungen und strukturieren nach diesen nicht nur Wissen, sondern auch Kompetenzbereiche, innerhalb derer die Figur des >Experten erst entstehen kann. Konrad Becker schreibt hierzu:

Schon immer gab es eine intime Beziehung zwischen Wissen und Machtausübung; die Möglichkeit der Einflussnahme liegt auch in der Autorität, etwas benennen zu können. Problemlösung beinhaltet einen Prozess der Benennung von Fragen und Gegenständen, der den Rahmen der Auseinandersetzung mit ihnen bestimmt. [...] Kategorisierung ist eine Art kognitives Voodoo. Der tief verwurzelte Glaube an eine von der Bannkraft der Namen verzauberte Welt, wo das Universum durch Benennung und Ordnung beeinflusst wird. (Becker 2010: 183)

Dieses >kognitive Voodoo< der Benennung hat, wie im letzten Kapitel schon dargelegt wurde, für Becker ein politisches Element: Klassifizierungen schaffen Realitäten, die den Anschein der Vorgefundenheit erwecken, tatsächlich aber das Machwerk menschlicher Entscheidungen sind (vgl. ebd.: 184). Genau deshalb sieht Becker ja im Fehlen von >Regalen` das revolutionäre Potential von Google - und in Kategorisierung schlechthin erst einmal einen Rückschritt gegenüber dem, was mittels Hyperund Cybertext eigentlich längst nicht nur möglich, sondern in weiten Teilen Wesensart digitaler Medien geworden ist (vgl. ebd.: 185).

Die Frage nach dem möglichen Nutzen Memex-artiger, hypertextueller Vernetzung von Datensätzen taucht in der Fachliteratur bisher allerdings so gut wie gar nicht auf, wenn es um die Möglichkeiten und Gefahren digitaler Buchführung geht. Vorrangig wird hier in Begriffen von Klassifizierung und Verschlagwortung gedacht, was möglicherweise nicht nur mit einem mangelnden Bewusstsein der Institution für ihren Netzwerkcharakter zusammenhängt, sondern durchaus programmatisch sein könnte: Während auf der Rezipientenseite Assoziation, Interpretation und mögliche Irrungen auf den Pfaden der Deutung durchaus tolerierbar zu sein scheinen, verlangt die Autorenseite nach Klarheit und Abgeschlossenheit. Wer in der Ausstellung eine >Realität ^ feilbieten möchte, der muss eine Vorstellung davon haben, wie diese beschaffen sein soll - unabhängig davon, wie explizit sie sich dann dem Publikum mitteilt und wie viel Gelegenheit man ihm einräumt, sie misszuverstehen. Guy Hermann sah hierin schon 1997 eine zentrale Fehlentwicklung im Umgang von Museen mit Datenbanken: Seit Beginn der Computerisierung seien Formatstandards - insbesondere proprietäre - der Albatros um den Hals digitaler Sammlungen gewesen, der über ihre Zukunftsfähigkeit ebenso entscheidet wie über ihre Fähigkeit, mit anderen Sammlungen zu interagieren. Viele ursprünglich groß gedachte und weit in die Zu- 
kunft geplante Virtualisierungsprojekte der 1990er Jahre seien an Fehlentscheidungen bei der Formatierung ihrer Inhalte zugrunde gegangen - und hier insbesondere an einer zu starken Abschottung vom Rest des Webs, die allzu oft von Angst um die Kontrolle über die eigenen Bestände getragen gewesen sei (vgl. Hermann 1997: $71 \mathrm{ff}$.). Anstatt die hochstandardisierte Zusammenziehung von Daten innerhalb eines einzigen Speichersystems voranzutreiben, sollten Museen vielmehr anstreben, eine dezentrale Landschaft von Datenbanken entstehen zu lassen, die untereinander dynamisch verlinkt sind und Zugriffsystemen unterliegen, die sich den Wünschen und individuellen Bedürfnissen von Nutzern anpassen (vgl. ebd.: 81) - was möglicherweise natürlich genau das ist, was heutzutage fast von allein passiert, wenn Museen ihre Inhalte in gängigen Formaten auf HTML-Seiten im Web zugänglich machen, allerdings ohne jede Form von kuratorischer Aufsicht.

\subsubsection{Daten versus Information}

Hermann teilt die eingangs erwähnte Einschätzung Richard Saul Wurmans, dass die elektronische Datenverarbeitung uns in weiten Teilen in ein >Nicht-Informations ‘Zeitalter gestürzt habe, und als Vollstrecker dieser Informationsvernichtung sieht er dabei Datenbanken, die eben meist nicht assoziativ-vernetzt angelegt sind, sondern über Kategorisierungssysteme funktionieren. Deren Problem sei, dass sie - wie der Name schon sagt - lediglich `Daten ` bunkern und für den Abruf bereithalten. Daten wiederum seien etwas entschieden anderes als Information:

How is information different from data? Where a data processing system provides facts, an information system answers questions. Information is contextual; it lets us see the broader picture. Where a catalog record in a data processing system might tell us the name of an object, its maker and the time period, an information system will let us ask questions such as: »What can you tell me about where this comes from? « or »What else is important to know about this period, person, style, genre? « Information systems define relationships: »What others [sic] things are like this? Where are they? What attributes do they share? « These questions might be losely defined as questions a curator could answer. (Ebd.: 69)

Das Museum und seine klassischen analogen Verwaltungstechnologien sind also Informationssysteme, während eine maschinenlesbare Datenbank ein System zur bloßen Datenverarbeitung ist. Informationssysteme sind Dispositive des Verstehens, Datensysteme hingegen Dispositive des bloßen Abrufs. In Informationssystemen wird Sinn verhandelt, in Datensystemen ist Sinn im wörtlichsten Sinne >gegeben $<$ - und auch vollkommen auf das Gegebene beschränkt. Jedes Objekt steht als Summe seiner vom System erhobenen Merkmale für sich allein und ist mit anderen Objekten nur soweit `verbunden`, wie es mit ihnen einzelne solcher Merkmale teilt. 
Während Suzanne Keene noch keine >Verwandtschaft zwischen den mehrdimensional navigierbaren Ausstellungsräumen des Museums und digitalen Hyperund Cybertextsystemen des WWW erkennt, schreibt auch sie die Geschichte des Einzugs von Computern in die Arbeitsabläufe der (vornehmlich angelsächsischen) Museen nicht als eine des Umbruchs, sondern reiht sie in Kontinuitäten ein. Für Keene ist in diesem Zusammenhang die >Multimedialität $<$ des Museums entscheidend. Das Museum sei als eine Einrichtung, die immer schon unterschiedliche mediale Ausdrucksformen miteinander konfrontiert hat, in besonderem Maße dazu geeignet, auch neue Informationstechnologien zu integrieren (vgl. Keene 1998: 16). Überhaupt habe das Informationszeitalter (das Keene als jene Epoche definiert, in der nach `Land und `Energie〈 nunmehr >Information « zur Basis des ökonomischen Lebens geworden sei) in den Kulturbetrieb schon weitaus tiefer eingegriffen als in viele andere Wirtschaftszweige, gerade weil dieser vorwiegend nicht mit konkreten materiellen Gütern, sondern mit abstrakten Inhalten umgeht. Schon im Januar 1995 identifizierte das Wall Street Journal den Handel mit digitalen Reproduktionsrechten nicht nur als eines der größten Segmente des Kunstmarktes, sondern vor allem auch als das am schnellsten wachsende (vgl. ebd.: 7). Für die Museen wiederum seien digitale Medien vor der Jahrtausendwende vor allem aus zwei Gründen interessant gewesen:

Der erste von Keene benannte Aspekt ist die Tatsache, dass es auf der Basis von Hypertextsystemen Museen erstmals ermöglicht wurde, nicht nur Dinge, sondern auch ihre Bedeutungen und wechselseitigen Bezüglichkeiten explizit aufzubewahren. Museen haben zwar immer schon Sinn geschaffen und bewahrt, aber dieser Sinn ist in der physischen Ausstellung ein impliziter, verborgen in der Anordnung der Dinge im Raum ebenso wie in den Akten, Registern und Katalogen der Verwaltung und natürlich in den Köpfen von Besuchern und Kuratoren. Die Digitalisierung der Sammlungsverwaltung habe erstmals die Informationsebene gleichberechtigt neben die Materialebene gestellt und eine Schicht der Ausstellungskonzeption über die existierende kuratorische Arbeit gelegt, auf welcher Exponate bar aller Materialität als reine Bedeutungsbausteine zirkulieren (vgl. ebd.: 1f.). Der zweite Aspekt ist die Wiederverwertbarkeit digitalen Datenmaterials, die in den Zettelkästen des 19. Jahrhunderts bereits anklang: Einmal erstellte digitale Multimedia-Inhalte sind im Gegensatz zu materiellen Originalobjekten nicht an einen einzigen Ausstellungskontext gebunden, sondern lassen sich gleichzeitig für mehrere Projekte gebrauchen - und im Gegensatz zur physischen Karteikarte fast ohne Aufwand beliebig oft reproduzieren (vgl. ebd.: 15).

Nun ist allerdings die Heranziehung von digitaler Technik für die innere Verwaltung einer physischen Sammlung für und durch die Kuratoren kategorisch verschieden von der Erstellung einer virtuellen, sich an eine Öffentlichkeit richtenden Ausstellung aus digitalen Reproduktionen von physischen Museumsdingen. Eine bloße administrative Objektdatenbank muss weder einem Verlangen nach Erlebnisqualität, 
noch einem nach publikumsorientierter Didaktik gerecht werden. Sie stellt zwar ältere, papiergestützte Inventarisierungsmethoden ebenso infrage wie die Wesensart von Museumsdingen und die Kompetenzbereiche von Kuratoren, nicht aber die Institution Museum und ihren Bewahrungsauftrag. Sie ist ein mächtiges und entschieden eigendynamisches Werkzeug des Museums, aber selbst noch keine Erscheinungsform des Musealen. Als Autoren wie Glen Hoptman Mitte der 1990er Jahre von >virtuellen Museen`zu sprechen begannen, war damit eine fundamental neue Debatte angezeigt: Es ging nun nicht mehr darum, wie sich Museen sehr allgemein $\mathrm{zu}>$ neuen Medien` verhalten sollten, sondern darum, ob das Museumsdispositiv aus dem materiellen Raum in ein digitales Abruf- und Visualisierungssystem transponierbar sei.

Dass die Materialität der Museumsdinge dabei auf der Strecke bleiben muss, ist kaum glaubhaft zu bezweifeln. Zwar lässt es sich trefflich darüber spekulieren, wie zukünftige technologische Entwicklungen die Präsentationsmöglichkeiten virtueller Museen erweitern könnten - holografische und haptische Interfaces drängen sich hier geradezu auf - aber die Trägertechnologien virtueller Museen sind augenblicklich das WWW und das heimische deck der Anwender. Die Oberfläche des Bildschirms ist nach wie vor die harte Grenze zwischen Rezipienten und Inhalten von Webangeboten, und dementsprechend muss jede Argumentation für die Möglichkeit virtueller Museen letztlich im Abstrakten ansetzen. Auf der einen Seite muss plausibel gemacht werden, dass beim >Besucher ein >Vertrauen` in die Authentizität des Dargebotenen hergestellt werden kann, das an jenes heranreicht, das er auch der physischen Institution entgegenbringt. Auf der anderen Seite müssen Modi der Präsentation gefunden werden, welche das epistemische und affektive Erleben im physischen Museum zumindest glaubhaft emulieren. Beides verweist letztlich auf Fragen nach den Möglichkeiten und Beschränkungen von Informationsarchitekturen. Diese ausdrückliche Schnittstellenfunktion des Museums zwischen informierten Experten und zu informierenden (und eben nicht nur mit Daten zu versorgenden) Laien erklärt, warum die Museologie die innere Virtualisierung des Museums durch Datenbanksysteme zur Bestandsverwaltung niemals so scharf problematisiert wie ihre äußere, deren Erscheinungsform das > virtuelle Museum ‘ ist: Leichte Verfügbarkeit von Inhalten auf der Kuratorenseite schafft Möglichkeiten der Artikulation der Experten gegenüber dem Publikum. Auf der Rezipientenseite hingegen macht sie solche Artikulationen schwierig, weil kuratorische Absichten mit ihr leichter unterlauf- oder auch völlig umgehbar werden. 


\subsection{DIGITALE AUTHENTIZITÄT}

Dabei ist die Frage nach der Authentizität vielleicht die dringendste, die an das Konzept des virtuellen Museums gerichtet werden muss. Zwar ist, wie bereits herausgearbeitet wurde, die Authentizität als kulturelle Kategorie durchaus nicht gleichbedeutend mit Originalität oder gar Echtheit - soweit es aber das Museum betrifft, wird sie traditionell natürlich innerhalb solcher Kontexte gedacht, denn auf dieses Versprechen gründet sich ja die Brückenfunktion zwischen An- und Abwesendem, die Museumsdinge erfüllen. Seine Anmutungsqualität erhält das Museumsding aus der (von seiner Anwesenheit im Museumsraum selbst verbrieften) Tatsache heraus, dass es in der Vergangenheit materiell zugegen gewesen ist. In virtuellen Museen sind die >Dinge < indes digitale Objekte und als solche immer nur auf dem Bildschirm präsent, also in Form von Abbildungen.

Nun haben digitale Abbildungen - wie bereits herausgearbeitet wurde - einen ganz anderen ontischen Charakter als analoge. Zu diesem gehört vorneweg, dass digitale Bilder nun einmal, soweit es den Computer betrifft, keine Bilder sind, sondern Text. Das analoge Bild ist im streng informationstheoretischen Sinne unendlich komplex, weil es sich - auch wenn die Informationsästhetik Max Benses anderes behauptet - eben nicht in eine endliche Zahl diskreter Zeichen auseinanderdividieren lässt und es keine unteilbar kleine Einheit seiner Oberfläche gibt. Folglich gibt es für analoge Bilder (bzw. analoge Objekte im Allgemeinen) kein Äquivalent zur Bibliothek von Babel, deren innere Logik ja daran hängt, dass der letztlich digitale Code der Schrift in seiner nackten Kombinatorik auf den Menschen nicht angewiesen ist. Das absolute Museum, wie es im Musée Napoleon erträumt wurde, ist hingegen grundsätzlich nur als ein Museum aller existierenden, nicht etwa aller potenziell möglichen Kunst zu denken.

Digitale Bilderzeugung indes weicht diese Unterscheidung auf: Die Zahl der Pixel, die von einer Bilddatei beschrieben werden können, ist ebenso endlich wie die Anzahl der Farben, die jeder dieser Pixel annehmen kann, und sowohl die zweidimensionale Bildschirmkoordinate als auch die Position im dreidimensionalen Farbkubus lassen sich als Zahlenwerte ausdrücken. Insofern wird eine `Galerie von Babel mit der Computergrafik bzw. aus deren Funktionsprinzipien heraus durchaus denkbar. So wie ein Computer Texte erzeugen kann, ohne diese zu >lesen sein, kann er auch Bilder entstehen lassen, die er nicht >sehen ২ kann - tatsächlich wäre der Vorgang genau derselbe. Macht man also, wie Erkki Huhtamo, den direkten Schritt vom Imaginären ins virtuelle Museum, so tritt man aus einem Museum dessen, was existiert und was somit kopiert und durch Neukonnotation transfomiert werden kann, in ein Museum dessen, was darstellbar wäre und damit eben in eine Flut virtueller Bildlichkeit, in der wir uns ebenso hoffnungslos verirren würden wie Borges' Bibliothekare. So offensichtlich natürlich die ideengeschichtliche Kontinuität 
zwischen Malrauxs Überlegungen zur Verfügbarkeit fotografisch reproduzierter Kulturgüter und den sich mit der Digitalisierung verbindenden Hoffnungen auf universelle Musealität im Internet ist, so wenig kommen wir um die Einsicht herum, dass in virtuellen Museen eine Anzahl von Instanzen am Werk sein müssen, welche den Zugriff auf Computerbilder nicht nur ermöglichen, sondern auch bändigen.

\subsubsection{Authentizität als Virtualität}

Der entscheidende praktische Unterschied zwischen einer analogen und einer digitalen Fotografie (bzw. zwischen digitalen und analogen Bildern schlechthin) ist hier die Tatsache, dass die klassische Fotografie - auch wenn sie technik- und kulturgeschichtlich im Kontext der Industrialisierung und der Massenproduktion steht - distinkte, individuelle Objekte produziert und im Sinne Hannah Arendts eine Technik des Herstellens von Gebrauchsgütern ist. Digitale Fotos hingegen sind in letzter Konsequenz Zeitobjekte. Ihre physikalische Existenz beschränkt sich auf den Computerspeicher, der von ihrem Informationsvolumen belegt wird. Alles darüber Hinausgehende ist das Ergebnis hochkomplizierter Aktualisierungsabläufe innerhalb des Computers und seiner Peripheriegeräte, die aus diesen binären physikalischen Zuständen Bilder generieren, die selbst keine physikalischen >Dinge sind. Ein analoges Gemälde ist ein weitgehend souveräner Gegenstand. Die digitale Kopie desselben Gemäldes ist als digitales Objekt eine Ansammlung von Eigenschaften, die ein Computermonitor abzubilden imstande ist (vgl. Besser 1997: 116).

Howard Besser stellt in diesem Zusammenhang die sehr interessante These auf, dass eigentlich erst unter dem Eindruck der digitalen Bilderzeugung deutlich wird, wie sehr die analoge Fotografie und ihre Verbreitung im Druck noch im Zeichen des Individuellen und der Materialität standen:

Photography has always seemed different from most previous art forms because multiple prints may be made from a single negative, giving many people the impression that these prints are identical to one another. Yet there is an artistry involved in in creating photographic prints from negatives, and those involved with art photography recognize that two photographic prints from the same negative are seldom identical. But digital photographs can be quickly and easily copied, and each copy can be absolutely identical to all the others. In fact, reproduction of digital photography produces far more consistent copies than the manufacturing of dolls, cars, or other types of commodities. (Ebd.: 116f.)

Die (Re-)Produktion digitaler Information unterliegt in Theorie und Praxis entsprechend gänzlich anderen ökonomischen Voraussetzungen als die analoger. Weil nahezu perfekte Duplikate derselben Inhalte ohne nennenswerten Aufwand erzeugt werden können, ist die individuelle Kopie in ihrer Materialität nahezu wertlos: 
Due to the ease of mass production, the concept of physical ownership of a digital photograph becomes subordinate to that of ownership of the intellectual property rights to duplicate the image. (Ebd.: 117)

Natürlich spielten Abbildungsrechte für das wirtschaftliche Überleben von Museen schon lange vor dem Aufkommen der Digitalfotografie eine gewichtige Rolle. Für virtuelle Museen sind sie indes das eigentliche Exponat: Entscheidend ist für ein virtuelles Angebot nicht der Besitz eines Museumsdinges, sondern der Besitz der rechtlichen Befugnis, sein Abbild zu präsentieren - und womöglich nicht einmal das, wenn vom entsprechenden Gegenstand bereits Abbildungen existieren sollten, die zur public domain gehören. Während Walter Benjamin die Vernichtung der Aura noch in technischen Reproduktionsprozessen schlechthin verortete, sieht Besser das Ende der klassischen Autorität des Kunstwerkes erst mit der Digitalfotografie heranbrechen. Analoge, physische Kopien von Museumsdingen, so stellt er fest, heben und akzentuieren letztlich die Autorität des Originals, weil sie in gerader Linie auf dieses zurückverweisen, auch wenn die Reproduktionsverfahren selbst die Erscheinung industrieller Massenfertigung annehmen (vgl. ebd.: 117f.): Je häufiger ein Kulturgegenstand reproduziert wird, desto ausgeprägter ist er im kollektiven Bewusstsein präsent und desto mehr Verweislinien laufen ihm aus der ihn umgebenden Welt entgegen. Bessers Logik ist hier im Grunde jene, die Roland Barthes 1980 in der Hellen Kammer auseinanderlegt: Das Foto erzählt zwar niemals eine ausführliche Geschichte, beweist aber aus technischer Notwendigkeit heraus mindestens die Realität der physischen Situation, in der es einst entstanden ist (vgl. Barthes 1989: 86f.). Weil aber digitale Bilder Text sind und aufgrund der völligen Adressierbarkeit aller ihrer kleinsten Bausteine auch rein kombinatorisch erzeugt werden können, beweist die Existenz einer Bilddatei grundsätzlich die Existenz von nichts außer ihrer selbst. Das digitale Bild (und die digitale Fotografie nimmt hier ontologisch keine Sonderrolle ein) setzt keine Entstehungssituation in der Kulturwelt und keinen menschlichen Schöpfer mehr voraus. Man gelangt von der digitalen Kopie indexikalisch also nicht mehr zum Original. Insofern untergräbt die Digitalfotografie für Besser unweigerlich die Autorität der Originale, weil sie diese in ihrer Funktion als materielle Referenzen von Abbildungen durch ein abstraktes Konzept des dinglichen Gegenstandes ersetzt, der weder in seiner eigenen Dinghaftigkeit in Erscheinung tritt, noch in der einer physischen Reproduktion (vgl. Besser 1997: 117f.).

Nun ist aber Authentizität, wie mit Rekurs auf Susanne Knaller bereits festgestellt wurde, weniger eine immanente Qualität von als authentisch identifizierten Objekten als vielmehr ein »Medienpakt« (Knaller 2005: 22), welcher deren Mittelbarkeit überbrückt. Authentizität ist also vor allem ein Attribut der Rezeptionssituation und damit eine Funktion oder ein Machtvektor im Netzwerk medialer Dispositive. Die kardinale Frage für virtuelle Museen ist demnach nicht die, ob ihre virtuellen Exponate authentisch sind, sondern ob sich auf ihrer medialen Grundlage ein ähnlicher Medienpakt 
schließen lässt wie jener, der das Authentizitätserlebnis im physischen Museum ermöglicht. Obwohl Friedrich Waidacher in seiner Kritik am Konzept >virtuelles Museum nicht in die Tiefen der Theorie digitaler Medien hinabsteigt, wird seine Feststellung, Virtualisierung sei »Verschiebung vom Sein in den Schein« (Waidacher 2000: 7) genau an dieser Stelle brisant. Denn wie im dritten Kapitel dieser Studie ausgeführt wurde, ist auch das physische Ding in seiner Eigenschaft als Objekt der Wahrnehmung und des Wissens durchaus kein vorgefundenes Naturphänomen, sondern ein kognitives Konstrukt und somit immer zumindest teilweise ebenfalls in der Domäne des >Scheins` beheimatet. Auch das physische Museum mit seinen unzweifelhaft präsenten, materiellen Exponaten ist vor diesem Sachverhalt nicht gefeit tatsächlich ist es sogar hochgradig von ihm abhängig, inszeniert es doch Dinge als etwas, das sie eben nicht aus ihrer bloßen Körperlichkeit heraus sind. Es wurde ferner auch bereits abgehandelt, dass Kopien in zahlreichen Museumskonzeptionen durchaus eine wichtige und exponierte Rolle spielen. Museen sind Orte der Virtualität und durchaus keine Tempel des `Seins`. Sie erfüllen vielmehr eine Scharnierfunktion zwischen Sein und Schein - und aus diesem Grunde erscheint es allzu billig, das virtuelle Museum als legitime Erscheinungsform der Institution Museum so schlank abzuwiegeln, wie es Waidacher tut.

Die >Rolle des Museumsdings ist eine Verkehrsform materieller Gegenstände, die vom Museumsdispositiv erzeugt wird, und die Kategorie des Authentischen ist sowohl Eigenart und Effekt als auch diskursive Voraussetzung dieser Verkehrsform. Musealität ist schlechterdings ein virtuelles Phänomen, und ob digitale Reproduktionen museal zu präsentieren sind, hängt demnach davon ab, ob Digitalität und Musealität vereinbar sind, und das heißt letztlich: ob digitale Objekte eine Verkehrsform annehmen können, die das Publikum als >museal zu akzeptieren bereit ist. Das physische Museum verbrieft dem Besucher den Sachverhalt, dass seine Ausstellungsstücke historische Originale sind - das virtuelle müsste ihm minimal (und kann ihm maximal) verbürgen, dass seine virtuellen Exponate in direkter reproduktiver Abkunft von solchen Originalen stehen. Interessanterweise geht es hier in beiden Fällen um die Garantie einer Qualität, welche die betreffenden Objekte nicht aus sich selbst heraus leisten können.

\subsubsection{Authentische Software}

Dabei ist die Vorstellung von Authentizität gerade im Zusammenhang mit digitalen Medien von großer Wichtigkeit, und zwar nicht nur obwohl, sondern gerade weil Software wesentlich Kopie ist. Dies zeigt sich wohl am offensichtlichsten in der Rede von >Raub<-Kopien. Auf der Homepage von Microsoft werden z.B. ausführliche Informationen darüber bereitgestellt, woran sich >originale`Microsoft-Datenträger von 
illegalen Abzügen unterscheiden lassen, und die hierzu ergriffenen Maßnahmen reichen durchaus an jene heran, mit denen Notenbanken Geldscheine fälschungssicher zu machen versuchen: Neben einem Certificate of Authenticity mit eingewobenem Metallstreifen und Vexiermuster auf der Verpackung sowie einem Product Key Label, das den 25-stelligen Produktschlüssel enthält, der bei der Installation eingeben werden muss, sind die Datenträger selbst mit einer Hologrammfolie versehen, die in die DVDs eingearbeitet ist und entsprechend nicht einfach abgezogen werden kann. Microsoft ermahnt seine Anwender darüber hinaus dazu, die Verpackungen ihrer Software auf offensichtliche Fälschungsmerkmale wie Rechtschreibfehler oder verschwommene Abbildungen hin zu untersuchen. ${ }^{4}$ Eine solche Kennzeichnung der materiellen Datenträger steht wiederum im weiteren Kontext des sogenannten Digital Rights Management (DRM), das vom watermarking (dem künstlichen Einfügen subtiler Änderungen in funktional identische Kopien, um diese unterscheidbar zu machen) über die genannte Verwendung von Verschlüsselungstechniken und Produktcodes bis hin zur Online->Aktivierung v von Programmen reicht, deren Extremform, das Always-Online-DRM, eine Verwendung der Software nur dann erlaubt, wenn diese ständig über eine Internet-Verbindung auf Vertreiberserver zugreifen und so ihre Echtheit bestätigen kann. Eine solche Form von Kopierschutz trägt nicht zuletzt die Gefahr in sich, dass Software unbenutzbar wird, wenn der Support durch den Vertreiber nicht länger gewährleistet werden kann (vgl. Zacny 2014).

Offenbar sind also zumindest aus Sicht der Softwareindustrie durchaus nicht alle Kopien gleich geschaffen, und ganz wie das Museum bedient sie sich zur Etablierung ihres Authentizitätsverständnisses bestimmter Formen der Institutionalisierung: In ihrem speziellen Falle sind dies u.a. das Konzept des geistigen Eigentums und seine gesetzlichen Ausprägung in verschiedenen nationalen Jurisdiktionen, daran anknüpfend dann die betreffenden Rechtssysteme und die Polizei, die gegen Raubkopierer vorzugehen befugt ist. Wo das Museum baulich einen Raum der Authentizität generiert, schaffen Softwareproduzenten technische Grenzen und Rahmen des Authentischen. Wie das Museum seinen Besuchern bestimmte Maßstäbe des Wohlverhaltens auferlegt, versuchen auch die Hersteller von Computerprogrammen bei Nutzern bestimmte Benimmregeln und Tabus geltend zu machen. Wer sich vor einen Computerbildschirm setzt und mit Software umgeht, der begibt sich ebenso in ein verschachteltes Gefüge von Dispositiven wie der Besucher, der eine Museumspforte durchschreitet - und in beiden Fällen ist Authentizität eine Erscheinungsform von Macht, die vertikal zu den Linien zwischen Medien(technologien), Institutionen, Aussagen und Sagbarkeiten usw. verläuft, welche das Dispositiv ausmachen und welche nur im Prozess ihres performativen Ausspielens überhaupt Bestand haben. Entsprechend gibt es also durchaus eine Authentizität der digitalen Kopien, die laufend behauptet, verhandelt und natürlich immer wieder auch angegriffen und unterlaufen wird.

4 Vgl. http://www.microsoft.com/en-us/howtotell/Software.aspx vom 19.05.2018. 
Der Bibliothekswissenschaftler Jeff Rothenberg setzt sich in einem Text aus dem Jahre 2000 mit der Authentizität digitaler Information auseinander und definiert diese wie folgt:

The term authenticity [...] is used here in its broadest sense. Its meaning is not restricted to authentication, as in verifying authorship, but is intended to include issues of integrity, completeness, correctness, validity, faithfulness to an original, meaningfulness, and suitability for an intended purpose. (Rothenberg 2000)

Er bezieht diese bewusst unscharfe Vorstellung von Authentizität auf Objekte, die er als »informational entities« (ebd.) bezeichnet und die in ihrer Anlage stark den digitalen Objekten Yuk Huis und den Attributobjekten Marcos Novaks ähneln:

The term informational entity, as used here, refers to an entity whose purpose or role is informational. By definition, any informational entity is entirely characterized by information, which may include contextual and descriptive information as well as the core entity. Examples of informational entities include digital books, records, multimedia objects, Web pages, e-mail messages, audio or video material, and works of art, whether they are »born digital« or digitized from analog forms. (Ebd.)

Dabei nimmt auch Rothenberg zur Kenntnis, dass die Transkodierungsprozesse zwischen computer layer und culture layer den Charakter einer solchen Informationsentität immer wieder verschwimmen lassen. Weil sie auf technischer Ebene nichts weiter ist als ein Satz von Handlungsanweisungen, die ein Computersystem zunächst einmal interpretieren muss, um sie kulturell lesbar zu machen, ist ihre Authentizität an das korrekte Funktionieren von Hardware und Software gebunden, bevor sie vor irgendwelche kulturellen Richtstühle gestellt werden kann. Die erste Voraussetzung für den authentischen Erhalt digitaler Daten ist demnach gemäß Rothenberg der parallele Erhalt kompatibler interpreters, welche (weil der Computer selbst ja eine Meta-Maschine ist) meist ebenfalls die Form von Programmen annehmen werden (vgl. ebd.).

Der Erhalt von digitaler Information in Gestalt von informational entities müsse drei Ebenen umfassen, die Rothenberg alle als Teil desselben Informationsobjektes betrachtet. Die erste Ebene ist der bit stream - also die zeitlich gestaffelte Abfolge binärer Signale -, welche den eigentlichen Kerninhalt des Objektes bildet. Die zweite Ebene ist ein weiterer Datenstrom, der Metadaten über das Objekt beinhaltet. Diese können z.B. eine Herkunftsbeschreibung und Änderungs- bzw. Versionschronik enthalten, oder auch Prüfsummen, die es ermöglichen, die Informationsentität auf Manipulationen zu überprüfen. Auch lassen sich in den Metadaten Angaben zur notwendigen Auslesesoftware unterbringen, welche die dritte Ebene des Erhalts bildet: Will man eine Bilddatei auslesen, benötigt man ein Anzeigeprogramm, welches die Form 
der Codierung von Positions- und Farbkoordinaten `versteht $\iota$, die das entsprechende Dateiformat verwendet (vgl. ebd.). Ähnliches gilt für Text- oder Audiodateien: Digitale Daten ohne einen interpreter zu archivieren, wäre »analogous to saving hieroglyphics without a rosetta stone« (ebd.).

Der authentische Datenerhalt kann indes nicht immer nur auf Softwareebene gewährleistet werden. Auch den Verfall physischer Medien heißt es dabei miteinzukalkulieren. Magnetische Datenträger wie Festplatten, Floppy-Disketten und Magnetbänder verfügen ebenso wie optische CDs und DVDs über Lebensdauern, die weit unter denen von Papier oder Mikrofilm liegen. Und nicht nur der Verfall dieser Medien selbst ist problematisch, sondern auch jener der entsprechenden Ablesegeräte. Die Bitströme auf einer zwanzig Jahre alten Diskette könnte auch ein zeitgenössischer Rechner mit entsprechender Software noch auslesen - nur kann man sie ihm nicht zuführen, wenn kein entsprechendes Laufwerk mehr zur Verfügung steht. Während analoge Information lediglich einen »Schlüssel« - wie eben den Stein von Rosette - benötigt, um in ihrer Codierung verständlich zu sein, hängt die Interpretierbarkeit digitaler Daten von einer ganzen Infrastruktur ab. Entsprechend führt unter praktischen Gesichtspunkten die Frage nach dem Wie der Erhaltung digitaler Authentizität unweigerlich immer auch wieder zurück zum $O b$, wenn es nämlich um die Wirtschaftlichkeit eines solchen Unterfangens geht. Papier benötigt, sofern es keinen selbstzerstörerisch hohen Säureanteil enthält, lediglich einen klimatisch günstigen Lagerraum, um Jahrhunderte zu überdauern. Mikrofilm weist vergleichbar hohe Lebensspannen auf und benötigt grundsätzlich keine komplexere technische Anordnung zu seiner Wiedergabe als eine Lichtquelle und ein Vergrößerungsglas. Computerdaten hingegen sind an Speichermedien gebunden, die gerade angesichts der rasant fortschreitenden Entwicklung digitaler Technik laufend obsolet werden. Dasselbe gilt für Softwarestandards: Formate lösen einander ebenso ab wie Qualitätsvorstellungen. Bild- und Videogrößen, die vor wenigen Jahren noch als >hochauflösend betrachtet wurden, sind heute längst nicht mehr befriedigend. Digitale Erscheinungen sind in ihrem Informationsgehalt endlich und genau vermessbar - und wieviel Information als sviek gilt, hängt sowohl von der zu ihrer Verarbeitung zur Verfügung stehenden Technik als auch von wirtschaftlicher Zweckrationalität ab. Letztlich sind es nicht etwa die Kulturwissenschaftler, sondern die Ingenieure, die darüber entscheiden, wie viele Bits den Digitalisaten unserer materiellen Kulturschätze zustehen. Ein einmal geschaffenes digitales Objekt lässt sich nur sehr bedingt aufskalieren ${ }^{5}$ und wird niemals eine höhere informative Komplexität aufweisen als jene, in der es ursprünglich

5 Upscaling-Verfahren kommen z.B. bei digitalen HD-Fernsehern und Blu Ray-Wiedergabegeräten zum Einsatz, um beim Abspielen von älterem Videomaterial unterhalb des HDStandards von 1920x1080 Bildpunkten das >Verpixeln zu verhindern. Upscaling ist hier ein Sammelbegriff für eine Reihe von Software-Verfahren, die mathematisch Farbverläufe zwischen den Pixeln des Ursprungsmaterials interpolieren und diesen Effekt abmildern. 
abgespeichert wurde. Indes steigt die Auflösung von Computerbildschirmen mit jeder Gerätegeneration an, während ihre physische Oberfläche nur unterproportional mitwächst - was ganz praktisch bedeutet, dass dieselbe Bild- oder Videodatei mit jedem neuen Monitor etwas kleiner erscheinen wird. Während sich aus dem Negativ der analogen Fotografie grundsätzlich Fotos jeder Größe entwickeln lassen, kann die digitale Bilddatei akkurat nur in genau jener Anzahl von Bildpunkten wiedergegeben werden, deren Beschaffenheit sie beschreibt. Wird sie kleiner dargestellt, bleibt Information unsichtbar, vergrößert man sie, erscheint das Bild >verpixelt « - was nichts anderes heißt, als das nunmehr die Information für einen einzigen Bildpunkt über mehrere Bildpunkte verteilt werden muss und einzelne Pixel somit >vergrößert scheinen. Die digitale Abbildung ist also niemals langfristig zukunftsfähig, sie >schrumpft` ab dem Augenblick ihrer Entstehung bereits im Verhältnis zu den Möglichkeiten ihrer sich ständig entwickelnden technischen Wiedergabemöglichkeiten.

\subsubsection{Authentisierung als mediale Strategie}

David Bearman und Jennifer Trant, die gemeinsam das Beraterunternehmen Archives $\&$ Museum Informatics betreiben und die jährliche Museums and the Web-Konferenz ins Leben gerufen haben, machen hier die sehr interessante Feststellung, dass digitale Objekte typischerweise in genau den funktionalen Bereichen die größten Authentizitätsprobleme an den Tag legen, in denen sich auch ihre vielversprechendsten didaktischen Eigenarten entfalten. Digitale Objekte sind, so beobachten sie, immer »tied to methods« (Bearman u. Trant 1998) der Aktualisierung. Sie sind nicht einfach in dinghafter Art und Weise präsent, sondern darauf programmiert, sich im Zusammenspiel mit Software und Hardware auf eine bestimmte Art zu >verhalten`, und insofern ist das digitale Objekt auf der Ebene des Interfaces, über das wir es erleben können, immer eine automatisierte »performance« (ebd.). Diese Performance ist grundsätzlich verschieden von der Inszenierung von Exponaten in einer Ausstellung. Museumsdinge (und auch ihre analogen Kopien) weisen in ihrer Materialität eine gewisse Autonomie des Vorhandenseins auf, der Ausstellungspraktiken zwar aufgesetzt werden können, aber nicht innewohnen. Das digitale Objekt hingegen ist für die Aktualisierung in einer ganz bestimmten Konfiguration von Hardware und Programmen gemacht. Für Bearman und Trant ergibt sich daraus ein ganz klarer Mehrwert: Das digitale Objekt kann sich auf Arten >verhalten`, die weder ein materielles Objekt noch ein analog verfasstes Mentefakt leisten könnten. Digitale Texte können von Sprachsynthesizern >gesprochen`, digitale Partituren von simulierten Instrumenten >gespielt « werden. Solche Arten maschinell-virtueller Wiedergabe können dem Rezipienten Interaktionsmöglichkeiten aufschließen, die ihm in der analogen Darbietung

Ein solcher Videofilter kann jedoch keine Details ins Bild bringen, die nicht in den Ursprungsdaten schon vorhanden waren (vgl. Bates 2015). 
nicht zur Verfügung stünden (vgl. ebd.). Das Fallstudienkapitel wird eine Anzahl von Möglichkeiten aufzeigen, wie virtuelle Museen auf diese Art ein virtuelles `Mehr aus ihren Exponaten generieren können.

Dieses \Mehr steht indes speziell bei Digitalisaten physischer Gegenstände im direkten Gegensatz zu ihrer >authentischen< Darbietung. Digitalisierung nimmt also musealen Objekten nicht nur etwas, sie fügt ihnen auch etwas anderes hinzu. Und während das, was sie ihnen nimmt, immer dasselbe ist (nämlich ihre Materialität und informationelle Komplexität), ist das, was sie ihnen hinzufügt, sehr stark davon abhängig, für welchen Zweck bzw. für welche Form der Aktualisierung ein Digitalisat geschaffen wird. Dessen Authentizität zu gewährleisten hieße daher idealerweise, nicht nur seine Entstehungsumstände transparent zu halten, sondern auch die technischen Bedingungen der Rezeptionssituation und das Regelwerk, nach dem digitale Objekte sichtbar werden, klingen, agieren usw. (vgl. ebd.).

Darüber hinaus ist im Hinblick auf digitale Information die Frage nach der Authentizität immer verbunden, nicht aber gleichbedeutend, mit jener nach »authentication«. Während Authentizität sich nämlich auf die Daten selbst, ihre innere Integrität, ihre Herkunfts- und Änderungsdokumentation usw. bezieht, geht es bei der Authentisierung in erster Linie um Zugriffsrechte bzw. darum, wer wann und unter welchen Umständen etwas mit digitaler Information anstellen darf (vgl. ebd.). Auch dies ist natürlich für virtuelle Museen, die im Netz einen musealen Anspruch geltend machen wollen, ein eminent wichtiges Problemfeld. Im physischen Museum ist aus der Institution und ihrer personellen Praxis heraus bereits weitgehend abgesichert, dass nur eine sehr kleine Gruppe ausgewiesener Experten in die Ausstellung eingreifen kann - um im Museum kuratieren zu dürfen, muss man (von hochgradig partizipativ angelegten Einzelprojekten einmal abgesehen) als Kurator angestellt sein, und dies wiederum setzt voraus, dass man einen entsprechenden Ausbildungshintergrund hat, sich im Einstellungsverfahren gegen Mitbewerber durchsetzen konnte, usw. Maßt es sich der Besucher an, Exponate anzufassen oder gar zu bewegen, wird das Museumsdispositiv dieses Fehlverhalten bestrafen - womöglich mit Hausverbot oder einer Anzeige wegen Sachbeschädigung. Auch wenn dem Museumsbesucher nicht immer klar sein kann, welche Individualperson für einen bestimmten Teil der Ausstellung verantwortlich zeichnet, so wird ihm doch üblicherweise zumindest bewusst sein, dass ausgebildete Fachleute die ihn umgebende Ausstellung nach ebenso sachbezüglich wie pädagogisch legitimen Gesichtspunkten gestaltet haben.

Das physische Museum verfügt über Sicherheitskräfte und verschließbare Schauschränke, um seine Exponate vor den Händen des Publikums zu schützen. Virtuelle Museen müssen - und zwar zunächst einmal unabhängig davon, ob sie von etablierten Museumsschaffenden oder von interessierten Laien betreut werden - andere Möglichkeiten finden, um eine klare Erkennbarkeit kuratorischer Handschriften zu gewährleisten. Authentizität wird hier, so Bearman und Trant, unter praktischen Gesichtspunkten gleichbedeutend mit »content assurance«, und ihre Voraussetzung ist 
»access control«: Authentisch sind digitale Daten dann, wenn nur berechtige User mit ihnen umgehen konnten (d.h. die Identität der Nutzer bei jedem Zugriff verifiziert wurde), und alle an ihnen vorgenommenen Änderungs- oder Kopiervorgänge dokumentiert sind (vgl. ebd.). Die grundsätzlichste und naheliegendste Form der Zugriffskontrolle ist die über passwortgeschützte Administrator- (oder kurz `admin (-)Benutzerkonten, die idealerweise mit einem klar identifizierbaren Einzelnutzer oder einer kleinen Nutzergruppe assoziiert sind.

Eine solche Authentisierungsstrategie kann allerdings nur die Herkünfte und Genealogien von Kopien etablieren, bzw.: Sie kann Authentizität nur bis zur MasterKopie sicherstellen. Sollte es ein ihr vorgeschaltetes analoges Original geben, steht dieses außerhalb der Authentisierungskette. Die Integrität der Kopie in Relation zu einem physischen Vorbild ist durch jene indexikalische Unterbrechung kurzgeschlossen, die alle digitalen Reproduktionsverfahren auszeichnet. Entsprechend weisen die mit digitalen Abbildungsverfahren einhergehenden Authentizitätsprobleme auch weit über das hinaus, was klassischerweise in den Kultur- und Geisteswissenschaften unter dem Begriff der `Fälschung` abgehandelt wurde und wird. Zwar hat es in der Kunstgeschichte immer wieder spektakuläre und bisweilen für die Disziplin blamable Fälschungsfälle gegeben, aber insgesamt ist die Nachahmung physischer Kunstobjekte mit großem Aufwand verbunden und die Wahrscheinlichkeit einer Aufdeckung der Fälschung relativ groß, sobald das Objekt in den Warenstrom des Kunstmarktes gelangt und dem Blick von Fachleuten ausgesetzt ist. Materielle Gegenstände können auf verschiedensten Wegen auf ihre Echtheit hin überprüft werden - bei einem Gemälde könnten z.B. die chemische Zusammensetzung der Farbe und Leinwand oder Alterungserscheinungen Aufschluss darüber geben, ob es tatsächlich aus der Region, Epoche oder Urheberschaft stammt, die ihm zugeschrieben wird. Darüber hinaus wird keine analoge Kopie jemals völlig identisch mit dem Original sein - schon gar nicht bei einer handwerklich durchgeführten Kunstfälschung. Die Bits im Informationsstrom einer Bilddatei können hingegen nicht nur völlig fehlerfrei reproduziert werden, sie sind darüber hinaus auch mit keiner erkennbaren Provenienz versehen. Im Gegensatz zur Farbe auf einer Leinwand, die eine autonome Dinglichkeit aufweist und daher aus einer Herstellungs-Situation hervorgegangen sein muss, sind sie lediglich logische Funktionsvariablen, die einen von zwei Werten annehmen können. Von daher kann man sie gar nicht >fälschen<: Ist eine Datei mit der Masterkopie bitidentisch, dann kann sie völlig zu Recht als authentische Kopie gelten auch, wenn sie tatsächlich von Affen zusammengetippt wurde.

\subsubsection{Manipulierbarkeit und Formatierung digitaler Objekte}

Nun sind diese ontischen Probleme natürlich eher ein Problem für die Medientheorie und haben nicht unbedingt Auswirkungen darauf, wie wir im Alltag mit digitalen 
Abbildungen umgehen und ihre Authentizität bewerten. Natürlich könnte die Mona Lisa oder American Gothic auch nach dem Babel-Prinzip als zufälliges Ergebnis digitaler Kombinatorik entstehen (und genau dasselbe gilt auch für jeden schriftlichen Text, der uns im Netz begegnet), aber erstens ist diese informationstheoretische Problematik den allermeisten Usern wohl bestenfalls peripher bewusst, und zweitens wäre das Netz als Medium kultureller Kommunikation kaum erfolgreich zu navigieren, wenn man tatsächlich durch die Inhalte auf die blanke Technizität der Informationsverarbeitung blicken wollte. Wenn wir im Netz auf kulturell interpretierbare Inhalte stoßen - und tatsächlich stoßen wir ja kaum auf etwas anderes - dann gehen wir nicht davon aus, einen absurden Glücksgriff in der Bibliothek von Babel getan zu haben, sondern davon, dass das entsprechende digitale Objekt unter menschlicher Anleitung und Mitteilungsabsicht entstanden ist. Gerade weil der Computer auf seiner funktionalen Ebene völlig kulturfremd agiert, impliziert Verständlichkeit schon aus sich heraus das Wirken eines menschlichen Autors und damit ein Mindestmaß an Authentizität - zumindest soweit es individuelle Webseiten betrifft und nicht die Bezüglichkeiten, die von Suchmaschinen produziert werden. Die praktischen Schwierigkeiten bei der Authentifizierung ergeben sich bei Bearman und Trant vielmehr aus drei anderen Faktoren, die zwar alle mit den Eigenarten digitaler Technik zusammenhängen, ursächlich aber auf den Menschen zurückverweisen: erstens nämlich aus der niedrigen Hürde für die Verbreitung von digitaler Information und damit die schiere Datenmenge, deren Authentizität es zu bestimmten gilt, zweitens aus der ebenso großen Anzahl von Akteuren, die Daten verbreiten und damit Vektoren der Autorschaft verschwimmen lassen, und drittens aus der schon bei Friedrich Kittler akzentuierten Manipulierbarkeit digitaler Daten (vgl. ebd.).

Bearman und Trant verweisen darauf, dass im Web von jedem einigermaßen relevanten Kulturgegenstand zahlreiche Abbildungen kursieren, die sich alle voneinander unterscheiden und die typischerweise nicht mit detaillierten Herkunftsinformationen versehen sein werden (vgl. ebd.). Diese von ihnen schon 1998 gemachte Feststellung lässt sich in Zeiten der Google-Bildersuche natürlich noch viel deutlicher nachvollziehen. Wer hier im Juni 2015 die Worte `birth of venus` eingibt, der erhält einige tausend relevante individuelle Suchtreffer für Boticellis Gemälde, die sich alle in irgendeiner Form voneinander unterscheiden. Abbildungen liegen in unterschiedlichen Auflösungen vor. Der Rahmen wird manchmal mitabgebildet, manchmal nicht. Einige Aufnahmen wurden offenbar direkt am Original mit Digitalkameras gemacht, andere sind offensichtliche Scans von analogen Fotografien. Die Belichtungen und damit die individuellen Farbausprägungen variieren. Einige der gefundenen Bilddateien umfassen das gesamte Gemälde, andere sind Detailansichten und Ausschnitte. Einige Fotografien zeigen das Bild nicht frontal, sondern seitlich im Kontext seines Ausstellungsraumes in den Uffizi, zuweilen mit davorstehender Touristengruppe. Klickt man einige der Suchtreffer an, so stellt man schnell fest, dass nur wenige dieser Bilder sich auf den Homepages von Museen oder Bildungseinrichtungen 
befinden (uffizi.it selbst stellt das Gemälde in einer maximalen Auflösung von 2500x1560 Pixeln zur Verfügung ${ }^{6}$ ), und selten geht der Quellennachweis auf privaten Seiten über den Titel des Gemäldes, den Namen des Künstlers und vielleicht noch den Ausstellungsort hinaus. Wie die spezifische Abbildung zustande gekommen ist - ob es sich um eine direkte Fotografie oder um einen Scan aus einem Bildband handelt, von wem die ursprüngliche Fotografie wann aufgenommen wurde, welche Technik bei der Ablichtung zum Einsatz kam (vielleicht die wichtigste Frage von allen!) - all dies bleibt üblicherweise unbeantwortet.

Viel gravierender als das Problem der >Fälschung` (und damit implizit natürlich auch einer `Echtheit`, welche digitale Kopien so gar nicht aufweisen können) ist also die Verzerrung des Objektes durch die Vielfalt seiner Reproduktionen und der Kontexte, in denen sie präsentiert werden. Dieses Verwischen kultureller Objekte ist sicherlich schon in den Benjamin'schen Thesen zur technischen Reproduzierbarkeit und in Malrauxs Imaginärem Museum auszumachen. Mit Computerbildern erlangt es allerdings nach Bearman und Trant eine neue Qualität: Die Bearbeitung von Fotografien sei so einfach geworden, dass irreführende Manipulation nicht mehr die Ausnahme sei, sondern von uns im Umgang mit fotografischen Abbildungen buchstäblich erwartet werde - so, wie in der analogen Fotografie nach und nach die kosmetische Retusche zur Normalität geworden sei. Bearmans und Trants denken damit also über die indexikalischen Implikationen digitaler Bilderzeugung noch hinaus. Das digitale Bild verweist ihnen zufolge nicht nur nicht länger unzweifelhaft auf eine Entstehungssituation, sondern es steht von vorneherein im Zeichen einer Normalität der Täuschung:

New digital works are also challenging our concept of authentic representations, particularly in realms such as photography, where digital manipulation has extended the practice of retouching photographic prints beyond cosmetic to the misleading. Our faith in »visual documentation« is changing, as we learn of nature photographers cloning zebras, and moving pyramids; in some venues, such as Wired, digital manipulation is expected. (Ebd.)

Clifford Lynch spricht hier von einem »pervasive deceit« (Lynch 2000), der die wesentliche Eigenart aller digitalen Medien sei. Diese alles >durchdringende Irreführung ist natürlich schlicht eine Erscheinungsform des Virtuellen, und zwar im Sinne einer Behauptung der Anwesenheit des Abwesenden. Lynch wischt damit die Möglichkeit einer Authentizität digitaler Daten allerdings nicht etwa beiseite, sondern unterstreicht vielmehr, dass sie eine besonders rigorose Beweisführung benötige, um sich sowohl gegen konkurrierende nicht-authentische Daten als auch gegen das Misstrauen zu behaupten, dass ihrer Trägertechnologie schlechthin entgegenschlägt.

6 Vgl. https://www.uffizi.it/en/artworks/birth-of-venus vom 19.05.2018. 
Will man die Authentizität eines Dokuments oder eines materiellen Gegenstandes im »Meatspace«, also in der physischen Wirklichkeit überprüfen, so gibt es nach Lynch typischerweise vier Herangehensweisen, derer wir uns bedienen können. Die Erste wäre eine Untersuchung der Herkunft des Objektes - also der Dokumentation der Aufbewahrungsgeschichte, sollte eine solche vorliegen. In einem zweiten Schritt wäre dann zu klären, in wieweit einer solchen Dokumentation und den verantwortlichen Aufbewahrenden überhaupt zu trauen ist. Es geht hier also um Metadaten - und zugleich um den vertrackten Sachverhalt, dass auf diesem Wege das Authentizitätsproblem natürlich nur weitereskaliert wird und sich nun die Frage nach der Authentizität von Metadaten zusätzlich zu jener nach der des eigentlichen Objektes stellt. Die zweite Herangehensweise ist nach Lynch daher die der Untersuchung des Dokumentes oder Gegenstandes selbst auf seine Form und seinen Inhalt hin. Hier gilt es herauszufinden, ob diese Merkmale bestimmten, vorab gesetzten Authentizitätskriterien gerecht werden. Das dritte Vorgehen funktioniert ähnlich, bezieht sich aber weniger auf das eigentliche Objekt als auf seine unmittelbare Peripherie, wie z.B. Unterschriften, Siegel und sonstige Elemente, die ebenfalls auf ihre Stimmigkeit mit der behaupteten Herkunft hin zu prüfen sind. Das vierte Verfahren geht vergleichend vor: Hier wird das Objekt ähnlichen Gegenständen gegenübergestellt, deren Authentizität bereits anderweitig etabliert werden konnte. Dieses Verfahren ist besonders nützlich bei solchen Objekten, die aus der industriellen Massenfertigung hervorgegangen sind (vgl. ebd.).

Zugleich beobachtet Lynch hier eine Zuspitzung der Authentifizierungsstrategien aus dem Konkret-Materiellen ins Abstrakt-Inhaltliche: Es gibt eine Authentizität der Echtheit, und eine der Wahrheit. Ein äußerlich authentisches Dokument kann problemlos einen absurden oder erlogenen Inhalt aufweisen, und umgekehrt kann ein inauthentisches Dokument die volle Wahrheit enthalten. Es gibt daher eine aufsteigende Hierarchie der analytischen Zugänge beim Umgang mit historischen Überresten: Die erste und grundlegende Ebene ist die forensische, auf der es ganz schlicht um die Etablierung der materiellen Echtheit geht. Die zweite Ebene ist die Diplomatik, bei der die Historizität und damit das Problem im Vordergrund steht, ob das Objekt wirklich in den konkret behaupteten Entstehungskontext gehört. Die dritte Ebene wäre die intellektuell-logische Analyse der inneren Plausibilität und Konsistenz des Objektes. Viertens schließlich geht es dann um die Bestimmung der Wahrheitstreue und >Richtigkeit` des Inhaltes (sofern es sich bei dem Objekt um eines handelt, auf das solche Kategorien anzuwenden sind). Die beiden >höheren`, diskursiv-inhaltlichen Ebenen sind für Lynch bei digitalen Datenressourcen weniger problematisch, weil inhaltliche Analysen auf Wahrheitskriterien hin auch innerhalb eines digitalen Objektes möglich seien. Die beiden >niedrigeren` Ebenen - Forensik und Diplomatik - seien hingegen die schwierigen, weil sie klassischerweise das Zugegensein des materiellen Gegenstandes erforderten (vgl. ebd.). 
Für Lynch ist die nachweisbare Integrität des Objektes die notwendige Bedingung seiner Authentizität. Integer ist ein Objekt dann, wenn Zeit und Überlieferung es nicht korrumpiert haben, wenn es also mit seinem Ursprungszustand identisch ist. Wie bereits festgestellt wurde, bedarf es bei digitalen Objekten hierzu einer verifizierten Masterkopie. Diese muss, so Lynch weiter, in einem »kanonischen« Format vorliegen (vgl. ebd.). Kanonische Formate erscheinen ihm schlechthin als Schlüssel zu einer authentischen Bewahrung digitaler Information: Sie sollen möglichst unkomprimierte Datencontainer sein, in denen Erstreproduktionen abgespeichert werden, und die bei jedem erneuten Speichervorgang unverändert bzw. bitidentisch bleiben. Dies ist durchaus nicht selbstverständlich: Textverarbeitungsprogramme wie Microsoft Word beispielsweise speichern dasselbe Dokument jedes Mal mit leicht veränderten Junk- oder Metainformationen ab, auch wenn am eigentlichen Text keine Veränderung vorgenommen wurde. Kanonische Formate hingegen sollen nichts enthalten außer dem digitalen Objekt selbst - und sich so ggfs. sogar zum notariellen Abgleich heranziehen lassen (vgl. Lynch 1999). Sie bilden damit gewissermaßen den Gegenpol (und zugleich die notwendige Ergänzung) zum >digitalen Wasserzeichen`, das ja immer einen Eingriff in die Information darstellt, deren Authentizität es absichern und beglaubigen soll - und dabei die Integrität des Objektes umso stärker kompromittiert, je fester es eingebaut ist. Kann man es hingegen leicht entfernen, ist die Integrität des gekennzeichneten Objektes zwar weniger beeinträchtigt, aber der Nutzen des Wasserzeichens ist überaus fraglich. Wasserzeichen können daher nur authentizitätsstiftend wirken, wenn sie mit einer unversehrten, in einem kanonischen Format vorliegenden Urkopie abgeglichen werden können (vgl. ebd.).

Mit der schon von den Digital Humanities im Hinblick v.a. auf Texte formulierten Formatfrage ist für virtuelle Museen allerdings ein massives logistisches Problem angezeigt: Museen weisen nämlich eine weit größere mediale und physiognomische Vielfalt in ihrer Sammlung auf als Bibliotheken oder Archive, was die Auswahl sinnvoller kanonischer Formate schwierig macht (vgl. Blackaby 1997: 222). Bei der Formatierung digitaler Exponate zeigt sich also ein ganz ähnliches Problem wie bei der Vereinheitlichung von Datenbanken: Es ist naheliegend, Gemälde zweidimensional, also als Bilddateien zu digitalisieren - wie verhält es sich aber mit Skulpturen, oder ethnographischen und technikgeschichtlichen Artefakten? Die (digital-)fotografische Abbildung ist augenblicklich noch die Leittechnologie virtueller Museen, aber auch die dreidimensionale Reproduktion mithilfe von optischen oder distanzbasierten 3DScannern ist längst technisch machbar. Die in Leinfelden-Echterdingen ansässige Firma Creaform beispielsweise stellt tragbare optische Geräte her, mit denen der zu digitalisierende Gegenstand lediglich aus verschiedenen Richtungen >geknipst « werden muss, um ein digitales Modell mit millimeterkleinen Toleranzen entstehen zu lassen - und wirbt ganz explizit nicht nur mit industriellen Anwendungen, sondern auch mit dem Nutzen für die Denkmalpflege und in der Bewahrung von Kunstgegen- 
ständen. ${ }^{7}$ Ein solches Scanverfahren erzeugt nicht nur eine `Karte` von Bildkoordinaten und Farbwerten, sondern komplexe Geometriedaten, die ein rendering des Objektes als ein in Echtzeit bewegliches 3D-Modell ermöglichen. Solche Datensätze müssen logischerweise ganz anders formatiert werden als reine Bilddateien, benötigen aber zugleich auch eine Oberflächentextur, die wieder als zweidimensionales Bild vorliegt. Darüber hinaus brauchen virtuelle Museen genau wie physische erklärende Texte, die es ebenfalls zu formatieren gilt (hier zumindest ist mit HTML bereits eine Auszeichnungssprache vorgegeben). Möglicherweise möchten virtuelle $\mathrm{Mu}-$ seen, sofern die Mittel und das Know-How zur Verfügung stehen, auch Video- und Tonmaterial zur Verfügung stellen. Alle diese digitalen Objekte erfordern andere Digitalisierungsstrategien und somit auch andere Formate - und diese Formate müssen nicht nur auf der Betreiberseite zweckdienlich, sondern sie müssen auch für die heimischen Nutzer und ihre jeweiligen decks anschlussfähig sein. Es geht also nicht nur um bestmögliche Bewahrung, sondern immer auch um die Antizipation von Schnittstellen - und damit wiederum um wirtschaftliche Erwägungen: Lohnt es sich z.B., für die Wiedergabe von Videodateien eine eigene Infrastruktur aufzubauen und damit die volle Kontrolle über das Material zu behalten? Oder wäre es praktischer, Videos auf Seiten wie Youtube oder Vimeo hochzuladen, sie von dort aus über von den Betreibern unterstützte Softwareskripte auf der eigenen Webseite einzubinden und sich damit die Kosten für eigene Server und Bandweite zu sparen, zugleich aber auch ihre Rezeption außerhalb der eigenen didaktischen Architektur zu ermöglichen bzw. vielleicht sogar Nutzungsrechte an kommerzielle Akteure abtreten zu müssen? Authentizität muss hier unweigerlich mit Praktikabilität abgewogen werden. Je spezifischer und individueller die Formatierung, desto leichter ist es für die Betreiber virtueller Museen, die Authentizität ihrer Daten zu gewährleisten. Je gewöhnlicher hingegen die Formatierung, umso größer ist die Kompatibilität ihres Angebotes mit einer möglichsten hohen Anzahl von decks, und damit aber auch das Maß der Veräußerung von Inhalten an Suchmaschinen und ihre Relevanzsysteme.

Überhaupt stellt das Fehlen verbindlicher Standards für die Formatierung musealer Digitalisate der Entstehung eines virtuellen Universalmuseums technisch mindestens ebenso sehr im Wege, wie es das klassische Selbstverständnis der Institution Museum kulturell tut. Es gibt derzeit keine großen Initiativen zur funktionalen Vereinheitlichung musealer Internetpräsenzen über gemeinsame Formatierungsstandards. Entsprechende Versuche finden eher im Kleinen statt. Ein Beispiel wäre hier die Arbeit des 2002 am Massachusetts Institute of Technology gestarteten Projekts Visualizing Cultures. Dieses hat es sich zur Aufgabe gemacht, interkulturelle Bildquellen für Wissenschaftler und Lehrende zu erschließen und innerhalb eines einzigen, geeinten Abrufsystems verfügbar zu machen. Damit sollen erstens zuvor nicht

7 http://www.creaform3d.com/lp/template1/goscan3d/de/index.php vom 19.05.2018. 
oder nur lokal zugängliche Schätze von Bildmaterial für ein breites und weit verstreutes Fachpublikum aufgearbeitet, zweitens die Voraussetzung für das Schreiben und die Veröffentlichung illustrierter Aufsätze geschaffen, und drittens neue Möglichkeiten für die computergestützte Analyse von Bildquellen geschaffen werden. Das Projekt möchte seinem Selbstverständnis nach ein Umschlagplatz zwischen den die Bildbestände bewahrenden Institutionen und den Wissenschaftlern sein, die für ihre Forschung auf diese Bestände angewiesen sind (vgl. Fleming, Shunk u. Steward 2008). Zu diesem Zweck arbeitet Visualizing Cultures mit einer Anzahl von Museen wie dem Bostoner Museum of Fine Arts zusammen, das seinen mehr als 350.000 Einzelobjekte umfassenden Fundus online zugänglich macht - inklusive der mit etwa 100.000 Exponaten größten Sammlung japanischer Kunst außerhalb Japans.

Das Projekt legt dabei sehr großen Wert auf die effiziente, technische Integration dieser digitalen Abbildungen in sein Datenbanksystem. Visualizing Cultures hat eine meta-museale Zielsetzung, die neben der Kooperation der Einzelinstitutionen auf gemeinsame Standards der Datenverwaltung und -verarbeitung angewiesen ist. Um nicht nur die Abrufbarkeit, sondern auch die Nutzbarkeit der Daten zu gewährleisten, müssen sie zwischen einzelnen Computersystemen beweglich bleiben - und das bedeutet vor allen Dingen, dass die eigentlichen Inhalte funktional von den jeweiligen Benutzerinterfaces und ihren Implementierungen getrennt gehalten werden müssen. Man spricht hierbei von einer Service-Oriented Architecture (SOA): Die Datenbank bringt keine eigene Benutzeroberfläche mit, sondern kann von ganz unterschiedlichen Interface-Systemen angesprochen werden, ohne dass die Authentisierung ihrer Inhalte davon betroffen wäre. Visualizing Cultures arbeitet dabei eng mit der Open Knowledge Initiative (OKI) zusammen, die sich die Etablierung möglichst universeller Digitalisierungs-Standards zum Ziel gesetzt hat, und deren Richtlinien die Schnittstelle für das MIT-Projekt bilden: Jeder Dienst, der sich an die OKI-Standards hält, kann grundsätzlich produktiv mit der Datenbank interagieren (vgl. ebd.).

\subsubsection{IVertrauen als Praxis des Authentischen}

Was sich hier beobachten lässt ist eine Kanalisierung des Authentischen in immer neue und zunehmend abstrakte Vektoren der Beglaubigung und Absicherung. Das Museum garantiert die für seine Besucher selbst nicht überprüfbare Authentizität seiner Exponate und stützt sich dabei auf ein Expertenwissen, das viel zu komplex ist, als dass es in der Ausstellung in seiner Gänze dargeboten werden könnte. Es überführt daher dieses komplexe Wissen in weiten Teilen in eine kaum hintergehbare institutionelle Autorität, in der nicht mehr wissenschaftliche Fundiertheit der direkte Garant der Authentizität ist, sondern die museale Inszenierung selbst (dies wäre eben die >Tempel<-Funktion des Museums). Ein meta-museales Projekt wie Visualizing 
Cultures wiederum borgt sich diese Autorität und übersetzt sie für seine eigene Ausstellungsabsicht abermals in eine praktische und zweckdienliche Form, die nun aber (der digitalen Trägertechnologie geschuldet) nicht mehr nur kulturell funktionieren kann, sondern eine funktionale Entsprechung auf dem computer layer erfordert. Diese Entsprechung sind eben Formate, Standards und Protokolle, welche die Kanonizität der Inhalte und das Wohlverhalten der User gleichermaßen absichern sollen.

Dabei ist allerdings, wie Clifford Lynch feststellt, das Authentizitätserlebnis im virtuellen Museum (und, so könnte man hinzufügen, aller Wahrscheinlichkeit nach auch im physischen) weniger an konkrete technische Verfahren der Authentifizierung als vielmehr an die Annahme gekoppelt, dass entsprechende Mechanismen im Hintergrund der >Ausstellung` wirksam sind. Vom Endnutzer könne man überhaupt nicht erwarten, die Daten, mit denen er umgeht, in irgendeiner Weise zu authentifizieren: Der >Besucher` eines virtuellen Museums wird üblicherweise weder Zugriff auf die Masterkopie, noch auf die genaue Herkunftsdokumentation eines digitalen Exponates haben, wie immer es auch verfasst und formatiert sei (vgl. Lynch 2000). Und natürlich würde die Einforderung einer solchen Leistung auch völlig dem musealen Erfahrungsmodus zuwiderlaufen, den wir aus dem physischen Museum gewohnt sind. Im Museum müssen wir normalerweise weder Kenner sein, die jeden Semiophor aus ihrem Vorwissen heraus als authentisch identifizieren können, noch müssen wir zu Bürokraten mutieren, welche in die Sammlungsdokumentation eintauchen und die Provenienz der Exponate an den papiernen Spuren ihrer Aufbewahrung nachhalten. Der Tempel gewährleistet die Heiligkeit seines Inhaltes aus dem Umstand heraus, dass er Tempel ist und von einer Priesterschaft als solcher bespielt wird. Die Abduktion ist per Institutionalisierung ermöglicht, während die Voraussetzungen für Induktion, Deduktion und Transduktion kuratorisch gemacht werden müssen.

Damit geht es also, fasst Lynch zusammen, letztlich auf der Rezipientenseite zentral immer um »Vertrauen« (ebd.). Dieses Vertrauen ist nicht einfach das aufsummierte Produkt zusammenwirkender Authentisierungsstrategien, sondern wieder eine Machtlinie im Netz eines Dispositivs, in welchem diese Strategien mit zahlreichen anderen Faktoren interagieren. Während also die Virtualisierung des Musealen zunächst darin besteht, Digitalisate von physischen Museumsexponaten zu erstellen und diese innerhalb einer virtuellen Informationsarchitektur für eine von musealen Vermittlungsabsichten getragene Präsentation aufzubereiten, heißt Musealisierung des Virtuellen vor allen Dingen: diese Informationsarchitektur so zu gestalten, an die Außenwelt anzubinden und zu narrativieren, dass sie von ihren Nutzern als ein Garant des `Echten von digitalen Objekten eine wichtige Rolle - äquivalent und zugleich nachgeschaltet jener von Fachwissenschaften wie Archäologie oder Kunstgeschichte, welche die Echtheit physischer historischer Überreste bestimmen und diese damit für museabel 
befinden. Zugleich aber müssen einem virtuellen Museum ganz ähnliche Fragen gestellt werden wie einem physischen, wenn man sein Wirken als Dispositiv verstehen will: Wie organisiert es Sichtbarkeiten und Sagbarkeiten? Wen lässt es sprechen, wen schweigen? Wie führt es Objekte zueinander und Betrachter zu Objekten? Und wie genau werden alle diese vernetzten Einzelelemente zusammengeführt, um welche Spielart des Musealen zu evozieren?

\subsection{DIE DISPOSITIVE DES VIRTUELLEN MUSEUMS}

Hier muss zunächst die ganze Tragweite der Tatsache ins Auge gefasst werden, dass das virtuelle Museum eben weder einen Ort noch ein Gebäude hat, die es beherbergen - und dass wir natürlich dennoch auch im Umgang mit digitaler Technik Wesen mit analogen Körpern bleiben, die sich im physikalischen Raum aufhalten. Dementsprechend erleben wir natürlich auch virtuelle Museen innerhalb von Räumen, und zwar bezeichnenderweise meist solchen, die keineswegs museal sind. Das virtuelle $\mathrm{Mu}-$ seum kann uns im Gegensatz zum physischen kein außeralltägliches soziales Setting auferlegen, das in einer baulichen Separation von der Außenwelt evident wäre. Stattdessen ist sein räumlicher Schauplatz immer der, in dem sich das deck befindet, mittels dessen es technisch aktualisiert wird. Natürlich sind Dispositive niemals abschließbar oder gar souverän, und auch das physische Museum bildet hier keine Ausnahme. Allerdings ist seine architektonische und institutionelle Erscheinung sehr dazu angetan, es dem Besucher als ein geschlossenes System erscheinen zu lassen, das >offen`allenfalls zu jener Vergangenheit ist, deren Überreste es im Empfang nimmt, bewahrt und ausstellt. Gerade darin begründet sich ja das Gegenweltliche und Halbsakrale, das Paul Valéry als so irritierend empfindet und in dem Krysztof Pomian das Vermächtnis des Musentempels erkennt.

Das virtuelle Museum hingegen kann sich nicht dem Sachverhalt entziehen, dass seine innere Dispositivstruktur, wie immer sie auch aufgebaut sein mag, nur >begehbar` ist innerhalb einer äußeren, die ganz und gar alltäglich bleibt. Die Computer, mit denen wir im Netz surfen, stehen in unseren Arbeits- und Wohnzimmern, wir benutzen sie auf Parkbänken und in Restaurants, bei der Arbeit und in der Freizeit, nehmen sie zuweilen gar mit ins Bett. Die in der Cyberspace-Idee anklingende und im Hinblick auf die von uns an digitale Medien gerichteten Erwartungshaltungen immer noch oft nachwirkende Vorstellung vom Virtuellen als medialem Ausnahmezustand bildet unsere Medienpraxis längst nicht mehr ab. Als Technologie sind Computer für uns nicht weniger alltäglich als Staubsauger, Toaster, Automobile oder Heizkörper. Wir gehen mit ihnen um, ohne sie noch wahrzunehmen - und damit sind sie eben Gebrauchsgegenstände des Aktionsraumes. Anette Spohns Feststellung, das Web schule uns auf eine das >Übersehen` ins Zentrum stellende Wahrnehmung, beschreibt 
im Grunde die gesamte Programmatik der digitalen Kultur und ihrer Interface-Systeme: Es geht darum, den Computer zu einem >zuhandenen « Gegenstand zu machen, der in seiner eigenen Funktionalität verschwindet.

\subsubsection{Alltäglichkeit und Auratizität des Virtuellen}

Damit ist die materielle Schnittstelle zwischen dem virtuellen Museum und seinem Publikum ironischerweise in jeder Hinsicht die Antithese des Museums und der Museumsdinge: Sie ist der Inbegriff der Alltäglichkeit und der Normalität. Eine Systematisierung der sozialen Räume der Computernutzung und der mit ihnen verbundenen Dispositive versucht Michael Liebe mit Augenmerk auf Computerspielen zu entwickeln. Der klassische Desktop-PC gehört seiner Auffassung nach ins Dispositiv "Arbeit« (Liebe 2008: 78): Er ist relativ groß und unhandlich, steht typischerweise auf einem Schreibtisch, vor dem der Nutzer aufrecht sitzt und besteht aus einer Anzahl von Einzelkomponenten, zu denen neben dem Rechner selbst ein Monitor und diverse Ein- und Ausgabegeräte gehören. Die Spielkonsole hingegen sei im Dispositiv »Wohnen« verortet: Sie wird an ein Fernsehgerät angeschlossen, das sich meist in einem Wohnzimmer befindet, und von einem Sofa aus in bequemer Körperhaltung mit einem einzigen, sehr beweglichen Steuergerät oder controller bedient (vgl. ebd.: 79). Die mittlerweile exotisch gewordene Gattung der »Arcade-Geräte« gehört nach Liebe ins Dispositiv »Freizeit«, weil sie für gewöhnlich gar nicht in Privathaushalten steht, sondern in öffentlichen bzw. in Geschäfts-Räumen beheimatet und in der Anschaffung überaus teuer ist (vgl. ebd.: 78). Handheld-Geräte wie Tablet-Computer und Smartphones schließlich fallen seiner Ansicht nach unter das relativ junge und noch schwammige Dispositiv »Mobilität«, weil sie batteriegetrieben, klein dimensioniert und entsprechend nicht ortsgebunden sind (vgl. ebd.).

Diese grobe und gar nicht den Anspruch auf Ausdifferenziertheit erhebende Klassifizierung von den Umgang mit Computern bedingenden Raumverhältnissen beschreibt nicht nur die Nutzerseite, sondern nach Liebe auch die gedachten Szenarien, für die Softwareentwickler Programme konzipieren. Der PC werde z.B. so sehr als Arbeitsrechner gedacht, dass selbst für den PC entwickelte Unterhaltungssoftware die Attribute von Arbeitsanwendungen aufweise, wie dies z.B. bei Strategiespielen oder Massively Multiplayer Games der Fall sei (vgl. ebd.: 79ff.). Software für Spielekonsolen (die mittlerweile ja längst nicht mehr nur `Spieleく im engsten Sinne beinhaltet) sei auf geselliges, freundschaftliches, aber auch wettbewerbsorientiertes Miteinander von Menschen ausgerichtet, die sich auch in Zeiten vernetzter MultiplayerErfahrungen noch häufig im selben Raum aufhalten und mit derselben Konsole spielen (vgl. ebd.: 79). Arcade-Spiele sind auf Profitmaximierung ausgerichtet und suchen dementsprechend die Balance zwischen »Lust und Frust«, die den Spieler ei- 
nerseits für seine Erfolge arbeiten lässt (ihn also immer wieder zu erneuten Versuchen animiert), ihn andererseits aber nicht so sehr frustriert, dass er das Handtuch wirft (vgl. ebd.: 83ff.). Software für Handheld-Geräte schließlich sei auf Spontanität und Unkompliziertheit ausgerichtet, dürfe also nicht zu viele Bedienelemente aufweisen und müsse sich jederzeit beenden oder anhalten lassen, wenn der Nutzer sein Gerät schnell einpacken oder beiseitelegen muss (vgl. ebd.: 88f.). Was Liebe für Computerspiele diagnostiziert, muss auch für virtuelle Museen gelten: Will man im Netz museal präsentieren, dann muss man ein bestimmtes Bild nicht nur vom Nutzer, sondern auch von seinem Endgerät und der Raumsituation haben, in der es sich befindet. In vielen Fällen wird dies eine Entscheidung für und gegen bestimmte Rezeptionsszenarien erforderlich machen, weil unterschiedliche decks unterschiedliche Designs und Informationsarchitekturen erfordern. Eine Webseite, die auf einem PC bzw. seinem großen Monitor gut aussieht und leicht zu handhaben ist, kann auf einem Tablet oder gar einem Smartphone kaum zu lesen, geschweige denn zu navigieren sein. Eine separate mobile Webseite zu erstellen kostet wiederum Zeit und Geld, das möglicherweise nicht immer zur Verfügung stehen wird.

Das kulturelle und räumliche Milieu des virtuellen Museums ist also ein prekäres, weil es tatsächlich notwendigerweise ein veräußertes Museum ist - und zwar veräußert nicht nur an das WWW, seine Technizität und die ihm aufgesetzten Such- und Ordnungsmaschinerien, sondern auch an die technischen Gegebenheiten von Endgeräten und die soziale Welt, in der diese betrieben werden. Der Frage, ob und wie ein virtuelles Museum seiner >Besucherschaft〈 irgendeine Form von Rezeptionserfahrung didaktisch vorzugeben imstande sein kann, ist grundsätzlich die Tatsache vorgeschaltet, dass es unmöglich die Gesamtsituation des virtuellen >Besuchs ‘ bestimmen kann. Das physische Museum ist - um abermals die Diktion Beat Hächlers aufzugreifen - eine soziale Szenographie, während das virtuelle sich innerhalb ganz anderer Settings entfalten muss, die keiner intentional-autorschaftlichen Gemachtheit unterliegen. David Filkins in Kapitel 3.3.2 dieser Arbeit diskutierte Rede von der >Missionierung` des WWW durch das Museum greift daher tatsächlich fast zu kurz. Will man die Missions-Metapher konsequent anwenden, dann zielt das virtuelle Museum in seinen Missionsbestrebungen nicht nur auf das Web, sondern tatsächlich auf den `Alltag $<$, bzw. auf jene kulturelle Normalität, von der geschieden zu sein zuvor definierendes Merkmal der Institution Museum war. Hatte das Imaginäre Museum Malrauxs die virtuelle Latenz der Möglichkeit beschrieben, Kulturobjekte außerhalb von Museumswänden miteinander kommunizieren zu lassen, will das ausgewiesen virtuelle Museum nun tatsächlich die Aktualität (!) musealen Erlebens unter den Voraussetzungen der Alltäglichkeit.

Zugleich aber liegt die große, immer noch andauernde Widersprüchlichkeit in unserer Bewertung digitaler Medientechnologien darin, dass Computern nach wie vor das ganze diskursive Erbe der Utopien und Machbarkeitsphantasmen anhaftet, die sich im Laufe ihrer Geschichte mit ihnen verbunden haben. Ihre Normalität ist 
eine gebrochene, in der die Selbstverständlichkeit im Umgang mit dem Einzelgerät einerseits einem scheinbar nicht totzukriegenden Verdacht der Irrealität und der Täuschung, andererseits einer womöglich völlig überspitzten Erwartungshaltung an die Technologie insgesamt gegenübersteht. Wie die Journalistin Astrid Herbold in ihrer Streitschrift Das große Rauschen pointiert feststellt, sind Digitalisierungsphänomene häufig von extrem optimistischen Fortschrittsversprechungen getragen: Hinter der oberflächlichen Spekulation auf größere Praktikabilität in der Verwaltung und Übermittlung von Daten stehe die größere Hoffnung darauf, kulturelle und geistige Entwicklungen flexibilisieren und beschleunigen zu können, indem man kulturelle Inhalte von sperrigen, materiellen Trägern löst. Die Idee der Universaldatenbank sieht Herbold nach wie vor als eine treibende Kraft hinter Virtualisierungsprojekten jedweder Art (vgl. Herbold 2009: 131ff.). Das Web als solches sei immer noch umgeben vom Nimbus der Möglichkeit, zu einem zugleich absoluten und von aller autorschaftlichen inhaltlichen Auslese befreiten Wissenssystem heranwachsen zu können, in dem der Leser sich Zusammenhänge nicht länger erarbeiten muss, sondern sie in Vollendung vorfindet (vgl. ebd.: 139ff.). Parallel dazu macht Herbold die interessante und durchaus nachvollziehbare Beobachtung, dass dem von Technikskeptikern und Kulturkritikern immer wieder geäußerten Täuschungsverdacht von den >digital natives` häufig mit einem großen Vertrauen in die Wahrhaftigkeit digitaler Information begegnet werde. Tatsächlich lebe das Web nicht etwa vom Versprechen perfekter Simulation und glaubhafter Sinnestäuschung, sondern vielmehr von jenem authentischer zwischenmenschlicher Kommunikation und >echten` Begegnungen im virtuellen Raum zwischen den Rechnern. Phänomene wie Online-Dating oder die Popularitätsexplosionen um Youtube-Persönlichkeiten sind nach Herbold sinnfällige Beweise dafür, dass das Publikum sich vom Web eben gerade Momente des Echten, des Unmittelbaren und der Aufrichtigkeit verspreche (vgl. ebd.: 81ff.).

Computer sind also in all ihrer Gewöhnlichkeit durchaus eine auratische (oder zumindest immer wieder aufs Neue auratisierte) Technologie, und die ihnen zugeschriebene Besonderheit wird auch im Umgang mit Computern als materiellen Gegenständen ausgespielt. Menschen übernachten dokumentiertermaßen vor Apple-Ge-

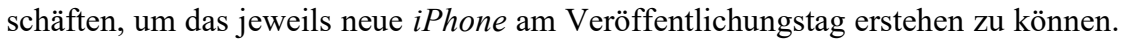
Case modder versehen ihre für Computerspiele gebauten PCs (die nicht selten als Sportgeräte wahrgenommen werden) mit bunten LED-Leuchten und Gehäusefenstern, die den Blick auf ihr eigentlich völlig unanschauliches Inneres freigeben. 2013 ergab eine Umfrage der Firma Vuclip, dass 61 \% der befragten Männer befürchteten, von anderen Menschen nach Marke und Modell des von ihnen benutzten Handys beurteilt zu werden. ${ }^{8}$ Computer sind ästhetisierte Statussymbole, in ihrer Gegenständ-

8 Vgl. http://www.pewinternet.org/fact-sheets/mobile-technology-fact-sheet/ vom 19.05.2018. 
lichkeit eine gewichtige Rolle in der sozialen Kommunikation spielen. Dies ist natürlich kein Novum in unserem Gesellschafts- und Wirtschaftssystem. Für Automobile gilt ja ganz ähnliches. Allerdings sind Computer eben nicht nur materielle Gegenstände, die in eine Semiotik des Konsums eingebunden werden können, sondern auch Medientechnologien, die ihrerseits für die Erstellung, Übertragung und Rezeption kultureller Inhalte eingesetzt werden. Der den Computer umgebende kulturelle Bedeutungskonnex betrifft also immer auch all die Information, die mittels des Rechners übertragen und rezipiert wird.

Die in Kapitel 6.1.1 dieser Studie festgestellte Tatsache, dass Museum und Web sehr gegensätzlich mit ihrem jeweiligen Netzwerkparadigma umgehen, betrifft in diesem Zusammenhang nicht nur ihre epistemischen (bzw. im Falle des Museums auch didaktischen) Eigenarten, sondern auch ihre affektive Anmutung. Die Aura der Museumsdinge und die Atmosphäre des musealen Raumes sind das Produkt einer Geschiedenheit von der Außenwelt und einer Verbriefung von Authentizität durch das Wirken eines auf Ab- und Ausschluss zielenden Ausstellungskonzeptes, das wiederum auf kuratorische Arbeit und damit die Autorität von Spezialisten zurückweist. Das Web und die decks, mittels derer wir es aktualisieren, beziehen ihre Anmutungsqualitäten hingegen gerade aus einer kulturellen Programmatik der (zumindest scheinbaren) Offenheit, der Zugänglichkeit, der Nichtabschließbarkeit und der Verhandelbarkeit von allem durch alle. Damit unterliegen die Erlebnisqualitäten von Museum und Web zugleich anderen Zeitlichkeiten. Das Museum will als kommemorative Einrichtung die Vergangenheit ins Heute bringen, artikuliert sich also im Präsens (und in der Präsenz) seiner Exponate über Sachverhalte, die grundsätzlich abgeschlossen sind. Das ist das Virtuelle an ihm und jener Brückenschlag zwischen Anund Abwesendem, den Pomian ins Zentrum seiner Charakterisierung der Institution stellt. Das Web hingegen ist, wie Erik Meyer feststellt, ein Medium von extremer Gegenwartsbezogenheit, und zwar sowohl im zeitlichen wie im räumlichen Sinne. Es stelle uns ein permanentes und zunehmend ortsunabhängiges >Dabeisein` und eine Teilhabe am Weltgeschehen in Aussicht, die sich unmittelbar verbinde mit einem dank digitaler Speichertechnik schier unbeschränkten Erinnerungspotential. Wir können, so Meyer, mittels digitaler Kommunikation die Kommemoration schon in Angriff nehmen, während sich die Geschichte noch ereignet (vgl. Meyer 2009: 196). Abwesenheit ist in einer solchen Präsenzkultur schlicht nicht mehr vorgesehen.

\subsubsection{Musealität zwischen Bildungsauftrag und Wunscherfüllung}

Die paradoxe Situation virtueller Museen ist also die, dass sie zwar einerseits imstande sind, eine viel größere >Öffentlichkeit zu adressieren, als es jedes individuelle, ortgebundene physische Museum könnte - andererseits diese Öffentlichkeit aber 
in der Domäne des Privaten >abholen` müssen. Damit stellen sie nicht nur die definitorischen Grenzen des Museumsbegriffs infrage, sondern auch den sozialen Ort der Institution. Zur medialen Wesensart des Museumsdings gehört die Tatsache, dass man es nicht aus der Ausstellung entfernen kann, ohne es seiner Sinnhaftigkeit zu berauben. Damit geht einher, dass der Museumsbesucher meist nicht in der Lage sein wird, die Exponate allein zu erleben. Das Erfahren einer Ausstellung ist immer ein soziales: Selbst wenn die Besucher nicht miteinander reden, teilen sie sich doch einen Raum und müssen einander allermindestens vor den Schaustücken Platz machen. Das spossessive individual Weinsteins und Krokers hat im physischen Museumdispositiv keinen Platz, weil dieses ihm aus seiner ganzen Anlage heraus eben den Besitz der Ausstellungsstücke unmöglich macht. Im virtuellen Museum hingegen kann das Objekt nicht nur in einer >autistischen`, hochindividualisierten Situation erlebt werden, man ist außerdem auch Eigentümer der materiellen Infrastruktur seines Erscheinens. Das Museumsding besitzt keine physische Autonomie mehr, sondern ist ein Funktionsbündel innerhalb der technischen Anordnung von Computer und Bildschirm.

Zugleich arbeiten Suchmaschinen in die genau gegensätzliche Richtung: Hier werden private Vorlieben einem Auswertungssystem offengelegt, das diese (angeblich anonymisiert und entpersonalisiert) an die >Öffentlichkeit` seiner Nutzer zurückkommuniziert, das also ständig das Individuum zur Masse ins Verhältnis setzt. Das >besitzergreifende Individuum ‘ wird hier gewissermaßen vom Subjekt zum Objekt: Indem es sich als souveräner Akteur begreift, der sich Information aneignet, wird es tatsächlich zu einem Ort innerhalb eines technosozialen Dispositivs gemacht, an dem Technologien Privatheiten und Öffentlichkeiten neu verhandeln, an denen sie inhaltlich gar nicht teilnehmen können. Der Preis einer hochindividualisierten Rezeptionserfahrung im Web ist tatsächlich die Entprivatisierung von Interessen und Entscheidungen.

Indes ist auch das physische Museum - in das, wie Eilean Hooper-Greenhill richtigerweise feststellt, die Besucher immer den gesamten >Rest ihres Lebens` mitnehmen - seit seiner Entstehung eine Schnittstelle zwischen privater und öffentlicher Lebenswelt gewesen. Die Wurzel des modernen Museums ist die private Sammlung - und der Museumsbesuch ist für uns meist im `Privatleben` verortet, gehört er doch, um bei den Begrifflichkeiten Michael Liebes zu bleiben, ins Dispositiv >Freizeit<. Das Museum ist, so rekapituliert Friedrich Waidacher einen wiederkehrenden Befund der Besucherforschung des 20. Jahrhunderts, für die meisten seiner Besucher keine ausgewiesene Bildungseinrichtung, sondern eine Zerstreuung. Insofern steht das klassische Museum weniger in Konkurrenz zu anderen Bildungsangeboten, als vielmehr zum Kino, zum Zoo oder zum Vergnügungspark (vgl. Waidacher 2000: 8) und das virtuelle womöglich zu all den anderen unterhaltsamen Dingen, die man mit Computern (gerade auch im Web) anstellen kann. Beide stehen vor der doppelten Herausforderung, sich erstens in diesem Wettbewerb behaupten und zweitens - denn 
das verlangt der sich mit der Institution verbindende Bildungsauftrag - ihren Besuchern auch dann Wissen vermitteln zu müssen, wenn deren Interesse sich eigentlich auf etwas ganz anderes richtet. Museen mediieren zwischen einem (zumindest angenommenen) öffentlichen Interesse an Bildung und Kultivierung von Gesellschaften und einem privaten an Unterhaltung und Erlebnissen. Insofern präsentiert sich die Museumsvirtualisierung der Gegenwart fast als eine Invertierung jenes Verhältnisses von Ausstellungsmachern und Publikum, aus dem im 17. Jahrhundert das Museum überhaupt erst hervorgegangen ist. In den Kunst- und Naturalienkammern, die sich in die ersten Museen verwandeln sollten, entschieden die Interessen und Weltbilder privater Sammler über das, was Besucher sehen, lernen und erleben konnten. Im World Wide Web sind es nunmehr die vermessbaren privaten Interessenkonnizes von Nutzern, die darüber entscheiden, ob museale Angebote zur Sichtbarkeit gelangen oder nicht - und die darüber hinaus laufend 〉Museen unserer selbst $`$ um uns herum bauen, die für niemanden außer uns selbst als Einzelperson überhaupt existieren.

David Anderson beobachtet unter dem Einfluss der Digitalisierung im Jahr 2000 einen Paradigmenwechsel in der Praxis der Kommunikation zwischen Museum und Publikum, den er als einen Übergang vom »objektfokussierten (object focussed)《 zum »nutzerfokussierten (user focussed) « Museum beschreibt. Das klassische, physische Museum sei objektfokussiert und begreife das Museumsdispositiv als eine Bank für Fachwissen und didaktische Expertise, die der Öffentlichkeit diametral gegenübersteht. Die Außenwände des Museums markieren die Grenze zwischen >hier drin « und >da draußen`, und museale Sagbarkeiten sollen in dieser Dispositivstruktur nur in eine Richtung funktionieren, nämlich von innen nach außen. Das Museum soll also sprechen, während das Publikum lauscht. Der letztlich nicht als spezifische Person begriffene Besucher verlässt das Museum idealerweise in Wissen und Bewusstsein transformiert (vgl. Anderson 2000). Das nutzerfokussierte Museum begreife sich hingegen als ein vernetztes, und zwar nicht nur innerlich, sondern auch nach außen: Nutzerfokussierung bedeutet für Anderson, die Maskerade der inneren Abgeschlossenheit und Gegenweltlichkeit des Museums aufzugeben, um stattdessen die Relevanz anderer gesellschaftlicher Systeme für das Museum und umgekehrt zu betonen und zu erforschen:

In a user-focussed museum, the expertise of professional staff (such as curators) is only a small part of - and dependent upon - the wider expertise of the whole community; the audience therefore must be »in here« as well as »out there« if the institution is to develop successfully. And in a user-focussed museum, there is a need for expertise of many kinds - for example, about how people can learn, create, make meanings for themselves and enjoy, as well as about objects. The user-focussed approach really does represent a very different philosophy of knowledge, and its implications for museums are significant. (Ebd.) 
Im Wesen dieses Vernetzungsgedankens (der interessanterweise gar nicht auf die Netzhaftigkeit von Ausstellungen selbst bezogen wird) ist für Anderson angelegt, dass das Museum sich nicht auf die Vermittlung von eng eingegrenzten historischen Sachverhalten und Narrativen oder auch von ästhetischer Herzensbildung beschränken dürfe. Vielmehr gelte es, die Voraussetzungen für den Erwerb von Wissen selbst zu thematisieren und Museen zu Orten zu machen, an denen das Publikum zu lernen lernt. Zu diesem Zweck müsse es die Kooperation mit anderen Kultureinrichtungen suchen und es sich zur Aufgabe machen, seine Besucher mit jenen Fähigkeiten auszustatten, die sie zur Teilhabe an der Wissensgesellschaft benötigen (vgl. ebd.). Bezeichnend ist dabei die Art, auf die Anderson diese Überlegungen an den Phänomenbereich Digitalisierung zurückbindet. Seiner Ansicht nach ist nämlich für den Erfolg der Institution Museum im Umgang mit dem Web nicht die Gestaltung von Museumshomepages im Hinblick auf Suchalgorithmen oder die Abgrenzung von anderen Webangeboten entscheidend. Solche Strategien wiesen letztlich auf die antiquierten Ausstellungsprinzipien der Objektfokussierung zurück, die das Museum nur aus seiner eigenen Warte zu konzipieren wussten. Viel wichtiger sei die Frage, was das Publikum in Zeiten einer digitalisierten Wissensexplosion vom Museum braucht. Dieses `Brauchen ist dabei durchaus pädagogisch zu verstehen und nicht identisch mit dem >Wollen`, wie es Suchmaschinen bedienen. Auch Anderson will dem Publikum etwas vermitteln, es erziehen. Anders als in der klassischen Museumsdidaktik geht es ihm dabei allerdings nicht nur um die Inhalte und Gegenstände der Ausstellung, sondern um das intellektuelle Handwerkszeug, um sich in virtuellen Wissenslandschaften zurecht zu finden:

It is often said that the new digital technologies are, or could be, a force for democratic change in society. But it is not the technologies themselves, or information, that will do this, but the development of the skills and opportunities that people need if they are to participate in cultural life of communities, that will provide the democratic foundations for use of new media. Our society does not, and will not, need more information. What it does need is to learn to use digital cultural resources creatively, and to ensure that this opportunity is open to groups that the market alone cannot reach. It is here that the real responsibilities of any publicity-funded museum lie. This is a much more demanding - and intellectually challenging - task than simply churning out existing object data. It is also a function that museums - like flightless birds on remote islands, isolated from evolutionary change - are currently ill-equipped, as a result of their neglect of their educational responsibilities, to deliver. (Ebd.)

Dieser letzte Satz führt uns zurück zu der in Kapitel 6.1 gemachten Feststellung, dass Museum und Web bei allen Ähnlichkeiten in ihrer Verfasstheit als Vernetzungssysteme sehr unterschiedliche Strategien im Umgang mit Offenheit und Vieldeutigkeit verfolgen. Ein museales Paradigma der Belehrung und Erziehung, getragen von starken kuratorischen Autorschaften, produziert womöglich einen Rezipienten, der zwar 
die konkreten Ausstellungsinhalte weitgehend so erlebt, wie es vom Kuratorium gewünscht ist, dabei aber beklagenswert schlecht vorbereitet wird auf einen Wissenserwerb in Gefügen, in denen solche Autorschaften nicht mehr gegeben sind. Um angesichts der epistemischen, pädagogischen und sozialen Implikationen des Internets relevant bleiben zu können, müsse das Museum nach Anderson ein ganz neues Selbstverständnis entwickeln: als Teil eines Ökosystems von Wissensinstitutionen, von denen keine monumental abgeschlossen sein kann, sondern jede einzelne nur eine Durchgangsstation auf den Bildungswegen ihrer individuellen Besucher darstellt. Das virtuelle Museum bedeutet in diesem Entwurf von der Rolle des Museums die Chance einer viel größeren Präsenz der Museen in der Lebenswelt der Öffentlichkeit, der sie dienen sollen (vgl. ebd.).

\subsubsection{Roy Ascotts spostmuseales Szenarior}

Eine sehr viel radikalere Vision von den Fernzielen der Museumsvirtualisierung entwirft der britische Computerkünstler Roy Ascott. Seine Überzeugung ist, dass das >ursprüngliche` Museum ein Ort kreativer Entfaltung und damit des Wandels gewesen sei, während das Museum der Moderne diese Funktion ins Gegenteil verkehrt und sich als konservativer Wertespeicher neu erfunden habe, dem es weniger um Inhalte ginge als um die Etablierung einer bestimmten Machtsituation zwischen Institution und Rezipient. Er schreibt:

Bevor ich jedoch das postmuseale Szenario darstelle, will ich die Frage stellen, was der Raum des Museums gewesen war, bevor es Museen gegeben hat. Das führt uns weit in die Vergangenheit zurück. Ich nehme an, daß es der Ort des kollektiven Gedächtnisses, der Feier oder sogar des Hedonismus, der Ort kreativer Imagination, der Gefahr und des Wagemuts gewesen ist. Es war der Ort der Transformation, besonders der geistigen Transformation, der in Bildern zum Ausdruck kam, die den Körper veränderten. Irgendwann im Laufe der Geschichte hat das Museum, wie ich glaube, dieses Erbe verloren. Es sollte ausschließend, konservativ, sogar vorsichtig werden. Es ging mehr um Gültigkeit als um Wert, mehr um Gewißheit als die Integration des Ungewissen. Das geschah nicht immer und nicht überall. Es schlug jedoch die falsche Richtung ein, als das Museum sich den Werten der alten Industriekultur anpaßte, einer Kultur des Ausschlußes, der Fragmentierung, des vereinheitlichten Selbst, der Angst, der Entfremdung, des exzessiven Individualismus, der Privatheit und der Geheimhaltung, also einer paranoischen Gesellschaft. (Ascott 1996)

Es wird hier nicht vollkommen klar, zu welcher Vergangenheit des Museums genau Ascott seine Gegenwart in Kontrast zu setzen versucht. Wie das zweite Kapitel dieser Arbeit deutlich machen konnte, war das Museum zu keiner Zeit seiner Geschichte nicht in politische Agenden verstrickt - und die Vorstellung vom Museum als Ort 
emanzipatorischer Selbstreflexion ist vor allem ein Produkt der Museumspädagogik der 1960er und 70er Jahre. Womöglich zielt Ascott hier tatsächlich auf das antike Museion als Kolleg von Philosophen und Forschern, also als soziales Gefüge, ab. In diese Richtung nämlich weist sein an die obigen Ausführungen anschließender Entwurf dessen, was er Eingangs als das >postmuseale Szenario beschreibt: Das Museum solle nicht nur die Peripherie zu seiner Umwelt einreißen, wie es in Malrauxs Imaginärem Museum in Aussicht gestellt wurde, sondern vielmehr auch jene zu Körper und Bewusstsein des Menschen:

Ich will, daß mein neuronales Netzwerk durch Synapsen mit den künstlichen neuronalen Netzwerken des Planeten verbunden ist. [...] Die Erkundung des menschlichen und des künstlichen Geistes, die möglicherweise ohne die Vermittlung von visuellen Formen und Repräsentationen vor sich gehen kann, scheint mir das Projekt der Kultur des 21. Jahrhunderts zu sein. (Ebd.)

Während Malraux mit dem Imaginären Museum das Ausbrechen von Bildern aus dem Ausstellungsraum beschrieb, will Ascott eine Musealität, die überhaupt nicht mehr über den Umweg des Visuellen funktioniert. Anstatt semiotische Brücken zwischen An- und Abwesendem, Aktuellem und Virtuellem zu bauen, will Ascott den direkten Umgang des Verstandes mit dem Abstrakten. Der Weg dorthin ist seiner Ansicht nach »die Verbindung einer auf Technik und wissenschaftlichen Metaphern basierenden Kunst mit einer geistigen und konzeptuellen Kunst« in einer Kultur, die Ascott als »technoetisch « bezeichnet: »Jetzt geht es um begriffliche Strategien, um Ideen und kognitives Verhalten, um die Entstehung eines neuen Bewusstseins« (ebd.).

Mit der Idee, Medientechnik und menschliches Bewusstsein zu verkoppeln, steht Ascott natürlich ganz und gar in der Tradition der Hypertexttheorie seit Vannevar Bush und seinem Entwurf von Memex als maschineller Erweiterung des menschlichen Gehirns. Wo Bush aber eine technische Schnittstelle zwischen die kategorial verschlagwortete Speicherfunktion der Bibliothek und die netzhafte menschliche Kognition setzen wollte, stellt Ascott nun explizit das Museumsdispositiv in den Mittelpunkt, und mit ihm die Idee von Vernetzung nicht nur als Kulturtechnik, sondern als Leitfigur einer neuen menschlichen Daseinsform. Das Museum, so Ascott, müsse so sehr zu einem Abbild des menschlichen Geistes werden, dass es letztlich nicht länger als mediale Anordnung verstanden werden könne, über die sich ein Kuratorium einem Publikum mitteilt. Vielmehr müsse sich das Museum zu einem aus seiner inneren Struktur heraus »intelligenten« System entwickeln, das nicht mehr Mittel oder Raum einer Kommunikation ist, sondern selbst kommuniziert. Ein Museum, das seinem Besucher gegenüber mit dem Anspruch auftritt, ihn zu belehren oder gar zu erziehen zu wollen, hat in diesem Zukunftsentwurf freilich keinen Platz mehr. Anstatt unsere Wahrnehmung (perception) zu schulen, gelte es für das Museum nun, deren 
veränderte mediale Voraussetzungen zu erlernen. Für Ascott nämlich ist die Vorstellung einer Abtrennbarkeit menschlichen Lernens und Erlebens von Technologien eine reaktionäre Fiktion, die an der Tatsache vorbeigeht, dass unser Bewusstsein und unsere Wahrnehmung längst zutiefst technisiert sind (vgl. ebd.).

Entsprechend sieht er in unserer Interaktion mit Computern und ihren Steuerungsmechaniken auch nicht unsere Fremdbestimmung durch einen unserem eigenen Urteilsvermögen übergeordneten Entscheidungsapparat, sondern vielmehr einen reziproken Vorgang, in dem unser Denken mit diesen Mechanismen verschmilzt. Für ihn ist dies keine gewaltsame Verzerrung unseres Bewusstseins, sondern der Erwerb eines neuen Sinnes, den er als »cyberception« bezeichnet: Wir denken und erfahren innerhalb der Netze, und zugleich denken die Netze in uns. Das Museum ist dementsprechend aus Ascotts Sicht auch gar keine Bildungsinstitution mehr, sondern vielmehr der Idealtypus einer Zusammenkunft von Menschen, Dingen und Konzepten in einem Netzwerk, das eine Eigenintelligenz entwickelt:

Ich spreche über das Museum als ein Gehirn, das seine eigene assoziative Gedankenwelt verkörpert, als einen überaus sensiblen Kortex, den man eher einen Cyberkortex nennen sollte, als ein kognitives Netz all der Ideen, Formen, Strukturen und Strategien, die im Zwischenraum, durch das assoziative Denken, durch die Hyperlinks einer tiefreichenden Vermaschung erzeugt werden und die jenen Bereich des Werdens zwischen dem Virtuellen und dem Realen begründen, der unser globales Heim ist. (Ebd.)

Während Malraux das Imaginäre Museum noch als das betrachtete, was passiert, wenn Reproduktionen auf einen menschlichen Verstand treffen, der zwischen ihnen assoziative Linien zieht, bildet für Ascott das Netz aus Menschen, Objekten und Technik selbst ein imaginierendes System. Das Museum der Zukunft ist daher seiner Ansicht nach auch nicht länger ein Raum, in dem Objekte inszeniert werden, sondern vielmehr ein Nicht-Ort, an dem Menschen und Kulturgüter virtuell kongregieren und neue Ausdrucksformen und Bedeutungen entstehen lassen können. Dieses Museum ist in der Diktion Ascotts ein »Museum der dritten Art«:

Die erste Art des Museums, in dem diejenigen, die die Zeit hatten, sich mit der Muse beschäftigten, ist vorbei. Das Museum der zweiten Art, in dem die Materialität der Kunst und ihre herrliche und unbeständige Gegenständlichkeit in ihr virtuelles Anderes überführt wird, kann nicht funktionieren. Ich spreche vom Museum der dritten Art, in dem die intime Begegnung des Geistes mit einem anderen Geist, des Kortex mit dem Hyperkortex, des Virtuellen mit dem Wirklichen zu einer Interaktivität auf der Höhe des Geistes führt. (Ebd.)

Das Museum erster Art wäre demnach also der Musentempel der Antike, das Museum zweiter Art eben die moderne Institution Museum - und während das Museum erster Art schlicht nicht länger existiert, sei das zweite letztlich an seinem Anspruch 
gescheitert, aus materiellen Objekten abstrakte (oder eben: virtuelle) Wissensgegenstände zu machen. Die Ursache und Natur dieses Scheiterns verortet Ascott in dem seiner Ansicht nach fehlgeleiteten Bestreben, mit simulatorischen Mitteln eine Vergangenheit rekonstruieren zu wollen, wo doch simulatorisches Denken immer auf Gegenwart und Zukunft ausgerichtet sei. Die Idee der Repräsentation und Rekonstruktion erscheint ihm tatsächlich als ein diskursives Machtmittel, mit dem Kuratoren ihre Autorität dem Publikum gegenüber behaupten und affirmieren - indem sie die Vorstellung verteidigen, es gäbe eine richtige Vergangenheit, die man in der Gegenwart wiederherstellen könne, und nicht etwa eine Vielzahl möglicher Gegenwarten, die sich kreativ miteinander konfrontieren lassen (vgl. ebd.). In den inszenatorischen Elementen musealer Ausstellungspraxis sieht Ascott also eine Unterschlagung auf Kosten des Publikums. Die Vorlage für das Museum der Zukunft ist für ihn daher eine ganz andere Form von virtueller Gegenwelt: nämlich die des Themenparks.

Der Vergnügungspark sei längst das »definitive Museum des 20. Jahrhunderts« geworden, und Museen ahmten ihn bereits nach, indem sie sich mit »einem Andenkenladen, einem Restaurant, Führungen, kunstvoller Beleuchtung « ausstaffierten und so Erlebnisdimensionen in das Museumsdispositiv einführten, die eigentlich nicht durch den etablierten Bildungsauftrag abgedeckt sind. Hiermit sei im Grunde bereits implizit eingestanden, dass Museen Simulacren innerhalb der Gegenwart und für die Gegenwart seien - Themenparks allerdings gingen ganz offen und unbefangen mit der Tatsache um, dass sie Orte der Simulation sind, während das Museum sich hinter dem Anspruch der Repräsentation verbarrikadiere und seinen Besuchern die Befriedigung der Teilhabe an der Konstruktion der sie umgebenden Welt verweigere. Simulation sei grundsätzlich »weicher und einbeziehender« als Repräsentation, weil ihre Gegenstände nicht unter dem Schutz von Experten stünden (vgl. ebd.).

Überhaupt sieht Ascott im Materialitätsparadigma der Institution Museum letztlich weniger eine Würdigung der auratischen Qualität und des authentischen Wesens von historischen Überresten, als vielmehr eine Zuspitzung dieses letztlich auf Deutungshoheiten zielenden Realitätsdiskurses. Tatsächlich nämlich schieße das Museum mit seiner Betonung des physischen Materials längst völlig an unserer medialen Lebenswirklichkeit vorbei. Der Wahrnehmungsmodus, den es uns auferlegt, ist für Ascott ausdrücklich keine Rückbesinnung auf das Authentische, sondern vielmehr eine völlig artifizielle Verstellung unseres Bewusstseins, während die cyberception in seiner Lesart längst zum authentischen Zustand unserer medialen Wirklichkeit geworden ist. Wo Claude Lévy-Strauss die Daseinsberechtigung des Museums aus einem angeblichen Verlust von Authentizität in der Alltagswelt ableitet, sieht Ascott in ihm vielmehr den letzten Bewahrer eines Authentizitätsbegriffes, der sich überall sonst längst überlebt habe (vgl. ebd.). Dabei habe sein Schwinden Ascott zufolge aber kein Vakuum der Authentizität hinterlassen, sondern vielmehr die Voraussetzungen für neue Formen des Authentischen geschaffen, die ganz explizit anti-monumental funktionierten: 
Wir fliegen von Metapher zu Metapher, von Standpunkt zu Standpunkt, und lassen uns nur für einen Augenblick nieder. Für uns sind diese allzu soliden Überzeugungen, diese tiefgründigen Visionen des Zeitalters der Vernunft mit ihrer unerschütterlichen Gewißheit und ihrer cartesianischen Vergewisserung nichts. Für uns ist alles Oberfläche, eine Oberfläche auf einer weiteren Oberfläche. (Ebd.)

So überkommen wie der fetischistische Umgang mit dem Originalobjekt in der $\mathrm{Mu}-$ seumspraxis sei notwendigerweise auch die Vorstellung von der physischen Bewegung des Besuchers durch den Museumsraum. Im postmusealen Szenario Ascotts, in dem Besucher und Ausstellungsobjekte zum denkenden Nervensystem verschmelzen, ist die Körperlichkeit des Betrachters ähnlich wie die materielle Gebundenheit des Exponats vor allem ein weiteres zu überwindendes Hindernis. Unsere Körper selbst sind für ihn Bedeutungsträger, die unsere Wahrnehmung verzerren und einengen. Ganz in der Tradition des Cyberpunk fordert er dementsprechend ein Museum nicht für den körperlich anwesenden Beschauer, sondern für das »entkörperte Selbst«, das eben in unserer medialen Umwelt längst nicht mehr an den Körper und seine fünf Sinne gekettet, sondern via cyberception in den Netzen distribuiert sei. Einem solchen Cyberbewusstsein könne das klassische Museumsexponat gar nicht mehr gerecht werden, weil es völlig unterhalb seiner Wahrnehmungsschwelle existierte:

Welchen Platz in unserem Bewußtsein können in diesem Eintauchen in das Immaterielle, die unsere Kultur der computervermittelten Ereignisse, der Fuzzy Logic, der Prinzipien der Ungewißheit, der Unentscheidbarkeit und des Chaos begründet, die Aufbewahrungsorte von alten Töpfen und Pfannen, Stöcken und Steinen, Knochen und Spielsachen einnehmen? Welche sinnvolle Rolle können in einer immateriellen Kultur das Aufbewahren, die Klassifizierung und Darstellung einer materiellen »Evidenz« vergegenständlichter Hypothesen spielen? Können Spuren nicht in Datenbanken gespeichert werden, um sie bei Bedarf in der Virtuellen Realität zu verwirklichen, wodurch der Benutzer nach seinen Wünschen Zugang zu kulturellen und geschichtlichen Erinnerungen erhält und seine eigenen Assoziationen. Vermutungen, Rekonstruktionen und Bedeutungen erschaffen kann? (Ebd.)

In anderen Worten: Die `neuen Medien` haben uns längst für das klassische Museum verdorben, und das virtuelle Abbild des Originalobjektes ist für unser neues Medienbewusstsein zum ihm überlegenen Sinnträger geworden. An die Stelle des Museumsgebäudes müsse und werde daher in Zukunft das treten, was Ascott »Wissenslandschaften« nennt: Es gehe nicht länger um die Inszenierung von Geschichtsbildern und um Ausstellungen, die im Zeichen benennbarer kuratorischer Entscheidungen stehen, sondern um »Gärten von Hypothesen«, die »sich im Raum zwischen dem Virtuellen und dem Realen befinden«. Diese botanische Metapher zeigt bereits an, dass Ascott hier in einer ganz ähnlichen Bildlichkeit denkt wie jener des Rhizoms: 
Sie wären den Kreisläufen des intellektuellen Wachstums und Wandels unterworfen und würden unsere sich verändernden Perspektiven, Werte und Interessen spiegeln. Der Garten der Hypothesen ist für die technoetische Kultur und für die Welt des Künstlichen Lebens und des Künstlichen Bewußtseins, für den Hyperkortex und die menschliche Cyberwahrnehmung, was die neo-georgianischen und Prunkbehälter des alten Museums für die cartesianische Konformität der klassischen Kultur waren. (Ebd.)

\subsubsection{Das Museum als Akteur-Netzwerk}

Während die unsteten Netzstrukturen des Rhizoms allerdings in erster Linie Ideen, Konzepte und Menschen miteinander verbinden und die Technik im Grunde nicht auftaucht bzw. allenfalls als passives Mittel der Vernetzung zu denken ist, spielt sie bei Ascott eine herausragende und dezidiert proaktive Rolle. Sie ist kein >Äußeres mehr, das Kommunikation zwischen Menschen hin und her trägt, sondern Teil einer Meta-Intelligenz, in welcher die Grenzen zwischen ihr, dem Menschen und den Inhalten verschwimmen. So sehr Ascotts Szenario in Sprache und Dimension die Merkmale eines salbungsvollen Techno-Utopismus tragen mag: Das hier projizierte Verhältnis zwischen Menschen und ihren Technologien ist ein in unserer Lebenswelt durchaus evidentes, das seine wohl bekannteste und folgenreichste Systematisierung und theoretische Durchdringung in der Akteur-Netzwerk-Theorie Bruno Latours erfahren hat.

Latours theoretisches Gebäude will dabei tatsächlich den Netzwerkbegriff wieder ablösen von der massiven Technisierung, die er seit dem Aufkommen von Computernetzwerken erfahren hat. Auf der Hardware-Ebene nämlich sind Computernetzwerke, so stellt Latour fest, extrem starre und hierarchische Gebilde, weil zwischen den einzelnen Rechnern eine notwendig materielle Verbindungsstruktur besteht, die zentral geplant und baulich umgesetzt werden muss (vgl. Latour 1996: 2). Zugleich aber will Latour sich mit der Akteur-Netzwerk-Theorie auch vom Studium sozialer Netzwerke abgrenzen, wie es in Jakob Morenos Soziometrie betrieben wurde. Dieser Ansatz nämlich verliert sich nach Latours Einschätzung zu sehr in der Untersuchung der Beziehungen zwischen individuellen menschlichen Akteuren und sei aus dem (durchaus legitimen) Bedürfnis hervorgegangen, staatlichen Verwaltungsbürokratien und übermäßig global angelegten soziologischen Theoriegebäuden einen Blick auf die Einzelperson (und damit >den Menschen`) entgegenzusetzen (vgl. ebd.). Die Akteur-Netzwerk-Theorie will indes den Blick auf »Aktanten« richten, die weder zwingend Menschen, noch Individuen sind (vgl. ebd.).

Was Latour damit anstrebt, ist eine Betrachtung der »Essenz« (ebd.) von sozialer und natürlicher Welt - nicht etwa eine Neubewertung von Netzwerken innerhalb der Sozialtheorie, sondern eine komplette Neukonstruktion aller Sozialtheorie aus der 
Betrachtung von Netzwerken heraus, und zwar ohne Privilegierung ausgewiesen >sozialer Netzwerke. Insofern ist die Akteur-Netzwerk-Theorie nach Latour mindestens ebenso sehr Ontologie und Metaphysik, wie sie Soziologie ist (vgl. ebd.). Ein zentraler Gedanke ist dabei das Durchbrechen der Raummetaphern, innerhalb derer wir üblicherweise über Netzwerke sprechen. Akteur-Netzwerke sind für Latour weder zwei- noch dreidimensional, ja tatsächlich gar nicht in den Kategorien cartesianischer Räumlichkeit zu denken. Stattdessen haben sie so viele >Dimensionen〈, wie sie Verbindungen aufweisen. Und weil ihre Dimensionen nicht räumlich sind, lassen sie sich auch nicht in Regionen, Territorien, Schichten oder Ebenen zerteilen. Die AkteurNetzwerk-Theorie soll indes solche Beschreibungsformen nicht etwa ausklammern vielmehr will sie die temporären Effekte begreifen helfen, die wir mit solchen Figuren produzieren, ohne sie als ontisches a priori zu akzeptieren. Dazu gehöre unweigerlich auch die Einsicht, dass sämtliche Wissenschaften als Disziplinen ebenfalls mit den gesellschaftlichen Netzen verwoben sind, die sie beschreiben wollen - und dass die Rückführung ihrer epistemischen und materiellen Artefakte in diese Netze zwingend erforderlich sei, wenn sie ihrer Aufgabe gerecht werden wollen. Damit geht laut Latour eine Wissensproduktion einher, die sich grob als eine Abkehr vom induktiven Denken (das ja Einzelphänomene aus bekannten Regelhaftigkeiten erklären will) und eine Hinwendung zu einer Mischung aus deduktivem und transduktivem erklären lässt, das nunmehr Vielheiten lokal begrenzter Vernetzungserscheinungen ins Zentrum stellt (vgl. ebd.: 3). Während klassische Epistemologien die Abweichung von bekannten Ordnungssystemen als den zu erklärenden Sonderfall betrachten, begreift die Akteur-Netzwerk-Theorie die raumzeitlich begrenzte Einzelbeobachtung als das tatsächlich >Normaleく, während die Ordnung den historisch gewachsenen Ausnahmezustand darstellt. Sie will die Lücken zwischen den Orten eines Netzwerkes ausdrücklich nicht mit vereinheitlichenden Theorien füllen. Insofern agieren hier die Netzwerke nicht mehr innerhalb einer kontinuierlichen Welt, sondern die ganze Welt, wie wir sie kennen und erleben, ist das Produkt von Interaktionen und Bewegungen innerhalb von Netzwerken (vgl. ebd.: 3f.).

Den besonderen Nutzen des Netzwerkbegriffes sieht Latour dabei darin, dass er eine Topologie von Nähen und Distanzen ermöglicht, die ganz anders funktioniert als jene des physischen Raumes und dabei vielen Gemengelangen weit besser gerecht wird als diese. Als einfache Beispiele führt Latour hier die Tatsachen an, dass ein Mensch, der räumlich direkt neben ihm stehe, ihm doch ferner sein könne als seine 6.000 Meilen entfernte Mutter; dass zwei Rentiere in Alaska zehn Meter voneinander getrennt sein könnten, aber eine zwischen ihnen verlaufende Pipeline ihnen doch jede Paarung unmöglich mache; oder dass sein Sohn und der in der Schule neben ihm sitzende arabischstämmige Klassenkamerad letztlich in sehr verschiedenen Welten aufwachsen werden (vgl. ebd.: 4). Für Latour gibt es in unserem Denken einen kaum zu umlaufenden Konflikt zwischen Geographie und Netzwerk, bzw. genauer zwischen der Anschaulichkeit spatialer Verhältnisse und der Abstraktheit tatsächlicher 
Zusammengehörigkeiten. Die Geographie des kontinuierlichen, physikalischen Raumes impliziert ein Verhältnis von Nähe und Ferne, das tatsächlich nicht existiert (vgl. ebd.). Insofern soll die Akteur-Netzwerk-Theorie auch die Trennung zwischen >Mikro<- und >Makro<-Erscheinungen überwinden, die für die Sozialwissenschaften immer noch bestimmend ist. Ihre qualitative Verschiedenheit soll sich auflösen in der quantitativen der Verdichtung und der Ausdünnung von Bezüglichkeiten in Netzwerken. Massen- und Individualphänomene gehören nicht unterschiedlichen Sphären der Analysierbarkeit an, sondern entstehen im selben Netzwerk aus denselben Mechanismen (vgl. ebd.: 5). Es gibt keine Unterscheidung von globalem und lokalem Blick, weil jede globale Betrachtung die lokale in sich trägt (vgl. ebd.).

Somit verschwindet auch - und dies ist für das museale Szenario natürlich besonders brisant - jede Möglichkeit, noch die Trennung zwischen innen und außen zu denken. Netzwerke sind, so Latour, »all boundary without inside and outside« (ebd.: 6). Sie haben, so sagt er »keinen Schatten« und sind eine positive Erscheinung, zu der es kein Negativ gibt (vgl. ebd.). Netzwerke kennen dementsprechend auch kein links, rechts, oben oder unten. Jede Verortung kann nur eine relative zu anderen Orten sein. Und an dieser Stelle kommt eben jener >Akteur ins Spiel, welcher Latours Theorie die Hälfte ihres Namens verleiht. Dieser Akteur ist ganz ausdrücklich keine notwendigerweise menschliche Person, die sich Handlungsmacht aneignet. Vielmehr ist der Akteur jener, der agiert oder dem von einer anderen Stelle im Netzwerk die Fähigkeit zum Agieren verliehen wird. Buchstäblich alles kann innerhalb eines Netzwerkes zum Akteur werden, solange von ihm in irgendeiner Form eine Aktion ausgeht (vgl. ebd.). Akteur-Netzwerke, so schreibt Latour, verbinden menschliche und nichtmenschliche Entitäten, verteilen menschliche und nichtmenschliche Charakteristiken auf beide, und transformieren dabei laufend sowohl die Akteure, als auch ihre Eigenschaften und die Verbindungen zwischen ihnen (vgl. ebd.: 7).

Damit ist die Methodik der Akteur-Netzwerk-Theorie folgerichtig zunächst eine Form von semiotisch vorgehender Diskursanalyse, denn es gilt vorrangig, zu beschreiben, wie Ordnungen innerhalb von Akteur-Netzwerken ausgehandelt und gerechtfertigt werden (vgl. ebd.: 8). Tatsächlich geht Latours Ansatz so weit, alle sozialen Tatsachen unserer kulturellen Umwelt - inklusive jeder Technologie - als semiotische Konstrukte zu verstehen, die es zu kartieren heißt, allerdings weniger in ihrer >tatsächlichen` Beschaffenheit als in den Voraussetzungen ihrer Entstehung und Benennbarkeit (vgl. ebd.: 9). Die Akteur-Netzwerk-Theorie will ausdrücklich das, was in digitalen Medien ja ohnehin längst implizite Normalität geworden ist, nämlich eine Aufhebung der Trennung zwischen der Welt und der Sprache, in der wir uns über sie verständigen - und damit auch jener zwischen den Dingen und ihrer Repräsentation. Latour spricht hier von einer »konterkopernikanischen Revolution« (ebd.: 10): Sinn entsteht in Netzwerken nicht unter den Vorgaben einer äußeren Autorität, sondern jedes Netzwerk schafft sich die Voraussetzungen seiner Sinnproduktion völlig de- 
zentral unter Mitwirkung aller beteiligten Akteure, die ihrerseits selbst netzartig beschaffen sind (vgl. ebd.). Und weil Dinge nur mehr das Produkt des Umgangs mit ihrer Repräsentation sind, gibt es keine äußere Referenz mehr, an der man ihr $>$ Wesen ‘ festmachen könnte. Jeder Blick auf das Netzwerk, jeder Versuch, es zu erklären oder beschreiben - ob er nun von innen oder von außen kommt - ist nur so gut oder so schlecht wie jeder andere. Die Perspektive des Analytikers ist nur mehr eine unter vielen (vgl. ebd.: 12) - und jeder Versuch der Analyse berührt und verändert unweigerlich seinen Gegenstand (vgl. ebd.: 13):

As I said above there is not a net and an actor laying down the net, but there is an actor whose definition of the world outlines, traces, delineate, limn, describe, shadow forth, inscroll, file, list, record, mark, or tag a trajectory that is called a network. No net exists independently of the very act of tracing it, and no tracing is done by an actor exterior to the net. A network is not a thing but the recorded movement of a thing. The questions AT addresses have now changed. It is not longer whether a net is representation or a thing, a part of society or a part of discourse or a part of nature, but what moves and how this movement is recorded. (Ebd.: 14)

Aus der Warte von Latours Theorie erscheint das Museum natürlich ganz unweigerlich als ein Akteur-Netzwerk, in dem Kuratoren, Besucher, Dinge, Architekturen und Technologien laufend miteinander umgehen und die Vektoren eines Sinnsystems entstehen lassen, in dem jedes Teilchen grundsätzlich die Fähigkeit zur Proaktivität besitzt. Selbst die Wände des Museums sind insofern keine passive Grenze der Institution, sie sind vielmehr Aktanten, die semiotisch die Unterscheidbarkeit des Netzwerks `Museum` von benachbarten, ihm teils ähnlichen, teils sehr von ihm verschiedenen Netzwerken etablieren. Der Wert der Akteur-Netzwerk-Theorie ist für diese Studie (und speziell die nun folgenden Betrachtungen des Fallstudienkapitels) daher vor allem folgender: Sie fragt nicht nach dem definitorischen >Wesen licher Einrichtungen, sondern nach den Bedingungen ihrer kommunikativen und semiotischen Hervorbringung - und damit ihrer `Essenz` oder dem, was Ascott womöglich meint, wenn er im Titel seines Traktates über das postmuseale Szenario vom »Geist des Museums« spricht. Aus der Sicht der Akteur-Netzwerk-Theorie ist die Frage nach der Möglichkeit eines Museums auf der Grundlage des World Wide Web allein dank der Existenz des Begriffs vom >Virtuellen Museum ২ bereits zu bejahen: Mit ihr existiert eine Bezeichnung für Netzwerke, die von den Akteuren dieser Netzwerke mit Bedeutung gefüllt werden kann. Interessant ist damit nicht, was ein virtuelles Museum ist oder nicht ist, sondern wie es sich selbst in unsere soziale Wirklichkeit hineinkommuniziert: $»[\ldots]$ AT is not about traced networks, but about the network-tracing activity.« (ebd.: 14) Und damit geht es letztlich nicht um Strukturen, sondern um Bewegungen. 



\section{Fallstudien}

Eine dezidierte Didaktik virtueller Museen ist in den augenblicklich existierenden Angeboten kaum auszumachen. Insgesamt scheint das virtuelle Museum auch über 20 Jahre nach der Entstehung des Begriffes noch als ein `Neuland zu werden: Virtuelle Museen sind in ihrer Erscheinung so heterogen, wie sie zahlreich sind - und verschwimmen an ihren Rändern immer wieder mit anderen kommemorativen Arten von Netzauftritten. Nahezu alle etablierten Akteure der öffentlichen Geschichtskultur sind in irgendeiner Form im Netz präsent: nicht nur die Museen, sondern auch die Archive, Gedenkstätten, Forschungsinstitute verschiedenster Art, journalistische Formate wie Zeitungen und Zeitschriften und - selbstverständlich - zahllose Privatpersonen und private Interessengruppen (vgl. Hein 2009: 145).

Statistische Daten zur Geschichts- und Erinnerungskultur im WWW liegen bisher kaum vor und unterscheiden meist nicht fundamental zwischen Angebotstypen und Trägerschaften. Entsprechend schwierig ist es, Aussagen über die Zusammensetzung des Gesamtangebotes zu treffen, sollte dieses überhaupt realistischerweise zu erheben sein. Dörte Hein, die eine der wenigen Untersuchungen hierzu vorgenommen hat, verwendet eine Strategie repräsentativer Eingrenzung, namentlich auf deutschsprachige Trefferseiten zum Google-Suchbegriff Holocaust. Wie Hein feststellt, befinden sich etwa $14 \%$ dieser Seiten in der Trägerschaft von Museen und Gedenkstätten - was nur ein unwesentlich größerer Anteil ist als jener der von Privatleuten (13 $\%$ ) und Archiven oder artverwandten Dokumentationseinrichtungen betriebenen Angebote $(10 \%)$. Ein deutlich größerer Teil der Treffer entfällt in ihrer Untersuchung auf die journalistischen Webpräsenzen (24\%), sowie auf Bildungseinrichtungen wie Universitäten und Hochschulen (20\%) und schließlich auf vereinsmäßig organisierte Interessengruppen wie Opferverbände (19\%) (vgl. Hein 2009, 148). Die etablierten Museen sind demnach also ein durchaus wichtiger, nicht aber dominanter Mitspieler in der geschichtsdidaktischen Landschaft des WWW. Eine Untersuchung wie jene Heins sagt allerdings noch nichts darüber aus, wie viele der von ihr erhobenen Webpräsenzen begrifflich als >virtuelle Museen` einzuordnen wären. Die Webseite eines Museums ist aus sich heraus ja noch lange kein virtuelles Museum, wenn sie ihrem 
Besucher nur Anfahrtswege, Öffnungszeiten und Eintrittspreise mitteilt - und umgekehrt könnte eine Webseite, die weder von einem physischen Museum betrieben wird, noch sich selbst als ein virtuelles bezeichnet, durchaus alle Eigenschaften aufweisen, die ein virtuelles Museum ausmachen.

Als Klassifizierungsbegriff taucht das virtuelle Museum bei Hein tatsächlich überhaupt nicht auf. Stattdessen ordnet sie existierende kommemorative Angebote im Web nach Trägerschaft und Funktionalität in fünf unterschiedliche Gruppen ein: Die erste Gruppe bilden Internetportale, die bewusst als $H u b$-Seiten angelegt sind und als thematisch ausgerichtete Wegweiser im Netz auftreten. Die zweite Gruppe sind von physischen Einrichtungen der Geschichtskultur (eben Museen, Gedenkstätten, Archiven usw.) betriebene Seiten serviceorientierter Art - Seiten also, die vor allen Dingen über ihre Mutterinstitution informieren sollen. Die dritte Gruppe bilden informationsorientierte, schwerpunktmäßig von privaten Interessengruppen betriebene Seiten zu sehr spezifischen Themensetzungen. Die vierte Gruppe nach Hein besteht aus journalistischen Online-Angeboten wie Zeitungs- und Zeitschriftenartikeln, beinhaltet aber auch E-Books. Die fünfte und letzte Gruppe bilden schließlich Online-Enzyklopädien und Lexika (vgl. ebd.: 149).

Der größte Teil der virtuellen Museen wäre damit in der zweiten Kategorie, also jener der informationsorientierten Angebote, beheimatet. Diese stellen, so Hein, in den meisten Fällen einen Versuch ihrer Betreiber dar, sich den bestehenden Mediennutzungsgewohnheiten ihres Publikums anzunähern: Wer heutzutage ein bestimmtes Interesse befriedigen wolle, der greife eben unweigerlich zunächst zum Computer bzw. zur Internet-Suchmaschine - und genau hier müsse man ihn abholen (vgl. ebd.: 155). Darüber hinaus verbinde sich mit Internetauftritten die Hoffnung, ein jüngeres Publikum erreichen zu können (vgl. ebd.: 152). Die Betreiber solcher Auftritte bildeten im Netz das, was Hein als eine »Szene« (ebd.: 160) mit ausgesprochen losen Vernetzungsstrukturen und sehr regem informellem Austausch bezeichnet. Für Angebote in öffentlicher Trägerschaft bestehe diese Szene als logische Fortsetzung von längst bestehenden Seilschaften zwischen den Mitarbeitern von Gedenkstätten und Bildungseinrichtungen. Privatleute hingegen fänden sich gerade über das Internet zu kleinen Gruppen von Enthusiasten zusammen (vgl. ebd.: 159f.).

Diese überaus losen Strukturen von Angeboten und ihrem Personal machen es schwierig, sinnvolle Beispiele für das Virtuell-Museale auszuwählen. Derzeit existiert schlicht kein virtuelles Äquivalent zum Louvre oder zum Museum of Modern Art in jenem Sinne, dass man es als Prototyp für Inhalt und Format seiner Gattung betrachten könnte. Der konvergenten, globalisierten und eben nicht abschließbaren Natur virtueller Museen würde eine solche Dominanz einer Einzelinstitution auch völlig zuwiderlaufen: Das Online-Portal MoOM (Museum of Online Museums) allein verzeichnet augenblicklich über 170 selbstdeklarierte Online-Museen, ${ }^{1}$ die von der

1 http://coudal.com/moom/ vom 20.05.2018. 
Homepage der Bodlean Libraries in Oxford ${ }^{2}$ bis zum Archive of VW Beetle Literature ${ }^{3}$ reichen.

Die Implikation für diese Studie ist eine doppelte: Zum einen wird es zu ihrem Abschluss unumgänglich sein, von der Meta-Ebene zu einer Betrachtung individueller Angebote in Form konkreter Fallstudien überzugehen. Zum anderen aber muss die Auswahl dieser Angebote unweigerlich Züge von Willkürlichkeit tragen, weil das kulturelle Milieu des virtuellen Museums - und womöglich verweist dies ja auf einen erfolgreichen Umgang seiner Produzenten mit seiner tragenden Medientechnologie - tatsächlich noch zu flach und zu vielgestaltig zu sein scheint, um eindeutige >Musterbeispiele $<$ hervorzubringen. Das heißt freilich nicht, dass es in der Publikumsgunst keine klaren Tendenzen zu bestimmten big players der Museumsvirtualisierung gäbe. Aber unter den Betreibern - privat, öffentlich und kommerziell - scheint sich bisher kein 〉Gondelende « der Praktiken virtuellen Kuratierens herausgebildet zu haben. Ungeachtet der präsentierten Inhalte existieren virtuelle Ausstellungskonzepte weitgehend unter long tail-Bedingungen.

Entsprechend erheben die folgenden Fallstudien weder einen Anspruch auf Vollständigkeit noch darauf, eineindeutige Tendenzen in der Museumsvirtualisierung abzubilden. Vielmehr wollen sie eine möglichst große Bandbreite der Formen aufführen, welche virtuelle Museen annehmen können - und wie sich diese Formen zwischen virtuell Ausstellenden und Publikum sowohl zum klassischen Museumsdispositiv als auch zur Technizität ihrer digital virtualisierten Rezeptionssituation verhalten. ${ }^{4}$

\subsection{VIRTUELLE MUSEEN ALS VERLÄNGERUNGEN DER PHYSISCHEN AUSSTELLUNG}

Den Anfang machen werden hier ausdrückliche Vorfeld-Angebote physischer Trägerinstitutionen. Anhand zweier Beispiele - jenem des J. Paul Getty Museum in Los Angeles und jenem des Städel Museums in Frankfurt am Main - sollen zwei unterschiedliche Strategien der Übertragung physischer Sammlungsbestände auf das For-

2 http://www.bodleian.ox.ac.uk/ vom 20.05.2018.

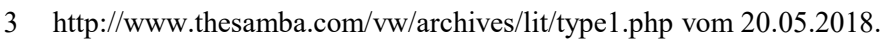

4 Es sei noch angemerkt, dass die folgenden Fallstudien zwischen Herbst 2015 und Frühjahr 2016 entstanden sind. Der Zeitaufwand für das Bewertungsverfahren dieser als Qualifikationsarbeit entstandenen Schrift sowie die anschließende Aufbereitung für die physische Drucklegung lassen es unvermeidlich werden, dass einige der diskutierten Webpräsenzen sich zum Zeitpunkt der Veröffentlichung bereits nicht mehr so präsentieren werden, wie sie hier noch dargestellt sind. 
mat einer Online-Ausstellung einander gegenübergestellt werden: Das Getty verwendet eine sehr konservative Datenbankstruktur, während das Städel sich einer vernetzten Architektur bedient, welche nicht nur im Hintergrund wirkt, sondern im Design der Webseite visuell aufgegriffen wird.

Beide Fallstudien stehen als professionell-museale Angebote repräsentativ für den Umgang der Institution mit ihrer Virtualisierung, und zwar jeweils im ausschließlichen Bezug auf sich selbst. In Kapitel 7.2 wird dieser Blick geweitet werden, um die Bedeutung von Virtualisierungserscheinungen zwischen Einzelinstitutionen näher zu beleuchten.

\subsubsection{Das J. Paul Getty Museum im Internet (www.getty.edu)}

Der amerikanische Ölmilliardär Jean Paul Getty (1892-1976) machte 1954 in Los Angeles erstmals seine umfangreiche Kunstsammlung der Öffentlichkeit zugänglich und schuf damit den Nukleus des heutigen J. Paul Getty Museum. Nach Gettys Tod ging sein Vermögen 1982 an den J. Paul Getty Trust, dessen Beisitzer sich den Erhalt und Ausbau von Gettys Lebenswerk zum Ziel setzten. ${ }^{5}$ Nach diversen Umzügen und Aufteilungen belegt das Museum heute zwei physische Lokalitäten: Einmal die 1974 errichtete Getty Villa in den Pacific Palisades, welche der villa dei papiri in Herculaneum nachempfunden ist, und ein weiteres, größeres Gebäude in Brentwood als Teil des Getty Center, zu dem darüber hinaus ein Forschungsinstitut und die Verwaltungsgebäude der Getty Foundation gehören. ${ }^{6}$

Den Kern der regulären Sammlung des Getty bilden vornehmlich antike Plastiken, europäische Malerei bis etwa zum Beginn des 20. Jahrhunderts, Manuskripte der bürgerlichen Aufklärung und Photographien des 19. Jahrhunderts. ${ }^{7}$ Herausragende Exponate besitzt das Museum vor allem im Bereich der Malerei, so z.B. Vincent van Goghs Schwertlilien ${ }^{8}$, das von Hyacinthe Rigaud um 1700 angefertigte Herrscherporträt Ludwigs XIV. von Frankreich ${ }^{9}$, Caspar David Friedrichs Abendspaziergang ${ }^{10}$ sowie Rembrandts Entführung der Europa ${ }^{11}$.

Die Homepage des Getty unter www.getty.edu ist sowohl ein Serviceangebot als auch eine virtuelle Erweiterung der Ausstellungsfläche. Sie informiert einerseits über das Museum selbst - seine Geschichte, seine Öffnungszeiten, laufende Ausstellungen

5 Vgl. http://www.getty.edu/about/ vom 20.05.2018.

6 Vgl. ebd., vgl. auch https://www.getty.edu/foundation/about/ vom 20.05.2018.

7 Vgl. http://www.getty.edu/museum/about.html vom 20.05.2018.

$8 \mathrm{Vgl}$. http://www.getty.edu/art/gettyguide/artObjectDetails?artobj=947 vom 09.09.2015.

9 Vgl. http://www.getty.edu/art/gettyguide/artObjectDetails?artobj=582 vom 09.09.2015.

10 Vgl. http://www.getty.edu/art/gettyguide/artObjectDetails?artobj=1046 vom 09.09.2015.

11 Vgl. http://www.getty.edu/art/gettyguide/artObjectDetails?artobj=1069 vom 09.09.2015. 
und Vortragsreihen, Führungen, Veranstaltungen, Publikationen, Anfahrtsmöglichkeiten usw. -, bietet aber zugleich auch die Möglichkeit, die gesamte reguläre Sammlung sowie ausgewählte Stücke aus wechselnden Ausstellungen in Form digitaler Abbildungen und erklärender Texte zu erforschen. Wer der Aufforderung »Explore the Collection« folgt, dem bietet sich zu diesem Zweck ein recht sparsames Interface $^{12}$ : Neuerwerbungen des Museums werden, in Form kleiner Ausschnitte auf einer Leiste, die nach links und rechts gescrollt werden kann, direkt sichtbar gemacht. Als einzige Form der >Einbindung « des Rezipienten läuft unten auf der Hauptseite der Sammlung laufend ein kleiner Ticker mit, über den Interessierte sich mittels Twitter über das Museum unterhalten und Erfahrungen austauschen können.

Der Zugriff auf die eigentliche Sammlung kann auf drei Wegen erfolgen: Der erste ist die einfache Eingabe eines Suchbegriffes, wie Künstlername oder Werkstitel. Der zweite ist die Verwendung eines alphabetischen Künstlerverzeichnisses. Der dritte ist die Navigation eines kategorischen Ordnungssystems, in dem die Exponate über zwei Größen durchsucht werden können: Über die Objektart bzw. das Medium (z.B. Gemälde, Photographie, Skulptur oder Keramiken) und über den Gegenstand der Darstellung (z.B. Mythologie, Religion, Tiere und Pflanzen oder Alltagsszenen). Diese Kategorien sind ferner noch mit Unterkategorien versehen. Wer >Keramiken anklickt, kann z.B. auswählen, ob er Vasen, Töpfe oder Trinkschalen sehen möchte. Wer sich für >Mythologie< entscheidet, hat darüber hinaus die Wahl zwischen mythischen Geschöpfen, Heroen, Sterblichen und Göttern.

Wer ein bestimmtes Objekt anwählt, wird zu einer separaten Seite weitergeleitet, die nur diesem singulären Ausstellungsstück gewidmet ist und auf kein bestimmtes anderes mehr verweist. Hier ist das gewählte Objekt als Scan (bei Gemälden und Fotos) oder Fotografie vor neutralem Hintergrund (z.B. bei Skulpturen) zunächst sehr klein abgebildet. Die meisten Abbildungen haben etwa 300 Pixel maximale Kantenlänge und können vom User per Mausklick auf das Doppelte vergrößert werden, so dass sie auf modernen Monitoren gut zu erkennen, aber nicht zur Anfertigung gedruckter Reproduktionen zu gebrauchen sind. Unter der Abbildung befindet sich in Form des Künstlernamens der einzige Link auf der Seite, nämlich jener zu anderen Werken des Künstlers. Darunter folgen technische Daten zu Herkunftsland, Ausführung, Abmessungen des Originals und das Datum der Aufnahme in die Sammlung des Getty. Nochmals darunter folgt ein Feld, welches darüber informiert, ob sich das betreffende Stück augenblicklich in der Ausstellung befindet, und falls ja, an welchem der beiden Getty-Standorte. Erst unter diesen Angaben folgt der erklärende Text, meist lediglich eine Zusammenfassung des Dargestellten - mit Details, die dem Betrachter üblicherweise nicht bekannt sein dürften oder auf die er von allein nicht aufmerksam werden würde. Die Seite zu Louis-Léopold Boillys Bild Eingang zum Jardin Turc beispielsweise weist den Betrachter darauf hin, dass der Künstler sich im

12 Vgl. http://www.getty.edu/art/ vom 09.09.2015. 
Gemälde selbst als Teil einer Menschenmenge dargestellt hat. Interpretationen und Deutungen der Kunstwerke werden indes nicht eingebracht. ${ }^{13}$ Seitlich dieses Hauptteiles befindet sich bei den meisten Exponaten noch eine Leiste, über die Detailansichten der Objekte aufgerufen werden können. Hierbei kann es sich um bemerkenswerte Aspekte handeln, die man gemeinhin am Gesamtbild übersehen würde, oder auch nur um Beschädigungen.

In dieser Nutzung mehrerer digitaler Bilder zur Darstellung einzelner Objekte knüpft das Getty an epistemische Eigenschaften von Reproduktionen an, die in dieser Studie wiederholt behandelt wurden: Die ent-auratisierte Kopie lädt zu allerlei konstruktiven Manipulationen ein. Vergrößerungen, Zeitlupen und Ausschnitte sind nicht notwendigerweise Beschädigungen des Kunstwerkes, sondern vielmehr sehr bewusste explorative Auseinandersetzungen mit ihm. Sie ermöglichen konzentrierte (und damit auch im Assmann'schen Sinne lange) Blicke auf das Objekt, die seine feineren Strukturen offenlegen und Rückschlüsse auf seine Entstehungsbedingungen zulassen. André Malraux spricht von einer Befreiung des Kunstwerkes aus seiner Befangenheit durch die »imaginären Über-Künstler« (Malraux 1960: 42): Im imaginären Museum werden einstmals singulär-abgeschlossene Kunstwerke zu einer »Folge der Abbildungen, die einen Stil so unmittelbar verlebendigen wie der Zeitraffer eine Pflanze im Film« (ebd.).

Indes präsentiert sich der Getty-Webauftritt eher als funktionale Erweiterung des Kunstbuches oder des Ausstellungskatalogs denn als ein Versuch der Übertragung musealer Präsentationsmodi auf das Web. Interessant ist er als einleitendes Fallbeispiel hier vornehmlich aus zwei Gründen, von denen der eine institutioneller, der andere konzeptueller Natur ist. Erstens nämlich ist getty.edu das professionell gestaltete und betriebene virtuelle Vorfeld einer etablierten und finanzstarken Mutterinstitution. Als solches existiert es als Präsentationsplattform für museale Inhalte in direkter Beziehung zu einem physischen Museumskomplex und seinen spezifischen Ausstellungssituationen. Zweitens aber unternimmt die Webseite keinerlei Anstrengungen, diese auch nur entfernt oder abstrakt abzubilden. Das Getty präsentiert sich auf seiner Homepage weniger als ein Museum denn als ein Archiv von verschlagworteten Abbildungen mit Textbeigabe, das technisch wiederum als eine durchkategorisierte Datenbank aufgebaut ist. Getty.edu überträgt weder das Dispositiv Museum im Allgemeinen, noch seine spezifische Erscheinungsform im J. Paul Getty Museum auf das virtuelle Medium. Insofern stellt diese Webpräsenz gewissermaßen trotz der quantitativen Fülle seiner Inhalte tatsächlich eine Minimalform des virtuellen Museums dar: Ihre Inhalte werden nicht im Web durch Präsentationspraktiken >musealisiert`, sondern ihr musealer Charakter wird vorausgesetzt - und verbürgt durch die

$13 \mathrm{Vgl} . \quad$ http://www.getty.edu/art/gettyguide/artObjectDetails?artobj=192074 09.09.2015. 
Mutterinstitution, deren Namen die Webseite in Domain und Titel gleichermaßen führt.

\subsubsection{Die digitale Sammlung des Städel Museums (www.staedelmuseum.de)}

Das 1815 auf Grundlage des Nachlasses des Bankiers Johann Friedrich Städel gegründete und zu den bedeutendsten Kunstmuseen Deutschlands zählende Frankfurter Städel Museum betreibt zum Zeitpunkt der Entstehung dieses Textes - nicht zuletzt anlässlich des 200sten Jahrestages seines Bestehens - eine großangelegte Auslagerung seiner Vermittlungstätigkeit ins Web. Das Städel spricht in diesem Zusammenhang ausdrücklich nicht von einem von der physischen Ausstellung abgekoppelten Angebot, sondern von einer »digitalen Erweiterung $«{ }^{14}$ und der Ausdehnung des »Bildungsauftrag[s] des Museums weit über die physischen Grenzen des Hauses« hinaus. ${ }^{15}$ Die Homepage zitiert Direktor Max Hollein im Jahre 2014 mit den Worten:

Die zunehmende Digitalisierung unserer Lebenswelt betrifft auch vermeintlich analoge kulturelle Inhalte wie ein 500 Jahre altes Dürer-Gemälde oder eine Handzeichnung von Henri Matisse. Wenn wir das Potenzial der voranschreitenden digitalen Entwicklung richtig nutzen und es uns gelingt, daraus ein echtes alternatives Angebot zu entwickeln, bereiten wir den Weg für die Zukunft der Institution und die nächsten 200 Jahre des Städel Museums. ${ }^{16}$

Ganz unverblümt wird hier also Virtualisierung nicht als Option, sondern als eine Notwendigkeit für die `Zukunft der Institution` verhandelt. Die Digitale Sammlung befindet sich im September 2015 in der Beta-Version. Sie verfügt dementsprechend noch nicht über den vollen Umfang der angepeilten Funktionen und enthält auch noch nicht die Gesamtheit des Bestandes. Im zugehörigen Impressum wird von den Betreibern offen die Bitte an die User gerichtet, sich mit Anregungen und Hinweisen auf Software-Fehler per E-Mail bemerkbar zu machen. ${ }^{17}$ Die Sammlung selbst kann über die reguläre Museumshomepage www.staedelmuseum.de aufgerufen werden und entspricht dieser in ihrer reduzierten, überwiegend in Weiß- und Beigetönen gehaltenen Ästhetik. In der Webseiten-Architektur ist sie allerdings unter der Domain digitalesammlung.staedelmuseum.de von ihr abgesetzt. Die Startseite der digitalen Sammlung bildet eine langsam seitwärts über den Bildschirm rollende Abfolge von Bildern aus der Sammlung. Hierbei handelt es sich sowohl um Scans von Gemälden,

14 http://www.staedelmuseum.de/de/geschichte vom 18.09.2015.

15 Ebd.

16 Ebd.

17 https://digitalesammlung.staedelmuseum.de/index.html\#/ vom 18.09.2015. 
als auch um Fotografien von Skulpturen. Gelegentlich erscheinen Bogenlinien zwischen zwei Werken, die von Worten wie `Bildelemente` oder `Stilrichtung « unterbrochen sind - hierbei handelt es sich um Gemeinsamkeiten zwischen Objekten, die den Schlüssel zur Erschließung der Sammlung darstellen. Ein Klick auf jedes dieser Bilder öffnet eine separate, dem jeweiligen Kunstwerk gewidmete Seite.

Unterhalb der Bilder-Slideshow befindet sich ein mit den Worten »Zeige mir Werke zu...« überschriebenes Zugriffsfeld. Der Nutzer kann hier zwischen den Rubriken »Künstlerbezug«, »Wirkung auf den Betrachter«, »Hauptmotiv«, und »Stilrichtung« wählen. Jedes dieser Felder eröffnet Zugriff auf abermals fünf Objekteigenschaften. Unter >Künstlerbezug` heißen diese Utrechter Caravaggisten, Blauer Reiter, Brücke, Leibl-Kreis und CoBrA, unter >Wirkung auf den Betrachter Erheiternd, Wütend, Provokant, Freudig und Romantisch, unter >Hauptmotiv Madonna, Venus, Akt, Stillleben und Landschaft, unter >Stilrichtung schließlich Kubismus, Neue Sachlichkeit, Bauhaus, Dadaismus und Konzeptkunst. Eine getroffene Auswahl öffnet ein Fenster mit allen zur Anfrage passenden Objekten. Unterhalb dieses Katalogfeldes befindet sich darüber hinaus ein einfaches Eingabefeld für eine Textsuche. ${ }^{18}$

Das Städel stellt also ähnlich wie das Getty ein Datenbank-System von Kategorien und `Etiketten das Getty allerdings den Zugriff komplett über subject headers organisiert, arbeitet das Städel mit einem interessanten Visualisierungsverfahren, das Gemeinsamkeiten zwischen Einzelwerken als Vernetzungen visualisiert - und zwar nicht nur auf der Startseite. Wählt man ein beliebiges Objekt aus, so wird eine separate, diesem Ausstellungsstück gewidmete Seite geöffnet. Diese zeigt zentral das gewählte Objekt mit Angaben zu Künstler, Titel und Jahr darunter. Rechts daneben laufen weitere Bogenlinien zu Miniaturansichten >verwandter Objekte, durch die mit dem Mausrad hindurchgescrollt werden kann. Claude Monets Gemälde Das Mittagessen aus dem Jahre $1868^{19}$ beispielsweise ist über die Linie Sammlungsbereich mit Eugène Delacroixs Werk Fantasia Arabe von 1833 verbunden, über die Linie Hauptmotiv mit Cornelis Begas Wirtshausszene von ca. 1660, über die Linie Zeit mit Carl Philipp Fohrs Wasserfällen von Tivoli von 1817, usw. Ein Klick auf diese Werke öffnet deren Seiten samt ihrer eigenen Schlagwortkonnizes. Kehrt man zum Ausgangswerk zurück, so gelangt man zu einem Itinerar der bisher angeklickten Werke samt der zwischen ihnen verlaufenden Assoziationslinien. Dieser >Verlauf « kann bearbeitet werden, indem man einzelne Werke aus ihm entfernt. Bei der Rückkehr auf die Seite

18 Vgl. ebd.

19 Vgl. https://digitalesammlung.staedelmuseum.de/index.html\#/exhibit/Resource_museum _exhibit_Staedel_3012 vom 18.09.2015. 
eines im Verlauf gespeicherten Individualobjektes stellt man fest, dass bereits angesehene verwandte Werke auf die linke Seite gewandert sind, während ihre Position auf der rechten von neuen Miniaturansichten eingenommen wird.

Die Einzelwerks-Ansicht bietet darüber hinaus drei Buttons unterhalb des Objektes zum Anklicken an: Ein kleines Herz ermöglicht es, das Werk als `Favoriten ‘ zu markieren (dazu gleich Näheres). Das Feld + Infos öffnet Beschreibungen und erklärende Texte zum Ausstellungsstück, die von Abmessungen und Angaben zu dargestellten Personen, Bauten und Landschaften bis hin zu Erklärungen der Lebensumstände des Künstlers zum Entstehungszeitpunkt des Werkes reichen. Hinzu kommen Angaben zu Sammlungsbereichen und Inventarnummern innerhalb der Sammlung des Museums. Diese Seite bietet außerdem Zugriff auf weiteres Medienmaterial zum Objekt, wie Audioguides und Videos. Von hier aus kann zuletzt auch auf die hochauflösende Objektansicht zugegriffen werden, die wohlgemerkt keinen Download erlaubt. ${ }^{20}$ Neben dem + Infos-Feld befindet sich eine kleine schematische Darstellung vernetzter Rechtecke, die ein erweitertes >Assoziations-Fenster öffnet: Hier können alle mit dem Objekt verbundenen Werke über die auch auf der Startseite verwendeten Rubriken aufgerufen werden.

Schließlich verfügt die Digitale Sammlung über einen am rechten Bildschirmrand fast verborgenen Reiter, der per Klick >ausgefahren « werden kann und der neben einem Impressum und einem Hilfsmodus vier über Icons anzusprechende Funktionen beherbergt. Ein Herzchen erlaubt es dem Nutzer, seine als >Favoriten` gekennzeichneten Objekte aufzurufen und zu verwalten. Das Feld, mit dem dieses Fenster geschlossen werden kann, trägt bezeichnenderweise die den Flaneur evozierende Aufschrift »Weiterschlendern«. Eine Lupe erlaubt das Durchsuchen der Sammlung nach Stichworten. Ein schematisch dargestelltes Männlein ermöglicht die Erstellung eines Kontos oder die Anmeldung in ein bestehendes, mit dem Favoriten und Suchverläufe gespeichert werden können. Zwei kleine Fenster schließlich erlauben den Blick auf aus dem Fundus zusammengestellte Sammlungen bzw. Alben, von denen es derzeit erst neun gibt und eines den Titel Test111 trägt - ein offensichtliches Symptom der Tatsache, dass das Angebot noch in der Entwicklung begriffen ist. Drei Einträge am rechten oberen Seitenrand, betitelt Städel, Öffentliche und Meine, sind zurzeit noch nicht anklickbar, deuten aber an, dass hier ein Element der Publikumsbeteiligung in Vorbereitung ist.

Das Google Art Project wird im kommenden Unterkapitel noch gesondert diskutiert werden, wenn es um virtuelle Plattformen geht, die verstreute Sammlungen vernetzen. Für den Augenblick sei schon einmal festgestellt, dass das Art Project und seine Funktionalitäten zahlreichen Features der Digitalen Sammlung Pate gestanden

20 Vgl. z.B. https://digitalesammlung.staedelmuseum.de/index.html\#/exhibit/Resource_ museum_exhibit_Staedel_3012 vom 18.09.2015. 
zu haben scheinen. Damit ist es zunächst einmal ein Beispiel für sich langsam etablierende Standards bei der Gestaltung virtueller Museumsangebote und wirft zugleich die (augenblicklich wohl noch nicht übergreifend zu beantwortende) Frage auf, nach welchen Größen eine Institution darüber entscheidet, eine eigene Plattform aufzubauen oder sich an einer bereits existierenden zu beteiligen. Die Direktion des Städel hat eine eigene gewählt und dabei eine durchkatalogisierte und verschlagwortete Datenbank mit einem visuellen Netzwerk der Exponate verbunden, die auf sehr interessante Weise den Zusammenhang von Verwaltungswissen und Ausstellungserleben illustriert: Das Netz der Kunstobjekte ist ein von digitaler Technik erzeugtes Abbild der katalogsmäßig erfassten Eigenschaften der Einzelobjekte im direkten Vergleich zueinander. Es geht also um connectedness, wenngleich in hochfunktionalisierter Form. Das digitale Städel inszeniert Museumsdinge ganz bewusst als konstitutive Bausteine von Sinnzusammenhängen und macht die Pfade und Vernetzungen zwischen den einzelnen Objekten selbst zu Exponaten, ohne dabei aber die gesamte `Landkarte` der Sammlung offenzulegen. Der Besucher kann immer nur die unmittelbare `Nachbarschaft $\triangleleft$ der Einzelobjekte überblicken. So versetzt ihn die Digitale Sammlung in eine ganz ähnliche Situation, wie es das physische Museum tut - ohne sich indes einer virtuellen Simulation spatialer Räume zu bedienen. Dabei wird ganz bewusst eine Überflutung mit Textinformationen vermieden.

Die Digitale Sammlung ist in ihrem Aufbau grundsätzlich (noch) unflexibel: Die Kategorisierungen der Objekte werden auf der Kuratorenseite vorgenommen, und die Favoriten-Galerien können von den Nutzern untereinander nicht geteilt werden. Indes stellt die bestehende Vermittlungsarchitektur eine Aussöhnung von Katalogprinzip und Netzwerkparadigma dar: Die Kategorien selbst werden zu Knotenpunkten der Vernetzung gemacht, die visuelle Beschaffenheit des Interfaces transformiert mit einfachen Mitteln das Archivarische ins Museale. Insofern haben wir es hier mit einem prototypischen virtuellen Museum nach Hoptman zu tun, welches connectedness ins Zentrum stellt und dabei zugleich das epistemische System des physischen Museums von innen nach außen wendet: Während dort die Sinnbezüglichkeiten der Objekte untereinander im sichtbaren Raum verborgen sind, werden sie hier tatsächlich ausgestellt - während andererseits jedwede `Räumlichkeit` nur eine empfundene sein kann, die sich eben aus dem relationalen Miteinander der Objekte und den individuellen Zugängen der Nutzer ergibt. Sichtbares und Unsichtbares wechseln also die Positionen. 


\subsection{VIRTUELLE AUSSTELLUNGEN, DISTRIBUIERTE SAMMLUNGEN}

Das >absolute Museum und die Aufhebung der Trennung sowohl zwischen allen musealen Sammlungsbeständen, als aber auch zwischen den Museen als Institutionen und der sie umgebenden Umwelt ist im Verlauf dieser Studie wiederholt als ein in der Fachliteratur immer wieder auftauchendes, finales Szenario der Museumsvirtualisierung diskutiert worden. Als kulturpädagogisches Gedankenspiel und Phantasma ist dieses hypothetische virtuelle Weltmuseum für seine Befürworter und Feinde gleichermaßen zum Bezugspunkt von Diskussionen geworden - und Didaktiken der Museumsvirtualisierung werden von beiden Lagern um die Vorstellung von seiner grundsätzlichen Machbarkeit herum konzipiert. Insofern braucht das Museum von Babel keinen tatsächlichen Bestand zu haben, um eine beständige Tatsache darzustellen: Wer über Museumsvirtualisierung spricht, der spricht unweigerlich auch über Momente der Auflösung und Neukonfiguration in der kulturellen Verortung von Sammlungsbeständen.

Dieser spekulativen Phantasmatik gegenüber steht indes eine Praxis der tatsächlichen Vernetzung von Einzelsammlungen, die Virtualisierung nicht prognostizieren, sondern gestalten will. Hinter schwammigen Hoffnungen und Ängsten in Bezug auf die Museumspädagogik der virtualisierten Zukunft stehen Unternehmungen, die technisch, politisch, pädagogisch und ökonomisch in Umsetzung begriffen sind. Dieses Unterkapitel möchte sich vier professionellen Projekten widmen, die >meta-museale`Ziele verfolgen, dabei aber zugleich zwischen den Wünschen von Publikum und Erinnerungseinrichtungen vermitteln wollen. Das Lebendige Museum Online wird von verschiedenen deutschen Museen und Archiven als gemeinsame Präsentationsplattform betrieben; das Virtual Museum of Canada will vornehmlich kanadischen Regionalmuseen einen zentralen Raum für virtuelle Ausstellungen zur Verfügung stellen; Europeana strebt die Verfügbarmachung des gesamten europäischen Kulturerbes nicht nur zur Betrachtung, sondern auch zur Weiterverwertung durch jedermann an - und das Google Art Project schließlich will in einer Kooperation zwischen Google und über 250 Museen big data mit high culture zusammenführen.

\subsubsection{Lebendiges Museum Online (www.dhm.de/lemo)}

Das Lebendige Museum Online ist eine bereits 1998 begonnene (und in seiner gegenwärtigen Form im Herbst 2014 neu gestartete) Kooperation zwischen der Stiftung Deutsches Historisches Museum (Berlin), der Stiftung Haus der Geschichte der Bundesrepublik Deutschland (Bonn) und des Bundesarchivs (Koblenz). Beheimatet unter der Domain des Deutschen Historischen Museums (www.dhm.de), steht das LeMO nach eigener Aussage im Zeichen der Absicht, Exponate und Archivalien aus den 
drei Trägereinrichtungen zusammenzuführen und »unabhängig von Öffnungszeiten und Vor-Ort-Präsenz « ${ }^{21}$ der Öffentlichkeit zur Verfügung zu stellen. Dabei wird auf klare Arbeits- und Aufgabenteilung gesetzt:

Das Deutsche Historische Museum verantwortet die Darstellung der Zeit vor 1945; das Haus der Geschichte bearbeitet die Zeitgeschichte nach dem Ende des Zweiten Weltkriegs bis zur Gegenwart. Das Bundesarchiv stellt Dokumente, Bilder und Medien zur Verfügung. ${ }^{22}$

Das LeMO will also im doppelten Sinne das >Museum ohne Wände< verkörpern: nämlich sowohl seinem Publikum gegenüber als auch in der Zusammenarbeit der teilnehmenden Häuser. Das Webseiten-Format überbrückt die räumliche Trennung zwischen den drei Einzelsammlungen ebenso wie die geographische Abwesenheit weiter Teile der >Besucherschaft . Inhaltlich befasst sich das LeMO mit der deutschen Geschichte vom 19. Jahrhundert bis in die unmittelbare Vergangenheit. Die Startseite stellt das epochale Ordnungsprinzip visuell direkt in den Mittelpunkt: Das Gros des Bildschirms wird von seitwärts scrollbaren zeitgenössischen Gemälden eingenommen, die jeweils Zeitabschnitte der deutschen Geschichte repräsentieren. Eine darüberliegende Zeitleiste weist diesen Jahreszahlen zu. Die behandelten Epochen sind >Vormärz \& Revolution〈 (1815), >Reaktionszeit` (1850), >Kaiserreich` (1871), >Erster Weltkrieg` (1914), >Weimarer Republikı (1918), >NS-Regime` (1933), `Zweiter Weltkriegく (1939), >Nachkriegsjahreく (1945), >Geteiltes Deutschland ‘ (1949), >Deutsche Einheit` (1989) und `Globalisierungく (2001) (vgl. Abbildung 1).

\section{Abbildung 1: Startseite des Lebendigen Museums Online}

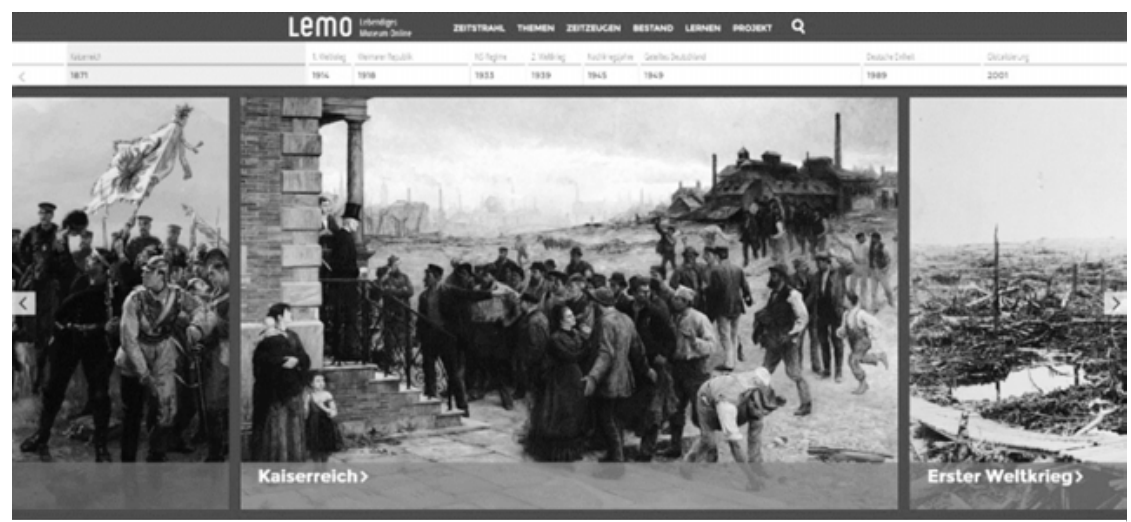

https://www.dhm.de/lemo vom 04.06.2018.

21 Vgl. https://www.dhm.de/lemo/projekt vom 22.09.2015.

22 Ebd. 
Unterhalb dieser illustrierten Zeitleiste befinden sich Links zu den Rubriken >Themen`, >Zeitzeugen «, >Bestand auch in einer Navigationsleiste am oberen Bildschirmrand auftauchen. Abermals darunter befinden sich wechselnde Links zu ausgewählten Themen und zu besonderen Inhalten, wie Videos und >360-Grad-Objekten $<{ }^{23}$

Greift man mittels der Zeitleiste auf eine der Epochen zu, so wird man umgehend mit einer großen Textlastigkeit und damit einhergehend einer starken Ausrichtung auf Narrativität konfrontiert: Jede Epoche erscheint hier als eine Sammlung illustrierter Sachtexte, die sich sowohl mit Ereignis- als auch mit Strukturgeschichte befassen und ihrerseits in Unterkapitel gegliedert sind. Zur Epoche >Vormärz \& Revolution beispielsweise sind fünf Kapitel mit den Titeln >Wiener Kongress $\measuredangle$, >Deutscher Bund`, >Alltagsleben`, `Kunst und Kultur` sowie `Revolution 1848 « vorhanden. Die jedes Kapitel und Unterkapitel illustrierenden Kunstwerke können angeklickt werden, woraufhin der Nutzer direkt auf die ihnen zugeordnete Bestandsseite gelangt. ${ }^{24}$ Epochenübergreifend ist jeder Zeitstrahl-Seite ein rotierbares >Flugrad 〈 beigeordnet, das den Zugriff auf >Jahreschroniken « erlaubt - kurze Artikel über Jahreszahlen der deutschen Geschichte zwischen 1850 und 2013, welche von den Kuratoren als besonders relevant empfunden wurden.

Während der Zeitstrahl das linear-narrative Element in den Vordergrund stellt, will der Reiter > Themen ` verstärkt das Element Hypertext ausspielen:

LeMO-Themen ergänzen die chronologische Darstellung in den Kapiteln, die unter Zeitstrahl zu finden sind. Sie haben einen Gegenwartsbezug und sollen dazu anregen, weiterzudenken. Weitergehende historische Einordnung ist durch Verlinkung in die Kapitel gewährleistet. Einige der neuen LeMO-Themen umfassen Spiele, die sich für den Einstieg eignen oder auch einfach $\mathrm{Spaß}$ machen. ${ }^{25}$

Die Verwendung des Plurals ist in der Selbstdarstellung ein kleiner Etikettenschwindel: Zur Stunde wird nur ein Thema angeboten, das vom Haus der Geschichte und dem Deutschen Historischen Museum gemeinsam ausgearbeitet wurde und den Titel Demokratie und Diktatur trägt. Weitere Themen verspricht das LeMO ausdrücklich. ${ }^{26}$ Demokratie und Diktatur befasst sich mit den Beziehungen zwischen BRD und DDR während der Periode der deutschen Teilung unter besonderer Berücksichtigung der Frage nach Freiheit und Bürgerrechten. Dabei sollen zugleich grundsätzliche Bedingungen einer Koexistenz von Demokratien und Diktaturen mitverhandelt werden. Im

23 https://www.dhm.de/lemo vom 22.09.2015.

24 Vgl. http://www.dhm.de/lemo/kapitel/vormaerz-und-revolution vom 22.09.2015.

25 Vgl. http://www.hdg.de/lemo/themen vom 22.09.2015.

26 Vgl. ebd. 
Zentrum stehen die zwei Fragen »Wie funktioniert das Nebeneinander?« und »Wie frei bin ich?«, die jeweils auf eine eigene Seite führen und den Nexus für eine Anzahl von Texten, Exponaten und ein Spiel bilden. ${ }^{27}$ So wird zur Frage nach dem Miteinander z.B. ein SED-Flugblatt aus dem Jahre 1963 präsentiert, das Bundesbürger zur Ausreise Richtung DDR veranlassen sollte, ${ }^{28}$ darüber hinaus das Trikot von DDRNationalspieler Jürgen Sparwasser, der bei der ersten Runde der Gruppenphase der Fußball-WM 1974 das 1:0 gegen die Bundesrepublik erzielte ${ }^{29}$ und eine 1988 herausgegebene Broschüre des Bundesministeriums für innerdeutsche Beziehungen zur Abwicklung von Besuchen in und aus der DDR. ${ }^{30}$ Jedes dieser Objekte wird mit einem Konterexponat konfrontiert: Das Flugblatt mit einer westdeutschen Karikatur von Paul Pribbenow, das einen ostdeutschen Bürger beim ZDF-Schauen zeigt, während aus seinem Fenster die Flagge der DDR weht; das Trikot mit einer Bild-Schlagzeile über die Fußballniederlage, welche die Buchstaben DDR in Anführungszeichen setzt; die Broschüre mit dem Foto einer ostdeutschen Besucherin vor dem Bonner Bundestag. ${ }^{31}$ Die Narrative funktionieren in dieser Rubrik also tatsächlich eher relational denn chronologisch, jedoch sind sie nach wie vor stark kuratiert - und vor allen Dingen ausformuliert: Im Gegensatz zur Offenheit des Raumes in einer physischen Museumsausstellung werden hier immer genau zwei Objekte einander gegenübergestellt, und der begleitende Text lässt dem Rezipienten kaum Spielraum für eine eigene Lesart oder einen eigenen Umgang mit den Exponaten.

Das beigefügte Spiel ist ebenfalls nicht auf die Erschließung der Bedeutungsebenen von Ausstellungstücken, sondern vielmehr auf ihre sachrichtige oder -falsche Zuordnung zu historischen Situationen ausgerichtet. Es geht hier darum, BRD und DDR bestimmte Objekte richtig zuzuordnen. So gilt es z.B., per drag and drop das jeweils richtige Sandmännchen, Verfassungsdokument oder Plakat auf jedes der beiden Deutschlande zu ziehen, oder zu entscheiden, ob Fotos von Demonstranten in Ost- oder Westdeutschland aufgenommen wurden (vgl. Abbildung 2). ${ }^{32}$

27 Vgl. http://www.hdg.de/lemo/themen/demokratie-und-diktatur/wie-funktioniert-dasnebeneinander. html vom 22.09.2015.

$28 \mathrm{Vgl}$. http://www.hdg.de/lemo/themen/demokratie-und-diktatur/wie-funktioniert-dasnebeneinander/ gegenseitige-beeinflussung.html vom 22.09.2015.

$29 \mathrm{Vgl}$. http://www.hdg.de/lemo/themen/demokratie-und-diktatur/wie-funktioniert-dasnebeneinander/ wettkampf.html vom 22.09.2015.

30 Vgl. ebd.

31 Vgl. ebd.

32 Vgl. http://www.hdg.de/lemo/themen/demokratie-und-diktatur/wie-funktioniert-dasnebeneinander/spiel-wie-funktioniert-das-nebeneinander.html vom 22.09.2015. 
Abbildung 2: Startbildschirm des Spiels >Wie funktioniert das Nebeneinander?

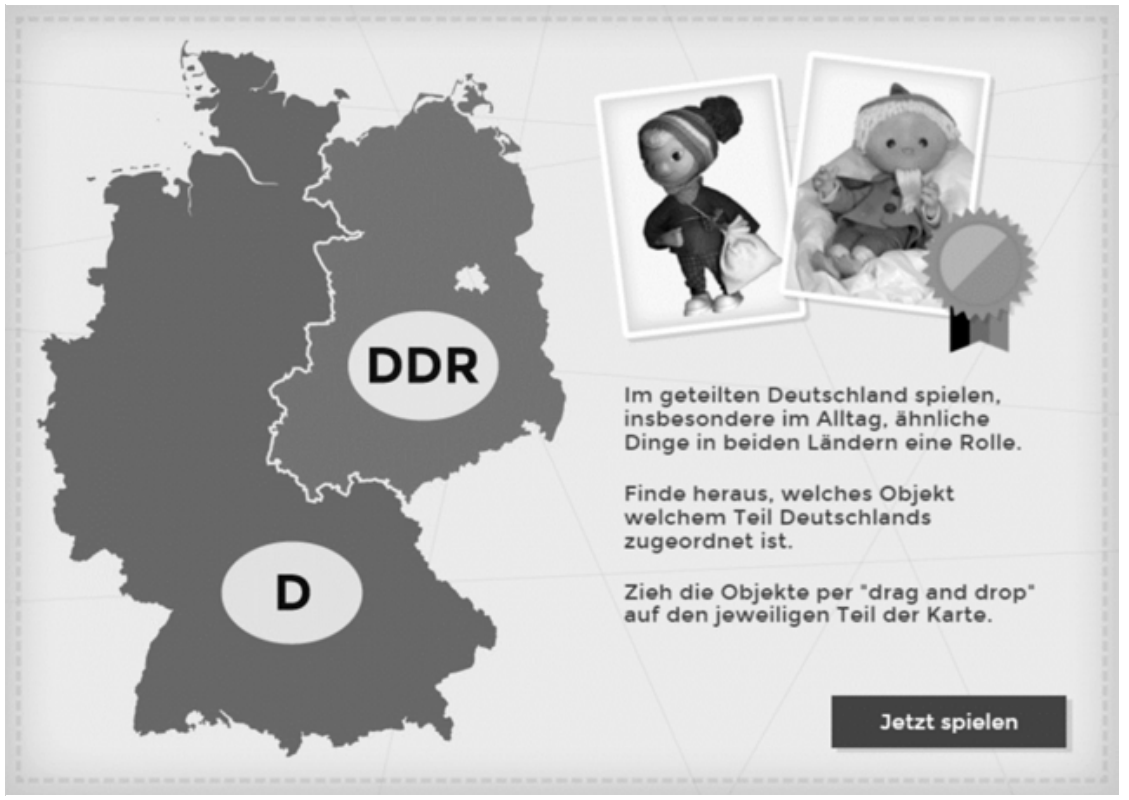

https://www.hdg.de/lemo/themen/demokratie-und-diktatur/wie-funktioniert-dasnebeneinander/spiel-wie-funktioniert-das-nebeneinander.html vom 04.06.2018.

Unter der Rubrik >Zeitzeugen` wird ein wachsendes Archiv von autobiografischen Berichten angeboten, in denen der Nutzer stöbern kann. Die individuellen Erzählungen sind dabei nach den Epochen des Zeitstrahls sortiert. Zugleich bietet die Startseite dieses Abschnitts am epochal geordneten Inhaltsverzeichnis vorbei direkten Zugriff auf die Neuzugänge sowohl des Hauses der Geschichte als auch des DHM. Bei den Erlebnisberichten handelt es sich sowohl um zeitgenössische Aufzeichnungen wie Briefe und Tagebücher als auch um Geschichten, die den Trägerinstitutionen von lebenden Zeitzeugen zugetragen wurden. Das LeMO fordert Besucher, die eine persönliche Geschichte erzählen und veröffentlicht sehen möchten, explizit zur Kontaktaufnahme per E-Mail auf. ${ }^{33}$

Die Artikel dieser Rubrik ähneln denen der Zeitleiste: Sie präsentieren sich als narrative, von den Zeitzeugen selbst verfasste oder diktierte Texte, die historisches Geschehen personalisieren und in der Erlebniswirklichkeit von >echten Menschen verankern. Navigierbar sind sie (neben der epochalen Einordnung) nach Schlagworten wie z.B. `NSDAP«, >Boxeraufstand «, >Trümmerleben` oder `Kindheit ${ }^{34}$ Auch

33 Vgl. http://www.dhm.de/lemo/zeitzeugen vom 22.09.2015.

34 Vgl. z.B. http://www.dhm.de/fileadmin/lemo/suche/search/index.php?q=*\&f[]=seiten typ:Zeitzeuge \&f[]=epoche:Nachkriegsjahre vom 22.09.2015. 
über den Namen des Zeitzeugen (von einigen liegen mehrere Berichte vor) und über Ortsnamen kann die Artikel-Datenbank durchforstet werden. Individuelle Artikel sind häufig mit Fotografien und Dokumenten aus dem Besitz der erzählenden Zeitzeugen versehen, die ihrerseits über eigene Objektseiten verfügen.

Der Reiter ১Bestand`schließlich führt überraschenderweise nicht unmittelbar zu den musealen Digitalisaten, sondern tatsächlich zu einem Gesamtverzeichnis nahezu sämtlicher im LeMO zusammengeführten Inhalte. Der Zugriff auf diese Gesamtdatenbank ist über 12 Einzelkategorien distribuiert: 〉Objekte < beinhaltet sowohl Museumsdinge als auch Dokumente und fotografisches Bildmaterial - zugleich können >Fotografien` und `Dokumente $<$ aber auch als eigene Kategorien angewählt werden, womit die Objektdatenbank unter Anwendung entsprechender Filter aufgerufen wird. Die Kategorie >Chroniken « öffnet die bereits unter der `Zeitstrahl<-Rubrik angebotenen Jahreschroniken, während `Zeitzeugen` den Zugriff auf die Zeitzeugenberichte erlaubt, die auch in der Kopfleiste verlinkt sind. Ebenfalls in der Kopfleiste gedoppelt ist die Kategorie >Lernen`, die ausgewählte digitale Ressourcen für den Schulunterricht bereitstellt. Die Kategorien >Audios` und >Videos` greifen quer über andere Kategorien auf Inhalte zu, die klingen oder sich bewegen. Die $>$ Rückblicke $<$ bilden eine eigene Kategorie von nur auf diesem Wege aufzufindenden Artikeln über den modernen Umgang mit zentralen Ereignissen der deutschen Geschichte. >Biografien< sind eben dies: Lebensdarstellungen wichtiger deutscher Persönlichkeiten. Unter >Karten $<$ finden sich sowohl historisches Kartenmaterial, als auch moderne Aufarbeitungen zur Geographie historischer Abläufe. Über die zukünftige Funktion der Kategorie `Statistiken`schließlich lässt sich augenblicklich nur spekulieren - sie ist nämlich noch völlig leer. ${ }^{35}$ Das LeMO setzt innerhalb seiner Verlinkungsstruktur sehr stark auf Redundanzen und Rekursivitäten: Fast jedes funktionale Areal des Angebotes kann auf verschiedenen Wegen erreicht werden, und wer sich zum Flanieren verleiten lässt, dem wird schnell auffallen, dass er immer wieder auf $H u b$-Seiten zurückgeführt wird. Obwohl seine Erzählstrukturen aufgrund seines artikelorientierten Aufbaus immer wieder sehr linear funktionieren, gleicht seine Topographie einem Netzwerk von sternförmigen Umschlagplätzen, die den Nutzer über kurze Folgen von Text- und Bildmaterial zum nächsten Orientierungspunkt weiterleiten.

Die Objekt-Datenbank umfasst zurzeit 5894 Digitalisate von Museumsobjekten, Fotografien und Archivalien. Bei fast allen handelt es sich um einfache Abbildungen in Form von Scans oder Digitalfotografien. Einige wenige Ausstellungsstücke liegen als sog. $>360^{\circ}$-Objekte $<$ vor. Hierbei handelt es sich nicht um frei rotierbare und in Echtzeit gerenderte 3D-Objekte, sondern um Gegenstände, die aus mehreren Positionen auf einer sie umgebenden >Umlaufbahn sprechend in diskreten Schritten um ihre Y-Achse >drehen $<$ lassen. Die Einteilung der

35 Vgl. http://www.dhm.de/lemo/bestand/ vom 22.09.2015. 
Objekte in der Datenbank geschieht nach Epoche, Medientyp, Schlagworten, Personen und Objektgruppen (z.B. >Plakat`, >Postkarte, , >Militaria $<$ ). Hier zeigt sich an verschiedenen Ungereimtheiten, wie sehr das LeMO noch in der Entstehung begriffen ist: Die Kategorie >Medien`z.B. enthält lediglich das Merkmal `Fotografie`, und zu diesem nur zwei Einträge. Zugleich findet sich die `Fotografieく aber auch als Eintrag in der Kategorie >Objekte $<$ - und macht hier mit 2253 korrespondierenden Inhalten fast die Hälfte der Sammlung aus. Darin manifestiert sich das bereits angesprochene grundsätzliche Problem beim Anlegen musealer Datenbanken: Die Betreiber selbst scheinen sich noch nicht ganz sicher zu sein, welche Merkmale ihrer virtuellen Ausstellungsstücke sie verzeichen und dem Nutzer als Zugriffsmodi anbieten, oder innerhalb welcher Kategorien sie diese Merkmale gruppieren möchten. Hinzu kommt, dass es weder eine kuratierte noch eine automatisierte Methode gibt, Objekte innerhalb der Datenbank miteinander in Verbindung zu bringen. Was nicht mit wenigstens einer gemeinsamen Datenbank-Kategorisierung versehen wurde, das muss einander fremd bleiben - und unsichtbar all das, was nicht auf ein Schlagwort gebracht wurde. Rätselhaft erscheint auch die Kategorie >Mehrwert`, die lediglich das Merkmal >Objekte in Ausstellungen` umfasst, ohne dass für den Nutzer ersichtlich würde, um welche Ausstellungen es hier geht. ${ }^{36}$

Die individuellen Objektseiten, zu denen man mittels eines Klicks auf die Abbildung in der Bestandsdatenbank gelangt, sind im Vergleich zur Textlastigkeit aller anderen Bereiche des LeMO nur mit spärlichen Textbeigaben versehen. Die Beschreibung beschränkt sich meist auf einige wenige Sätze, eine Datierung (soweit möglich), bei Stücken im Besitz der Trägerinstitutionen die Inventarnummer des Originals, je nach Objektart mitunter Angaben zu Material und Abmessungen, ferner eine Copyright-Angabe und eine Kontaktadresse für Bildnutzungsrechte, und zuletzt auf Schlagwörter als Hyperlinks. Letztere bilden die einzige Form der Querverstrebung zwischen individuellen Objektseiten. Die Abbildungen selbst liegen in vergleichsweise hoher Auflösung mit der üblichen HD-Kantenlänge von 1080 Pixeln vor und sind nicht vor Downloads durch den Nutzer geschützt. ${ }^{37}$

Während das J. Paul Getty seine digitalisierte Sammlung ohne weitere Umschweife in Datenbankmanier präsentiert und der virtuelle Auftritt des Städel kategoriale Zusammengehörigkeit in visuelle Vernetzung transponiert, schlägt das LeMO also einen ganz anderen Weg ein: Die Datenbank der digitalisierten Objekte ist hier eher Hintergrundressource, während die eigentlichen >Ausstellungs〈-Gegenstände Erzählungen sind. Insofern steht das LeMO mehr als jedes andere in diesem Kapitel diskutierte Angebot (mit Ausnahme vielleicht des im nächsten Unterkapitel bespro-

36 Vgl. http://www.dhm.de/fileadmin/lemo/suche/search/?q=*\&f[]=seitentyp:Objekt vom 22.09.2015.

37 Vgl. http://www.dhm.de/lemo/bestand/objekt/orden-pour-le-merite.html vom 22.09.2015. 
chenen 8bit-Museums) im Zeichen des Mediums Hypertext: Während Multi- und Intermedialität fest zum Anspruch des Angebotes gehören, bilden lineare, narrative Texte unverkennbar das Fundament seiner Didaktik. Zugleich begünstigt das $\mathrm{Zu}$ griffsinterface `Zeitstrahlく ganz klar ein chronologisches Lesen mit gelegentlichen Exkursen in abzweigende Artikel zu spezifischen Themen. Die ständige Rückführung des Nutzers auf Hub-Seiten lässt überraschenderweise für den Leser nicht die rhizomatische Textstruktur entstehen, die aus der `Vogelperspektive $<$ topgraphischer Darstellung erkennbar werden würde, sondern vielmehr die eines `Wurzelbuchs $\prec$. Es scheint hier eine klare Hierarchisierung von Wissensstrukturen vorzuliegen, die von innen nach außen und vom Allgemeinen ins Bestimmte funktioniert: vom Zeitstrahl in die Einzelepochen, von den Epochen in diverse mit ihnen assoziierte Themenbereiche, von diesen zu relevanten Jahreschroniken, Zeitzeugenberichten, Schaustücken usw.

Wilde Semiosen sind offenbar nicht vorgesehen und dürften im durchnarrativierten >Ausstellungs<-Bereich der Webseite auch kaum vorkommen. Interessant indes ist, dass die `Bestands`-Datenbank ihre Inhalte nur mit sehr spärlichen Beschreibungen versieht, die meist nicht über eine Datierung und Benennung der Provenienz hinausgehen. Das LeMO verhält sich zu keiner Zeit dazu, ob hinter dieser relativen Textarmut auf den Objektseiten eine didaktische Programmatik steht - oder ob die Objektdatenbank schlicht nicht als der Zugang gesehen wird, über den Nutzer zur Sammlung finden sollen. Es wird sich trefflich darüber streiten lassen, ob hiermit Freiheitsgrade von Bedeutsamkeit angezeigt sind oder bloße Beliebigkeiten: Es scheint in jedem Falle keine intime Verwobenheit ihrer kategorialen Ordnung mit dem pädagogischen Konzept des restlichen LeMO zu geben. Damit erscheint sie in erster Linie als eine Transparentmachung der Ressourcen und des Verwaltungswissens, aus denen >Ausstellungen` hervorgehen; als ein Blick in Fundus und Kartei gleichermaßen, und es liegt beim Nutzer, die kuratorischen Absichten zu dekodieren, die ihren Überführungen in den Ausstellungskontext zugrunde liegen.

\subsubsection{Das Virtual Museum of Canada (www.virtualmuseum.ca)}

Das bereits an anderer Stelle angesprochene Virtual Museum of Canada geht noch einen Schritt weiter, indem es überhaupt nicht mehr versucht, Sammlungen zusammenzuführen - sondern stattdessen eine Plattform zu sein, auf der existierende physische Museen Ausstellungen darbieten können. Es geht also ausdrücklich nicht um eine Öffnung des Fundus für den Besucher, sondern um eine Ausweitung kuratorischer Spielräume über Museumswände hinaus. Dies mag überraschen, hatten doch seine Gründer George MacDonald und Stephen Alsford noch 1997 das Meta-Museum in Aussicht gestellt und dabei bereits Kernthesen dieser Studie angedeutet: 
It is surely likely that the digital museum will adopt metaphors that make it look much like the real-world museum. Museum exhibits and the hypermedia environment of the Web already have characteristics in common. Each uses diverse media forms to communicate structured messages: texts, still images, audiovisual. Each is structured to facilitate exploration of knowledge domains. Each tends to have layered information, with main themes branching into sub-themes. And, yet, each offers visitors the chance to wander almost randomly, on associative principles that reflect highly personalized interests. (MacDonald \& Alsford 1997: 272)

Der Startschuss zur Schaffung des VMC fiel am 12. Oktober 1999, zwei Jahre nach der Entstehung der obigen Zeilen, in der Thronrede der kanadischen Generalgouverneurin Adrienne Clarkson. Unter dem Punkt >Kulturelle Infrastruktur heißt es darin:

New technologies offer new opportunities to strengthen the bonds between Canadians. The Government will bring Canadian culture into the digital age, linking 1.000 institutions across the country to form a virtual museum of Canada. It will put collections from the National Archives, National Library and other key institutions on-line. It will also increase support for the production of Canadian stories and images in print, theatre, film, music and video. In particular, it will increase support for the use of new media. ${ }^{38}$

Am 22. März 2001 ging nach ausgedehnten Konsultationen mit Museologen, teilnehmenden Institutionen und Beraterfirmen eine erste Version des VMC ans Netz, die 2003 um den Themenbereich Community Memories erweitert wurde, der in erster Linie kleinen Regionalmuseen die Möglichkeit zur Erstellung virtueller Ausstellungen bieten sollte. 2007 wurde das Project um das VMC Teachers Centre erweitert, das Schullehrern Materialien und Lehrpläne zur Verfügung stellt. 2009 wurde die Webseite des $V M C$ komplett überholt und in Kernbereichen neu entworfen, um ein zeitgemäßes Erscheinungsbild zu wahren. 2012 schließlich wurden inhaltliche Updates im Monatsturnus aufgenommen, »to give a visible face to the treasures that are entrusted to Canadian museums through innovative and dynamic approaches « ${ }^{39}$ Seit Sommer 2014 befindet das Projekt sich in der Trägerschaft des Canadian Museum of History in Gatineau, Quebec. ${ }^{40}$

Nach eigener Angabe hat das $V M C$ seit seiner `Eröffnung` im Jahre 200234 Millionen individuelle $>$ Besuche ${ }^{41}$ aus mehr als 200 Ländern ${ }^{42}$ verzeichnet. Die Partner

38 http://www.pco-bcp.gc.ca/index.asp?lang=eng\&page=information\&sub= publications\&doc=aarchives/ sft-ddt/1999-eng.html vom 01.10.2015.

39 Vgl. http://www.virtualmuseum.ca/about-vmc/ vom 01.10.2015.

40 Vgl. ebd.

41 Vgl. http://www.virtualmuseum.ca/faq/ vom 01.10.2015.

$42 \mathrm{Vgl}$. http://www.virtualmuseum.ca/about-vmc/ vom 01.10.2015. 
des Projektes umfassen etwa 1.600 Museen nebst diversen Regierungsbehörden, Bildungseinrichtungen und privatwirtschaftlichen Förderern. ${ }^{43}$ Das Online-Angebot beziffert derzeit ca. 500 virtuelle Ausstellungen, $150 »$ interactive resources« und 365 unterschiedliche Lehrmittel im Teacher's Centre. ${ }^{44}$ Über den Umfang des eigentlichen Schatzes an Exponaten bzw. digitalen Reproduktionen werden keine Angaben gemacht.

Seiner Mutternation entsprechend ist das $V M C$ sowohl auf Englisch als auch auf Französisch zu erreichen: als Virtual Museum of Canda unter der Domain www.virtualmuseum.ca, als Musée virtuel du Canada unter www.museevirtuel.ca. Wie bereits angeklungen ist, verfügt es über keine einheitliche Sammlung oder Ausstellung, sondern bietet den teilnehmenden physischen Institutionen eine Plattform und eine Infrastruktur für die Erstellung und Veröffentlichung eigener virtueller Ausstellungen. Entsprechend breit gefächert ist das Angebot: Natur-, regional- und industriegeschichtliche ausgerichtete Institutionen sind ebenso vertreten wie Kunst- und Völkerkundemuseen. Verbunden sind sie durch ihre Ansässigkeit in Kanada, ihr Bezogensein auf die kanadische Geschichte und eben ihre Teilnahme am Großprojekt $V M C$. Die erste navigatorische Konsequenz, die sich aus dem Fehlen einer gemeinsamen Sammlung oder Datenbank ergibt, ist die, dass man im VMC nicht nach individuellen Objekten suchen kann. Die einzelnen Ausstellungen sind sowohl Organisations- als auch Zugriffsmodus der Webseite. Die Startseite bietet über ein großes Banner zu jedem Zeitpunkt fünf besonders bemerkenswerte Ausstellungen feil. Darunter befindet sich ein Textsuchfeld, und abermals unter diesem acht kleinere Banner, die ebenfalls auf Ausstellungen verlinken und allem Anschein nach zufällig von der Software ausgewählt werden. ${ }^{45}$ In der Navigationszeile am oberen Bildschirmrand stehen Reiter zur Verfügung, die den Zugriff auf die Startseite, die Virtual Exhibits, die Community Memories, das Teacher's Centre und die About Us-Seite gestatten (vgl. Abbildung 3). Zwischen Virtual Exhibits und Community Memories besteht dabei kein struktureller Unterschied, wohl aber ein inhaltlicher: Bei Letzteren handelt es sich um sehr fokussierte Ausstellungen kleiner Regionalmuseen, die u.a. bemerkenswerte lokale Biographien, Persönlichkeiten, Ereignisse oder Bauten vorstellen. ${ }^{46}$

Beide Ausstellungsseiten werden von einer einfachen Suchmaske gekrönt. Hier können Suchbegriffe eingegeben, der Ausstellungstyp gewählt und Richtlinien zur Sortierung von Suchergebnissen bestimmt werden (alphabetisch auf- und absteigend

$43 \mathrm{Vgl} . \mathrm{http}: / / w w w . v i r t u a l m u s e u m . c a / f a q /$ vom 01.10.2015.

44 Vgl. http://www.virtualmuseum.ca/about-vmc/ vom 01.10.2015.

$45 \mathrm{Vgl}$. http://www.virtualmuseum.ca/home/ vom 01.10.2015.

46 Vgl. http://www.virtualmuseum.ca/virtual-exhibits/type/community-memories/ vom 01.10.2015. 
oder nach Neuheit der Ausstellung). ${ }^{47}$ Über den Schalter Advanced Search sind weitere, kategoriale Suchkriterien verfügbar. So können hier gezielt Ausstellungen zu bestimmten Themen (Arts and Leisure, Nature, Science and Technology, Transportation and Industry sowie History and Society) und Unterthemen (z.B. Fashion, Biology, Chemistry and Materials, Historic Figures oder Religion and Beliefs) abgefragt werden. ${ }^{48}$ Suchergebnisse werden unterhalb der Maske angezeigt. Der Nutzer kann sich dabei aussuchen, ob er eine kompakte $>$ Kachel $<$ - oder eine inhaltlich ausführlichere \Listen<-Ansicht vorzieht. Erstere besteht aus zwölf kleinen Abbildungen in zwei Zeilen von je sechs, die jeweils mit dem Namen der Ausstellung und dem Namen der Institution versehen sind, von der sie ausgerichtet wird. Die Listenansicht reiht dieselben Treffer untereinander auf, wobei Abbildungen und Bezeichnungen identisch sind, jedoch zu jeder Ausstellung noch eine Kurzbeschreibung dargestellt wird. Sollten mehr als die zwölf standardmäßig angezeigten Treffer gefunden werden, kann man sich sowohl in der Kachel- als auch in der Listenansicht (abermals in Zwölfer-Schritten) weitere relevante Ausstellungen anzeigen lassen. ${ }^{49}$

\section{Abbildung 3: Startseite des Virtual Museum of Canada}
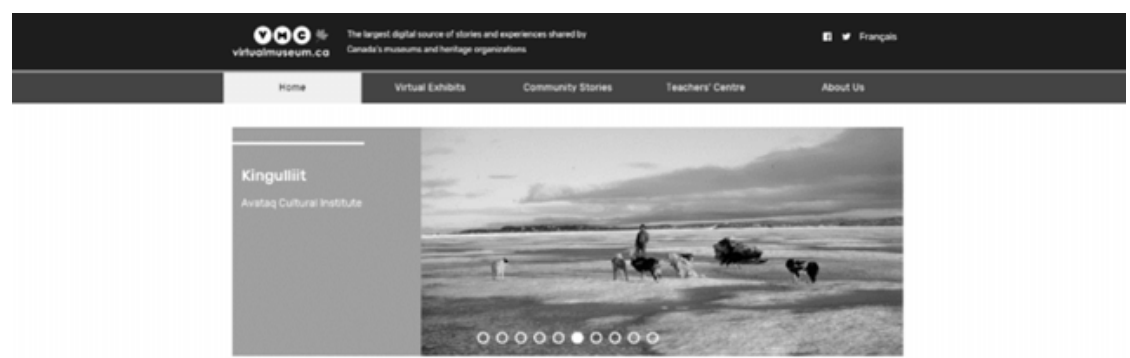

Find an Exhibit:

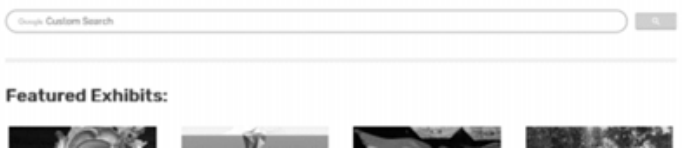

http://www.virtualmuseum.ca/home/ vom 04.06.2018.

Das $V M C$ selbst betreut lediglich die Soft- und Hardware, die den teilnehmenden Einrichtungen die Möglichkeit zur virtuellen Präsentation ihrer Inhalte bietet. Die individuellen Ausstellungen sind gänzlich Sache der jeweiligen Häuser. Zwar gibt es aus der Infrastruktur des $V M C$ heraus gewisse Gemeinsam- und Regelmäßigkeiten in

47 Vgl. http://www.virtualmuseum.ca/virtual-exhibits/type/virtual-exhibits/ vom 01.10.2015.

48 Vgl. http://www.virtualmuseum.ca/virtual-exhibits/type/virtual-exhibits/?adv=show vom 01.10.2015.

49 Vgl. ebd. 
der Gestaltung ihrer Webseiten, ein verbindlicher Qualitätsstandard aber ist nicht erkennbar. Tatsächlich stellt man schon bei oberflächlichster Flanerie durch das Angebot sehr zügig fest, dass viele der Ausstellungen offenbar nicht kontinuierlich betreut werden. Als Beispiel sei hier die vom Ausstellungszentrum der Universität Montréal im Jahre 2006 ausgearbeitete Ausstellung Echoes from the Past genannt, die sich mit der vorkolonialen Geschichte Quebecs befasst. ${ }^{50}$ Die in Englisch und Französisch verfügbare Ausstellung begreift ihren Gegenstand als »a story told by landscape $\ll^{51}$ und erschließt ihn nach den Rubriken `Konzepte` (der frühgeschichtlichen Historiographie), 〉Orte` (d.h., bedeutenden historischen Schauplätzen), `Zeit` (im Sinne einer Chronologie der Geschichte Quebecs), >Worte (im Sinne narrativer Überlieferung), >Kunst`, >Kontakte` (zwischen Eingeborenen und Europäern), und `Objekte`(die wiederum nach Fundorten geordnet sind). ${ }^{52}$ Dabei steht Echoes from the Past sowohl in einer Flash-Variante als auch - ein Relikt aus Zeiten, in denen zahlreiche Nutzer noch mittels 56k-Modems auf das Web zugriffen - in einer HTML-Version für langsamere Netzzugänge zur Verfügung. Der Nutzer, der fast ein Jahrzehnt nach ihrer Entstehung auf die Ausstellung zugreift, wird indes nicht mit der Geschwindigkeit seiner Internetverbindung zu kämpfen haben, sondern vielmehr (und dies gilt für die Flash- ebenso wie für die HTML-Version) mit einem Webseiten-Design, dass auf sehr viel kleinere und niedriger auflösende Monitore zugeschnitten ist als jene, die heute den Standard darstellen. Abbildungen liegen mit Kantenlängen von unter 200 Pixeln vor, Schriften sind so klein, dass sie kaum zu lesen sind. Für den Text kann hier die Zoomfunktion von Browsersoftwares helfen, Bilder verpixeln bei einer solchen Vergrößerung indes unvermeidlich. Auch ist im Rückblick kaum mehr nachzuvollziehen, welchen Mehrwert die Architekten der Webseite 2006 der Flash-Fassung zugeschrieben haben mögen. Ein Inhaltlicher kann es kaum gewesen sein, weil es in ihrer Struktur und Funktionalität keinen Unterschied zur HTML-Seite gibt. Vielmehr ist die Flash-Fassung mit einer Anzahl von audiovisuellen Stilblüten versehen: Klaviermusik spielt über der Startseite, ein animiertes Intro zeigt eine ebenfalls musikalisch unterlegte Collage von Bildmaterial, die kaum etwas über die Ausstellung verrät, Schaltflächen werden mit einer Wellenanimation unterlegt, wenn man mit dem Mauszeiger über sie fährt. Tatsächlich fehlen der Flash-Seite zahlreiche Funktionen, die in HTML selbstverständlich wären: Text kann nicht mit der Maus markiert und kopiert werden, Abbildungen lassen sich nicht per Rechtsklick auf dem eigenen Rechner abspeichern. Fast elegisch mutet der in der Flash-Version vorgeschaltete

50 Vgl. http://www.virtualmuseum.ca/sgc-cms/expositions-exhibitions/echo/e_index.html vom 01.10.2015.

51 http://www.virtualmuseum.ca/sgc-cms/exposition-exhibitions/echo/html/e-echos-01.html vom 01.10.2015.

52 Vgl. ebd. 
Hinweis an, dass Nutzer von Windows 95 und 98 Probleme bei der Anzeige bestimmter Sonderzeichen der französischen Sprache erleben könnten.

Das $V M C$ ist also nicht nur ein virtuelles Museum der kanadischen Geschichte, sondern auch - wenngleich unfreiwillig - eines von Webseitendesigns der frühen und mittleren 2000er Jahre und betreibt damit im allerwörtlichsten Sinne eine Musealisierung des Virtuellen. Mit dieser Feststellung ist hier durchaus keine spitzfindige Herabwürdigung des $V M C$ und dieses speziellen Nebeneffektes seiner Ausstellungskonzeption intendiert. Historische Prozesse sind immer auch Kommunikation, und die Zeugnisse dieser Kommunikation werden zu Quellen, aus denen Geschichte entsteht. Insofern wird Geschichte natürlich auch im Web gemacht, und wir müssen uns die Frage stellen, ob unsere Bestrebungen zum Erhalt unseres Kulturerbes nicht zunehmend auch das Web miteinbeziehen müssen. Private Nonprofits wie das in San Francisco ansässige Internet Archive (das uns im Unterkapitel 7.4 dieser Arbeit noch näher beschäftigen wird) versuchen bereits jetzt, der dem Web eingeschriebenen Veränderlichkeit und Vorläufigkeit mithilfe regelmäßiger >Schnappschüsseくvon Webseiten Herr zu werden und Kommunikation zu bewahren, die niemals für die Nachwelt (und in vielen Fällen kaum über den Augenblick des kommunikativen Aktes hinaus) gedacht war.

Die (hier freilich nicht im Sinne Ernst Blochs zu verstehende) Gleichzeitigkeit des Ungleichzeitigen, die uns im $V M C$ begegnet, birgt jedoch auch ganz spezifisch die Selbstbeschreibung des Angebotes als >virtuelles Museum « betreffende Implikationen. Physische Museen beherbergen ja nicht nur historisches Material, sie sind historisches Material und verhandeln dementsprechend nicht nur die Geschichte ihres Ausstellungsgegenstandes, sondern immer auch ihre eigene als Institution und als Haus. Insofern ist ein ausreichend altes Museum immer auch Palimpsest von Vermittlungsidealen und Didaktiken, die nicht mehr akut gegenwärtige Ausstellungen bestimmen, aber der Architektur, der Zusammensetzung von Sammlungen, der Verwaltung und dem Selbstverständnis der Einrichtung nach wie vor eingeschrieben sind. Virtuelle Museen sind notwendigerweise junge Erscheinungen, die noch auf keine lange Geschichte zurückblicken können - andererseits jedoch existieren sie in einer medialen Umwelt, in der >Veränderung`, welcher Art auch immer, sehr schnell vonstattengehen kann. Wenn es also um die Ablösung von Präsentations- und Verwaltungsstandards, die Neuevaluation von Ausstellungskonzepten, ja sogar grundsätzliche Umstellungen in Organisation und Philosophie kuratorischer Arbeit geht, dann kann ein virtuelles Museum effektiv sehr viel mehr >Geschichte in relativ kurzen Zeiträumen durchmachen als ein physisches. Indes hat es jedoch kein materielles Substrat, dem sich diese Geschichte einschreiben könnte. Wollten virtuelle Museen sie erhalten, dann müssten sie die überholten Versionen ihrer selbst archivieren und ggfs. ihren Nutzern zur Verfügung stellen. Dem Verfasser dieser Arbeit ist in mehrjährigen Recherchen über virtuelle Museen kein einziges begegnet, das sich auf diese Art bewusst selbst zu vergeschichtlichen versuchen würde. 
Eine Webseite wie Echoes of the Past erscheint gewissermaßen als eine virtuellmuseale Geisterstadt: Ihre Attraktion ist zehn Jahre nach ihrer Entstehung weniger ihr Gegenstand als ihre offensichtliche Obsoleszenz innerhalb einer Medientechnik, die obsoletes üblicherweise nicht lange fortbestehen lässt, sondern es entweder löscht oder mittels Updates aktuellen Standards und Erwartungen anpasst. Echoes of the Past weist also als digitales Objekt genau jene Eigenschaft auf, die auch das Museumsding ausmacht: Die virtuelle Ausstellung verkörpert in ihrer ganzen audiovisuellen Erscheinung einen Unterschied zwischen der Welt, in der sie entstanden ist und jener, in der wir sie jetzt immer noch abrufen können.

Dabei sind bestimmte Attribute von Echoes of the Past durchaus auch in aktuelleren Ausstellungen des $V M C$ noch lebendig. Dazu gehört vor allem eine dem LeMO durchaus ähnliche Textorientierung, die Abbildungen materieller Objekte eher illustrativ einsetzt, in Verbindung mit einem weitgehend linearen Aufbau. So ist z.B. Anfang Oktober 2015 die aktuellste Ausstellung des VMC eine vom Revelstoke Museum and Archives in Revelstoke (British Columbia) erstellte Präsentation über Lawinen mit dem Titel Land of Thundering Snow. Diese besteht aus sechs individuellen Kurzartikeln: Einem über bedeutende Lawinen-Ereignisse der kanadischen Geschichte, einem über Ursachen und Ablauf einer Lawine, einem über Maßnahmen zur Vorbereitung auf den Ernstfall, einem darüber, wie man Gefahrenzonen meidet und sich im Lawinenfall zu verhalten hat, einem über die Rolle von Lawinen im Ökosystem der Bergwelt von British Columbia und schließlich einer kleinen Sammlung von Ressourcen und Links zum Thema. ${ }^{53}$ Jeder einzelne Artikel besteht aus einem kurzen Einführungstext, dem eine Auswahl von Videos und interaktiven Applikationen folgt - zu welchen man gelangt, indem man entweder auf eine Schaltfläche klickt oder einfach hinunterscrollt. So findet man zum ersten Artikel eine Karte Kanadas mit einer Zeitleiste, mittels derer man sich die Schauplätze und Opferzahlen dokumentierter Lawinenunfälle für jede einzelne Jahreszahl zwischen 1782 und 2014 anzeigen lassen kann. Einige wenige dieser Unfälle sind als case studies mit einer kurzen Texterläuterung versehen, erkennen kann man sie an ihrem Pfeilförmigen Symbol auf der Karte. Auch eine grafische Verlaufsdarstellung von Opferzahlen steht hier zur Verfügung, wobei die Unfallarten (z.B. >Recreation`, >Industry ८ oder >Transportation $`$ farblich codiert sind (vgl. Abbildung 4) ${ }^{54}$ Die Ursachen von Lawinen werden in Form eines kleinen >Rezeptes` erklärt, durch das sich der Nutzer klicken darf und dessen vier Zutaten (Schnee, Gefälle, eine Ablagerung in lockeren Schichten durch Stürme und schließlich ein Auslöser) jeweils mit kurzen erklärenden Texten versehen sind. Am Ende darf der Nutzer sich zur Belohnung einen kurzen Audioclip von einem

53 Vgl. http://www.landofthunderingsnow.ca/index-eng.php vom 01.10.2015.

54 Vgl. http://www.landofthunderingsnow.ca/lecons_du_passe-lessons_from_the_past/index -eng.php vom 01.10.2015. 
Lawinenabgang anhören. ${ }^{55}$ Ähnlich geht es weiter: In der Rubrik \Staying Safe werden fünf Lawinenexperten und Rettungsarbeiter vorgestellt - jeweils mit Foto, Text und auf Wunsch einem kurzen Video. Unter dem Reiter >A Natural Part of Mountain Life findet sich eine Fotografie von einer Tallandschaft, in der einzelne Zonen angeklickt werden können. Es erscheinen dann Kurztexte, welche den Einfluss von Lawinen auf das gewählte Areal und seine Biosphäre erklären. ${ }^{56}$

\section{Abbildung 4: Historische Landkarte für kanadische Lawinenereignisse der} virtuellen Ausstellung >Land of Thundering Snow

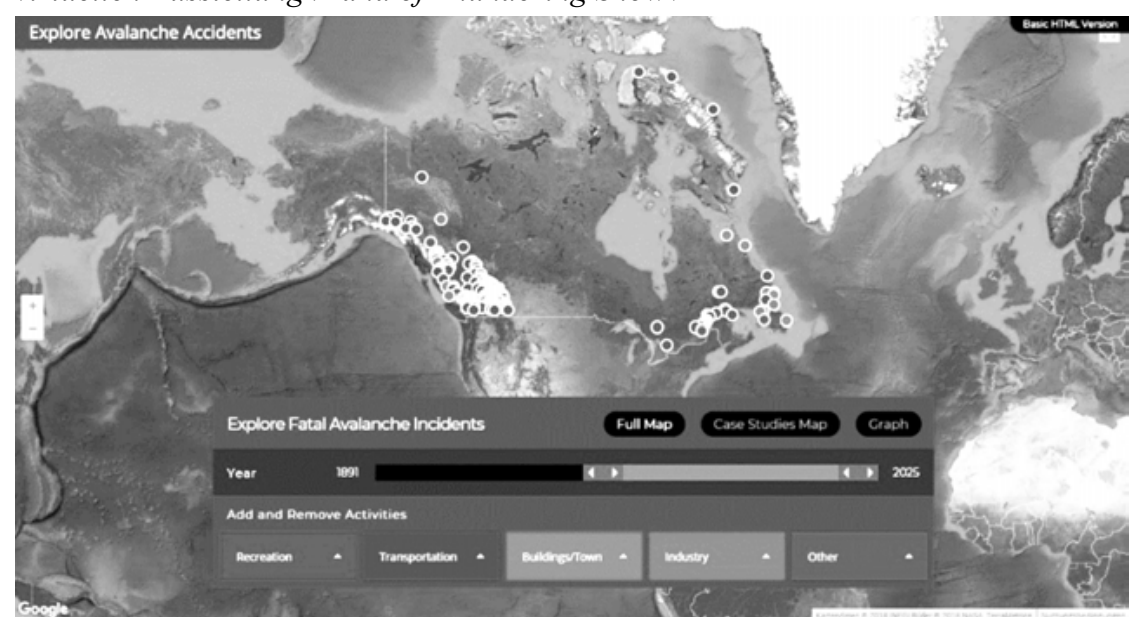

http://www.landofthunderingsnow.ca/lecons_du_passe-lessons_from_the_past/index-eng.php vom 04.06.2018.

Grundsätzlich wird man nicht gezwungen, diese Medienangebote in der vorgegebenen Sequenz zu rezipieren - es gibt allerdings auch kaum einen Grund, von ihr abzuweichen. Die allermeisten Ausstellungen im $V M C$ folgen einem ganz ähnlichen Schema: Sie vermitteln weniger den Eindruck eines virtuellen Museums als vielmehr den einer Bibliothek kurzer Dossiers und Bildmaterialsammlungen zu Themen der kanadischen Geschichte. Selbst wenn die Zugriffsoberfläche experimenteller gestaltet wird, bleibt diese Struktur erhalten. So veröffentlichte das Toronto International Film Festival im Jahre 2014 mittels des VMC eine Ausstellung über Leben und Werk des kanadischen Regisseurs David Cronenberg. Auf deren Startseite lässt sich über

55 Vgl. http://www.landofthunderingsnow.ca/anatomie_dune_avalanche-anatomy_of_an_ avalanche/index-eng.php vom 01.10.2015.

56 http://www.landofthunderingsnow.ca/une_partie_integrante_de_la_vie_en_ montagne_natural_part_of_mountain_life/index-eng.php vom 01.10.2015. 
neun Kacheln auf diverse Unterbereiche der Ausstellung zugreifen: so z.B. auf Biographisches zur Person Cronenberg, Einflüsse von Wissenschaft und Medizin auf die Bildersprache seiner body horror-Filme, eine sinteraktive Zeitleiste` (deren Interaktivität sich darauf beschränkt, dass der Nutzer durch sie hindurchscrollen und gelegentlich Felder anklicken darf, die Video- oder Audio-Schnipsel abspielen), >Hinterden-Kulissen<-Videomaterial, Filmrequisiten, usw. ${ }^{57}$ Schnell stellt sich jedoch heraus, dass die sich hinter diesen Kacheln verbergenden Inhalte tatsächlich überwiegend die Form filmwissenschaftlicher Traktate (inklusive Zitationsapparat) annehmen, die mit Video-, Audio-, und Bildmaterial illustriert sind, dem Nutzer aber nicht erlauben, dieses Material außerhalb ihrer linearen Textstruktur zu erkunden. In wieweit es hier noch Sinn macht, überhaupt den Museums- oder Ausstellungsbegriff zu bemühen, ist trefflich streitbar. Am musealsten erscheinen noch die stellenweise in die Texte eingefügten Filmrequisiten, die in hochauflösenden $360^{\circ}$-Fotografien aufgenommen wurden und per Mausklick entlang der Längsachse rotiert werden können. Hierzu gehören u.a. der Accumicon-Helm aus Videodrome (1983) und die organische Spielkonsole aus eXistenZ (1999). ${ }^{58}$

Das $V M C$ erscheint insgesamt als ein Mikrokosmos des Phänomens Museumsvirtualisierung schlechthin. Einerseits steht es im Zeichen großer Ziele digitalisierter Kulturvermittlung, die auf Malraux und Benjamin ebenso zurückweisen wie auf die Vordenker der Hypertexttheorie: Es will sowohl verstreute Sammlungsbestände zusammenführen als auch Plattform für zahlreiche in sich geschlossene imaginäre Museumsprojekte sein, die in den Räumen der Mutterinstitutionen nicht zu realisieren wären - zumindest nicht, ohne das bestehende Ausstellungsgefüge zu opfern, um die Objekte für ein neues freizustellen. Das ehrliche Verlangen, intermedial zu kuratieren - Text, Bild, Ton und Video miteinander zu verschränken und einander zuarbeiten, interaktive Elemente einfließen zu lassen - zieht sich sichtbar durch die verschiedenen Ausstellungen, auch wenn die Umsetzungen nicht immer geglückt scheinen. Das ganze Projekt ist ferner auf Prozesshaftigkeit und Skalierbarkeit ausgerichtet, soll mit den Ideen der ausstellenden Häuser und ihrer Kuratoren wachsen und ein weit über die kanadische Öffentlichkeit hinausreichendes Publikum bedienen.

Andererseits aber sammelt das $V M C$ mit seinen Ausstellungen auch technische Irrwege, verfehlte Vermittlungsstrategien und Missverständnisse dessen, was mit dem WWW und dem Medium Hypertext eigentlich angezeigt und möglich wäre. Besonders auffällig ist dabei der Verzicht des VMC auf Verschaltung und Connectedness der Sammlungen untereinander. Mit Recht darf man fragen, ob ein solcher überhaupt zu leisten wäre, ohne das Kernkonzept des Angebotes - nämlich eine Plattform

$57 \mathrm{Vgl}$. http://cronenbergmuseum.tiff.net/accueil-home-eng.html vom 01.10.2015.

$58 \mathrm{Vgl}$. http://cronenbergmuseum.tiff.net/artefacts-artifacts-eng.html vom 01.10.2015. 
für Museen zu sein, die virtuell ausstellen möchten und selbst nicht über die technischen Mittel verfügen - über den Haufen zu werfen. Indes zeigt sich in der Art, wie einzelne Ausstellungen funktionieren, immer wieder geradezu eine Vermeidung von rhizomatischen (oder auch nur netzwerkhaften) Strukturen: Ausstellungen wie Land of Thundering Snow scheinen nicht etwa darauf abzuzielen, eine bestehende Sammlung zu öffnen und die Möglichkeiten zur Assoziation und Vieldeutigkeit über das hinaus zu erweitern, was die physische Institution anbietet und sie damit folgerichtig fortzusetzen. Vielmehr hat man den Eindruck, es werde hier der Versuch unternommen, noch stärker zu linearisieren, zu narrativieren und den Besucher anzuleiten, als dies in einem dreidimensionalen Museumsraum überhaupt möglich wäre. Anstatt virtuell wirklich zu kuratieren, werden digitale Broschüren erstellt, die eine weitgehend lineare Textstruktur mit attraktiven audiovisuellen Effekten versehen, letztlich aber sowohl hinter den Möglichkeiten sowohl einer klassischen Museumsausstellung, als auch des Mediensystems WWW zurückbleiben. So wird das $V M C$ zu einer Bibliothek kleiner Bildbände, an der Malraux sicher durchaus Freude gehabt hätte, und ist meta-museal tatsächlich insofern, als dass es zahlreichen Einzelmuseen ein gemeinsames Dach für die Gestaltung von Inhalten bietet. Es ermöglicht aber keine Konfrontation dieser Inhalte über die Grenzen kuratierter Angebote hinweg, und gestattet auch dem Rezipienten keine Souveränität im Umgang mit dem Angebotenen.

\subsubsection{Europeana (www.europeana.de)}

Als das zu diesem Zeitpunkt noch als »digitale Bibliothek« bezeichnete und im Rahmen der Digital Agenda for Europe von der Europäischen Kommission finanzierte Europeana-Projekt am 20. November 2008 in einer Beta-Version mit zunächst gerade einmal 1.000 digitalisierten Objekten der Öffentlichkeit zugänglich gemacht wurde, kollabierte die das Unterfangen stützende Serverarchitektur buchstäblich unter der Last des Interesses. Mehr als 10 Millionen Aufrufe in der Stunde legten die Webseite noch am Tag ihrer Eröffnung lahm, machten ihre Abschaltung bis Mitte Dezember desselben Jahres erforderlich und ließen die Frankfurter Allgemeine titeln: »Erfolg ist, wenn man zusammenbricht« (Jungen 2008). Trotz der Selbstbeschreibung als Bibliotheksprojekt war Europeana schon zu diesem Zeitpunkt einem Bewahrungs- und Verbreitungsauftrag verpflichtet, der die ganze Spanne europäischer Kulturgüter umfasste. Hinter der noch sehr beschränkten Beta-Variante stand bereits 2008 ein Fundus von mehr als drei Millionen digitalisierten Büchern, Kunstobjekten, Fotografien und Filmen, sowie Textdokumenten unterschiedlichster Art, deren Originale über mehr als eintausend Einzelsammlungen in 27 Ländern verteilt waren (vgl. ebd.). 
Die >1.0<-Version der Seite ging im Februar 2009 online und übertraf schnell ihr von Europäischen Kommission vorgegebenes Ziel, bis 201010 Millionen Einzelobjekte verfügbar zu halten. Tatsächlich waren im November 2010, zwei Jahre nach dem holprigen Start, mehr als 14 Millionen Objekte digitalisiert, von denen Textdokumente nur mehr $34 \%$ ausmachten. $64 \%$ entfielen hingegen auf »digitalisierte Fotos, Landkarten, Museumsstücke und andere Bilder«, die letzten zwei Prozentpunkte auf Video- und Tonmaterial. ${ }^{59}$ Obwohl sämtliche Mitgliedsnationen der Europäischen Union sich an dem Vorhaben beteiligen, war 2010 noch keine Ausgewogenheit im Gesamtangebot erreicht: Frankreich stellte als größter Beiträger $18 \%$ des vorhandenen Materials, dicht gefolgt von Deutschland mit 17 \%. Die Anzahl der teilnehmenden Kultureinrichtungen war zu diesem Zeitpunkt bereits auf über 1.500 angestiegen. ${ }^{60}$

Im Oktober 2015 enthält Europeana rund 39 Millionen Einzelobjekte, von denen ca. 23 Millionen auf Bild-, 15 Millionen auf Textinhalte, jeweils etwa eine halbe Million auf Audio- und Videomaterial und schließlich fast 17.000 auf 3D-Scans entfallen. Deutschland und die Niederlande haben mittlerweile mit jeweils über 4 Millionen Objekten Frankreich den Rang als Spitzenbeiträger abgelaufen. Das Gros der Zugriffe auf Europeana kommt erwartungsgemäß aus dem EU-Gebiet selbst, wobei Deutschland mit ca. 565.000 Aufrufen in den ersten drei Quartalen 2014 den größten Anteil ausmacht, gefolgt von Spanien mit ca. 344.000, Polen mit 269.000, Frankreich mit 255.000, Italien mit 246.000 und dem Vereinigten Königreich mit etwa 219.000 Zugriffen. Die USA stellen mit einer weiteren Viertelmillion das größte außereuropäische Zugriffskontingent. Technisch basiert Europeana auf einer eigenen Digital Service Infrastructure, die von der (ihrerseits der Europäischen Kommission unterstehenden) Connecting Europe Facility (CEF) betrieben wird. ${ }^{61}$

Eigener Darstellung zufolge sieht sich Europeana »on a mission to transform the world with culture«:

We want to build on Europe's rich heritage and make it easier for people to use, whether for work, for learning or just for fun. In the future, we hope everyone will have the access they need to the shared heritage that belongs to us all. Europeana provides a platform that allows you to explore great achievements from the past to achieve great things in the future. We bring together the organisations that have heritage to share with the people and sectors who want to view, share and build with that heritage. ${ }^{62}$

59 Vgl. http://europa.eu/rapid/press-release_IP-10-1524_de.htm?locale=en vom 02.10.2015.

60 Vgl. ebd.

$61 \mathrm{Vgl}$. http://pro.europeana.eu/about-us/factsfigures vom 02.10.2015.

62 Vgl. http://pro.europeana.eu/about-us/who-we-are vom 02.10.2015. 
Auch Europeana versteht sich also nicht als ein souveränes Ausstellungsprojekt mit eigenen Inhalten, sondern als eine Plattform, die bestehende Institutionen mit einem Publikum jenseits ihrer institutionell-geographischen Einzugsbereiche verbinden soll. Der Dienst will Netzwerk sein - und zwar nicht nur zwischen Institutionen und ihren Besuchern, sondern auch all jenen Akteuren, die selbst keine $>$ Kulturarbeiter im engeren Sinne, wohl aber unentbehrlich für die Digitalisierung von Kulturobjekten sind: nämlich Ingenieuren, Technikern und Softwareentwicklern. Zugleich sieht Europeana sich aber auch als Interessenvertretung und Anwalt der teilnehmenden Kulturinstitutionen im sich vollziehenden Virtualisierungsprozess - und die Methode dieser Anwaltschaft soll einerseits eine rigorose Authentifizierung aller digitalisierten Inhalte, andererseits aber auch eine Offenheit und Flexibilität von Dokumentationsstandards sein:

We represent the cultural organisations that have safeguarded our heritage for hundreds of years. Who have organised it, structured it and made it accessible with great care and precision. We are committed to ensuring that our digital data is always authentic, trustworthy and robust, that it's easy to create with and that our network partners benefit from sharing it. ${ }^{63}$

Die Planungen für die unmittelbare Zukunft sind auf europeana.eu in Form der Strategy 2020 publiziert. Dieser Zufolge sind augenblicklich nur knapp $10 \%$ des kulturellen Erbes der EU-Mitgliedsstaaten digitalisiert, was ca. 300 Millionen Einzelobjekten entspricht. Nur etwa ein Drittel von diesen sei derzeit in irgendeiner Form online verfügbar - und wiederum nur ca. $3 \%$ dieses Drittels läge rechtlich und technisch in einer Form vor, die zur kreativen Weiterverwertung zu gebrauchen sei. Europeana will dazu beitragen, diese Anteile zu vergrößern, und zwar nach eigener Aussage »by embracing new technology, by changing copyright, by developing new business models $\ll .{ }^{64}$

Dies umzusetzen erfordert der Strategy 2020 zufolge drei »Prioritäten«: Die erste ist eine Verbesserung von Datenqualität und Digitalisierungsstandards. Hervorragende Digitalisate seien eine Grundvoraussetzung dafür, dass die teilnehmenden Einrichtungen Europeana ihre attraktivsten und wertvollsten Objekte zur Verfügung stellten. Zugleich dürften dabei aber keine Zugangshürden für finanziell schlechter ausgestattete Institutionen entstehen. Konkret bedeute dies, dass man sich von linear auf ein zentrales Speichersystem zulaufenden Digitalisierungswegen lösen und auf distribuierte Architekturen setzen müsse. Auf diesem Wege hoffen die Verantwortlichen, den Objektschatz bis 2020 verdreifachen zu können, während die entstehenden Digitalisate hochwertiger und zwischen unterschiedlichen technischen Schnittstellen anschlussfähiger werden sollen. Die zweite Priorität sei die Öffnung der Datensätze

63 Vgl. http://strategy2020.europeana.eu/ vom 02.10.2015.

64 Ebd. 
- und zwar nicht nur für die Betrachtung durch ein Publikum, sondern auch für ihre Weiternutzung innerhalb der Grenzen geltenden Urheberrechts. Europeana macht sich für eine Überführung digitalisierten Kulturerbes in die public domain stark und lobbyiert bei europäischen Entscheidungsträgern für eine Flexibilisierung von Copyright-Gesetzen. Ziel ist es, bis 2020 sowohl beim Publikum als auch bei den Institutionen zur ersten Anlaufstelle zu werden, wenn es darum geht, Kulturerbe zu digitalisieren oder in digitaler Form abzurufen. Die dritte Priorität schließlich betrifft die Frage nach Nutzen und Schaden von Virtualisierung für die teilnehmenden Einrichtungen: Europeana strebt an, innerhalb seines Netzwerkes von Endnutzern und Produzenten nach allen Richtungen Mehrwerte fließen zu lassen. Die teilnehmenden Häuser sollen im Austausch für ihre Inhalte eine größere Sichtbarkeit und eine Senkung der eigenen Verwaltungskosten durch ihren Anschluss an eine geteilte Dokumentationsinfrastruktur erhalten. Nicht zuletzt stellt ihnen Europeana auch die Vernetzung mit privatwirtschaftlichen Akteuren zum beiderseitigen Vorteil in Aussicht. $^{65}$

Das Projekt bezeichnet sich mittlerweile auch nicht länger als digitale Bibliothek, sondern als ein institutionsübergreifendes »single-access digital museum, library and archive for Europe - a place where you're invited to look back at the great achievements of the past « ${ }^{66}$ In dieser Rolle will Europeana ausdrücklich kein »Portal« sein, das lediglich die Auffindbarkeit digitaler Objekte gewährleistet, sondern strebt den Ausbau seiner Soft- und Hardwareinfrastruktur zu einer »multi-sided platform« an, die nicht nur Inhalte vernetzt und präsentiert, sondern auch die Menschen, die mit diesen Inhalten arbeiten möchten. ${ }^{67}$ Dieses Modell orientiert sich ganz bewusst an kommerziellen Web-Angeboten, die nicht etwa eigene Produkte feilbieten, sondern deren Service darin besteht, Menschen mit übereinstimmenden Interessenlagen zusammenzubringen: Ganz konkret nennt die Strategy 2020 das Unternehmen Airbnb, das der Hotelbranche Konkurrenz machen will, indem es Menschen auf der Suche nach Übernachtungsmöglichkeiten mit solchen in Kontakt treten lässt, die kurzfristig Wohnraum zu vermieten haben. Europeana will auf vergleichbare Art Menschen, die produktiv mit Kulturerbe umgehen möchten, mit den Institutionen ins Gespräch bringen, die es sammeln, erhalten und ausstellen. Die >mehrseitige Plattform ^ wird dabei nicht nur rhizomatisch gedacht, sondern im besten Sinne des Latour'schen Akteurnetzwerks als ein System, das die Subjekt-Objekt-Trennung zwischen menschlichen Kommunizierenden und den technischen Infrastrukturen ihrer Kommunikation verwischt. Die Architektur dieses Systems wird in zwei Schichten gedacht, die als core und access layer bezeichnet werden. ${ }^{68}$

\section{Ebd.}

66 Ebd.

67 Vgl. ebd.

68 Vgl. ebd. 
Der core setzt sich aus drei Komponenten zusammen: der Hardware im Sinne der Datenzentren und Servernetzwerke, dem content bzw. den konkreten digitalisierten Inhalten und zuletzt den Metadatensätzen, mit denen diese Inhalte versehen sind. Die ersten zwei Komponenten bilden gewissermaßen die Grundvoraussetzungen, denen Europeana zur Erfüllung seiner kulturellen Mission gerecht zu werden hat, nämlich das Vorhandensein vorzeigbarer digitaler Objekte und mit dem Internet verbundener Computer, auf denen diese abgespeichert und abrufbar sind. Die Metadaten hingegen sind laut der Strategy 2020 das entscheidende Alleinstellungsmerkmal Europeanas gegenüber privaten bzw. kommerziellen Angeboten: Sie nämlich bildeten ein an den physischen Institutionen beheimatetes Expertenwissen ab, auf das privatwirtschaftliche Content-Aggregatoren keinen Zugriff haben, weil sie nicht mit Kuratoren, Bibliothekaren, Archivaren usw. kooperieren. Europeana verspricht nicht weniger als institutionell verbürgte Authentizität, übersetzt in digitale Authentisierungsverfahren:

You might be thinking, , So what? I can find this material elsewhere on the web via Google, Flickr or Pinterest. « True, but what's unique about our repository is that our metadata describes the original material, authenticated by reliable, sector experts. Our aim is to become the largest trusted repository of cultural heritage in Europe as research tells us this is what users want unobstructed access to credible, quality material. ${ }^{69}$

Der core layer soll also nicht nur den technischen und inhaltlichen Unterbau der Unternehmung darstellen, sondern zugleich die Brücke bilden zwischen virtueller Verfügbarkeit und institutioneller Autorität - kurzum, er soll ein Fundament des Vertrauens sein und Authentizität auch in einer medialen Umwelt erfahrbar machen, in der das Publikum eigentlich darauf spekuliert, getäuscht zu werden. Die Allianz mit den >realen` Einrichtungen garantiert den Anschluss Europeanas an eine bedeutsame Kulturwelt.

Der access layer hingegen soll nach den Vorstellungen der Betreiber das gemeinsame und für alle Mitwirkenden möglichst faire Forum sowohl der Inanspruchnahme von Europeanas Inhalten und Diensten als auch des Austausches zwischen Betreibern, Konsumenten und Rezipienten sein - »a >Commons` or place where we have agreed upon the rules of engagement. $\ll^{70} \mathrm{Zu}$ dieser Funktion gehören unweigerlich Softwarestandards - insbesondere in Form des application programming interface (API), das als Schnittstelle zwischen der Datenbank und Softwares fungiert, die auf ihre Inhalte zugreifen möchten, aber auch des Open Archives Intiative Protocol for Metadata Harvesting (OAI-PMH), das von der namensgebenden Open Archives Initiative entwickelt wurde, um Dienste auf Metadaten aus unterschiedlichen Archivsystemen zugreifen lassen zu können. Weitere softwareseitige Bestandteile des access

69 Ebd.

70 Ebd. 
layer sind laut der Strategy 2020 die Anpassung von Programmfunktionen an die aus der IP-Adresse erkennbare geolocation des Anwenders und damit verbunden die Mehrsprachigkeit sämtlicher Interfaces. ${ }^{71}$

Über die Software hinaus besteht die Zugriffsebene aber auch aus Dienstleistungsaspekten. Europeana verspricht klare und transparente Richtlinien für die Nutzung vorhandenen Datenmaterials ebenso wie ein möglichst effizientes System zur Lizensierung urheberrechtlich geschützter Inhalte. Vor allem aber verschreibt sich das Projekt ausdrücklich der Idee von linked open data - also Daten, die sowohl verlinkt bzw. verlinkbar, als auch rechtlich zur Nutzung durch jedermann freigegeben sind. Europeana begreift sich insofern nicht als ein kuratiertes Ausstellungsformat dies wäre ja auch gar nicht vereinbar mit dem Anspruch, ein Repertorium für die Gesamtheit des europäischen Kulturerbes in all seinen Erscheinungsformen zu sein. Stattdessen sieht sich Europeana in der Rolle einer digitalen Schatzkammer, aus der sich Kulturschaffende jeder Couleur bedienen können. Die Strategy 2020 benennt hier drei Zielgruppen: Die erste bilden die professionals - womit all jene gemeint sind, die im unmittelbaren Umfeld von Einrichtungen arbeiten, die für Europeana relevantes Material betreifen. Die zweite Gruppe sind die end users als Rezipienten mit teilweise sehr speziellen, nach narrowcasting verlangenden Interessenlagen. Diese Nutzergruppe greift entweder direkt auf Europeana zu, oder sie nimmt den Umweg über Dienste, die ihrerseits Europeana-Ressourcen nutzen (wie z.B. Suchmaschinen, Wikipedia oder Pinterest). Endnutzer möchten außerdem oft imstande sein, Inhalte in sozialen Netzwerken zu teilen. Die letzte Zielgruppe sind die creatives. Europeana will hiermit gezielt die sog. >Kreativindustrien $<$ ansprechen, die mittlerweile 3,3\% des europäischen Bruttoinlandsproduktes ausmachen - mit dem erklärten Ziel, sowohl diesen Wirtschaftszweig als auch den Tourismus zu stärken. Beispiele für \Kreativeく wären u.a. App-Entwickler und Webdesigner, aber grundsätzlich auch die wissenschaftliche Forschung und jeder andere User, der EuropeanaInhalte mit Mehrwert weiterverwendet. ${ }^{72}$

Europeana, so bekennt die Strategy 2020, verfüge nicht über die nötige finanzielle und personelle Ausstattung, um gleichzeitig »broad and deep« zu sein. ${ }^{73}$ Man wolle deshalb zum »Inkubator « für Ideen und Konzepte von Kulturvermittlung werden, und die Stiftung von >Tiefe den hoffentlich zahlreichen Einzelprojekten zu überlassen, die sich am Schatz vorhandener Digitalisate bedienen und sie in die connectedness ihrer eigenen Interessenbereiche verspinnen:

Making high quality material available under favourable conditions is a great start, but it is not enough when you operate in an innovative space where demand is not yet fully established.

71 Vgl. ebd.

72 Vgl. ebd.

73 Ebd. 
This requires an additional level of effort, a much deeper level of involvement to bring the potential of the material to fruition: highly curated special interest channels for foodies, for fashionistas, for historians. We need co-creation formats, creative labs, business model workshops and access to capital for creative entrepreneurs. ${ }^{74}$

Insofern stellt Europeana gewissermaßen das diametrale Gegenmodell zum VMC dar: Während dieses eine virtuelle Ausstellungsfläche bietet, welche die teilnehmenden Museen selbst mit Inhalt zu befüllen angehalten sind, stellt Europeana Inhalte zur Verfügung, mit denen Partner kuratieren dürfen. Während das $V M C$ das Exponieren ins Zentrum seines Auftrages stellt, macht Europeana sich das Deponieren zur Aufgabe: Das Projekt ist weniger virtuelles Museum als offene Meta-Sammlung und kann als solche funktionieren, weil digitale Ausstellungsstücke eben weder singulär noch ortsgebunden sind.

Entsprechend präsentiert sich auch die Benutzeroberfläche von europeana.eu: Im Zentrum der Startseite stehen die Textsuche für die Datenbank, aktuell von Europeana geförderte Projekte (Anfang Oktober 2015 u.a. eine Kooperation mit Pinterest $t^{75}$ und ein Wettbewerb zur Erstellung animierter GIF-Bilder aus historischem Bildmaterial $^{76}$ ), Hinweise auf herausragende Sammlungsobjekte und Partnerinstitutionen (entsprechende Artikel verlinken direkt auf die Datenbank) und eine Leiste, welche laufend die neuesten digitalisierten Objekte anzeigt. ${ }^{77}$

Die Datenbank selbst (auf welche die meisten Nutzer mittels des auf der Startseite angebotenen Textsuchfeldes zugreifen dürften, das auch unterschiedliche Suchkategorien zur Auswahl stellt) ähnelt recht stark jener, die das J. Paul Getty auf seiner Homepage zur Nutzung anbietet: Zu jedem Objekt werden u.a. eine Kurzbeschreibung, der jeweilige >Schöpfer` (sofern bekannt und auf den Gegenstand anzuwenden), eine Zeitperiode, ein Objekttypus, einige thematische Schlagworte und die Besitzerinstitution erhoben. Suchanfragen werden mit einem Kachelraster beantwortet, das kleinformatige Abbildungen gefundener Exponate mit Titel zur Auswahl stellt. ${ }^{78}$ Für nicht wenige Objekte bleiben die Abbildungsfelder grau - diese Stücke sind dann zwar meist digitalisiert, aus Copyright-Gründen aber nicht zur Ansicht und Nutzung auf der Website freigegeben. Die Trefferanzeige kann jederzeit noch weiter gefiltert werden, indem man z.B. Suchbegriffe hinzufügt, Suchkategorien eingrenzt - oder

74 Ebd.

75 Siehe zu Pinterest Kap. 7.5.1 dieser Arbeit.

76 Vgl. http://www.europeana.eu/portal/ vom 02.10.2015.

77 Vgl. ebd.

78 Vgl. z.B. für die Anfrage nach Creator: Da Vinci http://www.europeana.eu/portal/ search.html?query=who\%3Ada+vinci\&rows $=24 \&$ start $=1 \& q \mathrm{qt}=$ false vom 02.10.2015. 
sämtliche Treffergegenstände ausblendet, die nicht zur kreativen Weiterverwertung verfügbar sind. ${ }^{79}$

Das Feature My Europeana erlaubt es Nutzern, sich ein Konto anzulegen und personalisierte Werkzeuge für den Umgang mit der Datenbank in Anspruch zu nehmen: So dürfen Suchbegriffe abgespeichert werden, um die laufend wachsende Sammlung jederzeit aufs Neue auf bestimmte Themengebiete abklopfen zu können, Objekte lassen sich mit tags bzw. Kennwörtern versehen, um ihre spezielle Relevanz für den Einzelnutzer zu vermerken, Lieblingsfundstücke können dauerhaft in einer kleinen >Privatsammlung ‘ abgelegt werden, und registrierten Softwareentwicklern wird die Möglichkeit gegeben, sich einen persönlichen API-Schlüssel generieren zu lassen. ${ }^{80}$

Fast versteckt befinden sich am unteren Bildschirmrand Links zu anderen Europeana-Seiten. Ein Blog informiert über jüngste Erweiterungen, Projekte und Kooperationen, ${ }^{81}$ Europeana Pro richtet sich an potenzielle Partnerinstitutionen, ${ }^{82}$ Europeana 1914-1918 befasst sich mit dem thematischen Schwerpunkt `Erster Weltkrieg und bietet neben Datenbankzugriff E-Books, kuratierte Materialsammlungen und die Möglichkeit, eigene Fundstücke hochzuladen. ${ }^{83}$ Das Projekt Europeana Remix knüpft hier an und ruft dazu auf, sich mit Erlebnisberichten und persönlichen Gegenständen für ein digitales Filmprojekt zu melden. ${ }^{84}$ Die Rubrik Europeana Exhibitions schließlich bietet 40 kleine >Ausstellungen $<$ an, ${ }^{85}$ die in ihrem Aufbau den Themendossiers des VMC ähneln. Themen im Herbst 2015 sind u.a. Explore the World of Musical Instruments, ${ }^{86}$ das buchhistorische Konzept 1514. Book. 2014., ${ }^{87}$ und Darwinism: Reception in Spain and Catalonia ${ }^{88}$ Einige dieser Ausstellungen werden in Zusammenarbeit mit Partnerseiten ausgerichtet. So befindet sich eine Präsentation zum Schwerpunkt History of European Television auf der Seite des mediengeschichtlichen EUscreen-Portals, ${ }^{89}$ eine weitere über Gewürze wird von der Biodiversity

79 Vgl. z.B. ebd.

$80 \mathrm{Vgl}$. http://www.europeana.eu/portal/usingeuropeana_myeuropeana.html vom 02.10 .2015 .

81 Vgl. http://blog.europeana.eu/ vom 02.10.2015.

82 Vgl. http://pro.europeana.eu/ vom 02.10.2015.

83 Vgl. http://www.europeana1914-1918.eu/de vom 02.10.2015.

84 Vgl. http://remix.europeana.eu/ vom 02.10.2015.

85 Vgl. http://exhibitions.europeana.eu/, vom 02.10.2015.

86 Vgl. http://exhibitions.europeana.eu/exhibits/show/musical-instruments-en vom 02.10 .2015 .

$87 \mathrm{Vgl}$. http://exhibitions.europeana.eu/exhibits/show/1514-book-2014 vom 02.10.2015.

$88 \mathrm{Vgl}$. http://exhibitions.europeana.eu/exhibits/show/darwin-darwinism vom 02.10.2015.

$89 \mathrm{Vgl}$. http://oldportal.euscreen.eu/exhibitions.html?id=history vom 02.10.2015. 
Library Exhibition gehostet, ${ }^{90}$ eine dritte über die Napoleonischen Krige von der European Library. ${ }^{91}$ Vier jüngere Ausstellungen - Cake? Cake! Sweet exploration of its history and meaning around the world; We Know This war by Heart. Portugal and the Great War; Photography on a Silver Plate und To My Peoples! The First World War 1914-1918 - werden sogar vom Google Cultural Institute betreut, dessen Kernangebot das im nächsten Kapitel behandelte Google Art Project ist. ${ }^{92}$

Diese sehr linearen und textlastigen Auswahlen aus dem Europeana-Fundus sind nach eigener Angabe in erster Linie als »Schaukästen« des Projektes zu verstehen, die seine Breite und Reichhaltigkeit demonstrieren sollen. ${ }^{93}$ Im Kern bleibt Europeana Ideen und Phantasmen verpflichtet, die weniger auf die Geschichte des Museums als auf jene des WWW bzw. des Mediums Hypertext zurückverweisen: Die Sammlung soll nicht eine Verfasstheit aufweisen und einem pädagogischen Prinzip unterworfen sein, sondern vielmehr gänzlich virtuell und damit gänzlich Potentialität sein. Sie steht gewissermaßen im Konjunktiv und setzt für ihre Aktualisierung in den Indikativ auf eine Figur, die weder als Besucher noch als Kurator, weder als Flaneur noch als Detektiv ausgewiesen, in jedem Falle aber produktiv und kreativ ist. Hierbei geht es weniger um partizipative Modelle von Museumspädagogik als womöglich um ein tatsächlich 'postmuseales Szenario<, in welchem die Hauptfunktion des Museums nicht mehr die Verinnerlichung unseres kulturellen Erbes ist, sondern dessen Veräußerung und Projektion in seine außermuseale Umwelt. Damit steht Europeana auch in höchstem Maße im Zeichen eines Malraux'schen Kulturverständnisses, in dem das Museum zum Funktionselement einer sozialen, medialen und technischen Apparatur wird, mittels welcher es sich letztlich in seiner klassischen Rolle abschafft. Interessanterweise geht es bei dieser >Abschaffung aber nicht um ein Ende des Museums als Einrichtung, als vielmehr um seine Erneuerung als antimonumentale, vernetzte und proaktive Institution, als Aktant lebendiger Erinnerungskultur im Gegensatz zum statischen Speicher und Erziehungsraum. Insofern wird hier vielleicht sogar Malraux über sich selbst hinaus weitergedacht und die Rettung des Museums aus der Idee seiner Überholtheit abgeleitet: Es sind nicht mehr nur die Exponate, die durch ihre Neuinterpretationen im Ausstellungskontext transformiert und zukunftsfähig gemacht werden müssen, sondern die Institution selbst lebt von der Veränderung und Anpassung an die Erfordernisse und Gelegenheiten wechselnder Epochen. Die Chance hierzu entsteht womöglich paradoxerweise gerade dann, wenn es in seiner etablierten Form überflüssig geworden zu sein scheint.

90 Vgl. http://spices.biodiversityexhibition.com/ vom 02.10.2015.

91 Vgl. http://www.theeuropeanlibrary.org/exhibition/napoleonic_wars/index.html vom 02.10 .2015 .

92 Vgl. https://www.google.com/culturalinstitute/exhibit/to-my-peoples/gQyspHgL?hl=enGB vom 02.10.2015.

93 Vgl. http://exhibitions.europeana.eu/about-exhibitions vom 02.10.2015. 


\subsubsection{Das Google Art Project (www.googleartproject.com)}

Am 1. Februar 2011 enthüllte Google mit dem Art Project das Ergebnis einer anderthalbjährigen Zusammenarbeit mit zunächst 17 international bedeutenden Kunstmuseen. $\mathrm{Zu}$ den teilnehmenden Gründerinstitutionen gehörten unter anderen die Alte Nationalgalerie in Berlin, die National Gallery in London, das Museum of Modern Art in New York, die Galleria degli Uffizi in Florenz, das Van Gogh Museum in Amsterdam und das Château de Versailles. Mittlerweile arbeitet das Projekt mit über 250 Partnerhäusern in über 40 Ländern zusammen. ${ }^{94}$ Nach eigener Darstellung will das Art Project Googles Methode sein, kulturelle Verantwortung zu übernehmen und existierende firmeneigene Technologien eben nicht nur in den Dienst selbstverstärkender Cyber-Popularität zu stellen, sondern Nutzern Zugriff auf kuratierte Ausstellungen aus aller Welt zu ermöglichen:

With a team of Googlers working across many product areas we are able to harness the best of Google to power the Art Project experience. Few people will ever be lucky enough to be able to visit every museum or see every work of art they're interested in but now many more can enjoy over 40.000 works of art from sculpture to architecture and drawings all in one place. We're also lucky at Google to have the technology to make this kind of project a reality. ${ }^{95}$

>Technik verpflichtet also ebenso, wie sie ermächtigt - und wo die Überzahl musealer Netzauftritte immer noch vorrangig auf die Kombination von Text und Bild setzt, will Google die ganze Bandbreite digitaler Intermedialität ausschöpfen:

In addition to the incredible artwork from collections around the world, such as paintings, drawings, sculptures, historic and religious artefacts, photographs and important manuscripts, there is a wealth of additional material. Expertly narrated videos, audio guides, viewing notes, detailed information, maps and so on provide an invaluable range of content for visitors to enjoy. ${ }^{96}$

Im Zentrum des Projektes steht dabei die »virtual gallery tour«, welche auf einer Technologie basiert, die ursprünglich für Googles (von Datenschützern umstrittenen) Street View-Dienst entwickelt wurde. Der Nutzer erlebt die teilnehmenden Museen aus der ersten Person in Form von Fotografien, die mit speziellen $360^{\circ}$-Kamerastativen aufgenommen wurden und ein rotierbares Panorama bilden. Die Verwendung dieser bereits etablierten Techik ermöglicht es den Rezipienten darüber hinaus, direkt aus den Straßen von Street View in die Museen des Art Project zu wechseln, also

$94 \mathrm{Vgl}$. https://sites.google.com/a/pressatgoogle.com/art-project/faqs vom 11.09.2015.

$95 \mathrm{Vgl}$. https://sites.google.com/a/pressatgoogle.com/art-project/technology-behind-the-artproject vom 11.09.2015.

96 Vgl. ebd. 
gewissermaßen das virtuelle Museum direkt als in der virtuellen Stadt verortet zu erleben. Google macht derzeit keine Angaben zur Anzahl der auf diese Art aufgenommenen Museumsräume, gibt aber an, dass das Projekt zum Startzeitpunkt 6.000 solcher Panoramen auf 385 Ausstellungsflächen umfasst habe. ${ }^{97}$

Von der Startseite des Art Project ${ }^{98}$ ausgehend kann der Nutzer die digitalisierten Sammlungen und Räumlichkeiten auf verschiedene Arten erkunden. Der überwältigende Großteil der Startseitenfläche wird dabei von Abbildungen »vorgestellter Objekte« eingenommen. Hierbei handelt es sich um aus Sicht von Googles Kuratoren herausragende Kunstgegenstände, zwischen denen mit Pfeiltasten an den Bildschirmrändern >geblättert` werden kann. Ein Klick auf die Taste >Objekt ansehen` ruft umgehend die dem Objekt gewidmete Seite auf. Am oberen Bildschirmrand stehen neben einem Textsuchfeld (das sowohl auf Namen von Institutionen als auch von Künstlern und Werken anspricht) die Reiter `Sammlungen`, >Künstler`, >Kunstwerke` und `Nutzergalerien` zur Verfügung. Die ersten zwei Kategorien rufen wahlweise alphabetisch oder chronologisch (nach der Aufnahme des Gegenstands ins Art Project) geordnete Listen auf, die am linken Rand Museen bzw. Künstlernamen zeigen, neben denen eine Anzahl von Werken in Miniaturansicht dargestellt wird. Wenn nicht alle zum jeweiligen Eintrag vorhandenen Objekte auf den Bildschirm passen (und besonders im \Sammlungs ‘-Menü ist dies fast immer der Fall), verweist ein graues Feld am rechten Bildschirmrand auf weitere, nicht dargestellte Objekte. Google legt dabei nicht offen, nach welchen Kriterien die Software darüber entscheidet, welche Objekte angezeigt werden und welche nicht. ${ }^{99}$ Der Reiter $>$ Kunstwerke hingegen öffnet ein komplexeres Zugriffssystem, mit dem die Gesamtheit aller digitalisierten Objekte (im September 2015194.308 an der Zahl) in Datenbank-Manier nach Textschlagworten durchsucht und nach Kategorien gefiltert werden kann. Formale Zugriffsrubriken sind hier abermals `Sammlung ( (im Sinne von >besitzender Institution ), > erstellt von` (gemeint ist hier der Künstler), >Materialく, >Medientyp (was sich interessanterweise auf die Beschaffenheit des Digitalisats bezieht, nicht etwa auf die Natur des Originalobjektes) und >Datum` (im Sinne der Datierung des Originalgegenstandes). Hinzu kommen drei inhaltliche Größen, die sich auf Darstellungsgegenstände beziehen: >Ereignis`, >Ortく und >Person২. Diese Rubriken erlauben es also, ganz im Sinne von Paisleys Segelschiff-Suche nach künstlerischen Darstellungen zu bestimmten Themen zu suchen. Das Such- und Filterfeld nimmt dabei nur

97 Vgl. https://sites.google.com/a/pressatgoogle.com/art-project/press-site-v1/press-releasev1 vom 11.09.2015.

98 Vgl. https://www.google.com/culturalinstitute/project/art-project?hl=de vom 13.09.2015.

99 Vgl. https://www.google.com/culturalinstitute/collections?projectId=art-project\&hl $=\mathrm{de}$, https://www.google.com/culturalinstitute/artists?projectId=art-project\&hl=de vom 12.09.2015. 
einen Teil der linken Bildschirmhälfte ein. Das Gros der Seite besteht aus einer seitwärts scrollbaren Aufreihung von Objekten, wobei eben dieses seitwärtige Scrollen für das Art Project hochgradig programmatisch ist: Gewohnt sind wir es von den allermeisten Webseiten, auf- und abwärts zu scrollen. Dies ist nur logisch, schließlich ist das Web immer noch in weiten Teilen ein Schriftmedium, und unsere Schrift läuft von links nach rechts und von oben nach unten. Die Wendung um 90 Grad erregt sofort unsere Aufmerksamkeit: Es wird der Effekt einer Galeriewand erzielt - und damit eine Fortsetzung des Paradigmas der Nachahmung einer physischen Ausstellung, welches dem Prinzip der >virtual gallery tour zugrunde liegt. Während diese jedoch die bestehenden Ausstellungskontexte der Originalmuseen nachbildet, beantwortet die zweidimensionale `Galerie〈 unter dem Reiter `Kunstwerke` individuelle Suchanfragen des Nutzers und kann auf drei unterschiedliche Arten geordnet werden. Die Einstellung >Standard `sortiert die Objekte auf Basis früherer Anfragen und Auswahlen nach Relevanz (folgt also mustergültig dem >Prinzip Google`), während die Menüpunkte `älteste zuerst und `neuste zuerst` die gefundenen Objekte nach dem Alter der Originalobjekte anordnen. ${ }^{100}$ Jede Suchanfrage lässt also hier ein kleines imaginäres Museum für den individuellen User entstehen, das sich funktional seinen Erkenntnisinteressen und Schaugewohnheiten anpasst.

Diese imaginären (bzw. von Mensch und Technik gemeinsam imaginierten) Museen müssen allerdings nicht in der Vorstellung und auf dem Monitor des Einzelnutzers verbleiben. Der vierte Reiter mit dem Titel `Benutzergalerien` öffnet eine Seite, auf der jeder Besitzer eines Google+-Kontos eine eigene Auswahl aus dem Gesamtfundus des Art Project zusammenstellen und veröffentlichen darf. Im September 2015 sind so über 43.000 kleine Galerien entstanden, die sich unterschiedlichsten Schwerpunkten widmen und von denen einige von Google als »vorgestellte Galerien« herausgehoben werden - hierzu zählen vorrangig solche, in denen Museumsdirektoren der teilnehmenden Einrichtungen ihre Lieblingswerke aus dem eigenen Haus präsentieren (vgl. Rieger u. Niewerth 2016: 517). ${ }^{101}$ Die Galerien des Laienpublikums decken dagegen völlig disparate Interessengebiete ab. So trägt z.B. eine den Titel KUSS - das Schönste an der Liebe und enthält 11 Darstellungen von Küssenden aus ebenso vielen Museen, die von mesoamerikanischen Plastiken aus dem 9. Jahrhundert über romantische und expressionistische Malerei bis zur chinesischen Gegenwartskunst reichen. ${ }^{102}$ Eine andere Nutzergalerie trägt den Titel Landschaftsaquarelle mit Berücksichtigung der Tiefenkriterien und erklärt sich damit umgehend

$100 \mathrm{Vgl}$. https://www.google.com/culturalinstitute/browse/?c.projectId=art-project\&v.view $=$ room\&v.filter $=$ items $\& h l=$ de\&projectId=art-project vom 13.09.2015.

$101 \mathrm{Vgl}$. https://www.google.com/culturalinstitute/user-galleries?hl=de\&projectId=artprojec vom 13.09.2015.

102 Vgl. https://www.google.com/culturalinstitute/user-gallery/kuss/dwISyzf_xQmEJA?hl $=$ de\&projectId $=$ art-project vom 13.09.2015. 
selbst. ${ }^{103}$ Viele Galerien tragen schlicht Titel wie Meine Lieblingsbilder oder Favorites und überlassen es dem Betrachter, Geschmack und Interessen des jeweiligen >Kurators zu dechiffrieren. Auch hier besteht die Möglichkeit, die Reihenfolge der gezeigten Galerien auf- und absteigend nach Alphabet oder Neuheit zu sortieren, während die Kriterien der Reihenfolge in der `Standard/-Einstellung nicht transparent gemacht werden. Offensichtlich erscheint lediglich, dass der geographische Standort des Nutzers einbezogen wird: Wer sich aus Deutschland einloggt, wird vorzugsweise Galerien mit deutscher Benennung zu sehen bekommen.

Abbildung 5: >Virtual Gallery Tour -Ansicht des Google Art Project, hier die Galleria degli Uffizi in Florenz

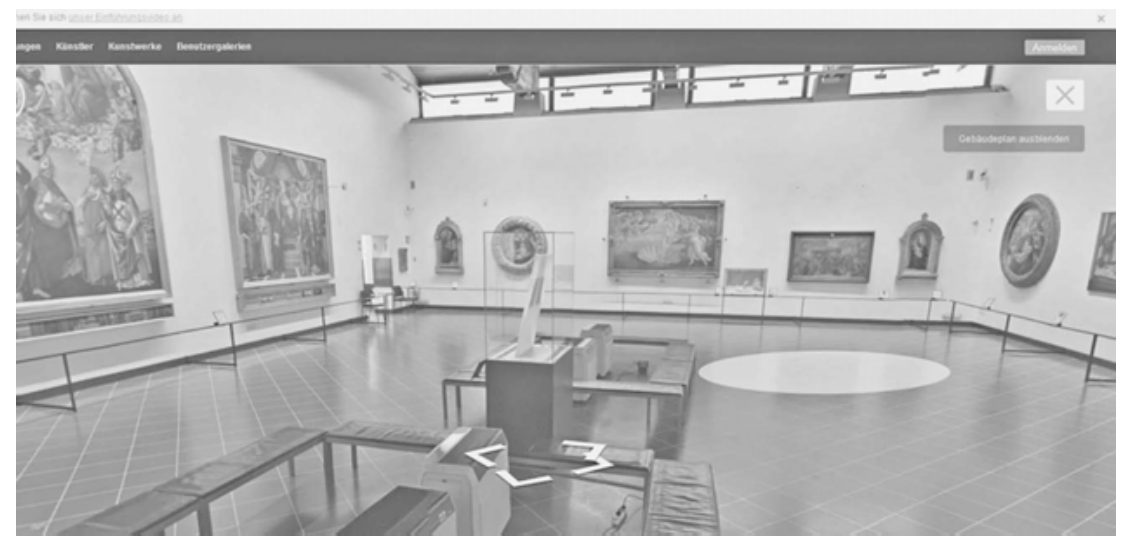

https://www.google.com/culturalinstitute vom 10.02.2015.

In die virtualisierten Ausstellungsräume der virtual gallery tour gelangt der User mittels des Sammlungs-Reiters. Nicht alle teilnehmenden Museen bieten solche Abbilder ihrer selbst an, und die vorhandenen umfassen nicht notwendigerweise das gesamte Haus. Eine tatsächlich freie Bewegung ist unter den technischen Voraussetzungen der Street View-Technik nicht möglich - die Museumsräume des Art Projekt sind keine laufend in Echtzeit generierten Szenerien, wie wir sie aus Computerspielen kennen, sondern eben Arrangements zweidimensionaler Fotografien, die den Raum nur implizieren. Die Museen können grundsätzlich nur von jenen Standpunkten aus erlebt werden, an denen sich die Kamera zuvor befunden hat. Die Innenansicht der Museumsräume wird zur Linken von einem Lageplan gesäumt, auf dem Position und Blickrichtung des Betrachters angezeigt werden, während am unteren Bildschirmrand kleine Abbildungen den `Sprung ‘ zu individuellen Kunstwerken ermöglichen.

103 Vgl. https://www.google.com/culturalinstitute/user-gallery/landschaftsaquarelle/jwJCy8 YAElGqJA ?hl=de\&projectId=art-project\&position=0\%3A17 vom 13.09.2015. 
In der Museumsansicht kann sich der Nutzer mittels verschiedener Werkzeuge räumlich orientieren: Ein \Kompass in der rechten oberen Ecke erlaubt es ihm, auf seiner Position zu rotieren, während eine Zoomleiste unterhalb der Windrose ihn das Bild vergrößern und damit faktisch >tieferく in den Raum eintreten lässt. Richtungspfeile am unteren Rand lassen ihn >Schritte in verschiedene Richtungen unternehmen (vgl. Abbildung 5). Wird der Mauscursor innerhalb der Raumansicht bewegt, dann folgt ihm ein rechteckiger weißer `Schatten`, mit dem sich eine bestimmte Bildregion vergrößern lässt: Ein Klick bringt das virtuelle Abbild des Besuchers dann an den nächstmöglichen Standort und zoomt den markierten Bereich näher heran. Die Räume auf dem Lageplan links der Ausstellungsansicht können ebenfalls angeklickt werden, um direkt in einen bestimmten Raum zu springen, ohne dorthin >wandern` zu müssen.

\section{Abbildung 6: >Gigapixel - Detailansicht aus Botticellis >Nascita di Venere}

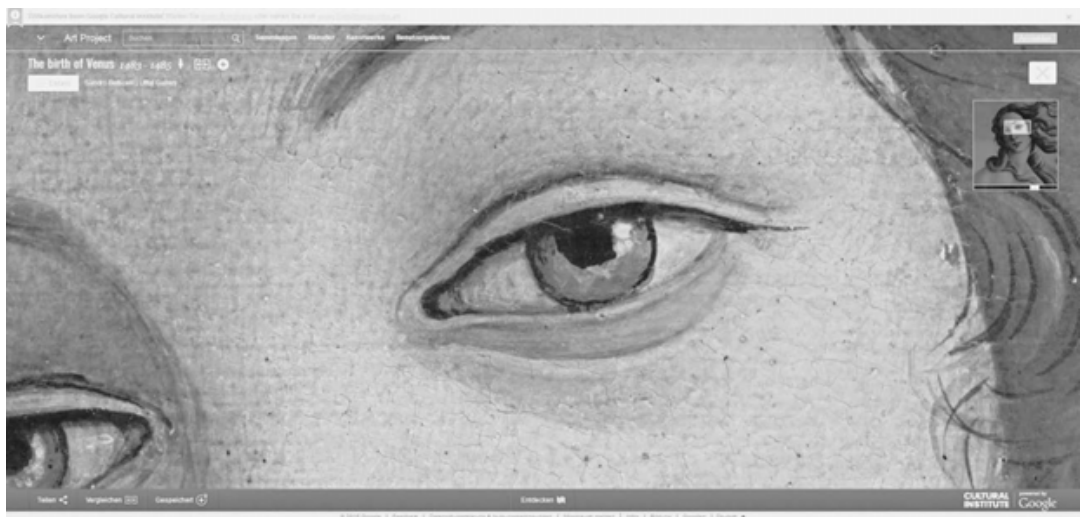

https://www.google.com/culturalinstitute vom 10.02.2015

Während die Panorama-Fotografien, über die man die Ausstellungsräume begehen darf, nur in relativ niedriger Auflösung verfügbar gemacht wurden, liegen die Gemälde und andere Ausstellungsstücke in sehr hoher Qualität vor. Will man sich also Objekte detailliert anschauen, verbleibt man nicht in der Ausstellungsansicht, sondern wechselt auf die Seite des fraglichen Schaustücks. Dies ist nicht nur über die Leiste unterhalb der Raumdarstellung möglich, sondern kann auch direkt aus den virtuellen Räumen heraus geschehen. Objekte, die entsprechend digitalisiert wurden, sind mit einem kleinen weißen Rechteck versehen, das hierzu lediglich angeklickt werden muss. Darüber hinaus wurde eine Anzahl herausragender Kunstwerke im sogenannten `Gigapixel<-Verfahren eingescannt. Die entsprechenden Reproduktionen enthalten über 7 Milliarden Pixel und füllen bei maximalem Zoom einige hunderte 
handelsüblicher Computerbildschirme, ohne unscharf zu werden bzw. zu verpixeln. ${ }^{104}$ Wer mithilfe des Art Project beispielsweise die virtuellen Uffizien erkundet, der wird feststellen, dass sich Botticellis Nascita di Venere so nah heranzoomen lässt, dass das rechte Auge der Venus allein einen Monitor mit der üblichen HD-Auflösung von 1920x1080 Pixeln auszufüllen imstande ist, und dass bei einer solchen Vergrößerung nicht nur die Struktur der Leinwand zu erkennen ist, sondern auch Risse und Abriebe in der über 500 Jahre alten Farbe sichtbar werden (vgl. Abbildung 6). ${ }^{105}$

Das Art Project betreibt damit nicht nur eine Intellektualisierung der Kunst und eine Reduktion auf den reinen Stil, wie Malraux sie der fotografischen Reproduktion zuschreibt, sondern auch eine Historisierung der Kunst in ihrer Materialität. Die Raumordnung der klassischen Museumsaustellung, die ja immer auch darum bemüht sein muss, den Besucher auf Distanz zum Exponat zu halten, wird überschrieben von einem Ausstellungsparadigma der Nähe. Dieses steht zur Telepräsenz der Objekte nicht etwa im Widerspruch, sondern stützt sich vielmehr auf diese. Die Alterungserscheinungen eines Kunstwerks werden sichtbar gemacht und zum Beleg dafür, dass dieses eine Geschichte hat, die über seine Entstehungssituation hinausgeht. In weiten Teilen besteht museale Tätigkeit gerade in Kunstmuseen (die Aufgabenfelder von Restaurierung und Konservierung sind hier sinnfällige Beispiele) darin, überschüssige (d.h., nicht zum Ausstellungskontext passende) Historizität von Exponaten zu verschleiern und sie Semiophoren sehr spezifischer Sinnzusammenhänge zu machen. Dies wird in Kunstaustellungen meist bedeuten, die vermeintlichen Intentionen des Autors in den Mittelpunkt zu rücken (vgl. Smith 1991: 20). Eine solche Illusion von historischer Eindeutigkeit und Zugehörigkeit ist schwer aufrecht zu erhalten, wenn die Spuren der Zeit dem langen Blick des Betrachters zugänglich gemacht werden. Botticellis Venus ist plötzlich keine versprengte Zeitreisende aus dem 15. Jahrhundert mehr. Sie ist vielmehr eine reife Dame, in deren Haut sich ein halbes Jahrtausend an Geschichte eingeschrieben hat. Jeder Makel und jede Blessur auf der Leinwand kann zum Aufhänger einer wilden Semiose werden (vgl. Rieger u. Niewerth 2016: 520). Dabei erschöpfen sich die virtuellen Ausstellungsobjekte nicht in flachen Abbildungen: Skulpturen werden zunehmend auch als rotierbare 3D-Modelle mit hochauflösenden, am Originalobjekt aufgenommenen Texturen präsentiert.

Das Google Art Project ist ein derzeit einmaliges Angebot, in welchem physisches, imaginäres und virtuelles Museum einen faszinierenden Trialog führen. Einerseits ist es eines der größten existierenden Projekte zur Digitalisierung und Verfügbarmachung materiellen Kulturerbes - und wohl das bedeutendste, das von seiner Entstehung an einen explizit musealen Anspruch verfolgte. Andererseits bezieht das

104 Vgl. https://sites.google.com/a/pressatgoogle.com/art-project/technology-behind-theart-project vom 11.09.2015.

$105 \mathrm{Vgl}$. https://www.google.com/culturalinstitute/asset-viewer/the-birth-of-venus/MQEeq 50LABEBVg ?hl=de\&projectId=art-project vom 15.09.2015. 
Art Project weder in didaktischer Konzeption noch in technischer Umsetzung eine spostmuseale< Position, welche die kuratierte Ausstellung in der Virtualität der Assoziierbarkeiten aufgehen lassen will. Vielmehr versucht Google die Aussöhnung des individuellen physischen Museums mit dem virtuellen Meta-Museum sowie die Rückbindung der zahl- und ortlosen digitalen Reproduktion an das einzigartige und geographisch gebundene Original. Das Museum mit Wänden steht jenem ohne Wände nicht als Gegenentwurf gegenüber, sondern die Wände werden optional - und damit wird dem Besucher zugleich das vor Augen geführt, was physische Museumsausstellungen ihm meist verheimlichen: dass nämlich jede Ausstellung das Ergebnis von Auswahlprozessen und Entscheidungen ist, die anders hätten ausfallen können, und dass jedes Exponat sich auch in andere Zusammenhänge einreihen ließe. Ganz unmittelbar kann er die Vieldeutigkeiten der Ausstellungsstücke bei der Erstellung von Nutzergalerien erleben, die ihn selbst zum Kurator werden lassen.

\section{Abbildung 7: >Comparer-Ansicht von Botticellis >Nascita di Venerer (Galleria degli Uffizi, Florenz) und Tizians >Venus Anadyomener (National Gallery of Scotland, Edinburgh).}

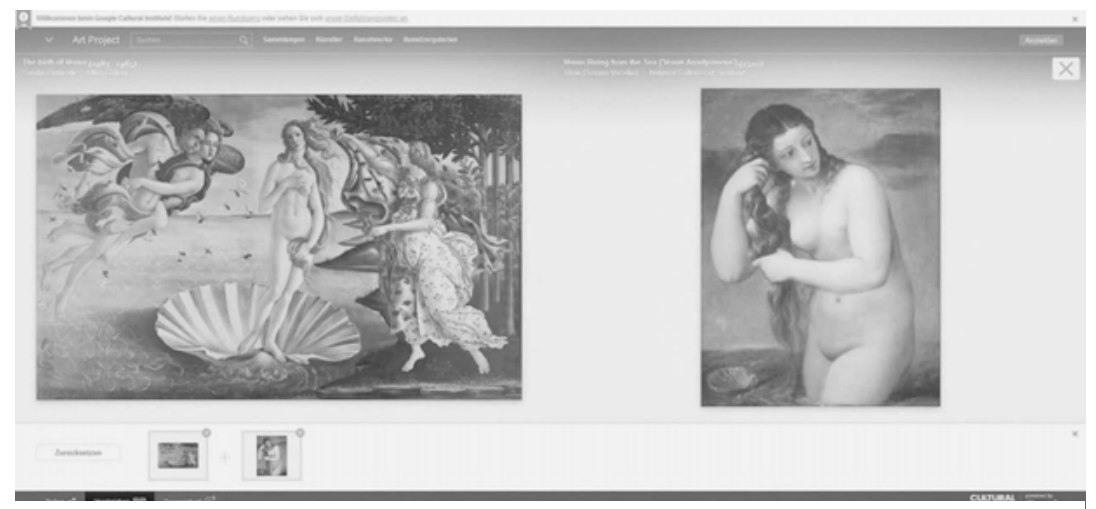

https://www.google.com/culturalinstitute vom 10.02.2015.

Ross Parry sieht in solchen Phänomenen des social tagging die Andeutung eines grundsätzlichen Wandels im Wesen kuratorischer Arbeit. Die klassische Ausstellung hat für ihn den Charakter einer Erzählung: Sie stellt eine Auswahl aus einer größeren Sammlung dar, die ohne gezielte Reduktion keine Aussagen zu artikulieren vermag. Hypertextsysteme indes sind laut Parry Sammlungen (von Textbausteinen), in denen die Aufgabe der Auswahl dem Leser zufällt. In sich laufend erweiternden virtuellen Museumsprojekten besteht seiner Ansicht nach die Gefahr, dass die `Kuratoren` (womit hier die Webseitenbetreiber gemeint sind) ihre Autorenfunktion einbüßen. An ihre Stelle trete die eines Kritikers, der das museale Narrativ nicht `schreibt`, sondern den Besucher nur mehr zur Zurechtfindung im Labyrinth der Inhalte anleitet (vgl. 
Parry 2006: 107ff.). Und tatsächlich scheint für das Art Project die Idee einer kritischvergleichenden Betrachtung von Kunstobjekten konzeptuell zentral zu sein: Eines seiner bemerkenswertesten Features ist ein unscheinbar am unteren Bildschirmrand positioniertes Feld mit dem Titel >Vergleichen`. Dieses öffnet eine Leiste, in die sich beim virtuellen Flanieren gefundene Objekte hineinziehen lassen, um sie auf einer eigenen Seite im direkten Vergleich miteinander zu betrachten. Es handelt sich also um nicht weniger als eine Parallelprojektion von Werken, wie sie ein fundamentales Werkzeug der Kunstgeschichte darstellt (vgl. Abbildung 7, vgl. Rieger u. Niewerth 2016: 517). Google indes überlässt den Besuchern des Art Project dieses Werkzeug ohne jede methodische Anleitung und ohne ihnen eine Möglichkeit zu geben, sich explizit über ihre >Entdeckungen`zu äußern. Paradoxerweise erlaubt die Plattform ihren Nutzern tatsächlich weniger explizite Kommunikation als der physische Museumsraum.

\subsection{VIRTUELLE MUSEEN ALS AMATEURPROJEKTE}

Neben der Vision vom Universalmuseum ist die Vorstellung von einer nivellierten und entprofessionalisierten Museumslandschaft eine der Kernideen der Museumsvirtualisierung: Virtuell kann und darf grundsätzlich jeder kuratieren - bedarf es doch weder eines Ausstellungsraumes noch rarer Originalobjekte, und entsprechend auch keiner besonderen Sorgfalt und Expertise im Umgang mit letzteren. Die >wilde ২ Virtualisierung des Musealen durch private Amateurprojekte ist dabei tatsächlich viel eher Musealisierung des Virtuellen: Zwar borgt sie sich Bezeichnung und Selbstbild von der klassischen Institution, in ihrer Vorgehensweise ist sie jedoch notwendigerweise auf das Web hin ausgerichtet - schon weil die Laien-Kuratoren keinerlei Zugriff auf die Bestände >tatsächlicher` Museen haben.

Solche Amateurmuseen leisten vor allem zweierlei. Erstens neigen sie dazu, Gegenstandsbereiche zu thematisieren, die üblicherweise nicht Thema physischer Museumsausstellungen werden würden. Zweitens stellen sie diese Gegenstände auf eine Art und Weise aus, die sich stark von den Relevanzkriterien und pädagogischen Leitlinien abhebt, welche die professionelle Museumsarbeit normalerweise bestimmen. Im Folgenden werden zwei solche Projekte vorgestellt werden: das sich aus Sammlerperspektive der Geschichte der Heimcomputer widmende 8bit-Museum, und das komplett aus einer privaten Sammlung von Amateurkunst entstandene Museum of Fred. 


\subsubsection{Das 8bit-Museum (www.8bit-museum.de)}

Das 1998 ins Leben gerufene 8bit-Museum ist das virtuelle Abbild der mehr als 700 Objekte umfassenden privaten Computersammlung des Bottroper Informatikers Stephan Slabihoud. Nach eigener Aussage sind Sammlung und Webauftritt aus rein hobbyistischer Begeisterung für obsolete Computertechnik entstanden. Der Betreiber schreibt hierzu:

Ich habe 1981 mit einem ZX81 angefangen zu programmieren. Ein Jahr später stand dann ein ZX-Spectrum auf dem Tisch. Während meiner Schulzeit habe ich zuerst einen CBM 8000 kennengelernt, später standen dann VC20 und C64 in dem (damals kleinen) Computerraum. 1986 legte ich mir dann stolz einen Atari 260ST zu, dem folgte drei Jahre später ein Atari TT. Irgendwann 1993/94 habe ich die Rechner wieder aus dem Keller geholt, gereinigt, überholt und in eine Vitrine gestellt. Ab da kamen dann hin und wieder weitere Geräte hinzu. So richtig zu wachsen begann die Sammlung aber erst mit der Eröffnung des 8Bit-Museums im Web. ${ }^{106}$

Interessanterweise ist hier also der typische Werdegang virtueller Museen auf den Kopf gestellt: Nicht die Sammlung ist der virtuellen Präsentation vorausgegangen, sondern das bereits begonnene virtuelle Museumsprojekt ist zum Motivator für eine Sammeltätigkeit geworden. Dabei muss gefragt werden, inwieweit man Herrn Slabihoud im Hinblick auf den Sammlungsgegenstand überhaupt als >Amateur $<$ bezeichnen darf: Als Programmierer hat er seit Mitte der 1980er Jahre Software für zahlreiche der vom 8Bit-Museum ausgestellten Systeme entwickelt und in Artikel in Computerzeitschriften veröffentlicht, die er z.T. über die Webseite zum Download anbietet. $^{107}$

Diese gliedert ihren Ausstellungsgegenstand in zwei Hauptgebiete: Unter der Überschrift The Number Crunchers werden Heimcomputer, Peripheriegeräte und verwandte Hardware präsentiert, während die Rubrik The Dot Eaters die Geschichte der Computerspiele thematisiert - letzteres in Kooperation mit der ebenfalls privaten englischsprachigen Partnerhomepage www.thedoteaters.com. Number Crunchers bilden dabei erkennbar den Schwerpunkt der virtuellen Ausstellung, und über die dokumentarische Tätigkeit hinaus sucht das 8bit-Museum auf verschiedenen Ebenen den Austausch mit privaten Hobbyisten und Sammlern unterschiedlichster Couleur: Der Betreiber bittet ausdrücklich um Kontaktaufnahme durch Besucher, die museumsrelevante Heimcomputer spenden, verkaufen oder gegen ein anderes Gerät eintauschen möchten ${ }^{108}$. Eine auf Deutsch und Englisch geführte Liste führt zu diesem

$106 \mathrm{Vgl}$. http://8bit-museum.de/internes/fragen-antworten-faq/ vom 12.11.2015.

$107 \mathrm{Vgl}$. http://8bit-museum.de/internes/veroeffentlichungen/ vom 12.11.2015.

$108 \mathrm{Vgl}$. http://8bit-museum.de/internes/spenden-ankauf-von-geraten/ vom 12.11.2015. 
Zweck Modelle auf, die Slabihoud augenblicklich anbietet oder aufzutreiben versucht. ${ }^{109}$

Auch die Startseite der Webpräsenz erinnert an ein serviceorientiertes Blog: Sie informiert nicht nur über neue Exponate und Entwicklungen im unmittelbaren $\mathrm{Zu}$ sammenhang mit dem 8bit-Museum, sondern trägt ein weites Spektrum von Nachrichten aus dem Bereich der Computernostalgie und der sich mit ihr verbindenden Hobbyszene zusammen. So erinnert die Seite am 1. Oktober 2015 an den 30. Geburtstag des Prozessorenherstellers Intel; bringt am 10. desselben Monats ein kleines Feature über neun CPUs, »die jeder kennen sollte«; weist eine Woche später auf einen neu in die `Sammlung ( aufgenommenen Artikel über die Computerspiele Manic Miner und Jet Set Willy hin; informiert zum Monatsende über die Veröffentlichung einer neuen Version des Multiple Arcade Machine Emulator (MAME) - einer Software, mit der sich die technische Umwelt verschiedener alte Arcade-Spielplattformen auf modernen PCs und Macs nachahmen lässt - und macht kurz vor Allerheiligen noch auf eine Stellenausschreibung der NASA aufmerksam, die einen neuen (mit der Fortran-Programmiersprache vertrauten und möglichst nicht weit über 50 Jahre alten) Programmierer für die 1977 gestarteten Voyager-Sonden benötigt. ${ }^{110}$

Im Kopfreiter der Seite bildet die Rubrik >Videospiele ২ den ersten inhaltlichen Zugang zum 8bit-Museum - und zwar unter völliger Umgehung der eigentlichen Sammlung. Die Geschichte der Computerspiele nämlich wird als weitgehend lineare Erzählung präsentiert, gegliedert in als Stages bezeichnete Kapitel mit Levels genannten Unterkapiteln, gegabelt lediglich in zwei separate Geschichten der Arcade-Maschinen und der Heimgeräte. Die vier Stages sind in erster Linie thematisch und in zweiter chronologisch angeordnet, wobei sie einander überlagern. Die erste Stage trägt den Titel Die Steinzeit und beginnt 1947 mit Thomas T. Goldsmith Jr.s Cathode Ray Tube Amusement Device. Sie endet 1976 mit dem Verkauf von Atari an Warner Communication. ${ }^{111}$ Die zweite Stage thematisiert Arcade-Spiele von den diversen $A$ tari-Automaten der 1970er Jahre bis zum in den frühen 1990er Jahren unternommenen Versuch, Arcade-Spiele über Laserdisc-Geräte auf heimische Fernseher zu bringen. ${ }^{112}$ Die Stage Heimvideospiele beginnt 1976 mit der Veröffentlichung des Channel F-Systems von Fairchild Camera and Instrument und schließt mit dem Tod des ehemaligen Nintendo-Chefs Hiroshi Yamauchi im Jahre 2013. Die letzte Stage über Computerspiele behandelt vor allem PC-Spiele mit einem starken Schwerpunkt auf den Vertretern des Adventure-Genres und dem Entwicklerstudio Rare. Der Abschnitt

109 Vgl. http://8bit-museum.de/internes/tauschangebote-trade-offers/ vom 12.11.2015.

110 Vgl. http://8bit-museum.de/ vom 12.11.2015.

$111 \mathrm{Vgl}$. http://8bit-museum.de/videospiele/stage-1-die-steinzeit/level-1-bits-aus-deranfangsphase/ und http://8bit-museum.de/videospiele/stage-1-die-steinzeit/level-2-ataristeigt-auf/ vom 12.11.2015.

112 Vgl. http://8bit-museum.de/videospiele/stage-2-arcade-spiele/ vom 12.11.2015. 
beginnt mit Hunt the Wumpus aus dem Jahre $1972^{113}$ und schließt mit Rares Spielen für die Xbox 360 in den mittleren und späten 2000er Jahren. ${ }^{114}$ Zudem wird eine Zeitskala angeboten, die wichtige Eckdaten der Computerspielgeschichte von 1889 (Gründung Nintendos als Hersteller von Spielkarten und Erfindung des Lochkartensystems durch Herman Hollerith) bis 1989/90 (Veröffentlichung von Microsoft Windows 1.0 und des ersten Sound Blaster-Audioprozessors von Creative Labs) verzeichnet. ${ }^{115}$ Jedem $>$ Level wird eine eigene Seite gewidmet, auf der dem historischanekdotenhaft erzählenden Text illustrierende Abbildungen von Personen, Geräten und Software-Screenshots beigestellt sind. Die Levels sind dabei abermals in kurze Sinnabschnitte unterbrochen, die mit einer per Klick >ausklappbaren< Liste von Links und Danksagungen an Mitwirkende schließen. Darüber hinaus ist jedem dieser >Unter-Unter-Kapitel eine kleine Sammlung von Bildmaterial beigeordnet, durch die geblättert werden darf. ${ }^{116}$ Hierzu gehören Fotografien von Geräten ebenso wie solche von Verpackungen, Werbematerial und Scans aus Computerzeitschriften - es handelt sich um Bilder, die das Verständnis der Texte nur begrenzt bereichern, aber einen Eindruck von Ästhetik, Technik und sozialer Verortung der Heimcomputer in ihren respektiven >Epochen $`$ vermitteln sollen. Sprachlich sind die Texte im saloppen Plauderton verfasst, getragen spürbar weniger von einem didaktischen Anspruch als vom Wunsch, die Begeisterung des Betreibers an die Besucher weiterzugeben.

Die eigentliche Sammlung des 8bit-Museums ist unter den Menüpunkten >Firmen A-Z $\prec$ und Firmen $M-L \ll$ verzeichnet. Ein anderes Ordnungsprinzip wird nicht genutzt: Die Computer sind zunächst alphabetisch nach Herstellern und anschließend chronologisch nach Erscheinungsjahr sortiert. Wählt man aus einer der beiden Listen einen Hersteller aus, so gelangt man zunächst zu einer narrativen Darstellung der Firmengeschichte, die ganz ähnlich aufgebaut ist wie die `Levels` der Computerspiele-Rubrik. Am oberen Rand der Seite kann weitergeblättert werden: Auf die $>$ Historie< folgt der Abschnitt \Modelle〈, der sich als reine Textliste entpuppt. Aufgelistet sind Modelle nach Jahreszahl mit technischen Daten wie Rechenleistung, Speicherplatz, Bildschirmgröße und -auflösung, Laufwerken usw. Auch hier zeigt sich der hobbyistische Ansatz des 8bit-Museums: So wird z.B. zur Liste der Apple-Geräte ganz freimütig Unvollständigkeit besonders bei nach 1992 hergestellten Modellen

113 Vgl. http://8bit-museum.de/videospiele/stage-4-computerspiele/level-1-textabenteuer/ und http://8bit-museum.de/videospiele/stage-4-computerspiele/level-5-spiel-das-spiel/ vom 12.11.2015.

114 Vgl. http://8bit-museum.de/videospiele/stage-4-computerspiele/level-5-spiel-das-spiel/ vom 12.11.2015.

115 Vgl. http://8bit-museum.de/videospiele/zeitskala/ vom 12.11.2015.

116 Vgl. z.B. http://8bit-museum.de/videospiele/stage-3/level-2-duell-der-pixelkaesten/ vom 12.11.2015. 
eingeräumt - mit der Bitte an die Leser, sich zu melden, sollten sie Angaben ergänzen können. ${ }^{117}$

Auf die Modelle folgt der Abschnitt `Hardware`, der Fotografien des Innenlebens klassischer Heimcomputer enthält - sowohl aus Slabihouds eigener Sammlung als auch aus den Beständen anderer Enthusiasten im In- und Ausland. Neuere Fotos liegen auch hochauflösend vor. Interessant ist, dass hier erstens keinerlei Aufnahmen kompletter, zusammengebauter Computer zu finden sind, und zweitens, dass die abgebildeten Platinen bis auf eine Modellangabe komplett unbeschrieben bleiben. Der nicht-sachkundige Besucher erfährt dementsprechend nichts über den funktionalen Aufbau der gezeigten Elektronik, deren Spektakelwert und Anschlussfähigkeit für >wilde Semiosen irgendwelcher Art ebenfalls sehr begrenzt erscheint. Dieser ganze Unterpunkt scheint sich vorrangig an Besucher zu richten, die mit der Materie bereits vertraut sind. ${ }^{118}$

Der darauffolgende Abschnitt >Verpackungen` zeigt genau dies: Nämlich die Kartons, in denen Heimcomputer und Zubehör ihrerzeit in den Geschäften angeboten wurden. Die Abbildung jeder Verpackung beschränkt sich dabei üblicherweise auf eine Frontalansicht der bedruckten Vorderseite. ${ }^{119}$ Ganz ähnlich funktioniert der nächste Abschnitt zum Thema >Werbung`. Gezeigt werden hier Scans von Werbeannoncen, die vorwiegend aus sowohl deutsch- als auch fremdsprachigen Computerzeitschriften stammen und gegenüber den Hardware-Fotografien die Vorzüge haben, erstens weitgehend selbsterklärend zu sein, zweitens die Exponate in zusammengebautem Zustand zu präsentieren und drittens einen Einblick in Einbindung und Wahrnehmung von Heimcomputern in der Alltagswelt zu ermöglichen, der aus ihrer reinen Technizität nicht herzustellen ist. ${ }^{120}$ Der Punkt >Reviews` zeigt Scans von zeitgenössischen Testberichten zu den Exponaten, wobei der Betreiber ausdrücklich darauf hinweist, dass diese mit Einvernehmen der Autoren und Verlage in die virtuelle Ausstellung aufgenommen wurden. ${ }^{121}$ Unter $>$ Screenshots` werden naheliegenderweise Screenshots von Software gezeigt - nicht nur von den Interfaces der Geräte, sondern auch von Anwendungen und Spielen, die unter den entsprechenden Betriebssystemen ausgeführt werden können. ${ }^{122}$ Unter >Scans« schließlich können Scans von Schaltplänen und Handbüchern heruntergeladen werden, wobei auch hier wieder der Hinweis

117 Vgl. http://8bit-museum.de/heimcomputer/apple/apple-modelle/ vom 12.11.2015.

$118 \mathrm{Vgl} \mathrm{z.B.} \mathrm{http://8bit-museum.de/heimcomputer/apple/apple-hardware/ \#} \mathrm{vom12.11.2015.}$

119 Vgl. z.B. http://8bit-museum.de/heimcomputer/apple/apple-verpackungen/\# vom 12.11.2015.

120 Vgl. z.B. http://8bit-museum.de/heimcomputer/apple/apple-werbung/\# vom 12.11.2015.

121 Vgl. z.B. http://8bit-museum.de/heimcomputer/apple/apple-reviews/ vom 12.11.2015.

122 Vgl. z.B. http://8bit-museum.de/heimcomputer/apple/apple-screenshots/ vom 12.11.2015. 
auftaucht, dass die Firmen (soweit sie noch existieren) ihr Einverständnis zu deren Verbreitung gegeben haben. ${ }^{123}$

Es fällt auf, dass die Dinge und ihr Kontext im 8bit-Museum weitgehend getrennt voneinander in Erscheinung treten. Die historischen Narrativierungen der Geschichte von Computerspielen und Heimcomputern sind fast völlig abgelöst von der Sammlung, die sich überwiegend aus Listen und >losen « - also weder aufeinander noch auf ein pädagogisches Gesamtkonzept bezogenen - Abbildungen zusammensetzt. Das 8bit-Museum macht insofern die Malrauxsche These, dass museale Bestände letztlich immer Verkettungen von Zufällen abbilden, nicht nur plausibel, es unterstreicht sie sogar völlig unprätentiös: Herr Slabihoud stellt aus, was er hat und was ihm von Besuchern geschickt wird. Hinter seiner Ausstellung steht kein professioneller Kurator und somit auch keine Didaktik, welche die Gemachtheit und Unabgeschlossenheit der Sammlung zu verhehlen trachten könnte. Genau darin liegt ihre Authentizität begründet: Es ist nicht die Beglaubigung durch Institution und Experten, die hier das 〉Echte` ausmacht, sondern die offensichtliche Lebendigkeit des Angebotes und die Verankerung der Ausstellung im Alltag ihres überall auf der Webseite präsenten Machers und des sozialen Netzwerks von Gleichgesinnten, zu dem er gehört. Gerade das Vorläufige, das Unvollständige, das im besten Sinne des Wortes Unprofessionelle (weil nicht von berufsmäßigen Museumsleuten betriebene) macht das 8bit-Museum zu einem authentischen Projekt: Das, was uns gezeigt wird, ist nicht abgeschlossene und akademisch beglaubigte Vergangenheit, sondern die in der Gegenwart vollends lebendige Passion >richtiger Menschen.

Zwei weitere Rubriken bietet die Navigationszeile noch an. Unter \Sonstiges « findet man kurze Überblicks-Artikel zur Geschichte der Rechenmaschinen vom Abakus bis zur Hollerith-Maschine und zur QWERTY-Tastatur ${ }^{124}$ sowie zur Entwicklung des Computers von Konrad Zuse bis zur Markteinführung des MITS Altair 8800-PCs im Jahre 1975. ${ }^{125}$ Ferner wird ein Quiz zu verschiedenen Rubriken der Ausstellung angeboten, das tatsächlich Detailfragen stellt und mit seinem Schwierigkeitsgrad überrascht. ${ }^{126}$ Scans von Werbeanzeigen für einige obskure Rechner, Peripheriegeräte und Softwares ${ }^{127}$ sind hier ebenso verfügbar wie eine Tabelle mit den Preisen zahlreicher Heimcomputer zum Zeitpunkt ihrer Herstellung. ${ }^{128}$ Nicht zuletzt finden sich

123 Vgl. z.B. http://8bit-museum.de/heimcomputer/apple/apple-scans/ vom 12.11.2015.

124 Vgl. http://8bit-museum.de/sonstiges/rechenmaschinen/ vom 12.11.2015.

$125 \mathrm{Vgl}$. http://8bit-museum.de/sonstiges/computer/ vom 12.11.2015.

126 Vgl. http://8bit-museum.de/sonstiges/heimcomputer-und-videospiele-quiz/ vom 12.11.2015.

127 Vgl. http://8bit-museum.de/sonstiges/werbung/ vom 12.11.2015.

128 Vgl. http://8bit-museum.de/sonstiges/preisliste/ vom 12.11.2015. 
hier Literaturempfehlungen ${ }^{129}$ und weiterführende Links ${ }^{130}$ - letztere ganz vorwiegend zu anderen virtuellen Museumsprojekten über Heimcomputer, Spiele und verwandte Themen. Die Rubrik >Internes « schließlich eröffnet dem Besucher einen Blick hinter die Kulissen des 8bit-Museums: Hier finden sich die Tausch- und Kaufangebote des Betreibers, ${ }^{131}$ das FAQ-Dokument zu Geschichte und Gegenwart der Sammlung und Ausstellung, ${ }^{132}$ Presseinformationen, ${ }^{133}$ Links zu Berichten über und Bezugnahmen auf das Projekt (spürbar nicht ohne Stolz zusammengetragen), ${ }^{134}$ sowie eine 〉Ehrentafel` aller Personen, die dem 8bit-Museum Exponate gestiftet haben - sei es in Form von materiellen Objekten oder Bildmaterial. ${ }^{135}$ Nicht zuletzt informiert Slabihoud hier auch darüber, wie sich alte Heimcomputer am besten reinigen lassen, womit abermals der hobbyistische Wert der Webseite in den Vordergrund gerückt wird. ${ }^{136}$

Interessant ist hier der Punkt >Plagiate $<$ Nachdem dem Betreiber über mehrere Jahre hinweg wiederholt Übernahmen ganzer Passagen und Seiten des 8bit-Museums durch andere Webseiten aufgefallen sind, werden hier gezielt entsprechende Fälle vorgestellt - offenbar auch zur Abschreckung potenzieller Plagiaristen. Erhellend sind Slabihouds einführende Kommentare:

Besonders interessant sind die Ausreden. Von »Das habe ich nicht gewusst! «, über »Ich dachte, alles im Internet darf man frei benutzen.« und »Das wurde mir von jemanden zugeschickt.«, bis hin zu einem einfachen »Na und?« reicht die Palette. Und es waren nicht nur Kids, die einfach nur schnell »'ne Homepage« haben wollen, sondern überwiegend Erwachsene. Jeder, der heute einen C64 im Keller findet, meint, er müsse dieses der Welt mitteilen und garniert das ganze dann noch mit der Firmengeschichte und weiteren Bildern. Da man aber nicht fähig ist, selbst einen zusammenhängenden Satz zu schreiben, wird das einfach kopiert. Internet sei Dank! ${ }^{137}$

Obwohl der Mann hinter dem 8bit-Museum offenbar kein Geld mit seiner (völlig werbefreien) Webseite verdient, nimmt er das Problem von Plagiaten und unerlaubter Weiterverwendung seiner Texte und Inhalte sehr ernst. Hier greift jene Ökonomie der Anerkennung, die Chris Anderson auch unter Wikipedianern am Werke sieht:

129 Vgl. http://8bit-museum.de/sonstiges/buchempfehlungen/ vom 12.11.2015.

130 Vgl. http://8bit-museum.de/sonstiges/links/ vom 12.11.2015.

131 Vgl. http://8bit-museum.de/internes/tauschangebote-trade-offers/ vom 12.11.2015.

132 Vgl. http://8bit-museum.de/internes/fragen-antworten-faq/ vom 12.11.2015.

133 Vgl. http://8bit-museum.de/internes/presseinformationen/ vom 12.11.2015.

134 Vgl. http://8bit-museum.de/internes/auszeichnungen-berichte/ vom 12.11.2015.

135 Vgl. http://8bit-museum.de/internes/credits/ vom 12.11.2015.

136 Vgl. http://8bit-museum.de/internes/reparatur/ vom 12.11.2015.

137 http://8bit-museum.de/internes/plagiate/ vom 12.11.2015. 
Die Wertschätzung und der Respekt innerhalb der Gemeinschaft werden zur verbindenden und motivierenden Währung. Entsprechend ist es, wie Slabihoud berichtet, immer wieder die peer group der Heimcomputerfans selbst, die ihn auf Plagiate aufmerksam macht:

Es gibt sogar Spezies, die schlagen »Ihre« Site für den History-Award vor, und ich finde dann nur eine Kopie meiner, oder einer befreundeten Site, vor. Den wenigsten scheint in den Sinn zu kommen, dass Sammler sich untereinander kennen und solche URLs weitergeben... ${ }^{138}$

Zur Authentizität von Amateurprojekten im Bereich der virtuellen Musealität gehört also offenbar auch der Respekt vor der eigenen Arbeit und der anderer - umso mehr, weil monetäre Belohnungen gar nicht zur Disposition stehen. Spannend dürfte es in diesem Zusammenhang auch sein, zu beobachten, ob Slabihoud seine unter den FAQs geäußerte Absicht umzusetzen imstande sein wird, das Virtuelle zu musealisieren: Als Fernziel gibt er an, eines Tages auch seine physische Sammlung der Öffentlichkeit zugänglich machen zu wollen. ${ }^{139}$

\subsubsection{Das Museum of Fred (www.museumoffred.com)}

Viel persönlicher noch als das 8bit-Museum präsentiert sich schon in seiner Benennung das Museum of Fred. Bei 〉Fred ‘ handelt es sich um den in Los Angeles lebenden Schriftsteller und Filmemacher Fred Beshid, nach eigener Aussage ein »product of the California public school system and the 1980s Los Angeles punk rock scene ${ }^{140}$ Beshid rief sein Online-Museum im Jahre 2000 mit dem Vorsatz ins Leben, seine private Kunstsammlung einer breiteren Öffentlichkeit zugänglich zu machen. Bezeichnend ist dabei, dass in dieser Sammlung keinerlei Künstler von Rang oder Namen vertreten sind - sie besteht gänzlich aus Amateurwerken, die, wie Beshid angibt, »primarily $[. .$.$] from thrift stores in the greater Los Angeles area« erstanden wur-$ den. ${ }^{141}$

Den FAQs des Museum of Fred zufolge war es zunächst studentische Armut, die seinen späteren Kurator in die Second-Hand-Läden der Welthauptstadt der Unterhaltungsindustrie trieb - und ein generelles Interesse an bildender Kunst, das ihn auf die dort angebotenen Gemälde aufmerksam werden ließ. Um die Jahrtausendwende habe ihm dann das Internet erstmals die Möglichkeit gegeben, sein Hobby mit der Welt zu teilen - und zugleich ein Statement darüber abzugeben, dass Kunst zu wichtig sei »to

138 http://8bit-museum.de/internes/plagiate/ vom 12.11.2015.

$139 \mathrm{Vgl}$. http://8bit-museum.de/internes/fragen-antworten-faq/ vom 12.11.2015.

140 http://museumoffred.blogspot.de/ vom 15.11.2015.

141 http://www.museumoffred.com/about.html vom 15.11.2015. 
be left only to art professionals «. ${ }^{142}$ Der Name Museum of Fred sei daher eine bewusste Parodie auf die Praxis der Selbstverewigung von Museumsstiftern in den Namen der von ihnen gestifteten Museen:

I wanted to parody the grand tradition of museum founders naming museums after themselves so I envisioned MOF as a parody vanity museum. I also wanted the name to reflect the museum's accessibility. I initially considered the name »Fred's Museum.« That didn't look right so I opted for the »Museum of Fred. ${ }^{143}$

Beshid betreibt das Projekt also durchaus mit Humor, allerdings nicht als Scherz. Das $M o F$ soll ganz explizit Aussagen machen über die Welt, in der wir leben - insbesondere über die Kunst und darüber, wie Museen sie gesellschaftlich positionieren. Amateurkunst, so Beshid, »feiert Individualität $\aleph^{144}$ und erlaube es, der Kreativität nicht nur ausgewiesener Künstler, sondern auch jener von Durchschnittsmenschen Würdigung wiederfahren zu lassen, die sonst im Marktkapitalismus nur als Konsumenten benötigt und geschätzt würden. ${ }^{145}$ Aus diesem Grunde bezeichne er seine Webseite auch bewusst als ein Museum, und nicht etwa als eine Galerie:

I called it a museum to challenge ideas about how the museum is defined. The word »museum « originally meant a place dedicated to muses. It was a place of inspiration. A place dedicated to our human creative potential. Since then museums have become institutions dedicated to defining and preserving cultural values. As such, those with power tend to set the agendas for museums. ${ }^{146}$

Ohne in die Sprache des Cyberpunk zu verfallen, vollzieht Beshids Motivation zur Gründung des Museum of Fred also die Gedankengänge hinter Ascotts postmusealem Szenario nach: Die `Zukunftstechnologie` des World Wide Web soll tatsächlich ein Mittel sein, um das Museum zu seinen Ursprüngen zurückzuführen - als es nicht nur ein Ort war, an dem die Produkte vergangener menschlicher Kreativität bewahrt und ausgestellt wurden, sondern einer, an dem diese Kreativität in der Gegenwart und für die Gegenwart wirkte.

Dabei ist der Aufbau des Museum of Fred der wohl einfachste aller in diesem Kapitel diskutierten Webpräsenzen. Beshid gliedert die Digitalisate seiner Bilder in sechs simple und komplett auf die Darstellungsebene bezogene Kategorien: Animals, Boats, Landscapes, Pets, Portraits und Western. Jeder dieser Bereiche enthält genau

$142 \mathrm{http} / / / \mathrm{www}$. museumoffred.com/faq.html vom 15.11.2015.

143 Ebd.

144 Ebd.

145 Vgl. ebd.

146 Ebd. 
vierzig Gemälde - mit Ausnahme der Boats, von denen nur 26 vorhanden sind - so dass die Ausstellung insgesamt aus 226 Gemälden besteht. Daten zu den einzelnen Objekten liegen nicht vor - was nicht zuletzt daran liegen dürfte, dass sie als Funde aus Second-Hand-Läden keinerlei Herkunftsdokumentation besitzen und meist weder Titel noch Schöpfer bekannt sind. Darüber hinausreichende technische Angaben wie Größe, Material usw. hat Beshid offenbar als für Verständnis und Deutung der Objekte unerheblich befunden. Jede der sechs Galerieseiten besteht aus drei Hauptsegmenten: Am oberen Rand steht eine Überschrift mit zwei erläuternden Sätzen, darunter befindet sich links ein Feld mit Miniaturabbildungen aller enthaltenen Objekte, rechts daneben wird vergrößert das Bild angezeigt, über das der Nutzer den Mauscursor bewegt.

Die ausgestellten Bilder bestechen im Allgemeinen durch nichts außer der Amateurhaftigkeit ihrer Ausführung und der Naivität in der Darstellung: Die Kategorie Animals enthält springende Delfine, Hirsche in Berglandschaften, Elefanten an Wasserlöchern und Tiger, die aus dem Dschungeldickicht hervorlugen. ${ }^{147}$ Pets zeigt vor allem Hunde und Katzen, meist in sitzender Pose, häufig mit leicht verzogener Proportion und Perspektive. ${ }^{148}$ Die Portraits sind Darstellungen meist unbekannter Menschen (die einzige Ausnahme bildet eine Nachahmung von Gilbert Stuarts 1797 angefertigtem Porträt George Washingtons) und weisen vor allem eine große ethnische Vielfalt auf. ${ }^{149}$ Die Kategorie Western besteht aus Prairieszenen, Cowboys zu Pferd und zu Fuß, ebensolchen Indianern (mitunter weinend) und Landschaftsbildern mit Grenzsiedlungen sowie Tipis und Wigwams. ${ }^{150}$ Unter Landscapes finden sich sowohl offensichtlich amerikanische Landschafts- und Stadtkulissen als aber auch Darstellungen unbestimmter und fiktiver Orte. Perspektivische Fehler finden sich hier in nahezu allen Werken. ${ }^{151}$ Die Boats zuletzt treten überwiegend als Darstellungen von Segelschiffen in Erscheinung, allerdings sind auch einige Hafenszenen, MississippiRaddampfer und Ruderboote vorhanden. ${ }^{152}$

Nahezu die komplette Sammlung Beshids fällt in den Bereich des dekorativen Kitsches und würde in der Alltagswelt sehr wahrscheinlich vollkommen unterhalb der Wahrnehmungsschwelle der meisten Betrachter verbleiben. Das MoF spielt insofern ein Spiel mit unserem Blick und den kulturellen Konventionen, die ihn normalerweise lenken würden. Indem es vermeintlichen `Schund ‘ zum musealen Exponat macht, zwingt es uns, diesen zuallermindest scherzhaft als solches zu betrachten

147 Vgl. http://www.museumoffred.com/animals.html vom 15.11.2015.

148 Vgl. http://www.museumoffred.com/pets.html vom 15.11.2015.

149 Vgl. http://www.museumoffred.com/portraits.html vom 15.11.2015.

150 Vgl. http://www.museumoffred.com/western.html vom 15.11.2015.

151 Vgl. http://www.museumoffred.com/landscapes.html vom 15.11.2015.

152 Vgl. http://www.museumoffred.com/boats.html vom 15.11.2015. 
und eines >langen Blickes`zu würdigen. Letztlich leitet Beshid den Betrachter also zur wilden Semiose an.

Dabei sind die Beschreibungen der Galerien ganz offensichtlich bewusste Persiflagen auf Texte, wie sie üblicherweise in Museumskatalogen und auf Erklärungstafeln zum Einsatz kommen würden. Weil die Exponate des $M o F$ keinen erkennbaren Stilrichtungen oder Schulen zuzuordnen sind, ihre Schöpfer unbekannt bleiben und sie meist nicht einmal mit Titeln versehen wurden, gibt es keine Faktengeschichte, die sich ihnen beiordnen ließe - und zugleich verlangen sie in ihrer unmissverständlichen Gegenständlichkeit auch nicht nach Erklärung und Interpretation. Beshid staffiert sie dementsprechend nur mit (zuweilen humorigen) Gemeinplätzen aus. Zur Tiergalerie heißt es:

In this gallery, we find artistic interpretations of wild animals in natural settings. Artists have been fascinated with wild animals for thousands of years as evidenced by ancient cave paintings. ${ }^{153}$

Der den Haustieren vorgeschaltete Text lautet:

Artists choose subjects they are passionate about so it's not surprising to find portraits of cherished pets. It is interesting that pets are often rendered in human-like poses. ${ }^{154}$

Indes finden sich hier durchaus auch erhellende Aussagen. So schreibt Beshid über seine Auswahl von Bootsdarstellungen:

As we can see from these paintings the lore of the sea continues to inspire artists. Whether they're ships dwarfed by giant waves or recovering in port these paintings seem to be illustrations from fantastic stories. ${ }^{155}$

Diese >fantastischen Geschichten` werden wir wohlgemerkt niemals zu hören bekommen, weil die Objekte ohne jeden Kontext sowohl auf der Darstellungs- als auch Entstehungsebene daherkommen. Sie sind insofern Referenten auf der Suche nach einer Referenz, die nur der Betrachter ihnen imaginierend verleihen kann. Dies führt dazu, dass die Exponate des $M o F$ trotz aller Gegenständlichkeit und vermeintlichen inhaltlichen Flachheit durchaus zu >schocken Haustier-Galerie z.B. die Darstellung eines Dackels im Profil. Über seinem Kopf

$153 \mathrm{http} / / / \mathrm{www}$. museumoffred.com/animals.html vom 15.11.2015.

$154 \mathrm{http}: / /$ www.museumoffred.com/pets.html vom 15.11.2015.

155 http://www.museumoffred.com/boats.html vom 15.11.2015. 
schwebt ein Heiligenschein, am rechten unteren Rand ist der Name Sam aufgebracht. ${ }^{156}$ Augenscheinlich handelt es sich um einen verstorbenen Dachshund, dessen vom Schöpfer des Gemäldes mit Liebe gedacht wurde. Doch ist Sam der Name des Haustiers oder der des Künstlers? Welche Geschichte ist der Darstellung vorangegangen? Wie lange war der Hund zum Zeitpunkt der Entstehung des Bildes bereits tot? Ist hier womöglich gar kein bestimmter Hund dargestellt, und entsprechende Gemälde mit Heiligenschein bewehrter Tiere wurden in Serie zum Verkauf an Trauer tragende Tierhalter gemalt? Oder ist es vielleicht sogar ein karikaturistischer Kommentar über die fehlgeleitete Vermenschlichung von Haustieren bis zu dem Punkt, an dem ihnen eine unsterbliche und erlösungsfähige Seele zugeschrieben wird (vgl. Abbildung 8)? So absurd solche Überlegungen scheinen mögen: Beshids völliger Verzicht auf Recherchen und Erklärungen zu seinen Ausstellungsstücken macht sie zu Rätseln, die zum >Spinnen` einladen - womöglich mehr als manch ein abstraktes Kunstwerk, das in konventionellen Museumskontexten mit so viel kunsthistorischem Beiwerk versehen wurde, dass auf \Schock im Sinne Korffs und Benjamins ebenso wenig zu hoffen ist wie auf Assmannsche wilde Semiosen.

Abbildung 8: Hundeporträt aus dem >Museum of Fred

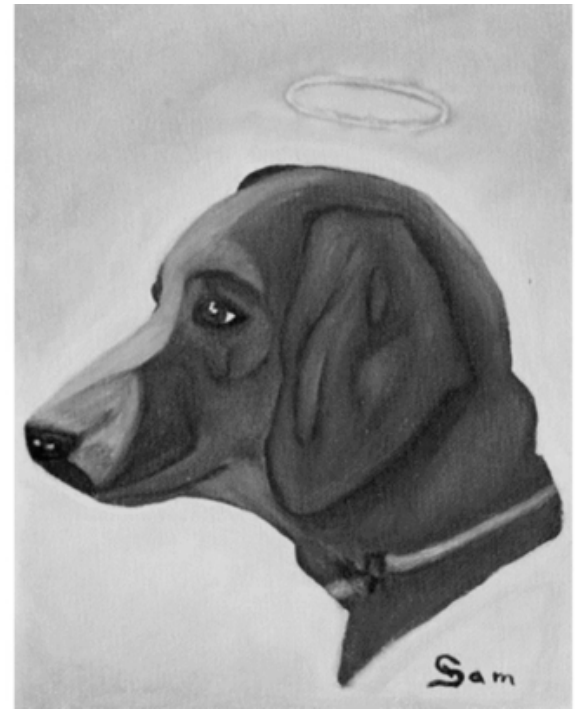

http://www.museumoffred.com/pets/IMG_0855.jpg

156 Vgl. http://www.museumoffred.com/pets/IMG_0855.jpg vom 15.11.2015. 
Dieser Schock scheint keineswegs ein zufälliger Nebeneffekt von Beshids Museumsphilosophie zu sein, sondern programmatisch in ihrem Zentrum zu stehen. Ganz und gar nicht trivial sind seine einleitenden Sätze zu den Porträts:

Because the identities of the subjects in these portraits are a mystery, they become portraits of humanity instead of individuals. They are an excellent representation of the cultural diversity of Los Angeles. ${ }^{157}$

Interessanterweise verortet Beshid also das Universelle der Exponate gerade in ihrer Hyperindividualität, die sie für den Besucher nur noch sehr begrenzt anschlussfähig sein lassen kann. Das Museum of Fred wird damit - trotz seiner technischen und ästhetischen Einfachheit - zu einer sehr pointierten Form von virtuellem Museum, welche die Virtualität des Mediums nutzt, um die Virtualität der Exponate zu unterstreichen. Im Mehrwert des Unbestimmten manifestiert sich dabei zugleich das Authentische: Die Echtheit der Ausstellungsstücke des $M o F$ äußert sich nicht in ihrer Herkunftsdokumentation, sondern in deren Fehlen, das gerade zum Beweis der Tatsache wird, dass die Objekte den unerzählten und unerzählbaren Lebensgeschichten wirklicher Personen entstammen. Viel mehr noch als das von Expertendiskursen umsponnene Kulturerbe, das wir in klassischen Kunstmuseen bewundern dürfen, unterstreichen sie Malrauxs Feststellung von der Transformation des Werkes durch den Verlust der Welt, der Zeit und der Räume, in denen es entstanden ist.

Auf diesen Umstand führt Beshid auch den Mangel an Interesse an Amateurkunst seitens der professionellen Kunstkritik und der wissenschaftlichen Kunstgeschichte zurück. Sie widersetze sich zu sehr der Kategorisierung und Objektivierung:

It seems scholars like to put things in tidy little boxes so we have a context in which to discuss ideas. The diversity of amateur art makes classification difficult so it's left out of art criticism, theory and discourse. ${ }^{158}$

Das $M o F$ ist im besten Sinne des Wortes ein virtuelles Museum, weil es das Unsichtbare sichtbar werden lässt und das Abwesende vergegenwärtigt: Es konfrontiert uns mit Objekten, die wir auf anderem Wege niemals zu Gesicht bekommen würden und hält uns an, sie auf eine Art zu betrachten, die ihnen in ihrer >natürlichen` Umgebung niemals zuteilwerden würde. Im Gegensatz zu Stefan Slabihoud plant Fred Beshid indes keine physische Ausstellung seiner Sammlung: »Yes, there's a physical MoF. No, you can't visit it because it's in my living room. «159

157 http://www.museumoffred.com/portraits.html vom 15.11.2015.

$158 \mathrm{http}: / / \mathrm{www}$. museumoffred.com/faq.html vom 15.11.2015.

159 Ebd. 


\subsection{DAS VIRTUELLE ALS AUSSTELLUNGSOBJEKT}

In Kapitel 3.2.2 dieser Arbeit wurde mit Eduardo Kac eine kategorische kulturelle Verschiedenheit von digitalisierten virtuellen Ausstellungsgegenständen und solchen festgestellt, die originär digital sind. Während erstere nämlich Referenten eines materiellen Originals sind, dessen kultureller Ort meist auch den kuratorischen Umgang mit der virtuellen Kopie diszipliniert, sind letztere in weit weniger eindeutige Verweisstrukturen eingebunden. Und wo Digitalisate einen klaren Vektor der Virtualisierung des Musealen bilden, stehen $a b$ origine digitale Objekte vielmehr im Zeichen einer Musealisierung des Virtuellen. Sie bilden den offensichtlichsten Ausstellungsgegenstand für virtuelle Museen, eben weil sie sich anders gar nicht ausstellen ließen - und es ist eben das kuratorisch-museale Prinzip der conncectedness, mittels dessen man sie sinnhaft zu machen trachtet.

Zwei Angebote sollen im Folgenden exemplarisch betrachtet werden, von denen eines als virtuelles Kunstmuseum auftritt, während das andere eher >ethnographischen < Charakter aufweist: Das Digital Art Museum stellt explizit computergenerierte Kunst aus und versteht sich als eine hybride Plattform aus Internetauftritt und physischer Galerie, welche digitaler Kunst zu öffentlicher Wertschätzung verhelfen soll. Das Internet Archive strebt nichts Geringeres an als die Konservierung virtueller Ressourcen für die digitale Nachwelt - inklusive des kompletten WWW in all seiner Fülle und Veränderlichkeit.

\subsubsection{Das Digital Art Museum (www.dam.org)}

Das Digital Art Museum entstand in den Jahren 1998 bis 2000 als Pionierprojekt für virtuelle Ausstellungen digitaler Kunst, vor allem in Form der Computergrafik. Sein Gründer Wolfgang Lieser gibt im Rahmen eines Interviews auf der Art Cologne im November 2005 an, dass vor allem die prekäre wirtschaftliche Situation von mit digitalen Medien arbeitenden Kunstschaffenden den Anstoß zur Gründung des DAM gegeben habe: Ende der 1990er Jahre habe es für diese kaum Möglichkeiten gegeben, ihre Arbeiten zu verkaufen oder auch nur zu präsentieren - obwohl nicht wenige von ihnen bereits seit Jahrzehnten aktiv waren. Hinter dem DAM stand also zuvorderst die Absicht, das Feld der Computerkunst der Öffentlichkeit vorzustellen und über seine Akteure und Absichten zu informieren. Zu diesem Zweck wurde es nicht als ein rein virtuelles Angebot konzipiert, sondern mit einer physischen Galerie in Berlin gekoppelt, welche die vom $D A M$ vertretenen Künstler nach außen repräsentiert. ${ }^{160}$

Das Museum ist seit 2009 unter zwei separaten Web-Adressen zu erreichen. Unter $w w w$.digitalartmuseum.org findet man die ursprüngliche, nicht mehr aktualisierte

160 Vgl. http://ia700408.us.archive.org/16/items/Wolf_Lieser_about_the_Digital_Art Museum/Interview_DAM.mp4 vom 15.11.2015. 
und in Angebot und Präsentation den frühen 2000er Jahren entsprechende Originalwebsite, die >for historical reference ${ }^{161}$ archiviert und online belassen wurde. Unter www.dam.org lässt sich die aktuelle Webpräsenz ausrufen, deren Startseite zur Wahl zwischen drei Hauptsegmenten auffordert: DAM Museum führt zur Homepage des eigentlichen virtuellen Museums, ${ }^{162}$ DAM Gallery zu einer Infoseite über die physische Galerie in Berlin, ${ }^{163}$ und DAM Award zum Webauftritt des DAM Digital Art Award (DDAA), ${ }^{164}$ mit dem das $D A M$ Digital-Künstler für Lebenswerke oder wichtige Werksgruppen ehrt.

Schon eine erste, oberflächliche Inaugenscheinnahme der Museums-Homepage lässt deutlich werden, dass das $D A M$ mehr als nur Plattform für virtuell-museale Darbietungen sein will. Während unterhalb der die Startseite krönenden Navigationsleiste drei Kacheln unmittelbar Museum und Sammlung betreffen (About Us, Featured Artist und Featured Exhibition), folgt auf diese direkt ein News-Bereich, der ausdrücklich über das $D A M$ selbst hinausblickt. ${ }^{165}$ Dieser weist auf Ausstellungen zu digitaler Kunst im In- und Ausland ebenso hin wie auf Veröffentlichungen, Preisausschreibungen und -verleihungen sowie Interviews und Performances. Das auch über die Navigationsleiste anzusteuernde Nachrichtenarchiv reicht zurück bis zum Start der neuen Museumsseite im Jahre 2009. ${ }^{166}$ Unterhalb des virtuellen Nachrichtentickers bietet die Startseite zwei Zugänge zur Sammlung an. Die Option Explore by artist ermöglicht die Erschließung der Bestände über die Namen von Künstlern. Zu diesem Zweck steht eine seitwärts scrollbare Leiste zur Verfügung, auf der die vertretenen Personen alphabetisch aufgelistet sind - repräsentiert nicht durch Fotografien der Person, sondern Miniaturdarstellungen wichtiger Werke. Die Option Timelines by era and artist öffnet eine Seite, auf der diese Zugriffsleiste in drei Ebenen aufgefächert wird, die entscheidende Perioden in der Entwicklung der Computerkunst abbilden sollen. ${ }^{167}$ Phase 1 befasst sich mit den ab 1956 wirkenden »Pionieren«, denen 1986 die vor allem auf digitale Bilderzeugung fokussierte Phase 2 in Form der »paintbox era« folgt, 1996 dann die Performance- und Installationskunst betonende $»$ multimedia era ${ }^{168}$. Wählt man einen Künstler aus - z.B. den 1950 geborenen und der >Paintbox<-Ära zugeordneten Deutschen Gerhard Mantz - so gelangt man zunächst auf eine mit der Abbildung eines Beispielwerkes und einer Kurzbeschreibung

$161 \mathrm{http}: / / w w w . d i g i t a l a r t m u s e u m . o r g / i n t r o . h t m l ~ v o m ~ 15.11 .2015$.

162 Vgl. http://dam.org/home vom 15.11.2015.

163 Vgl. http://www.dam-gallery.de/index.php?id=9 vom 15.11.2015.

164 Vgl. http://www.ddaa-online.org/ vom 15.11.2015.

165 Vgl. http://dam.org/home vom 15.11.2015.

166 Vgl. http://dam.org/newsarchive/2014 vom 15.11.2015.

167 Vgl. http://dam.org/artists vom 15.11.2015.

168 Ebd. 
seines Schaffens versehene Startseite. ${ }^{169}$ Über drei Reiter kann der zum jeweiligen Künstler gehörende Datensatz dann vertiefend erforscht werden: Unter Artworks / Work Phases finden sich mit kurzen Beschreibungstexten versehene Abbildungen von Kunstwerken, welche in einigen Fällen Phasen oder Serien von Werken zugeordnet sind, die wiederum als Unterkategorien fungieren. Im Falle von Mantz tragen diese die Bezeichnungen Virtual Landscapes (ebendies: gerenderte Landschaftsdarstellungen), Thicked and Clearance (ebenfalls gerenderte Landschaften, hier mit Betonung von Pflanzenwuchs), Virtual Objects (abstrakte Darstellungen imaginärer Gegenstände, die laut Mantz das Spannungsfeld zwischen der materiellen Anmutung und der Nicht-Repräsentativität von Computergrafiken erforschen sollen) und Real Objects (Übersetzungen solcher Gegenstände in physische Plastiken aus verschiedenen Materialien). ${ }^{170}$

Die Einzelansichten der Kunstwerke sind nicht über HTML in die Webseite eingebunden und können daher nicht ohne Umwege vom Nutzer heruntergeladen werden. Interessanterweise ist die einzige zu Computergrafiken gemachte Größenangabe jene über Abmessungen eines physischen Ausdrucks in Zentimetern, nicht etwa die dem Gegenstand eigentlich viel angemessenere über Auflösung oder Dateiformat und -größe. ${ }^{171}$ Tatsächlich scheint das $D A M$ sich insgesamt überraschend schwer mit der Idee zu tun, seine virtuellen Exponate tatsächlich in ihrer Virtualität und digitalen Abstraktheit auszustellen. Nicht nur, dass gezeigte Computergrafiken als digitale Abbilder von physischen Ausdrucken ursprünglich bereits digitaler Originale auftreten: Installationskunstwerke wie die Sexpuppen-Inszenierungen der amerikanischen Künstlerin und Filmemacherin Lynn Hershman Leeson werden in Form jeweils eines einzigen, ausschnitthaften Fotos vorgestellt, ${ }^{172}$ Filme (wie die Dokumentation!Woman Art Revolution! derselben Künstlerin) in jener eines Plakates. ${ }^{173}$

Auch scheint sich das $D A M$ bei der Präsentation seiner Ausstellungsstücke nur begrenzt darüber im Klaren zu sein, was für ein Publikum es eigentlich anzusprechen versucht. Während dem Projekt einerseits die Idee zugrunde liegt, dass digitale Kunst in Konzept und Ausführung noch nicht im Bewusstsein des weiteren Publikums angekommen sei, scheint die virtuelle Ausstellungspraxis häufig ein beachtliches Maß an Kenntnissen beim Besucher vorauszusetzen. Ähnlich wie das 8bit-Museum

169 Vgl. http://dam.org/artists/phase-two/gerhard-mantz vom 15.11.2015.

$170 \mathrm{Vgl}$. http://dam.org/artists/phase-two/gerhard-mantz/artworks-work-phases vom 15.11.2015.

$171 \mathrm{Vgl}$. http://dam.org/artists/phase-two/gerhard-mantz/artworks-work-phases/virtuallandscapes vom 15.11.2015.

172 Vgl. http://dam.org/artists/phase-three/lynn-hershman-leeson/artworks/2005-09 vom 15.11.2015.

173 Vgl. http://dam.org/artists/phase-three/lynn-hershman-leeson/artworks/since-2010 vom 15.11.2015. 
scheint das $D A M$ sich als Knotenpunkt für Enthusiastennetzwerke zu begreifen ohne dabei allerdings in den narrativen >Plauderton $<\mathrm{zu}$ verfallen, der das 8bit-Museum einerseits authentisch und andererseits zugänglich macht. Die einzige Featured Exhibition des DAM ist im November 2015 eine direkt der regulären Sammlung entnommene Zusammenstellung von Plotter-Grafiken aus den 1960er Jahren - versehen mit dem Kommentar, dass diese einen der ersten Schritte in der Entwicklung der digitalen Kunst darstellten. ${ }^{174}$ Eine technikgeschichtliche Einordnung findet schlicht nicht statt - und wer kein Vorwissen darüber mitbringt, worum es sich bei einem Plotter überhaupt handelt (nämlich um eine computergesteuerte Zeichenmaschine, die einen Stift über eine Papierbahn führt), dem wird kein Zugang zum Ausgestellten geboten.

Unter der Rubrik Essays bietet das DAM schließlich eine kleine Bibliothek von theoretischen Texten an. Auch hier handelt es sich um Literatur für >Fortgeschrittene`, die kaum zur Einführung des Laien in die Geschichte und kulturelle Programmatik digitaler Kunst herhalten kann. Ein Blick auf die Webseite der zum DAM gehörigen physischen Galerie in der Neuen Jakobstraße in Berlin lässt schließlich deutlich werden, dass der Schwerpunkt des $D A M$ eher die Präsentation und Vermarktung von Künstlerpersönlichkeiten zu sein scheint denn die Aufarbeitung der Kunstgeschichte des Computers. ${ }^{175}$ Von Oktober 2015 bis Januar 2016 widmet sich die Berliner Galerie in einer Ausstellung animierten GIF-Grafiken - die verblüffenderweise nur im physischen Haus zu sehen ist und online nur in Form von nicht-animierten Standbildern gezeigt wird. Diese tragen nicht minder verblüffenderweise jeweils eine Angabe zur »Auflage« - offenbar wird die in der Galerie gezeigte digitale Kunst zu Verkaufszwecken künstlich verknappt. ${ }^{176}$ Ob diese artifizielle Übertragung der Kategorie des Originals auf den Ausstellungsgegenstand des DAM nun lediglich geschickte Marketingstrategie oder doch cleverer Kommentar über den wesentlichen Unterschied zwischen klassisch >analogen eine damit verbundene Notwendigkeit zum Umdenken in kulturellen Gewohnheiten) ist, sei dahingestellt. Als Medienpraxis verweist er in jedem Falle darauf, wie sehr virtuelle Museen immer noch um >eigene Authentizitätsstrategien ringen - und wie groß Gefahr und Versuchung sein können, in Cargo-Kultismus zu verfallen, bzw.: auf digitale Information unanwendbare Methoden der auratischen Aufladung aus der physischen Ausstellungstätigkeit in die virtuelle importieren zu wollen.

174 Vgl. http://dam.org/exhibitions/plotter-drawings-from-1960s vom 15.11.2015.

175 Vgl. http://www.dam-gallery.de/index.php?id=7 vom 15.11.2015.

176 Vgl. http://www.dam-gallery.de/index.php?id=51\&tx_ttnews[tt_news]=409\&cHash= 7f42270ece82faa9dedf15d99676570a vom 15.11.2015. 


\subsubsection{Das Internet Archive (www.archive.org)}

Das Internet Archive entstand im Jahre 1996 zunächst als eine gemeinnützige Organisation mit dem Vorsatz, »historians, scholars, people with disabilities, and the general public « den Zugriff auf »collections that exist in digital format « in Form einer Bibliothek von Online-Texten zu ermöglichen. ${ }^{177} 1999$ weitete das Projekt seine Sammeltätigkeit über Texte hinaus auch auf Tondateien, bewegte und unbewegte Bilder sowie - mittlerweile womöglich das wichtigste und hier noch gesondert $\mathrm{zu}$ diskutierende Sammlungsgebiet von archive.org - Webseiten aus. Der Kernauftrag des Internet Archive ist seitdem schlechthin die Bewahrung des digitalen Kulturerbes der Menschheit. Gerechtfertigt wird dieser Anspruch in Anlehnung an traumatische Momente aus der Geschichte physischer Medien:

Libraries exist to preserve society's cultural artifacts and to provide access to them. If libraries are to continue to foster education and scholarship in this era of digital technology, it's essential for them to extend those functions into the digital world. Many early movies were recycled to recover the silver in the film. The Library of Alexandria - an ancient center of learning containing a copy of every book in the world - was eventually burned to the ground. Even now, at the turn of the 21 st century, no comprehensive archives of television or radio programs exist. But without cultural artifacts, civilization has no memory and no mechanism to learn from its successes and failures. And paradoxically, with the explosion of the Internet, we live in what Danny Hillis has referred to as our »digital dark age « ${ }^{178}$

Angesichts der Gefahr, dass sich vergangene Biblioklasmen an digitaler Information wiederholen könnten, will archive.org dem Internet seine Flüchtigkeit nehmen: Es gelte, so die about-Seite des Projekts, das Entschwinden des WWW und anderer »digital geborener ${ }^{179}$ Inhalte in die Vergangenheit zu verhindern. Das Internet Archive kollaboriert zu diesem Zweck mit namhaften Kulturinstitutionen wie der Library of Congress und dem Smithsonian Museum und stellt seine Bestände zur freien Weiterverwertung durch Jedermann bereit. Das Selbstbild ähnelt also augenscheinlich jenem Europeanas. Während Europeana allerdings die Digitalisierung materieller Kulturgüter vorantreiben möchte und vor allem ein Abruf-Paradigma in den Vordergrund stellt, das Nutzern räumlich weit entfernte und nicht akut vom Verschwinden bedrohte Kulturgegenstände naherücken lässt, zielt archive.org in erster Linie auf eine Speicherfunktion ab. Archive.org sammelt das, was gegenwärtig schon digital vorhanden und verfügbar ist - es aber morgen womöglich nicht mehr sein könnte.

177 Vgl. https://archive.org/about/ vom 02.01.2016.

178 Ebd.

179 Ebd. 
Insofern betreibt das Internet Archive gewissermaßen eine Umkehr dessen, was klassischerweise Museumsvirtualisierung ausmacht. Es will digitale Objekte nach eigener Aussage »from ephemera to artifact $\aleph^{180}$ verwandeln. Dies ist natürlich im strengen medientheoretischen Sinne unmöglich: Digitale Daten bleiben digitale Daten unabhängig davon, auf welche Dauern und Fristen die Umstände ihrer Speicherung abzielen. Nichtsdestoweniger spricht aus dieser Zielsetzung ein Kulturverständnis Arendtscher Prägung: Das im obigen langen Zitat erwähnte Angewiesensein von Gesellschaften auf historische Artefakte, um aus den Erfolgen und Fehlschlägen der Geschichte lernen zu können, verweist ja auf genau jenen von Hannah Arendt diagnostizierten Mechanismus, in welchem sich Kultur durch die Schaffung materieller Hinterlassenschaften perpetuiert. In diesem Sinne will archive.org also digitale Information in einen Zustand überführen, der ihr normalerweise zutiefst fremd ist: nämlich jenen des Abgeschlossen- und `Hergestellt`-Seins. Über die Bewahrung kultureller Kontinuität hinaus begründet archive.org diese Mission mit zwei Rechten jeder zivilen Öffentlichkeit, die es zu ebenfalls zu erhalten gelte: einem »right to know«, und einem »right to remember $«$. ${ }^{181}$

Das >Recht auf Wissen den, Regierungsunterlagen einzusehen. Paradoxerweise habe die gesamtgesellschaftliche Ausweitung der Internetnutzung diese Form der Einsichtnahme nicht etwa einfacher, sondern schwieriger gemacht. Vor dem Aufkommen des WWW bedeutete sie nämlich üblicherweise, dass man sich physisch zu einem Amtsgebäude bemühen musste, wo die entsprechenden Dokumente auslagen. Die Gesetzgebungen hätten diesem Umstand Rechnung getragen und seien zumindest in den USA nicht allzu restriktiv gewesen - der Aufwand regulierte die Nachfrage von allein nach unten. Unter dem Eindruck digitaler Informationsverbreitung gebe es einen spürbaren Trend unter Regierungen, den Zugriff auf öffentliche Aufzeichnungen erschweren zu wollen, weil der potenzielle Leserkreis nicht länger regional einzugrenzen ist. ${ }^{182}$

Das >Recht zu erinnern` bezieht sich auf die Bewahrung politischer Geschichte und damit auf die Möglichkeit einer Bevölkerung, ihre Regierung und Beamten für Verfehlungen zur Rechenschaft zu ziehen. Eine Gesellschaft, die ihre Kommunikation mittel Papier abwickelt, brauche aus diesem Grunde Bibliotheken und Archive. Eine Gesellschaft, die ihre Kommunikation ins Internet verlagert, brauche naheliegenderweise auch Internet-Bibliotheken und Internet-Archive, welche sie abspeichert und für die Zukunft verfügbar hält. Archive.org zitiert Steward Brand, den Präsidenten der Long Now Foundation, mit dem Wunsch, die amerikanische Öffentlichkeit

180 Ebd.

181 Ebd.

182 Vgl. ebd. 
möge eines Tages mit derselben Wertschätzung auf das Internet Archive blicken, die sie heute ihren öffentlichen Bibliotheken entgegenbringt. ${ }^{183}$

Über diese politischen Implikationen hinaus ist archive.org aber auch akademischen Interessenlagen verschrieben. Das Internet zu erhalten sei notwendig, um seine technische und ästhetische Entwicklung nachvollziehen zu können - und den Einfluss, den es auf die Welt ausübt, in der es kommunikativ genutzt wird. Das Web, so die Prämisse, schreibe sich unserer Kultur auf zahllosen Ebenen ein und verändere nicht zuletzt unsere Sprache und Wirtschaftsordnungen. Vor diesen Hintergrund soll das Internet Archive es Forschern ermöglichen, herauszuarbeiten, was das Netz »uns über uns selbst erzählt«. ${ }^{184}$

Insofern folgt das Angebot der Netzlogik digitaler Medien und damit tatsächlich einem eher musealen als einem archivarischen Auftrag. Allerdings bedient sich auch das Internet Archive zunächst einer kategorial sortierten Kopfleiste, um die Sammlung erschließbar zu machen. Die sechs durch Symbole ausgewiesenen Oberbereiche sind hier Web (diese Rubrik wird noch gesondert zu diskutieren sein), Texts, Video, Audio, Software und Image. Jede dieser Rubriken (mit der Ausnahme von Web) kann auf drei Arten durchsucht werden: über eine Textsuche mit Eingabefeld, eine alphabetische Liste von Schlagworten und Sprachen, oder über individuelle >Sammlungen . Die Sammlungen werden auch hier in Kachelform angezeigt: Jede Kachel enthält den Namen der entsprechenden Sammlung, eine Angabe zur Anzahl der in der Sammlung enthaltenen Items sowie in einigen Fällen eine kleine Illustration. Die Kacheln lassen sich nach Anzahl der Ansichten, Veröffentlichungsdatum, Titel und Namen ihrer Sammlungs->Kuratoren 〈 jeweils auf- oder absteigend sortieren.

Bei vielen dieser Sammlungen handelt es sich um Zusammenstellungen von Objekten, Texten oder Bildern aus physischen Einrichtungen, die mit Archive.org kooperieren. So findet man unter Texts zum Beispiel Zusammenstellungen von Digitalisaten aus den Bibliotheken der Duke University in Durham (North Carolina) oder aus der San Francisco Library. ${ }^{185}$ Die Rubrik Images präsentiert unter anderem Reproduktionen aus den Sammlungen des Metropolitan Museum of Art und des Brooklyn Museum, ${ }^{186}$ während unter Video aktuelles Bildmaterial der NASA zu finden ist. ${ }^{187}$ Während einzelne Bereiche anbieterseitig kuratiert sind und die Kopfleiste zu jeder Rubrik Features ausweist (z.B. Animation \& Cartoons im Bereich Video oder Children's Library im Bereich Texts), wird ein beträchtlicher Teil des Angebotes von Anwendern zusammengetragen und organisiert. In jedem der fünf auf diese Weise organisierten Sammlungsbereiche gibt es eine Community-Sammlung, welche alle

183 Vgl. ebd.

184 Ebd.

$185 \mathrm{Vgl}$. https://archive.org/details/texts?\&sort=-downloads\&page=2 vom 02.01.2016.

186 Vgl. https://archive.org/details/image vom 02.01.2016.

187 Vgl. https://archive.org/details/movies vom 02.01.2016. 
Objekte vereinigt, die von Privatleuten auf Archive.org hochgeladen wurden und ihrerseits das Repertorium für zahllose Nutzer-Sammlungen bildet. Das Internet Archive sammelt nahezu alles, solange es digital vorhanden und nicht durch Urheberrechte geschützt ist: Unter Videos findet man Filmklassiker mit erloschenem Copyright (z.B. F.W. Murnaus Nosferatu - Eine Symphonie des Grauens oder D.W. Griffiths Birth of a Nation) ebenso wie B-Movies (u.a. Ed Woods Plan 9 from Outer Space und William Castles House on Haunted Hill), als aber auch Mitschnitte historischer und zeitgenössischer Nachrichtensendungen, Aufnahmen der Predigten von Geistlichen verschiedener Religionen und amerikanische Kurzfilme zur Gesundheitsaufklärung aus den 1950er Jahren. Eine der gefragtesten Sammlungen im Frühjahr 2016 enthält Videomaterial über den Irakkrieg. ${ }^{188}$ Im Bereich Audio finden sich nicht nur Radioprogramme unterschiedlichster Art (von historischer Berichterstattung über Hörspiele bis hin zu aktuellem Webradio), sondern auch Sprachkurse, Kopien seltener Musikpressungen, Konzert-Bootlegs sowie die von Amateursprechern eingespielten Hörbücher des LibriVox-Projektes. ${ }^{189}$

Besonders bemerkenswert ist der Bereich Software, der tatsächlich in erster Linie Computerspielen gewidmet ist: Dieser enthält nicht nur Kopien klassischer PC-, Konsolen- und Arcade-Spiele, sondern auch die zugehörigen Emulationssoftwares, die für deren Ausführung auf modernen Computern notwendig ist und direkt in die Webseite eingebaut wurde. Es ist somit möglich, diese Spiele direkt im Browser zu spielen. ${ }^{190}$ Das Internet Archive lässt seine Besucher also nicht nur Exponate akquirieren und kuratieren, es hebt zugleich auch alle Distanz zwischen Betrachter und Ausstellungsstück auf, die das klassische Museumsdispositiv auszeichnet - es darf nunmehr buchstäblich mit ihnen gespielt werden.

Der interessanteste Sammlungsbereich von Archive.org ist indes die Rubrik Web. Hier findet der Nutzer weder Sammlungsfelder noch ein Schlagwortverzeichnis, sondern lediglich das Eingabefeld einer Suchmaschine namens Wayback Machine. Seit seiner Gründung im Jahre 1996 kooperiert das Internet Archive mit dem inzwischen von Amazon aufgekauften Analytics-Dienstleister Alexa Internet, um Webseiten zu archivieren - und zwar mit den Methoden der Big Data-Ökonomie. Mithilfe von Webcrawler-Programmen wurden in den ersten fünf Jahren des Projektes 100 Terabytes an öffentlich einsehbaren HTML-Seiten kopiert und archiviert, ${ }^{191}$ gegenwärtig lädt das Suchfeld der Wayback Machine zum Stöbern in über 462 Milliarden Webseiten ein.

Dabei funktioniert sie entschieden anders als Suchmaschinen, die das zeitgenössische Web erschließen sollen. Die Wayback Machine betreibt weder eine Textsuche,

188 Vgl. https://archive.org/details/movies?\&sort=-downloads\&page=1 vom 02.01.2016.

189 Vgl. https://archive.org/details/audio vom 02.01.2016.

$190 \mathrm{Vgl}$. https://archive.org/details/software vom 02.01.2016.

191 Vgl. https://archive.org/about/faqs.php\#The_Wayback_Machine vom 03.01.2016. 
noch ist sie in irgendeiner Form zu lernen imstande. Tatsächlich versteht sie nur eine einzige Angabe - nämlich URL-Adressen. Gibt man eine solche in das Suchfeld ein und hat das Internet Archive Webseiten unter der betreffenden Domain archiviert, so öffnet sich eine Kalenderseite, auf der Schnappschüsse der Seite zu unterschiedlichen Zeitpunkten ihres Bestehens ausgewählt werden können. Um nämlich der Veränderlichkeit des WWW gerecht werden zu können, werden Webseiten nicht nur einmal, sondern in einigermaßen regelmäßigen Abständen immer wieder archiviert. Dabei erwischen die Webcrawler natürlich nicht jede Seite, die jemals online war - und auch die gespeicherten sind nicht immer vollständig. Häufig fehlen z.B. Bilder, die nicht unter derselben Serverdomain abgespeichert waren wie die Webseite selbst, oder auch Flash- und Java-Applikationen, die von Software auf anderen Hostrechnern abhängig waren. Darüber hinaus kann Archive.org keine Seiten kopieren, die hinter Passwortschranken verborgen sind - E-Mails und Chatverkehr, aber auch Kundenkonten auf kommerziellen Webseiten (das gesamte sog. deep web) sind dementsprechend geschützt. ${ }^{192}$

Trotz solcher Hürden muss die Legitimität einer solchen digitalen Sammelwut natürlich hinterfragt werden. Das Internet Archive sieht sich grundsätzlich im Recht damit, jede öffentlich sichtbare Seite im Web zu kopieren und verfügbar zu halten wer seine Inhalte nicht archiviert sehen möchte, der kann dies über einen Eintrag in der sog. robots.txt-Datei der Site verhindern. Die im Schnitt extrem kurze Lebensspanne von Webseiten mache es unmöglich, die Archivierungstätigkeit differenzierter zu organisieren und über die Bewahrungswürdigkeit von Seiten individuell zu entscheiden:

The Archive collects Web pages that are publicly available, the same ones that you might find as you surfed around the Web. We do not archive pages that require a password to access, pages that are only accessible when a person types into and sends a form, or pages on secure servers. Pages tagged for robots.txt exclusion (for User-Agent: ia_archiver) by their owners are excluded from the Wayback Machine. [...] Given the rate at which the Internet is changing the average life of a Web page is only 77 days. If no effort is made to preserve it, it will be entirely and irretrievably lost. Rather than let this moment slip by, we are proceeding with documenting the growth and content of the Internet, using libraries as our model. ${ }^{193}$

Auch Archive.org steht also in der auf Vannevar Bush zurückgehenden Tradition der Hypertextgeschichte, sich in der historischen Nachfolge der Bibliothek zu sehen, und nicht etwa in jener des Museums. Jedoch hat die von der Wayback Machine erschlossene Sammlung von Webseiten musealen Charakter nicht nur in ihrer Vernetztheit,

192 Vgl. ebd.

193 Ebd. 
sondern auch in ihrem pädagogischen Anspruch. Es geht hier nämlich um Wiederherstellung einer historischen Umwelt, die sich nun nicht im physischen Raum, sondern eben im Cyberspace ausbreitet:

Visitors to the Wayback Machine can type in a URL, select a date range, and then begin surfing on an archived version of the Web. Imagine surfing circa 1999 and looking at all the Y2K hype, or revisiting an older version of your favorite Web site. The Internet Archive Wayback Machine can make all of this possible. ${ }^{194}$

Das von Archive.org angebotene Erlebnis soll eben nicht das eines Blätterns in digitalen Archivalien sein, sondern das einer Zeitreise in kommunikative Situationen einer Vergangenheit, die ein nicht unerheblicher Teil der Nutzer noch selbst erlebt haben dürfte. Insofern steht es im Zeichen eines Versprechens von Virtualität-als-Hyperrealität. Das archivierte Web ist nicht die mittelbare, inszenierte Anmutung einer >echten` bzw. >authentisch` rekonstruierten Vorzeit. Vielmehr ist es das Echte - die bitidentische Kopie des Webs, wie es sich tatsächlich dargestellt hat, ungefiltert durch kuratorische Autorschaften. Die Ordnung der Sammlung ist nicht die einer geplanten Ausstellung, sondern tatsächlich jene, die ihr von der Geschichte hinterlassen wurde. Die kulturelle Wahllosigkeit der archivierenden Crawler-Software wird zum Garanten der Authentizitätserfahrung - verbunden mit der Tatsache, dass die Nutzer selbst Mitgestalter des Ausstellungsgegenstandes gewesen sein könnten. Wer nach 1996 im Internet gepostet, gebloggt oder sich in irgendeiner Form geäußert hat, der kann sich auf Archive.org selbst im vollendeten Präteritum erleben - und sich auch sogleich wieder selbst vergegenwärtigen.

\subsection{GRENZGEBIETE DES MUSEALEN UND VIRTUELLEN}

Nachdem dieses Fallstudienkapitel sich bisher ausdrücklich solchen virtuellen $\mathrm{Mu}-$ seumsprojekten gewidmet hat, die im WWW mit konservatorischem Anspruch auftreten, sollen nun abschließend noch drei Phänomenbereiche betrachtet werden, die nicht direkt dem Komplex >Museumsvirtualisierung « zugehörig sind, jedoch weitreichende Implikationen für diesen bergen. Im Zusammenhang mit dem Dienst pinterest.com soll zunächst nach der Rolle `kuratorischen` Denkens und Handelns normaler User im Umgang mit Web-Inhalten gefragt werden. Anschließend werden Bildersuchmaschinen in den Blick genommen - und mit ihnen die Frage, was es für unser digitales und digitalisiertes Kulturerbe bedeutet, wenn Software nicht mehr nur über Schlagworte und Zugriffsmuster nach Inhalten zu suchen vermag, sondern Bildmaterial tatsächlich zu >sehen` und nach inhaltlichen Merkmalen zu verwalten imstande 
ist. Zuletzt wird die Entwicklung hin zu ubiquitous computing und augmented reality im Hinblick darauf diskutiert werden, wie die Allgegenwart tragbarer, internetfähiger Kleinstcomputer in Form von Handys und Tablets sowohl die Institution Museum als auch ihre Virtualisierung affiziert.

\subsubsection{Das Alltägliche kuratieren: www.pinterest.com}

Als >Musealisierung des Virtuellen` wurde in dieser Studie wiederholt die Übertragung kuratorischer Arbeitsprinzipien (also der Vernetzung von Objekten zu Aussagesystemen) auf digitale Daten bezeichnet. Während in den bisherigen Fallbeispielen jedoch Angebote diskutiert wurden, die ganz ausdrücklich mit musealem oder zumindest kommemorativem Anspruch auftreten - also zuvorderst Virtualisierungen des Musealen darstellen - erscheint es nun sinnvoll, Mechaniken und Strategien des virtuellen Kuratierens dort in den Fokus zu rücken, wo die Kategorie der Musealität gerade nicht beschworen wird.

Pinterest wurde im Jahre 2008 von Paul Sciarra und Ben Silbermann ins Leben gerufen. Sciarra hatte im August desselben Jahres seinen Job bei der New Yorker Risikokapitalgesellschaft Radius Capital gekündigt, Silbermann etwa zeitgleich seine Anstellung bei Google. Gemeinsam mit einem dritten Teilhaber, der nur wenige Wochen Teil des Unternehmens bleiben sollte, gründeten die beiden Studienfreunde eine Firma namens Cold Brew Labs, deren erstes Produkt die iPhone-Applikation Tote war. Tote sollte es Nutzern ermöglichen, beim Einkaufsbummel die Produktkataloge von Geschäften in der Umgebung einzusehen. Die App erwies sich als Flop, weil die technische Infrastruktur von Apples >App Store` nicht leistungsfähig genug war, um einer signifikanten Anzahl von Geschäften die Nutzung der Plattform zu ermöglichen (vgl. Carlson 2012). Silbermann machte jedoch bei der Auswertung von Telemetriedaten der Anwendung eine interessante Beobachtung über die Art, wie sie von ihren Anwendern genutzt wurde: Viele von ihnen verwendeten sie vorrangig, um sich selbst Bilder von Produkten zu schicken und buchstäbliche »Sammlungen« (ebd.) anzulegen. Cold Brew Labs' nächstes Produkt sollte um dieses emergente Verhalten herum konzipiert und diesmal für das WWW entwickelt werden, um nicht den Einschränkungen einer existierenden proprietären Plattform unterworfen $\mathrm{zu}$ sein (vgl. ebd.).

〉Shopping〈, so lautete die Feststellung, sei zwar eine zielgerichtete Tätigkeit (deren angestrebtes Ergebnis der Erwerb von Waren ist), zugleich aber in seiner Zielsetzung immer unspezifisch: Kunden suchen meist nicht nach einem bestimmten Produkt, sondern nach einer ungefähren Produktgruppe wie `Kleidern` oder `Schuhen. Die neue Software sollte es daher ihren Anwendern erlauben, Bilder von Dingen in »Eimern« (ebd.) abzulegen, die solche Kategorien und Interessenfelder repräsentieren - und dabei ganz ausdrücklich nicht mehr nur für die Situation des Einkaufens 
verwendbar sein. Den Namen Pinterest erhielt die neue Software am Erntedankfest 2009 von Silbermanns Lebensgefährtin (vgl. ebd.).

Im Juni 2015 beschrieb Ben Silbermann Pinterest anlässlich der vom Wirtschaftsmagazin Fortune ausgerichteten Fortune Brainstorm Tech-Messe nicht länger als ein soziales Netzwerk, sondern vielmehr als einen »catalog of ideas« (Nusca 2015). Der Dienst unterscheide sich von Facebook, Twitter und Konsorten vor allem in seiner Adressatenstruktur. Wo diese ihren Nutzern nämlich eine Plattform böten, Inhalte zum >liken` durch andere Anwender feilzubieten, sei Pinterest vor allem auf die eigenen Bedürfnisse des individuellen Nutzers ausgerichtet, dem es die für ihn jeweils >richtigen〈 Ideen zuzuführen hieße: »Our hope is that when we show you the right idea, you go out and do that thing« (ebd.). Zum Zeitpunkt dieser Statements beschäftigte Pinterest über 500 Mitarbeiter und war mit einem geschätzten Wert von 11 Milliarden US-Dollar eines der bestfinanzierten Technologie-Startups der Welt (vgl. ebd.).

Dabei ist die Funktionalität der Webseite grundsätzlich eine recht unspektakuläre. Pinterest erfordert zunächst eine Registrierung - für Surfer ohne eigenes Nutzerkonto ist die Webpräsenz nicht einsehbar. ${ }^{195}$ Wer sich für ein kostenloses Nutzerkonto entscheidet, der darf - wie der Name schon sagt - virtuelle Pinnwände anlegen, auf denen virtuelle Fundstücke gesammelt werden können. Gängige Praxis (allerdings nicht etwa Vorschrift) ist, dass Nutzer einzelne Pinnwände themenspezifisch kuratieren. Pinterest verfügt dabei über eine für soziale Netzwerke sehr untypische Nutzerdemographie: Von über 10 Millionen registrierten Anwendern im Jahre 2012 waren mehr als $80 \%$ weiblich, und die größte Altersgruppe unter den Nutzern war die im Bereich von 25 bis 34 Lebensjahren, die ein gutes Drittel der Gesamt->Bevölkerung stellte. Als die verbreitetsten Pinnwand- bzw. board-Themen unter amerikanischen Nutzern wurden dabei die Bereiche >crafts`, >gifts`, >hobbies/leisure`, >interior design` sowie >fashion designers/collections` identifiziert. Während das amerikanische Publikum materielle Objekte und Tätigkeiten ins Zentrum seiner Pinterest-Erfahrung stellte, nutzten britische Anwender die Plattform zum Austausch von Informationen über abstraktere Interessengebiete: Während auch hier die >crafts` prominent auftauchten, waren andere >trendende $<$ Themenfelder `venture capitalく, >web analytics und `marketing`(vgl. Crook 2012).

Pinterest-User können nicht nur ihre eigenen boards gestalten, sondern auch denen anderer Nutzer folgen und so über deren neueste `Exponate〈 informiert werden. Hierzu stehen ihnen zwei wichtige Werkzeuge zur Verfügung: der Pin und der Repin. Ein Pin ist die Erstellung eines genuin neuen Ausstellungsgegenstandes. Es handelt sich um ein betiteltes und zuweilen kommentiertes Bild, das vom Anwender auf die

195 Aus diesem Grund wird hier auf Fußnoten mit Hinweisen auf einzelne Seiten verzichtet. Dem interessierten Leser sei angeraten, sich einen eigenen Account zu erstellen und die Funktionalitäten des Dienstes selbst auszuloten. 
Plattform hochgeladen wird - sei es vom eigenen Rechner oder von einer anderen Webseite. Ein Repin hingegen ist die Kopie eines Pins vom Board eines anderen Nutzers. Repins sind - um Silbermanns Rhetorik aufzugreifen - gewanderte >Ideen`, die dupliziert, bewegt und neu kontextualisiert worden sind. Tatsächlich machen Repins das Gros des Kommunikationsvolumens auf Pinterest aus - 2012 waren über 80 $\%$ der Pinnwandinhalte nicht originär neu, sondern aus den feeds anderer Nutzer übernommen (vgl. ebd.).

Insofern weist Pinterest also die zentralen Merkmale des Imaginären Museums auf: Seine >Ausstellungsstücke` sind beliebig reproduzierbar und assoziierbar, und die einzigen Regeln der Reproduktion und Assoziation sind jene, die sich die Nutzer selbst auferlegen. Zugleich ist Pinterest auch - wenngleich Silbermann die Plattform nicht als ein soziales Netzwerk verstanden wissen will - eine Bühne für soziale Szenographien, die hier allerdings im Gegensatz zum Museum nicht zentral geplant und arrangiert werden, sondern emergent aus den Vektoren der Kommunikation entstehen, die Pinterest seinen Nutzern zur Verfügung stellt. Zu diesen gehört zuvorderst eben die Mechanik des >Folgens` und Zitierens in Form von Repins. Zugleich aber ist es den Nutzern auch erlaubt, Pins und Repins zu kommentieren - und eine der neusten Funktionen im Frühjahr 2016 ist ein eingebautes Messaging-System. ${ }^{196}$

Kuratieren wird also von der Kerntätigkeit materieller Kulturvermittlung zur Methode gemacht, die Kommunikation über Alltagsgegenstände zu organisieren - und von einem Top-Down-Prozess zu einem emergenten Ablauf in einer vielpoligen Akteurskonstellation. Insofern lässt sich Pinterest also durchaus als eine Übertragung des musealen Paradigmas auf die Alltagswelt lesen: Das Kuratieren lässt Gebrauchsgegenstände wie z.B. Kleidung und Möbelstücke vor einem Publikum sichtbar werden und belegt sie mit einer Aura der Begehrlichkeit und nicht zuletzt auch des Authentischen - sind es doch >echteく Menschen, die hier >echteく Begeisterung für >echteく Dinge teilen. Indes ist das Erbe der Shopping-App Tote, aus der Pinterest entstanden ist, durchaus noch lebendig. Neben den Millionen privater Nutzer, die Inhalte aus Interesse und zum Vergnügen teilen, weiterverbreiten und kommentieren, sind auch kommerzielle Akteure vertreten, die Pinterest als Vermarktungsplattform nutzen. Schon 2012 listete die Marketing-Webseite Socialfresh mehr als 250 Marken auf, die Pinterest als >viralen`Werbekanal nutzten (vgl. Keath 2012), und Pinterest selbst umgarnt große wie kleine (und damit short head- ebenso wie long tail-)Unternehmen mit »Erfolgsstories« von Händlern und Dienstleistern, die mittels Pinterest Kunden und potenzielle Kunden via Pins und Repins für sich werben lassen. ${ }^{197}$

Insofern betreiben Pinterest-Nutzer eine im doppelten Sinne hochsubjektivierte Form von >Ausstellungstätigkeit $<$ : Auf ihren Pinnwänden präsentieren sie nicht nur virtuelle Mini-Museen ihrer eigenen Vorlieben, Interessen und Identitätsentwürfe -

196 Vgl. https://about.pinterest.com/de/messages vom 05.01.2016.

197 Vgl. https://business.pinterest.com/de/success-stories vom 05.02.2016. 
sie verknüpfen diese Selbstdarbietung zugleich mit einer latenten (oder eben virtuellen) Möglichkeit der Aneignung. Vieles von dem, was dem Besucher auf Pinterest begegnet, darf man nicht nur telepräsent bewundern, sondern umgehend zum Besitz und Gebrauch bestellen. Händler-Schaltflächen sind in die Plattform eingebunden. Zum Virtualitätsgefüge, das uns im virtuellen Museum begegnet, bietet uns Pinterest das fotografische Negativ an: Während virtuelle Museen das materielle Objekt zu virtualisieren trachten, will Pinterest letztlich die Aktualisierung virtueller Vorlagen in der physischen Welt anstoßen - sei es, indem Nutzer ein Handwerksprojekt nachahmen, einen Modestil imitieren, Rezepte nachkochen, oder indem sie schlicht etwas kaufen, das sie zuvor auf Pinterest gesehen haben.

Die Pinnwände werden vor diesem Hintergrund zu >Museen` des individuellen Konsumverhaltens, die aber paradoxerweise dem Konsum nicht nachfolgen, sondern vorausgehen. Das `kuratorischeく Präsentieren virtueller Abbilder von Dingen wird in ähnlicher Weise zum Planspiel für den Einkauf, wie der von Ulfert Tschirner geschilderte Umgang mit Karteikarten im Germanischen Nationalmuseum des Hans von Aufseß die Ausstellung vorwegnimmt. Diese Beobachtung stößt uns abermals auf die Tatsache, dass auch Museen zukunftsorientiert sind, dass sie nicht nur vergangene Weltordnungen und Sinnsysteme konservieren, sondern auch zukünftige gestaltbar zu machen versuchen. Die Weltordnung und das Sinnsystem, das ein Dienst wie Pinterest verhandelt, unterliegt indes keiner pädagogischen oder politischen Kontrolle mehr - und ist keinem Bildungsideal verpflichtet. Stattdessen ist sein Kosmos ein konsumistischer und fragmentierter, in dessen Zentrum nicht etwa die Idee einer geteilten Identität und eines gemeinsamen Erbes steht, das von demokratisch legitimierten Institutionen bewahrt werden müsse, sondern die vom Subjekt als Baukastensystem, das aus der individuellen Aneignung der materiellen Welt hervorgeht. Diese Beobachtung wird museumsdidaktisch relevant angesichts des Umstands, dass Phänomene wie die Nutzergalerien des Google Art Project bereits in Ansätzen die Methodik solchen digitalen Kuratierens durch die Endnutzer auf unser materielles Kulturerbe übertragen. Eine zentrale Herausforderung für eine zukünftige Museumspädagogik wird es sein, die Werkzeuge kommerzieller Angebote für die Kulturvermittlung nutzbar zu machen, ohne die Logik des Marktes zum Leitbild kultureller Sinnbildung werden zu lassen.

\subsubsection{Sehende Software: Reverse Image Searches}

In den Ausführungen zu den automatisierten Ordnungsmechanismen des World Wide Web (Suchmaschinen, Empfehlungssysteme, usw.) ist in der vorliegenden Studie wiederholt deren >Blindheit` für kulturelle Inhalte und ihre Unfähigkeit hervorgehoben worden, die wechselseitigen Bezüglichkeiten der von ihnen verwalteten Gegenstände tatsächlich zu >verstehen`. Software, so wurde festgestellt, >sieht` nicht, 
stellt keine Semiosen (insbesondere keine wilden) an und ist sich über jede Form von kulturellen Zusammenhängen nur insofern im Klaren, wie diese sich in mathematische Koeffizienten übersetzen lässt - so eben z.B. durch das Zugriffsverhalten von Nutzermassen.

Es wurde ferner festgestellt, dass jedes auf einem Computerbildschirm angezeigte >Bild ‘ tatsächlich die technische Aktualisierung eines Textes ist, der rein numerische Farb- und Positionskoordinaten einander zuordnet. Entsprechend sind also auch Computerbilder völlig quantifizierte digitale Objekte und im Umfang ihres Informationsvolumens ebenso vermessbar wie in dessen Beschaffenheit. Genau wie sich ein digitaler Text auf bestimmte Worte oder Zeichenfolgen hin durchsuchen lässt, kann dementsprechend auch eine Bilddatei auf Farben, Muster und ähnliches hin abgetastet werden.

Damit ist angezeigt, dass die Suche nach Bildern nicht nur über Metadaten, sondern auch über die in den Bilddateien selbst enthaltene Information abgewickelt werden kann. Man spricht hier vom sogenannten content based image retrieval (vgl. Belongie, Carson, Greenspan u. Malik, 1998). Der offensichtlichste Vorteil eines solchen Abrufmechanismus für Bilddaten ist die Tatsache, dass der komplette Arbeitsschritt der Katalogisierung von Inhalten und der Erstellung von Metadaten gegenüber einer schriftlichen Textsuche entfällt - ihr offensichtlichster Nachteil betrifft die Schwierigkeiten bei der Eingabe von Suchanfragen, denn ein schriftliches Eintippen von Bildschirmkoordinaten und Farbwerten wäre selbst bei niedrigauflösenden Bilddateien kaum praktikabel (vgl. ebd.: 1).

Die erste content-basierte Bildersuchmaschine für die Massennutzung ging im Jahre 2008 in Form des Dienstes TinEye online. Diese vom kanadischen Unternehmen Idée, Inc. entwickelte Software war ursprünglich vor allem für kommerzielle Anwender konzipiert und sollte es diesen ermöglichen, die Verbreitung ihrer Firmenlogos und ihres Werbematerials im Web zu verfolgen und zu analysieren. Zugleich sollte potenziellen Konsumenten ein Werkzeug zur Verfügung gestellt werden, um ein Produkt anhand eines Schnappschusses ausfindig zu machen (vgl. George-Cosh 2008). Dabei gestaltet sich der Suchablauf anwenderseitig extrem simpel: Auf tineye.com kann ein Bild von bis zu 20 Megabytes Dateigröße entweder vom Computer des Nutzers hochgeladen oder ein bereits im Web vorhandenes per URL verlinkt werden. TinEye durchsucht dann die von seiner Crawlersoftware indexierten Bilder (im Januar 2016 nach eigener Angabe insgesamt 13.9 Milliarden) und präsentiert dem User `ähnlicheく Dateien. ${ }^{198}$

Die genaue technische Beschaffenheit dieser >Ähnlichkeit ` - und damit also des Algorithmus, welcher der Suchanfrage entsprechende Bilder auswählt - ist naheliegenderweise ein Betriebsgeheimnis von Idée, Inc. Was genau TinEye `siehtı, kann also nur gemutmaßt werden. Eine solche Mutmaßung stellt der Computerforensiker

Vgl. http://tineye.com/ vom 10.01.2016. 
Neal Krawetz 2011 in einem Artikel auf dem Hacker Factor Blog an. Nach seinem Dafürhalten bedient sich TinEye aller Wahrscheinlichkeit nach sogenannter Hash(oder Streuwert-)Funktionen. Hashes spielen unter anderem in der Datenverschlüsselung eine bedeutende Rolle: Stark verkürzt erklärt bilden sie eine große Menge an Eingangs- auf eine sehr viel kleinere Menge von Ausgangswerten ab. Hashfunktionen kommen z.B. bei einer Vielzahl digitaler Übertragungstechnologien wie dem USB-Standard zum Einsatz, bei denen die störungsfreie Übertragung von Daten dadurch gesichert ist, dass zu jedem übertragenen Daten->Paket automatisch eine jeweils individuelle Prüfsumme generiert und am Ziel mit den eingetroffenen Daten abgeglichen wird. Hash-Algorithmen wären dementsprechend eine naheliegende Möglichkeit zur Komplexitätsreduktion in großen Datenmengen, welche eine Bildersuchmaschine mit Milliarden indexierter Dateien unvermeidlich betreiben müsste. Krawetz beschreibt einen Hash-Vorgang, wie er auf TinEye möglicherweise zum Einsatz kommen könnte, folgendermaßen: Von Usern hochgeladene oder von Crawlern erfasste Bilddateien würden zunächst höchstwahrscheinlich verkleinert. Krawetz schlägt hier der Einfachheit halber eine Reduktion auf 8x8, insgesamt also 64 Pixel vor. Das ursprüngliche Seitenverhältnis müsse nicht erhalten bleiben. In einem zweiten Schritt gelte es dann, die Farbkomplexität zu reduzieren. Bei einem Farbbild müssen für jeden Pixel grundsätzlich drei Farbwerte - rot, grün und blau - erhoben werden. Für ein Bild mit 64 Pixeln sind dies also insgesamt 192 Farben. Rechnet man das Bild hingegen auf Graustufen herunter, muss für jeden Pixel nur noch ein Helligkeitswert gespeichert werden, womit sich seine Komplexität auf 64 Farbwerte reduziert, deren Durchschnitt in einem dritten Schritt berechnet wird. In einem weiteren Schritt wird dieses Graustufenbild abermals vereinfacht - durch die Übersetzung der 64 Pixel in Bits, welche je nachdem, ob sie über oder unter dem durchschnittlichen Helligkeitswert liegen, den Wert 0 oder 1 annehmen. Diese Bits schließlich lassen sich mittels einer Hashfunktion in eine kurze Zeichenfolge übersetzen, die dann mit denen anderer Bilder verglichen werden kann. Der Vorzug eines solchen Verfahrens ist laut Krawetz ein doppelter: Erstens ist es sehr schnell abzuwickeln, und zweitens ist es resistent gegen Änderungen am Bildmaterial. Eine Veränderung am Seitenverhältnis oder an den Farben eines Bildes wird sich meist nicht auf die Hashsumme auswirken - und durch die dem Hash vorgeschaltete Größen- und Komplexitätsreduktion werden kleine Änderungen am Bild automatisch vernachlässigt, weil sie schlicht verschwinden. Die `Zusammengehörigkeit`zweier Bilder lässt sich dann mittels der sog. Hamming-Distanz (benannt nach dem Mathematiker Richard Hamming) beziffern, die beschreibt, wie viele Bitpositionen in der Hash-Summe unterschiedlich sind. Ist die Distanz 0, handelt es sich sehr wahrscheinlich um dasselbe Bild - und je größer sie wird, desto verschiedener sind die den Hashes zugrundeliegenden Bilddateien (vgl. Krawetz 2011).

Bildersuchmaschinen folgen also letztlich der Logik der Textsuche vor Google: Sie suchen nach Ähnlichkeiten und führen Gleiches zu Gleichem. Insofern haben sie 
grundsätzlich nicht dieselben poetischen Qualitäten, welche analytics-basierte Rankingsysteme aufweisen. Google spricht bei der seit 2011 von seinem eigenen Dienst Google Images verwandten inhaltsbasierten Bildersuchmaschine sogar ganz explizit von einer $»$ reverse image search $\aleph^{199}$ und gibt damit den Vektor der kulturellen Anschlussfähigkeit des auf diese Weise erschlossenen Bildmaterials vor: Bilder lassen sich zu ihren Ursprüngen und damit in ihre Vergangenheit verfolgen, aber nicht in ihre Zukunft projizieren. Ihre Entstehungskontexte (bzw. zumindest jene des digitalen Abbildes) lassen sich ausfindig machen, nicht aber mögliche Zusammenhänge, in die sie sich womöglich stellen ließen. Insofern ist die rückwärtige Bildersuche in ihrer Technizität gewissermaßen das Gegenteil des Imaginären Museums nach Malraux: Sie >entwildert die Semiosen, die sich am Objekt entspinnen können, und sie disassoziiert den virtuellen Gegenstand von seinen Mehrdeutigkeiten. Freilich aber lassen sich reverse image searches mit anderen Suchmaschinen koppeln. Googles Search by Image-Funktion beispielsweise findet nicht nur dem vom Nutzer hochgeladenen Bild ähnliche Dateien, sondern kann anhand der Webseiten, auf denen diese auftauchen, zugleich Vorschläge bezüglich womöglich relevanter wortbasierter Suchbegriffe unterbreiten. ${ }^{200}$

Was diese nur scheinbar >sehenden< Bildersuchalgorithmen vor massive Probleme stellt ist eben die Kategorie des Objekts. Hash-Codierungen funktionieren synoptisch über die Gesamtheit einer Bilddatei hinweg und sind unfähig, individuellen Bildelementen Rechnung zu tragen. Eine Bildersuchmaschine kann zwar erkennen, dass ein Bild von Zebras einem anderen Bild von Zebras informationell ähnelt und durch Korrelation mit Fundseiten einen wahrscheinlichen Zusammenhang mit dem Suchbegriff `Zebra ( feststellen, wird aber nicht imstande sein, tatsächlich ein Zebra im Bild zu rerkennen<. Anderswo sind entsprechende Technologien bereits im Einsatz - man denke z.B. an soziale Netzwerke wie Facebook, die in hochgeladenen Fotos z.B. Gesichter zu markieren oder unkenntlich zu machen imstande sind. Bildersuchmaschinen müssen allerdings nicht nur mit einer extrem großen Datenmenge umgehen, sondern vor allem auch mit Bildmaterial, das eine enorme Spannweite von Gegenständen abbildet. Dies macht es schwierig, hier Objekterkennungs-Funktionalitäten einzubinden (vgl. Belongie; Carson; Greenspan u. Malik 1998).

Dabei wäre eine solche natürlich ungemein nützlich für die Anwender. Diese suchen nämlich typischerweise nicht nach Bildern, die bereits vorhandenen Bildern ähneln, sondern nach Bildern-von-etwas (vgl. ebd.). Objekterkennung würde heißen, dass die Software schriftliche Suchanfragen effektiv auf Bildinformationen übertragen könnte - und z.B. das Paisleysche Szenario von der Suche nach allen Objekten

199 Vgl. https://support.google.com/websearch/answer/1325808?hl=en vom 10.01.2016.

200 Vgl. https://www.google.de/imghp?hl=de\&tab=wi\&ei=Gvm3VtzVHozt6ASRtY14 \&ved=0EKouCB QoAQ vom 10.01.2016. 
zum Gegenstandsbereich `Segelschiff` zu realisieren fähig wäre, ohne dass Menschen zu diesem Zweck Metadaten erstellen (und damit also zunächst Bilder visuell auf Segelschiffe hin untersuchen) müssten. Ein im Jahr 1998 an der Universität Berkeley von Serge Belongie, Chad Carson, Hayit Greenspan und Jitendra Malik verfasstes Paper identifiziert als den großen Schwachpunkt aller zeitgenössischen Bildersuchmaschinen ihre Fokussierung auf »stuff« (ebd.): Gemeint sind hiermit »low level features « (ebd.) wie eben Helligkeiten und Farbverläufe. Dem 〉stuff` gegenüber stehen die »things« (ebd.): konkrete und diskrete Objekte, über die es sich in kulturellen Begrifflichkeiten sprechen lässt.

Das Forscherteam aus Berkeley legt dankenswerterweise im Gegensatz zu Google und Co. Pläne für ein Verfahren offen, mit dem sich Objekterkennung in Bildersuchmaschinen verwirklichen lassen könnte. Belongie et. al. sprechen hier vom sogenannten blobworld-Ansatz (ebd.). Blobworld sollte genau das leisten, was der Name impliziert: Komplizierte Abbildungen von Gegenständen sollen auf blobs reduziert werden, die jeweils einige wenige Eigenschaften aufweisen, vornehmlich Textur und Farbe. Während Farbe ein punktuelles Attribut digitaler Bilder ist, ist Textur ein regionales und beschreibt das Verhältnis von Farb->Nachbarschaften〈 zueinander (vgl. ebd.). Ähnlich wie der von Krawetz beschriebene Hash-Algorithmus wollte blobworld eine vereinfachte Repräsentation des Ursprungsbildes erzeugen. Zugleich aber sollte das Verfahren auch imstande sein, Übergänge und Kanten und somit separate Bildregionen zu identifizieren. Bestimmte Zusammenkünfte von spezifischen blobs könnten dann mit bestimmten Wahrscheinlichkeiten bestimmten Objekten zugeordnet werden. Grundsätzlich ließe sich so jeder nur denk- und abbildbare Gegenstand auf einen mathematischen Formalismus herunterbrechen (vgl. ebd.).

Die Implikation einer solchen Technologie ist noch längst nicht die, dass Computer tatsächlich kulturell zu >denken` lernen könnten. Allerdings erlaubt sie es ihnen, Objekte ontologisch zu erkennen, die wir der Kategorie der >Dinge< zurechnen. Damit macht Software wie blobworld einen entscheidenden Schritt dahin, die menschliche Welterfahrung im Computer abzubilden - ist doch die Unterscheidung zwischen things und stuff letztlich auch jene zwischen Dingen und Raum. Zugleich entsteht hier eine Form des Zugangs zu Bildern und bildlichen Objekten, die sich womöglich als raesthetic analytics` bezeichnen ließe und eine Umsetzung der Bense'schen Informationsästhetik mit den Mitteln von big data andeutet. Wenn Suchmaschinen lernen, kulturelle Dinge zu >sehen « und diese Dinge einem ähnlichen quantitativ-stochastischen Verwaltungsapparat unterwerfen können wie Webseiten und Suchbegriffe, dann sind sie grundsätzlich auch imstande, Dinge durchaus sinnhaft zu >kuratieren`. Wie sich das Museum sowohl in seiner physischen als auch in seiner virtuellen Erscheinungsform hierzu positionieren müssen wird, ist derzeit nicht einmal abzusehen - womöglich wird es aber bedeuten, dass die Autorschaft menschlicher Kuratoren sich in Zukunft mehr und mehr in Subversionen wider das Einvernehmen des kulturellen Mainstreams und des short head wird äußern müssen. 


\subsection{3 Überall museal: Ubiquitous Computing und Museumsapps}

Gute anderthalb Jahrzehnte bevor Michael Liebe die `Mobilität als eines der zentralen Dispositive der Computernutzung unserer Gegenwart ausmacht, diagnostizierte der amerikanische Informatiker Mark Weiser einen gerade beginnenden Wandel in Ort und Praxis des Umgangs mit digitalen Medien. Das neue Paradigma des Rechners überschrieb er mit dem Begriff des ubiquitous computing - wörtlich also der >allgegenwärtigen Berechnung`. Der sperrige und unbewegliche Tischrechner würde, so seine Überzeugung, zukünftig in sehr begrenzte und spezifische Aufgabenfelder zurückgedrängt werden. Die Zukunft gehöre portablen Geräten, die im Gegensatz zum Desktop nicht länger in einer »world of [their] own« (Weiser 1991: 94) gefangen seien, sondern digitale Datenverarbeitung zu einem miasmatischen und fast unsichtbaren Bestandteil unserer Alltagswelt werden lassen würden. Die Ubiquität wird dabei doppelt gedacht und bezieht sich sowohl auf das Vorhandensein dieser tragbaren Computer selbst, als auch auf die Möglichkeit, mit ihnen jederzeit auf Netzwerke und Datenbankbestände zuzugreifen (vgl. ebd.). Damit positioniert sich Weiser ganz explizit gegen die Cyberspace-Metapher und die Utopien der virtual reality, die sich mit ihr verbinden: Wo letztere nämlich die Transposition des Menschen bzw. seiner Wahrnehmung in die Scheinwelten immersiver Interfacegebäude anstrebt, will Weiser die Verwischung jeder wahrnehmbaren Grenze zwischen analoger und digitaler Welt mittels einer unmittelbaren Integration des Virtuellen ins >Reale (vgl. ebd.: 94ff.). Weisers Schätzung nach würden drei Gerätekategorien diese Entwicklung tragen und vorantreiben: Tabs sollten als kleinste Form portabler Computer etwa so groß wie Notizblöcke sein, pads in ihren Abmessungen etwa Büchern und Zeitschriften entsprechen und boards schließlich die Ausmaße von Schultafeln oder Anschlagbrettern annehmen (vgl. ebd.: 98; vgl. Niewerth 2013: 3).

Obwohl sich für die einzelnen Größenordnungen mobiler Computer andere Bezeichnungen durchgesetzt haben, ist die Weitsichtigkeit von Weisers Prognose heute offensichtlich: Das Dispositiv >Mobilität ist im Laufe des vergangenen Jahrzehntes womöglich zum wichtigsten unseres Umgangs mit Computerhard- und Software geworden. Es unterscheidet sich von allen anderen eben darin, dass es eigentlich keine klare und benennbare Dispositivstruktur mehr aufweist und keinen bestimmten, idealtypischen Ort mehr belegt. Während der Desktop auf einem Schreibtisch steht und die Spielkonsole üblicherweise an einen Fernseher gegenüber eines Sofas angeschlossen ist, werden mobile Geräte in allen nur denkbaren sozialen und räumlichen Situationen genutzt - inklusive solcher, die einst klar die Domäne anderer Computertypen waren. Die Existenz und Brisanz dieser neuen Form von digitaler Mediennutzung ist leicht zu attestieren, ihr tatsächliches >Wesen ‘ allerdings überaus schwierig zu umreißen. 
Für den Fall der Museumsvirtualisierung zumindest lässt sich eine zentrale Neuerung benennen, die mit dem ubiquitous computing einhergeht: Mit ihren Handys und Tablets bringen Besucher erstmals eigene Computer mit in den Ausstellungsraum. Damit muss notwendigerweise jede Vorstellung bröckeln, der gemäß virtuelle Angebote fest im >Vorher bzw. in der Anbahnung des physischen Museumsbesuches verortet seien und im Moment des >echten` Erlebens keinen Platz mehr hätten. Der Computer ist nicht länger in einer baulich von der Ausstellung abgeschiedenen Außenwelt beheimatet, sondern überbrückt die vermeintlich kategorische Differenz zwischen Alltag und Ausstellungssituation: Die alltäglich gewordenen Methoden und Bedingungen digitaler Informationsbeschaffung stehen während des Museumsbesuches ebenso zur Verfügung wie überall und jederzeit sonst auch.

Damit ist natürlich einerseits impliziert, dass das WWW mit all seinen Angeboten und Lenkungssystemen ins Museumsdispositiv einzieht und seine Sicht- und Sagbarkeitsverhältnisse potenziell einschneidend zu verändern imstande ist. Zugleich ist aber für das Museum auch ein neuer Kommunikationskanal in Richtung seiner Besucher und zurück aufgetan, der sich sowohl didaktisch als auch ökonomisch verwerten lässt. Die Kunsthistorikerin Dorian Ines Gütt thematisiert in ihrer 2010 an der Hochschule für Technik und Wirtschaft Berlin vorgelegten Abschlussarbeit die Verwendung von Handy-Apps in der deutschen Museumslandschaft - und erkennt vor allem drei Gebiete musealer Vermittlungsarbeit, auf denen sich die Institution Museum die von ihren Besuchern mitgebrachten Geräte zunutze machen könne. Erstens sei das Handy eine naheliegende Alternative zum klassischen Audioguide, der meist in Form speziell für die individuellen Häuser angefertigter Geräte daherkomme und technisch typischerweise von außermusealen Dienstleistern betreut werde, die sich hierfür an den Leihgebühren beteiligen ließen. Der Audio-Guide sei dementsprechend in dieser Form das Privileg sehr gut besuchter Ausstellungen. Apps fänden hingegen in den Telefonen der Besucher eine von diesen selbst finanzierte technische Infrastruktur vor - womit sich die Aufwendungen des Museums auf die Erstellung des Tonmaterials und evtl. die Anschaffung von Leihgeräten reduzierten, solange man das Vorhandensein eines Tablets oder Smartphones noch nicht bei allen Besuchern voraussetzen könne (vgl. Gütt 2010: 36f.). Auch verfüge ein Handy über ein weit vielseitigeres Einsatzprofil als ein typischer Audioguide: Weil es neben Tonaufnahmen auch Videos wiederzugeben imstande ist, könne es z.B. Guides in Gebärdensprache für gehörlose Museumsgänger bereitstellen (vgl. ebd.: 37).

Der zweite von Gütt ausgemachte Einsatzbereich von Apps ist die Ergänzung von Erklärungstafeln in Katalogtexten. Interessanterweise erteilt sie dabei der Befürchtung eine klare Absage, dass Wikis und Suchmaschinen jemals die redaktionell erstellten Textangebote der Ausstellung ersetzen könnten. Museumsbesucher, so stellt sie fest, vertrauten der Institution mehr als dem Netz und fänden außerdem »analoges Lesen entspannter« (ebd.: 38). Jedoch böten die von den Besuchern mitgebrachten Gerätschaften ihnen die Möglichkeit, sich selbst neue Plattformen zum Austausch 
über Ausstellungen zu schaffen, wo das Museum sich der Bereitstellung solcher verweigert. Es gelte deshalb, einen »Mittelweg« zu finden zwischen »Frontalansprache und Kommunikation auf Augenhöhe« (ebd.: 38): Mittels mobiler Applikationen könne man Besuchern die Möglichkeit geben, einander und den Kuratoren `Notizen zu individuellen Ausstellungsstücken zu hinterlassen. Die Schnittstelle hierzu könnten z.B. QR (Quick Response)-Codes sein - die mittlerweile hinlänglich bekannten Barcodes, die von einer Handykamera eingelesen werden können und eine URL codieren. Durch das Anbringen von QR-Codes an physischen Exponaten sollen sich diese einfach mit einer ihnen zugeordneten Webseite >verlinken lassen (vgl. ebd.: 38 f.).

Der dritte Anwendungsbereich nach Gütt bezieht sich auf mobile Geräte als Plattformen für den Umgang mit virtuellen Museen. Gütt sieht Museums-Apps nicht zuletzt auch als eine Erweiterung und Potenzierung des seit den 1960er Jahren immer wieder in Anschlag gebrachten Verfügbarkeitsparadigmas. Nicht nur, dass im Web ein enormer Reichtum digitaler Kulturgüter zum Abruf bereitsteht - der Abruf kann nun auch jederzeit von überall her erfolgen. »Das größte Museum der Welt« so stellt Gütt fest, »passt in eine Westentasche!« (ebd.: 40). Interessanterweise sieht sie diese Entwicklung allerdings nicht unter dem Stern wachsender Ortlosigkeit. Vielmehr ermöglichten es Mobiltelefone und Standortdaten, Nutzern jederzeit speziell ortsbezogenes Wissen zur Verfügung zu stellen. So könnte man z.B. Baudenkmäler und Sehenswürdigkeiten mit digitalen Angeboten verkoppeln, die dann vor Ort aufgerufen und genutzt werden können. Das verbindende Element zwischen physischem und virtuellem Raum könnten neben QR-Codes z.B. GPS-Koordinaten sein, in Zukunft womöglich auch Bilderkennungs-Softwares, die beim Blick durch die Kamera von selbst herausfinden, wo sich der Nutzer aufhält (vgl. ebd.: 40).

Ubiquitous computing lässt also nicht nur die Außenwelt ins Museum einsickern, sondern ermöglicht zugleich auch die Ausweitung musealer Ausstellungstätigkeit in die das Museum umgebenden urbanen Räume. Eine höchst funktionale Grenzgängerin zwischen Museum und Umwelt ist die Plattform museum.de. Das 2010 von seinem Entwickler Uwe Strauch in Xanten gegründete Projekt versteht sich als eine integrierte, offene Plattform, auf der Museen je nach ihren Bedürfnissen und Möglichkeiten Inhalte einstellen und pflegen können. ${ }^{201}$ Museum.de verfügt über eine Webseite (naheliegenderweise www.museum.de), ein vierteljährlich im Druck erscheinendes Magazin ${ }^{202}$ - und eine App, die sowohl über Apples App Store, als auch über den Google Play-Dienst für Android-Geräte bezogen werden kann. Die App soll es Endnutzern, die von Zuhause oder auf Reisen einen Museumsbesuch planen, erlauben,

201 Vgl. http://www.museum.de/de/about vom 20.01.2016.

202 Vgl. http://www.museum.de/de/magazine?page=1 vom 20.01.2016. 
Museen ausfindig zu machen und sich über diese zu informieren - mit der Möglichkeit, Standortkriterien einzubeziehen, also gezielt im Umfeld des eigenen Aufenthaltsortes nach Museen zu suchen. ${ }^{203}$

Seit 2015 beinhaltet die App darüber hinaus eine Audioguide-Funktion. Mittels dieser können teilnehmende Museen Audioguides anbieten, ohne selbst für entsprechende Geräte aufkommen zu müssen. Es wird empfohlen, den Besuchern WLANZugänge zur Verfügung zu stellen, damit die entsprechenden Daten nicht über den Mobilfunk geladen werden müssen. Der Zugriff auf individuelles Tonmaterial zu einzelnen Ausstellungsteilen oder -stücken soll dann mittels sog. iBeacons funktionieren - kompakte Bluetooth-Sender, die strategisch im Museumsraum zu verteilen sind. ${ }^{204}$

Ein Blick auf die Google Play-Seite von Museum.de ist indes ernüchternd: von 22 abgegeben Rezensionen im Februar 2016 bewerten 10 die App mit drei von fünf Sternen oder schlechter. In den Rezensionstexten wird wiederholt angeführt, die App funktioniere zwar, biete aber kaum tatsächliche Inhalte. $\mathrm{Zu}$ den meisten Museen stehen zwar Adressen und Öffnungszeiten zu Verfügung - Bild- und Textmaterial ist aber dünn gesät, und auch das Audioguide-Feature wird offenkundig kaum genutzt. ${ }^{205}$ Das Problem am offenen Prinzip von Museum.de scheint zu sein, dass die Attraktivität der App von ihrer tatsächlichen Nutzung durch individuelle Museen abhängt. Bleibt diese aus, leistet der Dienst nicht mehr als Google Maps es bereits tut und diese Applikation ist auf den allermeisten Android-Smartphones bereits vorinstalliert. Tatsächlich gleicht Museum.de einem leerstehenden Einkaufszentrum: Alle Infrastrukturen sind vorhanden, aber es fehlt an attraktiven Geschäften - und damit wiederum an Kundschaft, welche die Eröffnung neuer Läden rechtfertigen könnte. Ob die App die nötige kritische Masse erreichen wird, um sich als Plattform für Museen und Besucher gleichermaßen zu etablieren, bleibt abzuwarten.

Einen Kontrast zum offenen System von Museum.de bildet die vom Kölner Atelier für Mediengestaltung entwickelte App arttalk. Während Museum.de Kultureinrichtungen eine unentgeltliche, gemeinsame Plattform für ihre Inhalte anbietet und sich damit dem Risiko aussetzt, untergenutzt zu erscheinen, bietet arttalk individuelle, auf die Bedürfnisse einzelner Häuser hin zugeschnittene Lösungen - arttalk selbst bildet gewissermaßen das `Skelett`, um das herum Museumsapps gestrickt werden können. ${ }^{206}$ Dieses Skelett wiederum besteht aus drei Hauptelementen. Zuvorderst steht das »Informationssystem«, das die Funktionalität von Erklärungstafeln und Ausstellungskatalogeinträgen aufgreift und den Zugriff auf zusätzliches Text-

203 Vgl. http://www.museum.de/de/product vom 20.01.2016.

204 Vgl. http://www.museum.de/de/about vom 20.01.2016.

205 Vgl. https://play.google.com/store/apps/details?id=de.appsider.museum vom 02.02.2016.

206 Vgl. http://arttalk.mobi/ vom 02.02.2016. 
und Bildmaterial ermöglicht. Das »Audioguidesystem« ist eben dies: Es gestattet Besuchern, mittels ihres Handys auf eine Audio-Führung zuzugreifen, während den Häusern in Aussicht gestellt wird, zukünftig auf Audioguide-Geräte verzichten zu können. ${ }^{207}$

Interessant ist das dritte Kernelement des arttalk-Prinzips, das der App ihren Namen verleiht: Das »Kommunikationssystem« ist eines jener bei Gütt bereits in Aussicht gestellten virtuellen >Anschlagbretter`, mittels derer Besucher einander Fragen, Antworten und Kommentare zu Ausstellungsgegenständen hinterlassen können. ${ }^{208}$ Die Besucher bewegen sich also, indem sie die Ausstellung erkunden, zugleich in einem Netzwerk von Diskussionssträngen, das weniger die Raum- denn die Zeitstrukturen ihres Museumsbesuches überwindet: Das Kommunikationssystem bezieht sich für alle seine Nutzer auf denselben Raum, überschreibt aber die unterschiedlichen Zeitpunkte ihres Besuches mit der Gleichzeitigkeit einer Forensoftware, in der Beiträge persistent sind. Die vermeintlich flüchtige digitale Kommunikationsform wird also zur Verstetigung der Äußerungen von Besuchern genutzt, die normalerweise den Moment des Sprechens im musealen Raum nicht überdauern würden. Das Kommunikationssystem von arttalk ist darüber hinaus mit den sozialen Netzwerken Facebook, Twitter sowie Google+ verknüpft und erweitert damit den Raum musealer Kommunikation über den der Ausstellung selbst hinaus - ohne dabei aber von der materiellen Ausstellung abgelöst zu sein.

Damit zielt arttalk offensichtlich weniger auf die kuratorische, exponatseitige Komponente der Ausstellung ab als auf jene der sozialen Szenographie: Die App schafft vor allem neue Möglichkeiten für Besucher, miteinander zu kommunizieren - und für Betreiber, diese Kommunikation nachzuvollziehen, auszuwerten und für zukünftige Ausstellungskonzepte zu nutzen. Die Chance, mit solchen Strategien neue Nutzer ins Museum zu locken, indem man sie im Alltag abholt, sollte man nach Gütt allerdings nicht überschätzen: Entsprechende Apps seien in erster Linie interessant für Menschen, die ohnehin Interesse am Museumsbesuch haben - wen Ausstellungen nicht Reizen, den würden Apps kaum ins Museum locken (vgl. Gütt 2010: 43). Auch sei das Vermittlungspotential von Apps ein stark eingeschränktes: Zwar könnten sie auf verschiedenste Arten eine Ausstellung ergänzen, für sich allein genommen seien sie jedoch kaum zur Vermittlung komplexer Zusammenhänge zu gebrauchen - zu sehr seien sie auf die Übertragung bruchstück- und schlaglichtartiger Informationsfetzen ausgelegt (vgl. ebd.: 45).

Von daher erscheint es nur folgerichtig, wenn Gütt am Ende ihrer Studie resümierend feststellt, dass der Erfolg von Museumsapps letztlich davon abhinge, ob man sie erfolgreich in ein Ausstellungskonzept zu integrieren vermag - und sie nicht etwa 
aus einer vermeintlichen technologischen Folgerichtigkeit heraus die physische Ausstellung obsolet machen (vgl. ebd.: 48). Als Aktanten einer augmented reality-Umgebung (ebd.: 40), in der digitale Abbildung und physische Präsenzerfahrung miteinander koexistieren, interagieren und womöglich mehr und mehr an Unterscheidbarkeit einbüßen, hängt ihre Nützlichkeit nicht allein von ihrer inneren Funktionalität ab, sondern von ihrer Fähigkeit, als Schnittstelle zu wirken (vgl. ebd.: 49). Damit werden Museumsapps gerade aufgrund ihrer schwammigen Situiertheit im Museumsraum, außerhalb desselben und in allen Grauzonen zwischen seinem Innen und Außen zu exemplarischen Abbildern des aller Museumsvirtualisierung zugrundeliegenden Dilemmas: nämlich nicht etwa das Museum von Babel zu ordnen, sondern Lösungen für individuelle Museen, Ausstellungen und pädagogische Situationen zu finden, die den Versprechungen digitaler Vernetzung genügen, ohne sich ihren Eigendynamiken zu ergeben. 



\section{Schluss und Ausblick}

Bei ganz ähnlichen Überlegungen setzt ein 1995 von Friedrich Kittler verfasster Text mit dem Titel Museums on the Digital Frontier an. Kittler sieht das Museum darin ganz in der Tradition Valérys als eine Einrichtung, die aus der Ablösung der Kunst von der Architektur entstanden ist, oder etwas differenzierter: Es entstand im Zuge der Herausbildung einer Kunst-als-Kunst, die nicht mehr zweckdienlich den sozialen Kontexten der Privaträume zu genügen hatte, in denen sie hing. Darin war es nach Kittler fundamental verschieden von der Wunderkammer, in der Kunstobjekte, Naturalien und technische Apparaturen gleichermaßen Mirabilien gewesen waren. Mit der Geburt des Museums sei schon lange vor Humboldt eine Abgrenzung der Kunst von der Technik etabliert worden, die es zuvor so nicht gegeben habe und die heute unmittelbar den gesamten Phänomenbereich der Museumsvirtualisierung berühre (vgl. Kittler 1995: 67f.).

Denn natürlich ist, wie bereits ausgearbeitet wurde, das Museum als Speicherund Vermittlungssystem von einer Vielzahl technischer Systeme abhängig, wie eben jenen seiner Verwaltung. Kittler geht indes noch einen Schritt weiter: Für ihn existiert das Museum schlechthin nur in der Domäne der Technik, bzw. namentlich der Medientechnik. Das Museum ist für ihn ein immer schon hybrides Medium, das aus sich selbst heraus nur zu speichern imstande sei. Will es darüber hinaus Information prozessieren und übertragen - also die Funktionalität einer Von-Neumann-Architektur erfüllen, wie sie unseren Computern zugrunde liegt - dann muss es Medien hinzuziehen, die unabdingbarer Teil der Ausstellung, aber nicht als einer ihrer Gegenstände zu integrieren sind. Der Typus des Technikmuseums vertieft nach Kittlers Ansicht diese Spaltung noch, weil er zwar die Technik zum Ausstellungsgegenstand macht, sie dabei aber vom Rest der Kultur, in der sie wirkt, abtrennt (vgl. ebd.: 69f.):

Technological museums do not ask how the media have supplanted the arts, and art museums do not ask what the arts owe the media or the media the arts. (Ebd.: 70) 
Virtuelle Museen seien daher eine längst überfällige Erscheinung, deren legitimer musealer Charakter für Kittler gar nicht infrage zu stellen ist - tatsächlich seien sie womöglich die einzig zeitgemäße Form musealer Darstellung, weil in ihnen erstmals Technik und Kultur, Gegenstände und Bedingungen zusammenfallen: Register und Ausstellung verweisen nicht mehr aufeinander, sondern werden eins. Aus der Tatsache, dass jedes Exponat aus genau den Daten besteht, über die es adressierbar ist, ergibt sich für Kittler eine nahezu perfekte Verbindung von Existenz und Benennung, während die mit den Exponaten verbundenen Wissensinhalte massiv flexibilisiert werden (vgl. ebd.: 73). Der Computer erfordert nach Kittler eine ganz neue Museologie, die auf die Zusammenführung eines fragmentierten Wissenskosmos abzielt allerdings nicht in einer Universaldatenbank, sondern in der Synthese zwischen Kunst und Technik und der Verankerung aller Kultur in den Medien, die ihre Voraussetzung sind (vgl. ebd.: 74f.). Virtuelle Museen sollen daher vor allem Museen des Virtuellen sein und deutlich machen, wie sehr Rezeptionserfahrungen von ihren medialen Rahmenbedingungen abhängen: Das Ziel von Interface- und virtual realitySystemen soll es nicht etwa sein, Simulakren historischer Wirklichkeiten entstehen zu lassen, sondern vielmehr ihre eigene Beschaffenheit und Programmatik zu thematisieren. Das Digitale selbst soll Ausstellungsgegenstand, das virtuelle Medium selbst soll begehbar und transparent gemacht werden. Hierin sieht Kittler die Rolle des virtuellen Museums in einer Zeit, in der die Digitalisierung von Museumsdingen ohnehin fast von allein geschieht (vgl. ebd.: 77): Es darf nicht nur ein Speicher für konkrete Inhalte sein, sondern muss auch die Baupläne unserer Vermittlungsanordnungen enthalten. Nur dann nämlich könne es eine aufklärende Rolle für eine Welt einnehmen, in der mediale Trägertechnologien, die ihre eigene Natur verschleiern, uns stets mit dem neuen >neuen Mittelalter einer Priesterherrschaft der Programmierer drohen (vgl. ebd.: 78f.).

Womöglich stößt uns Kittler mit dieser Einschätzung nicht nur auf eine mögliche Strategie, derer sich die Institution Museum im Umgang mit digitaler Medientechnik bedienen könnte. Was sich hier anzudeuten scheint, wäre vielmehr genau jener goldene Schnitt, innerhalb dessen das Museum sein Selbstbild und seinen Bildungsauftrag für das digitale Zeitalter neu erfinden könnte, ohne mit seiner zu den antiken Tempelschätzen reichenden Tradition zu brechen - und der zugleich den Rahmen bilden könnte für eine Museumphilosophie, die ihre eigene Mittelbarkeit im Vollzug der Ausstellungstätigkeit mitdiskutieren imstande wäre.

Am Anfang dieser Studie stand die information anxiety Paul Valérys und mit ihr dessen Unvermögen, dem Museum so zu begegnen, wie es seine `Tempelhaftigkeit` eigentlich verlangen würde: in Ehrfurcht vor seiner Tradition und Anerkennung seiner Autorität, in Wertschätzung und Verständigkeit für seine kuratorischen Fügungen bei gleichzeitiger Einfühlsamkeit in die Würde und Einmaligkeit jedes einzelnen Ausstellungsstückes, und in duldsamer Dankbarkeit gegenüber der Fülle unseres kulturellen Erbes. An ihrem Ende steht nun die Diagnose einer ganz anderen Varietät 
von Informationsangst, die viel weniger das Publikum zu befallen scheint als die ausgebildeten Experten und Kulturarbeiter, die der Institution ihre Biographien verschrieben haben - und die nun einer vermeintlichen Medienrevolution entgegenblicken, die zu bewältigen es ihnen an technischem Know-How ebenso zu fehlen scheint wie an Bewusstsein für die bestehende Medialität des Museums.

Als selbst nicht dezidiert für den Umgang mit digitalen Medien ausgebildete Fachkräfte sind Museumsleute auch nicht davor gefeit, den üblichen Fehleinschätzungen, Gemeinplätzen und gelegentlichen Mystifizierungen aufzusitzen, welche den öffentlichen Diskurs über unsere Medienlandschaft informieren. Nick Poole stellt 2012 in einem Text für den Londoner Collections Trust fest: Der Digitalitätsbegriff sei mittlerweile so überstrapaziert, dass er außerhalb explizit technikbezogener Diskurse fast gar nichts mehr bedeute. Er sei zu einem Schlagwort geworden, mit dem sämtliche »Aktivitäten, Technologien, Geschäftsmodelle und Fähigkeiten« (Poole 2012) über einen Kamm geschoren würden, die in irgendeiner Form mit der Übermittlung von Einsen und Nullen mittels elektronischer Signale zusammenhingen. Mit dieser deskriptiven Leere verbinde sich indes eine konnotative Fülle, die Anpassung fordert und Unausweichlichkeit postuliert: Wo das Digitale Beschworen wird, da geht es um Modernität und »die Zukunft« (ebd.) schlechthin - auch, wenn sich vor dem Horizont der >Digitalität`als Sammelbegriff mittlerweile längst ausgedehnte Landschaften obsoleter und gescheiterter Technologien erstrecken (vgl. ebd.).

Das immer noch andauernde sprachliche Beharren auf Digitalität bzw. Digitalisierung als Hauptmerkmal unserer medialen Situation ist - wie in dieser Studie immer wieder angeklungen ist - in vielerlei Hinsicht nicht nur der Affe auf dem Rücken des Museums und seiner zahlreichen gegenwärtigen didaktischen Neupositionierungen, sondern schlechthin die Geißel aller Rede über kulturelle Kommunikation in unserer Gegenwart: Es macht die Technik selbst zum Bezugspunkt des Diskurses und verstellt uns den Blick auf den Umstand, dass die Technik sozial verortet, eingebunden und umsponnen ist - und dass jede neue Technologie auf eine bereits existierende Welt stößt, die auf sie reagiert und sie sich zu eigen macht, während sie ihrerseits von ihr vereinnahmt wird. Der Lichtblick für unsere laufenden Technikdebatten ist laut Poole der, dass das Digitale sich als ihre zentrale Größe zunehmend abnutze und ein neues Paradigma an seine Stelle rücke: jenes des »Sozialen« (ebd.). Mit diesem wiederum sei angezeigt (und man denke hier an das in Kapitel 2.4 diskutierte Hervorgehen unserer Netzwerkvorstellung aus der Sozialpsychologie), dass wir in einer Epoche der Relationen, der wechselseitigen Bedingtheiten und Bezüglichkeiten sowie schlicht der Netzwerke leben. Das Informationszeitalter sei damit nicht etwa wesentlich 〉digitalく, sondern in seiner täglichen Praxis vor allen Dingen »connected« (ebd.). Für Poole verbindet sich mit dieser Feststellung eine optimistische Zukunftsprognose nicht nur für das Museum, sondern auch für Archiv, Bibliothek und alle übrigen Einrichtungen der öffentlichen Erinnerungskultur. Das Paradigma des Miteinanders, der 
Vernetzung und der Kooperation nämlich sei diesen bereits eingeschrieben: »Connection is what we do« (ebd.).

Damit unterstreicht Poole grundsätzlich eine der Kerneinschätzungen dieser Arbeit: dass Computer, die Praxis ihrer Vernetzung untereinander und das Medium Hypertext nämlich keinesfalls die Antithese zum Museum und seiner Arbeitsweise darstellen, sondern diese vielmehr mit anderen Mitteln wiederspiegeln - und dass $\mathrm{Mu}-$ seen tatsächlich in vielerlei Hinsicht prädestiniert dafür scheinen, sich ihrer mit Gewinn zu bedienen. Während Poole jedoch in Verknüpfung und Vernetzung bereits das Wesentliche der medientechnologischen Entwicklungen der vergangenen Jahrzehnte ausmacht, müssen wir diese mit Rückblick auf die hinter uns liegenden sieben Kapitel lediglich als eines von vielen Attributen einer tatsächlich ihrem Wesen nach virtuellen medienhistorischen Situation identifizieren. Diese spezifische Virtualität verbindet sich gegenwärtig mit digitaler Technik - aber um das soziale und historische Setting der gegenwärtigen Museumsvirtualisierung zu verstehen, muss der Umstand mitgedacht werden, dass das Virtuelle schon lange vor den ersten integrierten Schaltkreisen immer wieder kulturell wirksam geworden ist.

Dass es sich beim >virtuellen Museum tatsächlich um einen tautologischen Begriff handelt, ist einer der zentralen Befunde dieser Arbeit gewesen. Museen waren immer schon Räume, in denen das Abwesende vergegenwärtigt und das Implizite artikulierbar gemacht wurde - und in denen Sinnbildung nicht in der konkreten Äußerung eines Expertensystems gegenüber einem Laienpublikum bestand, sondern in der Schaffung von Voraussetzungen für die Deutung von Zusammenhängen. Das Gebot der Stunde scheint zu sein, die der Vorstellung vom virtuellen Museum innewohnende Redundanz eben nicht im Sinne einer inhaltsleeren Tautologie zu verstehen, sondern als eine Akzentuierung medientheoretischer Tatbestände, für welche das (sicher nicht nur zu Unrecht) mantrisch beschworene Leitbild von Materialität und Echtheit die Museumswissenschaft blind gemacht hat. Wenn - wie mit Suzanne Keene in Kapitel 6.3.2 festgestellt wurde - die Einführung von Computern und Datenbanksystemen in die museale Verwaltungsarbeit die Museen zu einer bürokratischen >Professionalisierung < und fachlichen Neubewertung ihrer materiellen Sammlungsbestände gezwungen hat, so ist mit der Ausweitung der Ausstellungstätigkeit in computerisierte Interfacesysteme womöglich die Zeit für ein vertieftes Nachdenken über das Immaterielle des Museums angebrochen. Worin dieses Immaterielle bestehen könnte, hat diese Arbeit aus zahlreichen Blickwinkeln beleuchten, naturgemäß aber nicht abschließend darstellen können: Es umfasst die medial-epistemische und affektive Funktionalität von Ausstellungen ebenso sehr wie das institutionelle Selbstverständnis individueller Häuser, die Bildungswege und Qualifikationsprofile von Museumsmitarbeitern ebenso wie das Kulturverständnis und die technische Expertise von politischen Entscheidungsträgern, die kulturelle Sozialisation von Besuchern ebenso wie das Verhältnis von Museen zur sie umgebenden Außenwelt. 
Das zentral erforderliche (und sich in jüngeren Veröffentlichungen gelegentlich andeutende) Umdenken im Umgang der Museumswissenschaften mit virtuellen Museumsprojekten muss daher darin bestehen, diese gerade nicht nur daraufhin zu untersuchen, wie sie sich zur Materialität von Exponaten und Ausstellungssituationen verhalten. Denn hier geht es um die Virtualisierung des Musealen: Welcher Verfahren bedient man sich in der Erstellung von Digitalisaten physischer Ausstellungsobjekte? Wie bildet man die Strukturen des musealen Raumes nach und wie übt man noch kuratorische Autorität über den Besucher aus? Wie authentisiert man Inhalte in Abwesenheit der Originale? Kurzum: Wie emuliert man das museale Dispositiv in Ermangelung seines Raumes und seiner Dinge, und wie erfolgreich ist man damit? Diese Fragen bleiben unbenommen relevant, aber zu ihnen müssen sich jene danach gesellen, welche expliziten und impliziten Aussagen virtuelle Museen über die immaterielle Komponente musealer Vermittlung machen und welche Modelle von $\mathrm{Mu}-$ sealität sie eben gerade aus ihrer spezifischen medialen Verfasstheit heraus produzieren. Hiermit wäre also nach der Musealisierung des Virtuellen gefragt: Was stellen virtuelle Museen aus? Wie wählen sie ihre Themen und Exponate, und wie begründen sie diese Entscheidungen? Warum bezeichnen sie sich ausgerechnet als >Museen $\triangleleft$ ? Wo sind ihre Strategien des Kuratorischen, der Autorschaft und der Authentizität gerade nicht dem klassischen Museumsdispositiv abgeschaut, sondern gehen originär aus ihrem Angewiesensein auf digitale Medien hervor - und wie sehen diese Strategien konkret aus? Wie widersetzen virtuelle Museen sich der Flüchtigkeit ihrer medialen Umwelt - und welche Vorstellungen von kommemorativer Kultur legen sie dabei zugrunde? Und, damit verbunden, die von Kittler aufgeworfene Frage: Wie thematisieren virtuelle Museen selbst ihre mediale Beschaffenheit und ihre Verschiedenheit von physischen Einrichtungen, und was kann das Publikum daraus über sich selbst herausfinden und über die kulturelle Welt, in der es lebt und lernt?

Diese Studie hat ein komplexes medientheoretisches Instrumentarium zusammengetragen, mittels dessen sich der Phänomenbereich >Museumsvirtualisierung deskriptiv und analytisch systematisieren lässt. Begriffsgeschichtliche Ansätze wurden ebenso diskutiert wie literaturwissenschaftliche Zugänge zu nonlinearen Texten und ihrer Ästhetik, verschiedene Ding- und Objektkonzepte mit unterschiedlichen Schulen der Raumtheorie konfrontiert, technikhistorische Aspekte der Museumsgeschichte mit kultur- und geistesgeschichtlichen zusammengeführt, Utopien von Cyberspace und virtuellem Weltmuseum den technischen Realitäten des WWW gegenübergestellt. Rhizom, Dispositiv und Akteurnetzwerk wurden als mögliche Beschreibungen des >Wesens $`$ der Institution Museum ebenso vorgestellt wie Prognostiken und Phantasmen über deren virtualisierte Zukunft - vom emanzipatorischen Optimismus eines André Malraux über die unaufgeregten ökonomischen Erwägungen Chris Andersons bezüglich des long tail bis hin zur verführerisch-nebulösen CyberpunkApokalyptik Roy Ascotts. Vor allem befasste sich ein beträchtlicher Teil der Ausfüh- 
rungen dieser Arbeit mit den Infrastrukturen und Rahmenbedingungen, die das virtuelle Museum technisch, kulturell und diskursiv umgeben: Das Web, in welchem es heute sein Dasein behaupten muss, ist das Web von Google, Amazon, Facebook und Co. - und entsprechend lässt es sich über das virtuelle Museum nicht sprechen, ohne auch über diese Dienste und die medialen Praktiken zu reden, die aus ihnen hervorgegangen sind und von ihnen normalisiert wurden und werden.

Insbesondere die Idee vom >absoluten` oder >Meta`-Museum, die als utopisches Fernziel oder zu verhinderndes Endzeitszenario der Museumsvirtualisierung immer noch die Rotationsachse zahlreicher museumswissenschaftlicher Debatten darstellt, scheint in der Fachliteratur von den Realien des WWW völlig abgekoppelt zu sein. Während Projekte wie Europeana und das Virtual Museum of Canada ohne Zweifel Ziele verfolgen, die sich als >meta-museal beschreiben ließen, erscheint es zunehmend unwahrscheinlich, dass ein wie auch immer geartetes >Museum von Babel $<$ tatsächlich aus der konkreten Absicht von Kuratoren hervorgehen wird, die Wände zwischen den Sammlungen niederzureißen. Vielmehr scheinen es eben technische Aktanten zu sein, die nach der Gänze unseres Kulturerbes greifen: Suchmaschinen, Empfehlungsalgorithmen, analytics und data mining musealisieren das Virtuelle nicht nach den Vorgaben irgendeiner historischen Didaktik, sondern an der stetig fluktuierenden Schnittstelle von Individuum und Masse. Millionen von Nutzern lehren das System, was die Einzelperson interessieren könnte - und das System wiederum errichtet um unsere digitalen Platzhalter herum Sinn->Gebäude`, die nicht länger Museen einer wie auch immer beschaffenen Welt sind, sondern vielmehr Museen unserer selbst bzw. unserer Interessenlagen und Mausklicks. Wie das Museum zum Graus Paul Valérys die Hinterlassenschaften der materiellen Kultur in sich aufnimmt, so schwellen Googles Speicher mit den immateriellen Hinterlassenschaften unserer Entscheidungen für und gegen Links und Webseiten.

Hinter Malrauxs Vorstellung vom Imaginärem Museum stand die Hoffnung und Erwartung, dass die technische Reproduzierbarkeit von Kunstobjekten eine Kultur der Abbilder entstehen lassen würde, in der nicht nur buchstäblich alles für jedermann verfügbar sein, sondern in der auch jedes Objekt ständig in der Gesamtheit seiner möglichen Deutungskontexte stehen würde. In gewisser Weise hat das Web einen großen Teil dieses Versprechens eingelöst - allerdings um den Preis der Abtretung kuratorischer Autorschaften an ein weitgehend >kulturloses`System kybernetischer Rückkopplungen, hinter dem in erster Linie privatwirtschaftliche Interessen stehen und somit nicht etwa die Ideale emanzipatorischer Herzensbildung, sondern die Absicht von Dienstleistern, die scheinbaren Bedürfnisse ihrer Kundschaft zu befriedigen.

Die Musealisierung des Virtuellen müsste daher auch beinhalten, das museale Moment des Besonderen, des Außeralltäglichen, womöglich der Andacht innerhalb der Normalität des Datenabrufs wiederherzustellen. Hierfür kann es keine Universa- 
lanleitung geben - aber wollten virtuelle Museen sich widerspruchslos hinter der Maxime der unbedingten Auffindbarkeit und Assoziierbarkeit von allem mit allem unter Einbeziehung statistisch erzeugter Nutzerprofile einreihen, die augenblicklich die kulturelle Einordnung des WWW zu bestimmen scheint, dann wären sie im Grunde schon a priori obsolet und redundant. Gefälligkeit kann kaum die ökologische Nische des Museums im Netz sein. Stattdessen scheint es geboten, den Schock als Leitprinzip virtuellen Ausstellens wiederzuentdecken und den Nutzer aus dem Trott seiner gewohnten Surferfahrung herauszureißen: >Museal ist es eben nicht, den Besucher ohne Umwege zum Segelschiff zu führen, sondern ihn zum Nachdenken über seine Vorstellungen davon zu veranlassen, was ein Segelschiff eigentlich kulturell signifiziert - und woher sein Verlangen rühren mag, eines zu sehen. Lange hat es danach ausgesehen, als sei die von Kuratoren geleistete Kulturarbeit nicht zu automatisieren, geschweige denn gänzlich von Computern zu leisten. In Zukunft wird es darum gehen müssen, die Besucherschaft davon zu überzeugen, dass eine von Menschen informierte und kuratierte Museumsausstellung Mehrwerte gegenüber einer GoogleTrefferliste aufweist, und zwar gerade weil erstere nicht nur Antworten gibt, sondern auch Fragen aufzuwerfen vermag.

Verblüffenderweise muss am Ende all der auf Generalisierung und Objektivierung des Gegenstandes abzielenden Betrachtungen und Ausführungen dieser Arbeit die Einsicht stehen, dass es eine abschließbare Medientheorie des virtuellen Museums scheinbar ebenso wenig gibt wie eine grundsätzliche Pädagogik desselben. Obwohl das >absolute Museum Theoretiker wie Lev Manovich schon die Umstellung der Kulturwissenschaften auf dieselben big data-Methoden in Aussicht stellen, die ihrer Ansicht nach den Zugriff auf kulturelle Inhalte längst unhintergehbar bestimmen: Die Landschaft tatsächlicher virtuell-musealer Angebote im Web zeichnet sich vor allen Dingen durch Heterogenität, Experimentierfreude, Vielfalt in ihren Akteurskonstellationen und Widerständigkeit gegen jede Form von Standardisierung aus (und kann womöglich auch nur in dieser Form sinnvoll existieren). Das virtuelle Museum lebt - ironischerweise genau wie das physische, allerdings unter Ausschaltung geographischer Distanzen - von einer »situated creativity« (Potts, Hartley, Banks et. al. 2008: 460) und einem »situated knowledge« (ebd.), das weder gänzlich in den Köpfen bestimmter Personen noch in konkreten Inhalten und Gegenständen verborgen ist, sondern vielmehr in den situativen Zusammenkünften von Menschen, Orten, Medien, Organisationen usw. (vgl. ebd.).

Mit diesem Befund ist allerdings mitnichten angezeigt, dass die Museumswissenschaft bei jenem stückwerkhaften Kommentieren von Einzelphänomenen verbleiben sollte, welches ihre bisherige Auseinandersetzung mit dem virtuellen Museum weitgehend bestimmt hat. Vielmehr wird die im Fallstudienkapitel dieser Studie ausgemachte Vielgestaltigkeit virtueller Museen im Licht der diesem vorausgegangenen theoretischen und technischen Betrachtungen erst interpretierbar: Virtuelle Museen 
scheinen tatsächlich wie Simondons Kristalle um `Keimeく von Ideen, Konzepten, Inhalten und Akteuren herumzuwuchern - und zwar auf jene Arten, die ihr technisches, soziales und kulturelles Milieu ihnen gestattet. Will man Museumsvirtualisierung als Vorgang analytisch durchdringen, so muss man sowohl diese situativen Zusammenkünfte verstehen, als auch die Bedingungen, unter denen sie zustande kommen, den Keim und die aus ihm hervorgehenden Kristalle ebenso in den Blick nehmen wie das Milieu ihrer Entfaltung. Insofern ist die vorliegende Arbeit vor allem als eine erste umfassende `Milieustudie` darüber zu interpretieren, mit welchen institutionellen, medialen, pädagogischen, personellen, ästhetischen, epistemischen und disziplinären Voraussetzungen einerseits das Museum digitalen Medien und vor allem dem World Wide Web gegenübertritt, und was andererseits diese Medientechnologien dem Museum an technischer und formallogischer Infrastruktur für die Entfaltung seiner Wirkmacht und Arbeitsweise zur Verfügung stellen.

Die Frage nach der >Musealisierung des Virtuellen` wird in Zukunft - dies hat sich in den Fallstudienkapiteln über das Virtual Museum of Canada und Archive.org gezeigt - gerade auch im Hinblick darauf brisant werden, wie wir jenen Teil unseres kulturellen Erbes deponieren und exponieren, der originär digital ist. Die Hypertexttheorie ist aus der Bibliothekswissenschaft entstanden und hat sich Jahrzehntelang an der Bibliothek und ihren kategorial geordneten Katalogsystemen als $>$ Feindbild ‘ abgearbeitet. Das Museum hat sie so gut wie gar nicht thematisiert und sich damit womöglich Impulse vorenthalten, unter deren Einfluss ihre Ideengeschichte sehr anders hätte verlaufen können. Dabei zeichnet sich die potenzielle Relevanz des musealen bzw. kuratorischen Prinzips für die Verwaltung und Präsentation digital gespeicherten Wissens nicht nur darin ab, dass Museen über kontextabhängige Sinnmodule und deren >Vernetzung ‘ funktionieren. Entscheidend ist vor allem auch der Gebrauch, den sie von Raum und Räumlichkeit machen.

Hypertextsysteme werden topologisch konzipiert und in räumlichen Termini beschrieben. Keine Metaphorik des Virtuellen von den Gedächtnispalästen der Antike über Vannevar Bushs `Pfade des Interesses` bis hin zum Cyberspace kommt ohne Begrifflichkeiten aus, die raumzeitliche Verhältnismäßigkeiten beschreiben - Nähe und Ferne, Stillstand und Bewegung, Größenunterschiede und Richtungsangaben, Navigation, Flanerie und Irrwege. Der >virtuelle Raum ‘ ist nicht erst die Domäne von Computerspielen und virtual reality-Applikationen. Er ist vielmehr das Denkmodell, dessen wir uns bedienen, um Informationen als positive Gegenstände behandeln, sie verdinglichen zu können. Richard Saul Wurmans Informationsarchitektur kreist um genau die Einsicht, dass solche Verräumlichungen nicht erst post hoc beim Rezipienten als Lektürestrategien entstehen, sondern auf der Autorenseite bereits vorausgedacht werden müssen, wenn digitale Inhalte effizient vermittelt werden sollen. Das heißt konkret nichts anderes, als dass die Bedingungen digitaler Vermittlung architektonisch behandelt werden müssen, und die konkreten Vermittlungssituationen $k u$ - 
ratorisch. Auch diese Ironie gehört unweigerlich zur Diagnose der Lage des Museums in der digital-technisierten Welt: Es bangt um seine Zukunft zu einer Zeit, in der seine Expertise und Kompetenzen wertvoller und gefragter sein sollten denn je.

Das Bestreben dieser Arbeit, die Virtualisierung des Museums als Kontinuität statt als Bruch zu lesen, weist damit weit über mediengeschichtliche Spitzfindigkeiten hinaus. Wie deutlich gemacht werden konnte, ist es eben diese Fortführung einer Tradition des Virtuellen als Daseinsmodus, vermittels welcher sich das Museum als Referenzinstitution innerhalb laufender Medienwechsel positionieren könnte. Das Museum ist eben nur scheinbar eine >konservative< Einrichtung, die vorrangig speichert und bewahrt. Tatsächlich sind Museen, wie André Malraux schon in den 1940er Jahren erkannte, Stätten der laufenden Neubewertung und Uminterpretation von Bedeutungsträgern und den zwischen ihnen bestehenden Zusammenhängen für Öffentlichkeiten, die sich in Wechselwirkung mit ihnen verändern. Als Mediensysteme sind sie damit weit >flüchtiger`, als es sich Museumsleute meist einzugestehen gestatten. An der Tatsache, dass das Museum dieser Flüchtigkeit von Bedeutungen und Anschlussfähigkeiten zum Trotz (oder womöglich gerade ihretwegen!) seine monumentale Stellung durch die Jahrhunderte hindurch immer wieder behaupten konnte, lässt sich einiges über seine Fähigkeit ablesen, Virtualität zu bewältigen und Permanenz zu produzieren.

Indes kann und wird die soziokulturelle Verortung des Museums die fortschreitende Digitalisierung von Sammlungsbeständen und die Ausweitung der Ausstellungsfläche auf Milliarden von Computerbildschirme nicht unverändert überstehen. Der Museumsbegriff der Zukunft wird ein weiterer und weicherer sein als jener der Gegenwart, wie jener der Gegenwart bereits ein weiterer und weicherer ist als jener der Vergangenheit. Laienprojekte werden weiterhin ihr Recht einfordern, >museal auftreten zu dürfen - und keine Instanz wird es ihnen zu verweigern vermögen. Immer ausgefeiltere Suchalgorithmen werden die Grenzen zwischen individuellen Angeboten und damit auch zwischen Musealem und Profanem im Web weiter verwischen - und virtuelle Museen zu Kompromissen zwischen Schock und Anschlussfähigkeit bzw. zwischen Daseinsberechtigung und Auffindbarkeit zwingen. Die Verfügbarkeit immer hochauflösenderer Digitalisate von musealen Ausstellungsstücken wird das Bild, das sich das Publikum von den Dingen macht, ebenso verändern wie das Verhältnis, in dem es sich zu diesen Dingen sieht. Das Web und seine Kultur des unverzögerten Findens und Verwertens haben die Erwartungen und Forderungen des Publikums verändert und werden dies auch in Zukunft tun.

Wenn sich aus den Veröffentlichungen zur Museumsvirtualisierung der 1990er Jahre eine Lehre ziehen lässt, dann ist es die, dass extrem utopische oder apokalyptische Zukunftsprognosen meist ins Leere laufen und ihren Verfassern ein bis zwei Jahrzehnte später allenfalls zur Peinlichkeit gereichen. Das absolute Museum ist als solches bisher ausgeblieben - jedoch haben gänzlich unmuseal konzipierte Dienste viele seiner einstmals antizipierten Funktionen übernommen. Das Ideal permanenter 
Zweiwege-Kommunikation zwischen Kuratoren und Besuchern bleibt unverwirklicht - aber sowohl Kuratoren als auch Besuchern stehen neue Kanäle offen, sich einander mitzuteilen. Das Original hat weder Materialität noch Aura eingebüßt - aber digitale Technik hat uns neue Ansichten von Dingen und Räumen erschlossen, die wir nicht ungesehen machen können. Die Museumsvirtualisierung ist als Praxiserscheinung weder geglückt noch gescheitert, und sie läuft nicht in eine einzige, klar bestimmbare Richtung. Sie ist vielmehr selbst eine fortwährende Bricolage im Potenziellen und ein Ausloten der Möglichkeiten und Grenzen von Begriffen, Technologien, Institutionen und sozialen Akzeptanzen, das nicht auf Erfolg oder Misserfolg hin zu befragen ist, sondern auf Strategien und deren Resultate - und zwar sowohl auf Seiten der Produzenten als auch der Rezipienten.

Unter welchen technischen Voraussetzungen virtuelle Museen in Zukunft funktionieren werden, kann nur gemutmaßt werden. Eine naheliegende Voraussage ist allerdings jene, dass HTML-Seiten weiterhin das Gros virtueller Museumsprojekte unterbauen werden. Nach wie vor reflektieren vernetzte Webseiten überaus sinnfällig die mediale Logik von Ausstellungen und nach wie vor sind HTML und HTTP die wichtigsten, gängigsten und preisgünstigsten Schnittstellen für die Erstellung von Webinhalten. Dass Grafikengines, wie sie in Computerspielen zum Einsatz kommen, ihnen in absehbarer Zeit als Schlüsseltechnologie der Museumsvirtualisierung den Rang ablaufen könnten, ist unwahrscheinlich - schließlich existieren solche EchtzeitBildgebungsverfahren schon seit Jahrzehnten, ohne dass die Kulturvermittlung sie in großem Stil aufgegriffen hätte. Das soll nicht heißen, dass aus diesem Bereich nicht mit interessanten Neuerungen zu rechnen wäre. So befindet sich für das VR-Headset Oculus Rift derzeit eine Anwendung in der Entwicklung, die in ganz bewusster Anlehnung an André Malraux den Namen Le Musée Imaginaire trägt und ihren Nutzern nicht nur die Möglichkeit verspricht, eine fantastische Galerie mit Kunstwerken der unterschiedlichsten Epochen begehen, sondern auch, die Peripherie der $>$ Leinwand durchbrechen und in die Szenerien von Gemälden eintauchen zu können. ${ }^{1}$ Es wird also nicht weniger in Aussicht gestellt als eine immer komplexere Schichtung von Virtualitäten: Das Museum, das aus seiner medialen Natur heraus ohnehin ein virtueller Raum ist, wird übertragen in eine computergrafische Simulation, die nun das physisch unmögliche Phantasma >Wirklichkeit` werden lässt, in flache Bilder einzutauchen (und damit natürlich das fundamentale Funktionieren von Computergrafik, nämlich die Projektion dreidimensionaler Geometriedaten in die zweidimensionale Fläche des Bildschirms, pointiert ins Gegenteil wendet). All das geschieht auf Basis einer Technologie, die völlige Immersion in solchen simulierten Räumen verspricht und deren Potential für die Kulturvermittlung ebenso wenig absehbar ist wie ihre tatsächliche Tauglichkeit für den Massenmarkt.

1 Vgl. https://share.oculus.com/app/le-muse-imaginaire vom 03.03.2016. 
Dieses immer höhere Stapeln von Virtualitätsebenen scheint eine recht eindeutige Tendenz abzubilden: Museen werden längst nicht mehr virtuell, sondern virtueller. Virtuelle Museen werden mit sozialen Netzwerken verschaltet, physische richten sich darauf ein, nicht nur mit dem Besucher, sondern auch mit seinem Handy kommunizieren zu müssen. Die >augmentierteく Realität wird möglicherweise mehr noch als die svirtuelle $<$ das Museum in die Außenwelt und die Außenwelt ins Museum tragen. Museen waren zwar immer schon >vernetzte Einrichtungen, aber diese Vernetzung geschah innerhalb ihrer etablierten Kompetenzbereiche: als kuratorische Zusammenstellung von Exponaten, als Kooperation zwischen individuellen Häusern, als >soziale Szenographie< zwischen Besuchern. Die Virtualisierung verlangt nun von ihnen, sich mit Plattformen und Dienstleistern zu vernetzen, denen der Bildungsauftrag des Museums nicht nur fremd ist, sondern die ihm womöglich völlig zuwiderlaufen. Wenn Suchmaschinen >sehen` können, ist es ein Leichtes, sich Apps für Geräte wie Google Glass oder Microsoft HoloLens vorzustellen, die dem Träger einer solchen Datenbrille zu jedem Kunstwerk, das er sich im Museum anschaut, sofort auch den Wikipedia-Artikel und Zoom-Ansichten bereitstellen. Das Original-Exponat muss um seine Aura wohl auch in Zukunft nicht bangen - die stechnischen Dinge $<$ des Museums aber, allen voran die althergebrachte Erklärungstafel, sehen sich mit ganz neuer Konkurrenz konfrontiert. Dass die Museumsvirtualisierung grundsätzlich ein Prozess ist, und nicht etwa ein abschließbares Phänomen, und dass sie als Prozess nicht zuletzt auch eine Abfolge technischer Entwicklungen darstellt, muss als Ergebnis dieser Arbeit kaum betont werden. Die Implikation für die Museumswissenschaft ist aber eine brisante: Nicht nur, dass die Museumsvirtualisierung eine grundlegende Auseinandersetzung mit den medialen Eigenarten des Museums einfordert - sie bedingt auch, dass die Auseinandersetzung niemals zum Abschluss gebracht werden kann, weil ihre medialen Bedingungen nicht aufhören werden, sich zu verändern.

Ähnliches gilt für die soziale Situiertheit virtueller Museen und deren Verhältnis $\mathrm{zu}$ jener der physischen Institution. Ob (und falls ja, in welchem Ausmaß) sich die öffentliche Wahrnehmung der Institution Museum unter dem Eindruck von Virtualisierungsphänomenen verändert hat, ist derzeit kaum auszumachen. Recht eindeutig feststellbar ist jedoch die Tatsache, dass sich der Museumsbegriff (gerade unter dem long tail der Kulturvermittlung im Netz) mehr und mehr zum Schlagwort einer Aneignung von medialen Kanälen durch kulturell interessierte Laien entwickelt hat. Virtuelle Museen wie das Museum of Fred stellen das Museum und seine institutionellen Ausformungen auf den plebiszitären Prüfstand, affirmieren es aber zugleich als Gegenentwurf zur Beliebigkeit der Suchmaschinen und Empfehlungsaggregatoren schlicht aus der Tatsache heraus, dass sie im Web als kuratierte Angebote mit musealer Selbstbezeichnung auftreten. Die zahllosen von Privatpersonen betriebenen virtuellen Museen im Internet zeichnen sich überwiegend dadurch aus, dass sie sich so- 
wohl den Relevanzkriterien einer wie auch immer definierten Hochkultur wiedersetzen als auch jenen des stochastisch gemittelten Mainstreams von Suchalgorithmen und Rankingsystemen.

Die Idee der inhaltlichen Geschlossenheit und der autorschaftlichen Gemachtheit schwingt in der Selbstbeschreibung von Amateurprojekten als `Museen` unweigerlich mit. Ginge es nur darum, Bild- und Textmaterial mit anderen Interessierten zu teilen, ließe sich dies problemlos über irgendeines der zahlreichen sozialen Netzwerke abwickeln, die um Gunst und Daten des Publikums buhlen. Der Museumsbegriff impliziert eine konkrete, erzählerisch aufgeladene Vermittlungsabsicht mit spezifischer inhaltlicher Stoßrichtung und eine Bereitschaft zur Pflege und Bewahrung dieser Inhalte, und somit versteckt sich auch hier eine Kontinuität in einem vermeintlichen Bruch: Virtuelle Museen erlauben veränderte Akteurskonstellationen in der Museumslandschaft und damit auch das grundlegende Infragestellen von Didaktiken und Werten, aber sie lehnen sich dabei an jene Ideale und Prinzipien an, die auch die physische Institution im Innersten zusammenhalten. Sie stellen eben keine Abkehr von den Leitideen des klassischen Museumsdispositivs dar - nämlich der Herstellung von kultureller Kontinuität, der Bewahrung von Dingen und Bedeutungen, der Fruchtbarmachung der Vergangenheit für die Zukunft und des Anderen für uns sondern vielmehr den Versuch, dessen Mission auf eine mediale Infrastruktur zu übertragen, der das Vergessen gerade auch über sich selbst eingeschrieben zu sein scheint.

Insofern darf die Museumswissenschaft und -praxis durchaus mit Wohlwollen, wenn nicht gar mit Stolz, auf das virtuelle Museum blicken. Das museale Prinzip des Lernens und Erlebens ist lebendig, gefragt und zeitgemäß - wenn es sich auch nicht länger in der alleinigen Obhut professioneller Wissensarbeiter befindet, wenn auch die Dispositive seiner Rezeption verschachtelter, vielfältiger und uneindeutiger geworden sind, wenn auch ganz neue Wege gefunden werden mussten und müssen, um Authentizität zu generieren. Die Magie des Museums, seine Verbindung zwischen Sichtbarem und Unsichtbarem, An- und Abwesendem, seine virtus (die eben schon immer virtuell war) verschwindet nicht, sondern sie wird neu verhandelt, neu technisiert, neu konnotiert und neu inszeniert. Wie das geschieht und was es bewirkt, sind Fragen, die es entsprechend immer wieder aufs Neue zu beantworten gelten wird. Das virtuelle Museum ist gewissermaßen selbst ein epistemisches Ding im Rheinberger'schen Sinne: Es hat nichts `Eigentliches« an sich, sondern entsteht in der medialen Praxis und aus ihr heraus - und zu jeder seiner Iterationen lassen sich nur seine Eigenschaften und Tätigkeiten auflisten, die sich in der Domäne des Technischen manifestieren.

Diese Beschreibungsarbeit zu leisten, heißt das Technische zu zivilisieren, das Menschliche zu kennzeichnen und das Museum von Babel laufend neu zu kartieren - mal als Flaneur, mal als Detektiv, aber stets im Bewusstsein, dass auch in den Netzen die Musen sitzen. 


\section{Literatur}

Aarseth, Espen (1995): »Nonlinearity and Literary Theory«, in: George P. Landow (Hg.), Hyper/Text/Theory, Baltimore u.a: John Hopkins University Press, S. 5186.

Aarseth, Espen (1997): Cybertext. Perspectives on Ergodic Literature, Baltimore u.a.: John Hopkins University Press.

Abel, Günter (2000): »Sagen und Zeigen«, in: Werner Stegmaier (Hg.), Kultur der

Zeichen, Frankfurt a.M.: Suhrkamp, S. 61-98.

Agamben, Giorgio (2008): Was ist ein Dispositiv?, Zürich u. Berlin: Diaphanes.

Anderson, Chris (2007): The Long Tail. Der lange Schwanz. Nischenprodukte statt Massenmarkt: Das Geschäft der Zukunft, München: Hanser.

Anderson, David (2000): »Networked Museums in the Learning Age«, https://web.archive.org/web/20130723193107/http://www.cultivate-int.org/ issue2/networked/ vom 09.06.2018.

Andreae, Johann Valentin (1977): Christianopolis. Utopie eines christlichen Staates aus dem Jahre 1619, Leipzig: Koehler \& Amelang.

Andrews, James/Schweibenz, Werner (1998): »The Kress Study Collection Virtual Museum Project: A New Medium for Old Masters«, in: Art Documentaton 17, S. 19-27.

Arendt, Hannah (2013): Vita activa oder Vom tätigen Leben, München: Piper.

Aristoteles (2014): Poetik. Griechisch/Deutsch, Stuttgart: Reclam.

Ascott, Roy (1996): »Der Geist des Museums. Bauen in den Netzen«, http://www.heise.de/tp/artikel/6/6077/1.html vom 09.06.2018.

Assmann, Aleida (1988): »Die Sprache der Dinge. Der lange Blick und die wilde Semiose «, in: Hans Ulrich Gumbrich/Karl Ludwig Pfeiffer/Monika Elsner (Hg.), Materialität der Kommunikation, Frankfurt a.M.: Suhrkamp, S. 237-251.

Barthes, Roland (2000): »Der Tod des Autors«, in: Fotis Jannidis/Gerhard Lauer/Matias Martinez/Simone Winko (Hg.), Texte zur Theorie der Autoschaft, Stuttgart 2000: Reclam, S. 198-229. 
Barthes, Roland (1989): Die helle Kammer. Bemerkungen zur Photographie, Frankfurt a.M.: Suhrkamp.

Bates, Philip (2015): »Upscaling: How Does It Work and Is It Worth It?«, http://www.makeuseof.com/tag/upscaling-how-does-it-work-and-is-it-worth-it/ vom 09.06.2018.

Bateson, Gregory (1972): Steps to an Ecology of the Mind, Chicago: University of Chicago Press.

Battro, Antonio M. (1999): »From Malraux's Imaginary Museum to the Virtual Museum«, https://web.archive.org/web/20140213210343/http://www.byd.com.ar/ vm99sep.htm, vom 09.08.2018.

Bearman, David/Trant, Jennifer (1998): »Authenticity of Digital Resources. Towards a Statement of Requirements in the Research Process«, http://www.dlib.org/ dlib/june98/06bearman.html vom 09.06.2018.

Becker, Konrad (2010): »Die Macht der Klassifizierung. Abgründe des Wissens an den Klippen der Ordnung«, in: Ders. (Hg.), Deep Search. Politik des Suchens jenseits von Google, Bonn 2010: Bundeszentrale für politische Bildung, S. 182192.

Beier-de Haan, Rosmarie (2010): You Can Always Get What You Want. History, the Original, and the Endless opportunities of the Copy, in: International Council of Museums (Hg.), Original, Copy, Fake. On the Significance of the Object in History and Archeology Museums. 22nd ICOM General Conference in Shanghai, China, 7-12nd November 2010, http://network.icom.museum/fileadmin/user_upload/minisites/ icmah/publications/Actes-Shanghai-complet2.pdf, S. 2-5 vom 02.04.2016

Belongie, Serge/Carson, Chad/Greenspan, Hayit/Malik, Jitendra (1998): »Color- and Texture-Based Image Segmentation Using EM and Its Application to ContentBased Image Retrieval«, http://citeseerx.ist.psu.edu/viewdoc/download?doi= 10.1.1.57.748\&rep=rep1\&type=pdf vom 09.06.2018.

Benjamin, Walter (2008): »Das Kunstwerk im Zeitalter seiner technischen Reproduzierbarkeit«, in: Ders., Das Kunstwerk im Zeitalter seiner technischen Reproduzierbarkeit. Drei Studien zur Kunstsoziologie, Frankfurt a.M.: Suhrkamp, S. 744.

Benjamin, Walter (2007): »Über den Begriff der Geschichte«, in: Alexander Honold (Hg.), Walter Benjamin erzählen. Schriften zur Theorie der Narration und zur literarischen Prosa, Frankfurt a.M.: Suhrkamp, S. 129-140.

Bense, Max (1960): Programmierung des Schönen, Baden-Baden u. Krefeld: AgisVerlag.

Berners-Lee, Tim/Handler, James/Lassila, Ora (2001): »The Semantic Web. A New Form of Web Content that Is Meaningful to Computers and Will Unleash a Rev- 
olution of New Possibilities«, http://edu.cs.uni-magdeburg.de/EC/lehre/sommersemester-2015/semantic-web-technologien/material/tim-bernes-lee-jameshendler-ora-lassila-the-semantic-web/at_download/file vom 09.06.2018.

Besser, Howard (1997): »The Changing Role of Photographic Collections with the Advent of Digitization«, in: Katherine Jones-Garmil (Hg.), The Wired Museum. Emerging Technology and Changing Paradigms, Washington D.C.: American Association of Museums, S. 115-127.

Blackaby, James R. (1997): »Integrated Information Systems«, in: Katherine JonesGarmil (Hg.), The Wired Museum. Emerging Technology and Changing Paradigms, Washington D.C.: American Association of Museums, S. 203-229.

Boas, Franz (1907): »Some Principles of Museum Administration«, in: Science 25, S. 921-933.

Böhme, Gernot (1995): Atmosphäre. Essays zur neuen Ästhetik, Frankfurt a.M.: Suhrkamp.

Borel, Émile (1913): »La mécanique statique et l'irréversibilité«, in: Journal de Physique Théorique et Appliquée 3/1, S. 189-196.

Borges, Jorge Luis (2010): »Die Bibliothek von Babel«, in: Ders., Die unendliche Bibliothek. Erzählungen, Frankfurt a.M.: Fischer, S. 146-160.

Bredekamp, Horst (2007): Antikensehnsucht und Maschinenglauben. Die Geschichte der Kunstkammer und die Zukunft der Kunstgeschichte, Berlin: Verlag Klaus Wagenbach.

Brin, Sergey/Page, Larry (1998): »The Anatomy of a Large Scale Hypertextual Web Search Engine«, http://ilpubs.stanford.edu:8090/361/1/1998-8.pdf vom 09.06.2018.

Bührmann, Andrea D./Schneider, Werner (2008): Vom Diskurs zum Dispositiv. Eine Einführung in die Dispositivanalyse, Bielefeld: transcript.

Bush, Vannevar (1945): »As We May Think«, http://www.theatlantic.com/ magazine/archive/1945/07/as-we-may-think/3881/ vom 09.06.2018.

Bussel, Jennifer (2014): »Cyberspace«, http://www.britannica.com/topic/cyberspace vom 09.06.2018.

Cameron, Duncan F. (1972): »The Museum: A Temple or the Forum«, in: Journal of World History 14/1, S. 189-202.

Carlson, Nicholas (2012): »Inside Pinterest. An Overnight Success Four Years in the Making«, http://www.businessinsider.com/inside-pinterest-an-overnight-success -four-years-in-the-making-2012-4?op=1\&IR=T vom 09.06.2018.

Carlson, Patricia Ann (1995): »Varieties of Virtual. Expanded Metaphors for Computer-Mediated Learning«, in: Edward Barrett (Hg.), Sociomedia. Multimedia, Hypermedia and the Social Construction of Knowledge, Cambridge, MA: MIT Press, S. 53-77.

Certeau, Michel de (1988): Kunst des Handelns, Berlin: Merve. 
Crook, Jordan (2012): »This Is Everything You Need to Know About Pinterest«, http://techcrunch.com/2012/03/14/this-is-everything-you-need-to-know-aboutpinterest-infographic/ vom 09.06.2018.

Davis, Ben Howell (1994): »Digital Museums«, http://www.mit.edu/ bhdavis/ DigitalMus.html vom 09.06.2018.

Deleuze, Gilles/Guattari, Félix (1977): Rhizom, Berlin: Merve.

Deleuze, Gilles (1991): »Was ist ein Dispositiv?«, in: François Ewald (Hg.), Spiele der Wahrheit. Michel Foucaults Denken, Frankfurt a.M.: Suhrkamp, S. 153-162.

Deleuze, Gilles (1992): Differenz und Wiederholung, München: Fink Verlag.

DiNucci, Darcy (1999): »Fragmented Future«, in: Print 53/4, S. 32 u. 221-222.

Dotzler, Bernhard J. (2005): »Analog/digital«, in: Alexander Roesler/Bernd Stiegler (Hg.), Grundbegriffe der Medientheorie, Paderborn: Wilhelm Fink Verlag, S. 916.

Douglas, J. Yellowlees (1995): »>How Do I Stop This Thing?‘ Closure and Indeterminacy in Interactive Narratives «, in: George P. Landow (Hg.), Hyper/Text/Theory, Baltimore u.a.: John Hopkins University Press, S. 159-188.

Eco, Umberto (2011): Über Spiegel und andere Phänomene, München: DTV.

Eco, Umberto (2012): Nachschrift zum `Namen der Rose`, München: DTV.

Eco, Umberto (2015): Das Foucaultsche Pendel, München: DTV.

Ernst, Wolfgang (1997): »Geschichte und digitale Medien«, in: Klaus Bergmann (Hg.), Handbuch der Geschichtsdidaktik, Seelze-Velber: Kallmeyersche Verlagsbuchhandlung, S. 694-701.

Filkin, David (2002): »Is Anybody Listening?«, http://www.nobelprize.org/ nobel_organizations/nobelfoundation/symposia/interdisciplinary/ns120/lectures /filkin.pdf vom 09.06.2018.

Fleming, Jenna/Shunk, Scott/Steward, Jeff (2008): »The Meta Art Museum. Towards the Promise of an Open Collaboration Platform«, http://www.museumsandthe web.com/mw2008/papers/fleming/fleming.html vom 09.06.2018.

Flückiger, Barbara (2011): »Die Vermessung ästhetischer Erscheinungen«, in: Zeitschrift für Medienwissenschaft 5, S. 44-60.

Flusser, Vilém (1993): »Vom Virtuellen«, in: Florian Rötzer/Peter Weibel (Hg.), Cyberspace. Zum medialen Gesamtkunstwerk, München: Boer Verlag, S. 65-71.

Foucault, Michel (1978): Dispositive der Macht. Über Sexualität, Wissen und Wahrheit, Berlin: Merve.

Foucault, Michel (2012): Der Wille zum Wissen. Sexualität und Wahrheit 1, Frankfurt a.M.: Suhrkamp.

Garfield, Eugene (1984a): »»Science Citation Index^. A New Dimension in Indexing «, in: Ders. (Hg.), Essays of an Information Scientist, Wilmington: ISI Press, S. 525-535. 
Garfield, Eugene (1984b): »Towards the World Brain«, in: Ders. (Hg.), Essays of an Information Scientist, Wilmington: ISI Press, S. 8-9.

Gautier, Gary T. (1986): »National Museum of Natural History, Smithsonian Institution«, in: Richard B. Light/D. Andrew Roberts/Jennifer D. Steward (Hg.), Museum Documentation Systems: Developments and Applications, Oxford: Butterworth, S. 48-54.

George-Cosh, David (2008): »Idée's TinEye Next Frontier in Web Searches«, https://tineye.com/pdf/idee-national-post.pdf vom 09.06.2018.

Gibbons, Jemima (2009): Monkeys with Typewriters. Myths and Realities of Social Media at Work, Axminster: Triarchy Press.

Gibson, William (2003): »Burning Chrome«, in: Ders., Burning Chrome, New York: EOS / Harper Collins, S. 179-204.

Gibson, William (1984): Neuromancer, New York: Ace Books.

Gibson, William (1991): »Academy Leader«, in: Michael L. Benedict (Hg.): Cyberspace. First Steps, Cambridge, MA: MIT Press, S. 27-29.

Glass, Claudia u. Gugger, Beat (2011): »Grenzen und Chancen von partizipativen Projekten«, in: Susanne Gesser/Martin Handschin/Angela Jannelli/Sibylle Lichtensteiger(Hg.), Das partizipative Museum. Zwischen Teilhabe und User Generated Content. Neue Anforderungen an kulturhistorische Ausstellungen, Bielefeld: transcript, S. 174-178.

Glock, Andreas (2006): »Museion«, http://referenceworks.brillonline.com/entries/der-neue-pauly/museion-e812620 vom 09.06.2018.

Gottmann, Günther (1976): »Zum Bildungsauftrag eines technikgeschichtlichen Museums«, in: Ellen Spickernagel/Brigitte Walbe (Hg.), Das Museum. Lernort contra Musentempel, Giessen: Anabas-Verlag, S. 32-35.

Grossarth, Ulrike (2005): »Mentale Felder und andere Orte «, in: Anke te Heesen/ Petra Lutz (Hg.), Dingwelten: Das Museum als Erkenntnisort, Köln: Böhlau Verlag, S. 45-52.

Gruber, Thomas R. (1993): »A Translation Approach to Portable Ontology Specifications«, http://tomgruber.org/writing/ontolingua-kaj-1993.pdf vom 09.06.2018.

Grütter, Heinrich Theodor (1997): »Die historische Ausstellung«, in: Klaus Bergmann (Hg.), Handbuch der Geschichtsdidaktik, Seelze-Velber: Kallmeyersche Verlagsbuchhandlung, S. 668-674.

Gütt, Dorian Ines (2010): »App. Smartphone-Applikationen im Museumsbereich«, http://museums-app.com/archiv/Bachelorarbeit_Guett_mail.pdf_ vom 09.06.2018.

Habermas, Jürgen (1982): Strukturwandel der Öffentlichkeit. Untersuchungen zu einer Kategorie der bürgerlichen Gesellschaft, Darmstadt u. Neuwied: Luchterhand. 
Hächler, Beat (2011): »Gegenwartsräume. Ansätze einer sozialen Szenographie im Museum«, in: Susanne Gesser/Martin Handschin/Angela Jannelli/Sibylle Lichtensteiger (Hg.), Das partizipative Museum. Zwischen Teilhabe und User Generated Content. Neue Anforderungen an kulturhistorische Ausstellungen, Bielefeld: transcript, S. 136-145.

Hanak-Lettner, Werner (2011): Die Ausstellung als Drama. Wie das Museum aus dem Theater entstand, Bielefeld: transcript.

Harsdörffer, Georg Philipp (1648): Poetischer Trichter. Die Teutsche Dicht- und Reimkunst, ohne Behuf der Lateinischen Sprache in VI. Stunden einzugiessen. Erster Theil, Nürnberg: Wolfgang Endters.

Hartung, Olaf (2010): Kleine deutsche Museumsgeschichte. Von der Aufklärung bis zum frühen 20. Jahrhundert, Köln: Böhlau.

Heesen, Anke te (2005): »Verkehrsformen der Objekte«, in: Dies./Petra Lutz (Hg.), Dingwelten: Das Museum als Erkenntnisort, Köln: Böhlau, S. 53-64.

Heidegger, Martin (1992): Bauen Wohnen Denken, in: Dietmar Keller/Hans Wielens (Hg.), Der Mensch Sein Haus Das Glück. Aphorismen, Sprichwörter und literarische Sentenzen zu Architektur und Wohnen, Münster: Coppenrath Verlag, S. IXXII.

Hein, Dörte (2009): ») Seriöse Information` oder `schöne Bilder`? Kommemorative Kommunikation aus der Perspektive der Anbieter«, in: Erik Meyer (Hg.), Erinnerungskultur 2.0. Zur Transformation kommemorativer Kommunikation in digitalen, interaktiven Medien, Frankfurt a.M.: Campus, S. 145-173.

Herbold, Astrid (2009): Das große Rauschen. Die Lebenslügen der digitalen Gesellschaft, München: Droemer.

Hermann, Guy (1997): »Shortcuts to Oz. Strategies and Tactics for Getting Museums to the Emerald City«, in: Katherine Jones-Garmil (Hg.), The Wired Museum. Emerging Technology and Changing Paradigms, Washington D.C.: American Association of Museums, S. 65-91.

Hockey, Susan (2004): »The History of Humanities Computing«, http://www. digitalhumanities.org/companion/view?docId=blackwell/9781405103213/97814 05103213.xml\&chunk.id=ss1-2-1 vom 09.06.2018.

Hoffmann, Detlev (1976): »)Laßt Objekte sprechen!‘ Bemerkungen zu einem verhängnisvollen Irrtum«, in: Ellen Spickernagel/Brigitte Walbe (Hg.), Das Museum. Lernort contra Musentempel, Giessen: Anabas-Verlag, S. 101-120.

Hooper-Greenhill, Eilean (1995): »Museums and Communication. An Introductory Essay«, in: Dies. (Hg.), Museum, Media, Message, London u. New York: Routledge, S. 1-12.

Hoptman, Glen (1995): »The Virtual Museum and Related Epistemological Concerns«, in: Edward Barrett (Hg.), Sociomedia. Multimedia, Hypermedia and the Social Construction of Knowledge, Cambridge, MA: MIT Press, S. 141-160. 
Huhtamo, Erkki (2002): »The Origins of the Virtual Museum«, https://www. nobelprize.org/nobel_organizations/nobelfoundation/symposia/interdisciplinary/ns120/lectures/huhtamo.pdf vom 09.06.2018.

Hui, Yuk (2013): »Deduktion, Induktion und Transduktion. Über Medienästhetik und digitale Objekte«, in: Zeitschrift für Medienwissenschaft 8, S. 101-116.

Hume, David (2011a): »A Treatise of Human Nature«, in: Tom Griffith (Hg.), Hume. The Essential Philosophical Works, Ware: Wordsworth, S. 1-551.

Hume, David (2011b): »An Enquiry Concerning Human Understanding«, in: Tom Griffith (Hg.), Hume. The Essential Philosophical Works, Ware 2011: Wordsworth, S. 573-706.

Husserl, Edmund (1985): Texte zur Phänomenologie des inneren Zeitbewussteins (1893-1917), Hamburg: Felix Meiner Verlag.

Jameson, Frederic (1984): »Postmodernism, or the Cultural Logic of Late Capitalism«, New Left Review 146, S. 53-92.

Jank, Sabine (2011): »Strategien der Partizipation«, in: Susanne Gesser/Martin Handschin/Angela Jannelli/Sibylle Lichtensteiger (Hg.), Das partizipative Museum. Zwischen Teilhabe und User Generated Content. Neue Anforderungen an kulturhistorische Ausstellungen, Bielefeld: transcript, S. 146-155.

Jannelli, Angela (2011): »Wilde Museen. Das Amateurmuseum als partizipative Graswurzelbewegung«, in: Susanne Gesser/Martin Handschin/Angela Jannelli/ Sibylle Lichtensteiger (Hg.), Das partizipative Museum. Zwischen Teilhabe und User Generated Content. Neue Anforderungen an kulturhistorische Ausstellungen, Bielefeld: transcript, S. 164-173.

Jeanneney, Jean Noël (2007): Google and the Myth of Universal Knowledge. A View from Europe, Chicago: University of Chicago Press.

Jones-Garmil, Katherine (1997): »Laying the Foundation. Three Decades of Computer Technology in the Museum«, in: Dies. (Hg.), The Wired Museum. Emerging Technology and Changing Paradigms, Washington D.C.: American Association of Museums, S. 35-62.

Jungen, Oliver (2008): »Erfolg ist, wenn man zusammenbricht«, http://www.faz.net /aktuell/politik/europaeische-union/digitale-bibliothek-europeana-erfolg-ist-wenn -man-zusammenbricht-1724149.html vom 06.09.2018.

Kac, Eduardo (1997): »Das Internet und die Zukunft der Kunst. Immaterialität, Telematik, Videokonferenzen, Hypermedia, Networking, VRML, Interaktivität, Bildtelefone, Software für Künstler, Telerobotik, Mbone und darüber hinaus «, in: Stefan Münker/Alexander Roesler (Hg.), Mythos Internet, Frankfurt a.M.: Suhrkamp, S. 291-318. 
Kansteiner, Wulf (2009): »Alternative Welten und erfundene Gemeinschaften: Geschichtsbewusstsein im Zeitalter interaktiver Medien«, in: Erik Meyer (Hg.): Erinnerungskultur 2.0. Zur Transformation kommemorativer Kommunikation in digitalen, interaktiven Medien, Frankfurt a.M.: Campus, S. 29-54.

Kant, Immanuel (1995): Kritik der reinen Vernunft (= Werke Bd. 2), Köln: Könemann.

Keath, Jason (2012): »250+ Brands on Pinterest«, http://www. socialfresh.com/brands-on-pinterest/ vom 05.01.2015.

Keene, Suzanne (1998): Digital Collections. Museums and the Information Age, Oxford: Butterworth-Heinemann.

Kittler, Friedrich A. (1980): »Einleitung«, in: Ders. (Hg.), Austreibung des Geistes aus den Geisteswissenschaften. Programme des Poststrukturalismus, Paderborn u.a.: Schöningh, S. 7-14.

Kittler, Friedrich A. (1990): »Fiktion und Simulation«, in: Karlheinz Barck (Hg.), Aisthesis. Wahrnehmung heute und Perspektive einer anderen Ästhetik, Leipzig: Reclam, S. 196-213.

Kittler, Friedrich A. (1995): »Museums on the Digital Frontier«, in: Alexander García Düttmann (Hg.), The End(s) of the Museum. Els limits del museu, Barcelona: Fundacío Antoni Tàpies, S. 67-80.

Kittler, Friedrich A. (2002): »Computergrafik. Eine halbtechnische Einführung«, in: Herta Wolf/Susanne Holschbach (Hg.), Paradigma Fotografie. Fotokritik am Ende des fotografischen Zeitalters, Frankfurt a.M.: Suhrkamp, S. 178-194.

Kleinberg, Jon M. (1998): »Authoritative Sources in a Hyperlinked Environment«, http://www.cs.cornell.edu/home/kleinber/auth.pdf vom 09.06.2018.

Knaller, Susanne (2005): »Genealogie des ästhetischen Authentizitätsbegriffs«, in: Dies./Harro Müller (Hg.), Authentizität. Diskussion eines ästhetischen Begriffs, München: Fink Verlag, S. 17-35.

Korff, Gottfried (2002a): »Objekt und Information im Widerstreit«, in: Martina Eberspächer/Gudrun Marlene König/Bernhard Tschofen (Hg.), Museumsdinge. Deponieren - Exponieren, Köln, Weimar \& Wien: Böhlau, S.113-125.

Korff, Gottfried (2002b): »Zur Eigenart der Museumsdinge«, in: Martina Eberspächer/Gudrun Marlene König/Bernhard Tschofen (Hg.), Museumsdinge. Deponieren - Exponieren, Köln, Weimar \& Wien: Böhlau, S.140-145.

Korff, Gottfried (1999): »Bildwelt Ausstellung. Die Darstellung von Geschichte im Museum«, in: Ulrich Borsdorf/Heinrich Theodor Grütter (Hg.), Orte der Erinnerung. Denkmal, Gedenkstätte, Museum, Frankfurt a.M.: Campus, S. 319-335.

Korff, Gottfried (2005): »Betörung durch Reflexion. Sechs um Exkurse ergänzte Bemerkungen zur epistemischen Anordnung von Dingen«, in: Ankte te Heesen/Petra Lutz (Hg.), Dingwelten: Das Museum als Erkenntnisort, Köln: Böhlau, S. 89-107. 
Krameritsch, Jakob (2007): Geschichte(n) im Netzwerk. Hypertext und dessen Potenziale für die Produktion, Repräsentation und Rezeption der historischen Erzählung, Münster: Waxmann.

Krawetz, Neal (2011): »Looks Like It«, http://www.hackerfactor.com/blog/?/ archives/432-Looks-Like-It.html vom 09.06.2018.

Kroker, Arthur/Weinstein, Michael A. (1994): Data Trash, New York: St. Martin's Press.

Langford, David (1997): »The Net of Babel«, in: David Pringle (Hg.), The Best of Interzone, New York: St. Martin's Press, S. 450-454.

Laßwitz, Kurd (1998): Die Universalbibliothek, Hannover: Matthias Wehrhahn Verlag.

Latour, Bruno (1996): „On Actor-Network Theory. A Few Clarifications Plus More Than a Few Complications«, http://www.bruno-latour.fr/sites/default/files/ P-67\%20ACTOR-NETWORK.pdf vom 09.06.2018.

Leibniz, Gottfried Wilhelm (1996): Hauptschriften zur Grundlegung der Philosophie Teil I, Hamburg: Felix Meiner Verlag.

Lessig, Lawrence (2001): Code und andere Gesetze des Cyberspace, Berlin: Berlin Verlag.

Levenson, Jay A. (1998): »Digital Imaging and Issues of Authenticity in Art Museums«, in: Selma Thomas/Ann Mintz (Hg.), The Virtual and the Real. Media in the Museum, Washington D.C.: American Association of Museums, S. 89-101.

Lévi-Strauss, Claude (2002): Strukturale Anthropologie I, Frankfurt a.M.: Suhrkamp. Liebe, Michael (2008): »Die Dispositive des Computerspiels«, in: Jan Distelmeyer/ Christine Hanke/Dieter Mersch (Hg.), Game Over? Perspektiven des Computerspiels, Bielefeld: transcript, S. 73-94.

Linden, Greg/Smith, Brent/York, Jeremy (2003): »Amazon.com Recommendations. Item-to-Item Collaborative Filtering«, in: IEEE Internet Computing 7, S. 76-80. Lorenz, Maren (2009): »Repräsentation von Geschichte in Wikipedia, oder: Die Sehnsucht nach Beständigkeit im Unbeständigen«, in: Barbara Korte/Sylvia Paletschek (Hg.), History goes Pop. Zur Repräsentation von Geschichte in populären Medien und Genres, Bielefeld: transcript, S. 289-312.

Lovink, Geert (2010): »Die Gesellschaft der Suche. Fragen oder Googeln«, in: Konrad Becker (Hg.), Deep Search. Politik des Suchens jenseits von Google, Bonn: Bundeszentrale für politische Bildung, S. 53-63.

Löw, Martina (2000): Raumsoziologie, Frankfurt am Main: Suhrkamp.

Lutteroth, Johanna (2011): »Gescheuerte Kunst. Skandal um Beuys-Badewanne«, http://www.spiegel.de/einestages/skandal-um-beuys-badewanne-a-947414.html vom 09.06.2018.

Lynch, Clifford (1999): »Canonicalization. A Fundamental Tool to Facilitate Preservation and Management of Digital Information«, http://www.dlib.org/dlib/ september99/09lynch.html vom 09.06.2018. 
Lynch, Clifford (2000): »Authenticity and Integrity in the Digital Environment. Council on Library and Information Resources«, http://www.clir.org/pubs/ reports/pub92/lynch.html vom 09.06.2018.

MacDonald, George/Alsford, Stephen (1997): „Conclusion. Toward the Meta-Museum«, in: Katherine Jones-Garmil (Hg.), The Wired Museum. Emerging Technology and Changing Paradigms, Washington D.C.: American Association of Museums, S. 267-278.

Malraux, André (1960): Stimmen der Stille, Berlin u.a.: Deutsche Buch-Gemeinschaft.

Manovich, Lev (2002): The Language of New Media, Cambridge, MA: MIT Press.

Manovich, Lev (2007): »Cultural Analytics. Analysis and Visualization of Large Cultural Data Sets«, http://www.manovich.net/cultural_analytics.pdf vom 18.06.2012.

Maroevic, Ivo (1998): Introduction to Museology. The European Approach, München: Verlag Dr. Christian Müller-Straten.

Martin, Dieter (2011): »Mathematische Meditationen über das Unendliche. Kombinatorische Verfahren in der Literatur des Barock - mit einem Ausblick in die Nachkriegsavantgarde«, in: Andrea Albrecht/Gesa von Essen/Werner Frick (Hg.), Zahlen, Zeichen und Figuren. Mathematische Inspirationen in Kunst und Literatur, Berlin u. Boston: DeGruyter, S. 191-213.

Marx, Karl/Engels, Friedrich (1953): Die deutsche Ideologie. Kritik der neuesten deutschen Philosophie in ihren Repräsentanten, Feuerbach, B. Bauer und Stirner, und des deutschen Sozialismus in seinen verschiedenen Propheten, Berlin: Dietz Verlag.

Mauss, Marcel (1990): Die Gabe. Form und Funktion des Austauschs in archaischen Gesellschaften, Frankfurt a.M.: Suhrkamp.

Mayer, Katja (2010): »Zur Soziometrik der Suchmaschinen. Ein historischer Überblick der Methodik«, in: Konrad Becker (Hg.), Deep Search. Politik des Suchens jenseits von Google, Bonn: Bundeszentrale für politische Bildung, S. 64-83.

Metahaven (2010): »Periphere Kräfte. Zur Relevanz von Marginalität in Netzwerken«, in: Konrad Becker (Hg.), Deep Search. Politik des Suchens jenseits von Google, Bonn: Bundeszentrale für politische Bildung, S. 207-220.

Mendelson, Bert (1990): Introduction to Topology, New York: Dover Publications. Meyer, Erik (2009): »Erinnerungskultur 2.0. Zur Transformation kommemorativer Kommunikation in digitalen, interaktiven Medien«, in: Ders. (Hg.), Erinnerungskultur 2.0. Zur Transformation kommemorativer Kommunikation in digitalen, interaktiven Medien, Frankfurt a.M. 2009: Campus, S. 175-206.

Mintz, Ann (1998): »Media and Museums. A Museum Perspective«, in: Dies./Selma Thomas (Hg.), The Virtual and the Real. Media in the Museum, Washington D.C.: American Association of Museums, S. 19-34. 
Morozov, Evgeny (2012): »The Death of the Cyberflâneur«, http://www. nytimes.com/2012/02/05/opinion/sunday/the-death-of-thecyberflaneur.html?_r=2 vom 09.06.2018.

Morrissey, Kristine/Worts, Douglas (1998): »A Place for the Muses? Negotiating the Role of Technology in Museums«, in: Selma Thomas/Ann Mintz (Hg.): The Virtual and the Real. Media in the Museum, Washington D.C.: American Association of Museums, S. 147-171.

Moulthrop, Stuart (1995): »Rhizome and Resistance. Hypertext and the Dreams of a New Culture«, in: George P. Landow (Hg.), Hyper/Text/Theory, Baltimore u.a.: John Hopkins University Press, S. 299-319.

Münker, Stefan (1997): »Was heißt eigentlich »Virtuelle Realität«? Ein philosophischer Kommentar zum neuesten Versuch der Verdopplung der Welt«, in: Stefan Münker/Alexander Roesler (Hg.), Mythos Internet, Frankfurt a.M.: Suhrkamp, S. 108-127.

Münker, Stefan (2005a): »Information«, in: Alexander Roesler/Bernd Stiegler (Hg.), Grundbegriffe der Medientheorie, Paderborn: Wilhelm Fink Verlag, S. 95-105.

Münker, Stefan (2005b): »Virtualität«, in: Alexander Roesler/Bernd Stiegler (Hg.), Grundbegriffe der Medientheorie, Paderborn: Wilhelm Fink Verlag, S. 244-250.

Murray, Janet H. (1997): Hamlet on the Holodeck. The Future of Narrative in Cyberspace, New York: The Free Press.

Nelson, Theodore Holm (2003): »A File Structure for the Complex, the Changing and the Indeterminate $\ll$, in: Noah Wardrip-Fruin/Nick Montfort (Hg.), The New Media Reader, Cambridge, MA: MIT Press, S. 133-146.

Niewerth, Dennis (2013): »Heiße Töpfe. Digital Humanities und Museen am Siedepunkt«, http://www.mai-tagung.lvr.de/media/mai_tagung/pdf/2013/NiewerthDOC-MAI-2013.pdf vom 10.06.2018.

Niewerth, Dennis (2014): »Dive! Dive! Dive! Virtuelle (Unter-) Wasserwelten zwischen Beklemmung, Tiefenrausch und Umsetzbarkeit«, in: Christian Huberts/ Sebastian Standke (Hg.), Zwischen|Welten. Atmosphären im Computerspiel, Glückstadt: Verlag Werner Hülsbusch, S. 223-263.

Nora, Pierre (1990): Zwischen Geschichte und Gedächtnis, Berlin: Wagenbach.

Novak, Marcos (1991): »Liquid Architectures in Cyberspace«, in: Michael L. Benedict (Hg.), Cyberspace. First Steps, Cambridge, MA: MIT Press, S. 225-254.

Nusca, Andrew (2015): »Pinterest CEO Ben Silbermann: We're Not a Social Network«, http://fortune.com/2015/07/13/pinterest-ceo-ben-silbermann/ vom 10.06.2018.

O’Reilly, Tim (2005): »What Is Web 2.0? Design Patterns and Business Models for the Next Generation of Software«, https://www.oreilly.com/pub/a/web2/ archive/what-is-web-20.html? vom 10.06.2018. 
Olek, Daniela/Piepiorka, Christine (2012): »To Be Continued... Somewhere Else! Die Auswirkungen struktureller Räumlichkeit auf die Serialität im Kontext transmedialer Fernsehserien«, in: Peter M. Spangenberg/Bianca Westermann (Hg.), Im Moment des >Mehr . Mediale Prozesse jenseits des Funktionalen, Münster u. Berlin: Lit Verlag, S. 75-93.

Paisley, William J. (1968): »The Museum Computer and the Analysis of Artistic Content , in: The Metropolitan Museum of Art (Hg.), Computers and their Potential Applications in Museums. A Conference Sponsored by the Metropolitan Museum of Art, April 15, 16, 17, 1968, New York: Arno Press, S. 195-216.

Parry, Ross (2006): Recoding the Museum, London: Routledge.

Paul, Stefan (2005): »Kommunizierende Räume. Das Museum«, in: Alexander C.T. Geppert/Uffa Jensen/Jörn Weinhold (Hg.), Ortsgespräche. Raum und Kommunikation im 19. und 20. Jahrhundert, Bielefeld: transcript, S. 341-357.

Peirce, Charles S. (1966): Selected Writings (Values in a Universe of Chance). Edited with an Introduction and Notes by Philip P. Wiener, New York: Dover Publications.

Pias, Claus (2002): »Der Hacker«, in: Eva Horn/Stefan Kaufmann/Ulrich Bröckling (Hg.), Grenzverletzer. Von Schmugglern, Spionen und anderen subversiven Gestalten, Berlin: Kadmos, S. 248-270.

Pertsch, Erich (2008): Langenscheidt Handwörterbuch Lateinisch-Deutsch, Berlin, München u.a.: Langenscheidt.

Platon (2012): Theätet. Griechisch / Deutsch, Stuttgart: Reclam.

Pomian, Krzysztof (2007): Der Ursprung des Museums. Vom Sammeln, Berlin: Verlag Klaus Wagenbach.

Poole, Nick (2012): »What Comes After Digital?« https://web.archive.org/2013021 4233125/http://www.collectionstrust.org.uk/what-comes-after-digital/ vom 10.06.2018.

Potts, Jason/Hartley, John/Banks, John/Burgess, Jean/Cobcroft, Rachel/Cunningham, Stuart/Montgomery, Lucy (2008): »Consumer Co-Creation and Situated Creativity«, in: Industry and Innovation 15/5, S. 459-474.

Pratty, Jon (2006): »The Inside Out Web Museum«, http://www.museumsandtheweb .com/mw2006/papers/pratty/pratty.html vom 10.06.2018.

Propp, Wladimir (1972): Morphologie des Märchens, München: Hanser.

Redman, Samuel J. (2010): »Museums and Their Visitors. Historic Relationship«, https://works.bepress.com/samuel_redman/7/ vom 10.06.2018.

Rheinberger, Hans Jörg (2006): Experimentalsysteme und epistemische Dinge. Eine Geschichte der Proteinsynthese im Reagenzglas, Frankfurt a.M.: Suhrkamp.

Rieger, Stefan (2012): »Epistemische Selbstläufer. Zur Ökonomie der Wissenschaft«, in: Ders./Manfred Schneider (Hg.), Selbstläufer / Leerläufer. Regelungen und ihr Imaginäres im 20. Jahrhundert, Zürich u. Berlin: Diaphanes, S. 155-175. 
Rieger, Stefan/Niewerth, Dennis (2016): „Virtualität. Konzepte, Körper und Museen«, in: Arne Scheuermann/Francesca Vidal (Hg.), Handbuch Medienrhetorik (= Handbücher Rhetorik Bd. 6), Berlin u. Boston: DeGruyter, S. 501-523.

Rogers, Richard (2011): »Das Ende des Virtuellen. Digitale Methoden«, in: Zeitschrift für Medienwissenschaft 5, S. 61-77.

Ropohl, Günther (1999): Technologische Aufklärung. Beiträge zur Technikphilosophie, Frankfurt a.M.: Suhrkamp.

Rothenberg, Jeff (2000): »Preserving Authentic Digital Information«, http://www.clir.org/pubs/reports/pub92/rothenberg.html vom 10.06.2018.

Samida, Stefanie (2002): »Überlegungen zu Begriff und Funktion des >virtuellen Museums $\measuredangle$. Das archäologische Museum im Internet«, in: Museologie Online 4, S. 1-58.

Sandbothe, Mike (1997): »Interaktivität - Hypertextualität - Transversalität. Eine medienphilosophische Analyse des Internet«, in: Stefan Münker/Alexander Roesler (Hg.), Mythos Internet, Frankfurt a.M.: Suhrkamp, S. 56-82.

Scheer, Brigitte (2000): »Zeichen und Raum. Über bildnerische Zeichen in der Architektur«, in: Werner Stegmaier (Hg.), Kultur der Zeichen, Frankfurt a.M.: Suhrkamp, S. 234-251,

Schmidgen, Henning (2007): »Repetitions and Differences. Psychological Time Machines 1850-1865«, in: Silvia Wagnermaier/Siegfried Zielinski (Hg.), Variantology 1. On Deep Time Relations of Arts, Sciences and Technologies, Köln: Verlag der Buchhandlung Walther König, S. 145-158.

Schmolke, Michael (2002): "Ausstellungen und die Kommunikation der Gesellschaft. Eine Skizze«, http://www2.rz.hu-berlin.de/kulturtechnik/files/ Schmolke.pdf vom 12.12.2015.

Schreibman, Susan/Siemens, Ray/Unsworth, John (2004): The Digital Humanities and Humanities Computing. http://www.digitalhumanities.org/companion/view ?docId=blackwell/9781405103213/9781405103213.xml\&chunk.id=ssl1-1-3\&toc. id=ss1-1-3\&brand=default vom 10.06.2018.

Schröter, Jens (2009): »Die Ästhetik der virtuellen Welt. Überlegungen mit Niklas Luhmann und Jeffrey Shaw«, in: Ders./Manfred Bogen/Roland Kuck (Hg): Virtuelle Welten als Basistechnologie für Kunst und Kultur? Eine Bestandsaufnahme, Bielefeld: transcript, S. 25-36.

Schweibenz, Werner (1998): »The >Virtual Museum`: New Perspectives for Museums to Present Objects and Information Using the Internet as a Knowledge Base and Communication System«, in: Harald H. Zimmermann/Volker Schramm (Hg.), Knowledge Management und Kommunikationssysteme. Workflow Management, Multimedia, Knowledge Transfer. Proceedings des 6. Internationalen Symposiums für Informationswissenschaft (ISI '98) Prag, 3. - 7. November 1998 (= Schriften zur Informationswissenschaft Bd. 34), Konstanz: UKV, S. 185-200. 
Schweibenz, Werner (2001): »Das virtuelle Museum. Überlegungen zum Begriff und

Wesen des Museums im Internet«, http://www.mai-tagung.de/media/mai_ tagung/pdf/2001/schweibenz.pdf vom 10.06.2018.

Scott, David W. (1988): »Museum Data Bank Research Report: The Yogi and the Registrar«, in: Library Trends 37/2, S. 130-141.

Shannon, Claude Elwood (1948): »A Mathematical Theory of Communication«, in: The Bell System Technical Journal 27, S. 379-423 u. 623-656.

Shannon, Claude Elwood u. Weaver, Warren (1963): The Mathematical Theory of Communication, Chicago: University of Illinois Press.

Simanowski, Roberto (2002): Interfictions. Vom Schreiben im Netz, Frankfurt a.M.: Suhrkamp.

Simanowski, Roberto (2008): Digitale Medien in der Erlebnisgesellschaft. Kultur Kunst - Utopien, Reinbek bei Hamburg: Rowohlt.

Simon, Nina (2011): »Das partizipative Museum«, in: Susanne Gesser/Martin Handschin/Angela Jannelli/Sibylle Lichtensteiger (Hg.), Das partizipative Museum. Zwischen Teilhabe und User Generated Content. Neue Anforderungen an kulturhistorische Ausstellungen, Bielefeld: transcript, S. 95-108.

Simondon, Gilbert (2007): »Das Individuum und seine Genese «, in: Claudia Blümle/ Armin Schäfer (Hg.), Struktur, Figur, Kontur. Abstraktion in Kunst und Lebenswissenschaften, Zürich u. Berlin: Diaphanes, S. 29-45.

Smith, Charles Saumarez (1989): »Museums, Artefacts and Meanings«, in: Peter Vergo (Hg.), The New Museology, London: Reaktion Books, S. 6-21.

Spohn, Annette (2002): »What You See Is What You Want. Paradigmenwechsel in der visuellen Kultur«, in: Stefan Münker/Alexander Roesler (Hg.), Praxis Internet. Kulturtechniken der vernetzten Welt, Frankfurt a.M.: Suhrkamp, S. 249-275. Stiegler, Bernard (2009): Denken bis an die Grenzen der Maschine, Zürich u. Berlin: Diaphanes.

Stockhammer, Robert (2005): »Netzwerk«, in: Alexander Roesler/Bernd Stiegler (Hg), Grundbegriffe der Medientheorie, Paderborn: Wilhelm Fink Verlag, S. 200-209.

Text Encoding Initiative (2014): »TEI: History«, http://www.tei-c.org/About/ history.xml vom 10.06.2018.

Tschirner, Ulfert (2011): Museum, Photographie und Reproduktion. Mediale Konstellationen im Untergrund des Germanischen Nationalmuseums, Bielefeld: transcript.

Turkle, Sherry (1998): Das Leben im Netz. Identität in Zeiten des Internet, Hamburg: Rohwolt.

Urban, Andreas (2009): »Rettung der Vergangenheit - Verlust der Gegenwart? Museumskultur in der Postmoderne«, in: Sabine Horn/Michael Sauer (Hg.): Geschichte und Öffentlichkeit. Orte - Medien - Institutionen, Göttingen: Vandenhoeck \& Ruprecht, S. 70-79. 
Valéry, Paul (1958): »Das Problem der Museen«, in: Die Zeit vom 18.12.1958, S. 7. Vieregg, Hildegard (2008): Geschichte des Museums. Eine Einführung, Berlin: Wilhelm Fink Verlag.

Volk, Bettina (2009): »Das wissenschaftliche Volontariat am Museum. Einstieg in eine wissenschaftliche Karriere? Ergebnisse der >Verbleibstudie 1998-2008<, in: Mitteilungen des Deutschen Archäologen-Verbandes e.V. 40/2, S. 117-129.

Waidacher, Friedrich (2000): »Vom Wert der Museen«, in: Museologie Online 2, S. 1-20.

Wark, McKenzie (2004): A Hacker Manifesto, Cambridge, MA: Harvard University Press.

Weiser, Mark (1991): »The Computer for the 21st Century«, in: Scientific American 265/3, S. 94-104.

Weizenbaum, Joseph (2006): Inseln der Vernunft im Cyberstrom? Auswege aus der programmierten Gesellschaft, Bonn: Bundeszentrale für politische Bildung.

Wersig, Gernot (1997): »Museums and >Information Society«", https://de.scribd.com/document/371850253/Gernot-Wersig-Museums-and-Information-Society vom 10.06.2018.

Wexelblat, Alan (1991): »Giving Meaning to Place. Semantic Spaces«, in: Michael L. Benedict (Hg.), Cyberspace. First Steps, Cambridge, MA: MIT Press, S. 255271.

Wirth, Uwe (1997): »Literatur im Internet, oder: Wen kümmert's wer liest?«, in: Stefan Münker/Alexander Roesler (Hg.): Mythos Internet, Frankfurt a.M.: Suhrkamp, S. 319-337.

Woolgar, Steve (2002): »Five Rules of Virtuality«, in: Ders. (Hg.), Virtual Society? Technology, Cyberbole, Reality, Oxford u. New York: Oxford University Press, S. 1-22.

Woolley, Benjamin (1993): Virtual Worlds. A Journey in Hype and Hyperreality, London: Penguin.

Wurman, Richard Saul (1989): Information Anxiety, New York: Doubleday.

Zacny, Rob (2014): »Always-Online DRM and Service Shutdowns Endanger the PC's Back Catalog«, http://www.pcgamesn.com/always-online-drm-andservice-shutdowns-endanger-pcs-back-catalog vom 10.06.2018. 


\section{Museum}
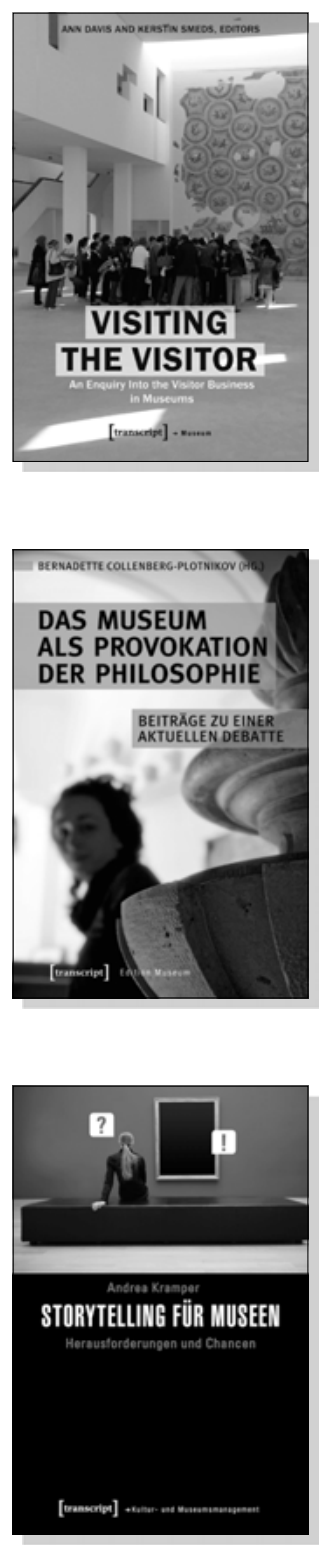

Ann Davis, Kerstin Smeds (eds.)

\section{Visiting the Visitor}

An Enquiry Into the Visitor Business in Museums

2016, 250 p., pb., numerous ill.

$39,99 €(D E), 978-3-8376-3289-7$

E-Book: 39,99 € (DE), ISBN 978-3-8394-3289-1

Bernadette Collenberg-Plotnikov (Hg.)

Das Museum als Provokation der Philosophie

Beiträge zu einer aktuellen Debatte

Januar 2018, 286 S., kart., zahlr. Abb.

$29,99 €(D E), 978-3-8376-4060-1$

E-Book: 26,99 € (DE), ISBN 978-3-8394-4060-5

Andrea Kramper

Storytelling für Museen

Herausforderungen und Chancen

2017, 140 S., kart., zahlr. Abb.

$19,99 €(D E), 978-3-8376-4017-5$

E-Book

PDF: $17,99 €(D E)$, ISBN 978-3-8394-4017-9

EPUB: $17,99 €(D E)$, ISBN 978-3-7328-4017-5 


\section{Museum}

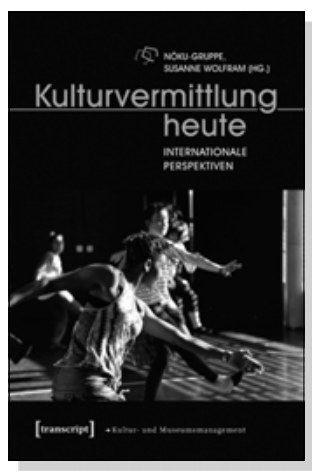

NÖKU-Gruppe, Susanne Wolfram (Hg.)

\section{Kulturvermittlung heute}

Internationale Perspektiven

2017, 222 S., kart.

$29,99 €(D E), 978-3-8376-3875-2$

E-Book: 26,99 € (DE), ISBN 978-3-8394-3875-6

\section{Canuen Monsch, ANGeu SACis, \\ AUSSTELIEN \\ UND VERMIITELN \\ IM MUSEUM \\ Carmen Mörsch, Angeli Sachs, Thomas Sieber (Hg.) \\ Ausstellen und Vermitteln im Museum der Gegenwart}

DER GEGENWART

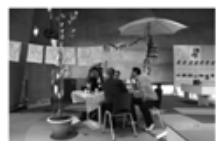

2016, 344 S., kart., zahlr. Abb.

$34,99 €(D E), 978-3-8376-3081-7$

E-Book: 34,99 € (DE), ISBN 978-3-8394-3081-1

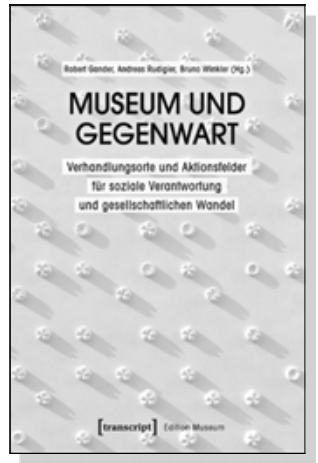

Robert Gander, Andreas Rudigier, Bruno Winkler (Hg.)

\section{Museum und Gegenwart}

Verhandlungsorte und Aktionsfelder

für soziale Verantwortung und gesellschaftlichen Wandel

2015, 176 S., kart., zahlr. z.T. farb. Abb.

$29,99 €(D E), 978-3-8376-3335-1$

E-Book: 26,99 € (DE), ISBN 978-3-8394-3335-5 
